\title{
Assessment of Regional Earthquake Hazards and Risk Along the Wasatch Front, Utah
}

\section{U.S. GEOLOGICAL SURVEY PROFESSIONAL PAPER 1500-K-R}

\section{Contributions from Utah Geological Survey,}

University of Utah, and Utah State University

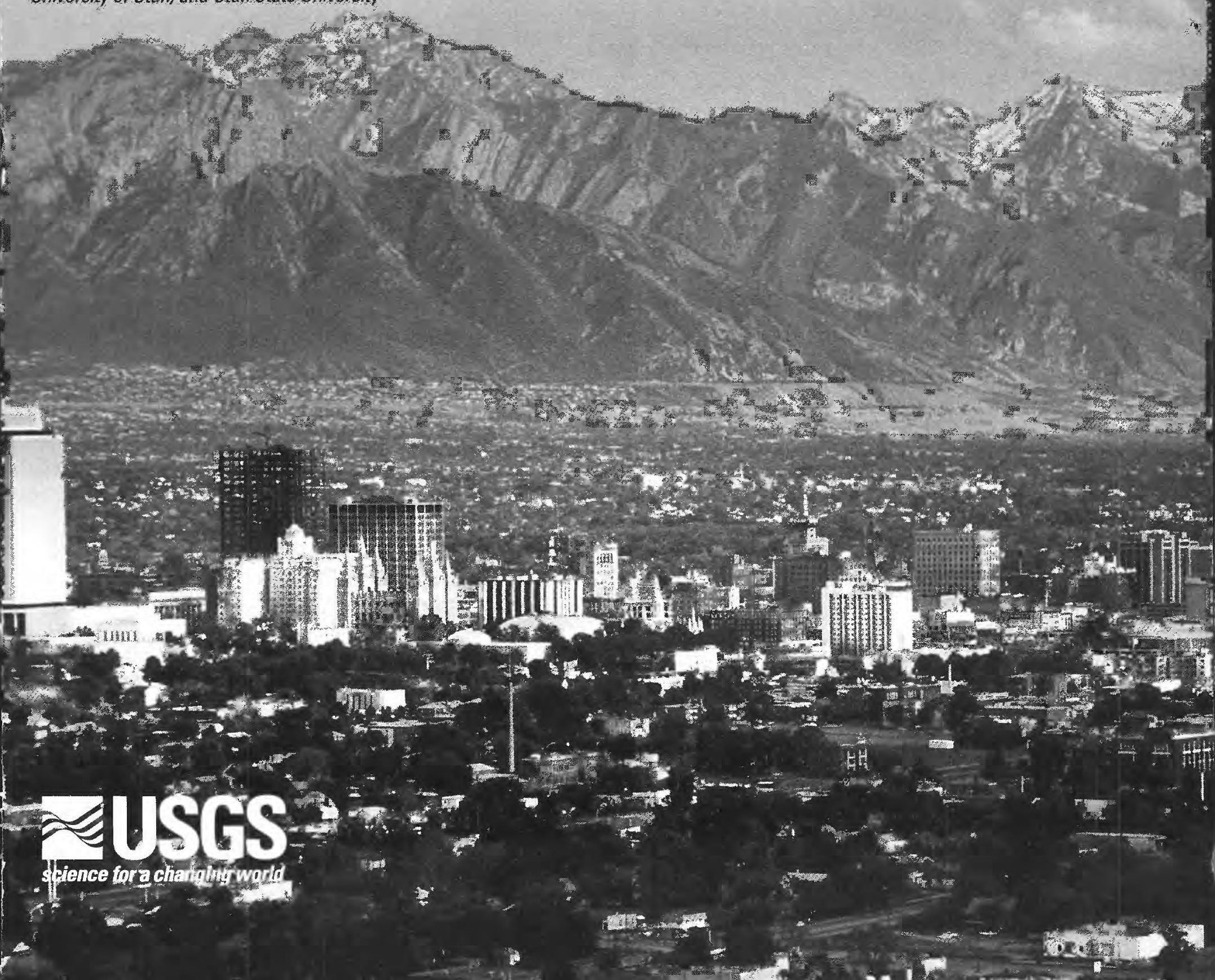


FronT COVER.- View to the southeast of downtown Salt Lake City, Utah, circa 1980. Wasatch Range with prominent Lake Bonneville shorelines in the background. 


\section{Assessment of Regional Earthquake Hazards and Risk Along the Wasatch Front, Utah}

PAULA L. GORI and WALTER W. HAYS, Editors

U.S. GEOLOGICAL SURVEY PROFESSIONAL PAPER 1500-K-R

Contributions from

Utah Geological Survey,

University of Utah, and

Utah State University

Chapters $K-R$ are issued as a single volume and are not available separately.

Chapter titles are listed in the volume

table of contents. 


\title{
U.S. DEPARTMENT OF THE INTERIOR \\ BRUCE BABBITT, Secretary
}

\author{
U.S. GEOLOGICAL SURVEY \\ Charles G. Groat, Director
} Any use of trade, product, or firm names in this publication is for descriptive purposes only and
does not imply endorsement by the U.S. Government.

Author affiliations given in this volume were correct at the time the report was approved for publication.

Published in the Eastern Region, Reston, Va. Manuscript approved for publication October 5, 1995.

Library of Congress Cataloging in Publication Data

Assessing regional earthquake hazards and risk along the Wasatch Front, Utah / edited by Paula $L$. Gori and Walter W. Hays.

p. $\quad \mathrm{cm} . \quad-$ (U.S. Geological Survey professional paper : $1500 \mathrm{~K}-\mathrm{R}$ )

Includes bibliographical references.

Supt. of Docs. no.: I19.16: $1500 \mathrm{KZ}$.

1. Earthquakes-Wasatch Range (Utah and Idaho) 2. Earthquakes-Utah. I. Gori, Paula. II.

Hays, Walter W. III. Series: U.S. Geological Survey professional paper ; 1500. QE535.2.U6A84 2000

$\begin{array}{lr}551.2^{\prime} 2^{\prime} 097922-\mathrm{dc} 20 & 92-33618\end{array}$

CIP

For sale by U.S. Geological Survey, Information Services

Box 25286, Federal Center, Denver, CO 80225 


\section{CONTENTS}

[Letters designate the chapters]

Introduction, by Paula L. Gori and Walter W. Hays

(K) Site Amplification in the Salt Lake City-Ogden-Provo Urban Corridor and the Implications for EarthquakeResistant Design, by Walter W. Hays

(L) Predicting Strong Ground Motion in Utah, by Kenneth W. Campbell

(M) Probabilistic Analysis of Earthquake Ground-Shaking Hazards Along the Wasatch Front, Utah, by R.R. Youngs, F.H. Swan, M.S. Power, D.P. Schwartz, and R.K. Green

(N) Relative Ground Response in Salt Lake City and Areas of Springville-Spanish Fork, Utah, by Kenneth W. King, Robert A. Williams, and David L. Carver

(O) In Situ Poisson's Ratio Measurements Near Provo, Utah, by Richard D. Miller, Don W. Steeples, Kenneth W. King, and Ralph W. Knapp

(P) Earthquake Losses in Central Utah, by S.T. Algermissen, E.P. Arnold, K.V. Steinbrugge, Margaret G. Hopper, and P.S. Powers

(Q) Isoseismals of Some Historical Earthquakes Affecting the Wasatch Front Area, Utah, by Margaret G. Hopper

(R) Seismic-Risk Methods and Estimates for Utility Systems and State-Owned Buildings Along the Wasatch Front, by Craig E. Taylor and Delbert B. Ward 



\title{
ASSESSMENT OF REGIONAL EARTHQUAKE HAZARDS AND RISK \\ ALONG THE WASATCH FRONT, UTAH
}

\section{INTRODUCTION}

\author{
By Paula L. Gori and Walter W. Hays
}

\section{THE EARTHQUAKE THREAT}

\begin{abstract}
There are many geologists who are very wise, but even they do not understand the forces which produce mountains. And yet it must be admitted, not only that mountains have been made, but that some mountains are still rising. The mysterious forces appear to act in different ways in different places, and it is possible that their nature is not universally the same. Suffice it to say that in the Great Basin the movements they cause are vertical. It is as though something beneath each mountain was slowly, steadily, and irresistibly rising, carrying the mountain with it.
\end{abstract}

So began an article in 1883 by Grove Karl Gilbert, the first Chief Geologist of the U.S. Geological Survey (USGS), warning the citizens of the Great Basin about the potential for damaging earthquakes in their region. Describing the damage and loss of life in a small town in California that he had just visited after an earthquake, Gilbert cautioned that a similar earthquake could occur in Salt Lake City. "It is useless to ask when this disaster will occur. Our occupation of the country has been too brief for us to learn how fast the Wasatch grows; and indeed, it is only by such disasters that we can learn. By the time experience has taught us this, Salt Lake City will have been shaken down...." (Gilbert, 1883, p. 4).

After more than a century of research, geologists and other scientists have increased their understanding of the tectonic processes at work in the Wasatch Front and are now beginning to answer the questions about the seismicity and tectonics of the Wasatch Front that Gilbert and others first posed. Scientists, engineers, architects, urban planners, and emergency managers are not waiting for a major earthquake disaster to learn that measures must be implemented to mitigate an earthquake's effects. They are taking actions now to prepare for and to mitigate the physical effects of such an earthquake.

The majority of Utah's population lives adjacent to the Wasatch fault zone (fig. 1), an active, north-trending zone of normal faulting that extends approximately $370 \mathrm{~km}$ at the western foot of the Wasatch Range. Earthquakes have been reported since the arrival of the Mormon pioneers in 1847. During the last two centuries, eight earthquakes of magnitude ${ }^{1}$ greater than or equal to 6 have occurred in Utah. The two largest were the magnitude $\left(\mathrm{M}_{\mathrm{L}} 7.0\right) 6.6$ Hansel Valley earthquake of 1934 (fig. 2) and the $\mathrm{M}_{\mathrm{L}} 6.5$ Richfield earthquake of 1901.

The historical record of seismicity in Utah has been broadened by incorporating geologic evidence and monitoring small earthquakes. Although no large earthquakes $(M>7.0)$ have occurred since Utah was settled, clear geologic and geomorphic evidence (Hamblin, 1976) demonstrates that large earthquakes have occurred repeatedly throughout the late Pleistocene ( 2 million years before present) and Holocene (last 10,000 years) on segments within the Wasatch fault zone. For this reason and because of the continuing low level of seismicity, scientists believe that some parts of segments of the Wasatch fault zone are overdue for a damaging earthquake (Schwartz and Coppersmith, 1984). Machette and others (this report) have identified 10 segments of the Wasatch fault that have produced large earthquakes on the average of every several hundred to 1,000 years.

\footnotetext{
${ }^{1}$ Magnitude is a "number that characterizes the size of an earthquake, based on measurement of the maximum motions recorded by a seismograph for earthquake waves of a particular frequency. Scales most commonly used in the Western United States are (1) local magnitude $\left(M_{L}\right)$ (commonly referred to as "Richter magnitude"), (2) surfacewave magnitude $\left(M_{S}\right)$, and (3) body-wave magnitude $\left(m_{s}\right)$. None of these scales satisfactorily measures the largest possible earthquakes because each relates to only certain frequencies of seismic waves and because the spectrum of radiated seismic energy changes with earthquake size. The recently devised moment magnitude $(\boldsymbol{M})$ scale, based on the concept of seismic moment, is uniformly applicable to all sizes of earthquakes" (Ziony, 1985, p. 18).
} 


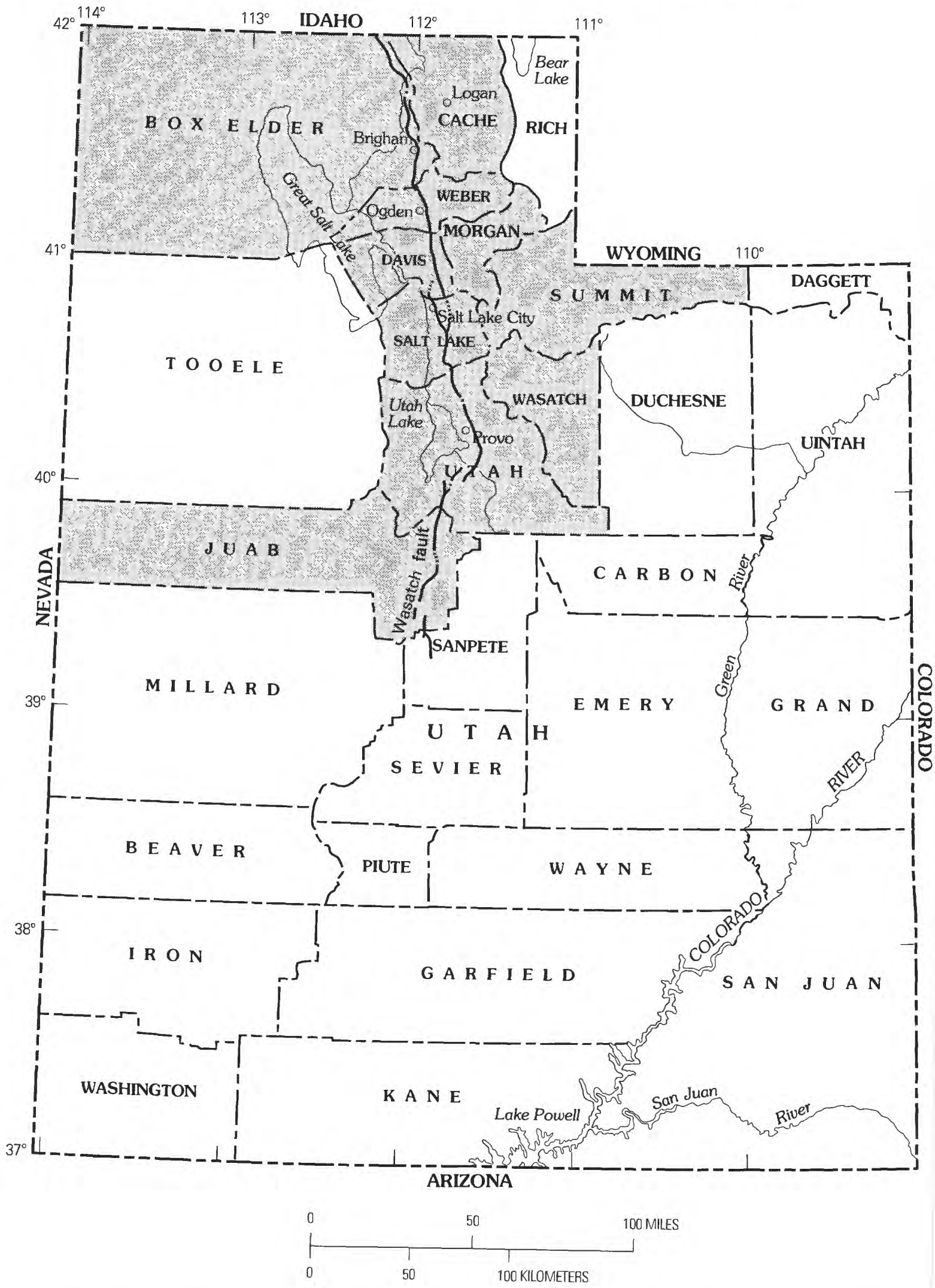

FIGURE 1 -Location map of the Wasatch Front study area (shaded), northern Utah. Generalized fault locations are also shown. 


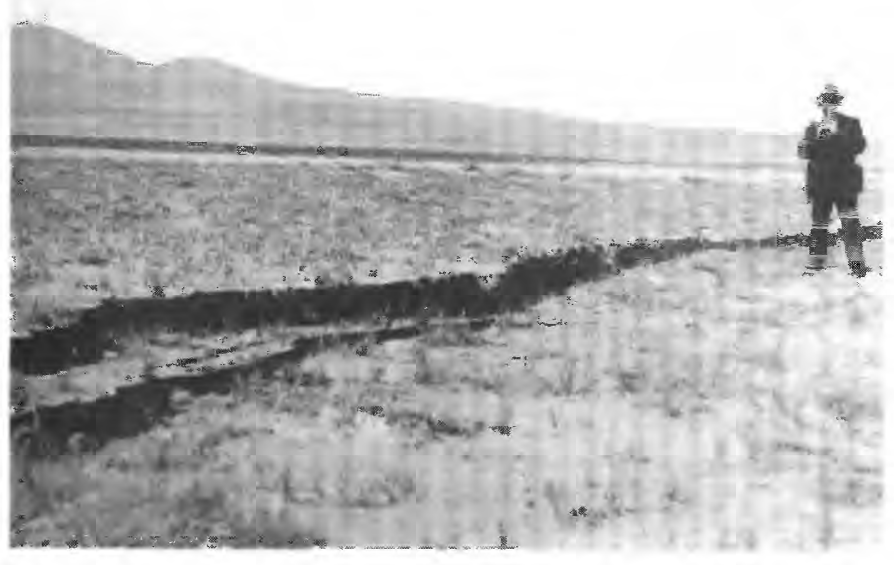

FIGURE 2.-Fault scarp formed in Utah's Hansel Valley north of Great Salt Lake in the 1934 Hansel Valley earthquake.

Utah's largest urban centers, where more than 80 percent of the State's 2 million people live, are located along the Wasatch Front. A large earthquake centered near Salt Lake City has the potential to cause extensive damage to buildings, lifelines, and public facilities. The expected level of peak ground acceleration would be in the range of 0.2 to $0.4 \mathrm{~g}$ or greater. Surface-fault rupture and tectonic deformation (fig. 3) as well as landslides and liquefaction would be expected to occur in many areas (fig. 4). Death and injury rates could be high, depending on the time of day that the earthquake struck and the nature and extent of pre-event mitigation actions.

The October 28, 1983, Borah Peak, Idaho, magnitude $\left(\mathrm{M}_{\mathrm{S}}\right) 7.3$, earthquake reminded scientists and policymakers that large earthquakes will recur in the Intermountain Seismic Belt (fig. 5). Scientists believe that the Borah Peak earthquake is a model of what might happen on the Wasatch Front (Smith and Richins, 1984 ). A magnitude 7.0 to 7.5 earthquake is now being considered as a scenario earthquake for emergency response planning in Utah.

\section{PURPOSE AND SCOPE OF THIS VOLUME}

In 1983, the USGS proposed the Wasatch Front of Utah as the target of a 5-year program of focused research on earthquake hazards and hazards reduction. The goals were to (1) accelerate the development of the knowledge base on seismic sources, size, frequency of occurrence, and physical effects of earthquakes in a 10-county area along the Wasatch Front, including Salt Lake, Davis, Juab, Weber, Wasatch, Summit, Morgan, Cache, Utah, and Box Elder Counties, and (2) foster implementation of earthquake hazards mitigation measures.
The USGS earthquake hazards program in the Wasatch Front area was conducted under the auspices of the "Regional Earthquake Hazards Assessment" element, one of five elements in the USGS' Earthquake Hazards Reduction Program. The element was established to provide concentrated and coordinated attention to geographic regions containing large urban areas at risk from earthquakes by utilizing past research and fostering partnerships with universities, the private sector, local government, and State and Federal agencies. The effort provides a technical basis for devising and implementing mitigation and loss reduction measures.

The five interrelated goals in the Utah comprehensive research and implementation program were:

Information systems. - To produce quality data along with a comprehensive information system, available to both USGS and non-USGS users, for use in earthquake hazards evaluations, risk assessment, and implementation of loss reduction measures.

Synthesis of geological and geophysical data.-To prepare synthesis reports describing the nature, extent, frequency of occurrence, and physical effects of the earthquake hazards of ground shaking, surface faulting, earthquake-induced ground failure, and tectonic deformation and recommend future research to increase the knowledge base required for the creation and implementation of mitigation and loss-reduction measures.

Ground-motion modeling.-To produce deterministic and probabilistic ground-motion models and maps of the ground-shaking hazard and commentaries on their use in building codes and land use regulations.

Loss estimation models.-To devise economical methods for acquiring inventories of structures and lifeline systems in urban areas, to create a standard model for loss estimation, to produce loss and casualty estimates for urban areas, and to prepare commentaries giving guidelines for use by agencies of State and local governments.

Implementation.-To foster the creation and implementation of measures to mitigate the earthquake hazards of ground shaking, surface-fault rupture, earthquakeinduced ground failure, and tectonic deformation in urban areas and to provide high-quality scientific information that can be used by local government decisionmakers as a basis for implementing and enforcing loss-reduction measures.

This report provides a comprehensive treatment of the knowledge gained by the research and implementation program in the Wasatch Front area. The two volumes are divided into sections dealing with individual components of the program that collectively define the nature of the earthquake hazards in the Wasatch Front area. The first volume deals with tectonic framework and earthquake potential. The second volume covers ground-shaking 


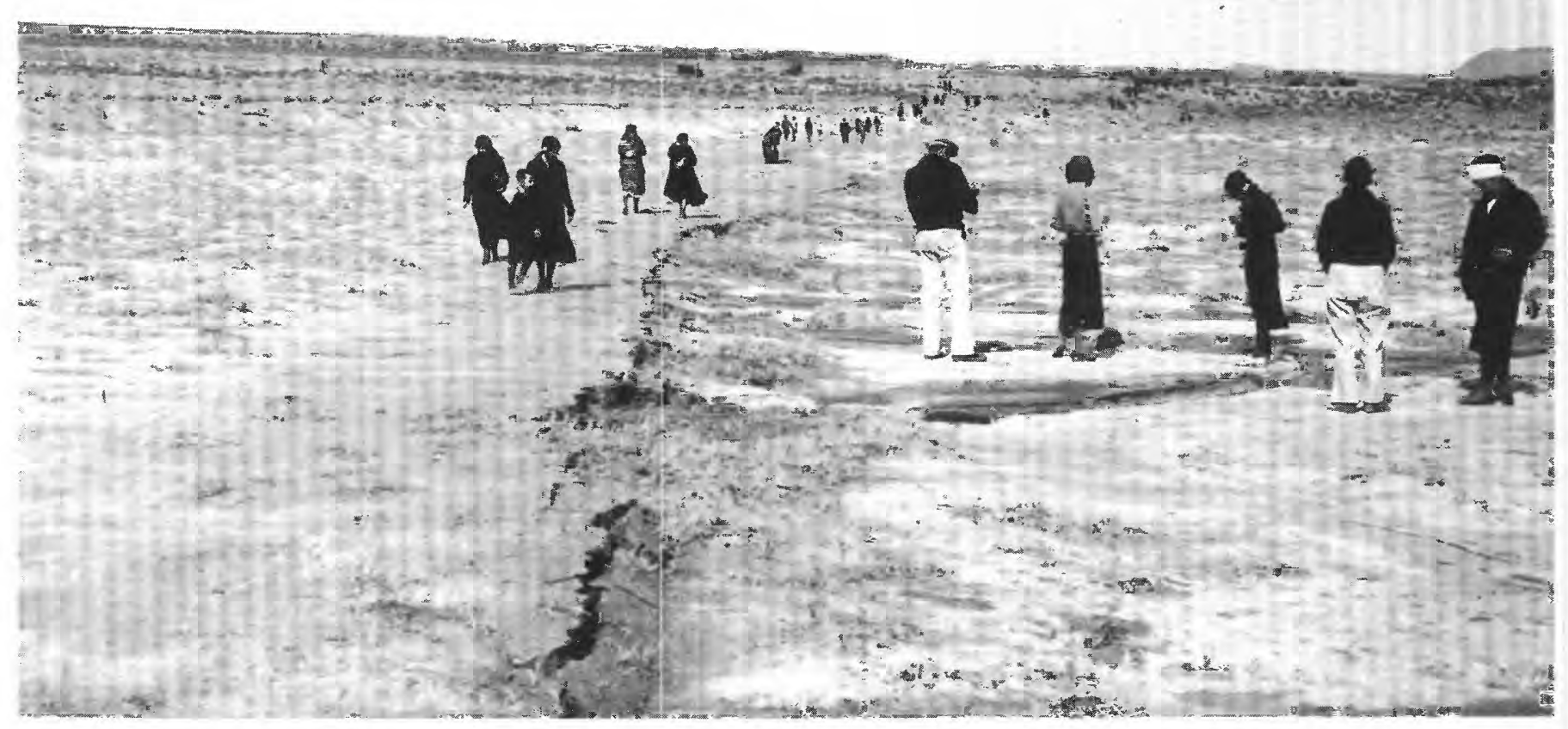

FiguRE 3.-Interested bystanders studying fault rupture formed in the 1934 Hansel Valley, Utah, earthquake. From the Thomas Adams Collection; courtesy of the Department of Geology and Geophysics, University of Utah, Provo.

hazards and aspects of loss estimation. The research results came from studies conducted by scientists and engineers of the USGS, the Utah Geological and Mineral Survey, universities, and private consulting firms. Funding was provided primarily by the USGS in the form of grants to non-USGS scientists and engineers.

\section{TECTONIC FRAMEWORK-AND EARTHQUAKE POTENTIAL OF THE WASATCH FRONT AREA}

The first volume of Professional Paper 1500 contains chapters devoted to geologic and geophysical studies aimed at improving the fundamental understanding of the potential for the occurrence of large, damaging earthquakes in the Wasatch Front area. In some cases, researchers have drawn on studies of other parts of Utah and the Intermountain Seismic Belt to gain an understanding of the large-magnitude earthquakes that may occur in the Wasatch Front. The geologic and seismological/geophysical studies composing this section are described in Chapters A through J:

Chapter A: Paleoseismology of the Wasatch Fault Zone:

A Summary of Recent Investigations, Interpretations, and Conclusions, by Michael N. Machette, Stephen F. Personius, and Alan R. Nelson. Ten discrete segments have been identified on the Wasatch fault zone. The fact that eight of these segments have demonstrable Holocene movement increases the possible number of separate localities where earthquakes may occur.

Chapter B: Persistent and Nonpersistent Segmentation of the Wasatch Fault Zone, Utah: Statistical Analysis for Evaluation of Seismic Hazard, by Russell L. Wheeler and Katherine B. Krystinik. The Wasatch fault zone has been segmented at four salientsPleasant View, Salt Lake, Traverse Mountains, and Payson-throughout much or all of its 10-m.y. history and will likely continue to be segmented there throughout the next several millenia, which is the time span of interest for hazard evaluation.

Chapter C: Subsurface Geology Along the Wasatch Front, by Don R. Mabey. Magnetic data suggest segment boundaries of the Wasatch fault zone that are generally consistent with segment boundaries inferred from surface mapping of the fault zone.

Chapter D: Observational Seismology and the Evaluation of Earthquake Hazards and Risk in the Wasatch Front Area, Utah, by W.J. Arabasz, J.C. Pechmann, and E.D. Brown. Background seismicity predominates on second-order faults in the Wasatch Front area. Small to moderate earthquakes are the largest contributor to the probabilistic ground-shaking hazard for exposure periods of 50 years or less. The earthquake data imply 


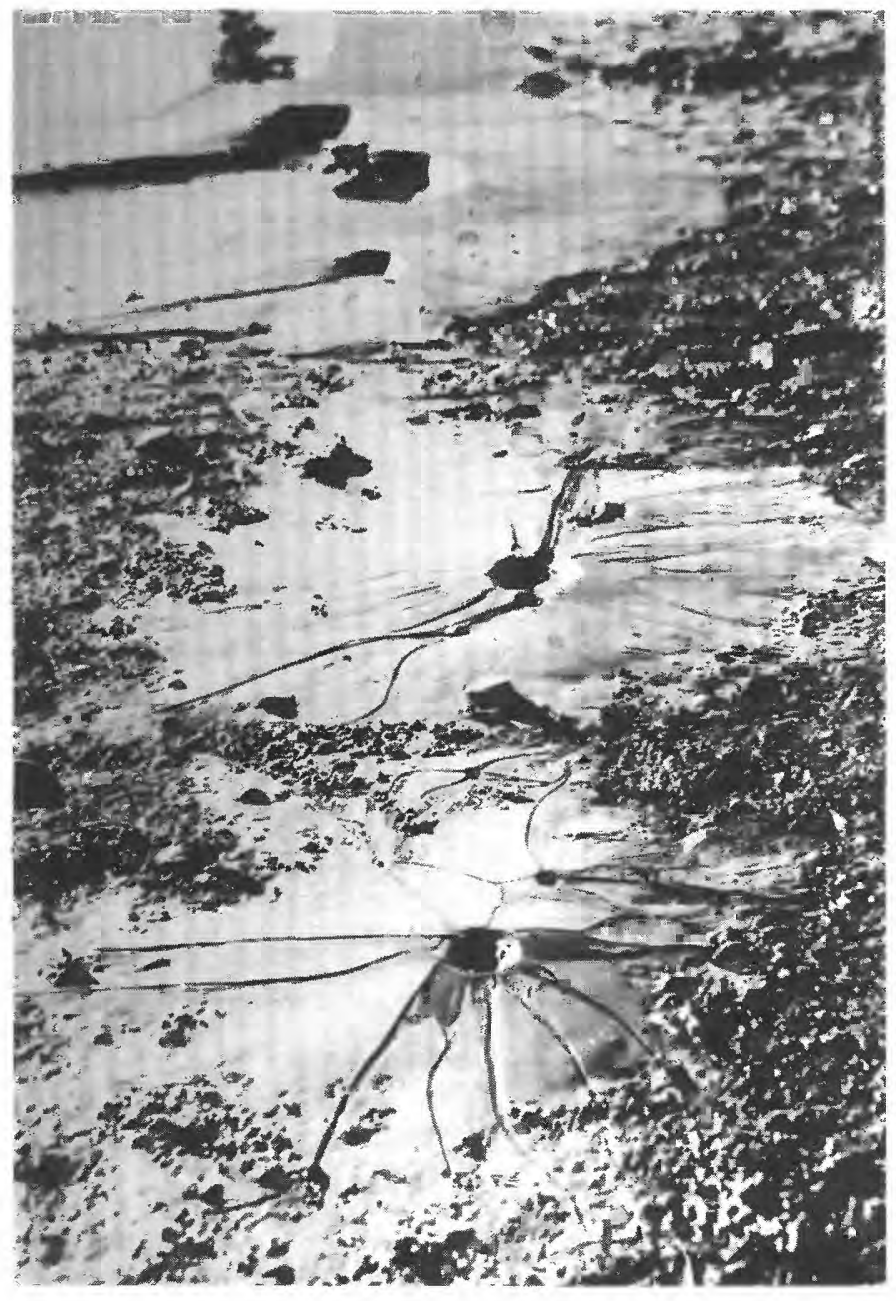

FIGURE 4.- Sand boils caused by liquefaction associated with the 1934 Hansel Valley, Utah, earthquake.

an average return period of $24 \pm 10$ years for potentially damaging earthquakes of magnitude 5.5 or greater along the Wasatch Front.

Chapter E: Superimposed Late Cenozoic, Mesozoic, and Possible Proterozoic Deformation Along the Wasatch Fault Zone in Central Utah, by Mary Lou Zoback. Thrust ramping and late Cenozoic normal faulting may be localized by a major west-dipping normal fault zone formed during the early phases of late Precambrian rifting of the western Cordillera.

Chapter F: Neotectonic Framework of the Central Sevier Valley Area, Utah, and Its Relationship to Seismicity, by $\mathrm{R}$. Emest Anderson and Theodore P. Barnhard. Normal faults in the Wasatch fault zone such as the Sevier fault probably cut one or more levels of potential structural detachment and penetrate to the base of the seismogenic part of the crust. Such faults are more likely to be the source of infrequent large earthquakes than are faults in the complex structural junctures where late Quaternary deformation is concentrated.

Chapter G: Neotectonics of the Hansel Valley-Pocatello Valley Corridor, Northern Utah and Southern Idaho, by James McCalpin, Robert M. Robison, and John D. Garr. The $1934 \mathrm{M}_{\mathrm{L}} 6.6$ earthquake may be a typical interpluvial maximum event (that is, long recurrence time and small displacement in comparison with the larger, more frequent surface-faulting events that are triggered by pluvial lake water loading).

Chapter H: Structure of the Salt Lake Segment, Wasatch Normal Fault Zone: Implications for Rupture Propagation During Normal Faulting, by R.L. Bruhn, P.R. Gibler, W. Houghton, and W.T. Parry. There are two potential sites of rupture initiation for large earthquakes at the central and southern ends of the Salt Lake fault segment of the Wasatch normal fault zone. The central site may have been the most common position for repetitive rupture initiation during the last 17 million years.

Chapter I: Late Quaternary Displacement on the Morgan Fault, a Back Valley Fault in the Wasatch Range of Northeastern Utah, by J. Timothy Sullivan and Alan R. Nelson. Paleoearthquakes having magnitudes in the range of 6.5 to 7 have occurred on the Morgan fault.

Chapter J: Late Quaternary History of the James Peak Fault, Southernmost Cache Valley, North-Central Utah, by Alan R. Nelson and J. Timothy Sullivan. The James Peak fault may be a westerly splay of the East Cache fault rather than a separate valley-bounding fault.

\section{THE GROUND-SHAKING HAZARD AND ASPECTS OF LOSS ESTIMATION IN THE WASATCH FRONT AREA}

The second volume of Professional Paper 1500, which is being published under separate cover, is concerned with predicting the effects of local site conditions on ground shaking in the Wasatch Front area and developing loss (risk) estimation procedures. Ground-motion and loss estimation studies composing this section are described in Chapters $\mathrm{K}$ through $\mathrm{R}$ :

Chapter K: Site Amplification in the Salt Lake CityOgden-Provo Urban Corridor and the Implications for Earthquake-Resistant Design, by Walter W. Hays. Evaluation of site amplification effects in Utah indicates that soil deposits in the Salt Lake CityOgden-Provo urban corridor should amplify earthquake ground motions, especially when the level of shear strain induced in the soil column is less than about 0.5 percent. 


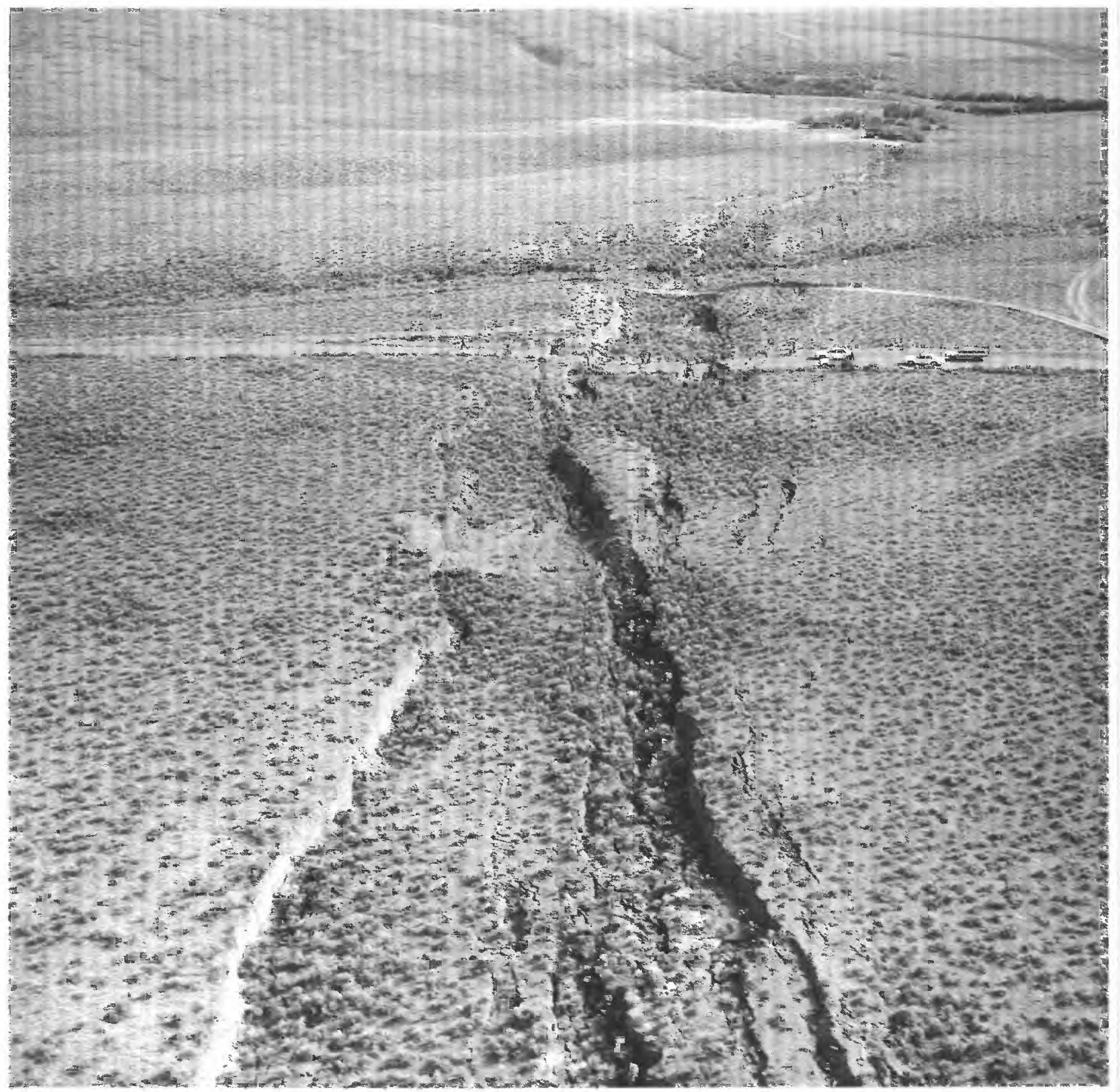

FIGURE 5.-Graben formed in the fault rupture of the 1983 Borah Peak, Idaho, earthquake.

Chapter L: Predicting Strong Ground Motion in Utah, by Kenneth W. Campbell. Near-source attenuation relationships for predicting peak horizontal acceleration and velocity in terms of earthquake magnitude, source-to-site distance, and several sources and site parameters are used to estimate strong ground motion in north-central Utah.
Chapter M: Probabilistic Analysis of Earthquake GroundShaking Hazards Along the Wasatch Front, Utah, by R.R. Youngs, F.H. Swan, M.S. Power, D.P. Schwartz, and R.K. Green. The ground-shaking hazard along the Wasatch Front urban corridor has been assessed by using the geologic and seismologic data base that has been developed for the region. 
Chapter N: Relative Ground Response in Salt Lake City and Areas of Springville-Spanish Fork, Utah, by Kenneth W. King, Robert A. Williams, and David L. Carver. To predict the ground-shaking intensity potential for the Wasatch Front urban corridor, a better understanding of how shallow underlying geology affects ground shaking was developed.

Chapter O: In Situ Poisson's Ratio Measurements Near Provo, Utah, by Richard D. Miller, Don W. Steeples, Kenneth W. King, and Ralph W. Knapp. Classification of sites according to their response to earthquake energy enables engineers to accurately determine structural requirements for individual sites in high- to moderate-risk earthquake zones.

Chapter P: Earthquake Losses in Central Utah, by S.T. Algermissen, E.P. Arnold, K.V. Steinbrugge, Margaret G. Hopper, and P.S. Powers. Estimates of losses in central Utah have been made for a series of simulated earthquakes. Expected maximum losses in the Salt Lake City urban corridor in 50 years at a 10-percent chance of exceedance were also found. The losses range from $\$ 830$ million for a $M_{L} 5.5$ shock on the Provo segment to $\$ 5.5$ billion for a $\mathrm{M}_{\mathrm{S}} 7.5$ quake on the Salt Lake segment.

Chapter Q: Isoseismals of Some Historical Earthquakes Affecting the Wasatch Front Area, Utah, by Margaret G. Hopper. Isoseismals were drawn for 13 historical earthquakes that caused damage-level intensities $(\mathrm{MMI}>\mathrm{VI})^{2}$ in the four Wasatch Front counties of Weber, Davis, Salt Lake, and Utah. The highest historical intensity within any of the four counties was MMI VII.

Chapter R: Seismic-Risk Methods and Estimates for Utility Systems and State-Owned Buildings Along the Wasatch Front, by Craig E. Taylor and Delbert B. Ward. Results of seismic risk projects on Utah facilities reaffirm the iterative nature of these projects.

\footnotetext{
${ }^{2}$ Intensity is "a subjective numerical index describing the severity of an earthquake in terms of its effect on the Earth's surface and on humans and their structures" (Ziony, 1985, p. 18).
}

\section{SUMMARY}

Efforts to assess regional earthquake hazards and risk along the Wasatch Front in Utah are dynamic and multidisciplinary. This report reflects the nature of that program and the research conducted before 1988. Not only are the topics varied-geology, seismology, engineering geology, urban planning, law, economics, and so on-but the level of complexity is also varied. Seismologists and geologists can draw upon many years of research in their disciplines in Utah, whereas researchers in engineering, land use planning, and implementation have had to be pioneers in their fields.

The timeliness and importance of the research contained herein have made it desirable to publish this report before the completion of all the research conducted during the 5 years of the program. The results from ongoing research in Utah are included in Professional Paper 1519 (Gori, 1993), published as a sequel to this one. Eventually, the tectonic processes and their physical and social effects in the Wasatch Front will be truly understood and documented.

\section{REFERENCES CITED}

Gilbert, G.K., 1883, Earthquakes: Salt Lake Daily Tribune, Sept. 16,1883, p. 4.

Gori, P.L., ed., 1993, Applications of research from the U.S. Geological Survey program, assessment of regional earthquake hazards and risk along the Wasatch Front, Utah: U.S. Geological Survey Professional Paper 1519, $167 \mathrm{p}$.

Hamblin, W.K., 1976, Patterns of displacement along the Wasatch fault: Geology, v. 4, p. 619-622.

Schwartz, D.P., and Coppersmith, K.J., 1984, Fault behavior and characteristic earthquakes: Examples from the Wasatch and San Andreas fault zones: Journal of Geophysical Research, v. 89, no. B7, p. 5681-5698.

Smith, R.B., and Richins, W.D., 1984, Seismicity and earthquake hazards of Utah and the Wasatch Front: Paradigm and paradox, in Hays, W.W., and Gori, P.L., eds., Proceedings of Conference XXVI, a workshop on Evaluation of regional and urban earthquake hazards and risk in Utah: U.S. Geological Survey Open-File Report 84-763, p. 73-112.

Ziony, J.I., ed., 1985, Evaluating earthquake hazards in the Los Angeles region-An earth-science perspective: U.S. Geological Survey Professional Paper 1360, 505 p. 

Site Amplification in the Salt Lake City-Ogden-Provo

Urban Corridor and the Implications for

Earthquake-Resistant Design

By WALTER W. HAYS

ASSESSMET OF REGIONAL EARTHQUAKE HAZARDS AND RISK ALONG THE WASATCH FRONT, UTAH

U.S. GEOLOGICAL SURVEY PROFESSIONAL PAPER 1500-K 



\section{CONTENTS}

Abstract.

Introduction

Background

Evaluation of the Bedrock Ground-Shaking Hazard in Utah.

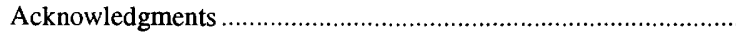

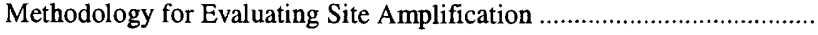

Soils Data

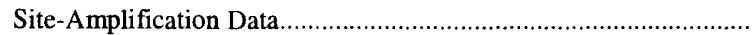

Maps of the Site-Amplification Factors for Salt Lake City, Ogden, and Provo....

Salt Lake City Region ..................................................................

Ogden Region

Provo Region....

Possible Uses of Site-Amplification Data and Maps

Uniform Building Code

Applications in Utah...

Arguments to Minimize or Eliminate Controversy in the

Application of These Data .....

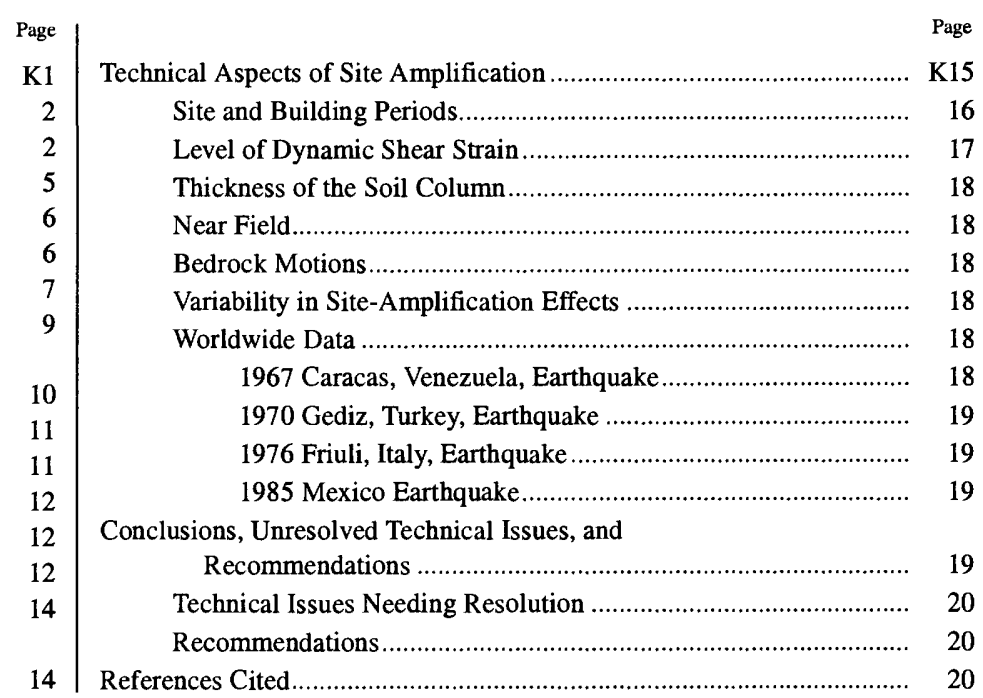

\section{ILLUSTRATIONS}

1. Map showing the Wasatch fault zone.

Page

2. Seismogram showing example of site amplification in Salt Lake City.

3. Schematic representation of the soil-rock column, the bedrock and surface acceleration time histories, the corresponding response spectra derived from them, and the transfer function

4. Graph showing the effect of different types of soil columns on the spectral composition of ground motion...

5,6. Maps showing:

5. Probabilistic bedrock peak horizontal ground acceleration in Utah

6. Probabilistic bedrock peak horizontal ground velocity in Utah

7. Graph showing the range of shear-wave velocities of surficial soils in the San Francisco Bay region

8. Schematic representation of the correlation of the response spectrum derived from a strong-motion accelerogram with a series of damped single-degree-of-freedom harmonic oscillators

9-13. Maps and graphs showing range of transfer functions showing horizontal ground response of sites relative to a rock site on the Wasatch Front, Salt Lake City area:

9. Underlain by thin deposits of sands and gravels (stations $6,8,10,11,12$ ) ...

10. Underlain by thick, soft deposits of silts and clays (stations 17-19, 24, 25)

11. Underlain by rock (stations $5,9,13$ ).

12. Underlain by thick, soft deposits of silts and clays (stations 2,6 ).

13. Underlain by thick, soft deposits of silts and clays (stations 3,4 )

14. Maps showing the spatial variation of site-amplification factors for the period band 0.2 to $0.7 \mathrm{~s}$ for the Salt Lake City,

Ogden, and Provo areas

15, 16. Graphs showing:

15. Estimated range of values of horizontal spectral velocity that might be expected in Salt Lake City, Ogden, or Provo within about $35 \mathrm{~km}$ of a large earthquake on the Wasatch fault zone.

16. Estimate of the level of dynamic shear strain as a function of epicentral distance and magnitude

17. Diagram comparing strong-motion accelerograms in a low-strain environment recorded on firm soil and in soft soil in the September 19, 1985, Mexico City earthquake ...

18. Graph showing the shape of normalized response spectra for three different soil columns proposed in 1985 by the Seismology Committee of the Structural Engineers Association of California.

K2 


\section{TABLES}

2. Locations of portable broadband seismograph stations in Utah that recorded nuclear explosions. 


\title{
ASSESSMENT OF REGIONAL EARTHQUAKE HAZARDS AND RISK ALONG THE WASATCH FRONT, UTAH
}

\section{SITE AMPLIFICATION IN THE SALT LAKE CITY-OGDEN-PROVO URBAN CORRIDOR AND THE IMPLICATIONS FOR EARTHQUAKE-RESISTANT DESIGN}

\author{
By WALTER W. HAYS
}

\begin{abstract}
Like many other urban areas in the United States, Utah's Salt Lake City-Ogden-Provo urban corridor is underlain by soil deposits that will amplify earthquake ground motions in narrow period bands under certain conditions. When soil amplification occurs, the demand on a structure can exceed its capacity to resist the enhanced ground shaking in the narrow period band. In that case, the structure may experience severe damage or collapse.

Estimating the level of surface ground shaking in the Salt Lake City-Ogden-Provo urban corridor is complex because the cities are founded on soils of differing thicknesses, softnesses, and spatial extents. Also, no empirical data from past earthquakes in Utah have been recorded on these soil deposits to demonstrate the effects that they have on the amplitude and spectral composition of the surface ground motion. This gap in knowledge makes it difficult to estimate the level and variability of ground motion expected from future moderate- to large-magnitude earthquakes occurring along the Wasatch Front.

In terms of bedrock motions, a 1982 analysis by S.T. Algermissen and others indicates that earthquakes along the Wasatch Front could, in a 50-year exposure time, generate bedrock ground motions having peak amplitudes of horizontal acceleration and velocity that reach $0.28 \mathrm{~g}$ and $16 \mathrm{~cm} / \mathrm{s}$, respectively. Ordinates of spectral velocity for 5-percent damping are expected to reach $100 \mathrm{~cm} / \mathrm{s}$ at sites underlain by bedrock and even higher values at sites underlain by soil.

The amplitude and spectral characteristics of the surface ground motions at sites in the urban corridor underlain by soil are difficult to quantify precisely, because one must consider (1) the magnitude and epicentral distance of the earthquake, (2) the propagation paths of the body and surface seismic waves, and (3) variations in the thicknesses, softnesses, and geometries of the near-surface soil deposits. To aid the analysis, small-amplitude nuclear-explosion ground-motion data, representative of the low-strain environment, were recorded at 71 sites in the urban corridor underlain by soil and rock. These data have provided new insight, especially in the period band 0.2 to $0.7 \mathrm{~s}$, which corresponds to the fundamental mode of response of two- to seven-story buildings, a dominant category in the Salt Lake City-Ogden-Provo urban corridor. These data, combined with observations of site amplification throughout the world, indicate that the ground-shaking hazard in the Salt Lake City-Ogden-Provo area is worst for sites in the centers of the valleys underlain by thick, soft silts and clays deposited in connection with the filling of the Great Salt Lake in the Pleistocene Epoch. These soft soil
\end{abstract}

deposits cause frequency-dependent amplification of ground motion relative to a bedrock site on the Wasatch Front, where soil-to-rock amplification factors can reach 10 (1,000 percent) in the period band 0.2 to $0.7 \mathrm{~s}$ under conditions of low (0.0001-0.1 percent) levels of shear strain. The soil-to-rock amplification factors in this period band are about 2 (200 percent) when the soil deposits are thin gravels and sands near the Wasatch Front. Because the thickness of silts and clays increases toward the valley centers, the soil-to-rock amplification factors also increase as distance from the Wasatch fault zone increases out to a distance of about $35 \mathrm{~km}$, the valley centers.

Evaluation of site-amplification effects in Utah, in the context of results obtained from worldwide postearthquake investigations and other regional studies, indicates unequivocally that the soil deposits in the Salt Lake City-Ogden-Provo urban corridor should be expected to amplify earthquake ground motions, especially where the Ievel of shear strain induced in the soil column is less than about 0.5 percent. This level of strain would be expected to occur either in large-magnitude earthquakes located tens of kilometers or more from the site or in smallto moderate-magnitude earthquakes having epicenters located as close as a few kilometers from the site. ALso, such an evaluation indicates that a high potential exists for damaging resonance in some two- to seven-story buildings at some locations in the Salt Lake City-OgdenProvo urban corridor during future earthquakes. Data from the September 19, 1985, Mexico earthquake are the best example of what might happen in Utah; they showed that "surprising" damage can occur at great epicentral distances (for example, $400 \mathrm{~km}$ ) when the frequency response of a soft soil column and the building are the same or almost the same.

The technical concern along the Wasatch Front is how to account for the nonlinear soil response in future moderate- to large-magnitude earthquakes that might nucleate directly under a city. Accurate depiction of the nonlinear response of soil to ground shaking in the nearsource area is still a controversial issue that will remain unresolved in Utah until adequate near-source ground-motion data can be acquired to define the bounds on the effect.

The potential for site amplification of ground motion and the matched responses of some soil columns and buildings (resonance) are the most important future implications for earthquake-resistant design of buildings along the Wasatch Front. The seismic design provisions of the Uniform Building Code need to be evaluated to determine if the level of ground motion (that is, peak ground acceleration, peak ground velocity, spectral velocity) expected in a given exposure time and the soil-to- 
rock amplification factors defined by the soil-structure interaction factor in the code are adequate for designing buildings and other facilities in the Salt Lake City-Ogden-Provo urban corridor.

\section{INTRODUCTION}

\section{BACKGROUND}

This paper presents information on site amplification in the Utah's Salt Lake City-Ogden-Provo urban corridor located adjacent to the Wasatch fault zone (fig. 1) and suggests ways to incorporate this information in earthquake-resistant design and land use practices. The Wasatch fault zone is $370-\mathrm{km}$-long zone of active, normal faulting within the Intermountain Seismic Belt. The largest population growth in Utah is occurring in this urban corridor, where approximately $1,000,000$ people (almost 80 percent of the State's population) now live. The building stock in this urban corridor is quite varied and includes low-, medium-, and high-rise buildings, schools, hospitals, the capital, government command centers, and lifeline systems (energy, water, communication, and transportation systems). The Wasatch fault zone has the potential for generating moderate- to large-magnitude earthquakes (Schwartz and Coppersmith, 1984). Ground shaking, surface fault rupture, and earthquake-induced landslides and liquefaction generated in such earthquakes could cause serious social and economic disruption throughout the State unless realistic mitigation measures are devised and implemented before these earthquakes occur.

The Salt Lake City-Ogden-Provo urban corridor, like many other urban areas in the United States (table 1), is underlain by soil deposits that have the potential for amplifying earthquake ground motions in narrow period bands. Before elaborating further, this paper will review some of the terminology used in ground motion literature.

Several terms (for example, site response, soil response, ground response, ground-motion response) are used interchangeably with site amplification in the literature. All of these terms generally carry the same meaning as the term "site amplification," which is used in this report. Amplification is always defined relative to a rock site (figs. 2, 3). Site amplification refers to the frequencyand strain-dependent physical processes that occur when an overlying soil deposit responds to bedrock ground shaking. These physical processes can modify the peak amplitudes of acceleration, velocity, and displacement recorded at the ground surface, but these effects are small and relatively insignificant in comparison with the effects that occur in a discrete period band of the response spectrum. The result is that the spectral composition of the ground motions recorded at the surface of a soil deposit will differ from that of the subsurface bedrock ground motions or the ground motion recorded on

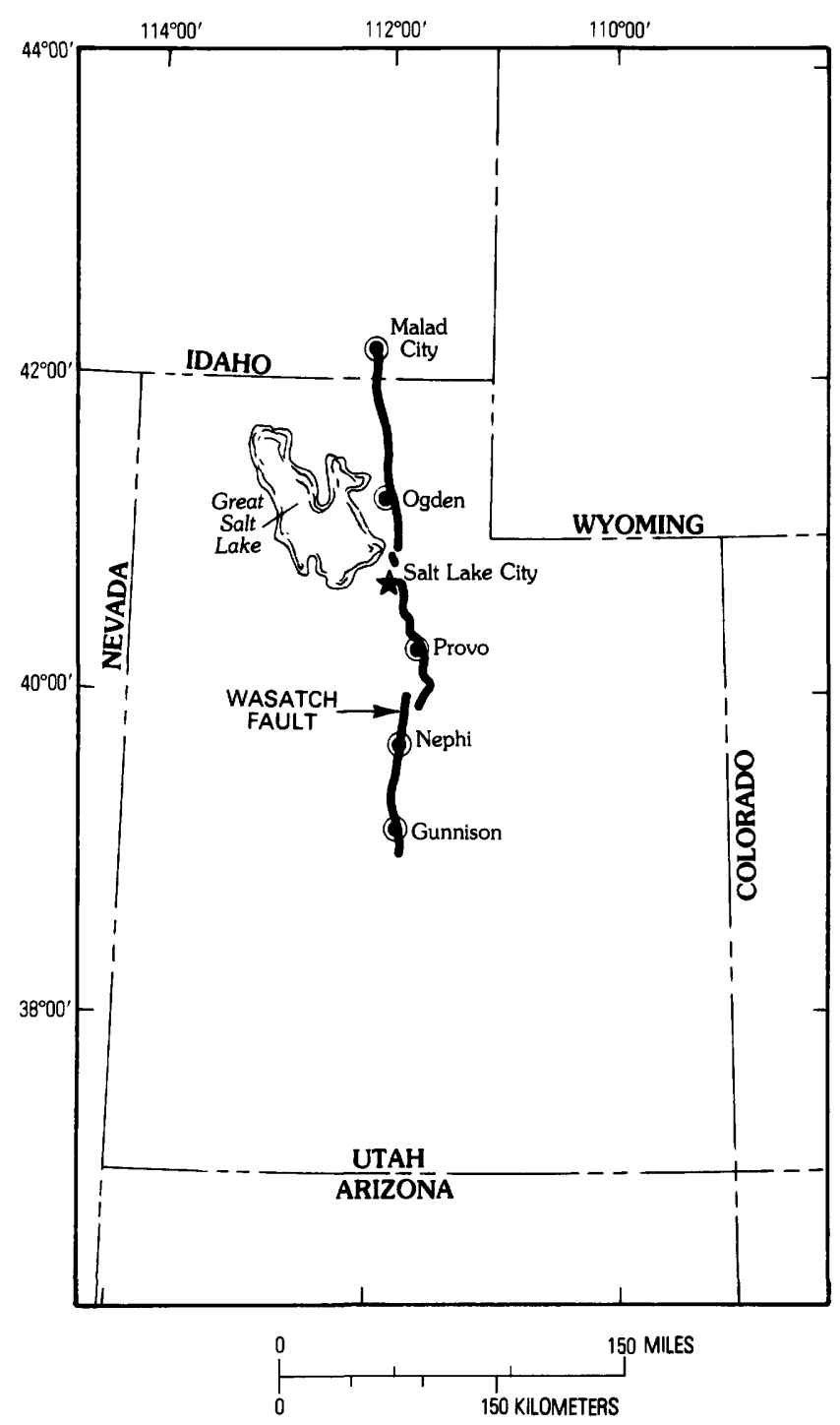

FIGURE 1.-The Wasatch fault zone, a major zone of active, normal faulting. The largest urban centers of Utah are located along the fault zone. Geologic and geomorphic evidence acquired primarily from paleoseismicity studies show that earthquakes having magnitudes of 7 or greater have occurred on the fault in the past 8,000 years.

surface outcrops of bedrock. Whether the peak amplitude of surface acceleration is increased or decreased by the soil column and by how much are the most controversial aspects of site amplification and the subject of continuing debate.

The soil-to-rock amplification factor is a multiplicative factor ranging from a fraction (deamplification) to values of about 10 (1,000 percent). The multiplicative factor is related to a specific part (period band) of the spectrum. A typical description is that the amplification is a factor of 5 (500 percent) for the period band 0.2 to $0.7 \mathrm{~s}$. Unless noted, the soil-to-rock amplification describes a frequency-domain effect for the horizontal component of 
TABLE 1.-Site-amplification effects in various urban areas

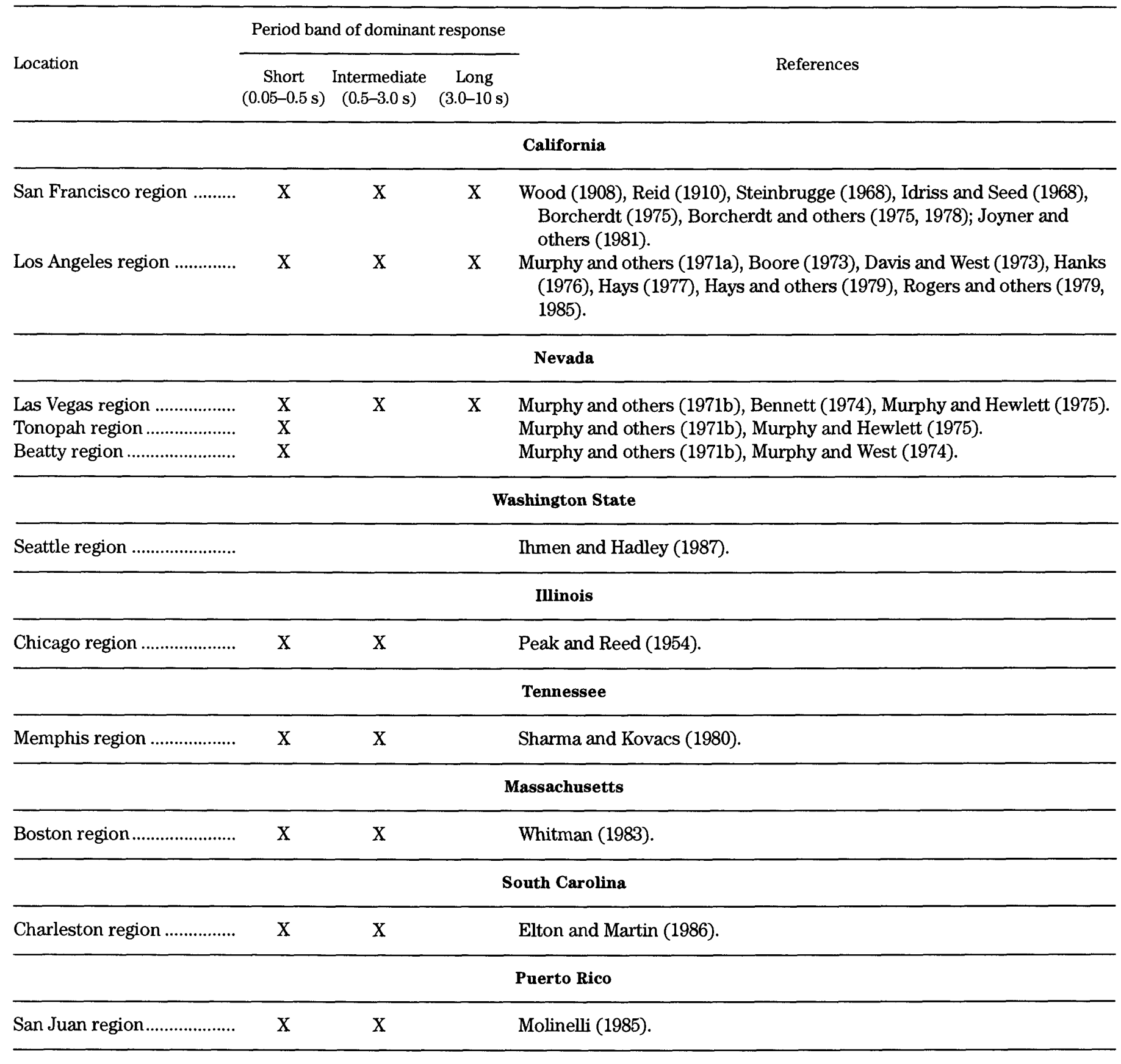

ground motion rather than a time-domain effect. The factor describes empirically what happened at the site underlain by soil relative to the reference site underlain by rock and is described in terms of a specific period, or period band, or the period where the maximum or dominant response occurred (fig. 4). A factor of 5 in the frequency domain does not correspond to a factor of 5 in the time domam. The extent to which the peak amplitude of ground acceleration is increased or decreased depends on what happens physically at zero period (that is, the very high frequencies).

The concept of a transfer function comes from the theory of linear operators (that is, Fourier and Laplace transforms). In this paper, the transfer function is used to describe site amplification in the frequency domaim, and, unless noted, the soil-to-rock transfer function is always derived. For a site underlaim by a soil deposit, the procedure for estimating the transfer function is to divide the 


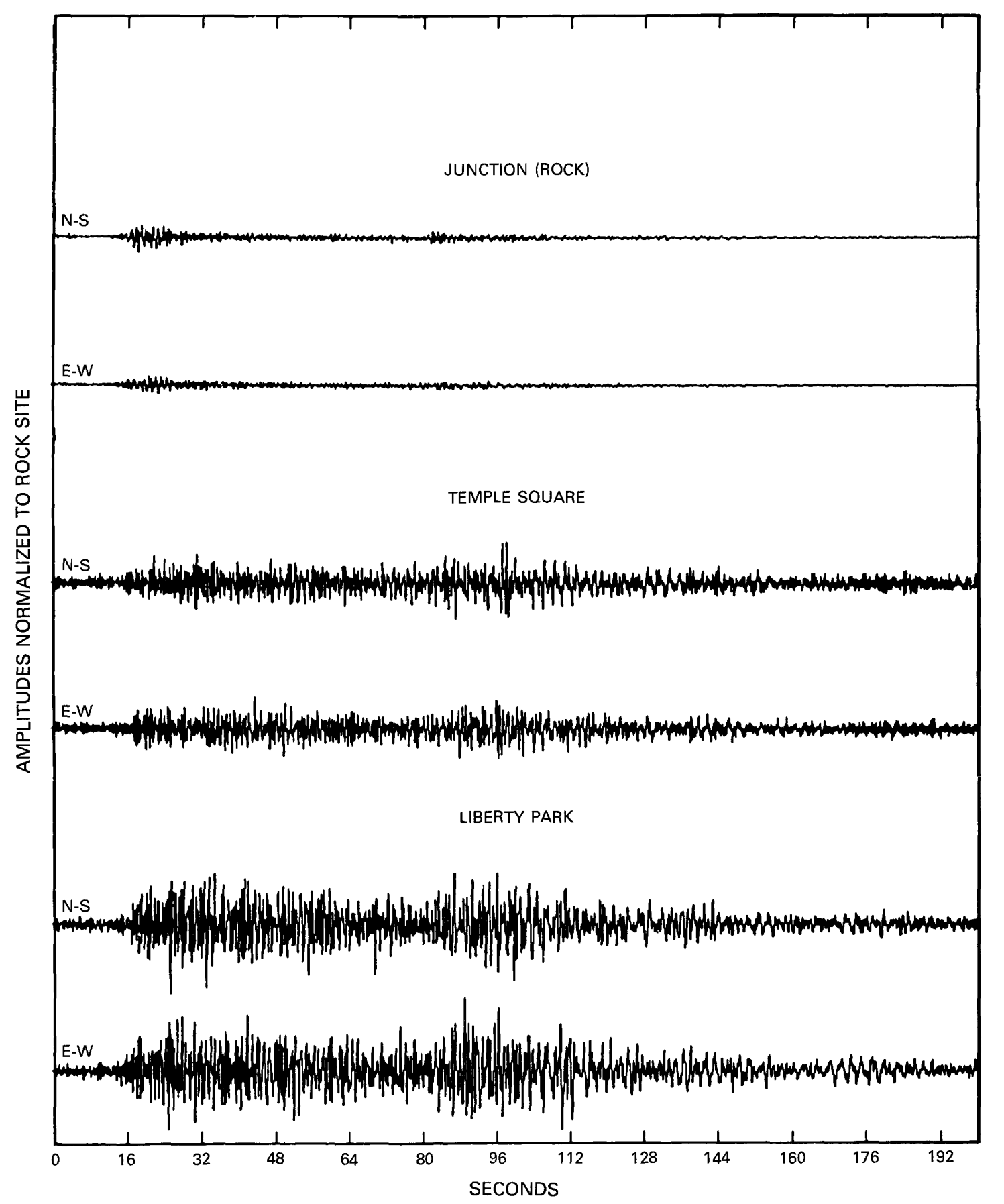

FIGURE 2.-Example of site amplification in Salt Lake City. The velocity time histories depict low-amplitude ground motions representing a low-strain environment, which causes essentially elastic response. The potential for site amplification in the Salt Lake City-Ogden-Provo urban corridor was recognized in the 1960's when ground-motion records at sites underlain by deep, soft soil exhibited higher levels of ground motion than records at nearby sites underlain by rocks or thinner soil deposits.

response spectrum by the corresponding response spectrum for a nearby site that is underlain by rock. The distance between the two sites must be small in comparison with the epicentral distance to each site. The soil-to-rock amplification factor for a discrete period band is deter- mined from the transfer function. In the Fourier analysis of ground-motion data, the typical procedure until recently was to use the amplitude spectrum (which is a display of the amplitude of the sinusoids composing the time history as a function of frequency) and to neglect the 

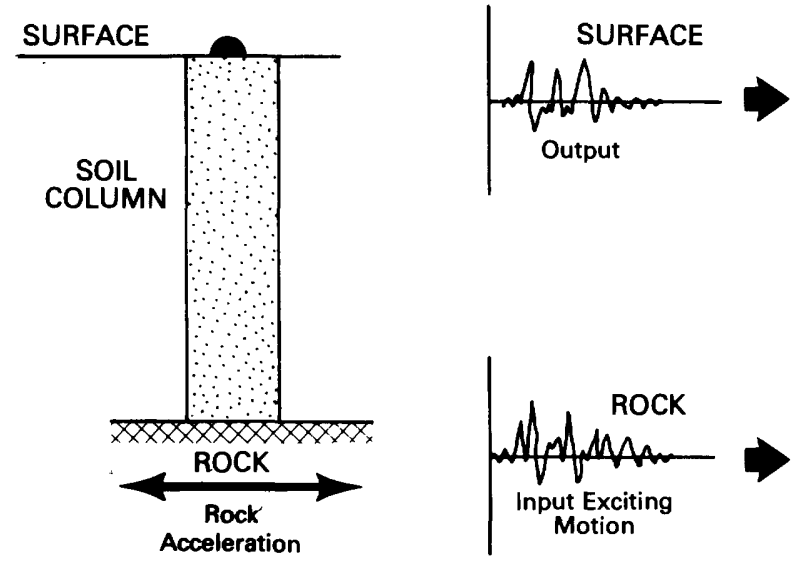

FIGURE 3.-(from left to right) The soil-rock column, the bedrock and surface acceleration time histories, the corresponding response spectra derived from them, and the transfer function. The peak amplitude of acceleration

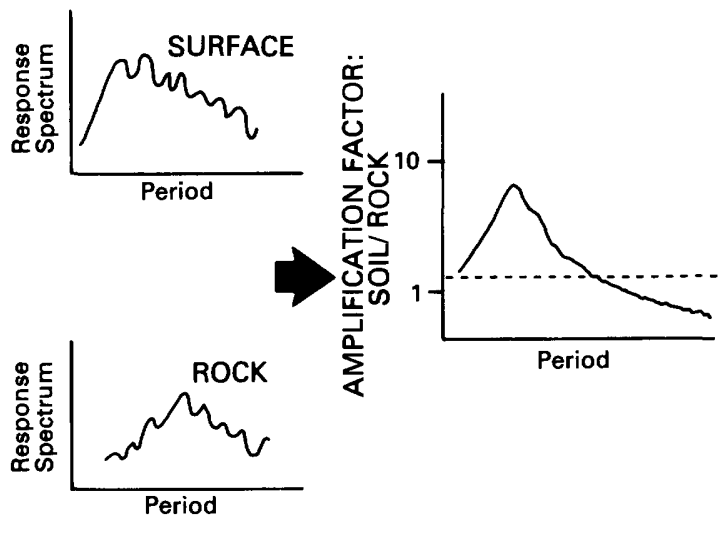

is read from the acceleration time histories. The soil-torock amplification factor for a discrete period band is read from the transfer function. $A$ is peak acceleration.

\section{EVALUATION OF THE BEDROCK GROUND-SHAKING HAZARD IN UTAH}

The bedrock ground-shaking hazard for a community is usually presented in map format, and the soil effects are considered in separate analyses. Such a map displays the spatial variation and relative severity of a physical parameter (such as peak bedrock ground acceleration or bedrock spectral velocity) and provides a basis for dividing a region into geographic zones, each region having a similar severity throughout its extent to earthquakegenerated ground acceleration (or some other groundmotion parameters such as ground velocity or spectral acceleration). Once the level and extent of ground shaking have been defined for all zones in a region, public policy can be devised to mitigate the potential effects through implementation of appropriate actions such as avoidance, land use planning, engineering design, and distribution of losses through insurance (Hays, 1981). Each mitigation strategy requires some sort of map to zone the ground-shaking hazard. The most familiar zoning map is contained in the Uniform Building Code (UBC). Soil amplification is not a part of the UBC zone map but is considered separately in the analysis.

Algermissen and Perkins (1976) and Algermissen and others (1982) constructed the first probabilistic maps that could be used to define the bedrock ground-shaking hazard in Utah. Later, Youngs and others (this volume) constructed a probabilistic ground-shaking hazard map for Utah that included consideration of the surface soil type through the attenuation relation. These maps were based on an integrated analysis of the following types of data:

1. Seismicity.

2. Earthquake source (seismogenic) zones. 


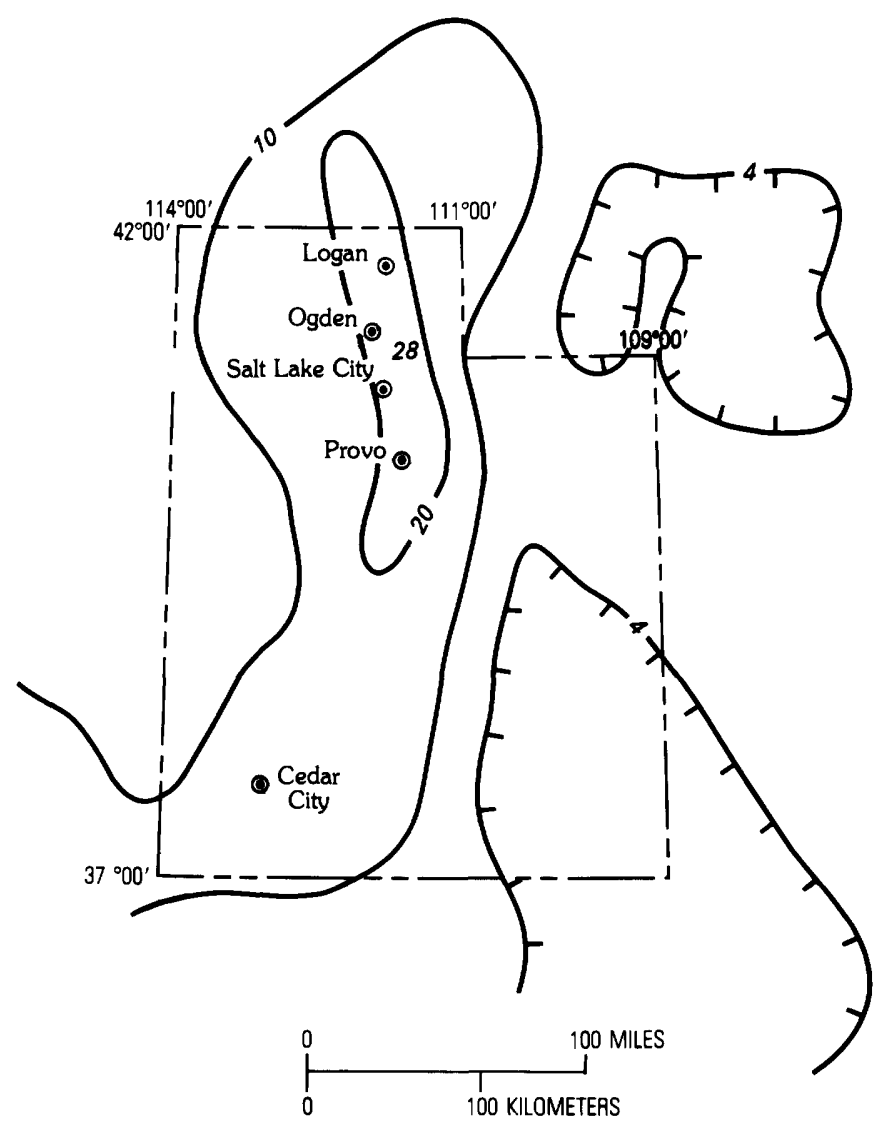

FIGURE 5.-Probabilistic bedrock peak horizontal ground acceleration in Utah. The map is a portion of the national map (scale 1:7,500,000). It represents a 90-percent probability of nonexceedance in a 50-year exposure time (from Algermissen and others, 1982). The contours are expressed in terms of a percentage of the force of gravity. The effects of soil amplification are considered separately.

3. Attenuation of peak acceleration (or another groundmotion parameter), holding bedrock or a soil type constant and allowing magnitude to vary.

The maps prepared by Algermissen and others (1982) were national maps; the portion for Utah is shown in figures 5 and 6 . These maps represent a 90 -percent probability of nonexceedance in an exposure time of 50 years. They display bedrock ground shaking at levels as high as $0.28 \mathrm{~g}$ (fig. 5) and $16 \mathrm{~cm} / \mathrm{s}$ (fig. 6).

\section{ACKNOWLEDGMENTS}

The technical contributions of Kenneth King and Robert Miller (U.S. Geological Survey) are gratefully acknowledged. Both individuals contributed significantly to the acquisition of ground-motion data and surficial geology data along the Wasatch Front and assisted in the analysis of the integrated data.

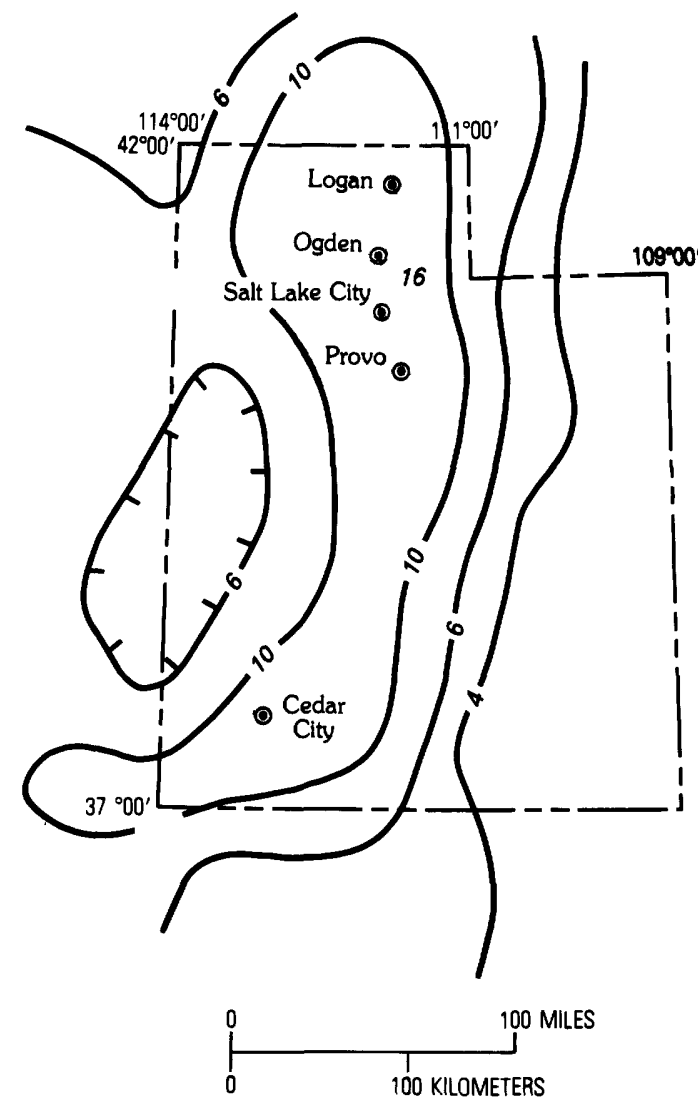

FIGURE 6.-Probabilistic bedrock peak horizontal ground velocity in Utah. The map is a portion of the national map (scale 1:7,500,000). The map represents a 90-percent probability of nonexceedance in a 50-year exposure time (from Algermissen and others, 1982). The contours are expressed in centimeters per second. The effects of soil amplification are considered separately.

\section{METHODOLOGY FOR EVALUATING SITE AMPLIFICATION}

Evaluation of the ground-shaking hazard, including soil effects, in the Salt Lake City-Ogden-Provo urban corridor has proceeded slowly. Scientific and geotechnical data must be acquired along the Wasatch fault zone, analyzed, and integrated with other relevant worldwide data, and a number of technical problems must be resolved (Hays and Gori, 1984).

Evidence from seismic reflection lines shows that individual faults in the Wasatch fault zone dip at low angles and that they probably become listric at a depth of about $8 \mathrm{~km}$, the depth above which earthquakes having magnitudes less than about 5.5 occur. Moderate- to largemagnitude (that is, magnitudes $\left(\mathrm{M}_{\mathrm{S}}\right)$ of about 6.5-7.5) earthquakes, although completely absent in the record of historical seismicity dating from 1847 , appear to nucleate 
at depths of 10 to $15 \mathrm{~km}$ in or near the zone of brittleductile transition (Smith and others, 1985). When frequency-magnitude plots of the recent instrumental seismicity data in Utah are extrapolated linearly, the frequency of small earthquakes is underestimated, and the frequency of large earthquakes is overestimated (Schwartz and Coppersmith, 1984). Geologic data from trenching (that is, fault-offset distances) show that the Wasatch fault is segmented and that repeated large-magnitude earthquakes have occurred in the past 8,000 years at average recurrence intervals of several hundred years (Schwartz and Coppersmith, 1984). The geologic and seismologic data also suggest that the Wasatch fault zone may generate characteristic earthquakes of magnitudes $\left(M_{S}\right)$ 7.0 to 7.5 and that the standard $\log N=a-b M$ relation does not apply in the strict sense (Schwartz and Coppersmith, 1984).

The estimated regional attenuation relation must be based on and constrained by California strong-groundmotion data, not Utah data. No acceleration-attenuation relation exists for Utah earthquakes because strongground-motion data have been recorded from only one earthquake in Utah, the 1962 magnitude 5.7 Cache Valley earthquake.

Empirical strong-motion data from past Utah earthquakes showing the frequency-dependent characteristics of ground response under low-to high-strain ground shaking are completely lacking along the Wasatch Front. Data on building response in Utah earthquakes are also lacking.

Special studies performed to overcome these limitations and to evaluate the potential for site amplification are described below.

\section{SOILS DATA}

A special effort was made in the 1970's (Miller, 1980) to quantify the physical properties of unconsolidated materials along the Wasatch Front so that the response of the various soil deposits to earthquake ground shaking could be determined. Miller's work yielded the following information. Salt Lake City, Ogden, and Provo are founded on several different types of soil deposits. These deposits are from several lakes that filled the Great Salt Lake Basin during the Pleistocene Epoch and can be grouped into three depositional types: onshore, nearshore, and offshore. Onshore deposits are primarily fluvial gravels and coarse sands that form a parallel band along the major mountain fronts. In contrast, nearshore and offshore deposits are lacustrine. Nearshore sediments were deposited on beaches, long shore spits and bars, deltas, and marshes. Offshore deposits consist of very fine sands, silts, and clays that accumulated in quiet, relatively deep water and probably represent the finer

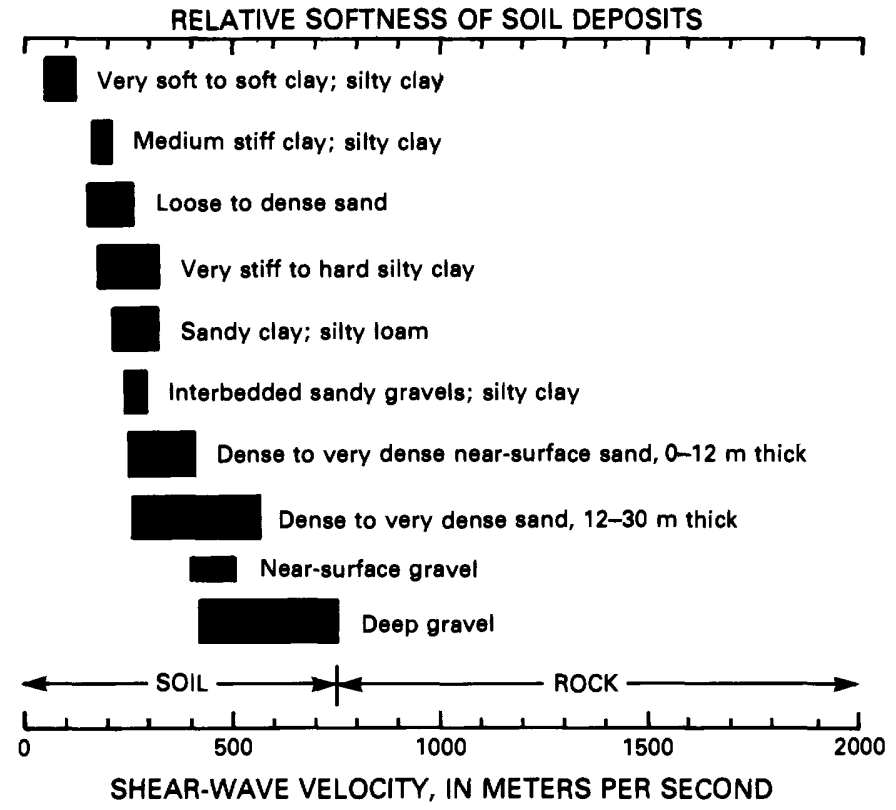

FIGURE 7.-Range of shear-wave velocities of surficial soils in the San Francisco Bay region. The relative softness increases from right to left. For comparison, the thick, soft clay and silt deposits in the Salt Lake City-Ogden-Provo urban corridor have an average shear-wave velocity of $200 \mathrm{~m} / \mathrm{s}$. (After Gibbs and others, 1976.)

portion of debris being carried into the lake from the mountains.

The soil columns in the Salt Lake City area range in thickness from about $100 \mathrm{~m}$ near the Wasatch Front to 900 $m$ in the deepest part of the Jordan River valley, where surficial materials have shear-wave velocities averaging about $200 \mathrm{~m} / \mathrm{s}$ and a natural moisture content by weight of about 43 percent (Miller, 1980). The available information on Ogden and Provo, although less than that on Salt Lake City, suggests that the physical properties of the soil column underlying Ogden and Provo are similar to those underlying the Salt Lake City area. A borehole in the Provo area indicates a shear-wave velocity of about 155 $\mathrm{m} / \mathrm{s}$ for the surficial materials (Miller, 1980). To provide a comparison with another urban area having soils that vary in thickness and softness, the range of values of shear-wave velocities determined for soils in the San Francisco Bay region are given below (Gibbs and others, 1976) and are shown graphically in figure 7 :

55 to $115 \mathrm{~m} / \mathrm{s}$ Very soft to soft clay and silty clay

160 to $190 \mathrm{~m} / \mathrm{s}$ Medium stiff clay to silty clay

150 to $250 \mathrm{~m} / \mathrm{s}$ Loose to dense sand

170 to $305 \mathrm{~m} / \mathrm{s}$ Very stiff to hard clay and silty clay

210 to $310 \mathrm{~m} / \mathrm{s}$ Sandy clay and silty loam

240 to $270 \mathrm{~m} / \mathrm{s}$ Interbedded sandy gravels and silty clay

250 to $400 \mathrm{~m} / \mathrm{s}$ Dense to very dense near-surface sand 0 to $12 \mathrm{~m}$ thick 
TABLE 2.-Locations of portable broadband seismograph stations in Utah that recorded nuclear explosions

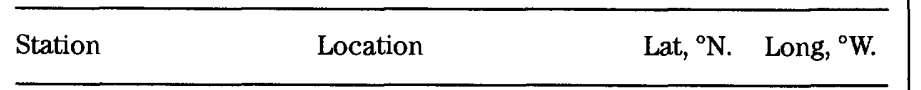

\begin{tabular}{lll}
\hline \multicolumn{3}{c}{ Logan area } \\
\hline 1..... Logan Airport & 41.846 & 111.894 \\
3..... Young Ward & 41.708 & 111.909 \\
4..... 90 S. Main, Providence & 41.707 & 111.816 \\
5 ..... Utah State University & 41.745 & 111.813 \\
16 ..... Logan Canyon & 41.741 & 111.786
\end{tabular}

\begin{tabular}{lll}
\hline \multicolumn{3}{c}{ Ogden area } \\
\hline $1 \ldots . .2095$ N 100 E & 41.288 & 111.983 \\
$2 \ldots . .1049$ Kiesel & 41.246 & 111.974 \\
$3 \ldots \ldots .4376$ W 2350 N & 41.303 & 112.086 \\
$4 \ldots .$. Rainbow Bowling Lanes & 41.236 & 111.928 \\
$5 \ldots .$. Rogers Poultry Farm & 41.253 & 111.969 \\
$6 \ldots .$. Weber Main Library & 41.221 & 111.964 \\
$7 \ldots . .4463$ Forrest Green Drive & 41.180 & 111.942 \\
$8 \ldots .$. Syracuse Fire Department & 41.092 & 112.055 \\
$11 \ldots . .4725$ S 300 W & 41.180 & 111.970 \\
$12 \ldots . .2550$ S 4476 W, Taylor & 41.164 & 112.123 \\
$13 \ldots .$. Hooper Post Office & 41.164 & 112.123 \\
$16 \ldots . .6675$ 900 S, West Warren & 41.266 & 112.152 \\
$20 \ldots . .100$ N 844 W, Farmington & 39.989 & 111.912 \\
\hline
\end{tabular}

Salt Lake City area

\begin{tabular}{|c|c|c|}
\hline 1...... West Bank of Jordan River & 40.652 & 111.929 \\
\hline $2 \ldots . .1663$ Mt. View & 40.639 & 111.844 \\
\hline 13...... Rotary Park & 40.826 & 111.801 \\
\hline 4...... Liberty Park & 40.749 & 111.870 \\
\hline${ }^{15}$....... Georges Hollow, Fort Douglas & 40.768 & 111.809 \\
\hline 6...... Utah Geological and Mineral Survey & 40.755 & 111.827 \\
\hline $17 \ldots . . .3100$ Kennedy Drive & 40.757 & 111.791 \\
\hline 8..... Southern side of Parleys Creek & 40.708 & 111.809 \\
\hline 19 ...... Mill Creek Canyon & 40.692 & 111.770 \\
\hline $10 \ldots . . .4500$ South Street & 40.679 & 111.801 \\
\hline 11 ...... Castro Springs & 40.673 & 111.809 \\
\hline 12 ...... North bank of Dry Creek & 40.569 & 111.821 \\
\hline${ }^{1} 13$...... Little Cottonwood Canyon & 40.573 & 111.763 \\
\hline 14 ...... 1932 Parkridge & 40.616 & 111.839 \\
\hline 15...... Sandy City Fire Station & 40.580 & 111.872 \\
\hline 16...... Murray City & 40.639 & 111.892 \\
\hline 17 ...... Salt Lake City International Airport & 40.785 & 111.955 \\
\hline 18...... Saltair & 40.769 & 112.101 \\
\hline $\begin{array}{l}19 \text {...... Salt Lake City International Airport } \\
\text { fire station }\end{array}$ & 40.783 & 111.979 \\
\hline 20 ...... Hidden Valley G.C. & 40.556 & 111.839 \\
\hline $21 \ldots . .12000 \mathrm{~S} 1700 \mathrm{E}$ & 40.536 & 111.830 \\
\hline
\end{tabular}

TABLE 2.-Locations of portable broadband seismograph stations in Utah that recorded nuclear explosions-Continued.

\begin{tabular}{|c|c|c|}
\hline Location & Lat, ${ }^{\circ} \mathrm{N}$. & Long, ${ }^{\circ} \mathrm{W}$. \\
\hline \multicolumn{3}{|c|}{ Salt Lake City area-Continued } \\
\hline 22.......Bateman Dairy Farm & 40.612 & 111.927 \\
\hline $23 \ldots \ldots . .10875 \mathrm{~S} 12 \mathrm{~W}$ & 40.554 & 111.922 \\
\hline 24........ North Jordan Park & 40.752 & 111.918 \\
\hline 25....... Salt Lake City Fire Station \#7 & 40.776 & 111.920 \\
\hline 26.......Capitol Building & 40.777 & 111.887 \\
\hline 27.......University of Utah & 40.776 & $111: 847$ \\
\hline 28.......Taylorsville & 40.663 & 111.949 \\
\hline $29 \ldots \ldots . . .4060 \mathrm{~S} 725 \mathrm{~W}$ & 40.683 & 111.910 \\
\hline 30.......Sugar House Library & 40.721 & 111.866 \\
\hline $31 \ldots \ldots 3702 \mathrm{~S} 645 \mathrm{E}$ & 40.691 & 111.872 \\
\hline $32 . . . . .2838$ Imperial & 40.709 & 111.843 \\
\hline $33 \ldots \ldots 6100 \mathrm{~S} 700 \mathrm{~W}$ & 40.641 & 111.917 \\
\hline $34 \ldots \ldots . . .4130 \mathrm{~S} 1221 \mathrm{E}$ & 40.682 & 111.856 \\
\hline 35.......2270 E. Evergreen Street & 40.699 & 111.832 \\
\hline $36 \ldots . . . .1560$ lndustrial Road & 40.773 & 112.011 \\
\hline 37......4036 South Golden Circle & 40.684 & 111.852 \\
\hline 38.......3915 Brooklane Drive & 40.687 & 111.848 \\
\hline 39......1759 Mt. View & 40.691 & 111.841 \\
\hline 41.......1964 East Evergreen Street & 40.697 & 111.832 \\
\hline
\end{tabular}

\section{Provo area}

\begin{tabular}{|c|c|c|}
\hline 1.......Olmstead Office Building & 40.315 & 111.655 \\
\hline 12.......Olmstead & 40.326 & 111.639 \\
\hline 3.......Orem Fire Station & 40.314 & 111.695 \\
\hline 4........ Orem city offices & 40.299 & 111.693 \\
\hline 5....... Cherry Hill Farm & 40.264 & 111.717 \\
\hline 6.......Provo Airport & 40.221 & 111.718 \\
\hline 7.......Boat house, Utah Lake & 40.236 & 111.736 \\
\hline 8.......Provo city offices & 40.238 & 111.671 \\
\hline $9 \ldots \ldots . . . K-96$ Radio Station & 40.213 & 111.671 \\
\hline 10.......Youd Farm & 40.133 & 111.730 \\
\hline 11.......Springville Fire Station & 40.167 & 111.610 \\
\hline
\end{tabular}

\begin{tabular}{|c|c|c|}
\hline \multicolumn{3}{|c|}{ Cedar City area } \\
\hline 1.......Three Peaks & 37.717 & 113.225 \\
\hline 12.......Coal Canyon & 37.679 & 113.050 \\
\hline 3........Rush Lake & 37.864 & 113.064 \\
\hline 4........Sevensville & 37.786 & 113.092 \\
\hline 5.......College of Southern Utah & 37.675 & 113.067 \\
\hline 6.......SUSC football field & 37.676 & 113.077 \\
\hline 7.......Highway 14 trailer park & 37.678 & 113.055 \\
\hline 8.......Cemetery & 37.689 & 113.063 \\
\hline $9 . \ldots . .$. Settling pond & 37.656 & 113.068 \\
\hline 10.......Imperial 400 Motel & 37.673 & 113.061 \\
\hline
\end{tabular}

\footnotetext{
1Sites underlain by rock; all other sites underlain by unconsolidated sediments.
} 


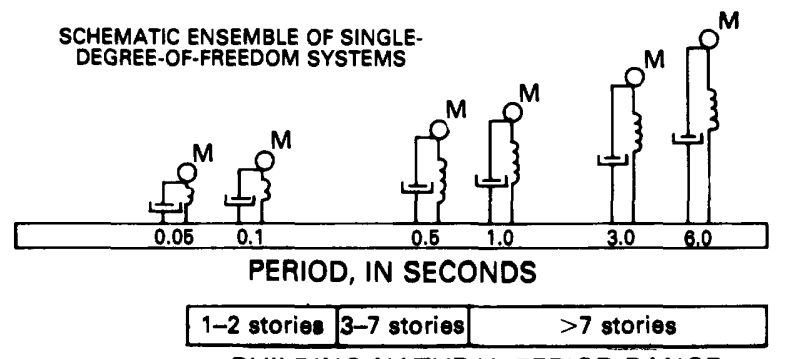

BUILDING NATURAL PERIOD RANGE

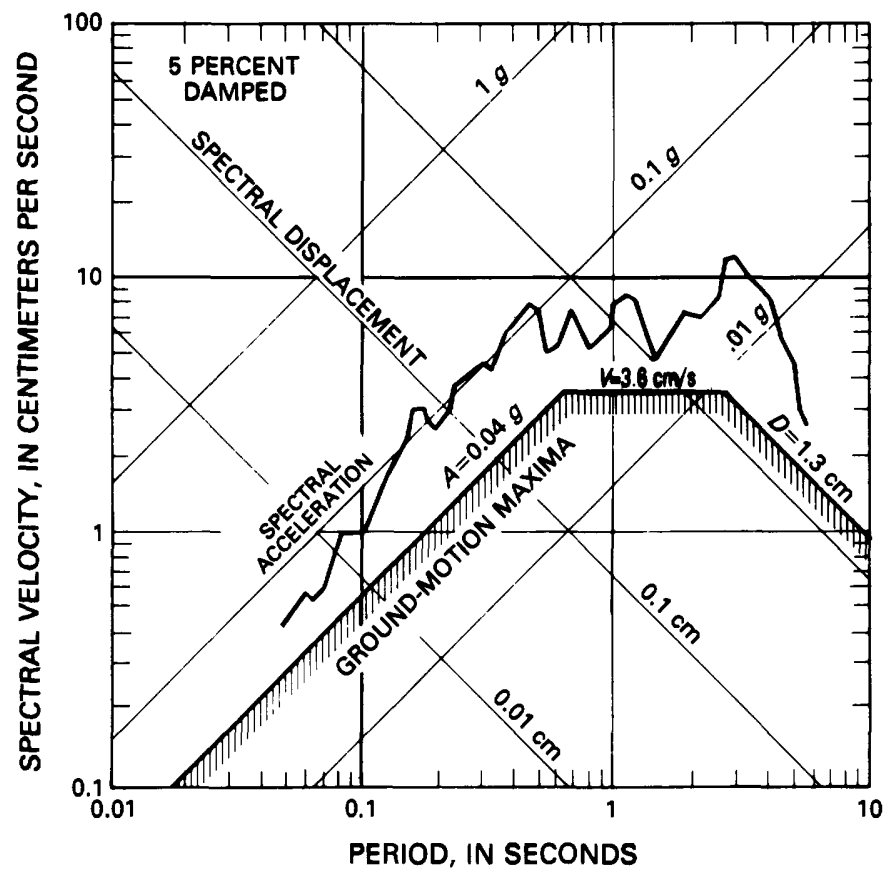

FIGURE 8.-Correlation of the response spectrum derived from a strongmotion accelerogram with a series of damped single-degree-offreedom harmonic oscillators. The peak amplitude of acceleration is the zero-period asymptote of the spectrum. The amplitude of peak displacement $(D)$ is the infinite-period asymptote. The site and building response are analyzed through the response spectrum. $M$ is mass, $A$ is peak ground acceleration, and $V$ is peak ground velocity.

250 to $570 \mathrm{~m} / \mathrm{s}$ Dense to very dense sand 12 to $30 \mathrm{~m}$ thick

400 to $55 \mathrm{~m} / \mathrm{s}$ Near-surface gravel

420 to $750 \mathrm{~m} / \mathrm{s}$ Deep gravel

\section{SITE-AMPLIFICATION DATA}

Two strategies were used to offset the limitations posed by the lack of ground-motion data from past Utah earthquakes (Hays and others, 1978; Hays, 1980): (1) nuclear-explosion ground-motion data recorded simultaneously at selected sites (table 2) underlain by soil and rock in each city were used as a basis for deriving soil transfer functions to give a bound on site amplification under low-strain conditions and (2) soil transfer functions were related to the depositional environment and physical properties (for example, shear-wave velocity, bulk density, lithology, and water content) of the 71 recording sites in the Salt Lake City-Ogden-Provo urban corridor. Ground-motion measurements from a dozen nuclear explosions at the Nevada Test Site were made simultaneously at sites underlain by soil and rock in each city as well as sites in Logan and Cedar City to provide some comparison of effects. Recording sites underlain by rock on the Wasatch Front encompassed limestone, quartz monozite, shale, and sandstone. Portable broadband velocity seismographs were deployed at each location. Acceleration and displacement time histories were derived from the velocity records along with 5-percent damped response spectra. These data provide complete information on the amplitude and spectral response of the ground motion recorded ar each site, but they are representative only of the small-amplitude, low-strain environment.

A brief discussion of the response spectrum is provided below to facilitate understanding. The response spectrum is a common representation of the spectral composition of earthquake and ground motion. The response spectrum (fig. 8) depicts graphically the peak amplitude of each time history, representing the individual response of each one of a series of damped, simple harmonic oscillators to the acceleration time history input at the base of the oscillator. The structural engineer uses the response spectrum having 2 to 5 percent damping as a tool to correlate characteristics of ground motion with the elastic response of buildings of various heights and types. The concepts of the response spectrum are also incorporated in the UBC and other building codes.

Soil transfer functions were derived in each city from the response spectra (figs. 9-13). Many investigators (for example, Borcherdt, 1975; Rogers and Hays, 1978; Hays and others, 1978, 1979; Hays, 1980) have shown that the transfer function, defined as the average ration of the 5percent damped, horizontal velocity response spectra for a pair of soil-rock sites, is a sensitive function of the properties of the soil columns underlying the sites. Rogers and Hays (1978) showed that a transfer function can be determined reasonably well from either earthquake or nuclearexplosion ground-motion data because the source effects are essentially eliminated when taking the ratios, although there may be a significant difference in the levels of peak ground accelerations and dynamic shear strain (defined approximately by the ratio of the peak particle velocity to the shear-wave velocity of the soil). Hays and others (1978) concluded from the lack of dependence of site amplification on amplitude that the response of some soil deposits in Nevada is probably linear up to about 0.5percent strain. However, this conclusion cannot be verified for the Salt Lake-City-Ogden-Provo urban corridor until earthquake data have been recorded. 


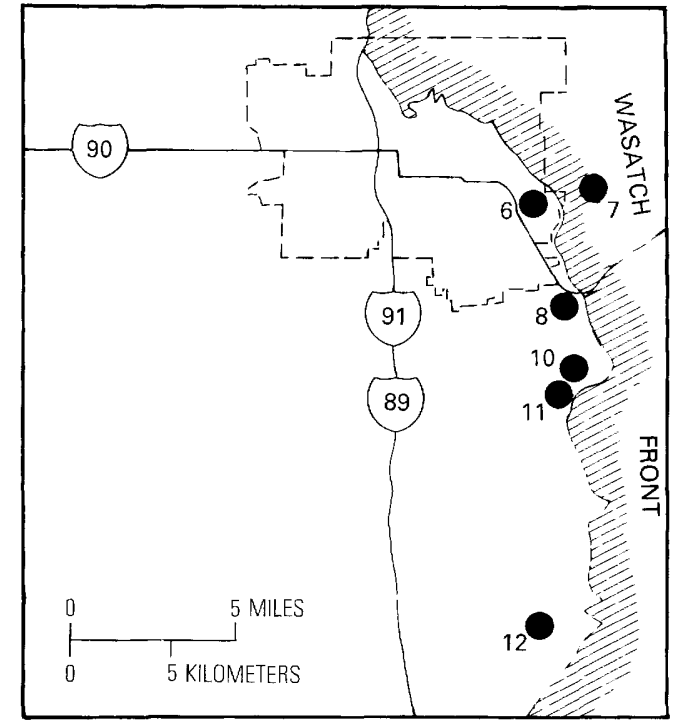

FIGURE 9.-Range of transfer functions showing horizontal ground response of sites underlain by thin ( $150 \mathrm{~m}$ or less) deposits of sands and gravels (stations $6,8,10,11,12$ ) relative to a rock site (station 7 ) on the Wasatch Front in

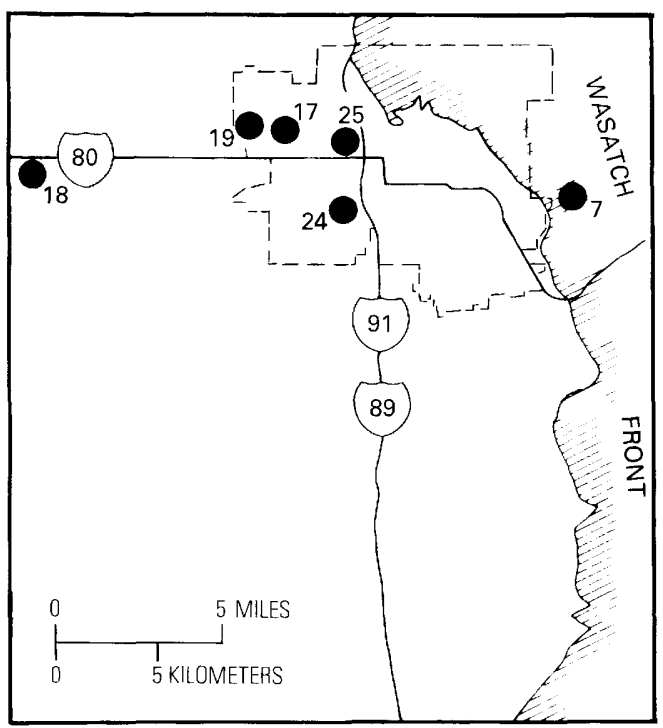

FIGURE 10.-Range of transfer functions showing horizontal ground response of sites underlain by thick $(450-750 \mathrm{~m})$, soft deposits of silts and clays (stations 17-19, 24, 25) relative to a rock site (station 7) on the Wasatch Front in

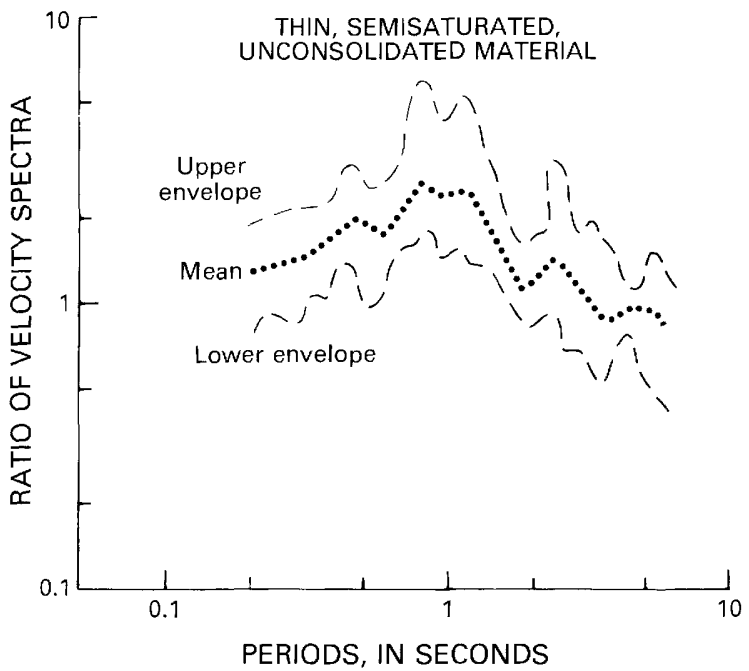

the Salt Lake City area. Ground response is shown in terms of a mean transfer function. These data represent a low-strain environment. The dashed line shows the Salt Lake City limits.

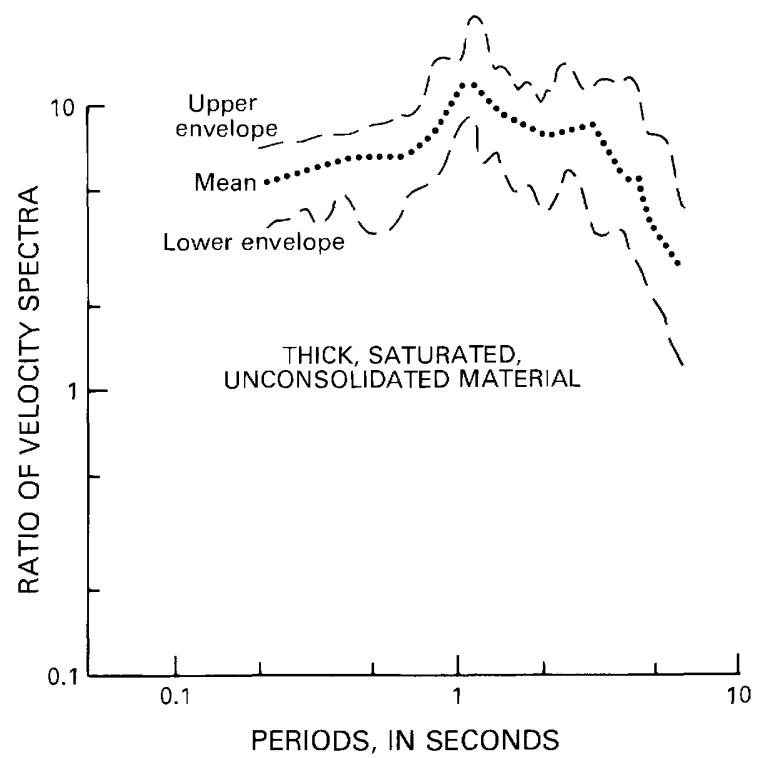

the Salt Lake City area. Ground response is shown in terms of a mean transfer function. These data represent a low-strain environment. The dashed line shows the Salt Lake City limits.

\section{MAPS OF THE SITE-AMPLIFICATION FACTORS FOR SALT LAKE CITY, OGDEN, AND PROVO}

Maps showing the spatial variation of the soil-to-rock amplification factors were prepared for Salt Lake City, Ogden, and Provo (fig. 14). These maps were based on the mean value of the soil transfer function in a specific period band- 0.2 to $0.7 \mathrm{~s}-$ derived from small-amplitude nuclear-explosion data (Hays and King, 1982, 1984). This period band was selected because the signal-to-noise ratio is best for this band and also because it correlates roughly with the fundamental response mode of two- to seven-story buildings, a dominant group in this urban corridor. 


\section{SALT LAKE CITY REGION}

Soil-to-rock or site-amplification factors in the Salt Lake City region for the period band 0.2 to $0.7 \mathrm{~s}$ are shown in figure $14 \mathrm{~A}$. Data for this period band indicate the following:

1. Site amplification factors vary from 1 to 8.5 within the corporate limits of the city.

2. Site amplification factors (relative to a site underlain by rock on the Wasatch Front) increase to the west with increasing distance from the Wasatch fault zone. This effect, which correlates with the transition from stiff soils near the Wasatch Front to thick, soft soils in

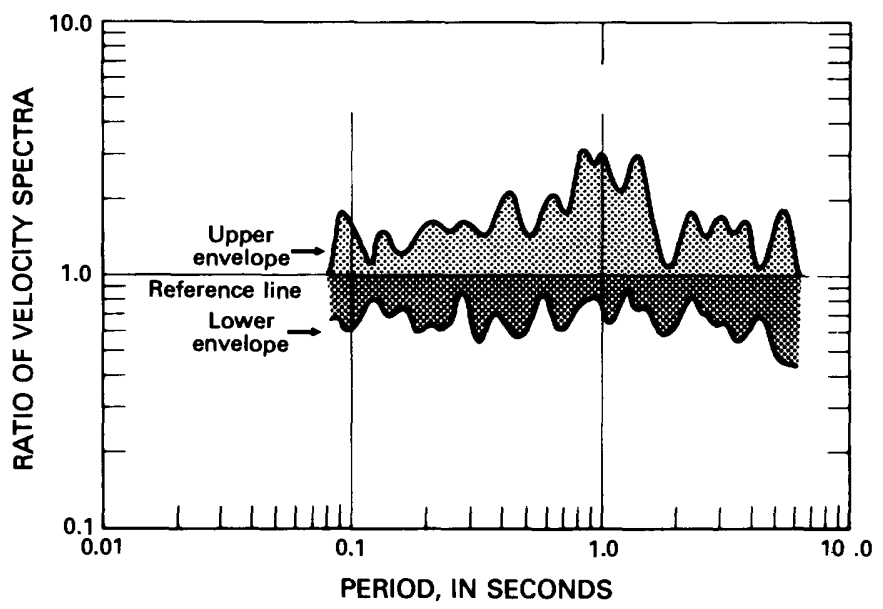

FIGURE 11.-Range of transfer functions showing horizontal ground response of sites underlain by rock (stations $5,9,13$ ). The reference bedrock station is station 7 on the Wasatch Front in the Salt Lake City area. the valley center, offsets to some degree the normal decay of the peak amplitudes and spectral ordinates of ground motion with distance from the fault zone. The effect would be most important when the hypocenters are 20 to $50 \mathrm{~km}$ from Salt Lake City.

3. Site-amplification factors are as much as $10(1,000$ percent) at sites underlain by the thick (500-900 m), soft deposits of clays and silts in the center of the valley, whereas they are about 2 (200 percent) at sites underlain by the relatively thinner $(150 \mathrm{~m})$ deposits of sand and gravels near the Wasatch Front. These data suggest a high damage potential for two- to seven story buildings in parts of Salt Lake City when the response of the soil column and the response of the building are closely matched.

\section{OGDEN REGION}

The site-amplification factors in the Ogden region for the period band 0.2 to $0.7 \mathrm{~s}$ are shown in figure $14 \mathrm{~B}$. Data for this period band show the following:

1. The spatial variation of the site-amplification factors is rapid but not as rapid as that in the Salt Lake City (and Provo) area.

2. The site-amplification factors (relative to a rock site on the Wasatch Front) are as great as 5 (500 percent) and are greatest for the thick, soft deposits of clays and silts located in the valley center some distance from the Wasatch Front. Except in one zone, the factors also increase with increasing distance from the surface trace of the fault zone. The explanation for the zone of
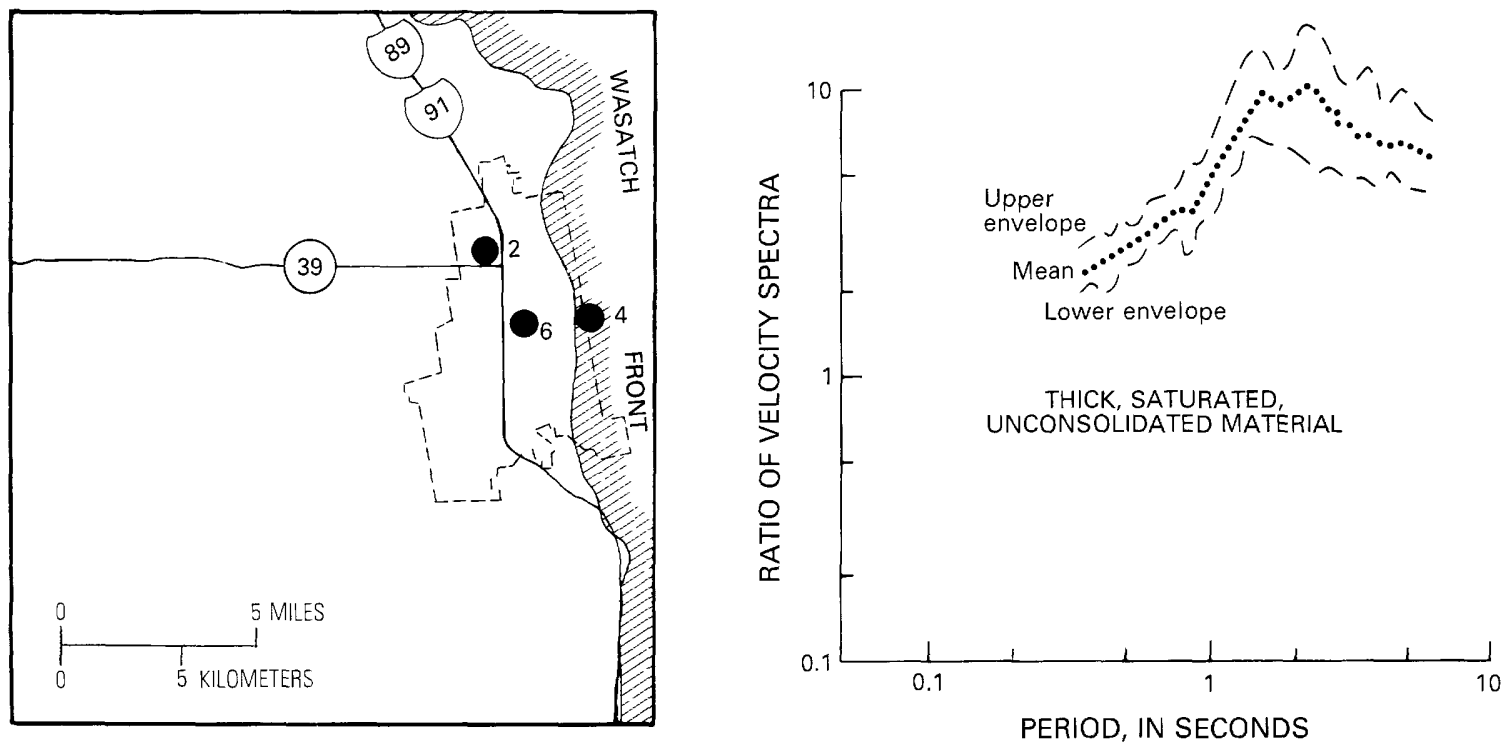

FIGURE 12.-Range of transfer functions showing horizontal ground response of sites underlain by thick, soft silts and clays (stations 2,6 ) relative to a rock site (station 4) on the Wasatch Front in the Ogden area. These data represent a lowstrain environment. The dashed line shows the Ogden city limits. 

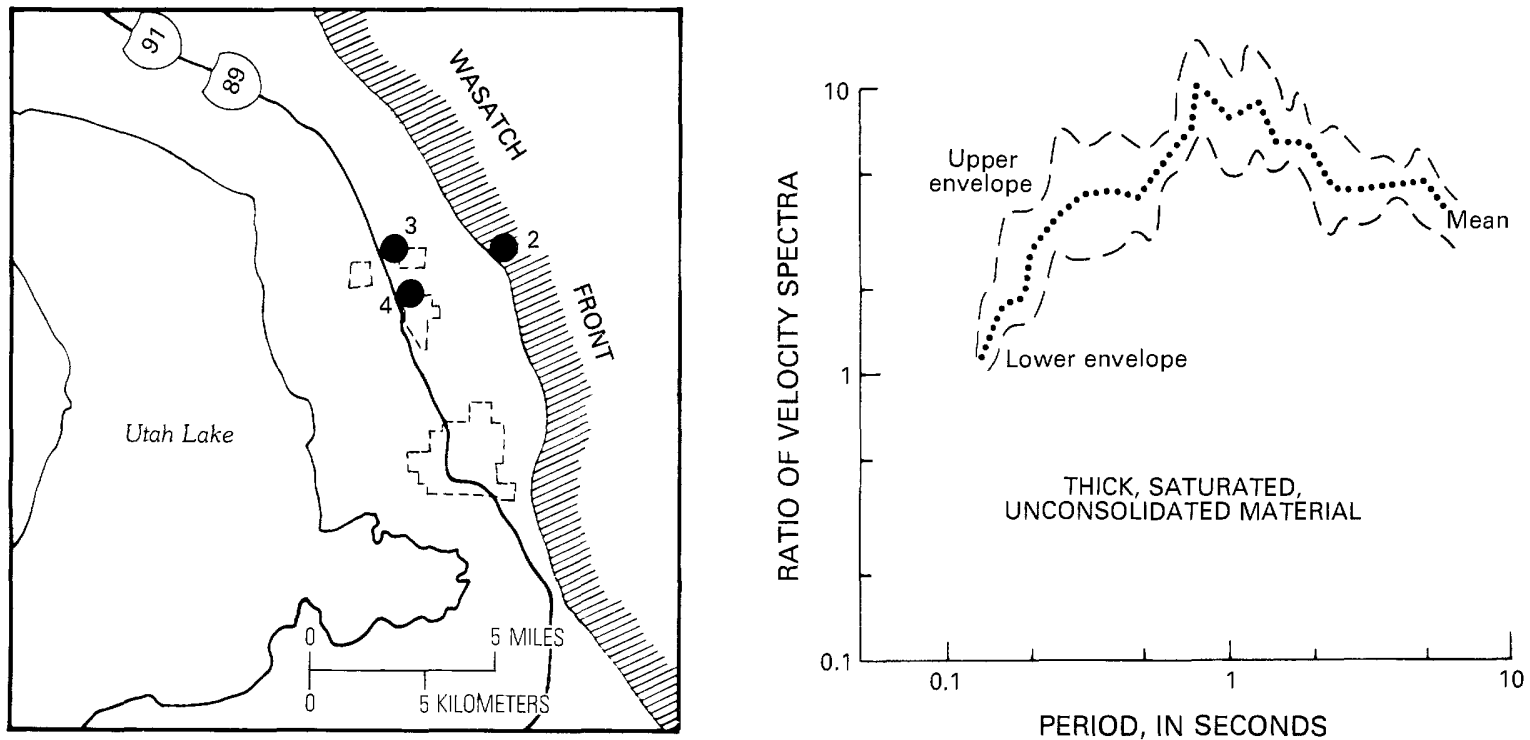

FIGURE 13.-Range of transfer functions showing horizontal ground response of sites underlain by thick, soft deposits of silts and clays (stations 3,4 ) relative to a rock site (station 2) on the Wasatch Front in the Provo area. Stations 3 and 4 are located in the Orem area. These data represent a low-strain environment. The dashed lines show municipal boundaries.

low site amplification is unknown at present, but a local soil deposit having a value of shear-wave velocity higher than normal is suspected as the cause.

\section{PROVO REGION}

The site-amplification factors (relative to a rock site on the Wasatch Front) in the Provo area are shown in figure $14 C$ for the period band 0.2 to $0.7 \mathrm{~s}$. These data lead to the following conclusions:

1. The site-amplification factors vary from 1 to 7.5 over a distance of only $10 \mathrm{~km}$ and increase with increasing distance westward from the surface trace of the Wasatch fault zone, as they do in Salt Lake City and Ogden.

2. The greatest site-amplification factors (fig. 14) correlate with thick, soft deposits of clays and silts located some distance from the surface trace of the fault zone, and the smallest site-amplification factors correlate with relatively thin deposits of gravel and sand near the Wasatch Front.

\section{POSSIBLE USES OF SITE-AMPLIFICATION DATA AND MAPS}

\section{UNIFORM BUILDING CODE}

In Utah, considerable new knowledge is becoming available on the earthquake potential of specific faults, the bedrock ground-shaking hazard, soil amplification, earthquake-induced ground failure, and other earthquake- related phenomena. Also, recent damaging earthquakes (for example, the September 19, 1985, Mexico earthquake) have provided engineers with important information on earthquake-resistant design. This new knowledge has not yet been fully incorporated in the UBC or in the design of structures in Utah.

The UBC (Uniform Building Code) (International Conference of Building Officials, 1988), the most widely used standard for earthquake-resistant design, contains the following commentary about seismic design:

\begin{abstract}
Basically, the problem is that the entire phenomenon, from the earthquake ground motion to the realistic response of structures to this ground motion, is very complex. Codes, of necessity, are generalized simplifications. Complex mathematical analyses have been made on simple and idealized structures subjected to past earthquake ground motions. These have been helpful in improving our understanding of the phenomenon. However, for purposes of design of the vast majority of structures, it is necessary to reduce this complex, dynamic problem to one of equivalent static lateral forces. These can be related to the dynamic characteristics of the structure. They provide the basic code criteria, applied with stresses within the elastic limit. However, in applying these simplified concepts, the structural engineer must do this with sound judgment that can only be developed with experience, observation, and study of the earthquake phenomenon. He must be especially aware of the nature of the response of the particular structure under design and he must evaluate the capabilities of the structure to perform satisfactorily beyond the elastic-code-stipulated stresses.
\end{abstract}

The UBC is a minimum standard to assure public safety. Its requirements are intended to safeguard against major failures and loss of life. The aim of the code is to provide structures that will: 

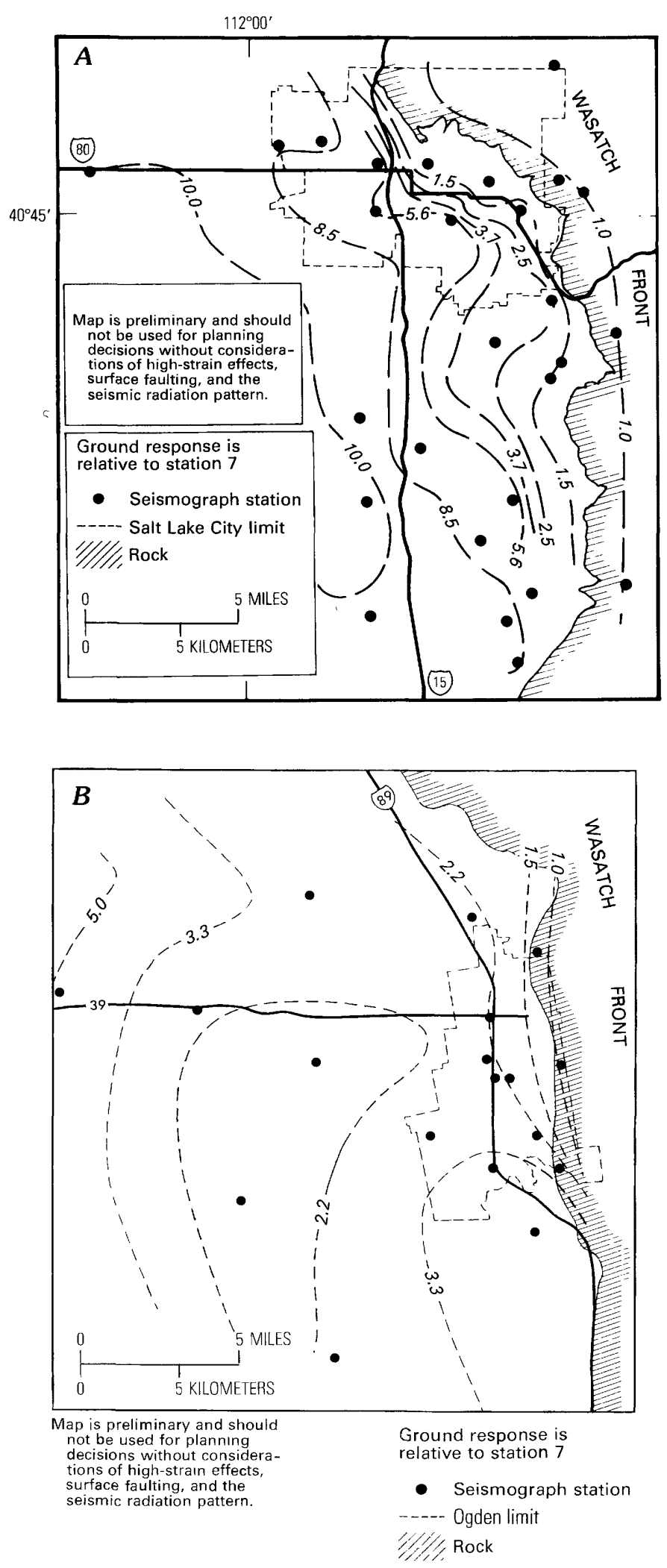

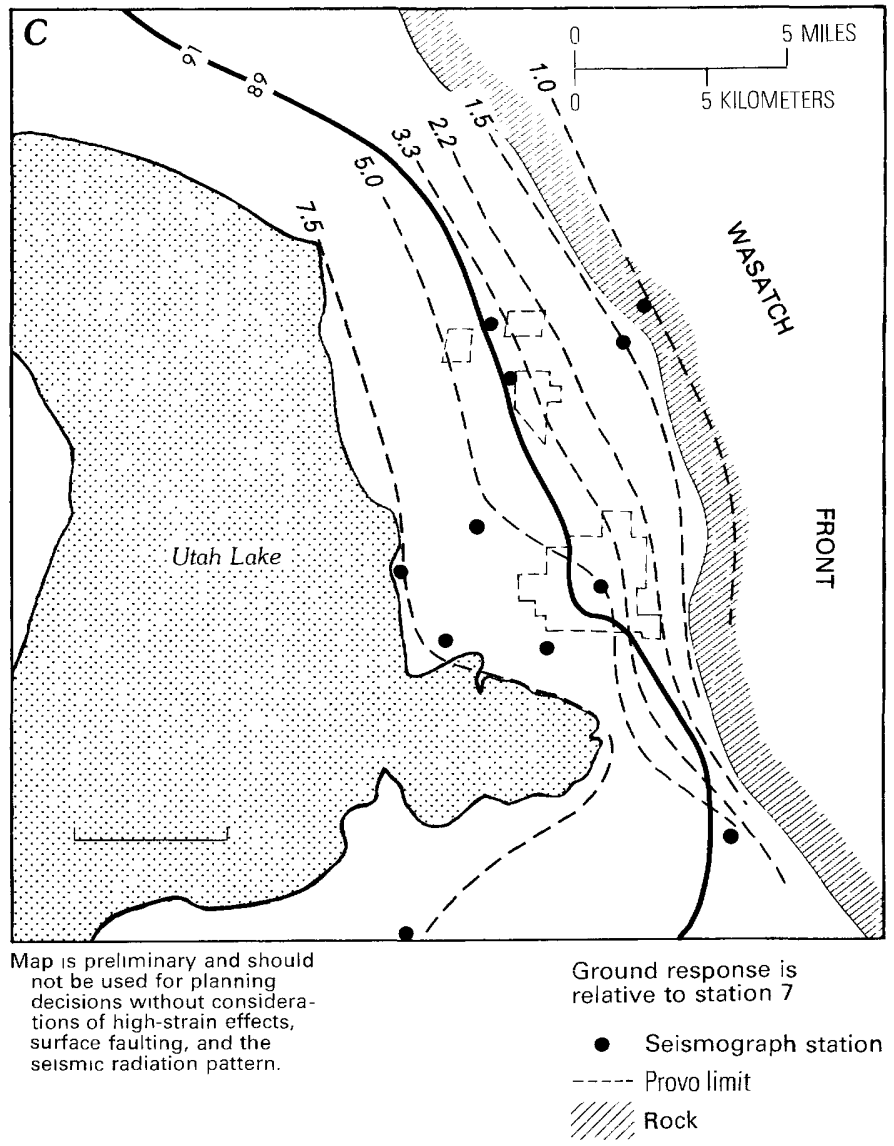

FIGURE 14.-Spatial variation of site-amplification factors for the period band 0.2 to $0.7 \mathrm{~s}$. Values on contours indicate the ratios of velocity response spectra that would be expected at sites underlain by soil relative to that same ratio experienced at sites underlain by rock on the Wasatch Front. These values provide an estimate of the spatial variation of ground motion in the period band for which two- to seven-story buildings have their fundamental natural period of vibration (from Hays and King, 1982). These data represent a lowstrain environment. Repeatability would be least certain when a moderate- to large-magnitude earthquake nucleates underneath the city. $A$, Salt Lake City area; $B$, Ogden area; $C$, Provo area.

1. Resist minor earthquakes without damage.

2. Resist moderate earthquakes without structural damage but with some nonstructural damage.

3. Resist major earthquakes without collapse but with some structural and nonstructural damage.

The basic formula used in the UBC is

$$
V=Z I K C S W
$$

where:

. $V$ is the base shear or total lateral force at the base of the structure.

- $Z$ is the zone factor, the numerical coefficient that depends on the seismic risk zone. Califorma is in 
zones 3 and 4; the Salt Lake City-Ogden-Provo urban corridor is in zone 2.

- $I$ is the occupancy importance factor for the building. - $K$ is an arbitrary horizontal force factor that, in effect, is a safety factor adjustment. Based on an arbitrary classification of the type of construction, it recognizes that different degrees of risk for collapse are inherent in different types of construction.

- $C$ is a numerical coefficient based on the fundamental period of the building. A plot of $C$ against period represents a response spectrum and roughly parallels the spectrum derived from the accelerogram of the Imperial Valley, Calif., earthquake recorded ar El Centro in 1940.

- $S$ is the soil-structure interaction factor that incorporates the potential for site-structure resonance. The values of $S$ range from 1 to 1.5 , the highest value occurring when the fundamental periods of vibration of the building and the soil column are equal.

- $W$ is the total dead load of the building.

A strategy for incorporating new information on earthquake hazards along the Wasatch Front should include the following activities:

1. Updating the seismic risk zone map that gives the $Z$ factor to reflect the latest information on the groundshaking hazard, as depicted probabilistically. For example, the map of Utah can be used to give the peak horizontal bedrock acceleration for a 50-year exposure time (the useful life of ordinary buildings) and a 90-percent probability of nonexceedance.

2. Reviewing the soil-structure interaction factor that is prescribed in the building code to determine if Utah soils are represented adequately, especially the thick, soft clays and silts in the valley centers.

Since the UBC undergoes vigorous evaluation and recommendations for change every 3 years, a mechanism already exists to implement changes that are relevant for Utah.

\section{APPLICATIONS IN UTAH}

Maps of the bedrock ground-shaking hazard (for example, those produced by Algermissen and others, 1982) and soil-to-rock amplification factors can be applied in building codes, land use guidelines, construction practices, and criteria for repairing, strengthening, and retrofitting existing buildings. Implementation of these kinds of loss-reduction applications in Utah would involve the following technical tasks:

Evaluation of the Uniform Building Code.-The need to modify the current edition of the UBC to provide design criteria that are realistic in terms of the current knowledge of both the earthquake potential and the ground-shaking hazard in the Salt Lake City-Ogden-Provo urban corridor should be evaluated carefully. In addition, the best available data on soil-structure interaction should be incorporated into recommended code changes to ensure that either poor site-structure combinations are avoided or appropriate engineering is performed to develop adequate structural capacity.

Evaluation of regional and urban land-use practices.-Alternatives to current practices should be identified to reduce the probability of constructing at sites having poor site-structure combinations (that is, siting of buildings on soil-rock columns where the natural period of the soil column, $T_{s}$, is the same as the natural period, $T_{b}$, of the building). Where there is no viable alternative, appropriate engineering can reduce the chance of severe damage.

Evaluation of construction practices for new buildings.-Alternatives to current practices that will ensure a higher level of quality of materials, workmanship, and inspection should be specified.

Evaluation of current practices to repair and strengthen existing buildings. - Alternatives to current practices should be identified to increase the seismic resistance of buildings designed and built to an earlier standard of earthquake resistance.

\section{ARGUMENTS TO MINIMIZE OR ELIMINATE CONTROVERSY IN THE APPLICATION OF THESE DATA}

The most important requirement for maps of the earthquake ground-shaking hazard (including siteamplification effects) is that they be useful for guiding engineering, social, and political decisions. From a scientific viewpoint, such a map must encompass all possible earthquake source-path-site combinations for a given exposure time, or the scale must be such that variations in source and path effects cause negligible changes in the expected values. The repeatability of site amplification must be reasonably consistent from earthquake to earthquake, especially for the larger magnitude earthquakes used to set design and construction practices and to guide response planning.

The results in the Salt Lake City-Ogden-Provo urban corridor are unequivocal, except for considerations involving near-source locations. At these locations, the source effects dominate the site effects. The trends of site amplification in the Salt Lake City, Ogden, and Provo areas shown in figure 14 can be expected to recur in small- to moderate-magnitude earthquakes occurring along the Wasatch fault zone and producing smallamplitude, low-strain ground motion causing essentially elastic response. The most significant implication of these results is that ground motion may be amplified by as much as a factor of 10 (1,000 percent) at some sites in the 0.2 - to $0.7-\mathrm{s}$ period band corresponding with the natural 


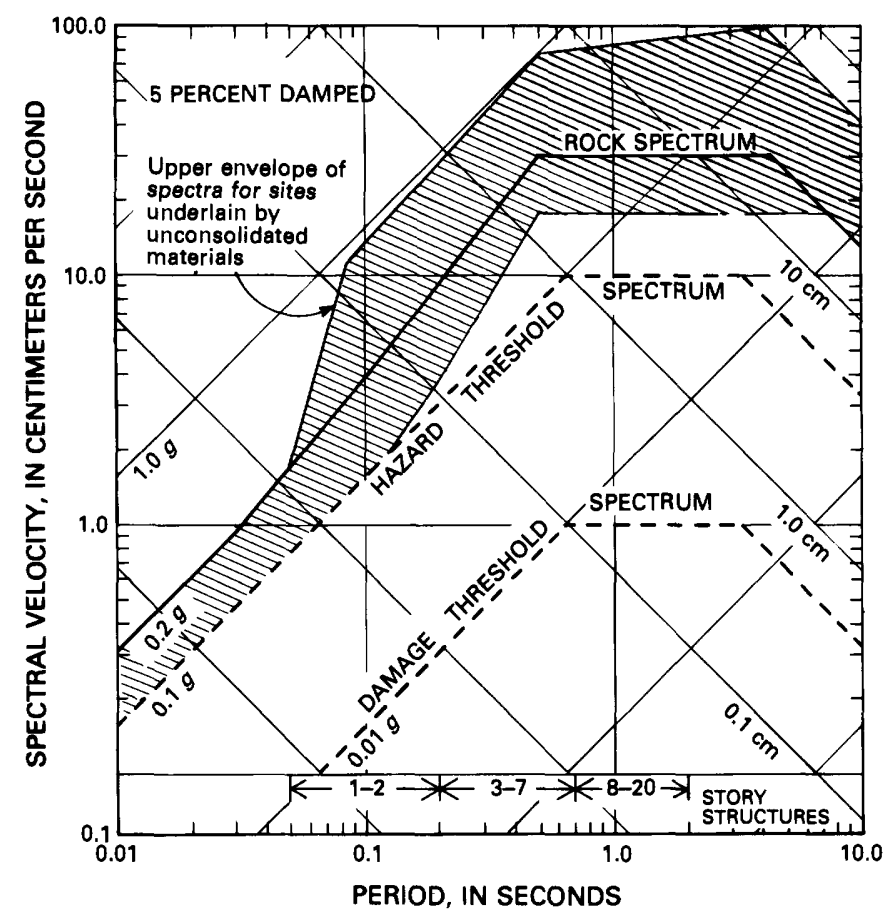

FIGURE 15.-Estimated range of values of horizontal spectral velocity that might be expected in Salt Lake City, Ogden, or Provo within about $35 \mathrm{~km}$ of a large $\left(\mathrm{M}_{\mathrm{S}} 7.5\right)$ earthquake on the Wasatch fault zone. Such an earthquake is currently estimated to produce a peak bedrock velocity of $16 \mathrm{~cm} / \mathrm{s}$ (Algermissen and others, 1982). The greatest controversy is over the question of strain dependency and whether the peak bedrock acceleration (zero-period asymptote of the response spectrum) would be increased or decreased at sites underlain by soil. The period band 0.2 to $0.7 \mathrm{~s}$ emphasized in this paper is shown on the graph.

periods of vibration of two- to seven-story buildings. This type of elastic or essentially elastic response could also be realized in a large, distant earthquake (occurring as far away as $100 \mathrm{~km}$ ), which could cause unusual damage to some buildings (for example, in a manner similar to the September 19, 1985, Mexico earthquake).

Significant differences in the trends of site amplification shown by these data should be expected in a moderate- to large-magnitude earthquake occurring at a depth of 10 to $15 \mathrm{~km}$ directly under one of the cities and causing a peak bedrock acceleration of $0.2 g$ or greater. Such a scenario would be the worst case of the near-source problem for a listric fault. The variability of ground motion can be expected to be greatest at sites closest to and aligned with the fault rupture. In such a case, the effects of the source and the path are both important; they are also difficult to separate. The amplification of ground motion expected to occur in the period band 0.2 to $0.7 \mathrm{~s}$ at sites underlain by thick, soft clays and silts located at distances ranging from the epicenter to $35 \mathrm{~km}$ from the zone of earthquake nucleation would tend to offset the normal attenuation of ground motion with increasing distance from the hypocenter. The most likely outcome in this case is that locations in a broad area in each city within about $35 \mathrm{~km}$ of the hypocenter would experience about the same level of ground shaking, as represented by peak ground acceleration or peak ground velocity, but exhibit considerable variability, as represented by the response spectrum. The range, represented on the smooth response spectrum, is shown in figure 15 . The effect of strain dependence on site amplification in the near-source area is the primary unknown (fig. 16). This question will not be completely resolved for Utah until ground motions near the fault are recorded in large-magnitude earthquakes either in Utah or in other parts of the world having a similar seismotectonic setting.

\section{TECHNICAL ASPECTS OF SITE AMPLIFICATION}

Because site amplification of earthquake ground motion is a controversial subject and the limited earthquake data in Utah require utilization of small-amplitude nuclear-explosion data, a brief review of worldwide siteamplification data will be given in the next section to provide a broader framework of understanding. Such understanding is needed for interpreting and using the siteamplification data obtained in Utah until a more complete data set is available.

Scientists and engineers throughout the world have recognized and documented since the 1800's that site amplification commonly occurs in earthquakes (MacMurdo, 1824; Idriss and Seed, 1968; Seed and Idriss, 1969; Seed and others, 1972; Tezcan and others, 1977; Joyner and others, 1981; Rosenblueth, 1986; Savy and others, 1986; State of California, 1990). Many earthquakes have shown scientists and engineers that two frequencydependent phenomena-site response and structural response-must be considered explicitly in earthquakeresistant design. A number of factual statements can now be made about various aspects of these phenomena:

1. During an earthquake, the characteristics of the earthquake ground motion in any city will vary widely, depending on the thickness, softness, and geometry of the local soil-rock columns and on the source phenomena causing the directivity and focusing of energy (Earthquake Engineering Research Institute, 1986). This observation means that there probably will be some "surprises" in the Salt Lake City-Ogden-Provo urban corridor in that some ground-motion phenomena in future earthquakes will not be able to be explained except in terms of site-amplification phenomena.

2. Damage to a structure at a particular site in an earthquake is complexly related to the dynamic frequencydependent properties of the earthquake source, the 


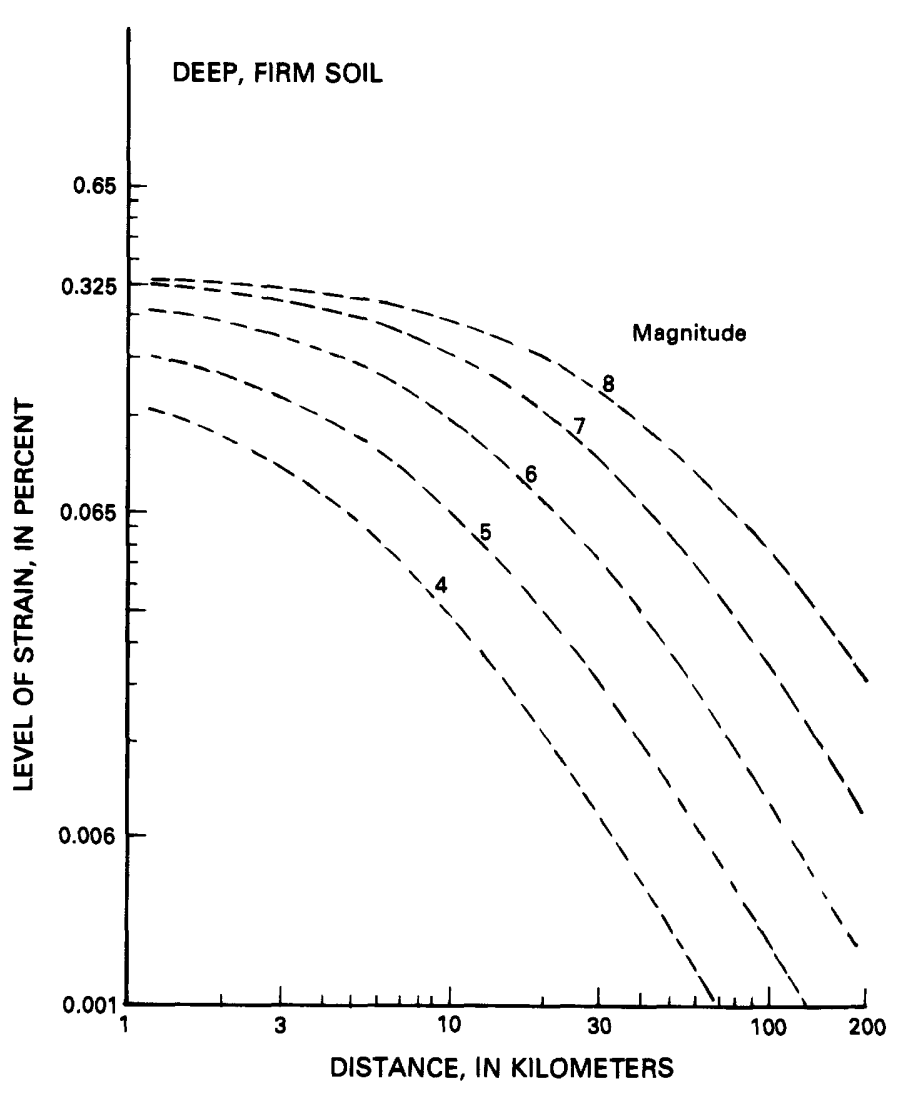

Figure 16.-Estimate of the level of dynamic shear strain as a function of epicentral distance and magnitude. A deep soil column having a near-surface shear-wave velocity of about $200 \mathrm{~m} / \mathrm{s}$ is modeled.

low-pass filtering characteristics of the wave propagation path, and the band-pass filtering characteristics of both the structure and the soil-rock column underlying the structure. The physical parameters of the earthquake and the earth that cause the soil-rock column and the structure to vibrate at the same period increase the potential for damage (Yamahara, 1970). These parameters are not completely known yet in the Salt Lake City-Ogden-Provo urban corridor. Additional geologic investigations needed to improve basic understanding are underway.

3. The level of dynamic shear strain and its effects on soil properties are the most controversial aspects of site amplification. The level of shear strain induced in the soil column by the input bedrock motion increases as the magnitude of the earthquake increases and decreases as the distance from the center of energy release increases (see fig. 16).

4. The response of the site to ground shaking depends strongly on the strain-dependent properties of the soilrock column underlying the site. The level of dynamic shear strain and the contrast in physical properties of the soil and rock determine whether the soil acts to transmit the energy or to dissipate it. As an energy transmitter, the soil column acts as a band-pass filter by modifying the amplitude and phase spectra of the incident body and surface seismic waves in selected periods (Murphy and others, 1971b) and increasing the duration of shaking (Hays, 1975). As an energy dissipator, the soil column can damp the earthquake ground motion, thereby reducing the level of peak acceleration. As a soil-structure system, part of the vibrational energy of both the soil column and the structure can be transmitted back into the Earth; this transmittal permits vertical movement, rocking, and side-to-side movement of the structure on its base (Wolf, 1985).

5. Site amplification (the frequency- and strain-dependent response of the soil-rock column to body and surface seismic waves) increases the amplitude of the surface ground motion in a narrow period band that can be related to the thickness, softness, shear-wave velocity, bulk density, and geometry of the soil column (Seed and others, 1976). The transfer function is one way to categorize the dominant spectral response in terms of the period band where it occurs. Although the response can be related to many discrete period bands, three are typically used to categorize the effect: short period ( $0.05-0.5 \mathrm{~s})$, intermediate period (0.5-3 s), and long period (3-10 s). Each period band correlates approximately with the fundamental mode of response of buildings of increasing heights and decreasing stiffness

6. The structure also acts as a band-pass filter as it responds to the ground shaking as its base. The spectral response of the structure can be increased or decreased in selected period bands that depend on the type of structure, the construction materials used in the lateral-force-resisting system, the lateral and vertical dimensions, the physical properties of the soil-rock column, and the wavelengths and amplitudes of the incident seismic waves. The demand on the structure is greatest when the dominant period of the bedrock motion, the fundamental natural period of vibration of the structure, and the natural period of the soil column are the same, a case that creates a condition for sitestructure resonance (figs. 3,4 ).

\section{SITE AND BUIIDING PERIODS}

Earthquake-resistant design must take into account the conditions that cause site amplification of ground motion and damaging soil-structure resonance. In an urban area, careful evaluation is required to identify the wide range of soil-rock columns and their physical properties, the various types of buildings, and the physical conditions that cause the soil and building responses to occur at or close to the same period. A soil column, like a 
building or structure (see fig. 13), has a natural period of vibration, $T_{s}$, given by the relation

$$
T_{s}=4 H / R V_{s}
$$

where $\mathrm{H}$ is the thickness of the soil column and $V_{s}$ is the shear-wave velocity measured at low levels $(0.0001$ percent) of strain. Soils, depending on their physical properties, typically have shear-wave velocities ranging from 50 to $600 \mathrm{~m} / \mathrm{s}$, whereas rocklike material and rock have shear-wave velocities greater than about $750 \mathrm{~m} / \mathrm{s}$.

One characteristic of site amplification in the Salt Lake City-Ogden-Provo urban corridor is that the response is not dominated by a specific period or period band. The entire spectrum at sites underlain by soil exceeds that at sites underlain by rock.

Soils clearly exhibit strain-dependent properties in laboratory tests (Seed and Idriss, 1969). Tests on "undisturbed" samples have shown that, as the level of dynamic shear strain increases, the material damping increases and the shear modulus decreases. The result is that $T_{s}$ increases as the level of shear strain increases. The basic empirical relation has been given by Seed (1975) as

$$
T_{s}=4 H /\left(R V_{s}\right)
$$

where $R$ is an empirical factor having the following values: (1) 0.9 for a magnitude 6 earthquake producing a peak effective acceleration of $0.1 g$, (2) 0.8 for a magnitude 6 earthquake producing a peak effective acceleration of $0.2 \mathrm{~g}$, and (3) 0.67 for a magnitude 7 earthquake producing a peak effective acceleration of 0.3 to $0.4 \mathrm{~g}$. The fundamental natural period of vibration $T_{b}$ of a building is given approximately by the relation

$$
T_{\mathrm{b}}=N / 10
$$

where $\mathrm{N}$ is the number of stories. However, the stiffness and flexibility of a building (design parameters controlled by the structural engineer and architect) can make its actual fundamental natural period shorter or longer. Observations from postearthquake investigations have shown that $T_{b}$ lengthens as the thresholds of various states of damage are reached. In an earthquake, the "worst" case for damage is when the value of $T_{s}$ coincides with that of $T_{b}$. This situation causes resonance of the building and can result in severe damage or collapse unless the building has been designed to withstand the forces generated by this phenomenon.

The type of structure being sited controls the scope of the evaluation. For example, amplification of surface waves is not typically considered in siting a nuclear powerplant, which is more sensitive to short-period vibrations of body waves than to long-period vibrations of surface waves. On the other hand, potential site amplification of long-period Rayleigh waves is an important consideration when siting a high-rise building, especially if the building is founded on a deep, soft soil deposit like those in the Salt Lake City-Ogden-Provo urban corridor.

\section{LEVEL OF DYNAMIC SHEAR STRAIN}

Assessing the level of dynamic shear strain and its effects on the physical properties of the soil column requires laboratory tests and good technical judgment. Laboratory measurements demonstrating that soils have shear moduli and damping characteristics that depend on the level of strain suggest that, under certain conditions, nonlinearities and inelasticities in the soil will attenuate rather than amplify the peak amplitudes of surface ground motion at sites underlain by soil. Current understanding is limited because the high levels of strain produced in the laboratory have not been duplicated in the in situ environment by actual strong-motion records of past earthquakes. For example, the greatest value of peak ground velocity ever recorded (in the 1971 San Francisco and 1979 Imperial Valley, Calif., earthquakes) is $110 \mathrm{~cm} / \mathrm{s}$. The empirical rule that

$$
\text { strain }=\frac{\text { peak velocity recorded at the site }}{\text { shear-wave velocity of the soil column at the site }}
$$

leads to the conclusion that the greatest level of strain induced in situ in soil columns in past earthquakes has reached only about 0.5 percent, much less than the level of strain developed in the laboratory environment.

Some researchers (for example, Hays, 1978; Hays and others, 1979; Hays and King, 1982) have shown that site response is essentially linear up to in situ strain levels of about 0.5 percent for some soil-rock columns. The epicentral distance to the strain level of 0.5 percent is only a few kilometers for soil columns like those in Salt Lake City having a shear-wave velocity of $200 \mathrm{~m} / \mathrm{s}$. The epicentral distance to 0.5 percent decreases as the shear-wave velocity of the soil approaches the shear-wave velocity of the bedrock.

The complexity in the specification of the dynamic properties of the soil is directly related to the differences in the laboratory and in situ environments and the problem of obtaining an "undisturbed" sample. The complexity increases below depths of $30 \mathrm{~m}$ because of the difficulty and expense of sampling.

\section{THICKNESS OF THE SOIL COLUMN}

Two different points of view have been used to define the critical thickness - of the soil column, the physical parameter that strongly affects the period of the dominant 
site amplification. One view (Seed, 1975) considers that the soil column includes only near-surface material having a shear-wave velocity less than $765 \mathrm{~m} / \mathrm{s}$. The other view (Kobayashi and Nagahashi, 1982) considers that the soil column extends to bedrock having a compressionalwave velocity of at least $3,600 \mathrm{~m} / \mathrm{s}$. In the first case, surface ground motions are assumed to be affected mainly by a short soil column, typically about $30 \mathrm{~m}$ thick, whereas, in the second case, surface ground motions are assumed to be affected by a much thicker soil column. The short soil column will mainly affect the short periods and the peak amplitudes of acceleration, whereas the thick soil column will affect mainly the intermediate- and long-period bands and the peak amplitudes of velocity and displacement. In the Salt Lake City-Ogden-Provo urban corridor, the effects of both short and deep soil columns are present because the thickness of the soil deposits adjacent to the Wasatch Front varies from about 150 to $900 \mathrm{~m}$.

\section{NEAR FIELD}

The near field (or near source) of an earthquake is the most complex area to evaluate for potential site amplification. The site is defined as being in the far field (or "far-source" region) of an earthquake when it is located far enough from the physical extent of the earthquake source that the solid angle subtended by the source and the site is very small. Estimating the characteristics of ground motion is much easier in the far fields than it is in the near field, where seismic energy arrives nearly simultaneously from many different directions. The difference is essentially one of using a point-source (the far field) or a line-source (the near field) approximation. The near-field problem in Utah is complicated because of the listric nature of the Wasatch fault zone, which makes it plausible for earthquakes to nucleate directly under any of the three cities. Analyses of strongground-motion data close to the causative fault have been made by a number of investigators (for example, Idriss, 1978; Hays, 1980; Singh, 985). For the near field, these analyses indicate the following:

1. Analytical separation of the frequency-dependent effects of the source from the effects of the soil-rock column is very difficult. Near the fault, the source tends to dominate the path and site effects. The directivity of the source can cause considerable variability in the values of the peak amplitudes of ground acceleration, velocity and displacement, and the ordinates of spectral velocity (Singh, 1985).

2. A "killer pulse," a pulse of approximately 1-s duration that typically does not have the greatest peak amplitude of acceleration but does have the greatest kinetic energy, is generated in some cases in the near field (for example, in the 1971 San Fernando earthquake) as a consequence of the "fling" of the fault (Bertero and others, 1978). Breakout and stopping phases of the fault rupture also can affect the near-field ground motion and complicate the analysis.

\section{BEDROCK MOTIONS}

Estimating bedrock ground motions is also a difficult task in evaluating site-amplification effects. The frequency-dependent characteristics of the bedrock motion that is put into the soil column depend on the details of the geology of the propagation path. These details are usually imprecise. Therefore, analytical calculations must be bounded; a suite of strong-motion accelerograms acquired in past earthquakes at sites underlain by rock can be used to constrain the analyses. The ideal data are from sites underlain by the same type of rock, located at about the same distance from the zone of energy release, and having the same geology underlying the propagation path as the site being evaluated. An adequate analog having the appropriate source-path-site characteristics does not yet exist for the Salt Lake CityOgden-Provo urban corridor.

\section{VARIABILITY IN SITE-AMPLIFICATION EFFECTS}

Several investigators (for example, Murphy and others, 1971b; Hays, 1980) have shown that site-amplification effects for some soils are fairly repeatable if the soil is soft relative to the bedrock, the level of strain is low (for example, 0.0001 to 0.1 percent), and the site is not near the fault zone. The degree of repeatability of the site transfer function is currently unknown for sites near the fault when the shear strain approaches and exceeds 0.5 percent.

\section{WORLDWIDE DATA}

Four examples of site amplification of ground motions representing a low-strain environment are described below because of their relevance to the Salt Lake City-Ogden-Provo urban corridor.

\section{CARACAS, VENEZUELA, EARTHQUAKE}

Soil-structure resonance occurred in Caracas, $56 \mathrm{~km}$ from the epicenter of this moderate $\left(M_{S} 6.4\right)$ earthquake. Severe damage was restricted mainly to tall buildings (higher than 12 stories) sited on thick, soft soil columns that were at least $160 \mathrm{~m}$ thick. The dominant site response occurred in the intermediate-period band, centered around 1.4 s (Seed and others, 1972). 

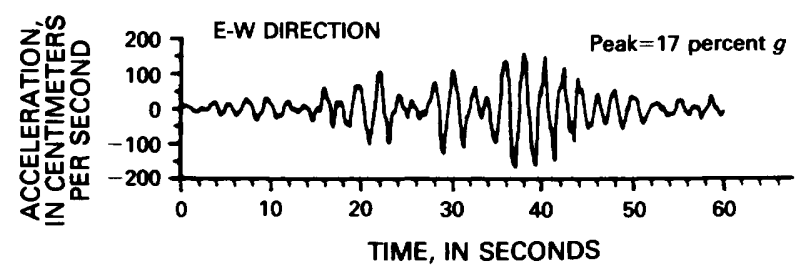

STATION SCT (MEXICO CITY LAKEBED)
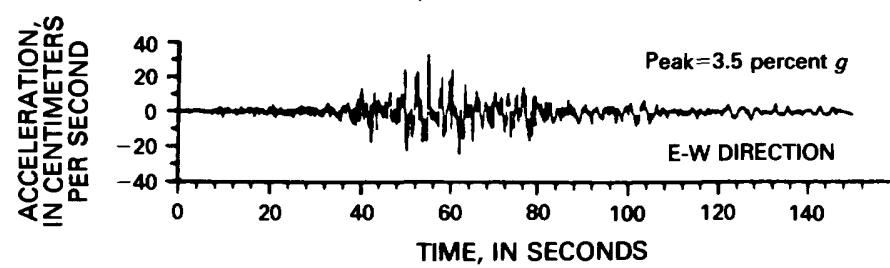

STATION TACUBAYA (MEXICO CITY ROCK SITE)

FIGURE 17.-Comparison of strong-motion accelerograms in a low-strain environment recorded on firm soil and in the soft soil (of the lakebed zone) in the September 19, 1985, Mexico earthquake. The soft soil in the lakebed zone of Mexico City located $400 \mathrm{~km}$ from the epicenter amplified the ground motion in a period band centered around $2 \mathrm{~s}$. The records were provided by the Universidad Nacional Autonoma de Mexico.

\section{GEDIZ, TURKEY, EARTHQUAKE}

Soil-structure resonance under small-amplitude ground motions caused the collapse of a one-story garage and paint workshop (a part of the Tofias automobile factory) located $225 \mathrm{~km}$ from the epicenter of this large $\left(\mathrm{M}_{\mathrm{S}}\right.$ 7.0) earthquake. The cause was the similarity of the predominant periods of the bedrock motions, the response of the 120- to 135-m column of alluvium, and the response of the building. The resonance occurred in the intermediateperiod band and was centered around $1.2 \mathrm{~s}$ (Tezcan and others, 1977).

\section{FRIULI, ITALY, EARTHQUAKE}

Site amplification of a factor of 4 (400 percent) occurred in the short- to intermediate-period band (0.2$0.7 \mathrm{~s}$ ) for a site underlain by $15 \mathrm{~m}$ of alluvium located 25 $\mathrm{km}$ from the epicenter. The peak amplitude of bedrock accelerations ranged from 0.10 to $0.53 g$ (Savy and others, 1986). The magnitude $\left(M_{S}\right)$ of the main shock was 6.9 .

\section{MEXICO EARTHQUAKE}

The great $\left(\mathrm{M}_{\mathrm{S}}\right.$ 8.1) earthquake produced two surprises: the low value of the peak amplitude of acceleration $(0.17 \mathrm{~g})$ in the epicentral region and the high $(3.5 \mathrm{~g}$ ) value of the peak amplitude of acceleration in certain parts of Mexico City located $400 \mathrm{~km}$ from the epicenter (fig. 17). Extensive damage occurred in 5- to 20-story buildings sited in the lakebed zone of Mexico City underlain by soft lakebed deposits (Rosenblueth, 1986). These deposits had been recognized in the 1960's (Zeevaert, 1964) as a 2-s band-pass filter. The largest ground motions in Mexico City occurred at sites underlain by 35 to $50 \mathrm{~m}$ of soft lakebed deposits having a shear-wave velocity of about $100 \mathrm{~m} / \mathrm{s}$. The dominant period of the accelerogram recorded in the lakebed zone was $2 \mathrm{~s}$. The response of the lakebed deposits was essentially elastic. They amplified the peak amplitude of acceleration (caused by Rayleigh waves) by about a factor of 5 ( 500 percent) relative to the level of peak acceleration observed at nearby sites underlain by stiffer, rocklike material (Rosenblueth, 1986). The ordinate of 5-percent damped spectral acceleration at $2 \mathrm{~s}$ reached $1 \mathrm{~g}$. The similarity of the soil response and the building response at many locations in the lakebed zone caused resonance that was a major cause of the severe damage to and collapse of about 400 engineered buildings. These buildings generally had fundamental natural periods ranging from 0.5 to about $2 \mathrm{~s}$. The number of severely damaged and collapsed buildings represented less than 1 percent of the total number of engineered buildings in Mexico City, an indication that buildings constructed according to the Mexican building code performed well everywhere but in the lakebed zone.

\section{CONCLUSIONS, UNRESOLVED TECHNICAL ISSUES, AND RECOMMENDATIONS}

Research on the ground-shaking hazard in the Salt Lake City-Ogden-Provo urban corridor has provided technical information that can be used to improve building codes, land use regulations, and construction practices in Utah. The soil columns underlying this urban corridor cause distinctive characteristics of site amplification depending on their softnesses, thicknesses, and locations relative to the zone of energy release. Observations at 71 sites in Utah, augmented by observations in other parts of the world, suggest that two- to seven-story buildings sited on thick, soft deposits of clays and silts in the Salt Lake City-Ogden-Provo urban corridor may face a demand that exceeds their capacity in moderate- to large-magnitude earthquakes. The hazard is far less for structures sited on thin deposits of gravel and sand near the Wasatch Front. In the case of a large earthquake (for example, the characteristic earthquake of magnitude $\mathrm{M}_{\mathrm{S}} 7.0$ to 7.5 ) nucleating at a depth of 10 to $15 \mathrm{~km}$ on the listric Wasatch fault zone directly under one of the cities, a large portion on the city within about $35 \mathrm{~km}$ of the surface trace of the fault zone could possibly experience severe ground shaking, and buildings could suffer extensive damage or possible collapse. In this case, the characteristics of the ground motion will probably be controlled mainly by parameters of the earthquake source, and directivity effects could be large, causing considerable variability in the distribution of ground motion and damage patterns. The trends indi- 


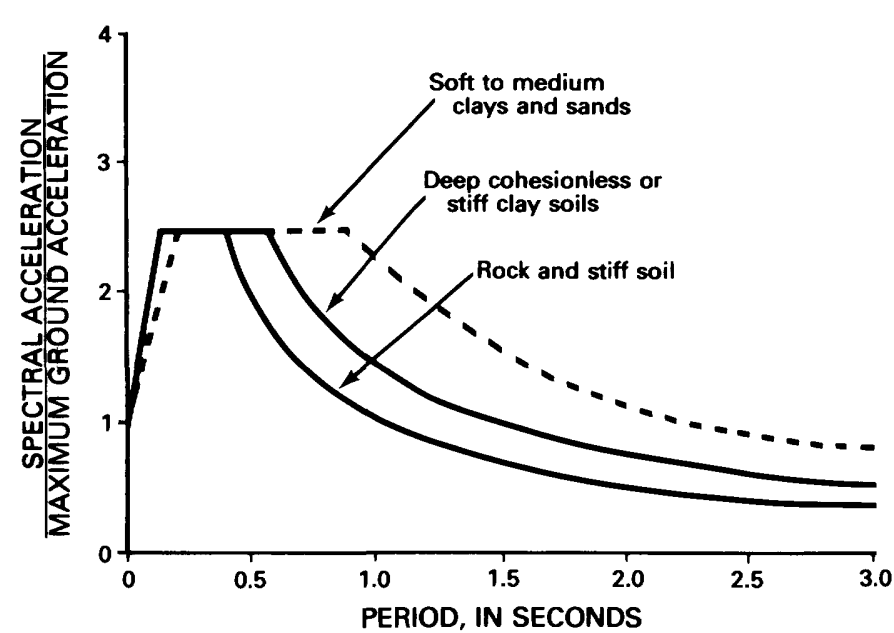

FIGURE 18.-Shape of normalized response spectra for three different soil columns proposed by the Seismology Committee of the Structural Engineers Association of California (1985). These curves are based mainly on ground-motion data recorded in California. A relevant question is, "To what degree do they represent soil columns in the Salt Lake City-Ogden-Provo urban corridor?" This paper asserts that the amplifying effects for soft to medium clays may be underestimated except for the near-source high-strain environment, the rarest case, which cannot be quantified empirically at present.

cated by the maps in this report would not be expected to be closely replicated because of lower soil-to-rock amplification factors and a shift to longer periods of dominant response, the primary results of high-strain effects. The trends shown by the maps would be replicated best when the hypocenter of a magnitude 7.0 to 7.5 earthquake is 50 $\mathrm{km}$ or more from any one of the principal cities, the result being a low-strain environment.

\section{IECHNICAL ISSUES NEEDING RESOLUTION}

Additional data and research on site amplification will aid in understanding and quantifying the following technical issues in Utah:

1. Do the characteristics of site amplification in the Salt Lake City-Ogden-Provo urban corridor derived from

- distant nuclear-explosion ground-motion data adequately represent what will happen on future earthquakes on the Wasatch Front?

2. How different will the characteristics of site amplification be in earthquakes having magnitudes of 7.0 to 7.5 for a site close to the source? For the same site far from the source?

3. What levels of dynamic shear strain will be generated in the in situ environment at sites near the source in moderate- to large-magnitude earthquakes? How will these levels of strain compare with strain produced in the laboratory environment?

4. Are the soil-to-rock amplification factors in current building codes and practices used in California adequate for earthquake-resistant design in the Salt Lake City-Ogden-Provo urban corridor (fig. 18)?

\section{RECOMMENDATIONS}

More detailed geologic investigations are needed to determine the controlling factors at each site, especially in the valley centers. Also, integration of the empirical ground-motion data with the results of analytical models is needed. Additional ground-motion data from earthquakes in the Intermountain Seismic Belt or in other parts of the world having analogous seismotectonic settings and soil-rock columns must be acquired and analyzed to quantify the ground-shaking hazard for the near-source and far-source environments of the Salt Lake City-OgdenProvo urban corridor.

Although current research on site amplification in Utah is incomplete and gaps in our knowledge exist, the results of this research can be implemented as preliminary design criteria that will probably have a useful life of 5 to 10 years because of the slowness of data acquisition to address the issues described above. Appropriate uses include:

1. Risk maps (zoning maps) for inclusion in the 1991 and subsequent editions of the UBC and other model codes.

2. Maps of site-amplification factors for discrete period bands that correspond to the full range of new and existing buildings in Utah.

3. Preliminary seismic microzonation studies and products that identify the areas of the Salt Lake City-OgdenProvo urban corridor that are best suited for certain types of construction and land use.

4. Studies of the potential vulnerability of existing two- to seven-story buildings as well as other categories of existing buildings, lifelines, and other facilities.

\section{REFERENCES CITED}

Algermissen, S.T., and Perkins, D.M., 1976, A probabilistic estimate of maximum acceleration in rock in the contiguous United States: U.S. Geological Survey Open-File Report 76416, $45 \mathrm{p}$.

Algermissen, S.T., Perkins, D.M., Thenhaus, P.C., Hanson, S.L., and Bender, B.L., 1982, Probabilistic estimates of maximum acceleration and velocity in rock in the contiguous United States: U.S. Geological Survey Open-File Report 82-1033, $99 \mathrm{p}$.

Bennett, T.J., 1974, Amplitude and propagation characteristics of short-period seismic surface waves in the Las Vegas Valley: 
Report NVO-1163-242, Environmental Research Corporation, $75 \mathrm{p}$.

Bertero, V.V., Mahin, S.A., and Herrera, R.A., 1978, A seismic design implications of near-field San Fernando records: Journal of Earthquake Engineering and Structural Dynamics, v. 6 , p. $31-42$.

Boore, D.M., 1973, The effect of simple topography on seismic waves: Implications for the acceleration recorded at Pacoima Dam, San Fernando Valley, California: Bulletin of the Seismological Society of America, v. 63, p. 1603-1610.

Borcherdt, R.D., ed., 1975, Studies of seismic zonation of the San Francisco Bay region: U.S. Geological Survey Professional Paper 94l-A, 102 p.

Borcherdt, R.D., Gibbs, J.R., and Fumal, T.E., 1978, Progress on ground motion predictions for the San Francisco Bay region: International Conference on Microzonation for Safer Construction Research and Applications, 2d, San Francisco, Calif., January 1, 1978, Proceedings, v. 1, p. 241254.

Borcherdt, R.D., Joyner, W.D., Warrick, R.E., and Gibbs, J.F., 1975, Response of local geologic units to ground shaking, in Borcherdt, R.D., ed., Studies for seismic zonation of the San Francisco Bay region: U.S. Geological Survey Professional Paper 941-A, p. A52-A67.

Davis, L.L. and West, L.R., 1973, Observed effects of topography on ground motion: Bulletin of the Seismological Society of America, v. 63, p. 283-298.

Earthquake Engineering Research Institute, 1986, Reducing earthquake hazards: Lessons learned from earthquakes: El Cerrito, Calif., Publication 86-02, 108 p.

Elton, D.J., and Martin, J.R., 1986, Site period study for Charleston, S.C.: U.S. Conference on Earthquake Engineering, 3d, Charleston, S.C., 1986, Proceedings, v. 1, p. 497-504.

Gibbs, J.F., Fumal. T.E., and Borcherdt, R.D., 1976, In situ measurements of seismic velocities in San Francisco Bay region: U.S. Geological Survey Open-File Report 76-731, $145 \mathrm{p}$.

Hanks, T.C., 1976, Observations and estimation of long period strong ground motion in the Los Angeles Basin: International Journal of Earthquake Engineering and Structural Dynamics, v. 4, p. 473-488.

Hays, W.W., 1975, A note on the duration of earthquake and nuclear explosion ground motions: Bulletin of the Seismological Society of America Bulletin, v. 65, p. 875-844.

1977, Evaluation of the seismic in the Sylmar-San Fernando area, California, from the 1971 San Francisco earthquake: American Society of Civil Engineers, Mechanics Division Specialty Conference of Dynamic Response of Structures, Los Angeles, 1977, Proceedings, p. 502-511.

1978, Ground response maps for Tonopah, Nevada: Bulletin of the Seismological Society of America, v. 68, p. 451469.

1980, Procedures for estimating earthquake ground motions: U.S. Geological Survey Professional Paper 1114, $77 \mathrm{p}$.

ed., 1981, Facing geologic and hydrologic hazards: Earth science considerations: U.S. Geological Survey Professional Paper 1240-B, $90 \mathrm{p}$.
Hays, W.W., and Gori, P.L., eds., 1984, Evaluation of regional and urban earthquake hazards and risk in Utah: U.S. Geological Survey Open-File Report 84-763, 687 p.

Hays, W.W., and King, K.W., 1982, Zoning of the earthquake ground-shaking hazard along the Wasatch fault zone, Utah: International Conference on Microzonation, 3d, Seattle, Wash., 1982, Proceedings, v. 3, p. 1307-1317.

1984, Seismic microzonation along the Wasatch fault zone, Utah: World Conference on Earthquake Engineering, 8th, San Francisco, Calif., July 21-28, 1984, Proceedings, v. 1, p. 1-12.

Hays, W.W., Algermissen, S.T., Miller, R.D., and King, K.W., 1978, Preliminary ground response maps for the Salt Lake City area: International Conference on Microzonation, 2d, San Francisco, 1978, Proceedings, v. 2, p. 487-508.

Hays, W.W., Rogers, A.M., and King, K.W., 1979, Empirical data about local ground response: Earthquake Engineering Research Institute, National Conference on Earthquake Engineering, 2d, Stanford, Calif., 1979, Proceedings, p. 223232.

Idriss, I.M., 1978, Characteristics of earthquake ground motions: American Society of Civil Engineers Earthquake Engineering and Soil Dynamics Specialty Conference, Proceedings, v. 3, p. 1151-1267.

Idriss, I.M., and Seed, H.S., 1968, Analysis of ground motions during the 1957 San Francisco earthquake: Bulletin of the Seismological Society of America, v. 58, p. 2013-2032.

Ihmen, Steven, and Hadley, D.M., 1987, Seismic hazard maps for Puget Sound, Washington: Bulletin of the Seismological Society of America, v. 77, p. 1091-1109.

International Conference of Building Officials, 1988, Uniform Building Code: Whittier, Calif., International Conference of Building Officials.

Joyner, W.B., Warrick, R.E., and Fumal, T.E., 1981, The effects of Quaternary alluvium on strong ground motion in the Coyote Lake, California earthquake of 1979: Bulletin of the Seismological Society of America, v. 71, p. 1333-1349.

Kobayashi, Hiroyoshi, and Nagahashi, Sumio, 1982, Response spectra on seismic bedrock during earthquakes, in Engineering seismology: Tokyo Institute of Technology, p. 22-27.

MacMurdo, J., 1824, Papers relating to the earthquake which occurred in India in 1819: Philadelphia Magazine, v. 63, p. 105-177.

Miller, R.D., 1980, Surficial geologic map along part of the Wasatch Front, Salt Lake Valley, Utah: U.S. Geological Survey Miscellaneous Field Studies Map MF-1198, scale $1: 100,000$.

Molinelli, Jose, 1985, Earthquake vulnerability study for the metropolitan area of San Juan, Puerto Rico, in Hays, W.W., and Gori, P.L., eds., A workshop on reducing potential losses from earthquakes in Puerto Rico, Proceedings of Conference XXX: U.S. Geological Survey Open-File Report 85-731, p. 211-277.

Murphy, J.R., and Hewlett, R.A., 1975, Analysis of seismic response in the city of Las Vegas, Nevada: A preliminary microzonation: Bulletin of the Seismological Society of America, v. 65, p. 1575-1598.

Murphy, J.R., and West, L.R., 1974, An analysis of surface and subsurface seismic measurements demonstrating the ampli- 
fication effect of near-surface geology: Report NVO-1163TM41 (to Atomic Energy Commission), Environmental Research Corporation, $21 \mathrm{p}$.

Murphy, J.R., Lynch, R.D., and O'Brien, L.J., 1971a, Predicted San Fernando earthquake spectra: Report NVO-1163-TM30 (to Atomic Energy Commission), Environmental Research Corporation, $38 \mathrm{p}$.

Murphy, J.R., Weaver, N.L., and Davis, A.H., 1971b, Amplification of seismic body waves by low-velocity layers: Bulletin of the Seismological Society of America, v. 61, p. 109-146.

Peak, R.B., and Reed, W.C., 1954, Engineering properties of Chicago subsoils: University of Illinois Engineering Experiment Station Bulletin 423, $43 \mathrm{p}$.

Reid, H.F., 1910, The California earthquake of April 18, 1906, in The mechanics of the earthquake: Report of the State Earthquake Investigation Commission: Carnegie Institute of Washington Publication 87, v. 2. 500 p.

Rogers, A.M., and Hays, W.W., 1978, Preliminary evaluation of site transfer functions developed from nuclear explosions and earthquakes: International Conference on Microzonation, 2d, San Francisco, 1978, Proceedings, v. 2, p. 753-764.

Rogers, A.M., Tinsley, J.C., Hays, W.W., and King, K.W., 1979, Evaluation of the relation between near-surface geological units and ground response in the vicinity of Long Beach, California: Bulletin of the Seismological Society of America, v. 69 , p. $1603-1622$.

Rosenblueth, Emilio, 1986, The Mexican earthquake: A firsthand report: Civil Engineering, January, p. 38-40.

Savy, Jean, Bernreuter, Don, and Chen, J.C., 1986, Site effects: A generic method for modeling site effects in seismic hazard analyses, in Hays, W.W., ed., Proceedings of Conference XXXIV: U.S. Geological Survey Open-File Report 86-185, p. 249-284.

Schwartz, D.P., and Coppersmith, K.J., 1984, Fault behavior and characteristic earthquakes: Examples from the Wasatch and San Andreas faults: Journal of Geophysical Research, $v$. 89 , no. B7, p. 5681-5698.

Seed, H.B., 1975, Design provisions for assessing the effects of local geology and soil conditions on ground and building response during earthquakes, in New earthquake design provisions: Seminar sponsored by Professional Development Committee of Structural Engineers Association of Northern California and San Francisco Section of American Society of Civil Engineers, Proceedings, p. 38-63.

Seed, H.B., and Idriss, I.M., 1969, Influence of soil conditions on ground motions during earthquakes: Proceedings of the American Society of Civil Engineers, Journal of the Soil Mechanics and Foundations Division, v. 95, p. 1199-1218.

Seed, H.B., Murarka, R., Lysmer, John, and Idriss, I.M., 1976, Relationships of maximum acceleration, maximum velocity, distance from source, and local site conditions for moder- ately strong earthquakes: Bulletin of the Seismological Society of America, v. 66, p. 1323-1342.

Seed, H.B., Whitman, R.V., Dezfulian, H., Dobry, R., and Idriss, I.M., 1972, 1972, Soil conditions and building damage in the 1967 Caracas earthquake: Proceedings of the American Society of Civil Engineers, Journal of the Soil Mechanics and Foundations Division, v. 98, p. 787-806.

Singh, J.P., 1985, Earthquake ground motions: Implications for designing structures and reconciling structural damage: Earthquake Spectra, v. 1, p. 239-270.

Sharma, S., and Kovacs, W.D., 1980, The microzonation of the Memphis, Tennessee, area: U.S. Geological Survey OpenFile Report 80-914, 129 p.

Smith, R.B., Richins, W.D., and Doser, D.I., 1985, The 1983 Borah Peak, Idaho, earthquake: Regional seismicity, kinematics of faulting, and tectonic mechanics, in Stein, R.S., and Bucknam, R.C., eds., On the Borah Peak, Idaho, earthquake: U.S. Geological Survey Open-File Report 85-290, p. 236-263.

State of California, 1990, Competing against time: Report to Governor George Deukmejian from the Governor's Board of Inquiry on the 1989 Loma Prieta Earthquake, 264 p.

Steinbrugge, K.V. chairman, 1968, The safety of fills: San Francisco, Report prepared for the San Francisco Bay Conservation and Development Commission, $33 \mathrm{p}$.

Structural Engineers Association of California, 1985, Tentative lateral force requirements: Sacramento, Calif., Report of Seismology Committee, $76 \mathrm{p}$.

Tezcan, S.S., Seed, H.B., Whitman, R.v., Serff, N., Christian, J.T., Durgunoglu, H.T., and Yegian, M., 1977, Resonant period effects in the Gediz, Turkey, earthquake of 1970: Earthquake Engineering and Structural Dynamics, v. 5, p. 157-179.

Whitman, R.v., 1983, An engineer's perspective on the Cape Anne, Massachusetts earthquake of 1755 [abs.]: Earthquake Notes, v. 54 , no. 1 , p. 8.

Wolf, J.P., 1985, Dynamic soil-structure interaction: Englewood Cliffs, N.J., Prentice-Hall, 466 p.

Wood, H.O., 1908, Distribution of apparent intensity in San Francisco, in The California earthquake of April 18, 1906: Washington, D.C., Report of the State Earthquake Investigation Commission, Carnegie Institute of Washington, p. 220-245.

Yamahara, H., 1970, The interrelation between frequency characteristics of ground motion and earthquake damage to structure: Soils and Foundations, v. 10, p. 57-74.

Zeevaert, L., 1964, Strong ground motion recorded during earthquakes of May 11 and 19th, 1962 in Mexico City: Bulletin of the Seismological Society of America, v. 54, p. 209-232. 
Predicting Strong Ground Motion in Utah

By KENNETH W. CAMPBELL

ASSESSMENT OF REGIONAL EARTHQUAKE HAZARDS AND RISK ALONG THE WASATCH FRONT, UTAH

U.S. GEOLOGICAL SURVEY PROFESSIONAL PAPER 1500-L 



\section{CONTENTS}

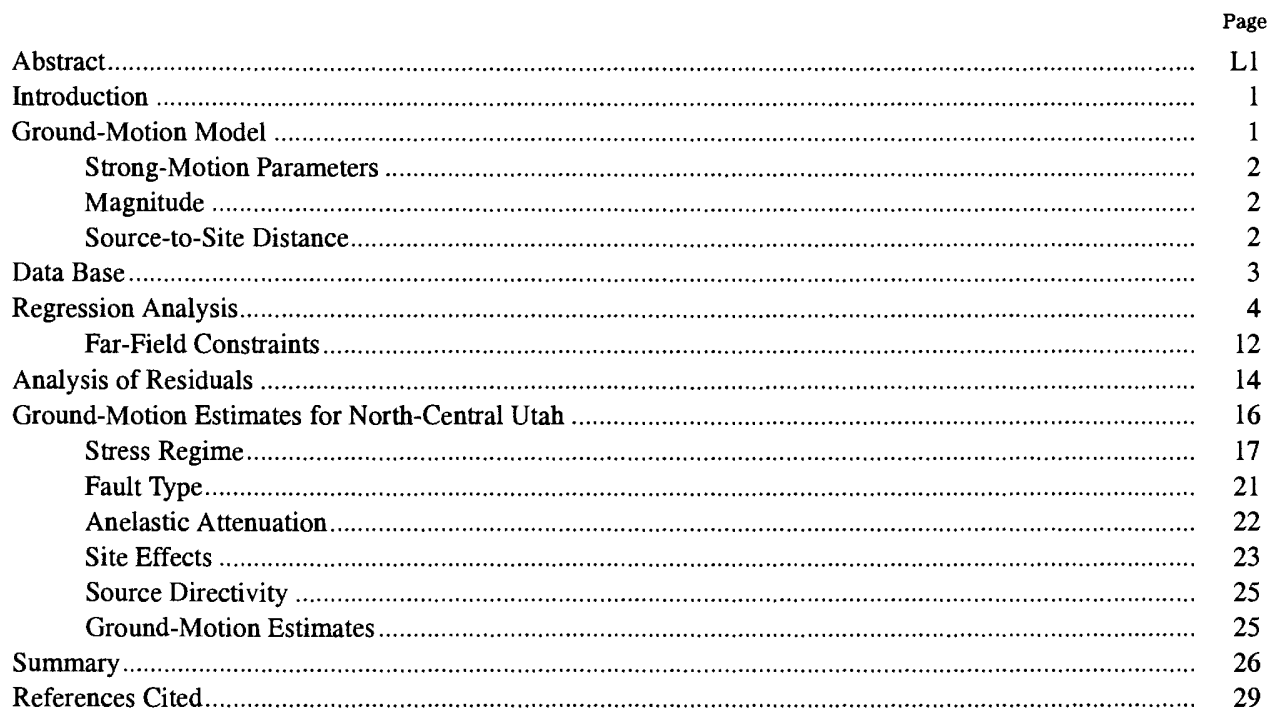

\section{ILLUSTRATIONS}

FIGures 1-13. Graphs showing:

1. Distribution of strong-motion recordings with respect to magnitude and distance ..................................................................... L L

2. Attenuation relationships of peak horizontal acceleration for various magnitudes ..................................................................... 12

3. Predicted magnitude scaling of peak horizontal acceleration for various distances ........................................................................

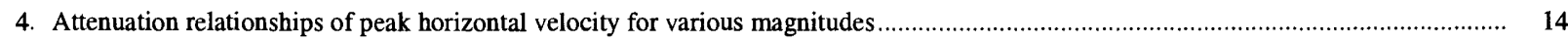

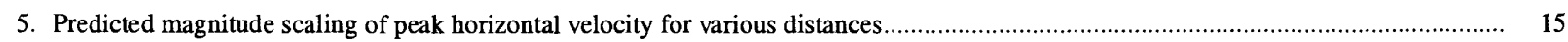

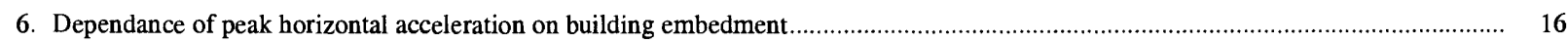

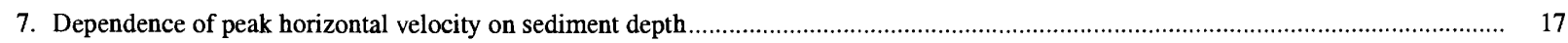

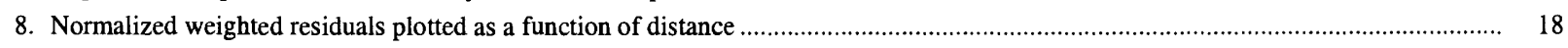

9. Normalized weighted residuals plotted as a function of magnitude …..................................................................................... 19

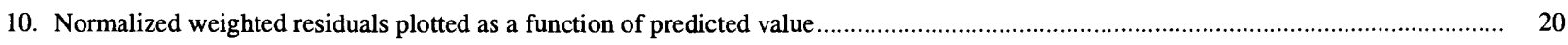

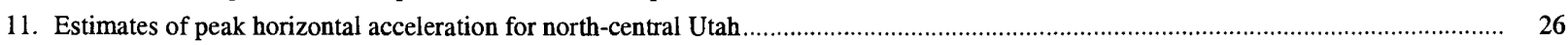

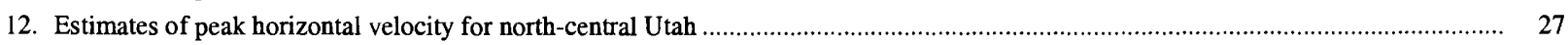

13. Median estimate of a 5-percent-damped pseudo-relative velocity spectrum for a site in north-central Utah located

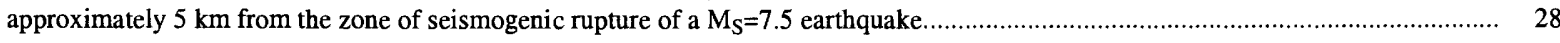

\section{TABLES}

TABLE 1. Earthquake data

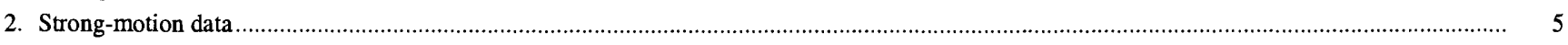

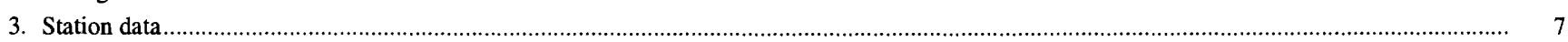

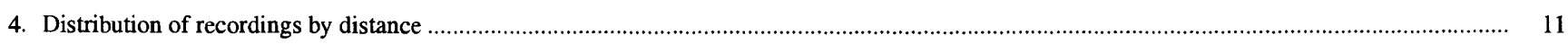

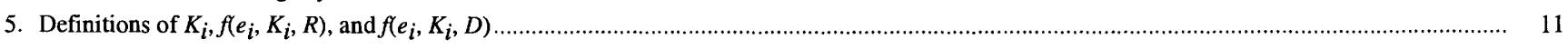

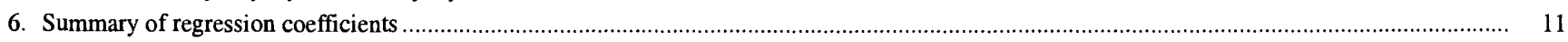




\title{
ASSESSMENT OF REGIONAL EARTHQUAKE HAZARDS AND RISK \\ ALONG THE WASATCH FRONT, UTAH
}

\section{PREDICTING STRONG GROUND MOTION IN UTAH}

\author{
By Kenneth W. Campbell
}

\begin{abstract}
Near-source attenuation relationships for predicting peak horizontal acceleration and velocity in terms of earthquake magnitude, sourceto-site distance, and several source and site parameters are used to estimate strong ground motion in north-central Utah. The range of estimates provided reflects uncertainty in the state of knowledge regarding the effects of stress regime, fault type, anelastic attenuation, and local site conditions. Regional data were used to quantify these effects when possible. For a site located directly above the rupture zone of an hypothesized $M_{S}=7.5$ earthquake on the Wasatch fault (a distance of approximately $5 \mathrm{~km}$ ), median estimates of peak horizontal acceleration and velocity were found to range from 0.55 to $1.1 \mathrm{~g}$ and 45 to $120 \mathrm{~cm} / \mathrm{s}$, respectively. These ground-motion estimates, when translated into median estimates of 5-percent-damped response spectral values using the Newmark-Hall procedure, result in estimates of pseudo-absolute acceleration for the 0.1 - to 0.5 -s period band that range from 1.05 to $2.1 \mathrm{~g}$ and estimates of pseudo-relative velocity for the 0.5 - to 3.0 -s period band that range from 70 to $200 \mathrm{~cm} / \mathrm{s}$.
\end{abstract}

\section{INTRODUCTION}

Near-source attenuation relationships for predicting peak horizontal acceleration and peak horizontal velocity from earthquake magnitude, source-to-site distance, and various source and site parameters are developed from strong-motion recordings of worldwide earthquakes having magnitudes ranging from 5.0 to 7.7. This report revises several previous studies (Campbell, 1981a, b, 1982a, b, 1983, 1984a). Major revisions include changes in the definition of parameters representing source-to-site distance, site geology, and building size and embedment

Two types of attenuation relationships are developed. The first, a near-source relationship, is empirically derived from a set of near-source strong-motion recordings having no constraint on its far-field behavior. It is similar to the unconstrained model of Campbell (1981a). The second relationship includes an anelastic attenuation term as a means of extrapolating the model beyond the near-source region. This latter relationship, similar to the constrained model of Campbell (1981a), provides a means of incorporating regional differences in anelastic attenuation when predicting strong ground motion.

\section{GROUND-MOTION MODEL}

The equation used to model the attenuation and magnitude-scaling characteristics of peak horizontal acceleration and velocity is given by the expression (Campbell, 1984a)

$$
\ln Y=a+b \mathrm{M}-d \ln \left[R+c_{1} \exp \left(c_{2} \mathrm{M}\right)\right]-\gamma R+\sum e_{i} K_{i}+\varepsilon
$$

where $Y$ is the ground-motion parameter being predicted, $\mathrm{M}$ is earthquake magnitude, $R$ is source-to-site distance, $K_{i}$ are variables representing source and site effects, $\gamma$ is the coefficient of anelastic attenuation, and $\varepsilon$ is a random error term having zero mean and standard deviation equal to the standard error of regression. The coefficients $a$ through $e$ are parameters to be determined from the data. All logarithms in equation 1 are given in terms of the natural logarithm. The nonlinear form of equation 1 was selected to accommodate any saturation of peak horizontal acceleration and velocity with magnitude and distance if supported by the data. The far-field properties of the model are characterized by the magnitude scaling coefficient $b$, the coefficient of geometrical attenuation $d$, and the coefficient of anelastic attenuation $\gamma$. The near-source properties of the model are characterized by the coefficients $c_{1}$ and $c_{2}$. The form of the term in brackets was first proposed by Esteva (1970) and later used by Hadley and others (1982) to model the near-source attenuation of simulated ground motions. For $c_{1}>0$, the strong-motion parameter saturates with decreasing distance, approaching a finite value at $R=0$. For $c_{2}>0$, the strong-motion parameter saturates with increasing magnitude at short 
distances until $c_{2}=-b / d$, when it becomes totally independent of magnitude at $R=0$.

The parameters $Y, \mathrm{M}, R$, and $K_{i}$ were defined according to guidelines set forth by Campbell (1985a). Brief definitions of these parameters follow.

\section{STRONG-MOTION PARAMETERS}

Peak horizontal acceleration and velocity were defined as the arithmetic mean of the peak horizontal values of acceleration and velocity, respectively. This mean, referred to as the mean peak horizontal component, was chosen because (1) it tends to minimize the variability associated with the near-random azimuthal orientation of the two orthogonal horizontal components and, thus, is statistically superior to the largest horizontal component (Campbell, 1982a) and (2) it avoids the error associated with using both peak horizontal components as independent observations (Campbell, 1985a).

The latter observation is particularly important because past investigators have commonly used both peak horizontal components as independent observations. This practice artificially increases the number of degrees of freedom and thereby invalidates the statistical interpretation of the results. This flaw is also true of analyses that use one of the horizontal components to predict the other. The only correct use of both horizontal components as individual variables is by means of multivariate multiple regression (Johnson and Wichern, 1982)-a technique that properly accounts for statistical correlation between dependent variables.

The mean peak horizontal component of acceleration has been found to be approximately 12 percent less and the mean peak horizontal component of velocity approximately 17 percent less than the largest peak horizontal component (Campbell, 1981a; Joyner and Fumal, 1985). On the other hand, median predictions of ground-motion parameters based on the mean peak horizontal component have been found to be virtually identical to those based on the use of both peak horizontal components (Campbell, 1982a). The above factors can be used to compare median predictions of ground-motion parameters in the current study with those in other studies available from the literature.

Peak accelerations were scaled from either uncorrected $^{1}$ time series or copies of the original accelerograms to avoid the reduction in amplitude caused by decimation and low-pass filtering of the records during routine processing. Peak velocities were scaled directly from the processed velocity time series.

\footnotetext{
${ }^{1}$ First stage of routine processing in which the accelerogram is dig itized and the baseline corrected. Unequal time intervals are used to preserve the peak amplitudes of the original accelerogram.
}

\section{MAGNITUDE}

Magnitude was defined as surface-wave magnitude $\left(M_{S}\right)$ when both local magnitude $\left(M_{L}\right)$ and $M_{S}$ were greater than or equal to 6.0 or as $\mathrm{M}_{\mathrm{L}}$ when both $\mathrm{M}_{\mathrm{S}}$ and $\mathrm{M}_{\mathrm{L}}$ were less than 6.0. Using the $M_{S}$ scale for the larger earthquakes serves as a uniform basis for characterizing the size of worldwide events and thus avoids saturation of the $\mathrm{m}_{\mathrm{b}}$ and $\mathrm{M}_{\mathrm{L}}$ scales (Campbell, 1985a, fig. 2).

Bakun (1984) and Hanks and Boore (1984) have found $\mathrm{M}_{\mathrm{L}}$ and moment magnitude, the magnitude measure recommended by Joyner and Boore (1981), to be roughly equivalent for $5.0 \leq \mathrm{M}_{\mathrm{L}} \leq 6.0$, and Hanks and Kanamori (1979) cited a similar equivalence between moment magnitude and $M_{S}$ for $5.0 \leq M_{S} \leq 7.5$. Furthermore, Nuttli (1979) has interpreted the commonly cited Richter magnitude scale (Richter, 1958), used in many previous groundmotion attenuation relationships, to represent $M_{L}$ for earthquakes less than about magnitude 6.0 and $\mathrm{M}_{\mathrm{S}}$ for larger earthquakes. Thus, the magnitude scale used in the current study is considered to be consistent with both the moment magnitude and the Richter magnitude scales for the range of magnitudes used in this study and thus does not constitute a significant departure from the magnitude scales used in previous ground-motion studies.

\section{SOURCE-TO-SITE DISTANCE}

Source-to-site distance was defined as the shortest distance between the recording station and the zone of seismogenic rupture, which was identified, when possible, from aftershocks of the earthquake. When the aftershock distribution was too diffuse, too inaccurate, or too limited to reliably define this zone, then modeling studies, past seismicity, geodetic data, refraction experiments, and geologic information-particularly the depth to basement-rock contact on the fault zone-were used to infer its spatial extent. Adopting this distance measure implicitly assumes that dynamic stresses within the upper sediments are too small to be seismogenic, even if significant displacement occurs within these sediments.

The current definition of distance is a revision of that used in the author's previous studies. The former distance measure-defined as the shortest distance between the site and the rupture zone-was found to be difficult to determine for many moderate-sized earthquakes. For large earthquakes $(M \geq 6.5)$, where surface rupture was clearly identified, the former distance was measured from the surface trace of the fault. For small to moderate earthquakes $(M \leq 5.5)$. where it could be reasonably assumed that rupture was confined to basement rock beneath the sediments, the former distance was measured from the inferred fault rupture at depth. However, for moderatesized earthquakes $(M \approx 5.5-65)$, where the surface expres- 
sion of rupture was identified only by a zone of small, discontinuous ground cracks in the vicinity of the fault trace, it was not clear whether rupture was confined to basement rock, terminated somewhere within the sediments, or propagated to the surface of the sediments. The revised definition of distance avoids these ambiguities and, in the opinion of this author, represents a more physically sound basis for modelling wave-propagation characteristics of strong ground motion.

The strongest phase of shaking recorded at a site may not always come from the closest part of the seismogenic rupture zone. In fact, Shakal and Bernreuter (1981, p. 19) suggested that ground-motion predictions made by using attenuation relationships based on closestdistance measures will "at best be accurate and at worst may significantly underpredict ground-motion levels." This assertion would be true only if the relationships were developed in terms of closest distance to seismogenic rupture and then applied in terms of distance to the actual source of the strongest phase of shaking-the distance measure preferred by Shakal and Bernreuter. Because it is not known in advance where the true source of the strongest ground motion will be, it is not feasible in practice to make predictions in terms of the latter distance measure. The distance measure used in the current study can be reliably estimated for both actual and hypothesized earthquakes and, if consistently applied, will appropriately account for uncertainty in the location of the actual source of the strongest recorded ground motion by including it as inherent variability.

\section{DATA BASE}

The data base consists of peak horizontal acceleration and velocity parameters obtained from accelerograms recorded in the near-source regions of selected worldwide earthquakes. The study was not restricted to earthquakes occurring only in western North America, as has been common practice in the past. Several factors have minimized the potential bias of the foreign data used in the analyses. The restriction to the near-source regime has made any regional differences in anelastic attenuation negligible in comparison with the inherent scatter from other factors. In addition, the foreign data used in this investigation come from events occurring within active tectonic provinces generally similar to the seismotectonic regime of western North America. Deep subduction events were excluded from the analyses because of potential significant differences in travel paths and tectonic stress conditions of such earthquakes in comparison with those of the shallow events used in the current study. To avoid a potential instrument bias, all the foreign data were recorded on instruments having dynamic char- acteristics similar to those commonly used in the United States.

The data base was assembled by using criteria designed to select only consistent and reliable data over a range of magnitudes and distances of greatest interest to engineers and engineering seismologists. Data were selected if (1) the largest horizontal component of peak acceleration was at least $0.02 g$; (2) the accelerograph triggered early enough to record the strong phase of shaking; (3) the magnitude of the earthquake was 5.0 or larger; (4) the closest distance to seismogenic rupture was less than 30 or $50 \mathrm{~km}$, depending on whether the magnitude of the earthquake was less than or greater than 6.25 ; (5) the shallowest extent of seismogenic rupture was no deeper than $25 \mathrm{~km}$; and (6) the recording site was located on unconsolidated deposits.

Rock sites-sites located on sedimentary or crystalline rock-were excluded from the analyses because of their potentially significant and extremely variable site effects (Campbell, 1983; Tucker and others, 1984; Cranswick and others, 1985). Such sites are typically located in areas of significant topographic relief, such as near the abutments of dams, or founded on rock having a large degree of weathering. In addition, the limited number of near-source recordings on rock makes it virtually impossible to empirically quantify any significant site effects for such sites.

Ideally, it would be desirable to restrict the analyses to strong-motion records obtained in the free field. However, as Campbell (1986) pointed out, there are very few true free-field recordings. Therefore, it was necessary to include records obtained at the foundation level of buildings in order to have a sufficient number of recordings for analysis. In accordance with the recommendations of Campbell (1984b, 1985a, 1986), the analyses were carefully evaluated for potential soil-structure interaction effects, which were modeled when found to be significant. Accelerograms recorded on instruments located on the abutments and toes of dams were excluded because of the potential effects of the dam

The earthquakes selected for analysis, together with their magnitudes and types of faulting, are listed in table 1; the peak accelerations, peak velocities, and source-to-site distances for each recording site are given in table 2; recording sites are described in table 3 . Figure 1 shows the distribution of recordings with respect to magnitude and distance. This figure indicates that there is little correlation between magnitude and distance for either peak horizontal acceleration or peak horizontal velocity, a positive attribute in regression analyses that treat these parameters as independent variables. The final data base contains 134 acceleration values, 107 velocity values, 130 recording stations, and 21 earthquakes that meet the criteria presented above. 
TABLE 1.-Earthquake data

[All earthquakes occurred in California, unless otherwise noted]

\begin{tabular}{|c|c|c|c|c|c|}
\hline \multirow{2}{*}{ Earthquake } & \multirow{2}{*}{$\begin{array}{c}\text { Date } \\
\text { (year-month-date) }\end{array}$} & \multirow{2}{*}{ Magnitude } & \multirow{2}{*}{ Fault type } & \multicolumn{2}{|c|}{ No. of recordings } \\
\hline & & & & Acceleration & Velocity \\
\hline Long Beach & $33-03-11$ & 6.2 & Strike slip & 2 & 2 \\
\hline Imperial Valley & $40-05-19$ & 7.1 & Strike slip & 1 & 1 \\
\hline Kern County & $52-07-21$ & 7.7 & Reverse & 1 & 1 \\
\hline Daly City & $57-03-22$ & 5.3 & Strike slip & 4 & 4 \\
\hline Parkfield & $66-06-28$ & 6.0 & Strike slip & 5 & 4 \\
\hline Borrego Mountain & 68-04-09 & 6.7 & Strike slip & 1 & 1 \\
\hline Lytle Creek & $70-09-12$ & 5.4 & Reverse & 5 & 4 \\
\hline San Fernando & $71-02-09$ & 6.6 & Reverse & 53 & 44 \\
\hline Managua, Nicaragua & $72-12-23$ & 6.2 & Strike slip & 1 & 1 \\
\hline Point Mugu & $73-02-21$ & 5.9 & Reverse & 1 & 0 \\
\hline Hollister & $74-11-28$ & 5.1 & Strike slip & 3 & 3 \\
\hline Oroville & $75-08-01$ & 5.7 & Normal & 1 & 0 \\
\hline Kalapana, Hawaii & $75-11-21$ & 7.1 & Thrust & 1 & 0 \\
\hline Gazli, U.S.S.R & $76-05-17$ & 7.0 & Reverse & 1 & 1 \\
\hline Santa Barbara & $78-08-13$ & 5.7 & Reverse & 5 & 3 \\
\hline Tabas, Iran & $78-09-16$ & 7.4 & Reverse & 1 & 1 \\
\hline Bishop & $78-10-04$ & 5.8 & Strike slip & 2 & 0 \\
\hline Malibu & $79-01-01$ & 5.0 & Reverse & 4 & 0 \\
\hline St. Elias, Alaska & $79-02-28$ & 7.2 & Thrust & 1 & 1 \\
\hline Coyote Lake & $79-08-06$ & 5.9 & Strike slip & 6 & 5 \\
\hline Imperial Valley & $79-10-15$ & 6.9 & Strike slip & 35 & 31 \\
\hline
\end{tabular}

\section{REGRESSION ANALYSIS}

The coefficients $a$ through $e$ in equation 1 were estimated by using a nonlinear least-squares regression routine developed by More and others (1980). The method was modified to incorporate weights used to control the influence of those earthquakes having a large number of recordings. The weighting scheme is identical to that described by Campbell (1981a, 1982a). Because it is dèsigned to give each earthquake an equal weight in the analysis at each of nine distance intervals, it thereby balances the information on magnitude scaling contributed by earthquakes whose recordings are poorly distributed with respect to distance with the information on distance scaling contributed by earthquakes whose recordings are well distributed with respect to distance. The distance intervals were selected to be roughly equal in logarithmic increments between 0 and $56.6 \mathrm{~km}$.

The weight of each recording was computed from the expression

$$
w_{i}=\left(n / n_{i}\right) / \sum_{j=1}^{n}\left(1 / n_{j}\right)
$$

where $n$ is the total number of recordings used in the analysis and $n_{i}$ is the number of recordings associated with the specific earthquake and distance interval containing the $i$ th recording. The quantity $n_{i}$ is not unique to a single recording; rather, it is the same for all recordings of the same earthquake whose distance falls within the specified distance interval. The above expression assures that the sum of the weights equals $n$, thus preserving the correct number of degrees of freedom. Table 4 gives the distribution of recordings with respect to the nine distance intervals used in the analyses.

Other investigators have proposed alternate methods of compensating for the bias associated with the erratic distribution of distances and numbers of recordings between earthquakes. The two most notable are the twostep regression procedure suggested by Joyner and Boore (1981) and the random-effects procedure suggested by Brillinger and Preisler (1984). Although the later technique may be more mathematically rigorous, all three techniques are fundamentally similar in their results. Therefore, the weighted regression procedure has been retained for the current study to be consistent with the author's previous analyses. 


\begin{tabular}{|c|c|c|c|c|c|c|c|c|c|}
\hline \multicolumn{5}{|c|}{$\begin{array}{c}\text { TABLE 2.-Strong-motion data } \\
{[-, \text { not available }]}\end{array}$} & \multicolumn{5}{|c|}{ TABLE 2.-Strong-motion data-Continued } \\
\hline Earthquake (year) & $\begin{array}{l}\text { Station } \\
\text { no. }\end{array}$ & $\begin{array}{c}\text { Source- } \\
\text { to-site } \\
\text { distance } \\
(\mathbf{k m})\end{array}$ & $\begin{array}{c}\text { Peak } \\
\text { horizontal } \\
\text { acceleration } \\
\text { (g) }\end{array}$ & $\begin{array}{c}\text { Peak } \\
\text { horizontal } \\
\text { velocity } \\
(\mathrm{cm} / \mathrm{s})\end{array}$ & Earthquake (year) & $\begin{array}{c}\text { Station } \\
\text { no. }\end{array}$ & $\begin{array}{l}\text { Source- } \\
\text { to-site } \\
\text { distance } \\
(\mathbf{k m})\end{array}$ & $\begin{array}{c}\text { Peak } \\
\text { horizontal } \\
\text { acceleration } \\
(g)\end{array}$ & $\begin{array}{c}\text { Peak } \\
\text { horizontal } \\
\text { velocity } \\
(\mathrm{cm} / \mathrm{s})\end{array}$ \\
\hline \multirow[t]{2}{*}{ Long Beach (1933) ................. } & 131 & 6.4 & 0.180 & 22.6 & \multirow{27}{*}{$\begin{array}{l}\text { San Fernando (1971) - } \\
\text { Continued ............................... }\end{array}$} & & & & \\
\hline & 288 & 22.0 & .140 & 22.9 & & 482 & 29.0 & .120 & 13.7 \\
\hline \multirow{2}{*}{ Imperial Valley (1940) ........... } & \multirow{2}{*}{117} & \multirow{2}{*}{8.3} & \multirow{2}{*}{.292} & \multirow{2}{*}{34.4} & & 160 & 29.1 & .220 & 18.6 \\
\hline & & & & & & 455 & 29.1 & .185 & 15.7 \\
\hline Kern County (1952) .................. & 1095 & 48.4 & .186 & 16.7 & & 163 & 29.3 & .105 & 16.4 \\
\hline \multirow{5}{*}{ Daly City (1957) ........................ } & \multirow{5}{*}{$\begin{array}{l}1080 \\
1065 \\
1078 \\
1049\end{array}$} & \multirow{5}{*}{$\begin{array}{l}12.9 \\
14.8 \\
14.8 \\
24.6\end{array}$} & \multirow{5}{*}{$\begin{array}{l}.083 \\
.053 \\
.047 \\
.038\end{array}$} & 4.6 & & 166 & 29.3 & .235 & 20.2 \\
\hline & & & & $\begin{array}{l}4.0 \\
2.2\end{array}$ & & 125 & 29.6 & .145 & 16.7 \\
\hline & & & & 3.8 & & 416 & 29.9 & .140 & 17.9 \\
\hline & & & & 1.6 & & 437 & 30.0 & .105 & 19.1 \\
\hline & & & & & & 469 & 30.0 & .205 & 19.2 \\
\hline \multirow[t]{5}{*}{ 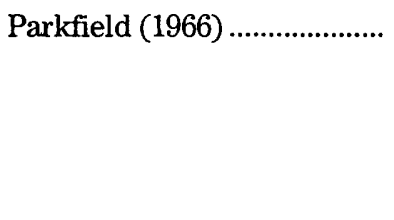 } & \multirow{5}{*}{$\begin{array}{l}1013 \\
1014 \\
1015 \\
1438 \\
1016\end{array}$} & \multirow{5}{*}{$\begin{array}{r}3.0 \\
6.3 \\
10.1 \\
11.0 \\
15.2\end{array}$} & \multirow{5}{*}{$\begin{array}{l}.400 \\
.435 \\
.275 \\
.350 \\
.066\end{array}$} & 61.2 & & 428 & 30.1 & .084 & 26.8 \\
\hline & & & & 24.0 & & 443 & 30.1 & .130 & 22.1 \\
\hline & & & & 11.3 & & 140 & 31.0 & .095 & 8.4 \\
\hline & & & & 一 & & $\begin{array}{l}140 \\
175\end{array}$ & 31.0 & .135 & 20.8 \\
\hline & & & & 7.5 & & 413 & 31.0 & .115 & 14.6 \\
\hline Borrego Mountain (1968) .... & 117 & 45.0 & .102 & 20.3 & & 425 & 31.1 & .090 & 13.5 \\
\hline Lytle Creek (1970) .................. & 290 & 12.4 & .175 & 8.8 & & 181 & 31.3 & .140 & 16.9 \\
\hline & 116 & 17.9 & .175 & - & & 184 & 31.3 & .090 & 13.0 \\
\hline & 112 & 20.0 & .068 & 3.5 & & 187 & 31.3 & .145 & 13.2 \\
\hline & 274 & 28.3 & .090 & 4.3 & & 121 & 32.1 & .160 & - \\
\hline & 113 & 28.8 & .043 & 2.2 & & 205 & 33.1 & .070 & 17.6 \\
\hline San Fernando (1971) .............. & 241 & 13.8 & .205 & 26.8 & & 288 & 34.8 & .100 & 16.3 \\
\hline & 458 & 16.0 & .115 & 30.1 & & 269 & 35.5 & .125 & - \\
\hline & 267 & 18.1 & .195 & 11.6 & & 229 & 42.2 & .060 & 14.0 \\
\hline & 128 & 18.7 & .325 & - & & 244 & 42.2 & .040 & 10.5 \\
\hline & 461 & 20.5 & .140 & 19.2 & & 247 & 42.2 & .030 & 12.1 \\
\hline & 253 & 21.6 & .225 & 21.6 & & 1052 & 48.2 & .090 & 7.3 \\
\hline & 466 & 21.6 & .185 & 25.6 & Managua (1972) ........................... & 3501 & 5.4 & .365 & 32.7 \\
\hline & 127 & 22.6 & .155 & - & Point Mugu (1973) ................. & 272 & 24.0 & .105 & - \\
\hline & 264 & 25.0 & .195 & 13.1 & & & & & \\
\hline & 232 & 25.4 & .165 & 18.8 & Hollister (1974) ....................... & - 1377 & 8.9 & .085 & 5.0 \\
\hline & 235 & 25.4 & .115 & 17.4 & & 1028 & 10.8 & .135 & 8.6 \\
\hline & 238 & 25.5 & .105 & 13.0 & & 1250 & 10.8 & .120 & 3.7 \\
\hline & 446 & 25.5 & .145 & 12.1 & 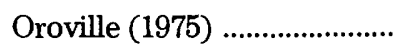 & . 1291 & 30.0 & .065 & - \\
\hline & 475 & 25.7 & .105 & 11.1 & & & & & \\
\hline & 133 & 26.7 & .130 & 18.2 & 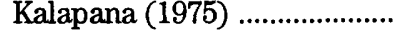 & · 2808 & 37.9 & .165 & - \\
\hline & 135 & 26.7 & .205 & 18.8 & 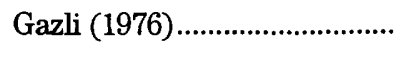 & . 9110 & 3.5 & .666 & 74.5 \\
\hline & 262 & 27.6 & .120 & 11.8 & Santa Barbara (1978) ............. & 5093 & 12.7 & .353 & - \\
\hline & 145 & 28.3 & .135 & 一 & & 885 & 12.9 & .331 & 32.9 \\
\hline & 148 & 28.3 & .185 & - & & 283 & 14.6 & .154 & 10.9 \\
\hline & 142 & 28.6 & .090 & 17.4 & & 5137 & 14.6 & .176 & 13.8 \\
\hline & 199 & 28.7 & .180 & - & & 9022 & 16.3 & .267 & - \\
\hline & 208 & 28.7 & .135 & 20.4 & & 0124 & 54 & 755 & $08 ?$ \\
\hline & 211 & 28.7 & .155 & 19.4 & 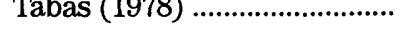 & - 9124 & 0.4 & .750 & 98.2 \\
\hline & 223 & 28.7 & .105 & 21.2 & 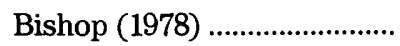 & 1008 & 30.7 & .045 & - \\
\hline & 431 & 28.7 & .105 & - & & 1490 & 30.8 & .060 & - \\
\hline & 452 & 28.7 & .075 & 14.1 & Malihu (1979) & & & 080 & - \\
\hline & 449 & 28.8 & .100 & - & 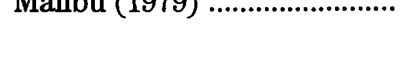 & $\begin{array}{r}5001 \\
5079\end{array}$ & $\begin{array}{l}10.1 \\
20.2\end{array}$ & .065 & - \\
\hline
\end{tabular}


TABLE 2.-Strong-motion data-Continued

\begin{tabular}{|c|c|c|c|c|}
\hline Earthquake (year) & $\begin{array}{c}\text { Station } \\
\text { no. }\end{array}$ & $\begin{array}{l}\text { Source- } \\
\text { to-site } \\
\text { distance } \\
(\mathbf{k m})\end{array}$ & $\begin{array}{c}\text { Peak } \\
\text { horizontal h } \\
\text { acceleration } \\
\text { (g) }\end{array}$ & $\begin{array}{c}\text { Peak } \\
\text { horizontal } \\
\text { velocity } \\
(\mathrm{cm} / \mathrm{s})\end{array}$ \\
\hline \multicolumn{5}{|l|}{ Malibu (1979)- } \\
\hline \multirow[t]{2}{*}{ Continued ................................. } & 657 & 20.7 & .040 & - \\
\hline & 757 & 23.7 & 0.45 & - \\
\hline St. Elias (1979) & 2734 & 36.4 & .136 & 27.3 \\
\hline \multirow[t]{6}{*}{ Coyote Lake (1979) } & 1411 & 5.4 & .243 & 28.7 \\
\hline & 1410 & 6.6 & .256 & 23.2 \\
\hline & 1409 & 8.4 & .225 & 21.1 \\
\hline & 1377 & 14.4 & .109 & 6.3 \\
\hline & 1492 & 16.2 & .106 & 6.5 \\
\hline & 1422 & 28.0 & 0.45 & - \\
\hline \multirow[t]{35}{*}{ Imperial Valley (1979) } & 6618 & 5.0 & .254 & 31.7 \\
\hline & 6616 & 5.2 & .278 & - \\
\hline & 6617 & 5.2 & .310 & 34.6 \\
\hline & 5028 & 5.5 & .440 & 76.4 \\
\hline & 5155 & 5.5 & .307 & 81.3 \\
\hline & 942 & 5.6 & .585 & 85.9 \\
\hline & 952 & 5.6 & .480 & 65.3 \\
\hline & 958 & 6.7 & .570 & 50.6 \\
\hline & 5054 & 6.8 & .735 & 43.9 \\
\hline & 955 & 6.9 & .495 & 57.4 \\
\hline & 6621 & 7.3 & .265 & 27.4 \\
\hline & 5060 & 7.5 & .195 & 36.2 \\
\hline & 5165 & 7.5 & .440 & 55.2 \\
\hline & 9034 & 7.5 & .352 & 36.4 \\
\hline & 117 & 8.3 & .335 & - \\
\hline & 5055 & 9.3 & .240 & 46.6 \\
\hline & 5154 & 9.4 & .240 & 48.7 \\
\hline & 6619 & 9.8 & .385 & - \\
\hline & 412 & 10.1 & .215 & 43.3 \\
\hline & 5057 & 10.9 & .245 & 41.6 \\
\hline & 5053 & 11.9 & .250 & 17.8 \\
\hline & 5115 & 12.3 & .380 & 28.9 \\
\hline & 5058 & 13.8 & .380 & 37.1 \\
\hline & 6622 & 14.6 & .169 & 12.4 \\
\hline & 5051 & 15.0 & .155 & 15.9 \\
\hline & 5056 & 16.0 & .150 & 12.9 \\
\hline & 5169 & 16.0 & .094 & 20.5 \\
\hline & 931 & 18.8 & .130 & 18.5 \\
\hline & 6605 & 21.7 & .292 & 27.0 \\
\hline & 5059 & 22.7 & .135 & 14.4 \\
\hline & 5061 & 23.7 & .110 & 13.7 \\
\hline & 5062 & 29.5 & .060 & - \\
\hline & 6610 & 30.8 & .142 & 7.0 \\
\hline & 5052 & 32.5 & .060 & 4.5 \\
\hline & 724 & 36.4 & .087 & 10.1 \\
\hline
\end{tabular}

For peak horizontal acceleration and velocity, the weighted nonlinear regression analysis resulted in the following unconstrained relationships:

$$
\begin{aligned}
\ln \mathrm{PHA}= & -2.817+0.702 \mathrm{M}-1.20 \ln [R+0.0921 \exp (0.584 \mathrm{M})] \\
& +f\left(e_{i}, K_{i}, R\right) \\
\ln \mathrm{PHV}= & -0.798+1.02 \mathrm{M}-1.26 \ln [R+0.0150 \exp (0.812 \mathrm{M})] \\
& +\mathrm{f}\left(e_{i}, K_{i}, D\right)
\end{aligned}
$$

where peak horizontal acceleration (PHA), peak horizontal velocity (PHV), and distance $(R)$ have units of $g$, centimeters per second, and kilometers, respectively. Magnitude and distance are as defined previously, and $D$ is the depth (in kilometers) of sediments beneath the recording site. Parameters $K_{i}$, functions $f\left(e_{i}, K_{i}, R\right)$ and $f\left(e_{i}, K_{i}, D\right)$ and coefficients $e_{i}$ are summarized in tables 5 and 6; the attenuation relationships are plotted in figures 2 through 5 for $K_{i}=0$. The standard errors of regression are 0.30 and 0.26 for equations 3 and 4, respectively.

The definitions and functional relationships for $K_{i}$ were determined from an analysis of residuals described later in the text. Because of the nonlinear form of equation 1, rigorous statistical tests to determine the significance of coefficients $a$ through $e$ require Monte Carlo simulation (Gallant, 1975), which is beyond the scope of this study. Therefore, the statistical significance of these coefficients is not precisely known. A visual inspection of the residuals did indicate a very strong need for all coefficients, except possibly $c_{2}$, an indication that these coefficients are statistically significant at least at the 90-percent confidence level. Coefficient $c_{2}$ is controlled by too few recordings to be judged solely on visual inspection. It should be noted, however, that the regression analyses for both strong-motion parameters resulted in a value for $c_{2}$ at its practical upper limit, $c_{2}=-b / d$. This value represents complete saturation of peak horizontal acceleration and velocity at the source of an earthquake, in accordance with some geophysicists' interpretations of earthquake rupture mechanics (Campbell, 1985a). Confirmation of the statistical significance of $c_{2}$ will have to await the outcome of Monte Carlo simulations.

The results presented in table 6 indicate that peak horizontal acceleration is systematically high when recorded on ground-level instruments located on shallow soils and that it is systematically low when recorded in basements of buildings more than three stories high. Shallow soils are defined as unconsolidated deposits less than about $10 \mathrm{~m}$ deep that overlie sedimentary or crystalline rock (Campbell, 1981a). The reduction in peak horizontal acceleration due to embedment was found to be dependent on building size and distance, buildings 10 stories and higher having lower accelerations than 3- to 9-story buildings and buildings further from the source having 
TABLE 3.-Station data

[All stations in California, unless otherwise noted. -, not available]

\begin{tabular}{|c|c|c|c|c|c|c|}
\hline $\begin{array}{l}\text { Station } \\
\text { no. }\end{array}$ & Description & Housing & $\begin{array}{l}\text { No. of } \\
\text { stories }\end{array}$ & Level & $\begin{array}{c}\text { Sediment } \\
\text { depth }(\mathbf{k m})\end{array}$ & Geology 1 \\
\hline 112 & Cedar Springs, Pump House & Building & 1 & Ground & 0.09 & A \\
\hline 113 & Colton, SCE Substation & do & 1 & do & .18 & $\mathbf{A}$ \\
\hline 116 & Devil Canyon, Filter Plant & do & 1 & do & - & $\mathrm{E}$ \\
\hline 117 & El Centro Array Station 9 & do & 2 & Basement & 5.0 & A \\
\hline 121 & Fairmont Reservoir & do & 1 & Ground & - & $\mathrm{E}$ \\
\hline 125 & Lake Hughes Array Station 1 & do & 1 & do & 3.0 & $\mathbf{A}$ \\
\hline 127 & Lake Hughes Array Station 9 & do & 1 & do & - & $E$ \\
\hline 128 & Lake Hughes Array Station 12 & do & 1 & do & - & $\mathrm{E}$ \\
\hline 131 & Long Beach, Public Utilities Building & do & 4 & Basement & 2.6 & $\mathrm{~B}$ \\
\hline 133 & Los Angeles, Hollywood Storage Building & do & 14 & do & 3.7 & A \\
\hline 135 & Los Angeles, Hollywood Storage PE Lot & Shelter & - & Ground & 3.7 & A \\
\hline 140 & Los Angeles, UCLA Math Science Building & Building & 7 & Basement & .91 & $\mathrm{~B}$ \\
\hline 142 & Los Angeles, $120 \mathrm{~N}$. Robertson & do & 9 & do & 3.4 & $\mathbf{A}$ \\
\hline 145 & Los Angeles, 222 Figueroa & do & 19 & Ground & - & $\mathbf{A}$ \\
\hline 148 & Los Angeles, 234 Figueroa & do & 19 & do & - & $\mathbf{A}$ \\
\hline 160 & Los Angeles, 533 S. Fremont & do & 10 & Basement & 3.0 & B \\
\hline 163 & Los Angeles, $611 \mathrm{~W}$. Sixth Street & do & 42 & do & 3.0 & $\mathbf{A}$ \\
\hline 166 & Los Angeles, $646 \mathrm{~S}$. Olive & do & 7 & Ground & 3.0 & A \\
\hline 175 & Los Angeles, $808 \mathrm{~S}$. Olive & do & 8 & do & 2.9 & A \\
\hline 181 & Los Angeles, 1640 Marengo & do & 7 & do & 3.4 & B \\
\hline 184 & Los Angeles, 1900 Avenue of the Stars & Building & 27 & Basement & 3.7 & B \\
\hline 187 & Los Angeles, 1901 Avenue of the Stars & do & 20 & do & - & B \\
\hline 199 & Los Angeles, 3407 W. Sixth Street & do & 8 & Ground & - & A \\
\hline 205 & Los Angeles, USC Phillips Hall & do & 12 & Basement & 4.6 & A \\
\hline 208 & Los Angeles, 3470 Wilshire & do & 12 & do & 2.9 & B \\
\hline 211 & Los Angeles, 3550 Wilshire & do & 20 & do & 2.9 & $\mathrm{~A}$ \\
\hline 223 & Los Angeles, 4680 Wilshire & do & 6 & do & 3.0 & B \\
\hline 229 & Los Angeles, 5250 Century & do & 7 & Ground & 2.4 & B \\
\hline 232 & Los Angeles, 6430 Sunset & do & 15 & do & 2.9 & A \\
\hline 235 & Los Angeles, 6464 Sunset & do & 11 & Basement & 2.9 & $\mathrm{~A}$ \\
\hline 238 & Los Angeles, 7080 Hollywood & do & 11 & do & 2.9 & A \\
\hline 241 & Los Angeles, 8244 Orion & do & 7 & Ground & 4.2 & $\mathrm{~A}$ \\
\hline 244 & Los Angeles, 8639 Lincoln & do & 12 & Basement & 2.4 & B \\
\hline 247 & Los Angeles, 9841 Airport & do & 14 & do & 2.4 & B \\
\hline 253 & Los Angeles, 14724 Ventura & do & 14 & Ground & 1.8 & $\mathrm{~A}$ \\
\hline 262 & Palmdale, Fire Station & do & 1 & do & .20 & A \\
\hline 264 & Pasadena, CIT Millikan Library & do & 9 & Basement & .01 & B \\
\hline 267 & Pasadena, JPL Building 180 & do & 9 & do & .027 & B \\
\hline 269 & Pearblossom, Pumping Plant & Shelter & - & Ground & - & $\mathrm{E}$ \\
\hline 272 & Port Hueneme, Naval Lab & Building & 1 & do & 一 & A \\
\hline 274 & San Bernardino, Hall of Records & do & 6 & Basement & 1.1 & A \\
\hline 283 & Santa Barbara, Courthouse & Building & 2 & Basement & 8.5 & B \\
\hline 288 & Vernon, CMD Terminal Building & do & 6 & do & 6.7 & A \\
\hline 290 & Wrightwood, 6074 Park Drive & do & 2 & Ground & .068 & B \\
\hline 412 & El Centro Array Station 10 & do & 1 & do & 4.5 & A \\
\hline 413 & Los Angeles, 1177 S. Beverly Drive & do & 7 & Basement & 4.1 & B \\
\hline 416 & Beverly Hills, 9100 Wilshire & do & 10 & do & 3.7 & A \\
\hline 425 & Los Angeles, 1800 Century Park East & do & 15 & do & 3.7 & B \\
\hline 428 & Los Angeles, 5900 Wilshire & do & 31 & do & 3.5 & B \\
\hline 431 & Los Angeles, $616 \mathrm{~S}$. Normandie & do & 16 & do & - & A \\
\hline
\end{tabular}


TABLE 3.-Station data-Continued

\begin{tabular}{|c|c|c|c|c|c|c|}
\hline $\begin{array}{l}\text { Station } \\
\text { no. }\end{array}$ & Description & Housing & $\begin{array}{l}\text { No. of } \\
\text { stories }\end{array}$ & Level & $\begin{array}{c}\text { Sediment } \\
\text { depth }(\mathbf{k m})\end{array}$ & Geology 1 \\
\hline 437 & Los Angeles, $1150 \mathrm{~S}$. Hill & do & 10 & do & 2.6 & A \\
\hline 443 & Los Angeles, 6200 Wilshire & do & 17 & Ground & 3.5 & A \\
\hline 446 & Los Angeles, 1760 N. Orchid & do & 23 & do & 2.9 & A \\
\hline 449 & Los Angeles, 2500 Wilshire & do & 13 & Basement & - & A \\
\hline 452 & Beverly Hills, 435 N. Oakhurst & do & 10 & do & 3.8 & A \\
\hline 455 & Beverly Hills, 450 N. Roxbury & do & 10 & Ground & 3.7 & A \\
\hline 458 & Los Angeles, 15107 Van Owen & do & 7 & Basement & 2.9 & A \\
\hline 461 & Los Angeles, 15910 Ventura & do & 16 & do & 1.8 & A \\
\hline 466 & Los Angeles, 15250 Ventura & do & 12 & do & 1.8 & A \\
\hline 469 & Los Angeles, 1625 W. Olympic & do & 10 & Ground & 2.9 & $\mathrm{~B}$ \\
\hline 475 & Pasadena, CIT Athenaeum & do & 2 & Basement & .91 & $\mathrm{~B}$ \\
\hline 482 & Alhambra, $900 \mathrm{~S}$. Fremont & do & 12 & do & 1.2 & $\mathrm{~B}$ \\
\hline 657 & Santa Monica, 201 Ocean & Building & 18 & Basement & - & $\mathrm{B}$ \\
\hline 724 & Niland, 8071 Luxor & do & 1 & Ground & 4.1 & A \\
\hline 757 & Sepulveda Canyon Control Facility & do & 9 & Basement & - & $\mathrm{B}$ \\
\hline 885 & Santa Barbara, UCSB Physical Plant & do & 1 & Ground & 8.4 & A \\
\hline 931 & El Centro Array Station 12 & Shelter & - & do & 4.4 & A \\
\hline 942 & El Centro Array Station 6 & do & - & do & 5.3 & A \\
\hline 952 & El Centro Array Station 5 & do & - & do & 5.5 & A \\
\hline 955 & El Centro Array Station 4 & do & - & do & 5.7 & A \\
\hline 958 & El Centro Array Station 8 & do & - & do & 5.1 & A \\
\hline 1008 & Bishop, Los Angeles Water Department & do & - & do & - & A \\
\hline 1013 & Cholame-Shandon Array Station 2 & do & - & do & 1.7 & A \\
\hline 1014 & Cholame-Shandon Array Station 5 & do & - & do & 1.7 & A \\
\hline 1015 & Cholame-Shandon Array Station 8 & Building & 1 & do & 1.7 & $\mathrm{~B}$ \\
\hline 1016 & Cholame-Shandon Array Station 12 & Shelter & - & do & 1.7 & A \\
\hline 1028 & Hollister, City Hall & Building & 1 & Basement & 1.4 & A \\
\hline 1049 & Oakland, City Hall & do & 15 & do & .3 & B \\
\hline 1052 & Oso Pumping Plant & Shelter & - & Ground & 3.0 & A \\
\hline 1065 & San Francisco, Alexander Building & Building & 15 & Basement & .043 & A \\
\hline 1078 & San Francisco, South Pacific Building & do & 12 & do & .087 & $\mathrm{~F}$ \\
\hline 1080 & San Francisco, State Building & Building & 6 & Basement & .062 & A \\
\hline 1095 & Taft, Lincoln School & do & & Tunnel & 6.4 & A \\
\hline 1250 & Gilroy, Gavilan College & do & 1 & Ground & .020 & B \\
\hline 1291 & Marysville, CDOT Maintenance Building & do & 1 & do & - & A \\
\hline 1377 & San Juan Bautista, 24 Polk & do & 1 & do & 1.2 & A \\
\hline 1409 & Gilroy Array Station 2 & Shelter & - & do & 4.0 & A \\
\hline 1410 & Gilroy Array Station 3 & do & - & do & 4.0 & A \\
\hline 1411 & Gilroy Array Station 4 & Building & 1 & do & 4.0 & A \\
\hline 1422 & Halls Valley, Grant Ranch & Shelter & - & do & - & A \\
\hline 1438 & Cholame-Shandon Array, Temblor & do & - & do & - & $\mathrm{E}$ \\
\hline 1490 & Mammoth Lakes, High School & Building & 1 & do & - & $\mathrm{B}$ \\
\hline 1492 & San Juan Bautista, 101/156 Overpass & Shelter & - & do & .015 & B \\
\hline 2734 & Icy Bay, Gulf Timber Company & Building & 1 & do & 6.1 & $\mathbf{F}$ \\
\hline 2808 & Hilo, UH Cloud Physics Lab & do & 1 & do & - & $\mathrm{E}$ \\
\hline 3501 & Nicaragua, Managua ESSO Refinery & do & 1 & do & 2.0 & A \\
\hline 5028 & El Centro Array Station 7 & do & 1 & do & 5.2 & A \\
\hline 5051 & El Centro, Parachute Test Site & do & 1 & do & 3.4 & A \\
\hline 5052 & Plaster City & do & 1 & do & 2.0 & A \\
\hline 5053 & Calexico, Fire Station & do & 1 & do & 4.3 & A \\
\hline
\end{tabular}


TABLE 3.-Station data-Continued

\begin{tabular}{|c|c|c|c|c|c|c|}
\hline $\begin{array}{l}\text { Station } \\
\text { no. }\end{array}$ & Description & Housing & $\begin{array}{l}\text { No. of } \\
\text { stories }\end{array}$ & Level & $\begin{array}{c}\text { Sediment } \\
\text { depth }(\mathbf{k m})\end{array}$ & Geology 1 \\
\hline 5053 & Bonds Corner & do & 1 & do & 5.7 & A \\
\hline 5055 & Holtville, Post Office & Building & 1 & Ground & 5.6 & A \\
\hline 5056 & El Centro Array Station 1 & do & 1 & do & 5.1 & A \\
\hline 5057 & El Centro Array Station 3 & do & 1 & do & 5.7 & A \\
\hline 5058 & El Centro Array Station 11 & do & 1 & do & 4.5 & A \\
\hline 5059 & El Centro Array Station 13 & Shelter & - & do & 3.8 & A \\
\hline 5060 & Brawlee, Airport & Building & do & 1 & 5.2 & A \\
\hline 5061 & Calipatria, Fire Station & do & 2 & do & 5.0 & A \\
\hline 5062 & Salton Sea Wildlife Refuge & do & 1 & do & - & A \\
\hline 5079 & Malibu, Kilpatrick Boy's School & do & 1 & do & - & $\mathbf{E}$ \\
\hline 5081 & Topanga, Fire Station & do & 1 & do & - & $\mathrm{E}$ \\
\hline 5093 & Santa Barbara, UCSB North Hall & do & 3 & do & - & $\mathrm{E}$ \\
\hline 5115 & El Centro Array Station 2 & Shelter & - & do & 5.5 & A \\
\hline 5137 & Santa Barbara, Freitas Building & Building & 4 & Basement & 8.5 & B \\
\hline 5154 & El Centro, Imperial County Center & Shelter & - & Ground & 4.8 & A \\
\hline 5155 & El Centro, Meloland Overpass & Vault & - & do & 5.1 & A \\
\hline 5165 & El Centro, Differential Array SMA-1 & Shelter & - & do & 5.0 & A \\
\hline 5169 & Westmorland, Fire Station & Building & 2 & do & 5.1 & A \\
\hline 6605 & Mexico, Delta & Shelter & - & do & 7.5 & A \\
\hline 6610 & Mexico, Victoria & do & - & do & 8.0 & A \\
\hline 6616 & Mexico, Aeropuerto & do & - & do & - & A \\
\hline 6617 & Mexico, Cucapah & Shelter & - & Ground & 7.0 & A \\
\hline 6618 & Mexico, Agrarias & do & - & do & 5.5 & A \\
\hline 6619 & Mexico, Mexicali, SAHOP & Building & do & - & - & A \\
\hline 6621 & Mexico, Chihuahua & Shelter & - & do & 7.0 & $\mathrm{~A}$ \\
\hline 6622 & Mexico, Compuertas & do & - & do & 5.5 & A \\
\hline 9022 & Goleta, SCE Substation & do & - & do & - & $\mathrm{E}$ \\
\hline 9034 & El Centro, Differential Array & Vault & - & do & 5.0 & A \\
\hline 9110 & U.S.S.R., Karakyr & Building & 1 & do & 1.4 & A \\
\hline 9124 & Iran, Tabas & do & 1 & do & 2.0 & A \\
\hline
\end{tabular}

\footnotetext{
${ }^{1}$ Geology code adopted from Campbell (1981a): A, Holocene deposits, rock $\geq 10 \mathrm{~m}$ deep; B, Pleistocene deposits, rock $\geq 10 \mathrm{~m}$ deep; E, Holocene or Pleistocene deposits <10 m deep overlying rock; F, extremely soft or loose Holocene deposits such as beach sand or recent flood-plain, lake, swamp, estuarine, and delta deposits.
}

smaller reductions than those closer in. This distance dependence was adequately modeled by a hyperbolic tangent function, where distance is expressed in kilometers. This function is plotted in figure 6 .

The results given in table 6 indicate that peak horizontal velocity is dependent on sediment depth (that is, depth to crystalline basement rock), increasing rapidly with depth at relatively shallow depths and becoming virtually independent of depth at depths of 5 to $6 \mathrm{~km}$. This dependence was found to be dependent on building size, buildings five stories and higher having peak velocities that increase faster with depth than those of smaller buildings and instrument shelters. For depths greater than about $5 \mathrm{~km}$, at which point the effect of sediment depth remains relatively constant, the effect of building size is less than about 10 percent. The depth dependence was adequately modeled by a hyperbolic tangent function, where sediment depth is expressed in kilometers. This function is plotted in figure 7. No amplification due to shallow soils nor any reduction as a result of building embedment was observed for peak velocity.

Both peak horizontal acceleration and peak horizontal velocity were found to be influenced by fault type, being higher for reverse and thrust faults than for strikeslip faults. The effect for velocity is somewhat larger than that for acceleration, but the difference may not be statistically significant.

During the analysis of residuals for both peak horizontal acceleration and velocity, three recordings were found to have such large positive residuals that they appeared to be outliers. All three recordings had weighted residuals exceeding four standard errors. Further investigation revealed that all three recordings had three factors in common: (1) they were associated with earthquakes 

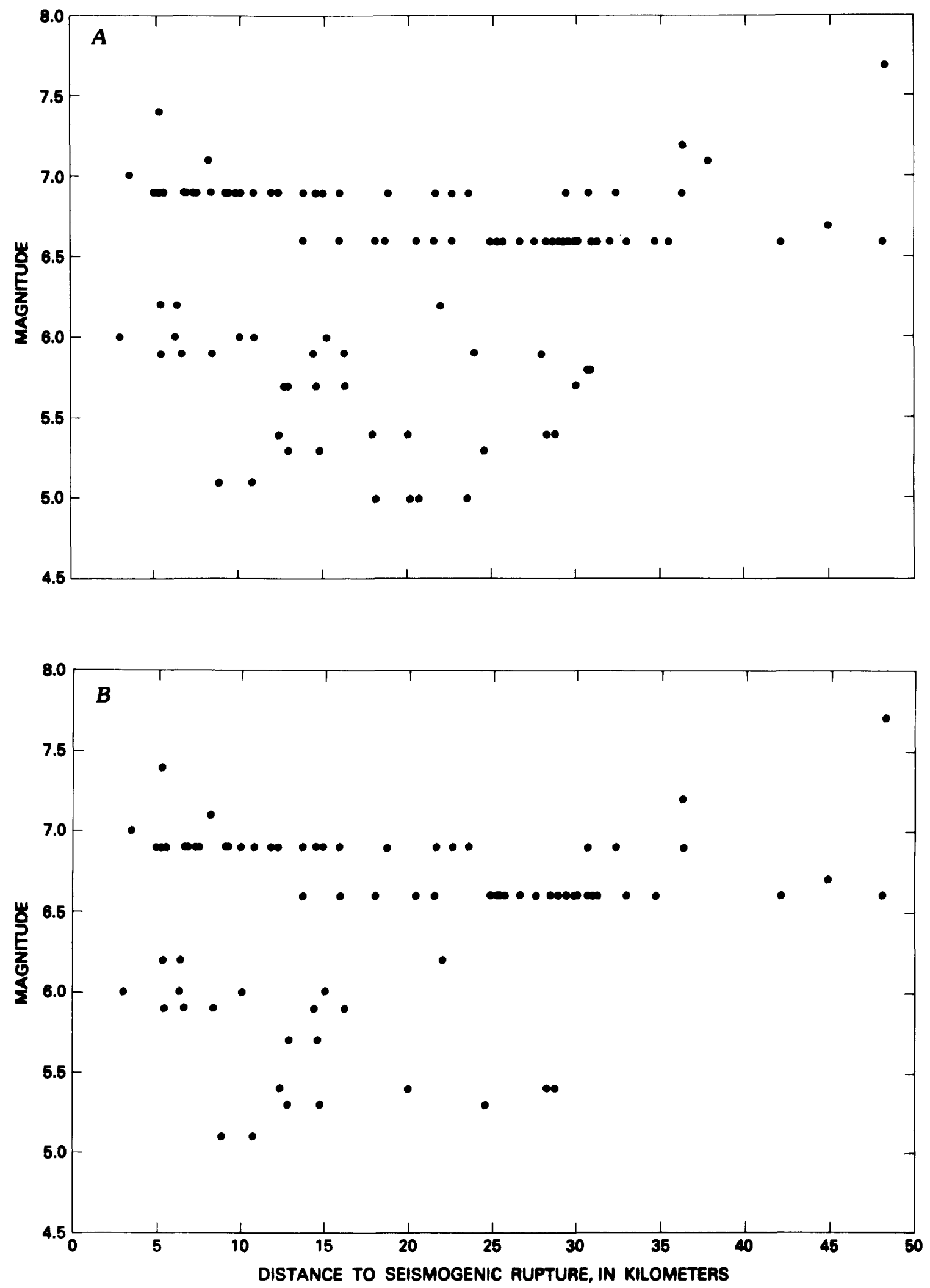

FIGURE 1.-Distribution of strong-motion recordings with respect to magnitude and distance. $A$, Peak horizontal acceleration; $B$, peak horizontal velocity. 
TABLE 4.-Distribution of recordings by distance

\begin{tabular}{|c|c|c|c|}
\hline \multirow{2}{*}{$\begin{array}{l}\text { Distance } \\
\text { range }(\mathrm{km})\end{array}$} & \multirow{2}{*}{ Earthquake (year) } & \multicolumn{2}{|c|}{ No. of recordings } \\
\hline & & Acceleration & Velocity \\
\hline $0-2.4$ & - & 0 & 0 \\
\hline $2.5-4.9$ & $\begin{array}{l}\text { Parkfield (1966) } \\
\text { Gazli (1976) }\end{array}$ & $\begin{array}{l}1 \\
1\end{array}$ & $\begin{array}{l}1 \\
1\end{array}$ \\
\hline $5.0-7.4$ & $\begin{array}{l}\text { Long Beach (1933) } \\
\text { Parkfield (1966) } \\
\text { Managua (1972) } \\
\text { Tabas (1978) } \\
\text { Coyote Lake (1979) } \\
\text { Imperial Valley (1979) }\end{array}$ & $\begin{array}{r}1 \\
1 \\
1 \\
1 \\
2 \\
11\end{array}$ & $\begin{array}{r}1 \\
1 \\
1 \\
1 \\
2 \\
10\end{array}$ \\
\hline $7.5-9.9$ & $\begin{array}{l}\text { Imperial Valley (1940) } \\
\text { Hollister (1974) } \\
\text { Santa Barbara (1978) } \\
\text { Coyote Lake (1979) } \\
\text { Imperial Valley (1979) }\end{array}$ & $\begin{array}{l}1 \\
1 \\
2 \\
1 \\
7\end{array}$ & $\begin{array}{l}1 \\
1 \\
1 \\
1 \\
5\end{array}$ \\
\hline $10.0-14.0$ & $\begin{array}{l}\text { Daly City (1957) } \\
\text { Parkfield (1966) } \\
\text { Lytle Creek (1970) } \\
\text { San Fermando (1971) } \\
\text { Hollister (1974) } \\
\text { Imperial Valley (1979) }\end{array}$ & $\begin{array}{l}1 \\
2 \\
1 \\
1 \\
2 \\
5\end{array}$ & $\begin{array}{l}1 \\
1 \\
1 \\
1 \\
2 \\
5\end{array}$ \\
\hline $14.1-19.9$ & $\begin{array}{l}\text { Daly City (1957) } \\
\text { Parkfield (1966) } \\
\text { Lytle Creek (1970) } \\
\text { San Fermando (1971) } \\
\text { Santa Barbara (1978) } \\
\text { Malibu (1979) } \\
\text { Coyote Lake (1979) } \\
\text { Imperial Valley (1979) }\end{array}$ & $\begin{array}{l}2 \\
1 \\
1 \\
3 \\
3 \\
1 \\
2 \\
5\end{array}$ & $\begin{array}{l}2 \\
1 \\
0 \\
2 \\
2 \\
0 \\
2 \\
5\end{array}$ \\
\hline $20.0-28.2$ & $\begin{array}{l}\text { Long Beach (1933) } \\
\text { Daly City (1957) } \\
\text { Lytle Creek (1957) } \\
\text { San Fernando (1971) } \\
\text { Point Mugu (1973) } \\
\text { Malibu (1979) } \\
\text { Coyote Lake (1979) } \\
\text { Imperial Valley (1979) }\end{array}$ & $\begin{array}{r}1 \\
1 \\
1 \\
13 \\
1 \\
3 \\
1 \\
3\end{array}$ & $\begin{array}{r}1 \\
1 \\
1 \\
12 \\
0 \\
0 \\
0 \\
3\end{array}$ \\
\hline $28.3-40.0$ & $\begin{array}{l}\text { Lytle Creek (1970) } \\
\text { San Fermando (1971) } \\
\text { Oroville (1975) } \\
\text { Kalapana (1975) } \\
\text { Bishop (1978) }\end{array}$ & $\begin{array}{r}2 \\
32 \\
1 \\
1 \\
2\end{array}$ & $\begin{array}{r}2 \\
25 \\
0 \\
0 \\
0\end{array}$ \\
\hline $28.3-40.0$ & $\begin{array}{l}\text { St. Elias (1979) } \\
\text { Imperial Valley (1979) }\end{array}$ & $\begin{array}{l}1 \\
4\end{array}$ & $\begin{array}{l}1 \\
3\end{array}$ \\
\hline $40.1-56.6$ & $\begin{array}{l}\text { Kern County (1952) } \\
\text { Borrego Mountain (1968) } \\
\text { San Fernando (1971) }\end{array}$ & $\begin{array}{l}1 \\
1 \\
4\end{array}$ & $\begin{array}{l}1 \\
1 \\
4\end{array}$ \\
\hline
\end{tabular}

TABLE 5.-Definitions of $\mathrm{K}_{i}, \mathrm{f}\left(\mathrm{e}_{i}, \mathrm{~K}_{i}, \mathrm{R}\right)$, and $\mathrm{f}\left(\mathrm{e}_{i}, \mathrm{~K}_{i}, \mathrm{D}\right)$

$f\left(e_{i}, K_{i}, R\right)=e_{1} K_{1}+e_{2} K_{2}+e_{3} K_{3}+e_{4} K_{4}+e_{5} K_{5}+e_{6}\left(K_{4}+K_{5}\right) \tanh \left(e_{7} R\right)$ for peak horizontal acceleration; $f\left(e_{i}, K_{i}, D\right)=e_{1} K_{1}+e_{2} K_{2}+e_{3} K_{3} \tanh \left(e_{4} D\right)+e_{5}[1-$ $\left.K_{3}\right] \tanh \left(e_{6} D\right)$ for peak horizontal velocity]

\begin{tabular}{|c|c|c|c|c|}
\hline \multirow[b]{2}{*}{ Parameter } & \multicolumn{4}{|c|}{ Definition } \\
\hline & \multicolumn{2}{|c|}{$\begin{array}{l}\text { Peak horizontal } \\
\text { acceleration }\end{array}$} & \multicolumn{2}{|c|}{$\begin{array}{l}\text { Peak horizontal } \\
\text { velocity }\end{array}$} \\
\hline \multirow[t]{2}{*}{ Fault type } & $K_{1}=0$ & Strike slip & $K_{1}=0$ & Strike slip \\
\hline & 1 & $\begin{array}{l}\text { Reverse and } \\
\text { thrust. }\end{array}$ & 1 & $\begin{array}{l}\text { Reverse and } \\
\text { thrust. }\end{array}$ \\
\hline \multirow[t]{2}{*}{ Source directivity } & $K_{2}=0$ & $\begin{array}{l}\text { All other } \\
\text { rupture } \\
\text { geometries. }\end{array}$ & $K_{2}=0$ & $\begin{array}{l}\text { Allother } \\
\text { rupture } \\
\text { geometries. }\end{array}$ \\
\hline & 1 & $\begin{array}{l}\text { Rupture } \\
\text { toward } \\
\text { site. }\end{array}$ & 1 & $\begin{array}{l}\text { Rupture } \\
\text { toward } \\
\text { site. }\end{array}$ \\
\hline \multirow[t]{2}{*}{ Shallow soil } & $K_{3}=0$ & $\begin{array}{c}\text { Soils }>10 \mathrm{~m} \\
\text { deep. }\end{array}$ & & - \\
\hline & & $\begin{array}{c}\text { Soil } \leq 10 \mathrm{~m} \\
\text { deep. }\end{array}$ & & \\
\hline \multirow[t]{2}{*}{ Building size } & - & & $K_{3}=0$ & $\begin{array}{c}\text { Buildings } \geq 5 \\
\text { stories. }\end{array}$ \\
\hline & & & & $\begin{array}{c}\text { Shelters and } \\
\text { buildings } \\
<5 \text { stories. }\end{array}$ \\
\hline \multirow[t]{4}{*}{ Embedment } & $K_{4}=0$ & $\begin{array}{l}\text { All other } \\
\text { recordings. }\end{array}$ & - & - \\
\hline & 1 & $\begin{array}{c}\text { Basements of } \\
\text { 3-to 9-story } \\
\text { buildings. }\end{array}$ & & - \\
\hline & $K_{5}=0$ & $\begin{array}{l}\text { All other } \\
\text { recordings. }\end{array}$ & & \\
\hline & & $\begin{array}{l}\text { Basements of } \\
\geq 10 \text {-story } \\
\text { buildings. }\end{array}$ & & \\
\hline
\end{tabular}

TABLE 6.-Summary of regression coefficients, $\mathrm{e}_{\mathrm{i}}$

If $\left(e_{i}, K_{i}, R\right)=e_{1} K_{1}+e_{2} K_{2}+e_{3} K_{3}+e_{4} K_{4}+e_{5} K_{5}+e_{6}\left(K_{4}+K_{5}\right) \tanh \left(e_{7} R\right)$ for peak horizontal acceleration; $f\left(e_{i}, K_{i}, D\right)=e_{1} K_{1}+e_{2} K_{2}+e_{3} K_{3} \tanh \left(e_{4} D\right)+e_{5}[1-$ $\left.K_{3}\right] \tanh \left(e_{6} D\right)$ for peak horizontal velocity]

\begin{tabular}{lccccc}
\hline & \multicolumn{2}{c}{$\begin{array}{c}\text { Peak horizontal } \\
\text { acceleration }\end{array}$} & & \multicolumn{2}{c}{ Peak horizontal velocity } \\
\cline { 2 - 3 } \cline { 5 - 6 } Coefficient & Equation 3 & Equation 4 & & Equation 5 & Equation 6 \\
& 0.32 & 0.34 & & 0.47 & 0.49 \\
$e_{1}$ & .52 & .53 & & .95 & .99 \\
$e_{2}$ & .41 & .41 & & .63 & .53 \\
$e_{3}$ & -.85 & -.86 & & .39 & .41 \\
$e_{4}$ & -1.14 & -1.12 & & .72 & .60 \\
$e_{5}$ & 87 & .89 & & .75 & .88 \\
$e_{6}$ & .068 & .065 & .0 & .0 \\
$e_{7}$ & & & & &
\end{tabular}




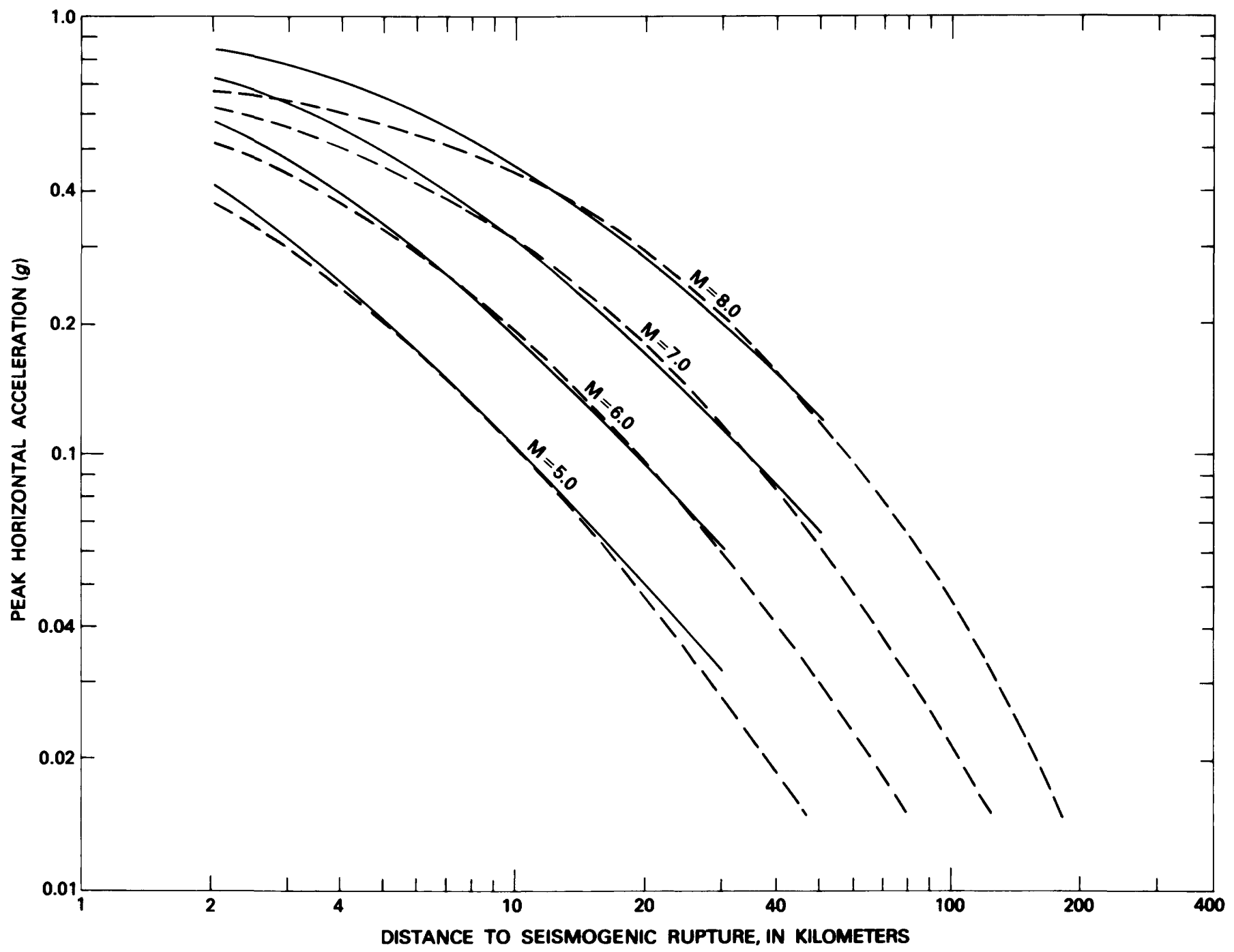

FIGURE 2.-Attenuation relationships of peak horizontal acceleration for magnitudes of 5.0, 6.0, 7.0, and 8.0. Solid line indicates unconstrained model (eq. 3); dashed line, constrained model, where $\gamma=0.0059$ (eq. 5). Relationships are plotted for $K_{i}=0$.

exhibiting unilateral rupture towards the site, (2) their azimuths with respect to the source were within $5^{\circ}$ to $10^{\circ}$ of the direction of rupture, and (3) they were sited on sediments at least $5 \mathrm{kn}$ deep. These results appeared to indicate a directivity effect, possibly enhanced by the thickness of the sediments. The effect was so strong, especially for peak velocity, that it was decided to include it as a parameter, even though it was represented by only three recordings. Other recordings in the data base may be affected to some degree by directivity, but only these three seem to represent a combination of factors that lead to a near-maximum effect of this phenomenon. A more thorough investigation of directivity effects is beyond the scope of the current study.

\section{FAR-FIELD CONSTRAINTS}

Because this study was not directly concerned with predicting far-field ground motion, accelerograms recorded farther than 30 to $50 \mathrm{~km}$ from seismogenic rupture were not included in the analyses. In order to develop attenuation relationships that could be extrapolated to larger distances, a second analysis was performed where $\gamma$, the coefficient of anelastic attenuation in equation 1, was constrained to values appropriate for the majority of data making up the data base.

Because of the similarity between the regional makeup of the current data base and that of Joyner and Boore (1981), we adopted their statistically determined 


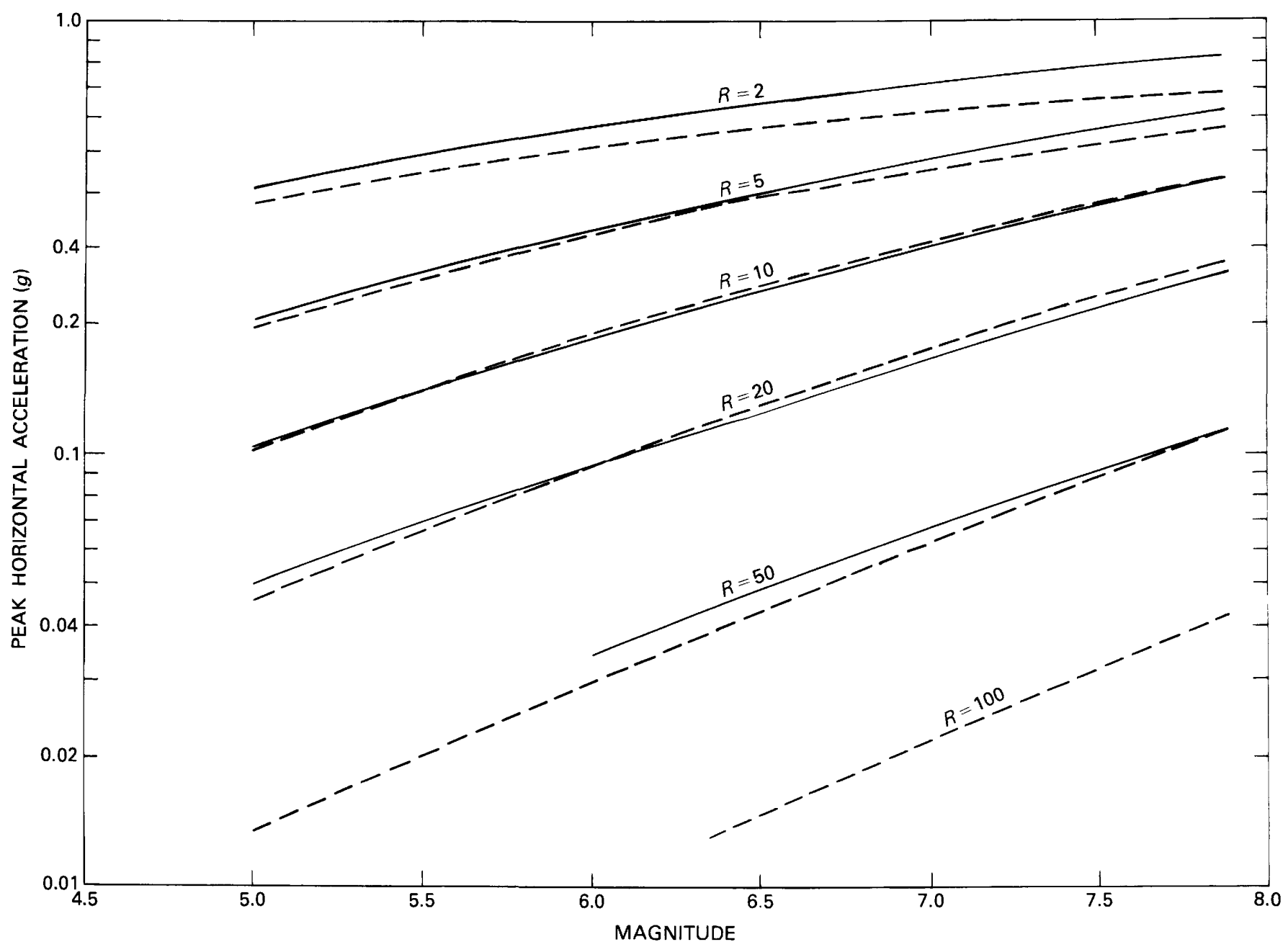

FIGURE 3.-Predicted magnitude scaling of peak horizontal acceleration for distances $(R)$ of $2,5,10,20,50$, and $100 \mathrm{~km}$. Solid line indicates unconstrained model (eq. 3); dashed line, constrained model, where $\gamma=0.0059$ (eq. 5). Relationships are plotted for $K_{i}=0$.

values of $\gamma$ for our constrained analyses. Repeating the weighted nonlinear regression analyses using $\gamma=0.0059$ resulted in the following constrained relationships 2 :

In $\mathrm{PHA}=-3.303+0.850 \mathrm{M}-1.25 \ln [R+0.0872 \exp (0.678 \mathrm{M})]$ $-\gamma R+f\left(e_{i}, K_{i}, R\right)$

$\ln \mathrm{PHV}=-1.584+1.18 \mathrm{M}-1.24 \ln [R+0.00907 \exp (0.951 \mathrm{M})]$ $-\gamma R+f\left(e_{i}, K_{i}, D\right)$

where all parameters are defined as in equations 3 and 4. The coefficients $e_{i}$, parameters $K_{i}$, and functions $f\left(e_{i}, K_{i}\right.$,

\footnotetext{
2 The analyses of Joyner and Boore (1981) resulted in the same value of $\gamma$ for both peak acceleration and peak velocity, suggesting that anelastic attenuation may be nearly independent of frequency in California.
}

$R)$ and $f\left(e_{i}, K_{i}, D\right)$ are summarized in tables 5 and 6 ; the relationships are plotted in figures 2 through 5 . The standard errors of regression for equations 5 and 6 are 0.30 and 0.27 , respectively.

Equations 5 and 6 were compared with the attenuation relationships of Joyner and Boore (1981) to verify that the attenuation characteristics were similar beyond distances of 30 to $50 \mathrm{~km}$ as originally intended. The comparison was made for $\mathrm{M}=6.5$ and $R \geq 30 \mathrm{~km}$ after modification to account for differences between the definitions of parameters in the two studies. The magnitude was chosen to be near the median magnitude of both studies. Comparisons were restricted to $R \geq 30 \mathrm{~km}$ to minimize the impact of differences in the near-source behavior of the two functional forms. Close agreement in the attenuation rates of both studies suggested that the extrapolation of equations 


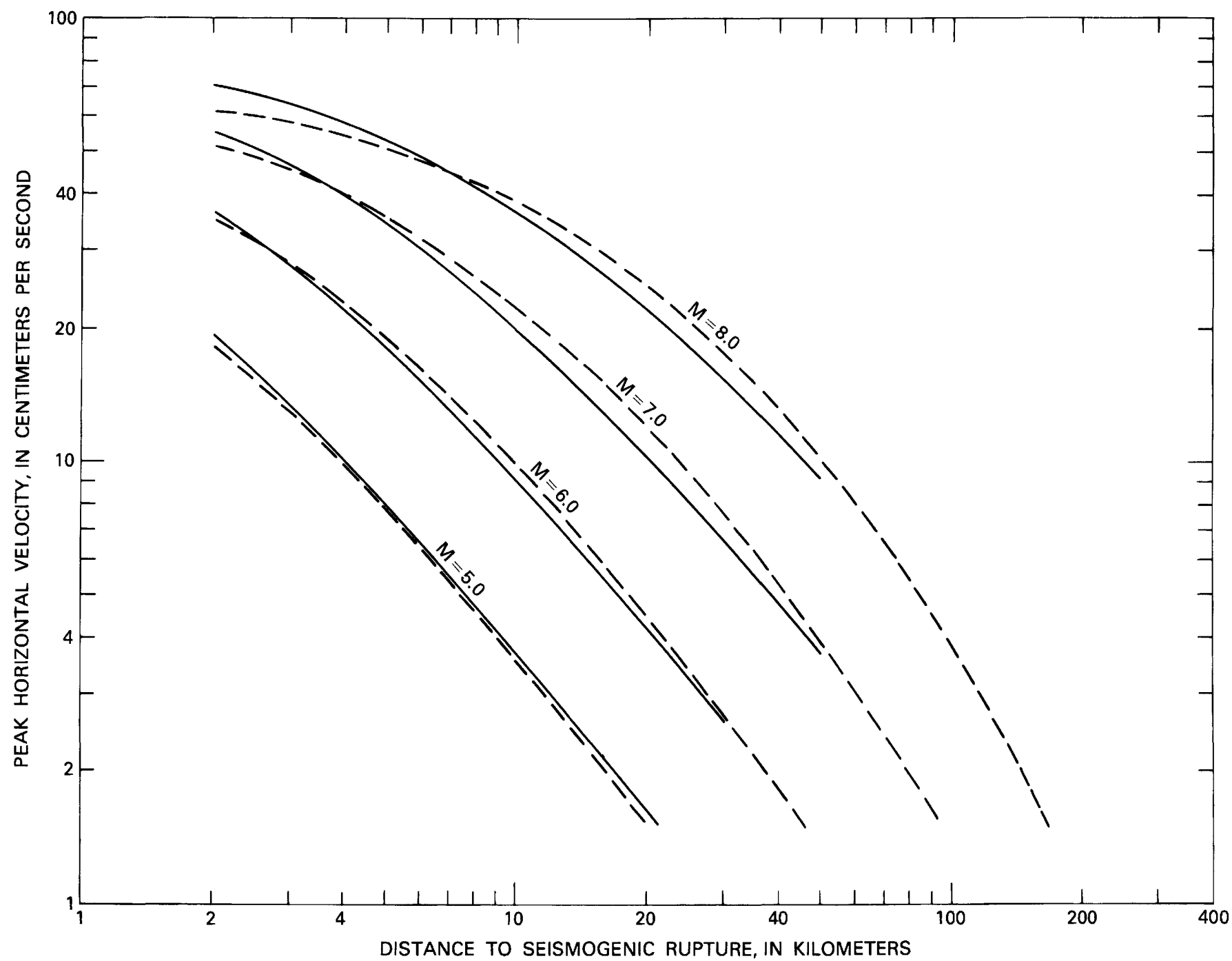

FIGURE 4.-Attenuation relationships of peak horizontal velocity for magnitudes of 5.0, 6.0, 7.0, and 8.0. Solid line indicates unconstrained model (eq. 4); dashed line, constrained model, where $\gamma=0.0059$ (eq. 6). Relationships are plotted for $K_{i}=0$.

5 and 6 beyond 30 to $50 \mathrm{~km}$ using $\gamma=0.0059$ was valid to distances of at least several hundred kilometers.

Coefficients derived for the constrained relationships are generally consistent with those derived for the unconstrained relationships, an indication that only relatively small adjustments were required to accommodate the constraint on anelastic attenuation imposed during the second analysis. It should be noted, however, that the coefficients presented in table 6 are constramed only by near-source recordings and may not be valid for distances greater than 30 to $50 \mathrm{~km}$. This fact is especially true for the shallow-soil and building-embedment parameters, which may become less important as distance (and, hence, wave period) increases.

\section{ANALYSIS OF RESIDUALS}

An analysis of residuals was used to (1) select and define the parameter used in the attenuation relationships and (2) check the adequacy of the final relationships. For convenience, the analysis used the normalized weighted residual,

$$
\mathrm{NWR}_{i}=\left[w_{i}\left(y_{i}-\hat{y}_{i}\right)-\mathrm{MWR}\right] / \sigma
$$

where $\mathrm{NWR}_{i}$ is the normalized weighted residual, $i$ is the index of the recording, $w_{i}$ is the weight assigned to the recording, $y_{i}$ is the observed value of $\ln Y, \hat{y}_{i}$ is the predicted value of $\ln Y, \sigma$ is the standard error of the regres- 


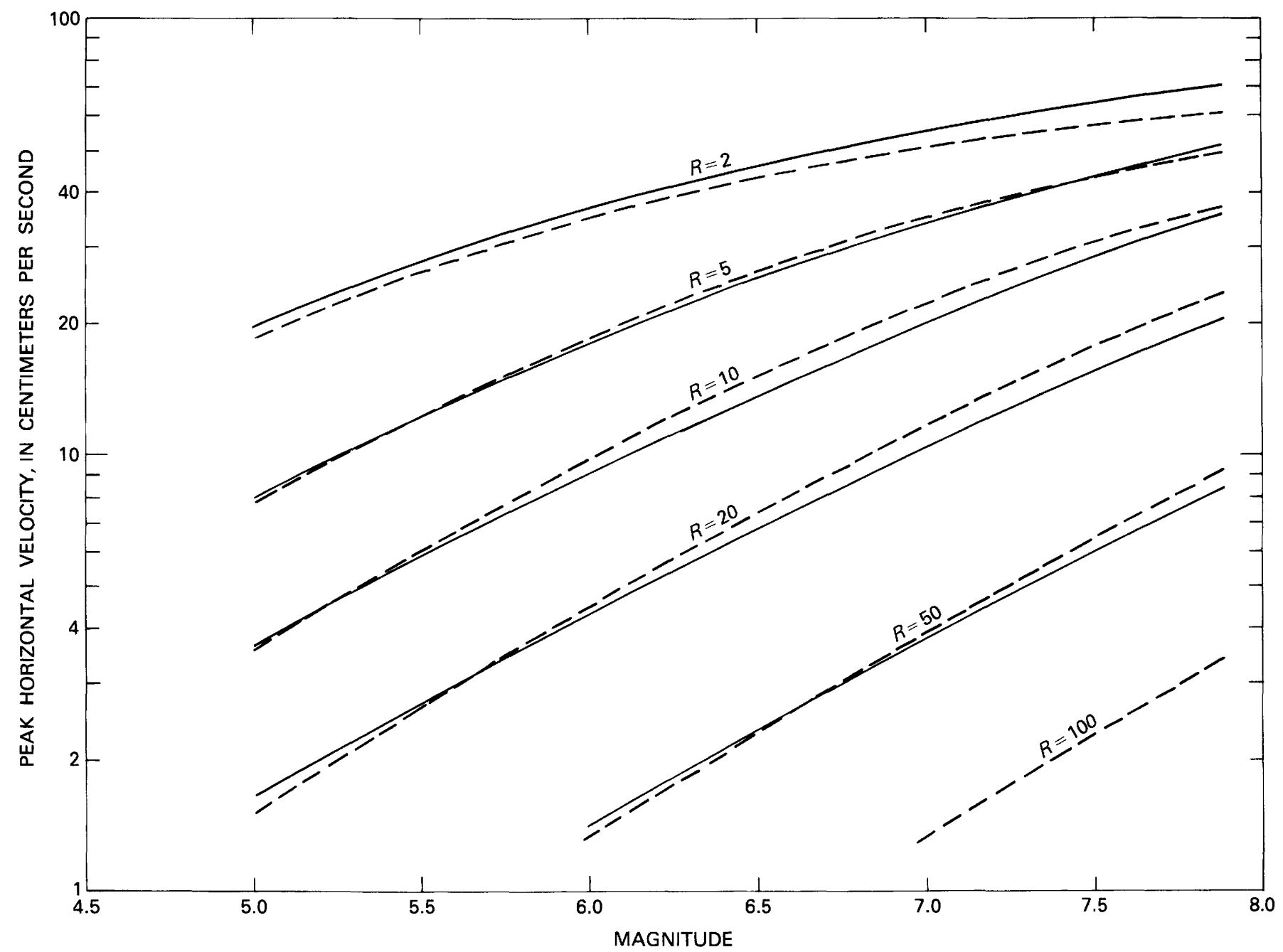

FIGURE 5.-Predicted magnitude scaling of peak horizontal velocity for distances $(R)$ of $2,5,10,20,50$, and $100 \mathrm{~km}$. Solid line indicates unconstrained model (eq. 4); dashed line, constrained model, where $\gamma=0.0059$ (eq. 6). Relationships are plotted for $K_{i}=0$.

sion, and MWR is the mean weighted residual, defined by the expression

$$
M W R=1 / n \sum_{i=1}^{n} w_{i}\left(y_{i}-\hat{y}_{i}\right)
$$

The definitions and functional forms of the parameters listed in table 5 were developed by an iterative procedure. First, a list of candidate parameters was selected from theoretical considerations of source, site, and soilstructure interaction effects available from the literature. Second, regression analyses were used to establish attenuation relationships in terms of $\mathrm{M}$ and $R$ by setting $K_{i}=0$ in equation 1 . In the case of continuous parameters such as sediment depth, the normalized weighted residuals were then plotted against the candidate parameters. In the case of classification or so-called "dummy" parameters such as fault type, the normalized weighted residuals associated with each class were plotted against $\mathrm{M}$ and $R$. When visually perceptible trends were identified from the residual plots, those parameters were added to the model. The process was repeated until all significant parameters and their proper functional relationships were identified and included in the model. From a purely scientific point of view, the above procedure might be criticized for its strong empirical basis, although, from a statistical standpoint, such procedures are accepted as standard modelbuilding techniques (Draper and Smith, 1971; Tukey, 1977).

The adequacy of the final attenuation relationships was assessed by plotting the normalized weighted residuals against each dependent and independent variable 


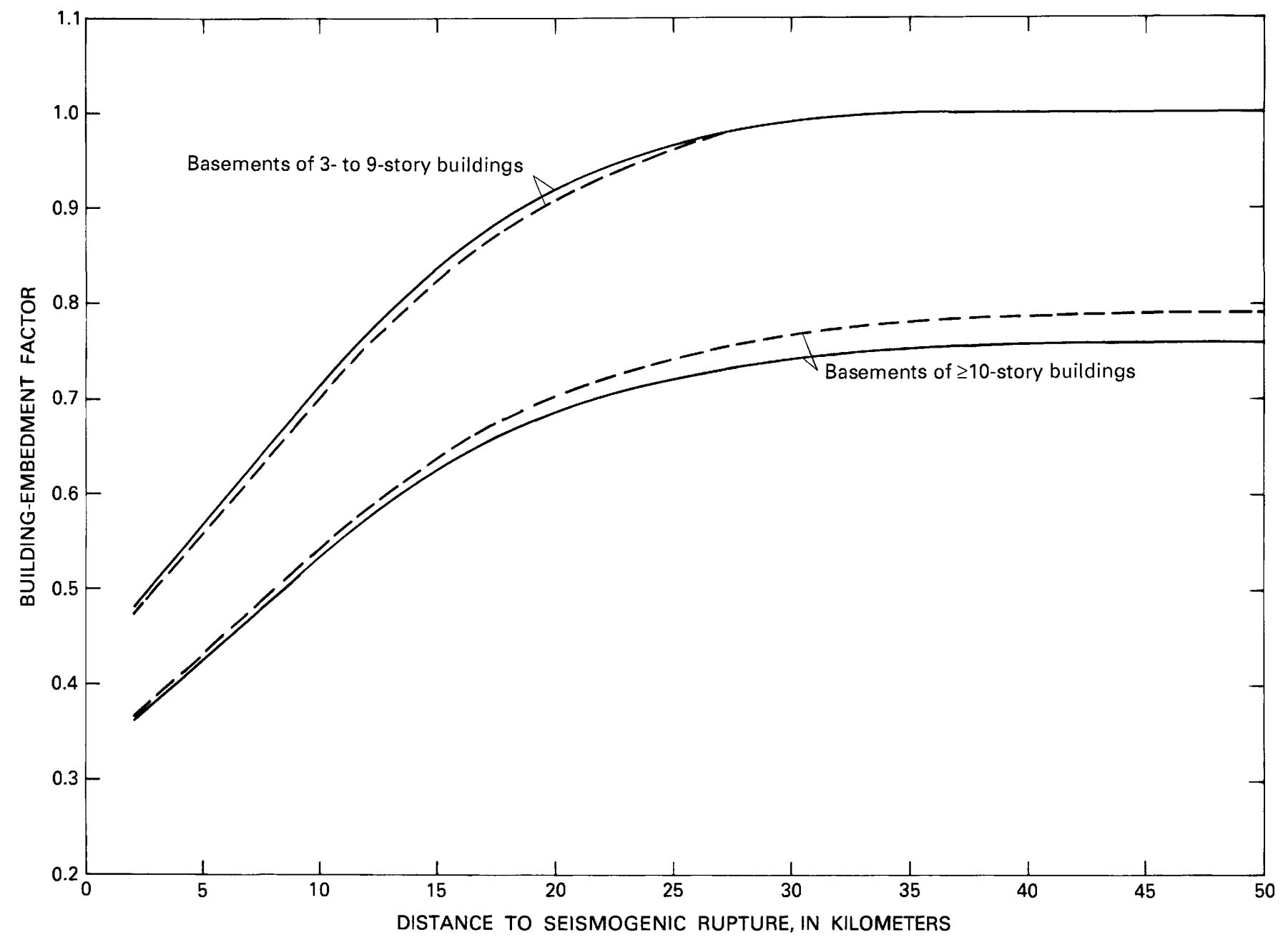

FIGURE 6.-Dependence of peak horizontal acceleration on building embedment. Solid line indicates unconstrained model (eq. 3); dashed line, constrained model (eq. 5). The embedment factor is a multiplicative factor given by the expression $\exp \left[e_{4} K_{4}+e_{5} K_{5}+e_{6}\left(K_{4}+K_{5}\right) \tanh \left(e_{7} R\right)\right]$, where $e_{i}$ and $K_{i}$ are defined in tables 5 and 6.

included in the models. The residual plots against distance, magnitude, and predicted value are given in figures 8 through 10 for the unconstrained relationships (eqs. 3, 4). A lack of any significant trend indicated that the models were statistically adequate. Similar results were found for equations 5 and 6 as well as for other independent variables included in the relationships.

\section{GROUND-MOTION ESTIMATES FOR NORTH-CENTRAL UTAH}

The region of north-central Utah contains the major population centers of Ogden, Provo, and Salt Lake City. The dominant feature of this region is the Wasatch Front, a massive 370-km-long scarp extending along the western margin of the Wasatch Mountains from Gunnison, Utah, to Malad City, Idaho. The scarp is a result of normal fault- ing along the Wasatch fault, which marks the boundary between the Basin and Range and Middle Rocky Mountain physiographic provinces (Fenneman, 1946). This boundary marks the transition from a northwest-southeast extensional stress regime on the west to a northwestsoutheast compressional stress regime on the east (Zoback and Zoback, 1981).

The Wasatch fault poses the greatest seismic threat of major earthquakes in this region. Geologic evidence indicates that surface faulting associated with earthquakes of magnitude 6.5 to 7.5 has occurred repeatedly along several segments of this fault at an average rate of one event every 444 years (Swan and others, 1980). In contrast, the greatest seismic threat in the next 100 years, assuming a Poisson model of earthquake occurrences, comes from small to moderate earthquakes located in the historically more active regions of the State (Youngs and others, this volume). 


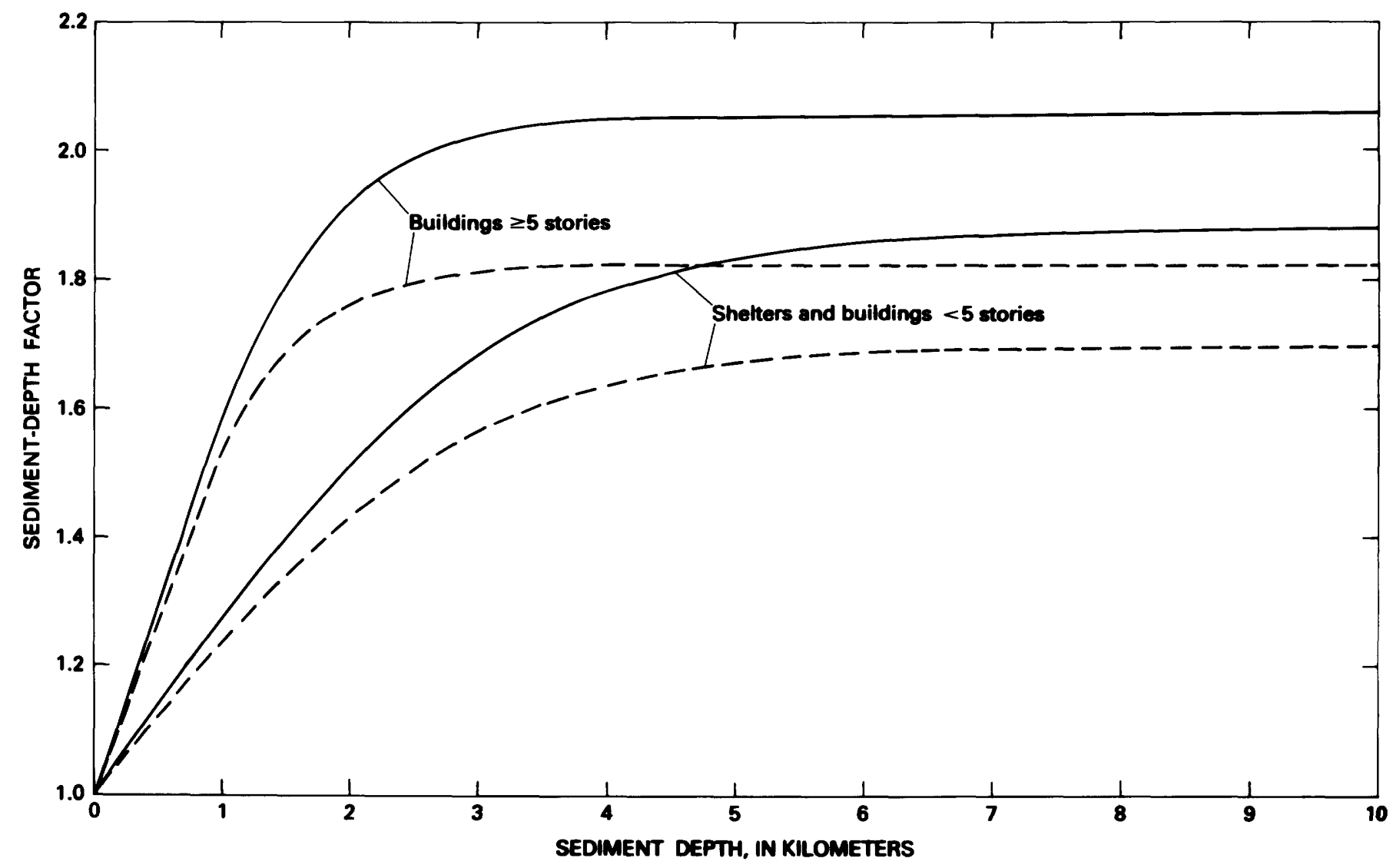

FIGURE 7.-Dependence of peak horizontal velocity on sediment depth. Solid line indicates unconstrained model (eq. 4); dashed line, constrained model (eq. 6). The sediment-depth factor is a multiplicative factor given by the expression exp[ $\left.e_{3} K_{3} \tanh \left(e_{4} D\right)+e_{5}\left(1-K_{3}\right) \tanh \left(e_{6} D\right)\right]$, where $e_{i}$ and $K_{i}$ are defined in tables 5 and 6.

There are several important issues that need to be addressed before attempting to estimate strong-motion parameters in north-central Utah. These issues are discussed below.

\section{STRESS REGIME}

McGarr (1984) presented theoretical and empirical results indicating that peak acceleration and peak velocity are strongly dependent on stress state and focal depth. He contended that, for a given seismic moment, both parameters are smaller for earthquakes occurring in an extensional stress regime than for earthquakes occurring in a compressional stress regime and that both parameters increase with focal depth. Differences due to stress regime are quite large, being as great as a factor of 3 for peak acceleration and a factor of 2 for peak velocity at a given depth.

Taken at face value, McGarr's results would have a considerable impact on the estimation of ground motion in the region of Utah west of the Wasatch Front. This region, including the Wasatch fault, is characterized by
Basin and Range extensional tectonics. In contrast, the majority of the strong-motion data used to develop the attenuation relationships in this study come from coastal California, a region undergoing predominantly northsouth compression (Zoback and Zoback, 1981). Thus, if McGarr were correct, one would expect substantially smaller ground motion in western Utah than equations 3 through 6 would predict. However, McGarr's results are not consistent with other empirical observations.

McGarr's results appear to be contradicted by this author's study of peak acceleration data from near-source recordings in California (Campbell, 1985b, 1989). In an attempt to identify regional differences in peak acceleration scaling relations, Campbell analyzed strong-motion data recorded within $20 \mathrm{~km}$ of $\mathrm{M}_{\mathrm{L}}=2.5$ to 5.0 earthquakes in Oroville, Calif., Imperial Valley, Calif., and coastal California. The Oroville region falls along the western margin or the Sierra Nevada physiographic province (Fenneman, 1946), a region characterized by east-to-northeast extension (Zoback and Zoback, 1981). Focal mechanisms in this area are predominantly normal. The other two areas are within the San Andreas physiographic province 

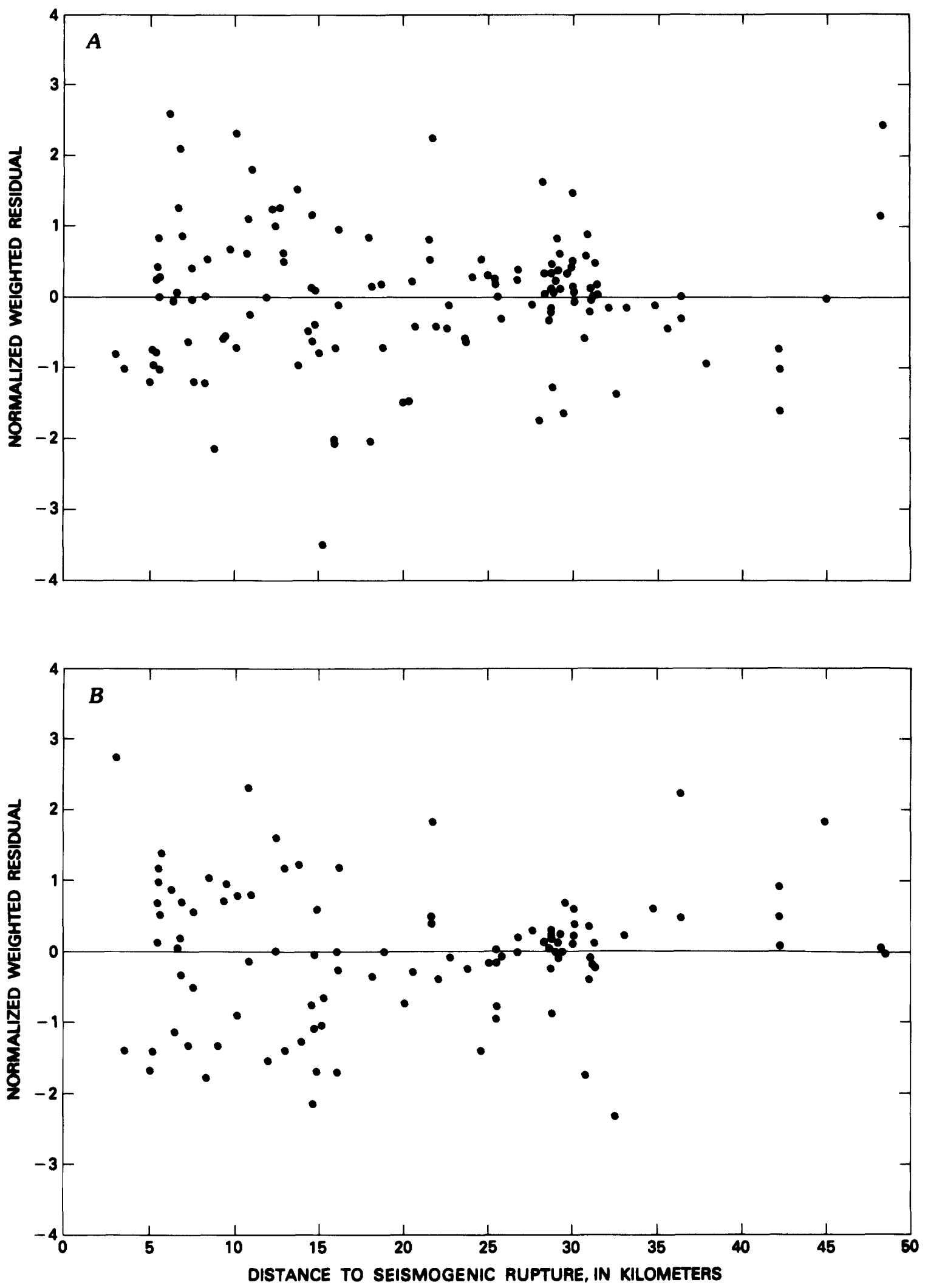

FIGURE 8.-Normalized weighted residuals plotted as a function of distance. $A$, Peak horizontal acceleration; $B$, peak horizontal velocity. Plots are shown for the unconstrained models (eqs. 3,4 ). Similar distributions were found for the constrained models. 

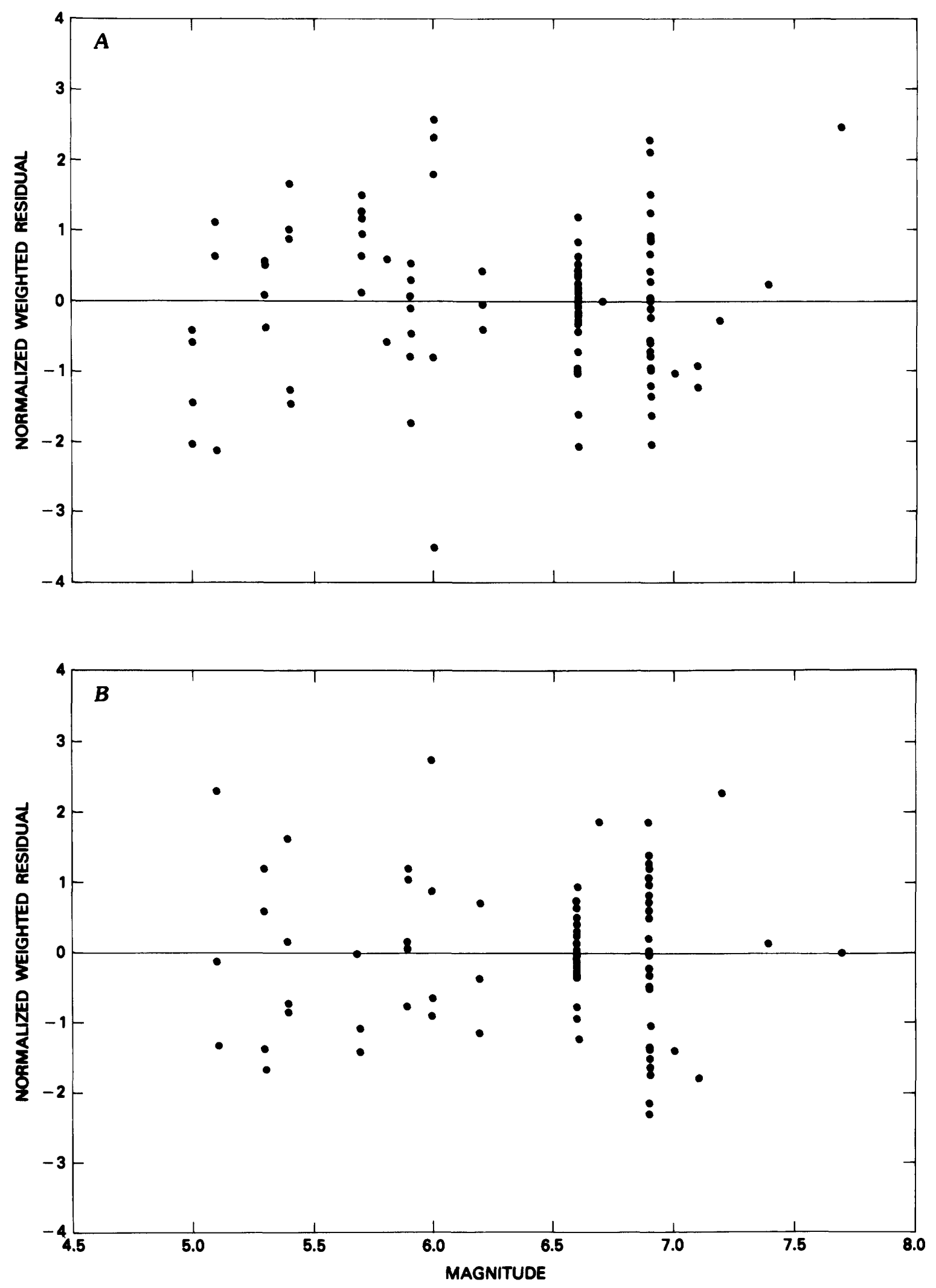

FIGURE 9.-Normalized weighted residuals plotted as a function of magnitude. $A$, Peak horizontal acceleration; $B$, peak horizontal velocity. Plots are shown for the unconstrained models (eqs. 3, 4). Similar distributions were found for the unconstrained models. 

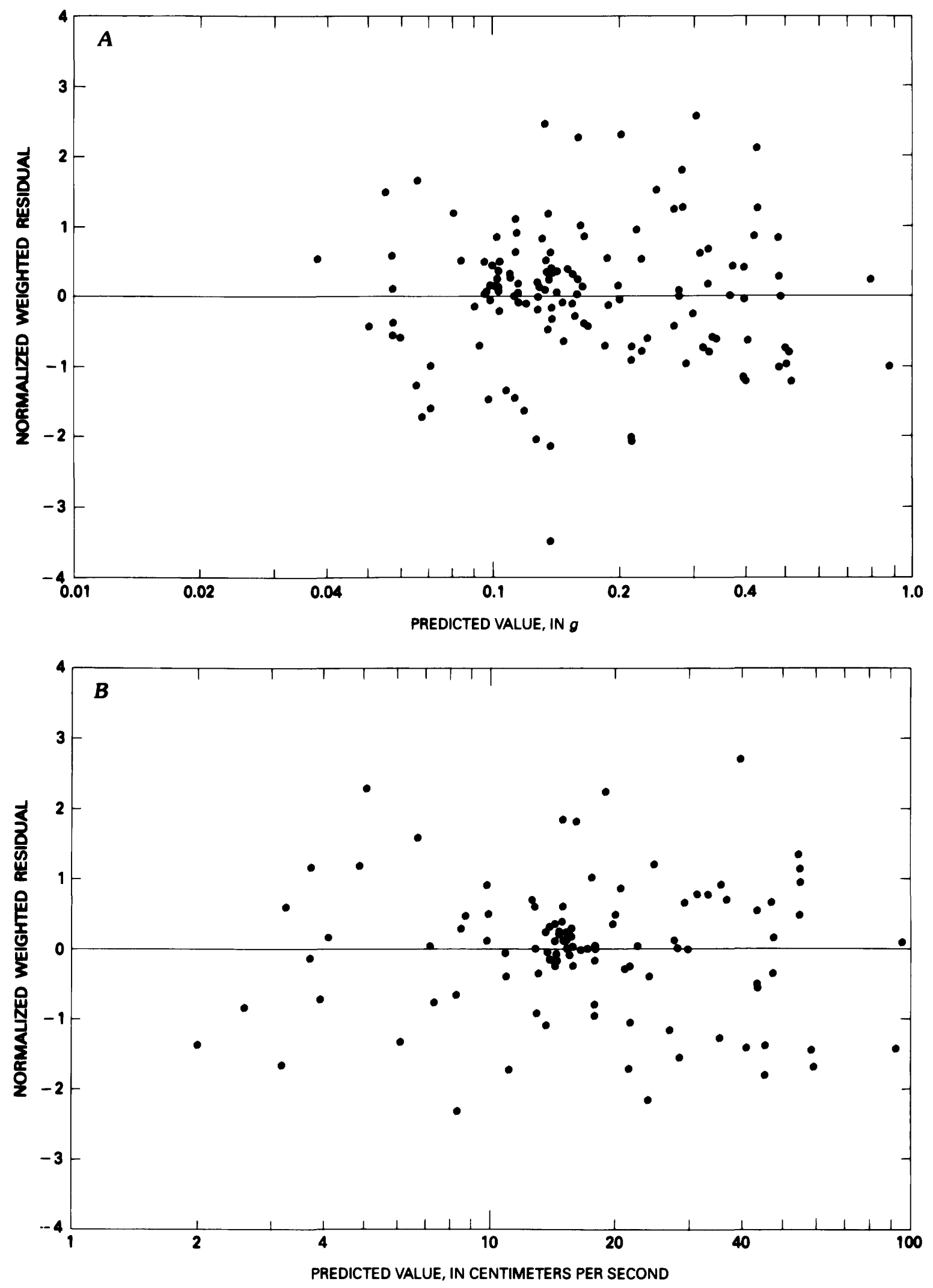

FIGURE 10.-Normalized weighted residuals plotted as a function of predicted value. $A$, Peak horizontal acceleration; $B$, peak horizontal velocity. Plots are shown for unconstrained models (eqs. 3, 4). Similar distributions were found for the constrained models. 
(Fenneman, 1946), a region characterized by north-south compression (Zoback and Zoback, 1981). Focal mechanisms in this region are predominantly strike slip on northwest-trending faults and reverse or reverse oblique on west-trending faults.

Campbell's regression analyses indicated only minor regional differences in magnitude and distance scaling. For magnitudes ranging from 3.5 to 4.5 and epicentral distances ranging from 5 to $10 \mathrm{~km}$ (about one to two focal depths), the scaling relations predict peak accelerations that vary by less than 10 to 15 percent between regions. Furthermore, the study found no significant dependence of peak acceleration on focal depth for depths in the range 4- to $10-\mathrm{km}$ range. These depths represent the major seismogenic portion of the crust in California. Similar results were found whether hypocentral distance or epicentral distance was used in the analyses.

The reasons for the discrepancy between the above results and those of McGarr are largely speculative. One major difference between the two studies that may help to explain this discrepancy is a difference in magnitude scaling. McGarr assumed that, at relatively short distances, peak acceleration should be relatively independent of seismic moment. On the other hand, the nearsource regression analyses of Campbell $(1985 \mathrm{~b}, 1989)$ indicate a strong correlation between peak acceleration and $\mathrm{M}_{\mathrm{L}}$ and, hence, seismic moment, In PHA being proportional to 0.5 to $0.7 \mathrm{M}_{\mathrm{L}}$. The latter dependence is generally consistent with magnitude scaling of peak acceleration from $\mathrm{M}_{\mathrm{L}}>5.0$ earthquakes (Campbell, 1981a, 1984a; Joyner and Boore, 1981). In fact, Campbell (1985b) found that, when an estimate of closest distance to fault rupture was used as the distance metric in his regression analyses. the near-source magnitude and distance scaling properties of peak acceleration for $M_{L} \leq 5.0$ earthquakes were remarkably consistent with the extrapolation of the nearsource attenuation relationships for $\mathrm{M}_{\mathrm{L}} \geq 5.0$ earthquakes developed by Campbell (1984a). Thus, either McGarr's assumption of magnitude independence of peak horizontal acceleration for hypocentral distances on the order of $10 \mathrm{~km}$ is wrong, or else $\mathrm{M}_{\mathrm{L}}$ scales with seismic moment, state of stress, and focal depth in a manner similar to his proposed scaling relationship for peak horizontal acceleration.

The hypothesis that $\mathrm{M}_{\mathrm{L}}$ and peak horizontal acceleration might have similar dependencies on stress state and focal depth is important because, if correct, it would imply that scaling relations between the two parameters are relatively independent of stress state and, thus, of tectonic regime. Some empirical evidence suggesting that this hypothesis may be correct stems from an observation by Boore (1980) that Western U.S. strong-motion records show a direct relationship between peak horizontal velocity and Wood-Anderson amplitude and, hence, $\mathrm{M}_{\mathrm{L}}$. Com- bining Boore's findings with McGarr's observation that both peak horizontal acceleration and peak horizontal velocity are dependent on stress state and focal depth suggests that $\mathrm{M}_{\mathrm{L}}$ is also dependent on stress state and focal depth.

A further implication of the above hypothesis is that the relationship between seismic moment and $\mathrm{M}_{\mathrm{L}}$ should be dependent on stress state. Such a relationship has been proposed by Thatcher and Hanks (1973) from source-parameter relations developed for Southern California. Their proposed relationship,

$$
\log \mathrm{M}_{\mathrm{o}}=2.0 \mathrm{M}_{\mathrm{L}}+14.2-\log \Delta \sigma
$$

suggests that the relationship between seismic moment and $\mathrm{M}_{\mathrm{L}}$ is dependent on stress drop, $\Delta \sigma$. The hypothesis is then validated if $\Delta \sigma$ can be considered dependent on stress state. McGarr used just such a proposed dependence to give theoretical credibility to his observations by inferring direct relationships between localized stress drop and crustal strength and between crustal strength and stress state. From considerations of tectonic stress, he suggested that crustal strength (and, thus, stress drop) is nearly a factor of 4 greater in compressional tectonic regimes than it is in extensional tectonic regimes and that stress drop is expected to increase linearly with depth. It is interesting to note that regional variations in stress drop and moment-magnitude relationships in Southern California and northern Baja California have also been attributed to regional differences in tectonic stresses by Thatcher (1972) and Thatcher and Hanks (1973).

All things considered, it would seem that McGarr's results may be irrelevant with respect to the estimation of strong-motion amplitudes, at least when magnitude is used as the measure of source strength. If his hypothesis is wrong, as suggested by the analyses of Campbell (1985b, 1989), then there is no need to consider stress regime as being important. If his hypothesis is correct, then there is evidence to suggest that scaling relations between ground-motion parameters and magnitude are relatively independent of stress state.

\section{FAULT TYPE}

In this study, as well as in previous studies (Campbell, 1983, 1984a), fault type has been found to be a significant factor in predicting strong ground motion. Its importance has been confirmed theoretically by studies done by Anderson and Luco (1983) and Boore and Boatwright (1984). Boore and Boatwright computed average radiation coefficients for three types of faulting: a vertical strike-slip fault, a $30^{\circ}$-dipping dip-slip fault, and a $45^{\circ}$-dipping oblique-slip fault. They found that the average radiation coefficients for dipping faults were 14 to 28 percent 
higher than those for vertical strike-slip faults for distances within about a focal depth of the source. At regional distances (tens to hundreds of kilometers), the opposite was found, dipping faults having average radiation coefficients 14 to 20 percent smaller than those of vertical strike-slip faults. These results suggest that, on average, near-source amplitudes of ground motion from dipping faults will start off higher but attenuate more rapidly than those from near-vertical faults, the transition occurring at a distance of approximately one focal depth. Indeed, such a result was observed in the analyses of the Oroville and Imperial Valley strong-motion recordings described in the preceding section.

Boore and Boatwright's results would seem to indicate that the effects of fault type should be negligible, on average, over the range of distances used in this study if differences in attenuation rate between different fault types are neglected. Yet, the current study found significantly higher ground motions from earthquakes on dipping faults. The most plausible explanation for these results is offered by the ground-motion simulation studies of Anderson and Luco (1983), who found that sites located directly above the rupture surface of dipping faults had the highest amplitudes of any other rupture configuration. Because the data in the present study include several such sites (for example, the 1976 Gazli and 1978 Tabas recordings), it is possible that these sites are largely responsible for the observed results. These results can have serious implications for cities like Ogden, Provo, and Salt Lake City that are located directly above the Wasatch fault. For this reason, the author has chosen to incorporate the uncertainty associated with the potential effect of fault type by estimating ground motions for a range of fault types $\left(K_{2}=0\right.$ and $K_{2}=1$ from table 5).

\section{ANELASTIC ATTENUATION}

There have been a number of attenuation studies conducted in the Basin and Range in the past with widely varying results. The closest study geographically was that conducted by King and Hays (1977). They measured ground motions from four aftershocks of the March 27, 1975 , Pocatello Valley, Idaho, earthquake $\left(M_{S}=6.0\right)$ along a 150-km linear array extending from southern Idaho to Salt Lake City. They concluded that this region exhibits higher attenuation of $1-$ to $10-\mathrm{Hz}$ pseudo-relative velocity response spectra than either California or Southern Nevada. This conclusion, however, is in direct contradiction to the results of Singh and Herrmann (1983).

Singh and Herrmann quantified the regional attenuation of $\mathrm{Lg}$ coda waves throughout the United States through the relationship

$$
Q=Q_{0} f^{n}
$$

where $Q$ is a measure of anelastic attenuation referred to as the quality factor, $Q_{0}$ is a measure of $Q$ at $1 \mathrm{~Hz}$, and $f$ is frequency. Their maps indicate that attenuation in northcentral Utah is represented by $Q_{0}=400$ and $n=0.2$, substantially higher than attenuation in coastal California, where $Q_{0}<200$ and $n=0.5$.

There is similar controversy regarding regional attenuation elsewhere in the Basin and Range. For example, in the southern Great Basin, Rogers and others (1987) found $Q_{0}=600$ and $n=0.1$ from vertical peak-amplitude earthquake data, $Q_{0}=143$ and $n=0.84$ from vertical coda-amplitude earthquake data, and $Q_{0}=188$ and $n=1.05$ from vertical coda-amplitude nuclear explosion data. In this same region, Singh and Herrmann (1983) found $Q_{0}=200$ and $n=0.4$, and King and Hays (1977) presented attenuation rates for pseudo-relative velocity spectra from nuclear explosions that are similar to earthquake attenuation rates in California over a broad range of frequencies. In the northern Great Basin, Chavez and Priestley (1985) found $Q_{0}=125$ to 280 from synthetic Wood-Anderson earthquake amplitudes, Chavez and Priestley (1986) found $Q_{0}=130$ and $n=0.85$ from nuclear explosion $\mathrm{Lg}$ amplitudes, and Singh and Herrmann (1983) found $Q_{0}=200$ to 300 and $n=0.4$ from Lg-coda amplitudes.

The above results seem to imply that there are large regional variations of attenuation characteristics throughout the Basin and Range and that the computed attenuation rates for the region are highly dependent on method and data. Large regional variations in attenuation are supported by Taylor and Patton (1986), who found that structural inversions of regionalized Rayleigh-wave dispersion curves indicate significant lateral variations in the crust and upper mantle structure of the Basin and Range and transition areas. The uncertainty in computed attenuation rates is supported by the extreme variability in attenuation characteristics derived for the same area by different investigators and different techniques.

Singh and Herrmann's maps also suggest that there is significant azimuthal variation in attenuation in northcentral Utah, although this variation is no larger than the variability associated with estimates of $Q$ in the Basin and Range provided by various investigators. Until a definitive study of attenuation in north-central Utah becomes available, it is necessary to estimate ground motion by using a range of attenuation rates that can be assumed to reasonably bracket the true attenuation rate of the region.

In order to incorporate anelastic attenuation in the prediction of ground-motion amplitudes in north-central Utah, the predictions were derived from equations 5 and 6 , where $\gamma$ is estimated from the relationship

$$
\gamma=\left(\pi f^{1-n}\right) / Q_{0} U
$$


where $Q_{0}$ and $n$ are as defined in equation 10 and $U$ is the group velocity of the particular phase amplitude used to derive $Q$ in kilometers per second. According to Singh and Herrmann (1983), the group velocity of Lg waves is approximately equal to $3.5 \mathrm{~km} / \mathrm{s}$.

For $n \neq 1, \gamma$ will be different for peak horizontal acceleration and velocity, because these parameters sample different parts of the frequency spectrum. For the present study, peak horizontal acceleration and velocity are assumed to have fundamental frequencies on the order of 5 and $1 \mathrm{~Hz}$, respectively (Nuttli, 1979). In actuality, these strong-motion parameters should be dependent on magnitude and frequency (Seed and others, 1969), but such a refinement seems unwarranted at this time in light of the large variability associated with $Q_{\mathrm{o}}$ and $n$. The various studies of attenuation in the Basin and Range cited above were used to bracket estimates of $\gamma$. The largest values were derived from the assumption of California-type attenuation, for which $\gamma=0.0059$ and $Q=152$ for both peak horizontal acceleration and peak horizontal velocity. This value of $\gamma$ was used to quantify anelastic attenuation for the purposes of deriving equations 5 and 6 . The smallest values of $\gamma$ were obtained from the study of Rogers and others (1987) for the southern Great Basin. Their nuclear explosion, vertical coda-amplitude study resulted in estimates of $Q=1020$ and $\gamma=0.0044$ for $5-\mathrm{Hz}$ waves, and their vertical peak-amplitude earthquake study resulted in estimates of $Q=600$ and $\gamma=0.0015$ for $1-\mathrm{Hz}$ waves. Therefore. for the purposes of the present study, peak horizontal acceleration was evaluated by using $\gamma=0.0044$ to 0.0059 , and peak horizontal velocity was evaluated by using $\gamma=0.0015$ to 0.0059 .

\section{SITE EFFECTS}

Recordings of nuclear explosions in Ogden, Provo, and Salt Lake City (Hays and others, 1978; Hays and King, 1982, 1984; Hays, this volume; King and others, this volume) show significant amplification of pseudo-relative velocity spectra on valley sediments in comparison with those on rock over a wide range of frequencies. In Salt Lake City, average amplifications as high as a factor of 10 were observed in the $5-$ to $10-\mathrm{Hz}$ and the $1.4-$ to $5-\mathrm{Hz}$ frequency bands, even higher amplifications being observed at specific frequencies. Areal contours of amplification show a rapid increase along profiles extending west from the range front out into the valley, maximum amplification being obtained within distances of as little as 5 to 10 $\mathrm{km}$. The 5- to $10-\mathrm{Hz}$ contours appear to correlate with the depth of unconsolidated deposits, maximum amplification being attained for depths exceeding approximately $300 \mathrm{~m}$ (Hays and others, 1973). The 1.4- to 5-Hz contours appear to correlate more with the depth of low-density sedimentary rock, which attains depths as great as $4 \mathrm{~km}$ along the range front valleys (Mabey, 1991).

The correlation of site amplification with subsurface geology, especially sediment depth, is well documented in the literature (Seed and others, 1976; Trifunac and Lee, 1978, 1979; Campbell, 1984a, this report; Joyner and Fumal, 1984, 1985; Rogers and others, 1984, 1985). However, simple relationships between ground-motion parameters and sediment depth appear to significantly underestimate the observed amplification of ground motion in Salt Lake valley. For example, the maximum amplification observed in Salt Lake City in the 1.4 - to $5-\mathrm{Hz}$ frequency band is larger by a factor of 2 or more than that estimated from the relationships of Trifunac and Lee (1978) and Rogers and others (1985) using reasonable estimates of sediment depth in Salt Lake valley (Mabey, 1991). For low to intermediate frequencies, this discrepancy may be caused by the rather large depth-to-width ratio of the range front valleys, which have the potential to amplify these ground motions by two to three times over valleys having relatively small aspect ratios (Bard and Bouchon, 1985). For intermediate to high frequencies, this discrepancy may be the result of seismic resonance within the unconsolidated deposits.

The phenomenon of seismic resonance is well documented in the literature (Campbell, 1981a, 1983, 1984a; Chiaruttini and Siro, 1981; Faccioli, 1981; Mueller and others, 1982; Prince, 1984; Rogers and others, 1984, 1985; Anderson and others, 1986). Resonance occurs when upward-propagating waves are trapped in a surface layer of relatively low velocity. For vertically incident seismic waves, the maximum amplification of ground motion at the surface (ignoring free-surface effects) is proportional to $\rho V_{2} / \rho V_{1}$, which is reached when the frequency of the incidence waves coincides with the natural frequency of the surface layer, $V_{1} / 4 H\left(V_{1}\right.$ and $V_{2}$ are the propagation velocities of the surface layer and underlying layer, respectively, and $H$ is the thickness of the surface layer). $\rho V_{2} / \rho V_{1}$ is referred to as the seismic impedance ratio. Theoretically, resonance can occur within a deposit of any thickness, as long as the impedance is large enough to overcome the effects of attenuation within the deposit. This condition becomes more difficult to meet as the deposits become thicker. The phenomenon is most commonly observed in relatively shallow deposits, where seismic impedances are more likely to be relatively large, as they are, for example, in the saturated unconsolidated deposits of the range front valleys of north-central Utah.

A recent example of the potentially devastating effects of seismic resonance is the destruction that beset Mexico City on September 19, 1985, as a result of the $M_{S}=8.1$ Michoacan, Mexico, earthquake (Anderson and others, 1986), which occurred off the western coast of Mexico some $350 \mathrm{~km}$ from Mexico City. The central por- 
tion of the city lies on lakebed deposits as much as $500 \mathrm{~m}$ thick. These deposits, composed of soft saturated clays, were known to resonate at a natural frequency of about $0.5 \mathrm{~Hz}$ from ground motions recorded during previous earthquakes. During the September 19 earthquake, 5-percent-damped absolute acceleration response spectra recorded on the lakebed deposits were again observed to peak near $0.5 \mathrm{~Hz}$, amplitudes being as much as a factor of 10 larger than those recorded on a nearby rock site south of the central portion of the city. In contrast, peak horizontal accelerations and spectral accelerations at nonresonant frequencies showed amplifications of a factor of 3 or less. The amplification due to resonance at the surface of the lakebed deposits was large enough to destroy hundreds of buildings whose natural frequencies coincided with the natural frequency of these deposits. Similar phenomena have been observed in Caracas, Venezuela (Seed and Idriss, 1982), and in Japan (Kanai, 1983).

The Mexico City experience is extremely relevant to north-central Utah. The average amplification of 5-percent-damped pseudo-relative velocity spectra from nuclear explosions recorded in Salt Lake valley reaches values at least as large as those observed in Mexico City for frequencies of 1.4 to $10 \mathrm{~Hz}$ (Hays and others, 1978; Hays and King, 1982, 1984; Hays, this volume; King and others, this volume). Thus, buildings having natural frequencies in this range are potentially vulnerable to damage from ground motions of even moderate strength, depending on their location within the valley. High-frequency resonance is also possible along the margins of the range front valleys, where shallow unconsolidated deposits and high impedance ratios are likely to be found. Large amplifications are also possible at frequencies greater than $1.4 \mathrm{~Hz}$ in the deepest parts of the valleys.

It must be emphasized that the observed amplification of pseudo-relative velocity spectra in Ogden, Provo, and Salt Lake City are for low-amplitude, low-strain ground motions. It is possible that high-amplitude ground motions from a large nearby earthquake on the Wasatch fault would induce strains large enough to significantly reduce the amount of amplification (Prakash, 1981), although this effect has been documented only from laboratory tests on disturbed soil samples. In any event, this effect would be restricted to only those sites located very near the source of the seismic waves. The only exception would be those sites susceptible to strong nonlinear behavior, such as loose, saturated sands and soft, sensitive clays where large strains could be induced by relatively small amplitudes

The spectral amplification data for Utah are not directly applicable to the estimation of peak horizontal acceleration and velocity. However, these data may be used to develop relative spectral amplification factors for Utah and California, which can then be used to infer rela- tive ratios for the peak ground-motion parameters of the two regions. Because the attenuation relationships developed in this study are based on California strong-motion recordings and thus represent California site conditions, the relative ratios of the peak ground-motion parameters of the two regions can be used to approximately adjust these relationships for Utah site conditions. The technique is admittedly crude, but it will have to suffice until attenuation relationships for response spectra are developed.

Spectral amplification factors for thick (450-750 m), saturated, unconsolidated sediments in Salt Lake valley (Hays and King, 1982) were used to establish site response for Utah. These factors represent an upper bound to those found for shallower deposits in Salt Lake valley, as well as for those found in the Provo and Ogden areas. Spectral amplification factors developed for the Los Angeles region by Rogers and others (1985) were used to establish site response for California. This latter study developed average spectral amplification factors for three frequency bands: 0.1 to $0.3,0.3$ to 1.0 . and 1.0 to $5.0 \mathrm{~Hz}$. The data consisted of recordings of nuclear explosions and accelerograms recorded during the 1971 San Fernando earthquake. Spectral amplification factors were computed in terms of Fourier spectra ratios, a crystalline rock site in Pasadena, Calif., being used as the reference site. For the current study, only the intermediate- and high-frequency bands are of interest, since these roughly coincide with the assumed predominant frequencies of peak velocity and peak acceleration, respectively.

For the deeper parts of the Los Angeles basin, Rogers and others (1985) found average spectral amplification factors ranging from 3.6 to 4.5 for the intermediate-frequency band and 3.6 to 6.5 for the high-frequency band. Hays and King (1982) found spectral amplification factors of roughly 9.0 and 7.0 for these same frequency bands for thick, unconsolidated sediments in Salt Lake valley. Thus, site amplification in Salt Lake valley appears to be roughly a factor of 2 times higher at intermediate frequencies and roughly a factor of 1.5 times higher at high frequencies in comparison with site amplification in the Los Angeles basin. The larger amplification in Salt Lake valley may reflect the two-dimensional resonance of the valley, as Bard and Bouchon (1985) suggested, or it may simply be that geotechnical factors such as soft soils, a shallow water table, and large velocity gradients lead to larger amplifications.

On the basis of the preceding discussion, equation 5 with $K_{3}=0$ was used to establish a lower bound median estimate of peak horizontal acceleration with respect to site effects for north-central Utah. This estimate is believed to be appropriate for sites located in Provo and Ogden and for those sites located on relatively shallow ( $<150 \mathrm{~m})$, unconsolidated sediments in Salt Lake valley. 
This estimate is probably also appropriate for rock, at least for sources within about $50 \mathrm{~km}$ of the site, although the actual values could be somewhat smaller or larger than this estimate, depending on factors such as the type of rock, the degree of weathering, and local topography (Campbell, 1983; Tucker and others, 1984). For very shallow, unconsolidated deposits near the range front, the shallow soil factor in table $5\left(K_{3}=1\right)$ was used to establish an upper bound median estimate for peak horizontal acceleration. This multiplicative factor of 1.5 was also used to account for the additional amplification expected at high frequencies at sites underlain by thick, unconsolidated deposits in Salt Lake valley.

Equation 6 with $K_{3}=1$ and $D=0$ was used to establish a lower bound median estimate for peak horizontal velocity with respect to site effects. This estimate is appropriate for sites located on hard rock. The soil-depth factor in table $5\left(K_{3}=1, D \rightarrow \infty\right)$, augmented with an additional factor of 2 to represent the additional amplification at intermediate frequencies expected at sites underlam by thick, unconsolidated sediments, was used to establish an upper bound median estimate for peak horizontal velocity.

\section{SOURCE DIRECTIVTTY}

Source directivity is the focusing or defocusing of seismic energy as rupture propagates toward or away from a site. The current study has shown that rupture toward a site can lead to substantial amplification of ground motion in some cases (see table 6). Similar effects have been observed by Boatwright and Boore (1982) and Singh (1985). The cities of Ogden, Provo, and Salt Lake City are particularly vulnerable to this phenomenon because they lie directly above the Wasatch fault. Because of their locations, they lie at relatively small azimuths with respect to the fault plane and would probably be subject to some kind of focusing for almost any rupture configuration. The only configuration that would tend to defocus ground motions would be unilateral rupture away from one of these cities.

Although potentially important, directivity was not taken into account in the prediction of ground motion in north-central Utah for several reasons. First, there is no definitive empirical study on which to base the selection of appropriate amplification factors. Second, directivity effects have never been known to result in peak horizontal accelerations and velocities in excess of about $1.3 \mathrm{~g}$ and $100 \mathrm{~cm} / \mathrm{s}$, respectively, these values being within the upper bounds estimated for $\mathbf{a}_{\mathrm{S}}=7.5$ earthquake in northcentral Utah. If one is concerned about the potential effects of directivity, it is recommended that estimates of ground motion presented in the next section be multiplied by an additional factor to account for these effects. However, one should be careful not to exceed reasonable upper bound values for peak horizontal acceleration and velocity. What constitutes reasonable upper bound limits of these parameters is a subject of some controversy. Practically speaking, median estimates that approach the maximum near-source estimates of peak horizontal acceleration and velocity for the $M_{S}=7.5$ earthquake presented below might be considered reasonable upper limits. A rough estimate of what may be considered near-maximum directivity effects can be obtained from the factors in tables 5 and 6 , which suggest that amplification due to directivity may be as large as a factor of 1.7 for peak horizontal acceleration and 2.7 for peak horizontal velocity.

\section{GROUND-MOTION ESTIMATES}

Ground-motion attenuation curves for north-central Utah are presented in figures 11 and 12 . The range of values reflects variability associated with fault type, site amplification, and anelastic attenuation, as discussed in the preceding sections. This variability can be reduced only with regional studies designed to better define and quantity these effects. Until such studies become available, it is believed that a range of estimates is the only reasonable means of quantifying this variability.

The development of attenuation relationships for pseudo-relative velocity response spectra is currently in progress. Until these relationships become available, it is recommended that response spectra be estimated from estimates of peak acceleration and velocity according to the procedures proposed by Newmark and Hall (1982). This method is preferred over the use of attenuation relationships available in the literature (for example, Joyner and Fumal, 1985), because regional uncertainties in fault type, anelastic attenuation, and site effects included in estimates of peak horizontal acceleration and velocity are readily incorporated in the spectra.

As an example of the procedure, figure 13 displays a median estimate of a 5-percent-damped pseudo-relative velocity spectrum for a site located approximately $5 \mathrm{~km}$ from the zone of seismogenic rupture of a $M_{S}=7.5$ earthquake. This scenario probably represents the largest ground motion that can be expected anywhere in Utah. It is roughly equivalent to the level of ground motion that might be expected in Ogden, Provo, or Salt Lake City as a result of the largest earthquake that has been geologically inferred on the Wasatch fault (Swan and others, 1980).

Figures 11 through 13 present median estimates of ground motion. If some other percentile is desired, then it should be estimated from the expression (Draper and Smith, 1981)

$$
y_{\alpha}=\hat{y}+t_{\alpha, v}\left[\left(\sigma^{2} / n_{0}\right)+(\sigma \hat{y})^{2}\right]^{1 / 2}
$$




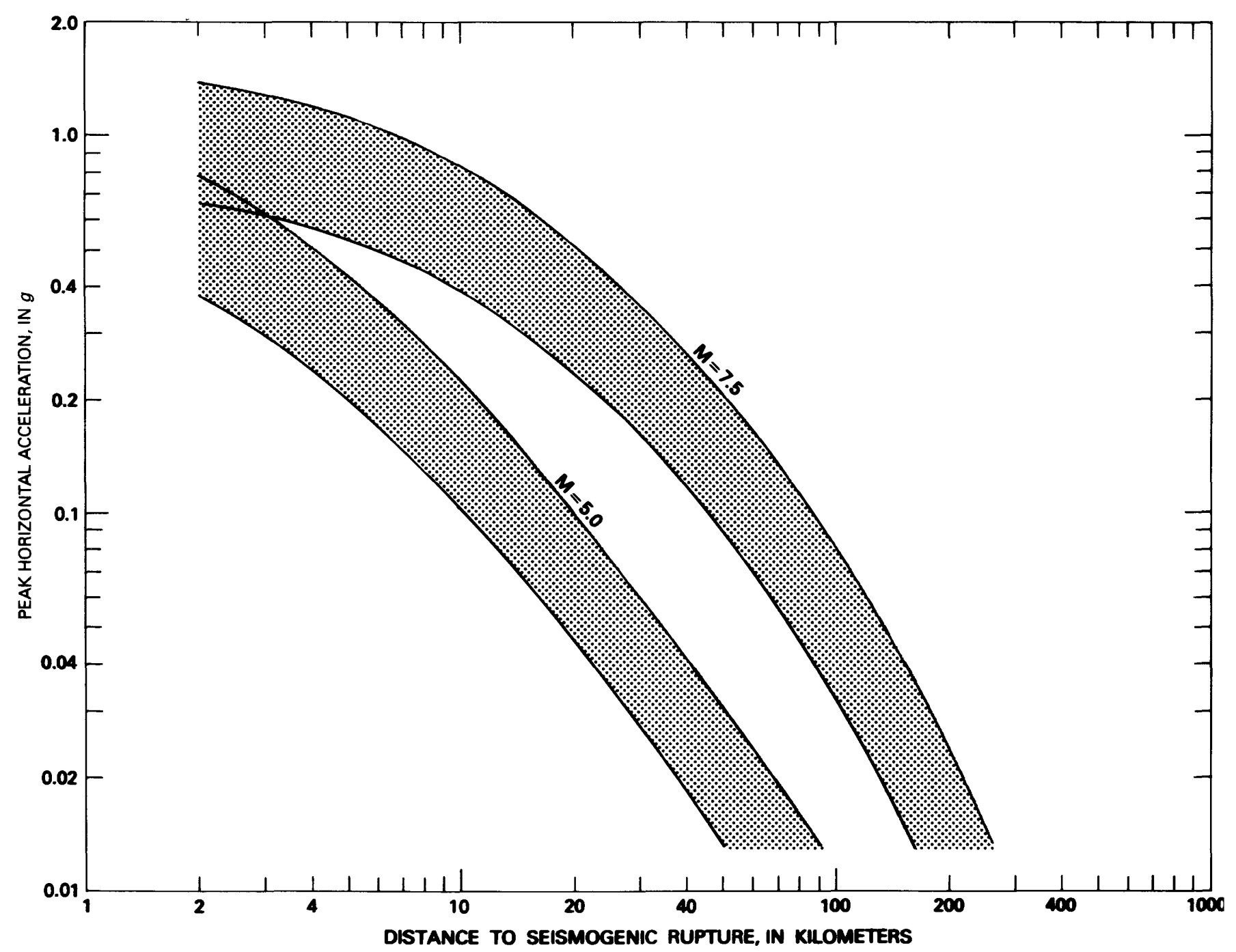

FIGURE 11.-Estimates of peak horizontal acceleration for north-central Utah. The shaded zone represents the range in median estimates of acceleration due to variability in fault type, site amplification, and anelastic attenuation (see text).

where $y$ represents $\ln$ PHA or $\ln$ PHV, $y_{\alpha}$ is the $\alpha$-percentile value of $y, \hat{y}$ is the median or predicted value of $y, t_{\alpha, v}$ is the $t$ statistic associated with a cumulative probability $\alpha$ and $v=n-p-1$ degrees of freedom, $n$ is the number of observations used in the analysis, $p$ is the number of coefficients in the model, $n_{\mathrm{O}}$ is the number of future observations (usually 1 ), $\sigma$ is the standard error of regression, and $\sigma_{\hat{y}}$ is the standard deviation of $\hat{y}$.

For large $v, t_{\alpha, v}$ can be replaced by $z_{\alpha}$, the standard normal variable, and because one is usually interested in the prediction of a single future observation, $n_{0}=1$. Thus, the only quantity that is not known is $\sigma_{\hat{y}}$, which, because of the nonlinear form of equations 5 and 6 , can only be estimated by Monte Carlo simulation. Such simulation is beyond the scope of this study. For estimates near the centroid of the data (that is, near the middle of the scat- tergrams in fig. 1), $\sigma \hat{y}$ is very small and can be neglected. In this case, equation 12 becomes

$$
y_{\alpha}=\hat{y}+z_{\alpha} \sigma
$$

For estimates involving an extrapolation of the model, $\sigma_{\hat{y}}$ cannot be neglected, and equation 13 will substantially underestimate the value of $y_{\alpha}$ for $\alpha>0.5$.

\section{SUMMARY}

In this study, empirical attenuation relationships for horizontal components of peak acceleration and peak velocity have been developed from as many as 134 nearsource strong-motion recordings. These records were 


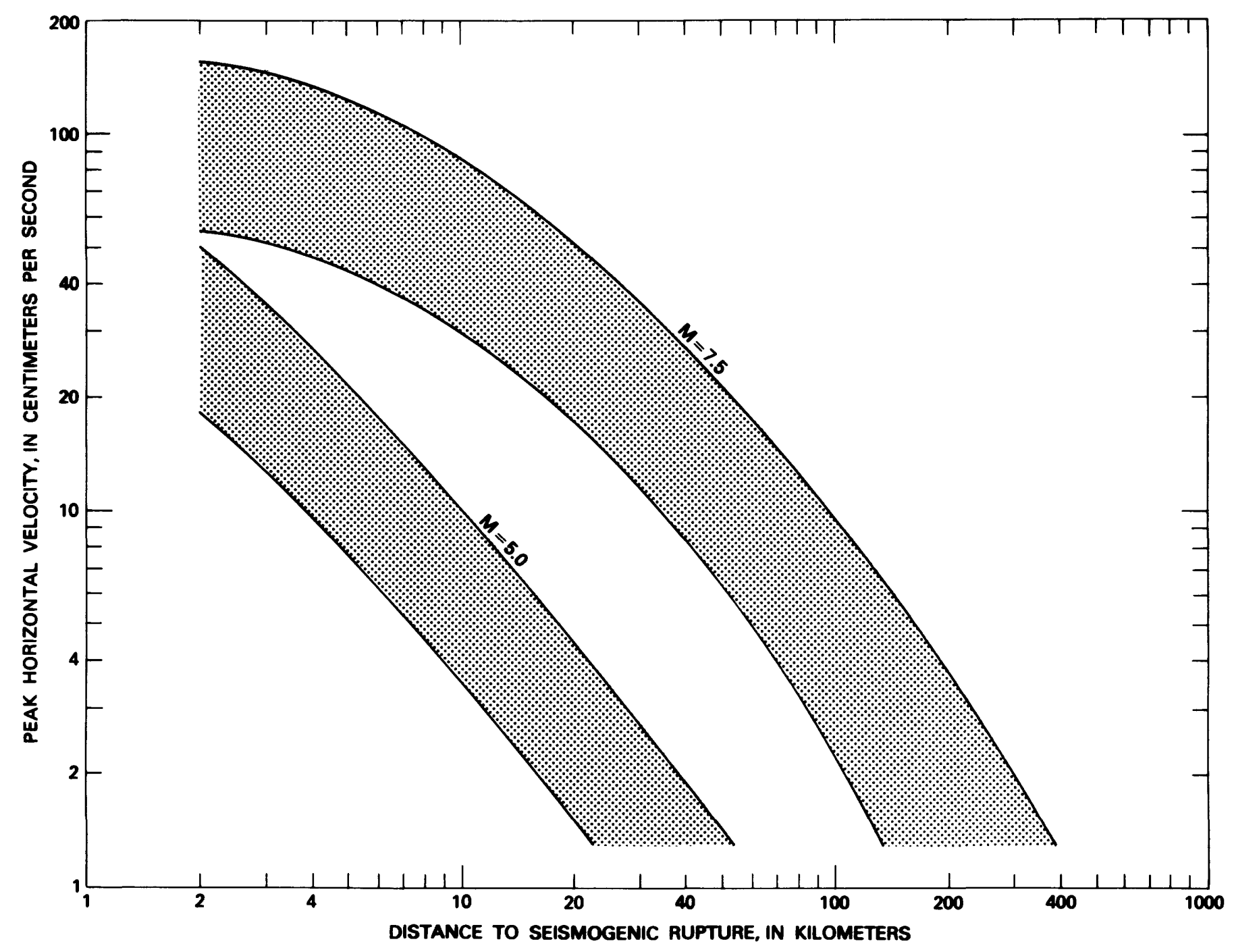

FIGURE 12.-Estimates of peak horizontal velocity fornorth-central Utah. The shaded zone represents the range in median estimates of velocity due to variability in fault type, site amplification, and anelastic attenuation (see text).

obtained within 30 to $50 \mathrm{~km}$ of 21 earthquakes worldwide whose magnitudes range from 5.0 to 7.7 . Because all recordings come from sites located on relatively low velocity, unconsolidated deposits, limitations associated with the small number of available rock recordings are avoided. These attenuation relationships provide models for predicting peak acceleration and peak velocity from a suite of parameters characterizing source, propagation, and site effects, the most important being earthquake magnitude and distance to the zone of seismogenic rupture. Empirical analyses indicated that factors such as fault type, building size, building embedinent, and shallow soil influence the prediction of peak acceleration, whereas factors such as fault type, building size, and depth of sediments influence the prediction of peak velocity.
Two types of attenuation relationships were developed in the study: an unconstrained relationship, whose coefficients were all derived directly from regression analyses, and a constrained relationship, whose anelastic attenuation term was constrained to provide a relationship that could be reliably extrapolated beyond the nearsource limit of the strong-motion data. Both relationships provide virtually identical estimates of ground motion within about 30 to $50 \mathrm{~km}$ of the source, but only the constrained relationship provides reliable estimates of ground motion to distances of about $100 \mathrm{~km}$. A significant advantage of the constrained relationship is its ability to provide estimates of ground motion in regions whose attenuation characteristics are different from California's.

A striking feature of all four attenuation relationships developed in this study is the empirical constraint that 


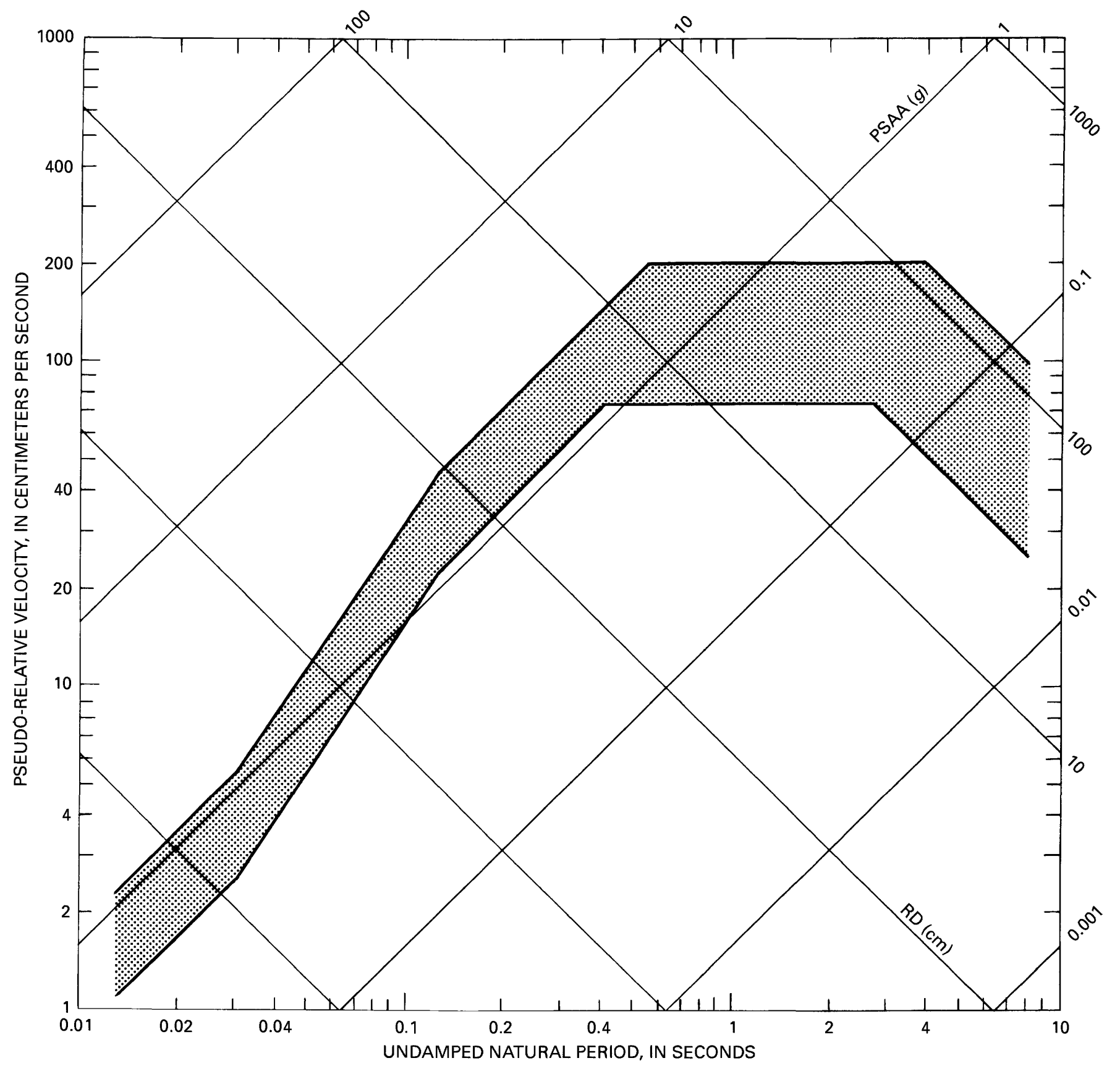

FIGURE 13.-Estimate of the 5-percent-damped pseudo-relative velocity spectrum for a site in north-central Utah located approximately $5 \mathrm{~km}$ from the zone of seismogenic rupture of a $\mathrm{M}_{\mathrm{S}}=7.5$ earthquake. The shaded zone represents the range in the median estimate of pseudo-relative velocity due to variability in fault type and site amplification (see text). RD, relative displacement; PSAA, pseudo-absolute acceleration.

peak ground-motion amplitudes be independent of magnitude at the earthquake source. This characteristic, referred to as ground-motion saturation, has been proposed by many geophysicists as a fundamental property of the earthquake source. Its empirical basis, however, has been the subject of great controversy in the past (Campbell, 1985a).
The constrained attenuation relationships developed in this study were used to provide median estimates of strong ground motion for north-central Utah. A range of estimates was provided to reflect uncertainties in the state of knowledge and regional variability associated with the potential effects of fault type, anelastic attenuation, and site effects. A range of values for anelastic atten- 
uation believed to be appropriate for the Basin and Range was taken from the literature. Regional studies of site effects were used to modify the estimates for local site conditions. The range of estimates for a given value of magnitude and distance was found to be quite large, an indication that regional studies of ground motion should be undertaken to better define the effects of fault type and anelastic attenuation.

A method developed by Newmark and Hall (1982) for estimating response spectra from estimates of peak ground-motion values was used to provide a median 5percent-damped pseudo-relative velocity spectrum for a $\mathrm{M}_{\mathrm{S}}=7.5$ earthquake hypothesized to occur on the Wasatch fault approximately $5 \mathrm{kn}$ from a site located within one of the range front valleys. This scenario leads to what the author considers to be the largest ground motion that can be expected to occur in the cities of Ogden, Provo, and Salt Lake City.

\section{REFERENCES CITED}

Anderson, J.G., Bodin, P., Brune, J.N., Prince, J., Singh. S.K., Quaas, R., and Onate, M., 1986, Strong ground motion from the Michoacan, Mexico, earthquake: Science, v. 233, p. 1043-1049.

Anderson, J.G., and Luco, J.E., 1983, Parametric study of nearfield ground motions for oblique-slip and dip-slip dislocation models: Bulletin of the Seismological Society of America, v. 73 , p. $45-57$.

Bakun, W.H., 1984, Seismic moments, local magnitudes, and coda-duration magnitudes for earthquakes in central California: Bulletin of the Seismological Society of America, v. 74, p. $439-458$.

Bard, P.-Y., and Bouchon, M., 1985, The two-dimensional resonance of sediment-filled valleys: Bulletin of the Seismological Society of America, v. 75, p. 519-541.

Boatwright, J.A., and Boore, D.M., 1982, Analysis of the ground accelerations radiated by the 1980 Livermore Valley earthquakes for directivity and dynamic source characteristics: Bulletin of the Seismological Society of America, v. 72, p. 1843-1865.

Boore, D.M., 1980, On the attenuation of peak velocity: World Conference on Earthquake Engineering, 7th, Istanbul 1980, Proceedings, v. II, p. 577-584.

Boore, D.M., and Boatwright, J.A., 1984, Average body-wave radiation coefficients: Bulletin of the Seismological Society of America, v. 74, p. 1615-1621.

Brillinger, D.R., and Preisler. H.K., 1984, An exploratory analysis of the Joyner-Boore attenuation data: Bulletin of the Seismological Society of America, v. 74, p. 1441-1450.

Campbell, K.W., 1981a, Near-source attenuation of peak horizontal acceleration: Bulletin of the Seismological Society of America, v. 71, p. 2039-2070.

1981b, A ground motion model for the Central United States based on nearsource acceleration data: Conference on Earthquakes and Earthquake Engineering: The Eastern U.S., Knoxville, Tenn., 1981, Proceedings, v. 1, p. 213-232. -1982a, Near-source scaling characteristics of peak horizontal acceleration for moderate-to-large earthquakes, in Boatwright, J., ed., Proceedings of Workshop XVI; The dynamic characteristics of faulting inferred from recordings of strong ground motion: U.S. Geological Survey Open-File Report 82-591, p. 120-184.

-1982b, A preliminary methodology for the regional zonation of peak acceleration: Third International Conference on Earthquake Microzonation, 3d, Seattle, Wash., 1982, Proceedings, v. I, p. 365-376.

-1983, The effects of site characteristics of near-source recordings of strong ground motion, in Hays, W.W., ed., A workshop on "Site-specific effects of soil and rock on ground motion and the implications for earthquake-resistant design": U.S. Geological Survey Open-File Report 83845 , p. $280-309$.

-1984a, Near-source attenuation of strong ground motion for moderate to large earthquakes; an update and suggested application to the Wasatch fault zone of north-central Utah, in Hays, W.W., and Gori, P.L., eds., Proceedings of Conference XXVI; a workshop on Evaluation of regional and urban earthquake hazards and risk in Utah: U.S. Geological Survey Open-File Report 84-763, p. 483-499.

$-1984 \mathrm{~b}$, Observed structural modification of recorded strong ground motion, in Critical aspects of earthquake ground motion potential: Palo Alto, Calif., Report ATC-101, Applied Technology Council, p. 43-52.

-1985a, Strong motion attenuation relations: A ten-year perspective: Earthquake Spectra, v. 1, p. 759-804.

-1985b, Near-source estimation of strong ground motion for the eastern United States: Washington, D.C., Secondquarter progress report to the U.S. Nuclear Regulatory Commission, 5 p.

-1986, Empirical prediction of free-field ground motion using statistical regression models, in Workshop on soilstructure interaction, Bethesda, Md., 1986: Upton, N.Y., Report NUREG/CP-0054, Brookhaven National Laboratory, p. $12-41$.

1989, The dependence of peak horizontal acceleration on magnitude, distance, and site effects for small-magnitude earthquakes in California and Eastern North America: Bulletin of the Seismological Society of America, v. 79, p. 13111346.

Chavez, D.E., and Priestley, K.F., 1985, $\mathrm{M}_{\mathrm{L}}$ observations in the Great Basin and $M_{o}$ versus $M_{L}$ relationships for the 1980 Mammoth Lakes, California, earthquake sequence: Bulletin of the Seismological Society of America, v. 75, p. 1583-1598.

-1986, Attenuation of regional crustal phases in the Great Basin [abs.]: Earthquake Notes, v. 57, no. 1, p. 9.

Chiaruttini, C., and Siro, L., 1981, The correlation of peak ground horizontal acceleration with magnitude, distance, and seismic intensity for Friuli and Ancona, Italy, and the Alpine Belt: Bulletin of the Seismological Society of America, v. 71, p. 1993-2009.

Cranswick. E., Wetmiller, R., and Boatwright. J., 1985. High-frequency observations and source parameters of microearthquakes recorded at hard-rock sites: Bulletin of the Seismological Society of America, v. 75, p. 1535-1567. 
Draper, N.R., and Smith, H., 1981, Applied regression analysis (2d ed.): New York, John Wiley.

Esteva, L., 1970, Seismic risk and seismic design decisions, in Hanson, R.J., ed., Seismic design for nuclear power plants: Cambridge, Mass., M.I.T. Press, p. 142-182.

Faccioli, E., 1981. The use of RMS acceleration as a measure of soil amplification in strong earthquakes, in Erguray, O., and Erdik, M., eds., State-of-the-art in earthquake engineering,1981: Ankara, Turkey, Turkish National Committee on Earthquake Engineering, p. 98-105.

Fenneman, N.M., 1946, Physical divisions of the United States: U.S. Geological Survey Map, scale 1:7,000,000.

Gallant, A.R., 1975, Nonlinear regression: The American Statistician, v. 29 , p. $73-81$.

Hadley, D.M., Helmberger, D.V., and Orcutt, J.A., 1982, Peak acceleration scaling studies: Bulletin of the Seismological Society of America, v. 72, p. 959-979.

Hanks, T.C., and Boore. D.M., 1984, Moment-magnitude relations in theory and practice: Journal of Geophysical Research, v. 89 , no. B7, p. 6229-6235.

Hanks, T.C., and Kanamori. H., 1979. A moment magnitude scale: Journal of Geophysical Research, v. 84, p. 2348-2350.

Hays, W.W., and King, K.W., 1982, Zoning of the earthquake ground-shaking hazard along the Wasatch fault zone, Utah: International Earthquake Microzonation Conference, 3d, Seattle, Wash., 1982, Proceedings, v. III, p. 1307-1318.

-1984, The ground-shaking hazard along the Wasatch fault zone, Utah, in Hays, W.W., and Gori, P.L., eds., Proceedings of Conference XXVI; a workshop on Evaluation of regional and urban earthquake hazards and risk in Utah: U.S. Geological Survey Open-File Report 84-763, p. 133-147.

Hays, W.W., Algermissen, S.T., Miller, R.D., and King. K.W., 1978, Preliminary ground response maps for the Salt Lake City area: International Earthquake Microzonation Conference, 2d, San Francisco, Calif., 1978, Proceedings, v. 2. p. 497-508.

Johnson, R.A., and Wichern, D.W., 1982, Applied multivariate statistical analysis: Englewood Cliffs, N.J., Prentice-Hall, 594 p.

Joyner, W.B., and Boore, D.M., 1981, Peak horizontal acceleration and velocity from strong-motion records including records from the 1979. Imperial Valley, California, earthquake: Bulletin of the Seismological Society of America, v. 71, p. 2011-2038.

Joyner, W.B., and Fumal, T.E., 1984, Use of measured shear-wave velocity for predicting geologic site effects on strong ground motion: World Conference on Earthquake Engineering, 8th, San Francisco, Calif., 1984, Proceedings, v. II, p. 777-784.

1985, Predictive mapping of earthquake ground motion, in Ziony, J.I., ed., Evaluating earthquake hazards in the Los Angeles region-An earth-science perspective: U.S. Geological Survey Professional Paper 1360, p. 203-220.

Kanai, K., 1983, Engineering seismology: Tokyo, University of Tokyo Press, $251 \mathrm{p}$.

King, K.W., and Hays, W.W., 1977, Comparison of seismic attenuation in northern Utah with attenuation in four other regions of the western United States: Bulletin of the Seismological Society of America, v. 67, p. 781-792.
Mabey, D.R., 1992, Subsurface geology along the Wasatch Front, in Gori, P.L., and Hays, W.W., eds., Assessment of regional earthquake hazards and risk along the Wasatch Front, Utah: U.S. Geological Survey Professional Paper 1500-C, p. C1C16.

McGarr, A., 1984, Scaling of ground motion parameters, state of stress, and focal depth: Journal of Geophysical Research, v. 89, no. B8, p. 6969-6979.

More, J.J., Garbow, B.S., and Hillstrom, K.E., 1980, User guide for MINPACK-1: Argonne, Ill., Report ANL-80-74, Argonne National Laboratory, $260 \mathrm{p}$.

Mueller, C.S., Boore, D.M., and Porcella, R.L., 1982, Detailed study of site amplification at El Centro strong-motion array station no. 6: International Earthquake Microzonation Conference, 3d, Seattle, Wash., 1982, Proceedings, v. I, p. 413424.

Newmark, N.M., and Hall, W.J., 1982, Earthquake spectra and design: Berkeley, Calif., Earthquake Engineering Research Institute Monograph, $103 \mathrm{p}$.

Nuttli, O.W., 1979, The relation of sustained maximum ground acceleration and velocity to earthquake intensity and magnitude, in State-of-the art for assessing earthquake hazards in the United States: U.S. Army Engineer Waterways Experiment Station Miscellaneous Paper S-73-1, Report 16.

Prakash, S., 1981, Soil dynamics: New York, McGraw-Hill, 426 p.

Prince, J., 1984, Influence of the number of response maxima on the observed seismic behavior of structures, in Critical aspects of earthquake ground motion and building damage potential: Palo Alto, Calif., Report ATC-10-1, Applied Technology Council, p. 57-66.

Richter, C.F., 1958, Elementary seismology: San Francisco, Calif., W.H. Freeman, 768 p.

Rogers, A.M., Tinsley, J.C., and Borcherdt, R.D., 1984, Geographic variation in ground shaking as a function of changes in near-surface properties and geologic structure near Los Angeles, California: World Conference on Earthquake Engineering, 8th, San Francisco, Calif., 1984, Proceedings, v. II, p. 737-744.

1985, Predicting relative ground response, in Ziony, J.I., ed., Evaluating earthquake hazards in the Los Angeles region-An earth-science perspective: U.S. Geological Survey Professional Paper 1360, p. 221-247.

Rogers, A.M., Harmsen, S.C., Herrmann, R.B., and Meremonte, M.E., 1987, A study of ground motion attenuation in the southern Great Basin, Nevada-California, using several techniques for estimates of $Q_{s}, \log A_{o}$, and coda $Q$ : Journal of Geophysical Research, v. 92, no. B5, p. 3527-3540.

Seed, H.B., and Idriss, I.M., 1982, Ground motions and soil liquefaction during earthquakes: Berkeley. Calif., Earthquake Engineering Research Institute Monograph, 134 p.

Seed, H.B., Idriss, I.M., and Keifer, F.W., 1969, Characteristics of rock motions during earthquakes: Proceedings of the American Society of Civil Engineers, Journal of the Soil Mechanics and Foundations Division, v. SM95, p. 1199-1218.

Seed, H.B., Ugas, C., and Lysmer, J., 1976, Site-dependent spectra for earthquake-resistant design: Bulletin of the Seismological Society of America, v. 66, p. 221-243. 
Shakal, A.F., and Bernreuter, D.L., 1981, Empirical analysis of near-source ground motion: Washington, D.C., Report NUREG/CR-2095, U.S. Nuclear Regulatory Commission, $65 \mathrm{p}$.

Singh, J.P., 1985, Earthquake ground motions: Implications for designing structures and reconciling structural damage: Earthquake Spectra, v. 1, p. 239-270.

Singh, S., and Herrmann, R.B., 1983, Regionalization of crustal $Q$ in the continental United States: Journal of Geophysical Research, v. 88, no. B1, p. 527-538.

Swan, F.H., III, Schwartz. D.P., and Cluff, L.S., 1980, Recurrence of moderate-to-large magnitude earthquakes produced by surface faulting on the Wasatch fault zone: Bulletin of the Seismological Society of America Bulletin, v. 70, p. 14311478.

Taylor, S.R., and Patton, H.J., 1986, Shear-wave velocity structure from regionalized surface-wave dispersion in the Basin and Range: Geophysical Research Letters, v. 13, p. 30-33.

Thatcher, W., 1972, Regional variations of seismic source parameters in the northern Baja, California, area: Journal of Geophysical Research, v. 77, no. B8, p. 1549-1565.
Thatcher, W., and Hanks, T.C., 1973, Source parameters of Southem California earthquakes: Journal of Geophysical Research, v. 78, no. B35, p. 8547-8576.

Trifunac, M.D., and Lee, V.W., 1978, Dependence of the Fourier amplitude spectra of strong motion acceleration on the depth of sedimentary deposits: Los Angeles, Calif., Report CE78-14, University of Southern California Department of Civil Engineering, $39 \mathrm{p}$.

1979, Dependence of pseudo-relative velocity spectra of strong motion acceleration on the depth of sedimentary deposits: Los Angeles, Calif., Report CE79-02, University of Southern California Department of Civil Engineering.

Tucker, B.E., King, J.L., Hatzfeld, D., and Nersesov, I.L., 1984, Observations of hard rock site effects: Bulletin of the Seismological Society of America, v. 74, p. 121-136.

Tukey, J.W., 1977, Exploratory data analysis: Reading, Mass., Addison-Wesley.

Zoback, M.L., and Zoback, M.D., 1981, State of stress in the conterminous United States: Journal of Geophysical Research, v. 86 , no. B6, p. 4981-4998. 

Probabilistic Analysis of Earthquake Ground-Shaking Hazards Along the Wasatch Front, Utah

By R.R. YOUNGS, F.H. SWAN, and M.S. POWER, GeoMatrix Consultants, D.P.

SCHWARTZ, U.S. Geological Survey, and R.K. GREEN, Woodward-Clyde Consultants

ASSESSMENT OF REGIONAL EARTHQUAKE HAZARDS AND RISK ALONG THE WASATCH FRONT, UTAH

U.S. GEOLOGICAL SURVEY PROFESSIONAL PAPER 1500-M 



\section{CONTENTS}

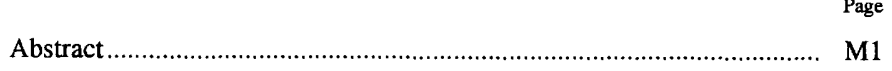

Introduction

Acknowledgments

Approach.

Regional Seismicity

Earthquake Catalog

Identification of Dependent Events

Catalog Completeness

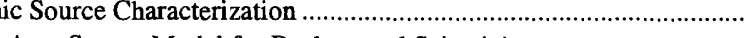
Area Source Model for Background Seismicity.............................. Quaternary Faulting.

Earthquake Magnitude Distribution and Recurrence Assessment

Unsegmented Versus Segmented Fault-Rupture

Model

Fault Dip and Depth...

Maximum Earthquake Magnitude Assessment Techniques

Wasatch Fault Zone Maximum Earthquake Magnitude ............................ 23 Earthquake Recurrence Rate.................................... 23

Oquirrh Mountain Fault Zone ............................................. 29 Segmentation....................................................... 29 Activity ............................................................. 30 Total Length ........................................................... 30

Maximum Earthquake Magnitude ........................... 30

Earthquake Recurrence Rate................................... $\quad 30$

East Cache Fault .

Segmentation...

Maximum Earthquake Magnitude

Earthquake Recurrence Rate.

West Valley Fault Zone Activity
Seismic Source Characterization-Continued

Maximum Earthquake Magnitude ............................... M32

Earthquake Recurrence Rate ...................................... 32

Hansel Valley Fault Zone ................................................... 32

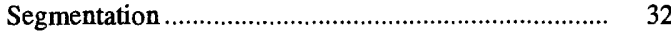

Activity ................................................................ 32

Maximum Earthquake Magnitude ............................... $\quad 32$

Earthquake Recurrence Rate ..................................... $\quad 32$

East Bear Lake Fault............................................................ 33

Segmentation ........................................................ 33

Maximum Earthquake Magnitude ................................ 33

Earthquake Recurrence Rate ...................................... 33

Comparison of Predicted and Observed Earthquake Frequency

Attenuation Relationships

Earthquake Source Characteristics................................................ 34

Source-to-Site Attenuation Characteristics ..................................... 34

Local Site Effects ........................................................................... 35

Selected Attenuation Relationships for Peak Ground Acceleration.................................................................... 36

Selected Attenuation Relationships for Response Spectral Values .................................................................... 39

Analysis Results and Sensitivity .......................................................... 40

Computed Hazard ........................................................................ 40

Contributions to Uncertainty......................................................... 44

Additional Sensitivity Analyses................................................ 48

Peak Acceleration Hazard Maps ................................................... 55

Response Spectra ................................................................ 58

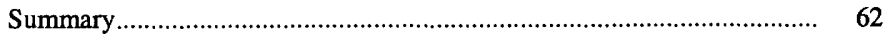

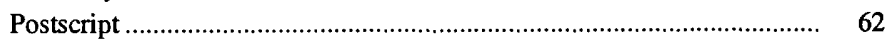

References Cited.........................................................................

Appendix: Comparison of Strong-Motion Data from the Study

Region with Selected Attenuation Relationships

\section{ILLUSTRATIONS}

FIGURE 1. Map showing location of the study area for ground-shaking hazard mapping and the Quaternary faults modeled in the seismic-hazard analysis

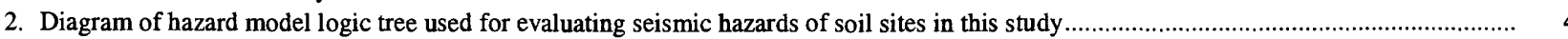

3, 4. Maps showing:

3. Catalog of independent events of magnitude $\mathrm{M}_{\mathrm{L}} \geq 2$ occurring prior to July 1,1962 .

4. Instrumental catalog of independent events of magnitude $M_{L} \geq 2$ occurring between July 1,1962 , and April 1, 1986

Graphs showing:

5. Criteria used for time and distance windows in identifying independent events

6. Estimates of catalog completeness and regional recurrence for north-central Utah................

7. Cross sections through six segments of the Wasatch fault showing instrumental seismicity recorded between October 1974 and April 1986

8. Recurrence estimates for background seismicity source delineated in figures 3 and 4 ..... 
9. Comparison of recurrence models used in the analysis for equal recurrence rate of maximum events and equal rate Page

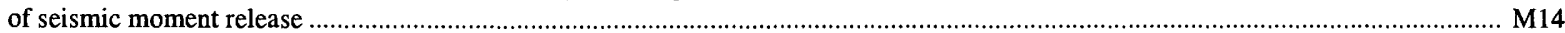

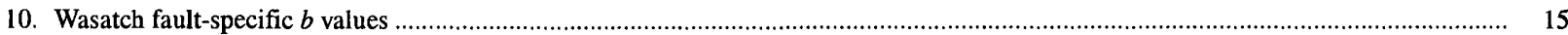

11. Relationship between seismic moment and earthquake magnitude .......................................................................................... 16

12. Diagram showing weighting factors for maximum magnitude assessment techniques for two cases ......................................................... 18

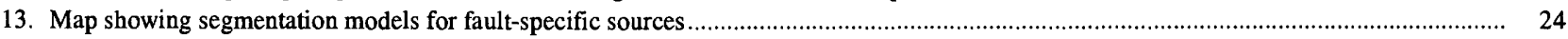

14. Diagram showing maximum magnitude logic tree for the Wasatch fault zone ................................................................................. 26

15-23. Graphs showing:

15. Comparison of predicted recurrence rates for seismic sources and observed frequency of earthquakes.

16. Peak horizontal acceleration attenuation relationships used in seismic hazard analysis

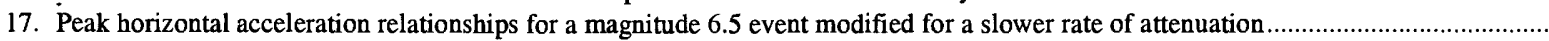

18. Typical response spectral acceleration attenuation relationships for soil-site conditions used in seismic-hazard analysis.....

19. Computed distributions for frequency of exceeding various levels of peak ground acceleration on soil at three locations

20. Peak ground acceleration hazard curves on soil for three locations.

21. Contributions of various sources to the computed mean hazard for six locations

22. Variation in the computed mean hazard along the length of the Wasatch fault zone from Nephi to Collinston

23. Contributions of different magnitude events to total frequency of exceeding various levels of peak ground acceleration at three locations

24-32. Graphs showing contribution to uncertainty in exceedance frequency from uncertainty in:

24. Selecting the appropriate soil-site attenuation relationship

25. Recurrence model.

26. Source segmentation

27. Segmentation model at six locations along the Wasatch fault

28. Source activity

29. Fault dip..

30. Use of either recurrence data from the segment only or an average value from the central segments of the fault in modeling earthquake recurrence for the fault segments

31. Maximum magnitude

32. Recurrence rate

33. Graph showing comparison of mean hazard curves for soil and rock sites at three locations.

34-36. Graphs showing effect on computed hazard of:

34. Postulated lower Utah attenuation rate in Utah in comparison with California rates at three locations

35. Choice of lower bound magnitude cutoff at three locations...

36. Using realtime estimates of earthquake occurrence probabilities at two locations along the Wasatch fault zone

37. Maps showing contours of peak ground acceleration on soil sites having 10-percent probability of being exceeded in 10,50 , and 250 years

38-40. Graphs showing equal hazard response spectra at three locations for:

38. Soil and rock sites computed by using two attenuation relationships

39. Soil sites

40. Rock sites

41-43. Graphs showing:

41. Proposed spectral shapes for developing equal-hazard response spectra.

42. Example of the development of equal-hazard response spectra for a 10-percent probability of exceedance in 50 years for soil and rock sites near Magna

43. Preliminary estimates of ranges in response spectral shapes for lake deposits.

Graphs comparing:

A1. Peak ground accelerations recorded at Logan during the 1962 Cache Valley, Utah, earthquake and median attenuation relationships

A2. Response spectra of ground motions recorded during the 1962 Cache Valley, Utah, earthquake and median and 84th-percentile spectra from attenuation relationships

A3. Peak ground accelerations recorded during the 1983 Borah Peak, Idaho, earthquake and median attenuation relationships

A4. Peak ground accelerations recorded during the 1983 Borah Peak, Idaho, aftershocks and median attenuation relationships 


\section{TABLES}

TABle 1. Fault characterization parameters and associated weights for the seismic-hazard mod

2. Parameters and relationships used to estimate maximum magnitude and associated weights

M19

22

3. Geologic parameters used to characterize earthquake recurrence rate for the Wasatch fault zone.........

4. Values of coefficients for the attenuation relationships of Sadigh and others (1986) for horizontal peak ground acceleration and pseudo-absolute spectral accelerations. 



\title{
ASSESSMENT OF REGIONAL EARTHQUAKE HAZARDS AND RISK \\ ALONG THE WASATCH FRONT, UTAH
}

\section{PROBABILISTIC ANALYSIS OF EARTHQUAKE GROUND SHAKING HAZARDS ALONG THE WASATCH FRONT, UTAH}

\author{
By R.R. Youngs, F.H. Swan, M.S. Power, D.P. Schwartz, and R.K. Green
}

\begin{abstract}
This paper presents a probabilistic assessment of the ground-shaking hazard along the Wasatch Front urban corridor, utilizing the extensive geological and seismological data base that has been developed for the region. Using a logic tree methodology, the approach formally incorporates uncertainty in earthquake source geometry and fault segmentation, maximum earthquake magnitude, earthquake recurrence rate, ground-motion attenuation, and other parameters and model components. The analysis results are presented on maps showing contours of peak ground acceleration on soil-site conditions for probabilities of exceedance of 10 percent in 10 years, 10 percent in 50 years, and 10 percent in 250 years. The major contributions to uncertainty in the hazard are uncertainties in selecting the appropriate models for earthquake recurrence on the faults and ground-motion attenuation. Repeating the analyses for rock-site attenuation relationships indicates that rock-site peak accelerations can be obtained by multiplying the soil-site accelerations by a factor of 1.1 for a probability of exceedance of 10 percent in 10 years and by a factor of 1.2 for probabilities of exceedance of 10 percent in 50 years and 10 percent in 250 years.

Response spectral shapes for soil- and rock-site conditions are presented for the probability of exceedance levels used in mapping peak ground acceleration. Absolute response spectra can be obtained by multiplying these spectral shapes by the corresponding values of peak ground acceleration. A preliminary estimate is presented for the additional spectral amplification that might occur in areas of soft lake deposits.
\end{abstract}

\section{INTRODUCTION}

The urban corridor along the Wasatch Front, which includes more than 85 percent of Utah's population, is considered one of the highest risk areas within the conterminous United States with respect to earthquake hazards. The seismic hazards of this region are related primarily to the presence of the Wasatch fault zone, which extends for more than $370 \mathrm{~km}$ along the western front of the Wasatch Range. Paleoseismicity studies (Swan and others, 1980; Hanson and others, 1981a, b; Schwartz and others, 1984;
Schwartz and Coppersmith, 1984) have demonstrated that the Wasatch fault zone has repeatedly produced largemagnitude earthquakes throughout the Holocene and that it is likely to be the source of future damaging earthquakes. In addition, the region may be affected by earthquakes originating on other faults exhibiting Quaternary movement, including the Oquirrh Mountains fault zone, the East Cache fault, the West Valley fault, the Hansel Valley fault, and the East Bear Lake fault. As figure 1 indicates, Logan, Brigham City, Ogden, Salt Lake City, and Provo, the largest cities in Utah, all lie along active faults capable of producing damaging earthquakes.

During the past two decades, geological studies have been conducted for the specific purpose of identifying and evaluating the potential earthquake hazards along the Wasatch Front (Utah Geological Association, 1972; Evernden, 1980; Hays and Gori, 1984). Extensive telemetered seismic arrays have been operating to assess the earthquake hazard along the Intermountain Seismic Belt since 1974. Prior to that, instrumental monitoring of the Wasatch Front dates back only to 1962 (Arabasz and others, 1980).

This study makes a quantitative assessment of the ground-shaking hazard along the Wasatch Front urban corridor (fig. 1), utilizing the extensive geological and seismological data base that has been assembled for the region. The ground-shaking hazard is related to (1) the location and geometry of the earthquake sources relative to urban areas, (2) the recurrence of earthquakes of various magnitudes on these sources, and (3) the attenuation of ground motions from the sources to various locations within the study area. A probabilistic approach is used to formally incorporate the uncertainty in modeling the regional seismicity and attenuation characteristics into the hazard assessment. In this approach, distributions of 


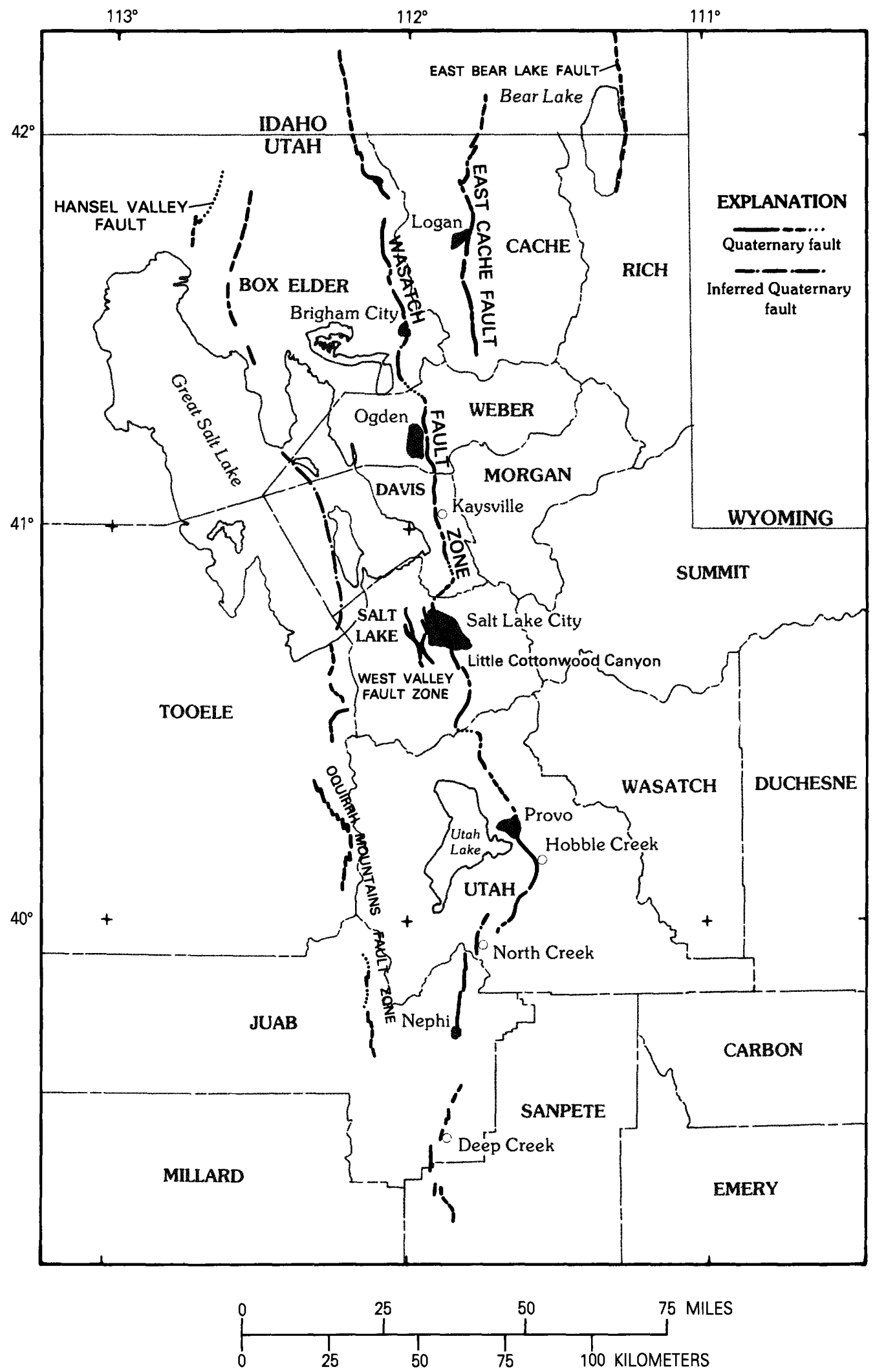

FIGURE 1.-Location of the study area for ground-shaking hazard mapping (shaded regions) and the Quaternary faults modeled in the seismic-hazard analysis. 
values for source geometry, maximum earthquake magnitude, earthquake recurrence rate, characteristics of ground-motion attenuation, and other parameters that are not known with certainty are selected to reflect the best understanding of the available data. The seismic-hazard analysis integrates these data on source characteristics and ground motion attenuation to evaluate the probability of exceeding specified levels of ground motion within designated time intervals. The ground-motion parameters addressed include both horizontal peak acceleration and horizontal spectral acceleration on soil- and rock-site conditions. A principal product of the study consists of maps showing the spatial variation of peak horizontal acceleration levels for three selected levels of probability of exceedance. The uncertainty in the estimated hazard is analyzed and discussed with respect to the uncertainty in the various input parameters and sensitivity to models incorporated in the analysis. These analyses provide a means of evaluating the impact of new information on the results presented in this paper.

\section{ACKNOWLEDGMENTS}

The work presented in this paper was carried out under U.S. Geological Survey (USGS) contracts 14-080001-2194 and 14-08-0001-G1189. The authors wish to thank Walter Arabasz and James Pechmann of the University of Utah, Bernice Bender and Kathie Fraser of the USGS, Ken Campbell of Dames and Moore (Evergreen, Colo.), and Peter Knuepfer of the State University of New York for their helpful review comments. We also appreciate the help of Ethan Brown of the University of Utah in providing the earthquake catalog used in this study and Tony Crone and Michael Machette of the USGS for providing unpublished data for the East Bear Lake fault zone.

\section{APPROACH}

In probabilistic terms, seismic hazard is defined as the likelihood that various levels of ground motion will be exceeded at a site during a specified time period. It is commonly assumed that the occurrence of individual main shocks can be represented as a Poisson process. Following the approach developed by Cornell (1968), the probability that, at a given site, a ground motion parameter $Z$ will exceed a specified level $z$ during a specified time period $t$ is given by the expression

$$
\mathrm{P}(Z>z \mid t)=1-e^{-v(z) \bullet t} \leq v(z) \cdot t
$$

where $v(z)$ is the average frequency during time period $t$ at which the level of ground-motion parameter $Z$ exceeds $z$ at the site resulting from earthquakes on all sources in the region. The inequality at the right of equation 1 is valid regardless of the appropriate probability model for earth- quake occurrence, and $v(z) \bullet t$ provides an accurate and slightly conservative estimate of the hazard for probabilities of 0.1 or less, provided that $v(z)$ is the appropriate value for the time period of interest.

The frequency of exceedance, $v(z)$, is a function of the uncertainty in the time, size and location of future earthquakes and uncertainty in the level of ground motions that they may produce at the site. It is computed by the expression

$$
v(z)=\sum_{n} \alpha_{n}\left(m^{0}\right) \int_{m^{0}}^{m^{u}} \int_{r=0}^{r=\infty} \mathrm{f}(m) \bullet \mathrm{f}(r) \bullet \mathrm{P}(Z>z \mid m, r) \mathrm{d} r \mathrm{~d} m
$$

where $\alpha_{n}\left(m^{0}\right)$ is the frequency of earthquakes on source $n$ above a minimum magnitude of engineering significance, $m^{0} ; f(m)$ is the probability density function for event size between $m^{0}$ and a maximum event size for the source, $m^{u} ; \mathrm{f}(r)$ is the probability density function for distance to the earthquake rupture; and $\mathrm{P}(Z>z \mid m, r)$ is the probability that, given a magnitude $m$ earthquake at a distance $r$ from the site, the ground motion exceeds level $z$.

The probability functions contained in equations 1 and 2 represent the uncertainties inherent in the natural phenomena of earthquake generation and seismic-wave propagation. In the north-central Utah region (as is usually the case in any region), selecting the appropriate models and model parameters required to apply equation 2 involves considerable uncertainty because of limited data and (or) alternative interpretations of the available data. The approach used in this study explicitly incorporates these additional uncertainties into an analysis to assess their impact on the estimate of the expected level of seismic hazard as well as the uncertainty in that estimate.

The uncertainty in modeling natural phenomena is incorporated into the hazard analysis through the use of logic trees. The logic tree formulation for seismic-hazard analysis (Power and others, 1981; Kulkarni and others, 1984; Youngs and others, 1985; Coppersmith and Youngs, 1986; Electric Power Research Institute, 1987) involves specifying discrete alternatives for states of nature or parameter values and specifying the relative likelihood that each discrete alternative is the correct value or state of the input parameter. The relative likelihoods of the different parameter values are typically based on subjective judgment because the available data are too limited to allow an objective statistical analysis.

Figure 2 displays the logic tree representing the seismic-hazard model developed for this study. The logic tree is laid out to provide a logical progression from general aspects or hypotheses regarding the characteristics of seismicity and seismic-wave propagation in the region to specific input parameters for individual faults and fault segments. The rationale for developing the various levels 


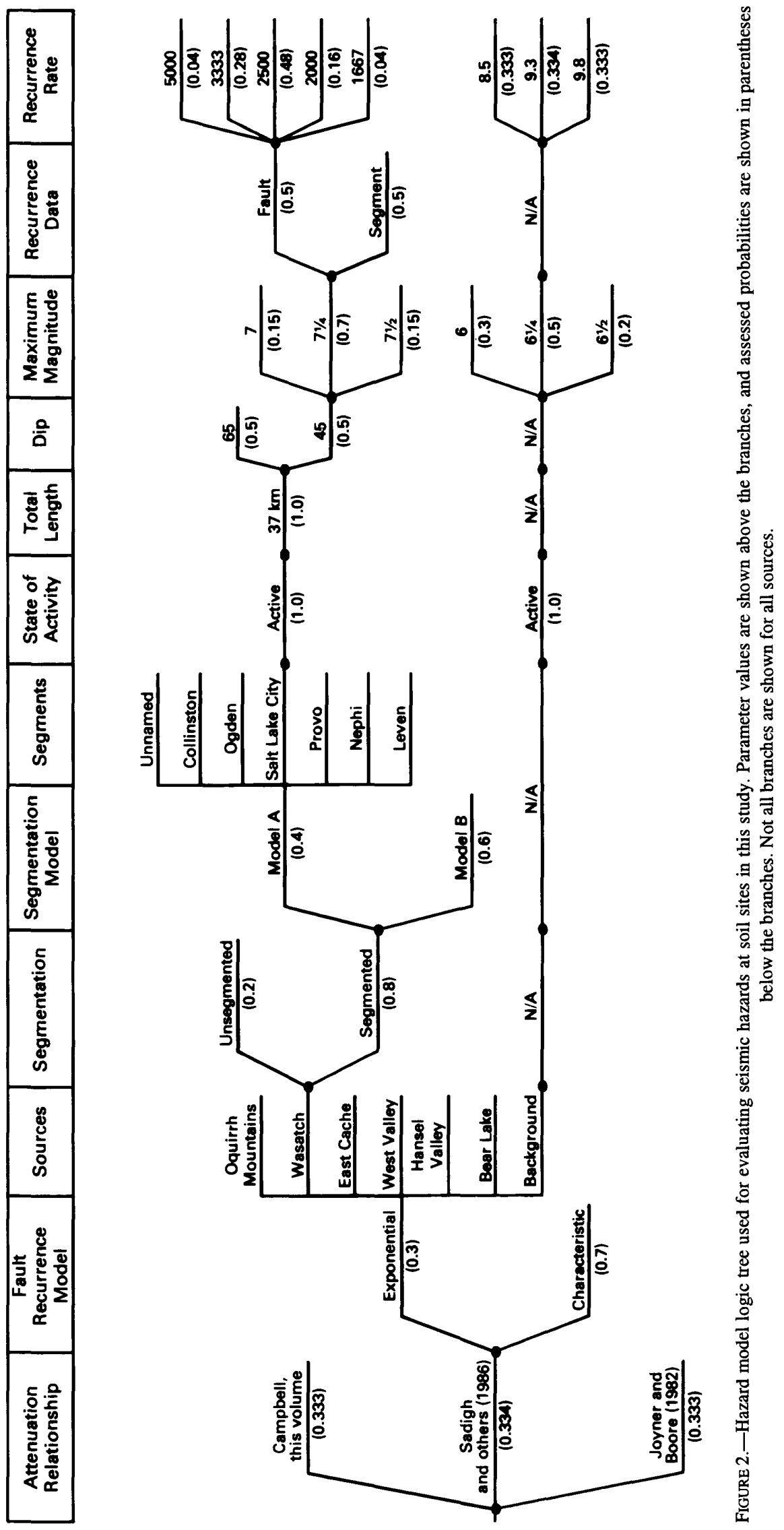


of the logic tree is discussed below. The bases for selecting the parameter values and assigning relative weights are presented in the following sections of this paper.

The first node of the logic tree represents the uncertainty in selecting the appropriate strong-ground-motion attenuation relationship. Attenuation was placed first in the tree because it is felt that a single relationship (whichever relationship may be "correct") is applicable to all earthquake sources in the region. Alternative, recently developed attenuation relationships are used in the analysis. As figure 2 indicates, three attenuation relationships developed for soil-site conditions were used. Four attenuation relationships were used to evaluate peak accelerations for rock-site conditions. Response spectral values were evaluated by using two published relationships for soil sites and two for rock sites.

The second node of the logic tree represents the uncertainty in selecting the appropriate form of the recurrence relationship for modeling the distribution of earthquake size for events occurring on faults. Although the exponential model has been commonly used in hazard analyses, it was derived on the basis of large regional seismicity catalogs (Gutenberg and Richter, 1954). Recent studies (for example, Schwartz and Coppersmith, 1984) suggest that the size distribution for individual faults and fault segments may be better represented by a "characteristic" model that implies more frequent large events than intermediate-sized events. In modeling the magnitudefrequency distribution for the regional background seismicity, only the exponential model is assumed to be applicable.

At this point, the logic tree is expanded into subtrees, one for each of the seismic sources included in the analysis, to model the additive hazard from multiple sources. Seven seisinic sources were included in the analysis. Six sources consist of mapped fault zones having Quaternary displacement that have the potential of generating largemagnitude events (fig. 1). In addition, a regional background zone was included in the analysis to model possible (random) locations for small- to moderate-magnitude events, a reflection of the diffuse zone of seismic activity observed in the region (figs. 3, 4). The historical seismicity and its implications for modeling earthquake occurrence are discussed in following sections. To the right of this node of the logic tree, each source is considered to be acting independently, and the distribution in the total computed hazard is obtained by convolving the independent distributions obtained for each seismic source.

The first two nodes of the logic tree for each fault represent the uncertainty in whether a fault zone is segmented and, if segmented, in choosing the appropriate segmentation model. Segmentation affects both the assessment of maximum earthquake magnitude and the distribution of seismicity along the fault zone. If the fault is segmented, the logic tree is again expanded into subtrees, one for each segment identified for a particular segmentation model. As was the case for the expansion at the seismic source level, each segment is considered to be acting independently, and the distribution in the computed hazard for the fault as a whole is obtained by convolving the independent distributions obtained for each segment.

The remaining nodes of the logic tree for faults address specific parameters used in the hazard computation: whether the fault or fault segment is currently active, affecting whether it contributes to the hazard; uncertainty in the fault geometry in terms of total fault length and fault plane dip, affecting the distribution of distance to fault rupture, the assessment of maximum magnitude, and earthquake recurrence rate based on seismic moment rate; uncertainty in maximum magnitude; and uncertainty in estimating earthquake recurrence. The development of the conditional maximum magnitude distribution incorporates additional variables that are not shown in the overall logic tree of figure 2 . These variables are discussed further in "Seismic Source Characterization" (p. M17).

The logic tree branches shown in figure 2 are representative of the type of input parameters developed at each level for the seven seismic sources. As shown, many of the levels of the logic tree are not applicable to the background zone, and only uncertainty in maximum magnitude and recurrence rate (shown in fig. 2 as the return period for a magnitude 5 or greater event within the zone) is incorporated.

\section{REGIONAL SEISMICITY}

\section{EARTHQUAKE CATALOG}

A comprehensive earthquake catalog for the State of Utah has been developed by researchers at the University of Utah Seismograph Stations. Their published catalog (Richins, 1979) together with recent updates through March 1986 (E. Brown, personal commun., 1986) were utilized in this study. The catalog can be divided into two primary periods of reporting, pre-instrumental and instrumental. The pre-instrumental catalog covers the time period from 1850, when the first newspaper was published in Utah, to July 1962, when the first Statewide seisnograph network was established. The assigned location for most events occurring before 1950 is the population center where the event was most strongly felt, and the location error is estimated to be 25 to $50 \mathrm{~km}$ (Richins, 1979). Nearly all of the magnitudes reported in the catalog for events occurring before July 1962 were obtained from epicentral intensity by using the relationship $\mathrm{M}_{\mathrm{L}}=4_{3} I_{0}+1$ developed by Gutenberg and Richter (1956). Earthquake 


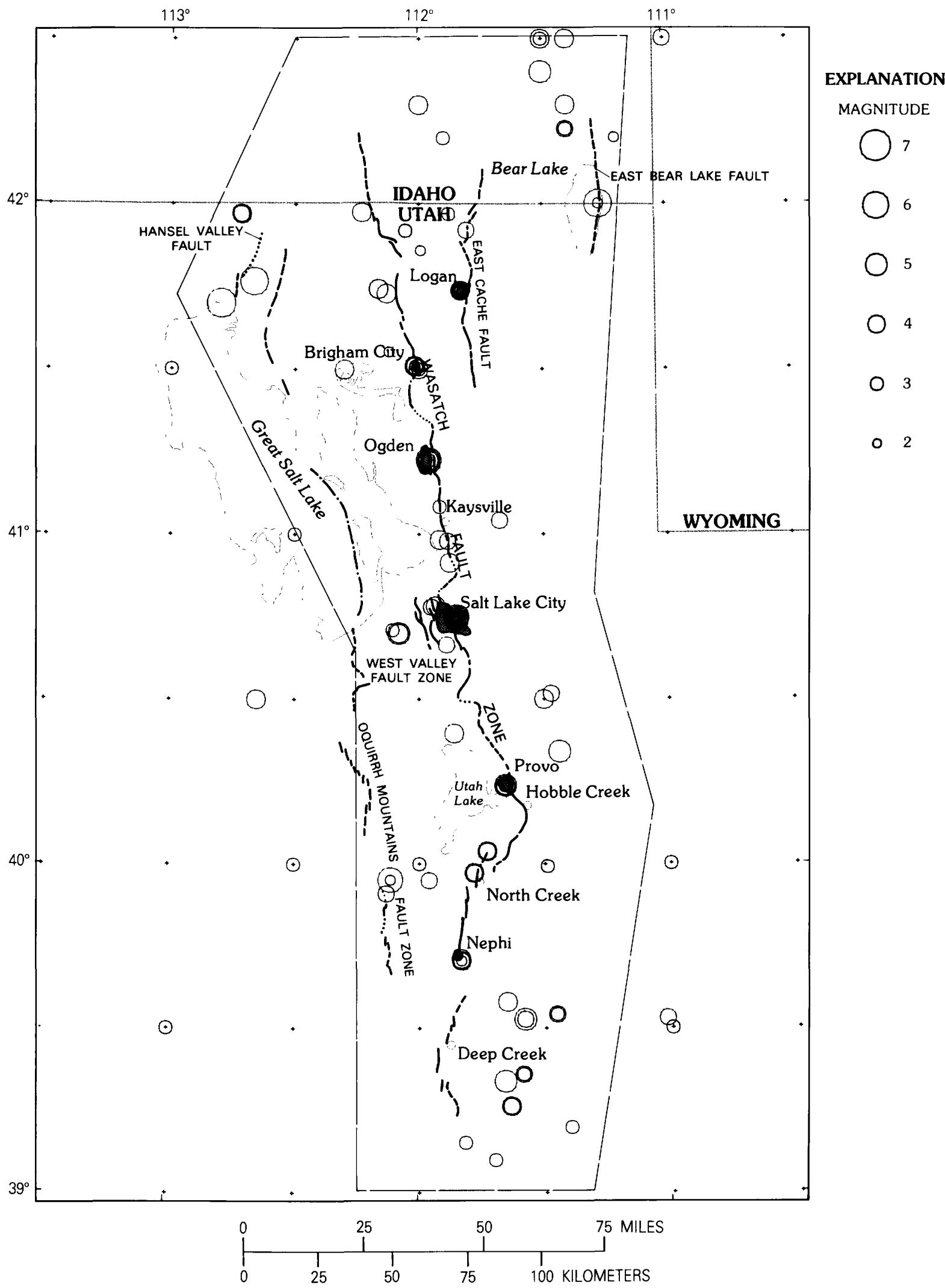

FIGURE 3.-Catalog of independent events of magnitude $M_{L} \geq 2$ occurring prior to July 1,1962 . Magnitudes represent either instrumentally determined values or values obtained from epicentral intensity by using the relationship $M_{L}=2 / 3 I_{0}+1$. Dashed boundary defines limits of background seismic source. 


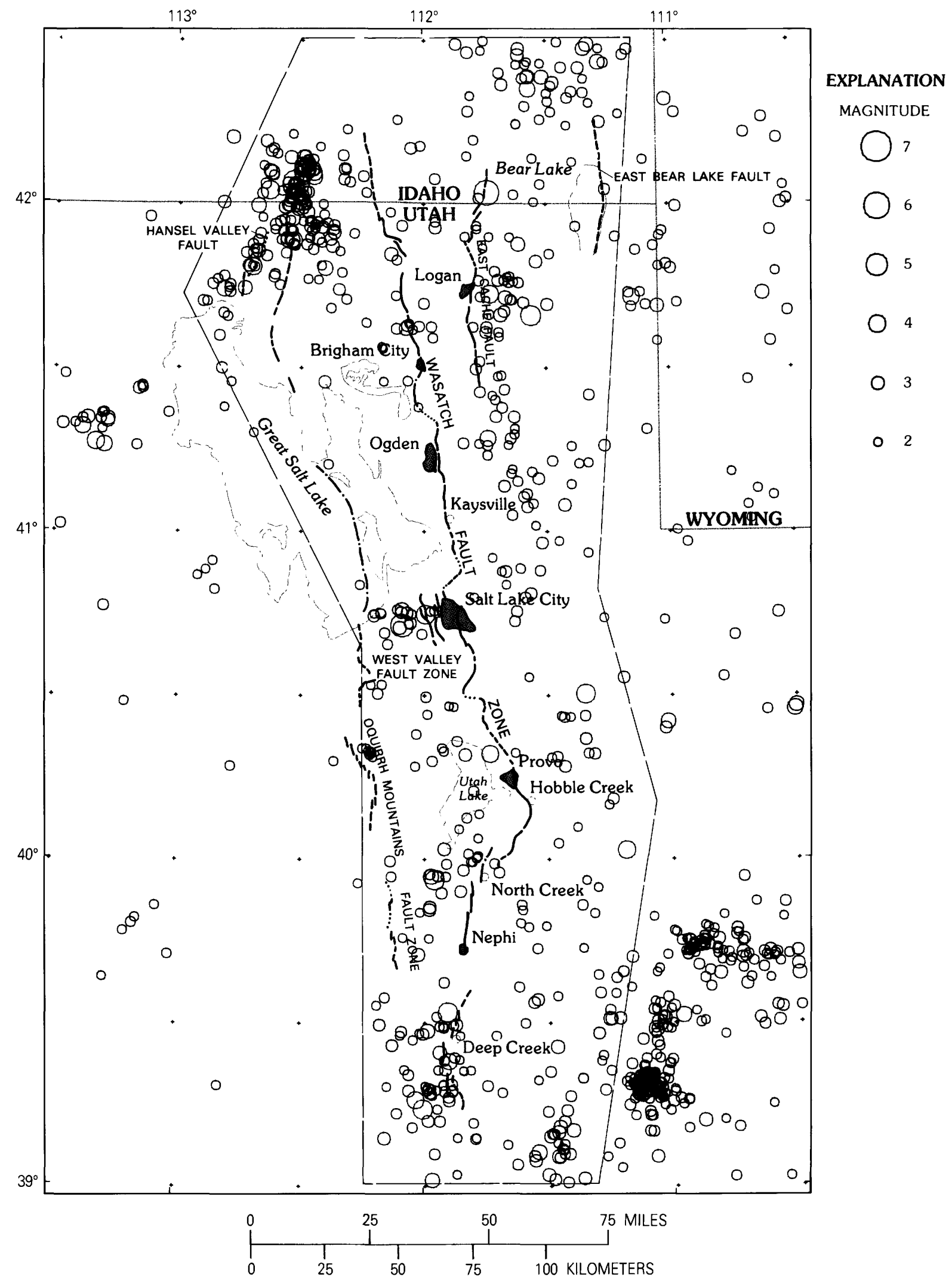

FIGURE 4.-Instrumental catalog of independent events of $M_{L} \geq 2$ occurring etween July 1, 1962, and April 1, 1986. Dashed boundary define limits of background seismic source. 

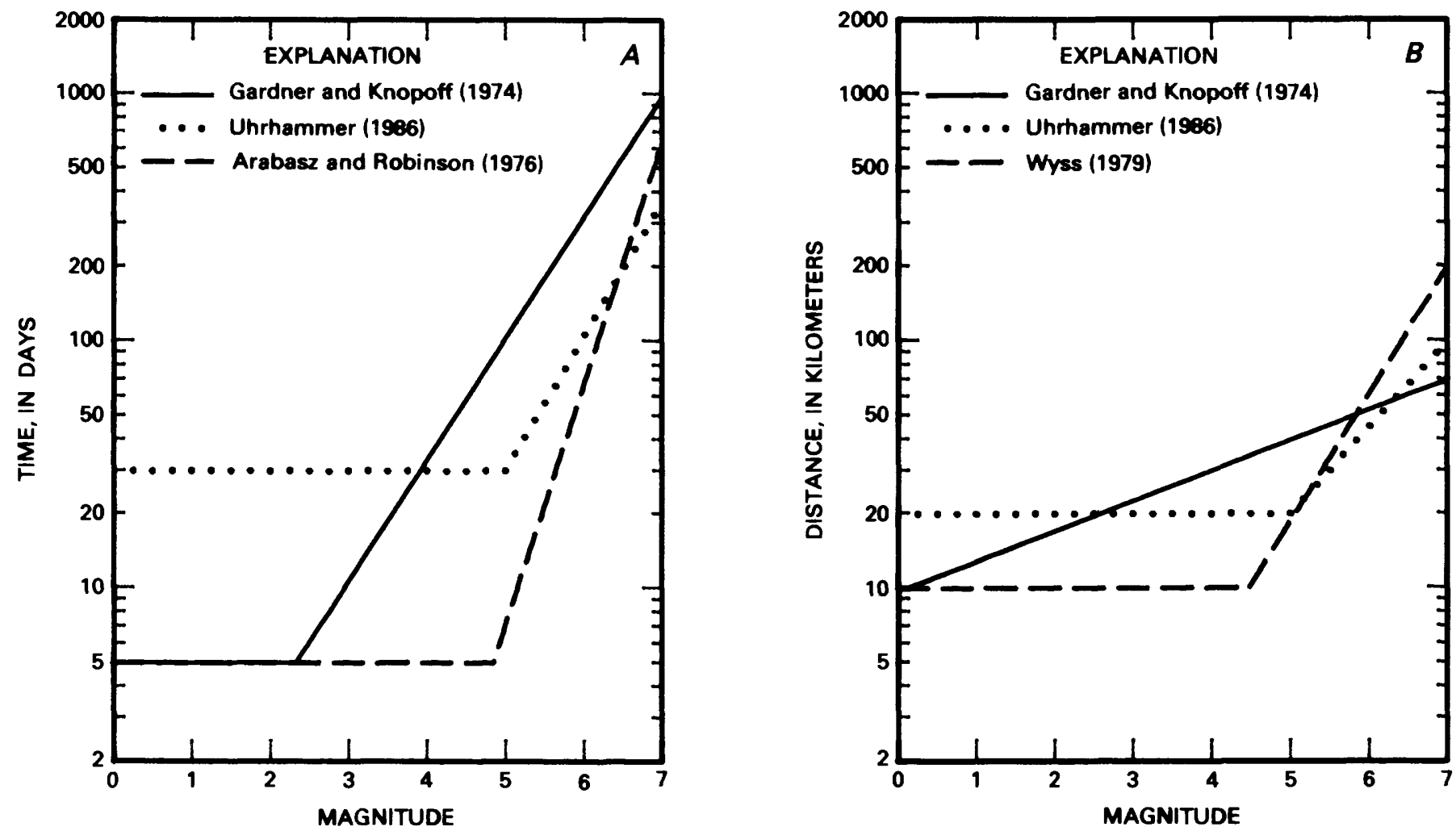

FIGURE 5.-Criteria used for time $(A)$ and distance $(B)$ windows in identifying independent events.

recurrence estimates for the study region were found to be relatively insensitive to the use of other intensity-magnitude conversions. Figure 3 displays the locations of events in the pre-instrumental catalog for the region long $110.5^{\circ}$ to $113.5^{\circ} \mathrm{W}$., lat $39^{\circ}$ to $42.5^{\circ} \mathrm{N}$.

The instrumental catalog used extends from July 1 , 1962 to April 1, 1986. Events occurring in the period July 1962 to October 1974 were located with the focal depth fixed at $7.0 \mathrm{~km}$, and the size of the horizontal error ellipsoid is $10 \mathrm{~km}$ or greater for most of the events (Richins, 1979). From 1974 to 1978, a Statewide telemetered network was deployed, resulting in improved seismic monitoring. The size of the horizontal error ellipsoid for events occurring after 1974 is generally less than $5 \mathrm{~km}$ (Richins, 1979).

The focal depths are less well determined owing to the regional station spacing of the network (Arabasz, 1984). Magnitudes are reported in terms of local magnitude, $\mathrm{M}_{\mathrm{L}}$. Figure 4 displays the locations of earthquakes contained in the instrumental catalog for the region.

\section{IDENTIFICATION OF DEPENDENT EVENTS}

The mathematical formulation used in this (and most) hazard analysis is based on an assessment of the frequency of occurrence of independent earthquakes. It has been shown that the inclusion of dependent events (for example, foreshocks and aftershocks) in the analysis results in only a minor increase in the computed hazard (Mertz and Cornell, 1973; Veneziano and Van Dyck, 1985). For this study, dependent events in the earthquake catalog were identified by the following procedure. The largest event in the catalog was identified, and a spatial and temporal window was specified on the basis of empirical criteria for the size of foreshock-aftershock sequences as a function of earthquake magnitude. All events falling within the window were flagged as dependent events. The next largest unflagged event was then selected, and the process was repeated down to the smallest-magnitude event.

Three sets of empirical criteria for foreshockaftershock sequence size were used: Gardner and Knopoff's (1974) criteria for southern California, Uhrhammer's (1986) criteria for California, and the time window developed by Arabasz and Robinson (1976) from California and New Zealand data combined with a multiple of earthquake rupture size evaluated from data presented by Wyss (1979). These three sets of criteria for window size are shown graphically in figure 5 . The time window for aftershocks was used to identify foreshocks. The three criteria were judged to perform equally well in identifying after- 
shocks because they all (1) identified as dependent events nearly all of the earthquakes labeled as aftershocks by Arabasz and McKee (1979) in the pre-instrumental catalog, (2) yielded instrumental catalogs of independent events that pass the Kolmogorov-Smirnov goodness-of-fit test for a Poisson process at similar levels of significance, and (3) yielded identical catalogs of events of magnitude $\mathrm{M}_{\mathrm{L}} \geq 4$. The number of independent events in the magnitude range of 2 to 4 varies by about 25 percent, depending on which set of window criteria is used. As discussed below, this variation results in differences in the $b$ value computed for the region. The uncertainty in identifying a catalog of independent events was incorporated in the earthquake recurrence estimates used in the hazard analysis. The catalog data shown in figures 3 and 4 are for independent earthquakes of magnitude $M_{L} \geq 2$.

\section{CATALOG COMPLETENESS}

To estimate earthquake recurrence frequencies, one must estimate the time periods over which independent events of various magnitudes can be considered completely reported in the catalog. These time periods were estimated by plotting the observed frequency of occurrence of independent events in different magnitude intervals as a function of time before April 1, 1986, the observed frequency being equal to the number of events observed in the last $T$ years divided by $T$. If it is assuming that the earthquake occurrence rate on a regional scale is stationary in time, then the time when the observed frequency begins to steadily decrease with increasing time represents the date before which the catalog cannot be considered complete. This approach to evaluating catalog completeness is similar to the method proposed by Stepp (1972).

Figure $6 A$ presents a plot of the frequency of earthquakes as a function of time for earthquakes within the region outlined in figures 3 and 4 . This region was defined to encompass the seismic activity along the Intermountain Seismic Belt from lat $39^{\circ}$ to $42.5^{\circ} \mathrm{N}$. The region around Price, Utah (area of concentrated seismicity in the southeastern corner of fig. 4), was excluded because it contains a significant level of mining-induced seismicity (Arabasz, 1984). The events are sorted into magnitude intervals two-thirds of a magnitude unit wide centered on the magnitudes obtained from the Gutenberg and Richter (1956) relationship given above by using unit intensities. The periods of catalog completeness for the study region estimated from the results shown in figure $6 \mathrm{~A}$ are:

\footnotetext{
Magnitude range

$0.7-1.3$

$1.3-4.0$

$4.0-5.3$
}

\author{
Period of completeness \\ Incomplete \\ October 1974-March 1986 \\ January 1938-March 1986
}

The numerical results presented in figure $6 \mathrm{~A}$ do not lend themselves to precise estimates of periods of completeness. The dates tabulated above were selected to correspond with known major changes in seismicity reporting in the Utah region: the initial operation of a telemetered network in October 1974 and the development of a cooperative agreement between the University of Utah and the U.S. Coast and Geodetic Survey (now the National Ocean Survey) for routine transmission of seismographic information in 1938 (Arabasz, 1979). For earthquakes larger than magnitude $\mathrm{M}_{\mathrm{L}} 5.3$ (epicentral intensity VII or greater), there are too few events to make an estimate of completeness by using the above method, so the completeness periods estimated by Arabasz (1979) for events of intensity VII (1875) and for events of intensity VIII (1850) were used in the analysis. These dates correspond to the start of the Townley and Allen (1939) catalog for Utah in 1875 and the first routinely published newspaper in 1850.

Figure $6 B$ shows cumulative annual frequencies based on the data in figure $6 \mathrm{~A}$ for periods of complete reporting. The error bars represent 16th- to 84th-percentile cumulative rates computed by using the formulation given by Weichert (1980). The data indicate that there may not be complete reporting at present for events smaller than magnitude 2.0. The regional $b$ value for independent events computed by using the Weichert (1980) maximum likelihood technique ranges from $0.75( \pm 0.03)$ to $0.83( \pm 0.03)$, depending on the choice of aftershock window criteria. Within the zone outlined in figure 4 , the frequency of events of magnitude $M_{L} 4$ or larger is one event every 1.3 years.

\section{SEISMIC SOURCE CHARACTERIZATION}

Active Quaternary faults along the Wasatch fault and in the adjacent areas have long been recognized as potential earthquakes sources (for example, Gilbert, 1890). Numerous studies have been made in recent years to identify the locations of and assess the seismic potential of faults having Quaternary displacement in the study area. At a regional scale, the concentration of earthquakes in the Intermountain Seismic Belt appears to align with the Quaternary active faults (fig. 4), but, when examined in detail, many of the small- to moderate-magnitude events cannot be directly associated with mapped Quaternary faults (Arabasz and others, 1980; Arabasz, 1984). It should be noted that the apparent concentration of historical seismicity along the Wasatch fault indicated in figure 3 reflects the fact that noninstrumental epicenters were assigned to the location reporting the strongest felt effects and that the established communities are concentrated along the Wasatch Front (Arabasz and others, 1980). 

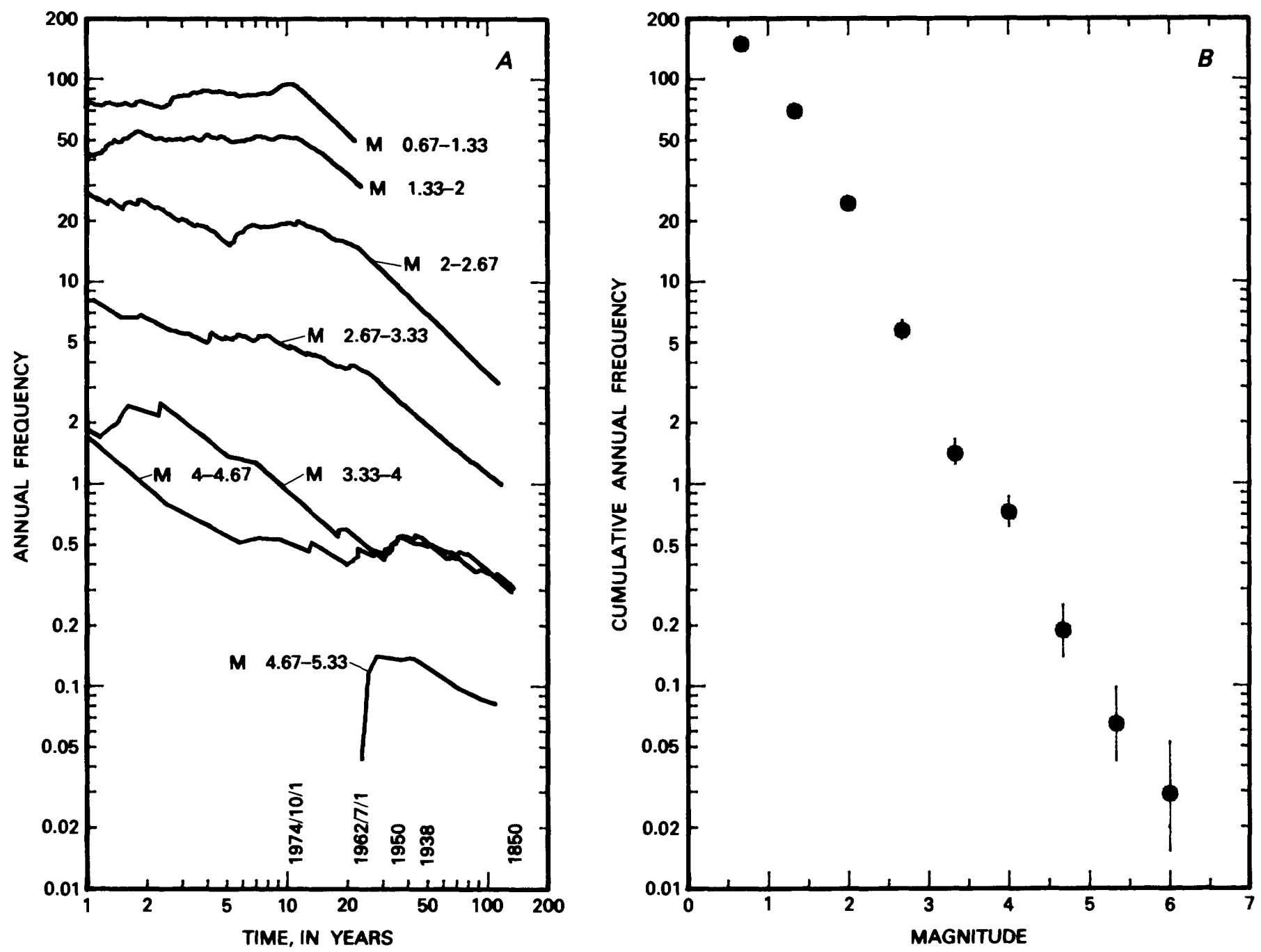

FIGURE 6.-Estimates of catalog completeness and regional recurrence for north-central Utah. $A$, Curves showing the frequency of occurrence for events in different magnitude intervals as a function of time prior to April 1, 1986. B. Cumulative event frequencies obtained for the periods of completeness indicated in $A$. The vertical line denotes the 68-percent confidence interval (16th-84th percentile) on the cumulative frequency.

The lack of signature of the Quaternary faults in the instrumental seismicity is illustrated in figure 7. Shown are approximately east-west cross sections of the instrumental seismicity recorded in the period October 1974 to April 1986. In each cross section, the events occurring along the length of one of the segments of the Wasatch fault identified by Schwartz and Coppersmith (1984) are projected onto a plane normal to the fault trace. The locations and estimated range of dips of the identified Quaternary faults are shown, the Wasatch fault being located at distance zero in the plots. As can be seen, there is a poor correlation of instrumental seismicity with the identified faults.

Because of the poor correlation of smaller magnitude seismicity with mapped Quaternary surface faulting, two types of earthquake sources are included in the seismichazard model: fault-specific sources representing the mapped active faults that may be the source of moderateto large-magnitude earthquakes $\left(\mathrm{M}_{\mathrm{L}} \geq 6\right)$ and an area source that models the background seismicity of smaller magnitude earthquakes that may be occurring on unknown faults or faults that are not mapped as active in the Quaternary. On the fault-specific sources, only the occurrence of events of magnitude 6 or larger was modeled. Although smaller magnitude events may also occur on the mapped active faults, they do not appear to occur with a frequency discernible from the background rate. Therefore, the background source was used to model the occurrence of all smaller magnitude events. 

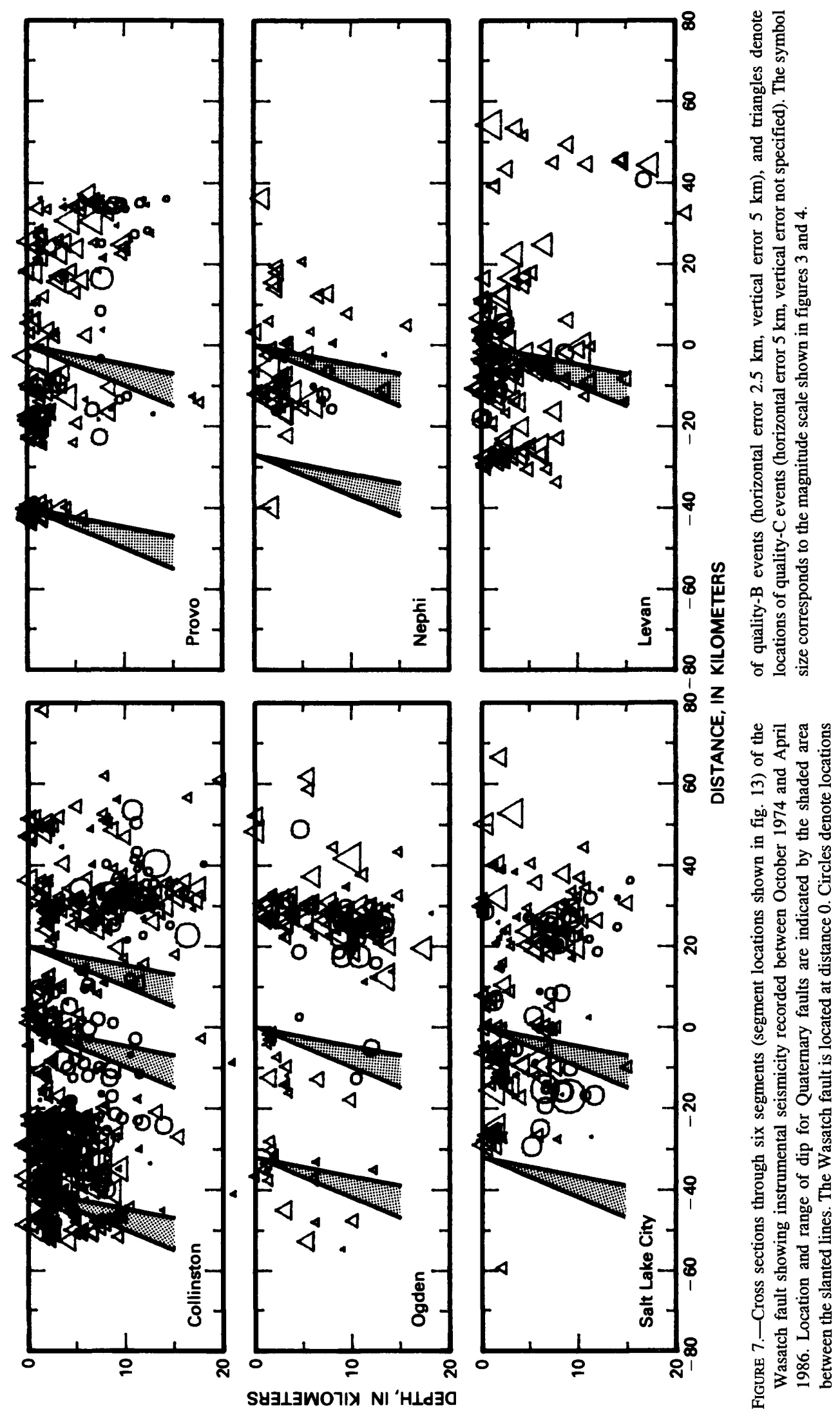


\section{AREA SOURCE MODEL FOR BACKGROUND SEISMICITY}

Conceivably, there could be many faults within the region capable of generating small to moderate earthquakes that do not rupture to the surface. For this analysis, the spatial distribution of future small- to moderatemagnitude seismicity is assumed to be uniform within the zone outlined in figures 3 and 4 . Seismicity occurring in areas to the east and west of the source zone shown in figures 3 and 4 was not modeled in the analysis, because small to moderate earthquakes occurring in these areas would be too far from the study area defined in figure 1 to contribute significantly to the ground-shaking hazard.

The maximum magnitude for events in the background zone is constrained by the threshold for surfacefaulting events, which has typically been considered to be about magnitude 6 to $61 / 2$. Surface faulting was reported for the $1934 \mathrm{M}_{\mathrm{L}} 6.6$ Hansel Valley earthquake, whereas no surface faulting was found for the $1962 \mathrm{M}_{\mathrm{L}} 5.7$ Cache Valley and $1975 \mathrm{M}_{\mathrm{L}} 6.0$ Pocatello Valley earthquakes. It is very unlikely that there are faults along the Wasatch Front long enough to generate earthquakes larger than about magnitude $6 \frac{1}{2}$ that have not been mapped. Accordingly, the maximum magnitude for events in the background source was judged to lie in the range of 6 to $6 \frac{1}{2}$. The maximum magnitude and assigned weights are magnitude 6 (0.3), magnitude $6 \frac{1}{4}(0.5)$, and magnitude $6 \frac{1}{2} 2(0.2)$.

Earthquake recurrence for the background zone was based on the recorded seismicity located within the zone shown in figures 3 and 4 . As discussed previously, the three different criteria used to identify aftershocks in the catalog resulted in a variation of about 25 percent in the number of events of magnitude 2 to 4 . Figure $8 A$ shows the cumulative frequency plot for the three catalogs of independent events and the associated recurrence relationships obtained by using Weichert's (1980) maximum likelihood technique. The three recurrence curves shown in figure $8 \mathrm{~A}$ were used in the hazard analysis with equal weight. The mean annual frequency of events of magnitude $\mathrm{M}_{\mathrm{L}} \geq 5$ ranges from 0.10 to 0.12 and has associated $b$ values of 0.75 to 0.83 . The uncertainty in the regional recurrence estimates was incorporated into the analysis by constructing a joint distribution for cumulative earthquake frequency and $b$ value using relative likelihoods for various parameter combinations (for example, Bender, 1983). Figure $8 B$ shows the resulting 90-percent confidence interval estimates of earthquake recurrence utilizing the joint distributions of recurrence relationship parameters.

\section{QUATERNARY FAULTING}

The major faults having Quaternary displacement in the region that are close enough to the study area to be significant to the seismic-hazard evaluation of the study area are shown in figure 1 . These faults include the Wasatch fault zone; a discontinuous zone of faults along the western side of the East Tintic and Oquirrh Mountains, referred to here as the Oquirrh Mountains fault zone; the East Cache fault; the West Valley fault zone; the Hansel Valley fault; and the East Bear Lake fault. The Quaternary active back-valley faults east of the Wasatch, such as the Strawberry Valley fault, are not specifically included in the seismic source model because of their distances from urban areas and their low recurrence rates (Nelson and Van Arsdale, 1986).

Fault-specific parameters that can significantly affect seismic hazard are shown in the overall logic tree for the study in figure 2. Certain elements of the seismic-hazard logic tree are common to all the faults, either because all the faults are believed to have certain characteristics that are shared in common or because, for some characteristics (for example, dip and maximum depth of faulting), there are insufficient data to discriminate among the different faults. Elements that are common for all the faults include the form of earthquake magnitude distribution and the methods used to assess recurrence; whether a fault consists of separate segments; fault dip and maximum depth of rupture; and the techniques used to assess maximum earthquake magnitude. These factors are discussed below.

\section{EARTHQUAKE MAGNITUDE DISTRIBUTION AND RECURRENCE ASSESSMENT}

Although the exponential magnitude distribution generally fits regional seismicity data, as the data in figure $6 B$ show, recent studies (for example, Schwartz and Coppersmith, 1984) have suggested that the magnitude distribution for individual faults and fault segments may be better represented by a "characteristic" size implying that large events are relatively more frequent than intermediate-sized events. The characteristic model of Schwartz and Coppersmith (1984) was developed on the basis of data from the Wasatch fault zone and the San Andreas fault in California. For this study, both the exponential magnitude distribution and the characteristic magnitude distribution-the latter as developed by Youngs and Coppersmith $(1985 \mathrm{a}, \mathrm{b})$-were used to model earthquake recurrence for the faults. The characteristic model was favored over the exponential model (probability 0.7 versus 0.3 ) because comparisons of the geologic and seismicity data from the Wasatch fault zone originally formed the basis for the model.

Recurrence estimates for the fault-specific sources were based on two approaches. Where displacement data for individual past events were available, they were used to estimate the recurrence rate for the characteristic or 


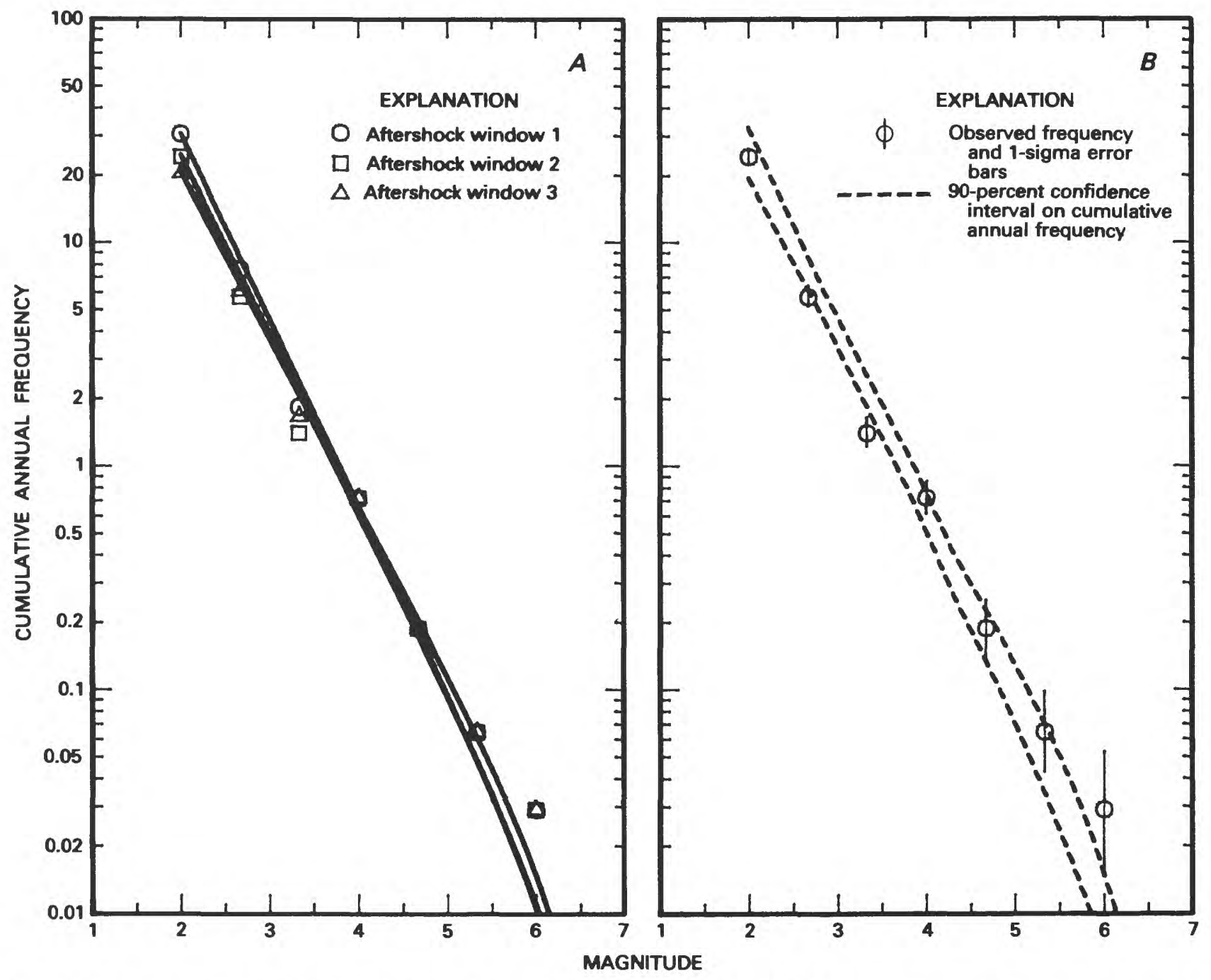

FIGURE 8.-Recurrence estimates for background seismicity source delineated in figures 3 and 4 . A, Recurrence relationships resulting from use of the three aftershock window criteria shown in figure 5. B,90-percent confidence interval, including uncertainty in cumulative frequency and $b$ value.

maximum event, and the form of the characteristic or exponential magnitude distribution was used to define the frequency of events down to magnitude 6.0 . If only slip rate data were available for a fault or fault segment, then a moment rate approach was used, the seismicity rate being defined by the relationship given by Anderson (1979) for the exponential model and by the relationship given by Youngs and Coppersmith (1985a, b) for the characteristic model. In these approaches, the recurrence estimates for individual faults are anchored to the mean repeat times of the largest events estimated from geological evidence rather than from an extrapolation of the observed frequency of small events. The geologically based estimates of recurrence of large-magnitude events are considered more reliable than the extrapolation of small-magnitude seismicity rates because of the difficulty in attributing seismicity to specific faults.
In applying Youngs and Coppersmith's (1985a, b) characteristic magnitude distribution, the maximum magnitude assessed for the fault, $m_{\max }$ is taken to be the expected magnitude for the characteristic size event, individual events being uniformly distributed in the range of $m_{\max } \pm 1 / 4$ magnitude units. The cumulative frequency for earthquakes of magnitude $m_{\max }-1 / 4$ is then set equal to the annual frequency of maximum events assessed for the fault, and the upper bound magnitude, $m^{u}$, in equation 2 is equal to $m_{\max }+1 / 4$. To provide a consistent interpretation for the exponential model, the standard truncated exponential distribution (Cornell and Van Marke, 1969) was modified to treat the upper bound magnitude in the density function as uniformly distributed over the range of $m_{\max } \pm 1 / 4$ magnitude units. The effect is to smear out the upper boundary of the magnitude distribution without altering the general shape of the recurrence relationship. 


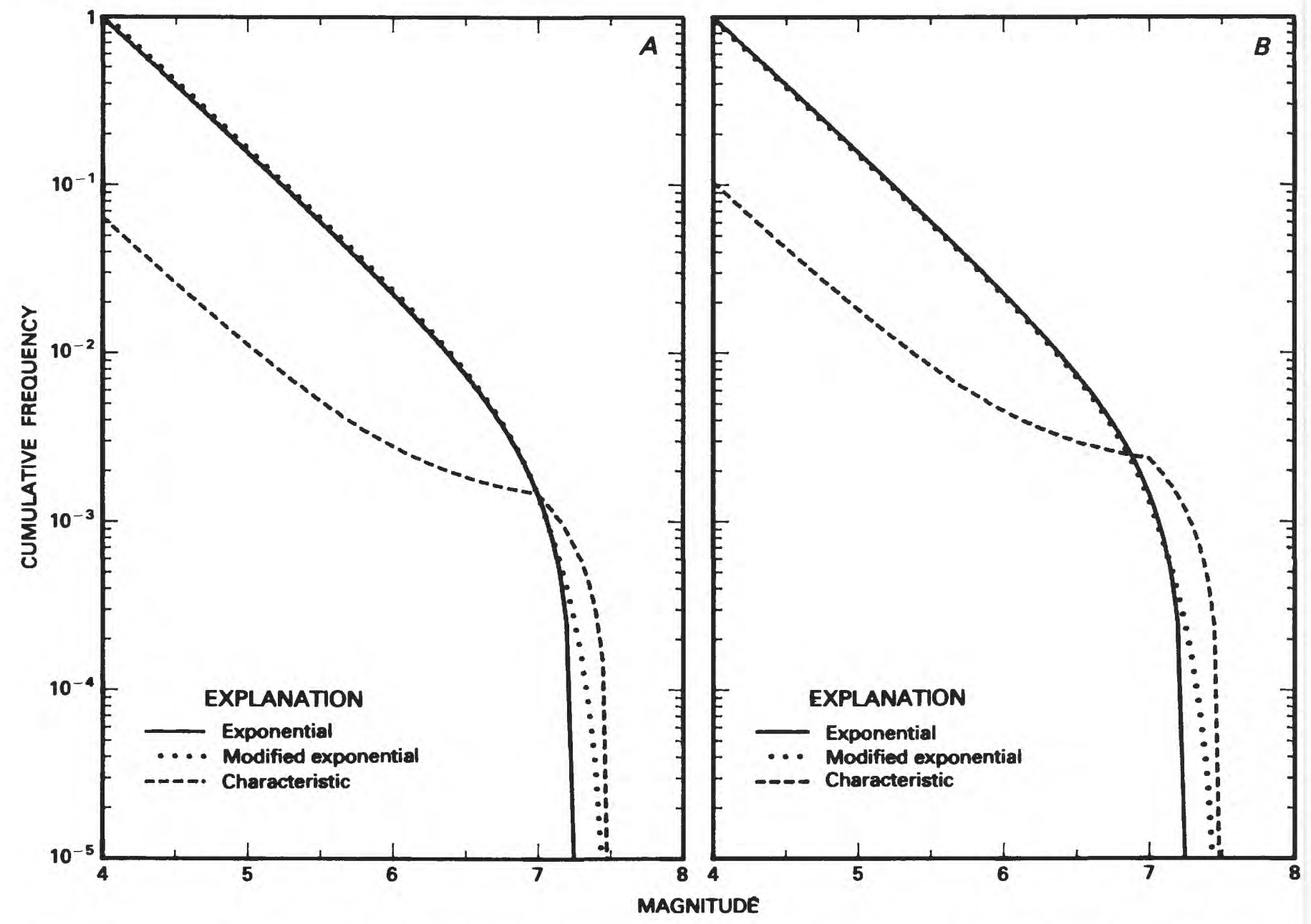

FIGURE 9.-Comparison of recurrence models used in the analysis for $(A)$ equal recurrence rate of maximum events $(M \geq 7)$ and $(B)$ equal rate of seismic moment release. Curves are constructed by using a $b$ value of 0.8 .

The cumulative frequency for earthquakes of magnitude $m_{\max }-1 / 4$ is again set equal to the annual frequency of maximum events assessed for the fault and the upper bound magnitude, $m^{u}$, is equal to $m_{\max }+1 / 4$. In this modified form, the distribution of events in the range $m_{\max } \pm 1 / 4$ remains nearly exponential.

Figure 9 compares the shape of the exponential, modified exponential, and characteristic magnitude distributions. Figure $9 \mathrm{~A}$ shows the three distributions developed for an assessed fault $m_{\max }$ of 7.25 , the frequency of events larger than magnitude 7 being held constant in all three models. Figure $9 B$ shows the magnitude distributions developed on the basis of equal rate of seismic moment release. As can be seen, the modified exponential distribution is essentially equal to the exponential distribution except at the upper bound. The characteristic magnitude distribution results in about a factor of 10 reduction in the frequency of small-magnitude events in comparison with the exponential model when the abso- lute level of the distribution is fixed by either the frequency of the largest events or by the rate of moment release.

Application of the two models requires specification of a $b$ value for the fault in order to be able to define the frequency of smaller magnitude events. Figure 10 presents frequency data for independent events from a 15$\mathrm{km}$-wide corridor representing the surface projection of the west-dipping Wasatch fault between lat $40^{\circ}$ and $41.5^{\circ}$ N., which encompasses the more active central portion of the fault zone. The earthquake frequencies for the smallmagnitude events are based on instrumental seismicity, and the frequency of large-magnitude events is based on the paleoseismic data described later in this paper. In figure 10A, characteristic and exponential magnitude distributions are anchored to the frequency of large-magnitude events and then extended to smaller magnitudes by using the $b$ value of 0.8 obtained for the regional seismicity. As can be seen, the frequency of smaller magnitude events 


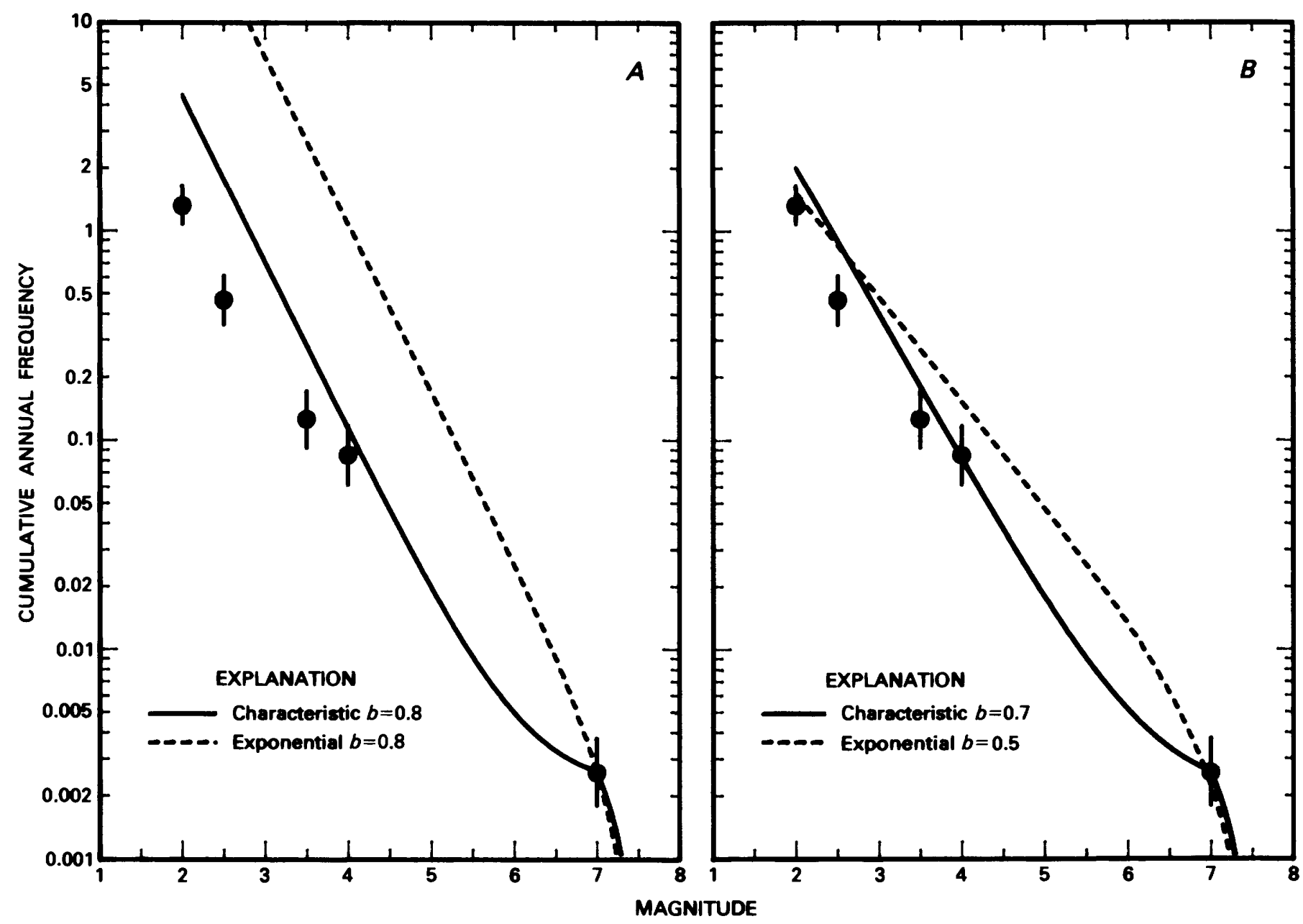

FIGURE 10.-Wasatch fault-specific $b$ values. $A$, Recurrence curves using regional $b$ values. $B$, Recurrence curves using selected fault-specific $b$ values. In modeling the fault-specific sources for the hazard analysis, only events of magnitude greater than 6 are modeled; smaller events occur in the background source. Solid circles show the earthquake frequencies and their 1- $\sigma$ error bars.

that may be occurring on the fault is overestimated, especially by the exponential model. To provide more reasonable estimates of the frequency of smaller magnitude events occurring on the faults, fault-specific $b$ values were developed. Figure $10 B$ shows that the recurrence curves obtained by using a $b$ value of 0.7 with the characteristic model and a $b$ value of 0.5 with the exponential model provide a much better fit to the observed frequencies of small magnitude events. These two fault-specific $b$ values were used to model earthquake recurrence for all of the fault-specific sources. As discussed above, only the faultspecific recurrence estimates for events of magnitude 6 or greater are included in the analysis.

Use of the moment rate approach requires a relationship between earthquake magnitude and seismic moment. Doser and Smith (1982) analyzed the relationship between seismic moment and magnitude for the Utah region and concluded that the relationship was signifi- cantly different from that developed for California earthquakes. Doser and Smith's preferred relationship estimates seismic moment, $M_{o}$, as a function of $\mathrm{M}_{\mathrm{L}}$ magnitude and was developed on the basis of events of $M_{L}$ magnitude 3.7 to 6.0 . This study requires a seismic momentmagnitude relationship applicable to events as large as $\mathrm{M}_{\mathrm{S}} 73 / 4$ and consistent with the attenuation relationships used in the hazard analysis. These relationships were derived largely on the basis of strong-motion data from California, where the moment magnitude scale as defined by Hanks and Kanamori (1979) is equivalent to $\mathrm{M}_{\mathrm{L}}$ in the range of 3 to 7 and equivalent to $M_{S}$ in the range of 5 to 7.5. To apply these relationships in Utah, we have made the assumption that ground motions are more directly correlated with magnitude than with seismic moment. This assumption is supported by the theoretical model of ground motion developed by Hanks and McGuire (1981) in which ground-motion levels are fixed by both seismic 
moment and stress drop. Boore (1983) has shown that this model can be used to simulate the characteristics of both strong-motion attenuation and measurement of $\mathrm{M}_{\mathrm{L}}$ in California. Regional differences in the seismic moment and stress drop thus should have similar effects on strong ground motion and on measured magnitude. We have made the assumption that events having similar measured magnitudes in Utah and California will have similar levels of strong ground motion, although the total seismic moment release may be different in the two regions.

For this study, we have developed a modified form of the Doser and Smith relationship by including data for large $\mathrm{M}_{\mathrm{S}}$ magnitude events reported by Doser and Smith (1982) and by Doser (1984). These events include the 1959 Hebgen Lake and 1983 Borah Peak earthquakes. The resulting data set is plotted in figure 11. A least-squares fit to the data yields the relationship $\log \left(M_{o}\right)=1.04 M+18.8$, which is only slightly different from Doser and Smith's (1982) preferred relationship. This modified Doser-Smith relationship was used for all moment-rate-constrained recurrence estimates.

Also shown in figure 11 for comparison is the relationship proposed by Hanks and Kanamori (1979), which clearly does not fit the trend of the data. Because the Hanks and Kanamori relationship predicts larger seismic moments for earthquakes of magnitude 6 or greater, its use would result in somewhat lower earthquake frequencies estimated on the basis of the moment rate approach.

Application of the moment rate approach requires an estimate of the average slip rate for the fault or fault segment. Slip rates estimated from data for a single location or only a few locations may not reflect the average slip rate along the entire fault because the locations selected for detailed study are usually where the fault is well expressed topographically; hence, these locations may represent points where the slip rate is somewhat greater than the average over the whole fault or segment length. Accordingly, the distributions of possible values of the average slip rate assessed for the faults reflect the uncertainty in the point estimates of slip rate together with a possible bias in the point estimate. The amount of possible bias was judged to range from 1.0 (no bias) to 0.5 (point estimate twice the average rate), the expected amount of bias in the point estimates being set to 0.8 .

\section{UNSEGMENTED VERSUS SEGMENTED FAULT-RUPTURE MODEL}

The formulation used in this study (and in most other seismic hazard analyses) treats the location of future earthquake rupture on a seismic source as a random process, usually a uniform distribution. For fault zones modeled as a single fault-specific source, this formulation would result in earthquake ruptures uniformly distributed

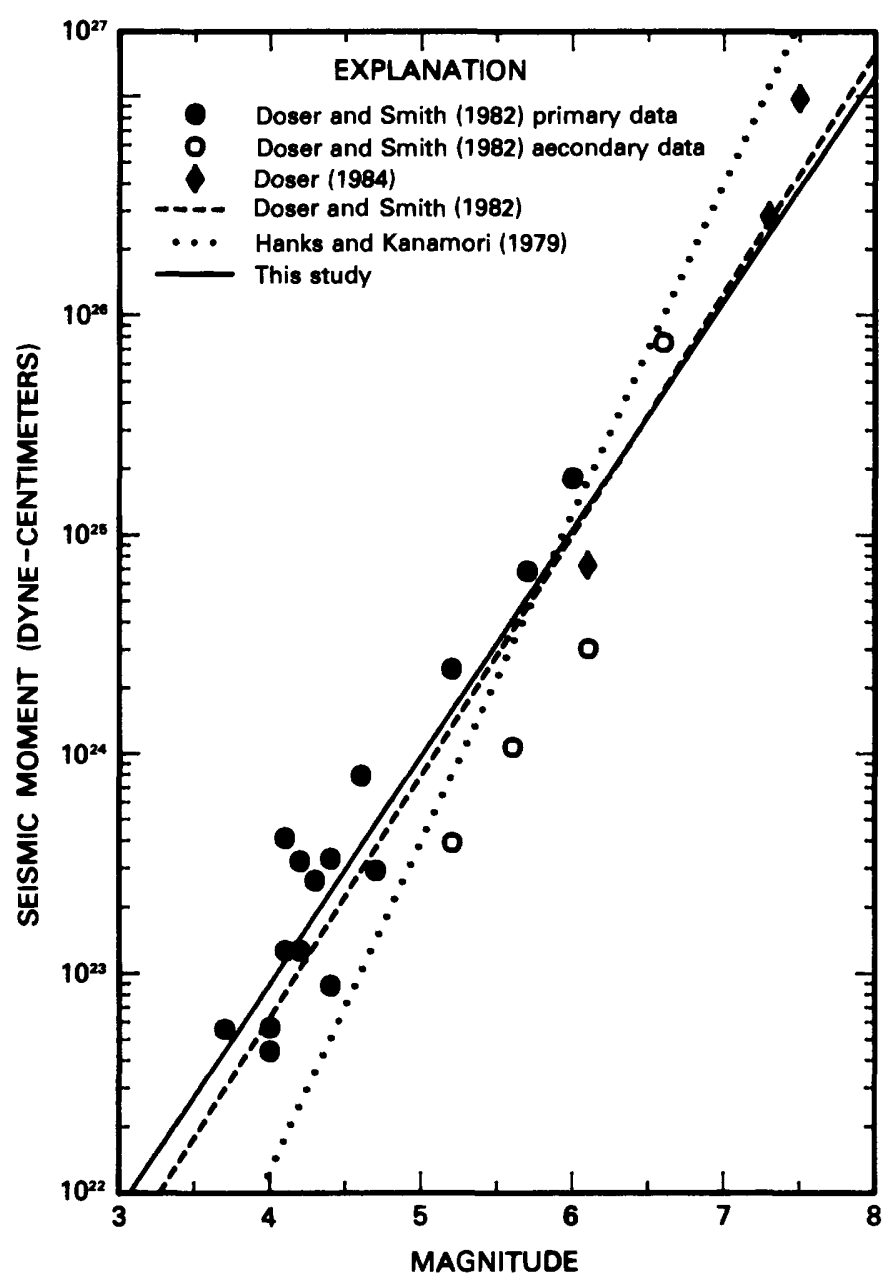

FIGURE 11.-Relationship between seismic moment and earthquake magnitude. "Primary data" are data used by Doser and Smith (1982) to develop their preferred relationship, shown in the figure.

along the length of the fault. However, on the basis of the results of paleoseismic investigations, Schwartz and Coppersmith (1984) proposed that faults may consist of separate segments that appear to rupture completely and independently during successive earthquakes of characteristic sizes, implying that the individual segments of a fault should be modeled as separate sources in the hazard analysis. The segmentation model not only affects the distribution of ruptures along the fault, it also provides constraints on the maximum rupture length and, therefore, on maximum earthquake magnitude and may also affect recurrence estimates.

Convincing arguments supporting fault segmentation have been presented by Schwartz and Coppersmith (1984, 1986), Aki $(1979,1984)$ and Slemmons and Depolo (1986). Studies by several investigators (Schwartz and Coppersmith, 1984; Mayer and MacLean, 1986; Machette and others, 1986; Personius, 1986) report evidence for distinct 
segments along the Wasatch fault zone. However, detailed analysis of some historical surface-faulting earthquakes suggests that faulting can rupture across and (or) skip over barriers between adjacent segments. For example, the October 10, 1980, El Asnam, Algeria, earthquake appears to have been produced by rupture of two or three adjacent segments (Deschamps and others, 1982; King and Yielding, 1984). Similarly, surface faulting during the October 28, 1983, Borah Peak, Idaho, earthquake ruptured across the bedrock hills east of Willow Creek Summit, which may represent a major segment boundary along the Lost River fault separating the Warm Springs Valley segment from the Thousand Springs Valley segment (Crone and Machette, 1984).

To account for the uncertainty in fault-rupture behavior, both an unsegmented model and a segmented model were included for each fault. The unsegmented model allows for rupture across the segment boundaries during events and for the simultaneous rupture of two or more adjacent segments. Rupture during successive earthquakes is assumed to be uniformly distributed along the entire length of the fault zone, and the maximum length of rupture is not necessarily constrained by boundaries between segments. The segmented model assumes that rupture will not occur across the segment boundaries and that the segments behave independently, the maximum length of rupture on a given segment being equal to the segment length. The results of paleoseismic investigations indicate that the segmented fault model is more representative of the fault-rupture behavior of normal-slip Basin and Range faults. Accordingly, the unsegmented and segmented conditions for all the faults are assigned weights of 0.2 and 0.8 , respectively. For the Wasatch fault zone, two segmented fault models are included to account for uncertainty in the actual number of segments, as discussed later.

\section{FAULT DIP AND DEPTH}

The downdip geometry of the fault plane affects the seismic-hazard computation in several ways. For nearby faults, it can affect distribution for distance to earthquake rupture. It is a factor in determining fault-rupture area used in the assessment of maximum earthquake magnitudes and earthquake recurrence estimates based on seismic moment rate.

All the faults included in the seismic source model are high-angle normal faults. There are insufficient data on the downdip geometry of these faults to discriminate among them. Therefore, the downdip geometry is treated the same way for all the faults.

Nearly all the microseismicity along the Wasatch Front occurs at depths of about $15 \mathrm{~km}$ or less (fig. 7). On the basis of microseismicity and aftershock data, the July 6 , 1954, Fallon Stillwater, Nev., earthquake $\left(M_{S} 7.1\right)$, the August 18, 1959, Hebgen Lake, Mont., earthquake ( $\mathrm{M}_{\mathrm{S}}$ 7.5), and the October 28, 1983, Borah Peak, Idaho, earthquake $\left(M_{S} 7.3\right)$ are all interpreted to have occurred on $45^{\circ}$ to $65^{\circ}$-dipping normal faults that nucleated at depths of about $15 \mathrm{~km}$ (Smith and others, 1985). Accordingly, all faults are assumed to have dips ranging between $45^{\circ}$ and $65^{\circ}$, a maximum depth being $15 \mathrm{~km}$. In the analysis, dips of $45^{\circ}$ and $65^{\circ}$ were used with equal likelihood.

\section{MAXIMUM EARTHQUAKE MAGNITUDE ASSESSMENT TECHNIQUES}

Maximum earthquake magnitudes for the fault-specific sources are assessed by estimating the physical parameters of length, area, and displacement for the maximum-size event and then relating these parameters to earthquake magnitude by using published correlations for magnitude as a function of rupture length $R L$ [Slemmons (1982), $\mathrm{M}_{\mathrm{S}}=0.819+1.341 \log _{10}$ ( $R L$ in meters); Bonilla and others (1984), $\mathrm{M}_{\mathrm{S}}=5.171 .237 \log _{10}(R L$ in kilometers)], rupture area $R A$, [Wyss (1979), $\mathrm{M}_{S}=4.15+\log _{10}(R A$ in square kilometers)], and seismic moment. The relationship used to estimate magnitude from seismic moment, $M_{0}$, was developed by utilizing the data presented by Doser and Smith (1982) and Doser (1984) and shown in figure 11. A least-squares fit to the data shown in figure 11 yielded the relationship $M=-16.22+0.885 \log _{10}\left(M_{O}\right.$ in dyne-cm) where $M$ is assumed to be equivalent to $M_{L}$ in the range of 3 to 7 and $M_{S}$ in the range of 5 to 7.5. The distribution of possible values for the physical parameters of maximum rupture length, maximum rupture area, and average displacement in a maximum event are developed by extending the logic tree formulation shown in figure 2 .

Completion of the assessment of maximum magnitude requires selection of the appropriate relationship between rupture parameters for a maximum event and earthquake magnitude. The relative weights assigned to the various techniques used to estimate the maximum earthquake magnitude for each fault and fault segment are illustrated in figure 12. Where three techniques (that is, length versus magnitude, area versus magnitude, and moment versus magnitude) could be used, the greatest weight, 0.5 , is assigned to magnitudes based on seismic moment because this relationship incorporates essentially all the physical factors controlling earthquake size (fault rupture area, amount of slip, and rigidity of the rock). The lowest weight, 0.2 , is assigned to the lengthversus-magnitude relationship because it incorporates the least number of these controlling factors. The balance, 0.3 , is assigned to the area-versus-magnitude relationship.

The Wasatch and East Cache faults are the only faults having sufficient data to estimate the average fault dis- 


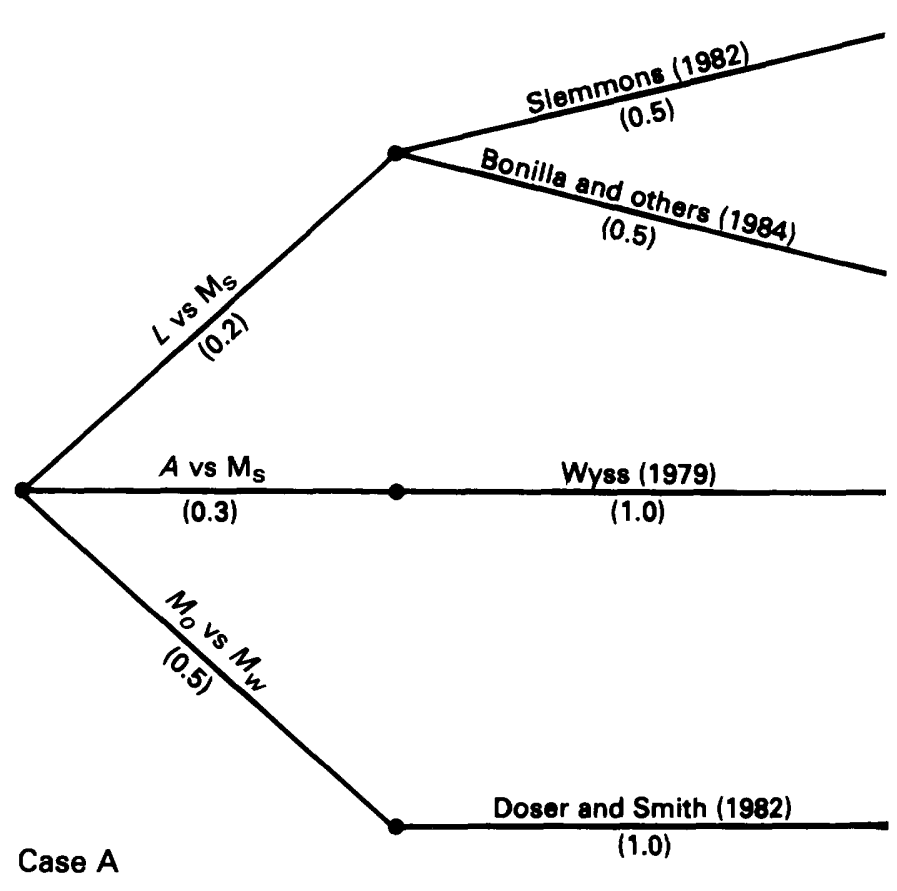

Case A

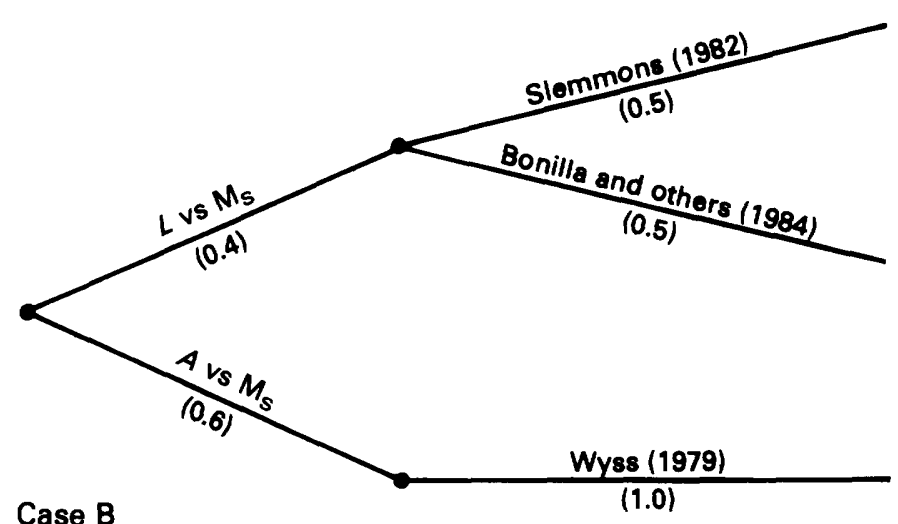

FIGURE 12.-Weighting factors for maximum magnitude assessment techniques for case $\mathrm{A}$, in which data on displacement per event are available, and case $\mathrm{B}$, in which data on displacement per event are not available. $L$ is the log of the rupture length, $A$ is the log of the rupture area, $M_{O}$ is seismic moment, $M_{S}$ is surface-wave magnitude, and $M_{w}$ is moment magnitude.

placement. Therefore, the moment-versus-magnitude technique could not be used for the other faults. Where only length-versus-magnitude and area-versus-magnitude relations were used, the techniques are assigned relative weights of 0.4 and 0.6 , respectively. Given the lengthversus-magnitude relationship, the relationships of Slemmons (1982) and Bonilla and others (1984) are assigned equal probability of reflecting the correct value. After maximum magnitude distributions are obtained from the logic trees such as those illustrated in figure 12, these distributions are discretized into quarter-magnitude intervals for use in the analysis.

The remaining parameters incorporated in the analysis (fig. 2) include different segmentation models, whether a fault is active (that is, capable of independently producing earthquakes), total fault length, maximum earthquake magnitude, and earthquake recurrence rate. The assessed fault-specific parameter values and associated weights are summarized in table 1 and are discussed below for each source. Table 2 lists the fault parameters and probability weights used for assessing maximum magnitude for each of the faults.

\section{WASATCH FAULT ZONE}

The Wasatch fault zone is an active westward-dipping normal fault (figs. 1, 13). Paleoseismic studies demonstrate that repeated large-magnitude earthquakes have occurred on most segments of this fault zone throughout the Holocene (Swan and others, 1980, 1981a, b, c, 1982; Hanson and others, 1981a, b; Schwartz and Coppersmith, 1984). These data are incorporated in the seismic-hazard model in the following manner.

\section{Segmentation}

In addition to the question of whether the fault-rupture process is characterized by unsegmented or segmented behavior, discussed earlier, there is uncertainty regarding the actual number of fault segments along the Wasatch fault zone. Schwartz and Coppersmith (1984) proposed that the fault zone south of Collinston, Utah, consists of six separate segments. They did not discuss the fault zone north of Collinston, which may include a seventh unnamed segment (fig. 13A). On the basis of morphological discriminant analysis of selected geomorphic parameters (drainage basin shape, mountain front sinuosity, steepness of trunk streams, locations of steep sections of stream channels and valley shape), Mayer and Maclean (1986) proposed that the zone may consist of nine separate segments. Machette and others $(1986,1991)$ suggest that the zone consists of at least 10 segments.

At present, there are insufficient data to conclusively define the actual number of segments (Wheeler, 1984). Therefore, two segmentation models are included in the hazard analysis (fig. 13, table 1). The minimum number of segments proposed along the Wasatch fault zone is 7 


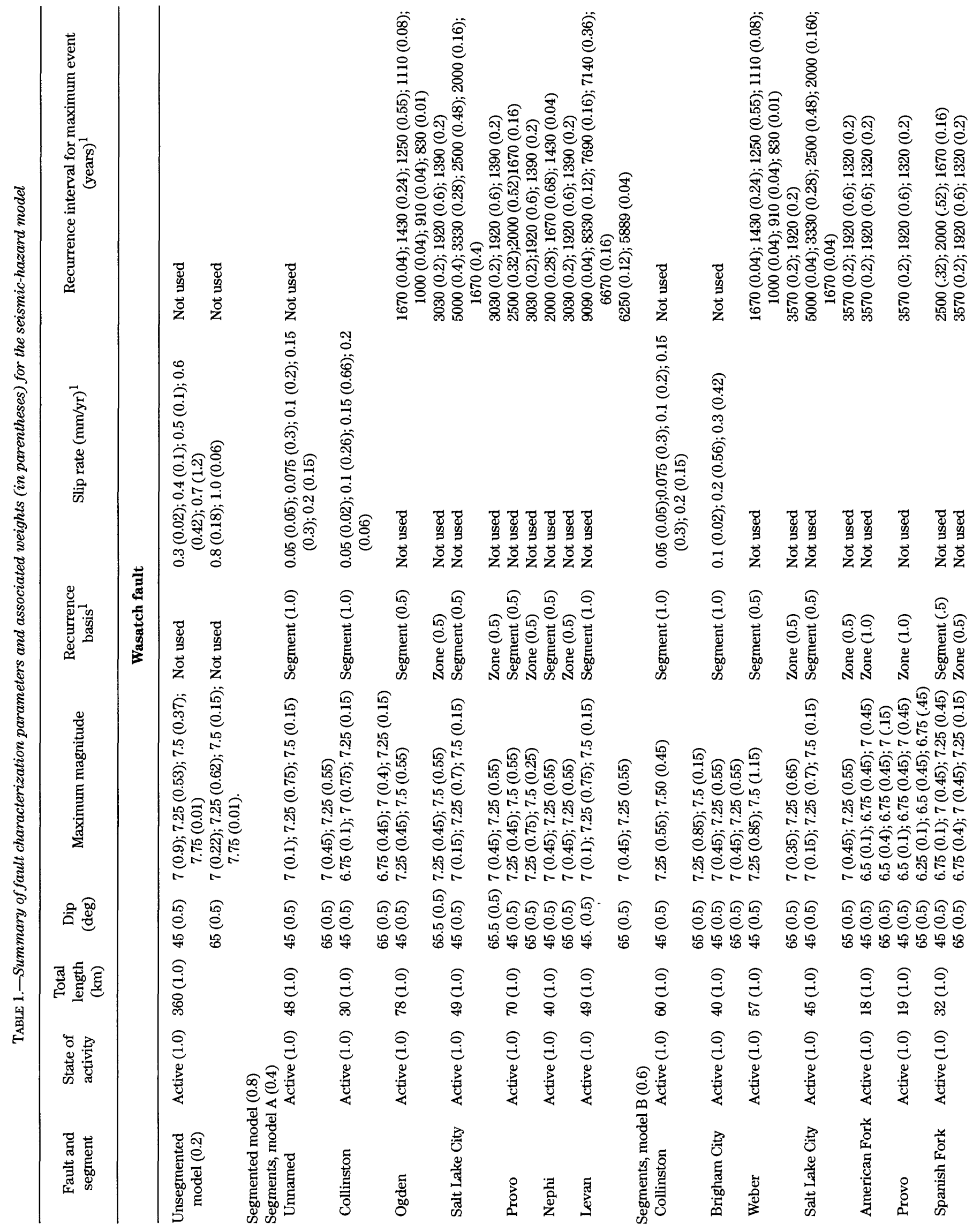




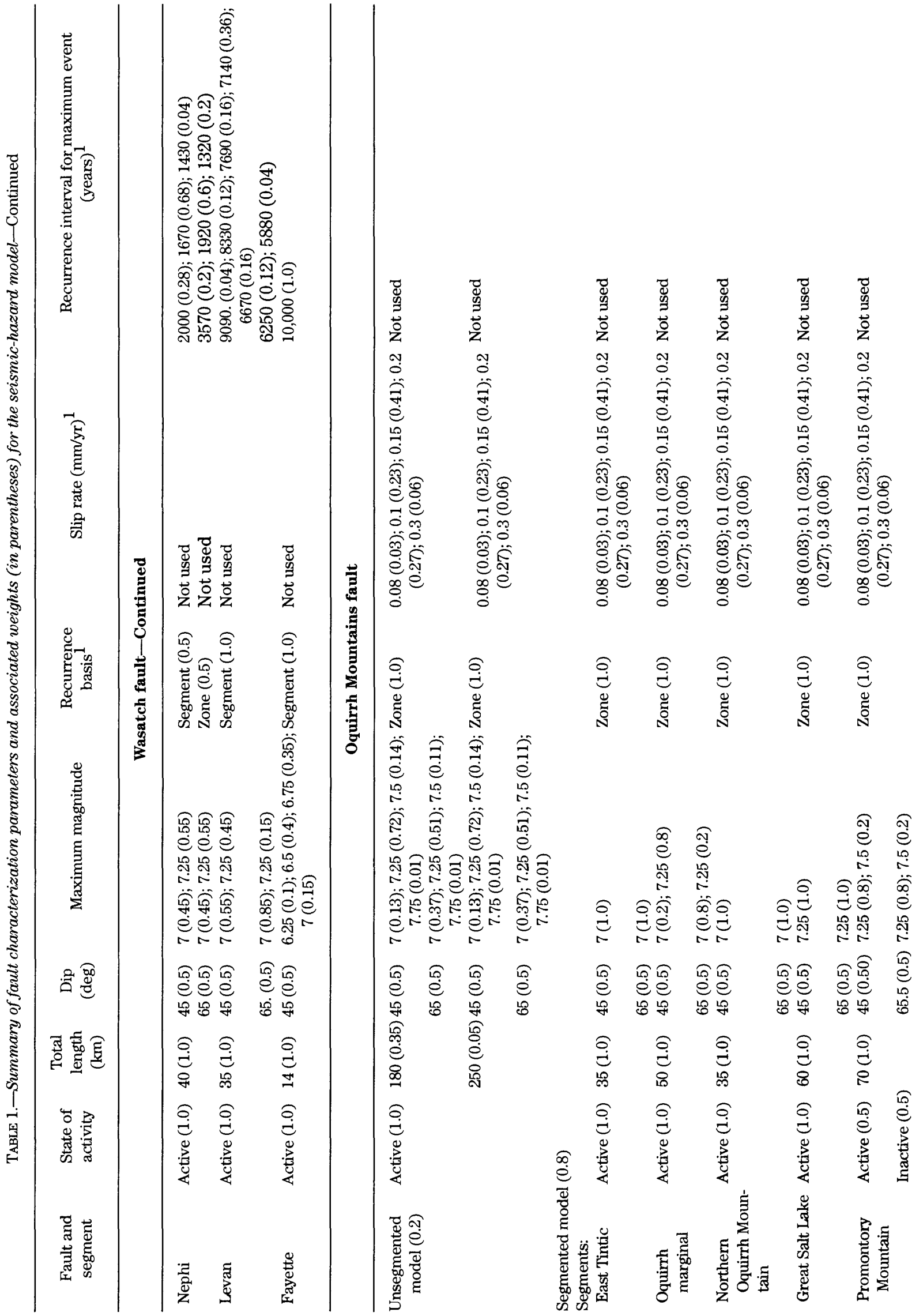



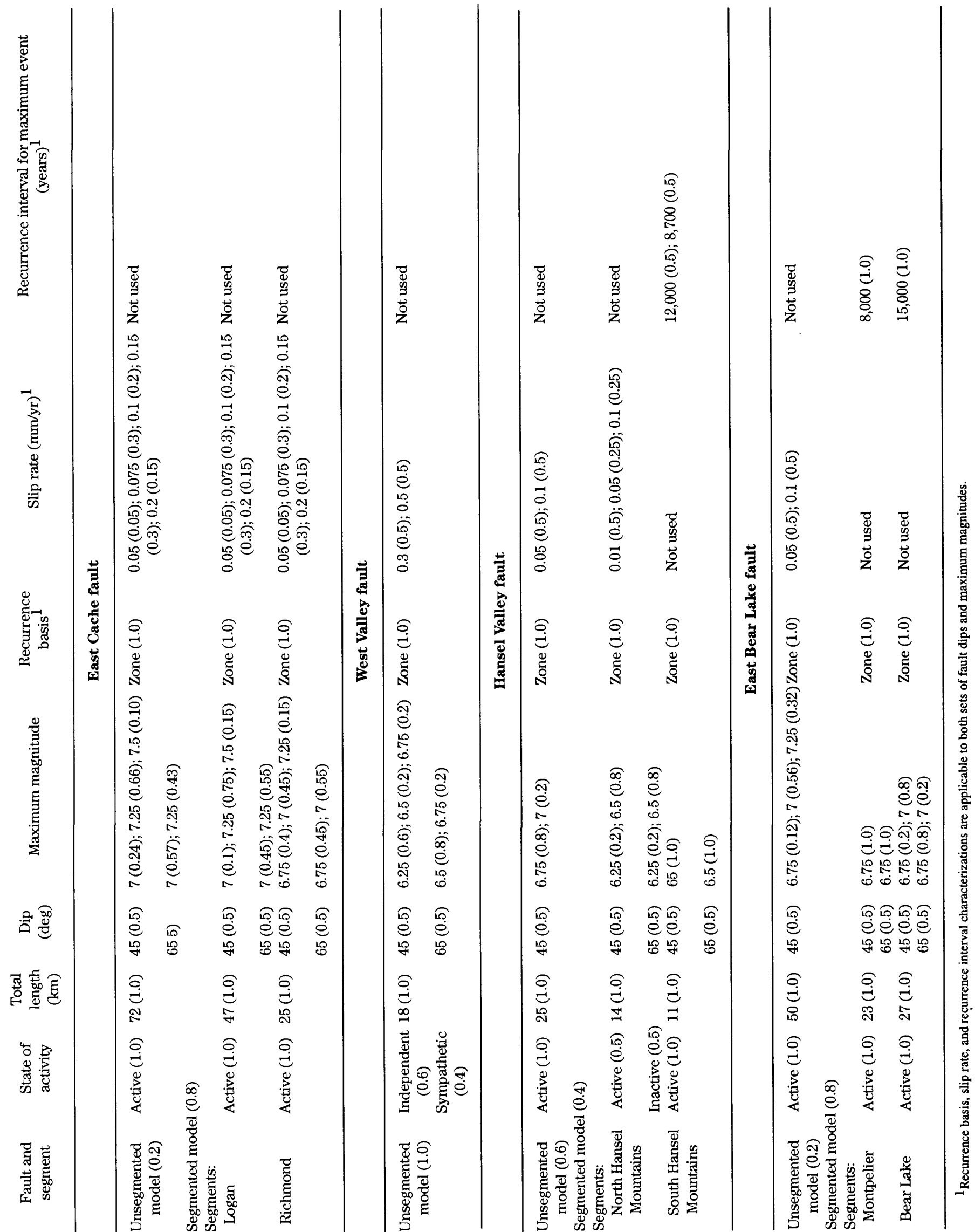
TABLE 2.-Summary of parameters and relationships used to estimate maximum magnitude and associated weights

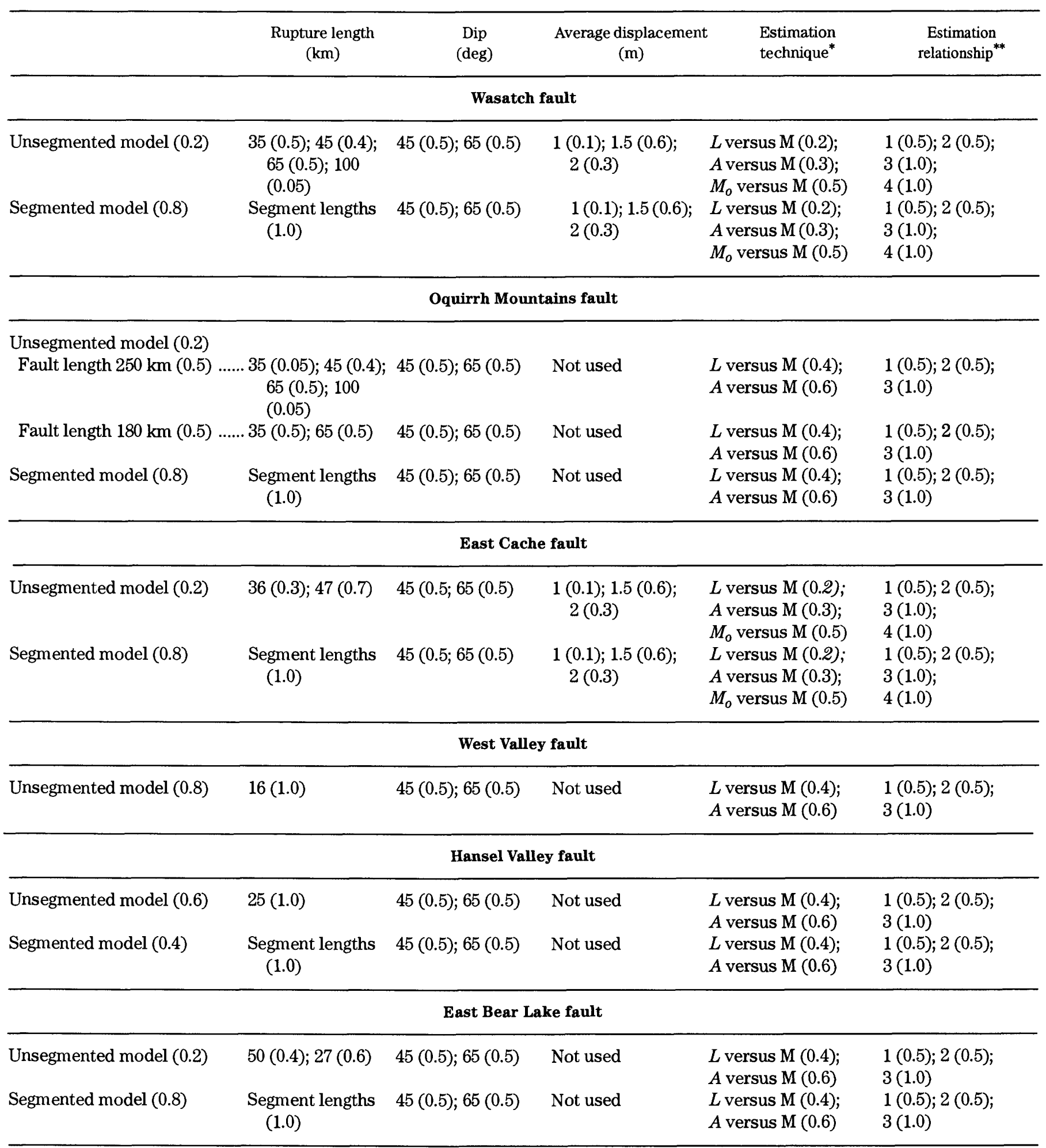

${ }^{*} L$, length; $\mathrm{M}$, magnitude; $A$, area; $\mathrm{M}_{0}$, seismic moment.

** Slemmons (1982) ( $L$ versus $M$ ); 2, Bonilla and others (1984) ( $L$ versus $M$ ); 3, Wyss (1979) ( $A$ versus $M$ ); 4 , this study $\left(M=16.22+0.885 \log M_{o}\right.$ ). 
(segmentation model A, fig. 13A); the maximum number proposed is 10 (segmentation model $\mathrm{B}$, fig. $13 B$ ). The actual number of segments probably lies within this range. Model $\mathrm{A}$ and model $\mathrm{B}$ were assigned relative weights of 0.4 and 0.6 , respectively, to reflect our judgment that model B is slightly more likely. Both models are conditional on the fault's being segmented (fig. 2).

Maximum Earthquake Magnitude

Figure 14 presents the logic tree used to assess maximum magnitude for the Wasatch fault zone. Given an unsegmented fault model for the Wasatch fault, the rupture length likely to be associated with the maximum earthquake may be significantly longer than the length of individual mapped segments. Bonilla and others (1984) have developed a relationship relating displacement to rupture length for normal faults. The maximum net vertical displacement reported from paleoseismic investigations along the Wasatch fault zone is $4.75 \mathrm{~m}$ at Dry Creek (Lund and Schwartz, 1987). Using Bonilla and others' (1984) relationship relating rupture length to maximum displacement for normal faults and displacements of 4.75 $\mathrm{m}$ yields an expected rupture length (mean value) of 53 $\mathrm{km}$. The longest historical surface fault rupture reported from the Basin and Range is $61 \mathrm{~km}$ associated with the October 3, 1915, Pleasant Valley, Nev., earthquake. However, if two or three of the identified fault segments were to rupture simultaneously (for example, the Ogden and Salt Lake City segments or the Provo, Spanish Fork, and Nephi segments), a maximum rupture length of about 100 $\mathrm{km}$ might be expected. This case, however, is considered to be very unlikely. To account for uncertainty in the maximum rupture length, values ranging from 35 to $100 \mathrm{~km}$ are considered in the hazard analysis. Table 2 summarizes the assessed maximum rupture lengths and the relative weights assigned to each value for the unsegmented fault model. Given the segmented fault models, the maximum rupture lengths are assumed to be the lengths of the individual segments as shown in table 1 and figure 14 .

Schwartz and others (1983) and Schwartz and Coppersmith $(1984,1986)$ summarized the available displacement data from five locations along the Wasatch fault zone on the basis of paleoseismic investigations. The values, which have been corrected for distortions due to effects of graben formation and backtilting, represent net vertical tectonic slip at specific locations along the fault zone. The values range from 1.6 to $2.7 \mathrm{~m}$ per event and average about $2 \mathrm{~m}$ per event. It is not known where these measurements are located with respect to the maximum displacement during the individual rupture events or how they relate to the average displacement along these surface ruptures.
Detailed measurements of recent surface-faulting events show that there is a great deal of variability in the displacement along the length of the surface rupture. For example, the maximum displacement of $2.7 \mathrm{~m}$ during the October 28, 1983, Borah Peak earthquake occurred along less than $1 \mathrm{~km}$ of the $34-\mathrm{km}$-long rupture. Only 49 percent of the rupture was characterized by displacements equal to or greater than the average displacement of $0.8 \mathrm{~m}$ (Crone and Machette, 1984). Therefore, it is unlikely that the measured displacements along the Wasatch fault represent the maximum displacement along the surface rupture. If the locations where measurements were made had been randomly selected, it would be reasonable to assume that the average of all the displacements, which is about $2 \mathrm{~m}$, would approximate the average displacement per event for past surface-faulting events. However, because the locations were selected where the fault is well expressed topographically, the results may be biased toward values that are too large.

To account for uncertainties in the displacement data, a range of values for the average displacement associated with the maximum earthquake is included in the probabilistic assessment of the maximum earthquake magnitude. Values of $1,1.5$, and $2 \mathrm{~m}$ are assigned probabilities of $0.1,0.6$ and 0.3 , respectively (fig. 14 , table 2 ). Given the unsegmented model, the expected maximum earthquake on the Wasatch fault zone is about $M_{S} 7 \frac{1}{4}$. If the fault is segmented, the expected maximum magnitudes for the segments range from $M_{S} 6 \frac{1}{2}$ to $7 \frac{1}{2}$ (table 1 ).

\section{Earthquake Recurrence Rate}

The slip rate and displacement per event data presented in table 3 are used to assess the earthquake recurrence rate of major surface-faulting events on the various segments of the Wasatch fault zone and for the zone as whole. In addition to incorporating uncertainly in the correct recurrence model, described previously, the seismichazard model also includes uncertainty in the primary data-namely, uncertainties in the measured cumulative displacement, in the age of the displaced strata, and in the average displacement per event. Quantifying the uncertainty in each of these parameters allows the calculation of the probability distributions for the slip rate. The resulting probability distributions are presented in table 1.

Given the unsegmented fault model, the earthquake recurrence rate was calculated on the basis of the seismic moment rate obtained from the estimated average slip rate. To arrive at an average rate, the slip-rate data in table 3 were weighted to reflect the segment lengths for model A, which was used because there are no independent sliprate data for the American Fork and Provo segments in 


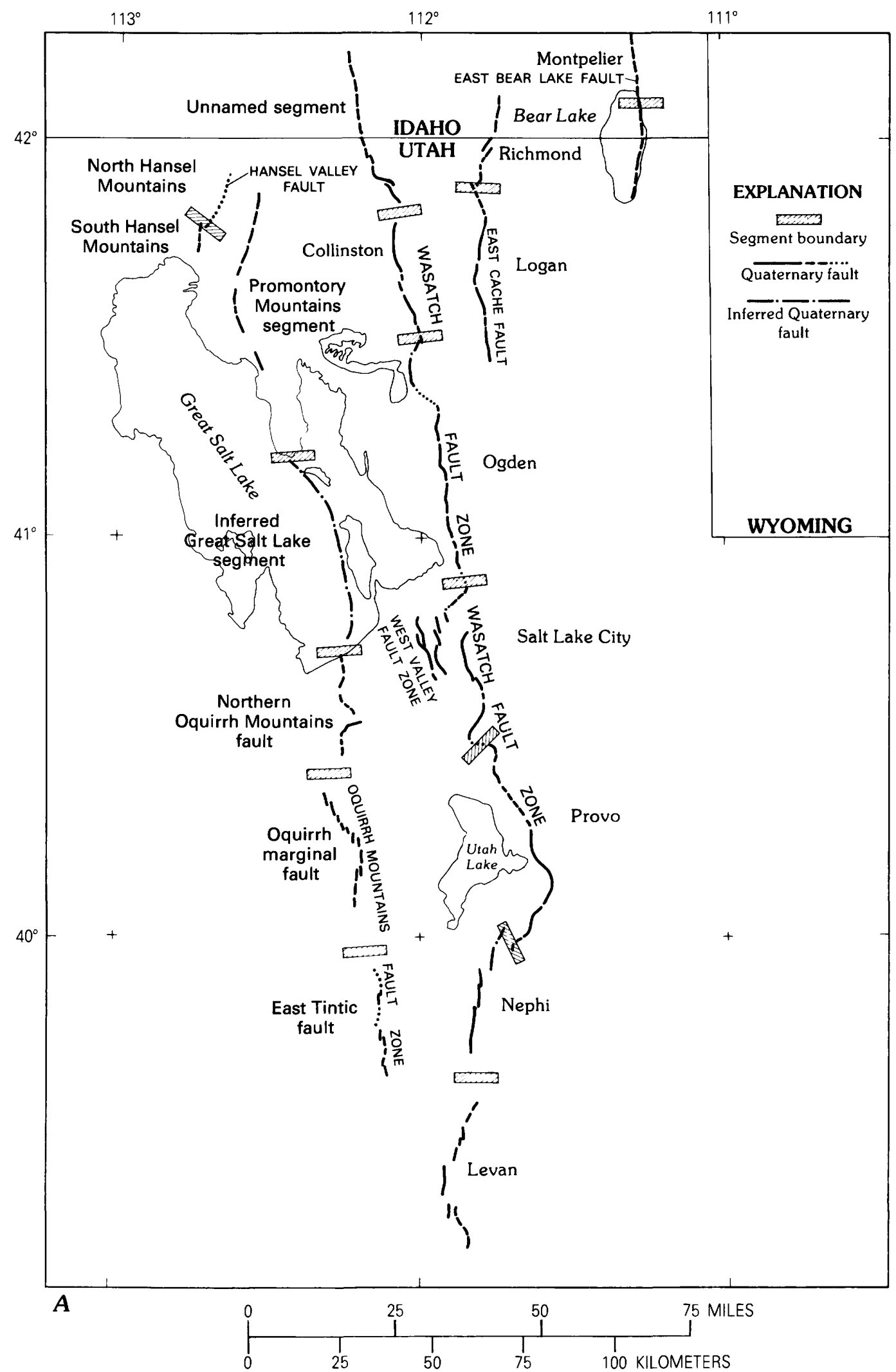

FIGURE 13.-Segmentation models for fault-specific sources. $A$, Wasatch fault model A and all other faults; $B$, Wasatch fault model B. 


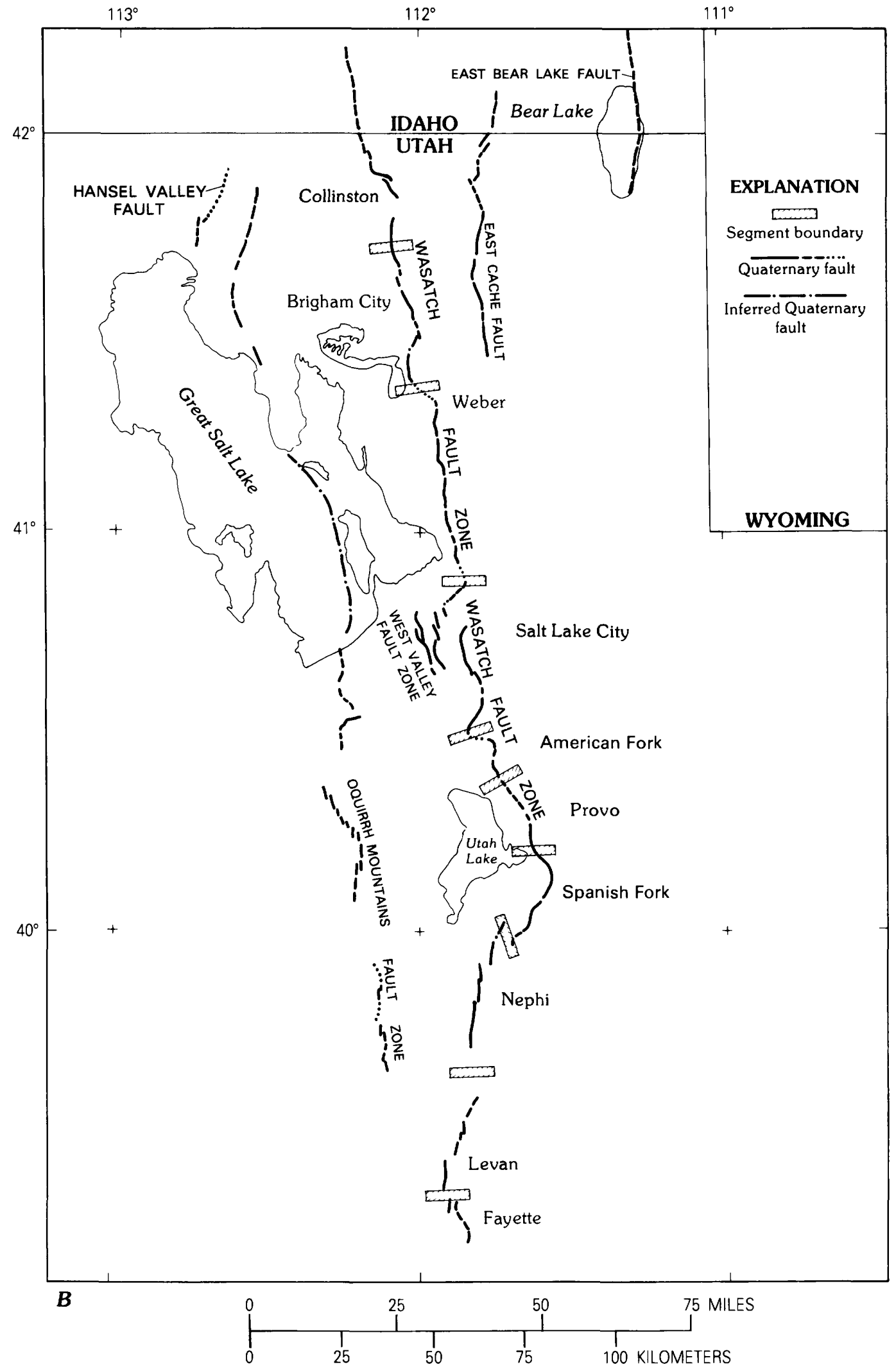

FIGURE 13.-Segmentation models for fault-specific sources. $A$, Wasatch fault model A and all other faults; $B$, Wasatch fault model B-Continued. 


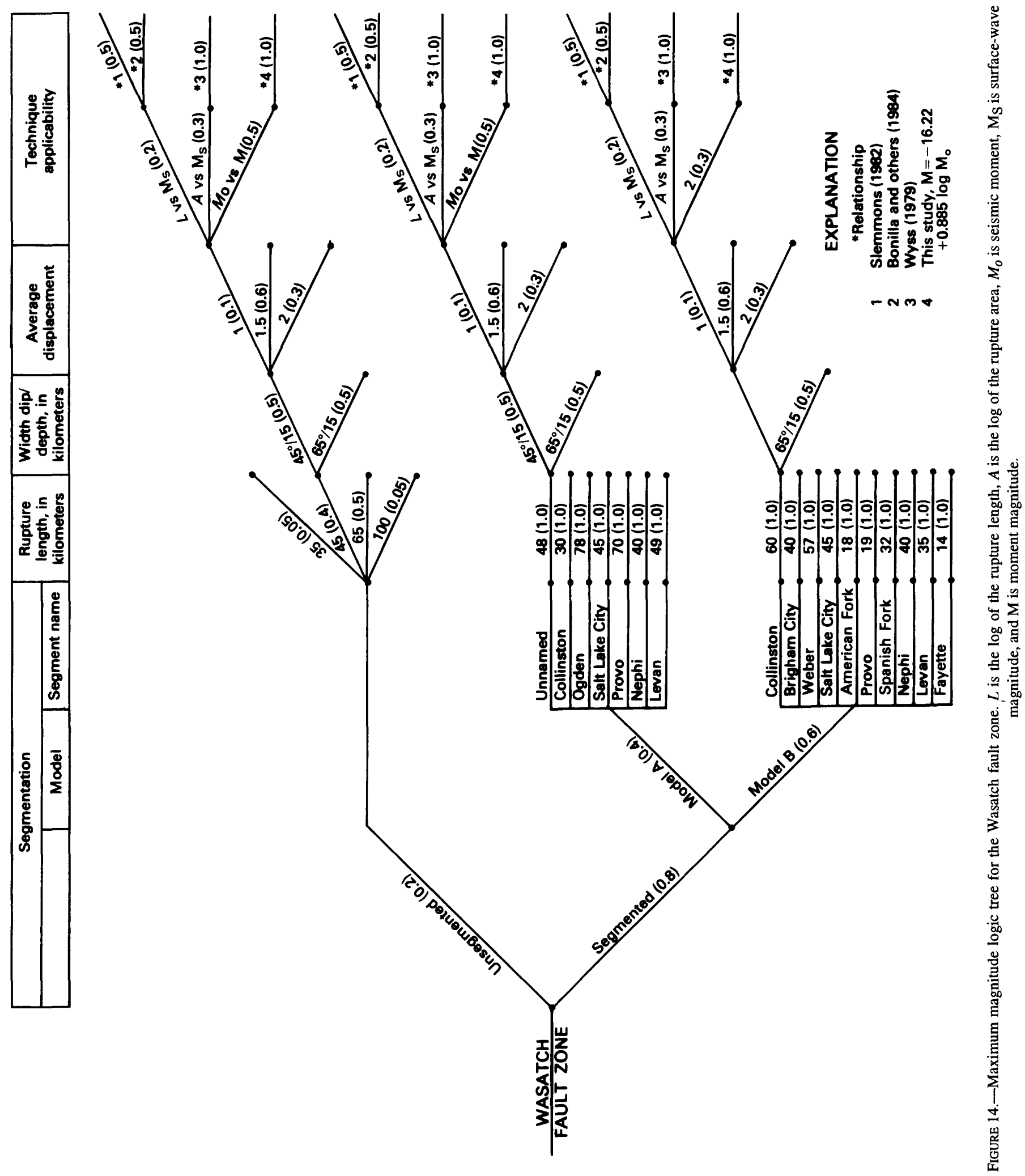


TABLE 3.-Summary of geologic parameters used to characterize earthquake recurrence rate for the Wasatch fault zone

[N/A, not applicable]

\begin{tabular}{|c|c|c|c|c|c|c|c|c|c|}
\hline \multirow{2}{*}{$\begin{array}{l}\text { Recurrence } \\
\text { basis }\end{array}$} & \multicolumn{2}{|c|}{ Segment } & \multirow{2}{*}{ Site } & \multirow{2}{*}{$\begin{array}{l}\text { Cumulative } \\
\text { vertical } \\
\text { displacement } \\
\text { (m) }\end{array}$} & \multirow{2}{*}{$\begin{array}{c}\text { Age } \\
\text { (thousands of } \\
\text { years B.P.) }\end{array}$} & \multirow{2}{*}{$\begin{array}{l}\text { Point } \\
\text { estimate of } \\
\text { slip rate } \\
(\mathrm{mm} / \mathrm{yr})\end{array}$} & \multirow{3}{*}{$\begin{array}{l}\text { Vertical } \\
\text { displace- } \\
\text { ment per } \\
\text { event } \\
\text { (m) }\end{array}$} & \multirow{2}{*}{$\begin{array}{l}\text { Mean } \\
\text { recurrence } \\
\text { interval for } \\
\text { maximum } \\
\text { earthquake } \\
\quad \text { (yr) }\end{array}$} & \multirow{2}{*}{$\begin{array}{l}\text { Comments and } \\
\text { sources of data }\end{array}$} \\
\hline & Model A & Model B & & & & & & & \\
\hline \multicolumn{9}{|c|}{ Segmented fault-rupture model } & \\
\hline Zone & Unnamed & Collinston & N/A & N/A & N/A & 0.15 & N/A & 8,800 & $\begin{array}{l}\text { Slip rate assumed to be } \\
\text { comparable to or less } \\
\text { than that on East Cache } \\
\text { fault (Swan and others, } \\
\text { 1983). Slip rate assumed } \\
\text { to be accurate to within } \\
\text { about } 30 \text { percent. }\end{array}$ \\
\hline Segment & Ogden & Weber & Kaysville & $\begin{array}{l}10(0.5) \\
11(0.5)\end{array}$ & $\begin{array}{l}6(0.1) \\
8(0.7) \\
9(0.2)\end{array}$ & 1.3 & $\begin{array}{l}1.6 \\
{[2]}\end{array}$ & 1,350 & $\begin{array}{l}\text { Swan and others (1980, } \\
\text { Schwartz and others } \\
\text { (1984). }\end{array}$ \\
\hline \multirow[t]{3}{*}{ Segment } & $\begin{array}{l}\text { Salt Lake } \\
\text { City. }\end{array}$ & $\begin{array}{l}\text { Salt Lake } \\
\text { City. }\end{array}$ & $\begin{array}{l}\text { Little } \\
\text { Cottonwood } \\
\text { Canyon. }\end{array}$ & $\begin{array}{l}11.5(0.2) \\
14.5(0.7) \\
24.5(0.1)\end{array}$ & $\begin{array}{l}17(0.2) \\
19(9.6) \\
21(0.2)\end{array}$ & 0.76 & $\begin{array}{l}2.0 \\
{[2]}\end{array}$ & 2,550 & $\begin{array}{l}\text { Swan and others (1981b), } \\
\text { Schwartz and Copper- } \\
\text { smith (1984). }\end{array}$ \\
\hline & & $\begin{array}{l}\text { American } \\
\text { Fork. }\end{array}$ & N/A & N/A & N/A & N/A & N/A & 1,900 & $\begin{array}{l}\text { "Zone" recurrence basis } \\
\text { only. }\end{array}$ \\
\hline & & Provo & N/A & N/A & N/A & N/A & N/A & 1,900 & $\begin{array}{l}\text { "Zone" recurrence basis } \\
\text { only. }\end{array}$ \\
\hline Segment & Levan & Levan & Deep Creek & $2.5(1)$ & $\begin{array}{l}6.3(0.2) \\
7.3(0.6) \\
8.3(0.2)\end{array}$ & 0.35 & $\begin{array}{l}2.5 \\
{[1]}\end{array}$ & 7,100 & $\begin{array}{l}\text { Hanson and others (1981b), } \\
\text { Schwartz and Copper- } \\
\text { smith (1984). }\end{array}$ \\
\hline & & Fayette & N/A & N/A & N/A & 0.20 & N/A & 10,000 & $\begin{array}{l}\text { This report. Slip rate } \\
\text { assumed to be accurate } \\
\text { to within about } \\
50 \text { percent. }\end{array}$ \\
\hline "Zone" & $\begin{array}{l}\text { Central par } \\
\text { (Brighan } \\
\text { Nephi). }\end{array}$ & $\begin{array}{l}\text { t of zone } \\
\text { n City to }\end{array}$ & N/A & N/A & N/A & 1.1 & 2.1 & $\begin{array}{c}1,900 \\
\text { per segment }\end{array}$ & $\begin{array}{l}\text { Average of data from } \\
\text { Kaysville, Little Cotton- } \\
\text { wood Canyon, Hobble } \\
\text { Creek, North Creek, and } \\
\text { Deep Creek sites. }\end{array}$ \\
\hline
\end{tabular}

Unsegmented model

\begin{tabular}{lllllllll}
\hline N/A & N/A & N/A & N/A & N/A & N/A & 0.80 & N/A & 280 \\
\hline N/A & N/A & N/A & N/A & N/A & N/A & N/A & N/A & 330 \\
\hline
\end{tabular}

${ }^{1}$ Standard deviation of mean assumed to be 0.15 . Number of events averaged is shown in brackets. 
model B. The overall average slip rate (weighted by segment length) is $0.8 \mathrm{~mm} / \mathrm{yr}$. The slip rate was distributed along the fault so as to produce a slip rate of $1.1 \mathrm{~mm} / \mathrm{yr}$ in the central part of the fault consistent with the observed variation in rate.

Given the segmented fault model, the earthquake recurrence rate for the segments north of Brigham City and south of Nephi were estimated by using the seismic moment rate approach because there are no data on the slip per event or on the timing of individual events for these segments.

For the central part of the fault zone, where there are slip-rate and displacement-per-event data from several localities, the recurrence rate for maximum events is estimated by dividing the slip rate by the average displacement per event. Uncertainty in these parameters was incorporated in the analysis as indicated by the distribution for recurrence rate shown in table 1 . Two bases were used to estimate the average slip rate and displacement per event. In one case (the "zone" recurrence basis in table 1 and fig. 2), the segments along the central part of the fault between Brigham City and Nephi are considered to have the same rate of activity, and the recurrence basis for these segments was calculated on the basis of the average of the slip-rate and displacement-per-event data from the five sites located along this stretch of the fault (table 1). The slip rate for the central part of the zone, based on data summarized by Schwartz and others (1984), is $1.1( \pm 0.15) \mathrm{mm} / \mathrm{yr}$. The average displacement per event reported for paleoseismic events identified at the five sites along the central segments of the Wasatch fault zone is $2.1( \pm 0.1) \mathrm{m}$. These values were used to calculate the distribution for the recurrence interval for the maximum event shown in table 1 for the "zone" recurrence basis. In the second case (the "segment" recurrence basis in table 1), the slip rate and displacement data from each site shown in table 3 were used to characterize the earthquake recurrence for the specific segments. In some cases (for example, the American Fork and Provo segments of segmentation model B), only the "zone" recurrence basis could be used. Where both the "zone" recurrence basis and the "segment" recurrence basis were used, they were given equal weight.

The activity on the fault north of about Brigham City is significantly less than that on the central part of the zone (Personius, 1986). On the basis of the subdued geomorphic expression of the northernmost part of the zone (that is, the unnamed segment in fig. 13A), it is assumed that the long-term slip rate on this part of the fault is comparable to or less than the rate on the East Cache fault (see discussion below), and a nominal slip rate of 0.15 $\mathrm{mm} / \mathrm{yr}$ was assigned to this part of the fault zone.

Immediately north of Honeyville, Utah (lat $41^{\circ} 33^{\prime} \mathrm{N}$ ) (that is, the Collinston segment on fig. $13 \mathrm{~A}$ and the
Brigham City segment on fig. 13B), Scott (1980) reported that an alluvial fan, which he estimated to be about 150,000 years old, is displaced $26 \mathrm{~m}$. This displacement suggests an average slip rate of $0.17 \mathrm{~mm} / \mathrm{yr}$, comparable to the rate inferred for the northernmost part of the zone. There is insufficient information to directly assess the accuracy of these slip rates. In estimating the uncertainty in the earthquake recurrence rate on these segments of the fault, it is assumed that these slip rate values are accurate only to within about 30 percent.

The basis for slip-rate and displacement-per-event data at the Kaysville, Little Cottonwood Canyon, Hobble Creek, North Creek, and Deep Creek sites (fig. 1, table 3) are well documented in several papers and U.S. Geological Survey (USGS) Open-File Reports by Swan and others $(1980,1981 \mathrm{a}, \mathrm{b}, \mathrm{c})$ and have been summarized by Schwartz and others (1984) and Schwartz and Coppersmith $(1984,1986)$. To quantify the uncertainty in the earthquake recurrence rates, distributions have been assigned to displacement and age data to reflect the uncertainty in these primary data. For example, at the Kaysville site, the cumulative vertical displacement is reported as 10 to $11 \mathrm{~m}$ since deposition of an alluvial fan estimated to be $8,000(+1,000,-2,000)$ years old. The actual displacement is equally likely to be anywhere within the 10- to $11-\mathrm{m}$ range, so these values are assigned equal weight (table 3 ). The preferred age is assigned the highest probability weight (0.7). Ages of 6,000 and 9,000 years were assigned weights of 0.1 and 0.2 , respectively, to reflect the judgement that it is unlikely that the fan is as young as 6,000 years and that it could be as old as 9,000 years (Schwartz and Coppersmith, 1984). Where the age of the displaced unit is based on radiocarbon dates (for example, the age of $7,300( \pm 1,000){ }^{14} \mathrm{C}$ years B.P. for the age of the displaced alluvium at the Deep Creek site), the reported error for this date is assumed to be within about one standard deviation of the actual age.

The available data indicate that the activity on the Wasatch fault zone dies out south of Levan. There are no reports on the rate of slip on the Fayette segment (model B), which was assigned a nominal slip rate of $0.2 \mathrm{~mm} / \mathrm{yr}$ on the assumption of an event about every 10,000 years.

Table 3 presents the mean recurrence times for major surface-faulting events on each of the fault segments. These times are interpreted to represent the average repeat time for the maximum earthquake. Table 1 shows that the distribution in the earthquake recurrence rates reflects the uncertainty in the slip rate and recurrence data. Figure 15 presents the predicted recurrence rate for the entire zone. On the basis of the hazard model, the estimated return period for events of magnitude 7 or greater is $330( \pm 90)$ years for the entire zone. This value compares favorably with an earlier estimate of 400 to 666 years based on the number of paleoseismic events inferred to 

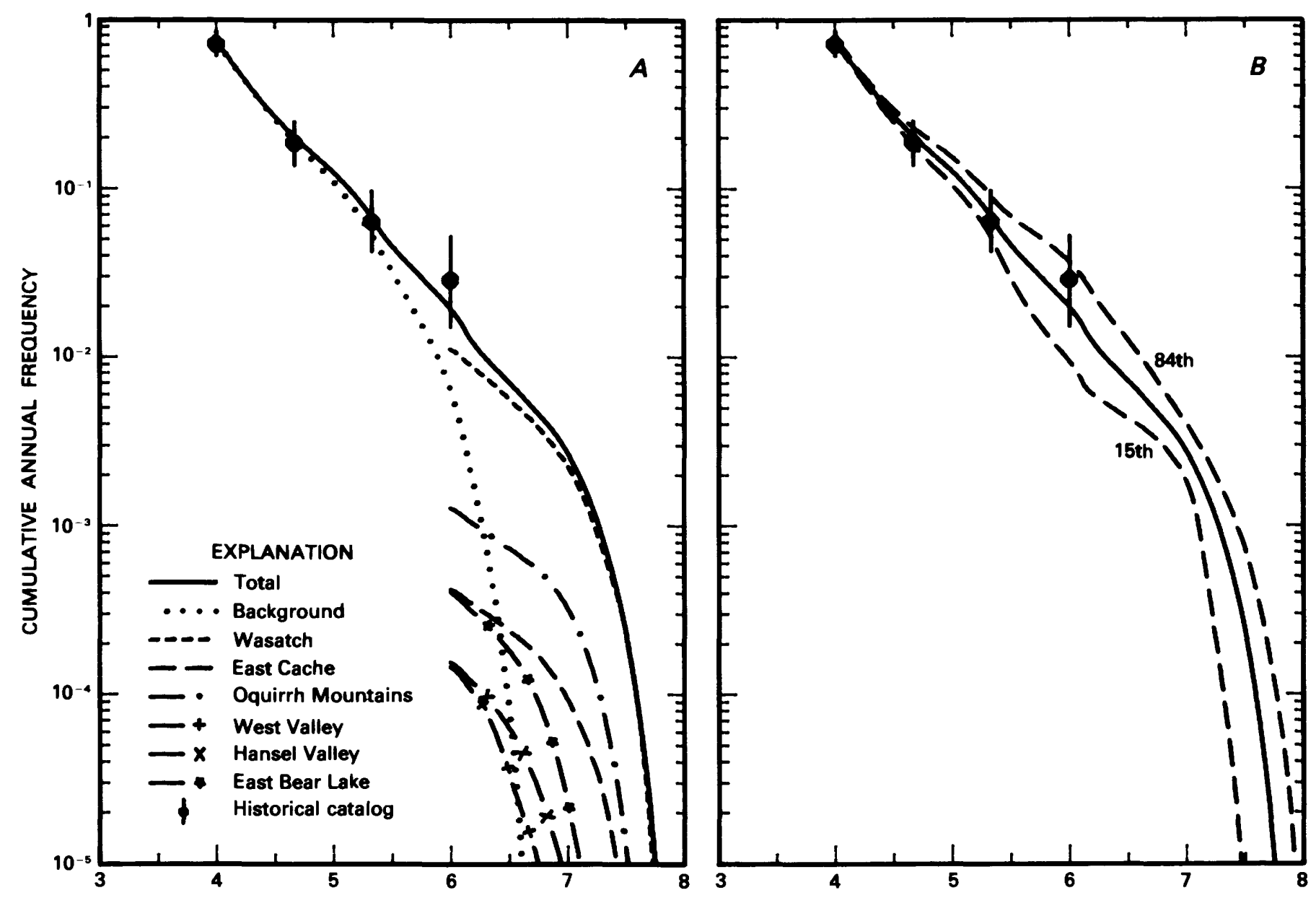

MAGNITUDE

FIGURE 15.-Comparison of predicted recurrence rates for seismic sources and observed frequency of earthquakes. $A$, Mean recurrence estimates for individual sources and total of all sources. $B$, Mean (solid) fractiles of predicted distributions of earthquake recurrence in comparison with one standard deviation error bars for regional recurrence rate based on observed seismicity.

have occurred on the central segments (Brigham City to Nephi) during approximately the past 8,000 years (Schwartz and Coppersmith, 1984). The shorter return period predicted by the model developed here is due to the inclusion of additional segments within the central part of the fault zone in the alternative segmentation model and contributions from the northern and southern segments of the fault zone that were not included in the Schwartz and Coppersmith estimate.

\section{OQUIRRH MOUNTAINS FAULT ZONE}

The Oquirrh Mountains fault zone lies 25 to $50 \mathrm{~km}$ west of the Wasatch Front (figs. 1, 13). The fault zone consists of an alignment of late Pleistocene fault scarps at or near the boundary between the alluvial basin fill and the bedrock along the western side of the East Tintic and
Oquirrh Mountains (Anderson and Miller, 1979) that indicates the presence of active westward-dipping normal faults along this trend. This fault zone is discontinuous and is shown as two faults by Everitt and Kaliser (1980)the Oquirrh marginal fault along the eastern margin of Tooele Valley and the Oquirrh-Boulter-Tintic fault zone along the eastern margin of Rush Valley. The mapped onland faults extend northward along the western flank of Antelope Island beneath the Great Salt Lake (fig. 13A). The northern limit of Quaternary faulting is uncertain, and similar faults may exist along the western flank of the Promontory Mountains.

\section{Segmentation}

Both unsegmented and segmented fault models are used in the seismic-hazard model to characterize the 
fault-rupture behavior of the Oquirrh Mountains fault zone. Figure $13 \mathrm{~A}$ shows the locations of the five segments considered if the zone is segmented. Additional studies would undoubtedly result in a refinement of these somewhat arbitrarily defined segments, but comparison of the results from the alternative segmentation models used to characterize the Wasatch fault zone suggests that further refinement would not significantly affect the overall results of the hazard analysis.

\section{Activity}

Quaternary faulting has been recognized along all segments of the Oquirrh Mountains fault zone except the Promontory Mountains segment. Given the segmented fault model, a probability of 0.5 that the fault is an active seismogenic fault was assigned to the Promontory Mountains segment to account for the uncertainty regarding the existence of Quaternary faulting along this part of the zone.

\section{Total Length}

Uncertainty in the total length of an unsegmented Oquirrh Mountains fault zone was modeled to account for the uncertainty concerning the existence of active faulting north of the Great Salt Lake. Values of 180 and $250 \mathrm{~km}$ are considered; $180 \mathrm{~km}$ is the combined lengths of the mapped traces along the four southern segments, and 250 $\mathrm{km}$ is the combined length if the zone extends to the northern end of the Promontory Mountains (fig. 13A). The two values were assigned equal weight.

\section{Maximum Earthquake Magnitude}

Because there are insufficient paleoseismic data on the amount of displacement during past surface-faulting events on this fault, the assessment of earthquake magnitude was based on rupture length and rupture area only (fig. 12, case B; table 2). If the fault zone is unsegmented and $250 \mathrm{~km}$ long, the rupture-length distribution was assumed to be the same as the rupture-length distribution for the unsegmented Wasatch fault (table 2). If the fault zone length is $180 \mathrm{~km}$, a 100-km rupture length is not considered credible, and weights were assessed for the remaining rupture lengths (table 2). Given the segmented model, the maximum rupture lengths are assumed to be equal to the segment lengths (table 1).

Table 1 presents the results of the maximum earthquake magnitude assessment for the Oquirrh Mountains fault zone. If the fault zone is unsegmented, the most likely maximum earthquake is about magnitude $7^{1 / 4}$. If the fault zone is segmented, the most likely maximum earthquakes on the individual segments range from about magnitude 7 to $7 \frac{1}{4}$.
Earthquake Recurrence Rate

The available data do not tightly constrain the time since the most recent surface-faulting event or the recurrence interval between events on the Oquirrh Mountain fault zone. Along the northern part of the Oquirrh marginal fault (fig. 13A), a series of recessional shorelines below the Provo level (younger than about 13,500 yr B.P.) appears to be displaced across a prominent curvilinear fault scarp. The fault scarp just north of Bates Canyon is about $9 \mathrm{~m}$ high. It consists of an upper slope 4.6 to $6 \mathrm{~m}$ high that has been modified by shoreline or sublacustrine wave erosion and a lower, steeper slope 3.6 to $4.6 \mathrm{~m}$ high that appears unaffected by lake processes and therefore represents a post-Provo surface-faulting earthquake (Everitt and Kaliser, 1979; Woodward-Clyde Consultants, 1982). On the basis of the geomorphic expression of the fault and the absence of faulting in younger alluvial fans, Swan and Schwartz estimated that this event occurred between about 8,000 and 10,000 years ago and that the recession of the lake from the Provo level occurred about 13,500 years ago (Woodward-Clyde Consultants, 1982).

Most of the faulting along the East Tintic fault occurs within pre-Bonneville alluvial fan deposits (older than about $15,000-14,000$ yr B.P.) that lie above the Bonneville shoreline and therefore provides little information on the recency of faulting. Locally, Everitt and Kaliser (1979) have mapped $0.6-$ to 3 -m-high scarps in strandline and alluvial-fan deposits just below the Bonneville shoreline. Although the field relationships are not unequivocal, there seems to have been at least one major post-Bonneville surface-faulting earthquake along the East Tintic fault (Woodward-Clyde Consultants, 1982).

The slip rate on the Oquirrh Mountain fault zone is very poorly constrained. The scarp heights reported above suggest a post-Provo slip rate of about $0.3 \mathrm{~mm} / \mathrm{yr}$ on the Oquirrh marginal fault and a post-Bonneville slip rate of about 0.04 to $0.2 \mathrm{~mm} / \mathrm{yr}$ on the East Tintic fault. The assessed distribution for average slip rate shown in table 1 was based on the uncertainty in these point estimates of slip rate together with possible biases (described previously). Because of the limited data, no attempt was made to discriminate between the unsegmented and segmented models, and all segments are assumed to have slip rates within this range. On the basis of the fault characterization parameters presented in table 1 , the estimated return period for earthquakes of magnitude 7 or greater on the Oquirrh Mountains fault zone is 2,200 $( \pm 800)$ years.

\section{EAST CACHE FAULT}

The East Cache fault lies on the eastern side of Cache Valley along the -western base of the Bear River Range approximately 20 to $40 \mathrm{~km}$ east of the Wasatch Front 
(figs. 1, 13). It extends as a zone of westward-dipping Quaternary normal faults in a north-south direction for a distance of about $72 \mathrm{~km}$ from just north of James Peak in Utah to Preston, Idaho (Cluff and others, 1974). Late Quaternary fault scarps along the East Cache fault are discontinuous and in many locations are subdued owing to erosion or are buried by Holocene alluvial fans. Paleoseismic investigations (Swan and others, 1983; McCalpin, 1987) show that there have been repeated late Pleistocene surface-faulting events and at least one Holocene event on the East Cache fault near Logan, Utah.

\section{Segmentation}

Both unsegmented and segmented fault models are used to characterize the rupture behavior of the East Cache fault. In this analysis, the fault was divided into two segments - the Logan segment, which is $47 \mathrm{~km}$ long, and the Richmond segment, which is $25 \mathrm{~km}$ long (fig. 13A). A salient in the range front immediately north of Smithfield Canyon is interpreted to reflect a structural barrier between these segments. McCalpin (1987) proposed a three-segment model suggesting the possibility of shorter segments. This model, however, has not been explicitly incorporated into the analysis.

\section{Maximum Earthquake Magnitude}

The maximum magnitude logic tree for the East Cache fault is similar to that for the Wasatch fault shown in figure 14. If the fault is assumed to be unsegmented, two rupture lengths are considered (table 2) $-36 \mathrm{~km}$, which is 50 percent of the total fault length, and $47 \mathrm{~km}$, which is equivalent to the longest segment included in the seismic source model. There are insufficient paleoseismic data along the East Cache fault to assess the average displacement per event. Swan and others (1983) and McCalpin (1987) reported displacements for individual events on the fault near the mouth of Logan Canyon of 1.4 $\mathrm{m}$ to possibly as much $2.4 \mathrm{~m}$. These values are comparable to the fault displacements observed along the Wasatch fault zone (table 3). Therefore, the range of values and assigned probabilities used to characterize the average displacement per event during a maximum earthquake on the Wasatch fault zone were also assumed to be representative of the East Cache fault. If the East Cache fault is unsegmented, the most likely maximum earthquake is about magnitude $7 \frac{1}{4}$. If the fault is segmented, the most likely maximum earthquakes on the Logan and Richmond segments are about magnitude $71 / 4$ and 7 , respectively (table 1).

\section{Earthquake Recurrence Rate}

The slip rate and recurrence data for the East Cache fault are not well constrained. Two surface-faulting events that postdate the recession of Lake Bonneville from the Bonneville shoreline 14,000 to 15,000 years ago have been identified near the mouth of Logan Canyon (Swan and others, 1983). These events suggest an average recurrence rate of about 7,250 $( \pm 250)$ years for maximum events. The second-most-recent event occurred after 15,000 yr B.P. and before formation of the Provo delta about 13,500 years ago. The age of the most recent post Provo displacement is not well constrained, so the actual interval between these events is not known.

At the mouth of Logan Canyon, the cumulative displacement of the Bonneville shoreline deposits is about $2.8 \mathrm{~m}$, and the displacement of the Provo delta is $1.4 \mathrm{~m}$, suggesting average slip rates of about 0.2 and $0.1 \mathrm{~mm} / \mathrm{yr}$, respectively. These rates are about 4 to 13 time slower that the rates reported for the Wasatch fault zone between Brigham City and Nephi (table 3).

Slip rates ranging from 0.05 to $0.2 \mathrm{~mm} / \mathrm{yr}$ were included in the source model for the East Cache fault (table 1); these rates reflect possible bias in the single point estimate as well as the facts that the slip rates are calculated on the basis of only two slip events and that the timing of the next event could have a significant impact on the calculated slip rates. Most of the weight is assigned to values close to the rates observed near Logan. The average slip rate is assumed to be the same on both segments of the East Cache fault. On the basis of the seismic-hazard analysis, the average recurrence interval for earthquakes of magnitude 7 or greater on the whole East Cache fault zone is $7,500( \pm 2,700)$ years.

\section{WEST VALLEY FAULT ZONE}

The West Valley fault zone, originally called the Jordan Valley fault zone and subsequently renamed by Keaton and others (1986), consists of a series of mostly east-dipping normal faults that displace late Quaternary lake deposits in Salt Lake Valley. West-facing scarps form graben locally. As mapped by Keaton and others (1986), the total length of the zone is about $18 \mathrm{~km}$. The fault zone is within about $5 \mathrm{~km}$ of downtown Salt Lake City (figs. 1, 13).

\section{Activity}

The relation of the West Valley fault zone to the Wasatch fault zone is not clear. The short length relative to the height of the fault scarps, the discontinuous nature of the fault, and its close proximity to the Wasatch fault indicate that the West Valley fault zone may represent sympathetic faulting caused by large earthquakes on the Wasatch fault zone. Keaton and others (1986) argued that the size of the fault scarps, the location of earthquake epi- 
centers in the central part of Salt Lake Valley, and the evidence for repeated Holocene displacements strongly suggest that the West Valley fault zone is a seismogenic structure that operates independently of the Wasatch fault zone. Both of these interpretations are included in the analysis with equal probability.

\section{Maximum Earthquake Magnitude}

Given the fact that the West Valley is an independently active source, it is modeled as a single fault segment because its overall length is so short. The maximum rupture length is assumed to be equal to the total length of the zone $(18 \mathrm{~km})$. The probability distribution for the maximum earthquake magnitude on the West Valley fault was calculated on the basis of a rupture length of $18 \mathrm{~km}$. The range of downdip geometries considered included the effect of truncation of the fault by the west-dipping Wasatch fault. The maximum earthquake magnitude probability distribution is presented in table 1 . The available data indicate that the most likely maximum magnitude on the West Valley fault zone is about $6 \frac{1}{2}$ if the fault is an independent seismogenic structure.

\section{Earthquake Recurrence Rate}

The earthquake recurrence on the West Valley fault zone is estimated on the basis of Holocene slip-rate data from Keaton and others (1986). The ranges of values that they calculated for different post-Lake Bonneville marker horizons (12,000 years old and younger) indicate that the Holocene slip rate is likely to be in the range of 0.3 to 0.5 $\mathrm{mm} / \mathrm{yr}$. The actual slip rate is judged equally likely to be anywhere within this range; therefore, both values are assigned equal weights (table 1). If it is assumed that the West Valley fault zone is independently generating earthquakes, these values yield a repeat time for earthquakes of magnitude $6 \frac{1}{2}$ or greater of about 8,000 years. This value is within the range of Keaton and others' preliminary estimates for the recurrence of surface-faulting events based on their displacement data.

\section{HANSEL VALLEY FAULT ZONE}

Hansel Valley was the source of the March 12, 1934, Hansel Valley earthquake ( $M_{L}$ 6.6). Surface-fault rupture occurring along the western side of Hansel Valley for a distance of about $11 \mathrm{~km}$ produced a series of scarps up to half a meter high in an area of older Holocene fault scarps (Anderson and Miller, 1979). Slemmons (1977) reported a maximum displacement of $1.2 \mathrm{~m}$ for this event. The zone of Quaternary faulting is inferred to extend northward along the western flank of the Hansel Mountains (Anderson and Miller, 1979), this inference suggesting a total fault length of about $25 \mathrm{~km}$. The activity of the northern part of the zone is not known.

\section{Segmentation}

Despite the short length of the fault, both an unsegmented and a segmented model are included in the source model for the Hansel Valley fault because of the apparent differences in the Quaternary displacements along the fault. Nonetheless, because of the short overall length of the fault, it seems less likely that the segmented model would define the maximum earthquake. Accordingly, the unsegmented model is assigned a slightly higher weight (0.6) than the segmented model (0.4) (table 1).

\section{Activity}

If the fault is unsegmented, then the entire length of the fault is assumed to be active. In the segmented model, the fault is divided into two segments. The southern segment coincides with the 1934 surface rupture, and the northern segment consists of the 14-km-long inferred extension to the north. The segment boundary coincides with a marked change in the character of the range and a large saddle along the crest of the range. The northern segment is assumed to have a 50-50 chance of being active (table 1).

\section{Maximum Earthquake Magnitude}

Given the unsegmented model, it is assumed that the entire 25-km-long fault could rupture during the maximum earthquake; given the segmented model, the maximum rupture lengths are assumed to be equal to the segment lengths (table 1). Table 1 shows the discretized distribution resulting from the maximum earthquake magnitude logic tree. Given the unsegmented model, the expected maximum magnitude is about $63 / 4$. Given the segmented model, the expected value is about magnitude $61 / 2$ for both segments. In this case, the 1934 Hansel Valley earthquake would represent a maximum event.

\section{Earthquake Recurrence Rate}

For the unsegmented fault model and for the segmented model for the North Hansel Mountains segment of the zone, the rate of earthquake recurrence is estimated on the basis of slip rate. The rate on the South Hansel Mountains segment also incorporates the results of McCalpin's (1985) study of the Quaternary history of faulting in the Hansel Valley area.

Slip-rate data on the Hansel Valley fault are not well constrained. McCalpin (1985) reported that the probable tectonic throw during the past 26,000 years ranges from 
1.2 to $2.5 \mathrm{~m}$. This suggests a slip rate of from $0.05 \mathrm{~mm} / \mathrm{yr}$ to $0.1 \mathrm{~mm} / \mathrm{yr}$. These values were used to characterize the average slip rate on the Hansel Mountains segment and for the entire fault for the unsegmented model (table 1). The values were assigned equal weight.

McCalpin inferred that there have been three surfacefaulting events in Hansel Valley during about the past 26,000 years. This estimate suggests an average recurrence interval of about 8,700 years. He reported that the most recent event prior to the 1934 earthquake occurred about 12,000 years ago, indicating an interval of about 12,000 years between events. These two estimates of the recurrence rate were assigned equal weight (table 1).

Given the segmented model, there are no available data to constrain the timing of past events or the slip rate on the North Hansel Mountains segment. The lack of evidence for late Quaternary faulting and the subdued geomorphic expression of the fault indicate that the slip rate on the North Hansel Mountains segment is comparable to or less than the slip rate on the South Hansel Mountains segment. Slip rates ranging from 0.01 to $0.1 \mathrm{~mm} / \mathrm{yr}$ were assigned for the North Hansel Mountains segment. The recurrence interval for earthquakes of magnitude $6 \frac{1}{2}$ or greater on the Hansel Valley fault zone is $11,000( \pm 5,000)$ years.

\section{EAST BEAR LAKE FAULT}

The East Bear Lake fault is approximately 65 to 75 km east of the Wasatch Front (figs. 1, 13). It is an approximately $50-\mathrm{km}$-long westward-dipping normal fault that lies along the eastern side of Bear Lake and Bear Lake Valley, separating the valley to the west from the Bear Lake Plateau and the southern part of the Aspen Range to the east.

\section{Segmentation}

Both unsegmented and segmented fault-rupture models are included in the source model for the East Bear Lake fault. Preliminary reconnaissance of the East Bear Lake fault by the USGS suggested that the late Quaternary history of faulting is different for the northern and southern parts of the fault (A.J. Crone and M.N. Machette, 1986, personal commun., 1986). North of Bear Lake, the fault appears to have undergone very recent displacement. Where the fault crosses the alluvial terraces along Bear River, the fault scarps appear to displace all but the youngest meander scars, suggesting late Holocene faulting. To the south, no evidence of Holocene faulting has been observed. Wave-cut scarps associated with higher middle Holocene(?) lake levels postdate the most recent faulting. The youngest deposit, displaced by the fault where it crosses North Eden Canyon and South Eden Canyon, is estimated by A.J. Crone (personal commun., 1986) to be late Pleistocene in age (approximately 15,000 years old). It is possible that the recent faulting observed to the north also occurs to the south on a fault trace that might be beneath the lake west of the mapped trace of the fault. Accordingly, two models are considered: an unsegmented model that treats the fault as a single $50-\mathrm{km}$-long fault and a segmented model that treats the $23-\mathrm{km}$-long Montpelier segment to the north and the 27-km-long Bear Lake segment to the south as independent sources characterized by different fault behaviors. The available data suggest that the fault is segmented, so the unsegmented model is assigned a weight of only 0.2 (tables 2,3 ).

\section{Maximum Earthquake Magnitude}

Except for the lack of data on the amount of displacement per event, the approach used to estimate the probability distribution for the maximum earthquake magnitude is the same as that used for the Wasatch fault zone. If the East Bear Lake fault is unsegmented, two maximum rupture lengths are considered. Because there have been historical surface-fault ruptures in the Basin and Range as long as $61 \mathrm{~km}, 100$ percent rupture of the 50$\mathrm{km}$-long East Bear Lake fault is considered as a possible maximum rupture length. Twenty-seven kilometers, which is the length of the longest segment and is approximately equivalent to 50 percent of the mapped length of the fault, is considered to be a slightly more likely maximum rupture length (table 2). Regardless of the segmentation model, the most likely maximum earthquake on the East Bear Lake fault is $63 / 4$ to 7 (table 1).

Earthquake Recurrence Rate

The available data indicate a long interval between surface-faulting events on the East Bear Lake fault. The rate of activity is probably less than the rate of activity on the East Cache fault. On the basis of their limited reconnaissance investigations of the fault, M.N. Machette and A.J. Crone (personal commun., 1987) estimated that there has been only one surface-faulting event on the Montpelier segment during approximately the past 8,000 years. The freshness of the fault scarp indicates that this event, which had a displacement of about $2 \mathrm{~m}$, probably occurred fairly recently. There do not appear to have been any faulting events on the Bear Lake segment for about the past 15,000 years. Despite the poor constraints on the recurrence interval for the East Bear Lake fault, the available evidence clearly indicates that the fault is significantly less active than the Wasatch fault. Intervals of 8,000 and 15,000 years are assumed to characterize the recur- 
rence of surface-faulting events on the Montpelier and Bear Lake segments, respectively, and the slip rate is assumed to be on the order of 0.05 to $0.1 \mathrm{~mm} / \mathrm{yr}$ (table 1 ). The seismic-hazard model gives a return period for maximum events of $7,200( \pm 2,000)$ years for the fault zone.

\section{COMPARISON OF PREDICTED AND OBSERVED EARTHQUAKE FREQUENCY}

The hazard model developed above can be used to predict regional earthquake recurrence rates. Figure 15 compares predicted earthquake cumulative frequencies with the observed seismicity rate. Figure $15 \mathrm{~A}$ shows the mean recurrence estimates for individual sources and the sum of the recurrence for all sources. The recurrence estimates for the West Valley fault and the Oquirrh Mountains fault zone have been weighted by the probabilities of activity assigned to the various segments. Figure $15 B$ compares the fractiles of the distribution for earthquake recurrence obtained from the distribution in source parameters with the one-standard-deviation error bars on the regional seismicity rate. As can be seen, the sum of the predicted rates for all sources yields an estimated rate consistent with the historical record. The wider distribution in the estimated frequency of events near magnitude 6 results from uncertainty in the appropriate form of the magnitude distribution. The Wasatch fault zone represents the dominate source of potential future large-magnitude events in the region.

\section{ATTENUATION RELATIONSHIPS}

Attenuation relationships define the values of a ground-motion parameter, such as peak ground acceleration, velocity, displacement, or response spectral values, as a function of earthquake magnitude and distance. For this study, attenuation relationships for peak ground acceleration and response spectral accelerations are required as inputs to the probabilistic ground-motion analysis.

Attenuation relationships in the United States that are well constrained by strong-motion data have been developed on the basis of statistical analyses of data that are largely from California. To date, only one strongmotion recording has been obtained in Utah-in Logan at a distance of about $30 \mathrm{~km}$ from the $1962 \mathrm{M}_{\mathrm{L}} 5.7$ Cache Valley earthquake. During the $1983 \mathrm{M}_{\mathrm{S}} 7.3$ Borah Peak, Idaho, earthquake, several recordings were obtained in Idaho at distances of about 90 to $100 \mathrm{~km}$. Aftershocks of the Borah Peak earthquake produced recordings at closer distances. The appendix to this paper compares ground-motion data recorded during these earthquakes with recently developed attenuation relationships that are based largely on data from California. From the comparisons presented in the appendix, it is concluded that the Cache Valley and the Borah Peak data exhibit the degree of scatter relative to the attenuation curves that is typically observed in strong-motion data. The data are too limited to either strongly support or refute the applicability of California attenuation relationships to Utah.

In general, the earthquake ground motion recorded at a site can be viewed as the product of the earthquake source characteristics, the attenuation characteristics along the travel path between the earthquake source and the site, and the local site effects. Each of these factors may influence the attenuation relationships appropriate for a given region. Evidence regarding similarities or differences between these factors for Utah and California are briefly reviewed below.

\section{EARTHQUAKE SOURCE CHARACTERISTICS}

McGarr $(1982,1984)$ has suggested that normal faulting, the type of faulting expected for major earthquakes along the Wasatch front, produces weaker ground motion than strike-slip faulting or reverse faulting for a given size event. Because California-type attenuation relationships are based on strong-motion data predominantly from strike-slip and reverse faulting earthquakes, McGarr's studies suggest that the normal faulting environment might result in lower ground motion in Utah than in California. On the other hand, studies reported by Campbell (this volume) indicated only minor differences in groundmotion attenuation between extensional and compressive stress environments within California. Campbell (this volume) also found significantly stronger ground motion for dip-slip faulting than for vertical strike-slip faulting. However, his results for dip-slip faulting are based on data taken almost entirely from reverse- and thrust-faulting earthquakes. The most comprehensive study to date of ground motion recorded during normal-faulting earthquakes was done by Westaway and Smith (1989). They evaluated peak ground accelerations recorded during normal-faulting earthquakes in the Western United States, Italy, Greece, Turkey, and New Zealand and concluded that such earthquakes result in peak ground accelerations equivalent to those seen in reverse-faulting and strike-slip earthquakes. Their studies found no evidence that weaker ground motions result from normal-faulting earthquakes.

\section{SOURCE-TO-SITE ATTENUATION CHARACTERISTICS}

Several studies have addressed regional attenuation characteristics in Utah and in adjacent and broader regions of the Western United States. King and Hays (1977) analyzed velocity seismograph data in northern Utah from four aftershocks $\left(\mathrm{M}_{\mathrm{L}} 2.9-4.1\right)$ of the 1975 Pocatello Valley, Idaho, earthquake. They concluded that 
higher frequency (greater than $1 \mathrm{~Hz}$ ) response spectral values in northern Utah attenuated at a faster rate than those in California.

Griscom and Arabasz (1979) examined regional attenuation in Utah from a study of Wood-Anderson seismograph data. They concluded that the rate of attenuation in Utah might be greater than the rate of attenuation in southern California. Griscom (1980) analyzed WoodAnderson seismograph data for Utah and also analyzed the attenuation of Modified Mercalli intensities for five Utah earthquakes. On the basis of both these analyses, she concluded that attenuation in Utah may be slightly greater than that in coastal California.

McGuire (1983) analyzed the attenuation of Modified Mercalli intensities for five northern Utah earthquakes and four other earthquakes from the Rocky Mountain region. He combined results of his analyses of intensity attenuation with ground motion versus intensity relationships (the latter relationships based largely on California strong-motion data) to derive ground motion attenuation relationships for northern Utah. By comparing his derived expression for velocity attenuation with the attenuation relationships for Wood-Anderson seismograph standard amplitudes for California, McGuire concluded that the rate of velocity attenuation in Utah could be slightly lower than that in California, but that, given the uncertainties in the analysis, the differences were not resolvable.

Several studies have examined Modified Mercalli intensity attenuation in broad regions of the United States. As they pertain to evaluating attenuation along the Wasatch Front in northern Utah, all of these studies have the limitation that the regions considered are much larger than the specific region of the Wasatch Front. The studies by Evernden (1975), Howell and Schultz (1975), Chandra (1979), and Brazee (1980) all indicate that the rate of intensity attenuation in the western mountain States is somewhat lower than that in California.

Recent studies have also been conducted of the intrinsic attenuation properties of the crust in different regions of the United States. Singh and Herrmann's (1983) regionalization of $Q$ throughout the United States indicates that the rate of attenuation in Utah is lower than that in California. Chavez and Priestly (1985) found that the rate of attenuation at the Wood-Anderson instrument frequency (approximately $1.25 \mathrm{~Hz}$ ) in Nevada was greater than that in southern California and equal to or slightly less than that in central California. On the other hand, Rogers and others (1987) concluded that the rate of attenuation in the southern Great Basin of Nevada and California was lower than that in central and southern California. Although these studies address intrinsic crustal attenuation over broad regions of the country, including Utah and other parts of the Great Basin, they have the limitation of not specifically addressing attenuation in Utah.

The available evidence summarized above is equivocal. The studies that have focused specifically on Utah (King and Hays, 1977; Griscom and Arabasz, 1979; Griscom, 1980; McGuire, 1983) suggest that the rate of attenuation in Utah is comparable to or perhaps greater than the rate of attenuation in California. On the other hand, some broad regional studies suggest that the rate of attenuation in Utah may be less than that in California.

\section{LOCAL SITE EFFECTS}

Local site conditions can also influence attenuation relationships. With the exception of areas underlain by lake deposits, the subsurface soil and rock conditions along the Wasatch Front are considered to be comparable to the range of conditions in California where ground motions have been recorded. Therefore, except for areas underlain by lake deposits, site effects are not expected to lead to significant differences between attenuation relationships for Utah and those for California.

Shear-wave velocities of sediments for many locations in Salt Lake Valley along the Wasatch Front have been reported by Tinsley and others (1991). At several of these locations, the lake deposits exhibit shear-wave velocities that are lower than those of typical alluvial sites in California where ground motions have been recorded. At such locations on the lake deposits, it may be anticipated that low-amplitude peak ground accelerations will be amplified relative to peak accelerations on firm soils and rock; however, high-amplitude peak accelerations may experience little or no amplification or might even experience deamplification owing to nonlinear soil response (Seed and others, 1976a; Idriss, 1991). Studies by Idriss (1990) suggest that the demarcation between amplification and deamplification of peak ground acceleration may be defined by a peak rock acceleration of about $0.4 \mathrm{~g}$ for earthquakes of magnitude approximately equal to 7 .

Hays and King (1982, 1984a, b), King and others (1983), and Rogers and others (1984) have investigated site response effects on response spectral values along the Wasatch Front during very small amplitude motions produced mainly by distant underground nuclear blasts at the Nevada Test Site. Their studies indicate large spectral values for ground motions on the lake deposits relative to rock or to shallower, coarser grained soils along the Wasatch Front. Also, comparison of their results with similar data for younger soil deposits in the Los Angeles region of California (Rogers and others, 1985) indicates that soil-to-rock spectral ratios for the lake deposits are significantly larger than those for the California soil deposits. The results of studies by Hays and King (1982, 
1984a, b), King and others (1983), and Rogers and others (1984) provide an excellent guide to the relative soil amplification hazard of different geologic conditions along the Wasatch Front during future earthquakes. At present, it is difficult to use these results to quantify absolute levels of response spectral attenuation relationships for the lake deposits for strong ground-shaking conditions because of potentially significant differences in the values of the spectral ratios for strong earthquake shaking as compared with those for very small ainplitude shaking. The potential differences arise from nonlinear soil response effects and possibly from differences in the duration and frequency content of motions from local earthquakes and distant nuclear blasts.

Another factor that could influence ground motion along the Wasatch Front is the valley subsurface geometry (two- and three-dimensional wave-propagation effects). Benz and Smith (1988) conducted two-dimensional simulations of wave propagation and site amplification due to normal-faulting earthquakes in the Salt Lake Valley. Their studies indicate that the basin geometry could significantly influence ground motions. However, basin effects on attenuation relationships have not been quantified to date.

On the basis of presently available data and the evaluations discussed earlier, it is reasonable to assume that California attenuation relationships are applicable to areas along the Wasatch Front underlain by rock and stiffer, denser soils such as predominantly sandy and gravelly fluvial and deltaic deposits. These relationships are probably not applicable to areas of soft lake clays and silts, but alternative relationships are not available at present. The possible influence of soft soil conditions on response spectra obtained from the analysis is discussed later.

The attenuation relationships selected for the basic analyses are summarized below. Also summarized is a modified peak acceleration attenuation relationship that exhibits a lower rate of attenuation than the relationships used in the basic analyses. This relationship was developed and used to test the sensitivity of the results to a rate of crustal intrinsic attenuation that may possibly be lower in Utah than it is in California.

\section{SELECTED ATTENUATION RELATIONSHIPS FOR PEAK GROUND ACCELERATION}

Two sets of peak acceleration attenuation relationships have been used in the basic analyses: one set for firm soil-site conditions and the other for rock-site conditions. The soil-site set of relationships includes the relationships of Joyner and Boore (1982), Sadigh and others (1986), and Campbell (this volume). The modified rela- tionship, which is consistent in this respect with the relationships of Sadigh and others (1986) and Campbell (this volume), was used. Sadigh and others' (1986) relationship is summarized in table 4. Campbell's (this volume) relationship incorporates an anelastic attenuation term; his value of anelastic attenuation for California was used. Sadigh and others (1986) and Campbell (this volume) distinguished the effect of the type of faulting (whether strike slip or reverse) in their attenuation relationships. Their relationships for strike-slip faulting, which give lower peak accelerations than those for reverse faulting, were used.

McGuire's (1983) attenuation relationships were not used in the analysis because of the large uncertainties involved in deriving peak acceleration attenuation relationships from intensity data. McGuire's relationships show about the same rate of attenuation as those selected for use and differ significantly in amplitude (give higher amplitudes) only for events of magnitude less than about $\mathrm{M}_{\mathrm{L}} 6$.

The median attenuation curves for the selected relationships are compared in figure 16 for earthquake magnitudes of 5.5, 6.5, and 7.5. The relationships were developed by using magnitude definitions that are equivalent to $M_{L}$ magnitude in the range of 3 to 7 and $M_{S}$ magnitude in the range of 5 to 7.5. As discussed earlier, it is assumed that the relationship between strong ground motion and $\mathrm{M}_{\mathrm{L}}$ and $\mathrm{M}_{\mathrm{S}}$ magnitudes in Utah is similar to what has been observed in California.

Distance definitions for the attenuation relationships differ. For purposes of the comparisons shown in figure 16 , distance is as defined by each investigator (closest distance to fault-rupture surface for Sadigh and others (1986), closest distance to fault-rupture surface in the seismogenic zone for Campbell (this volume), and closest horizontal distance to the vertical projection of fault rupture to the ground surface for Joyner and Boore (1982). In using Campbell's (this volume) relationship, a depth to the seismogenic zone of $2 \mathrm{~km}$ has been assumed. Therefore, in figure 16, acceleration values are not plotted for distances less than $2 \mathrm{~km}$ for Campbell's relationship. In the probabilistic seismic-hazard analysis, distances used in each case are consistent with the definitions for the respective relationships.

The rock-site set of relationships selected for the analysis includes two of the above-mentioned relationships-Joyner and Boore (1982) and Campbell (this volume)-and two additional relationships-those of Seed and Schnabel (1980) and Sadigh and others (1986) (the latter relationship is summarized in table 4). The relationships of Seed and Schnabel (1980) and Sadigh and others (1986) shown in figure 16 were specifically developed for rock-site conditions. The relationship of Joyner and Boore (1982) does not distinguish between peak ground 
TABLE 4.-Values of coefficients for the attenuation relationships of Sadigh and others (1986) for horizontal peak ground acceleration and pseudo-absolute spectral accelerations

[Coefficients $b_{1}$ through $b_{7}$ are for use in the relationship $\ln y+b_{1}+b_{2} M=b_{3}(8.5-M)^{b} 4+b_{5} \ln \left(R+b_{6} \mathrm{e}_{7} M\right)$, where $M$ is moment magnitude. $\sigma_{y}$ is the standard error of estimate of the relationship. The relationships are those derived for strike-slip-faulting earthquakes]

\begin{tabular}{|c|c|c|c|c|c|c|c|c|c|}
\hline \multirow{2}{*}{ Ground motion parameter $y$} & \multirow{2}{*}{ Period (s) } & \multicolumn{8}{|c|}{ Coefficient } \\
\hline & & $b_{1}$ & $b_{2}$ & $b_{3}$ & $b_{4}$ & $b_{5}$ & $b_{6}$ & $b_{7}$ & $b_{y}$ \\
\hline \multicolumn{10}{|c|}{ Soil-site conditions } \\
\hline Peak ground acceleration & $\sim 0.03$ & -2.611 & 1.1 & 0 & 2.5 & -1.75 & $\begin{array}{l}0.8217^{\mathrm{l}} \\
.315^{2}\end{array}$ & $\begin{array}{c}0.4814^{1} \\
.628^{2}\end{array}$ & $\begin{array}{l}1.260-14 M^{1} \\
.35^{2}\end{array}$ \\
\hline \multirow[t]{7}{*}{$\begin{array}{l}\text { Pseudo-absolute spectral accelera- } \\
\text { tion (5-percent damping) }\end{array}$} & .1 & -2.024 & 1.1 & .007 & 2.5 & -1.75 & $\begin{array}{l}.8217^{1} \\
.315^{2}\end{array}$ & $\begin{array}{l}.4814^{1} \\
.6286^{2}\end{array}$ & $\begin{array}{l}1.332-1.48 M^{1} \\
.37^{2}\end{array}$ \\
\hline & .2 & -1.696 & 1.1 & 0 & 2.5 & -1.75 & $\begin{array}{l}.8217^{1} \\
.3157^{2}\end{array}$ & $\begin{array}{l}.4814^{1} \\
.6286^{2}\end{array}$ & $\begin{array}{l}1.453-.162 M^{1} \\
.40^{2}\end{array}$ \\
\hline & .3 & -1.638 & 1.1 & -.008 & 2.5 & -1.75 & $\begin{array}{l}.8217^{1} \\
.3157^{2}\end{array}$ & $\begin{array}{l}.4814^{1} \\
.6286^{2}\end{array}$ & $\begin{array}{l}1.486-.164 M^{1} \\
.42^{2}\end{array}$ \\
\hline & .5 & -1.659 & 1.1 & -.025 & 2.5 & -1.75 & $\begin{array}{l}.8217^{1} \\
.3157^{2}\end{array}$ & $\begin{array}{l}.4814^{1} \\
.6286^{2}\end{array}$ & $\begin{array}{l}1.584-.176 M^{1} \\
.44^{2}\end{array}$ \\
\hline & 1.0 & -1.975 & 1.1 & -.060 & 2.5 & -1.75 & $\begin{array}{l}.8217^{1} \\
.3157^{2}\end{array}$ & $\begin{array}{l}.4814^{1} \\
.6286^{2}\end{array}$ & $\begin{array}{l}1.62-.18 M^{1} \\
.45^{2}\end{array}$ \\
\hline & 2.0 & -2.414 & 1.1 & -.105 & 2.5 & -1.75 & $\begin{array}{l}.8217^{1} \\
.3157^{2}\end{array}$ & $\begin{array}{l}.4814^{1} \\
.6286^{2}\end{array}$ & $\begin{array}{l}1.62-.18 M^{1} \\
.45^{2}\end{array}$ \\
\hline & 4.0 & -3.068 & 1.1 & -.160 & 2.5 & -1.75 & $\begin{array}{l}.8217^{1} \\
.3157^{2}\end{array}$ & $\begin{array}{l}.4814^{1} \\
.6286^{2}\end{array}$ & $\begin{array}{l}1.62-.18 M^{1} \\
.45^{2}\end{array}$ \\
\hline \multicolumn{10}{|c|}{ Rock-site conditions } \\
\hline Peak ground acceleration & $\sim 0.03$ & -1.406 & 1.1 & 0 & 2.5 & -2.05 & $\begin{array}{r}1.353^{1} \\
.579^{2}\end{array}$ & $\begin{array}{r}0.406^{1} \\
.537^{2}\end{array}$ & $\begin{array}{l}1.26-0.14 M^{1} \\
.35^{2}\end{array}$ \\
\hline \multirow[t]{7}{*}{$\begin{array}{l}\text { Pseudo-absolute spectral accelera- } \\
\text { tion (5-percent damping) }\end{array}$} & .1 & -.688 & 1.1 & .007 & 2.5 & -2.05 & $\begin{array}{r}1.353^{1} \\
.579^{2}\end{array}$ & $\begin{array}{l}.406^{1} \\
.537^{2}\end{array}$ & $\begin{array}{l}1.332-.148 M^{1} \\
.37^{2}\end{array}$ \\
\hline & .2 & -.479 & 1.1 & -.008 & 2.5 & -2.05 & $\begin{array}{r}1.353^{1} \\
.579^{2}\end{array}$ & $\begin{array}{l}.406^{1} \\
.537^{2}\end{array}$ & $\begin{array}{l}1.453-162 M^{1} \\
40^{2}\end{array}$ \\
\hline & .3 & -.543 & 1.1 & -.018 & 2.5 & -2.05 & $\begin{array}{r}1.353^{1} \\
.579^{2}\end{array}$ & $\begin{array}{l}.406^{1} \\
.537^{2}\end{array}$ & $\begin{array}{l}1.486-.164 M^{1} \\
.4^{22}\end{array}$ \\
\hline & .5 & -.793 & 1.1 & -.036 & 2.5 & -2.05 & $\begin{array}{r}1.353^{1} \\
.579^{2}\end{array}$ & $\begin{array}{l}.406^{1} \\
.537^{2}\end{array}$ & $\begin{array}{l}1.584-.176 M^{1} \\
.44^{2}\end{array}$ \\
\hline & 1.0 & -1.376 & 1.1 & -.065 & 2.5 & -2.05 & $\begin{array}{r}1.353^{1} \\
.579^{2}\end{array}$ & $\begin{array}{l}.406^{1} \\
.537^{2}\end{array}$ & $\begin{array}{l}1.62-.18 M^{1} \\
.45^{2}\end{array}$ \\
\hline & 2.0 & -2.142 & 1.1 & -.100 & 2.5 & -2.05 & $\begin{array}{r}1.353^{1} \\
.579^{2}\end{array}$ & $\begin{array}{l}.406^{1} \\
.537^{2}\end{array}$ & $\begin{array}{l}1.62-.18 M^{1} \\
.45^{2}\end{array}$ \\
\hline & 4.0 & -3.177 & 1.1 & -.150 & 2.5 & -2.05 & $\begin{array}{r}1.353^{1} \\
.579^{2}\end{array}$ & $\begin{array}{l}.406^{1} \\
.537^{2}\end{array}$ & $\begin{array}{l}1.62-.18 M^{1} \\
.45^{2}\end{array}$ \\
\hline
\end{tabular}

$\mathrm{1}_{\text {Magnitude }<6.5}$

${ }^{2}$ Magnitude $\geq 6.5$. 


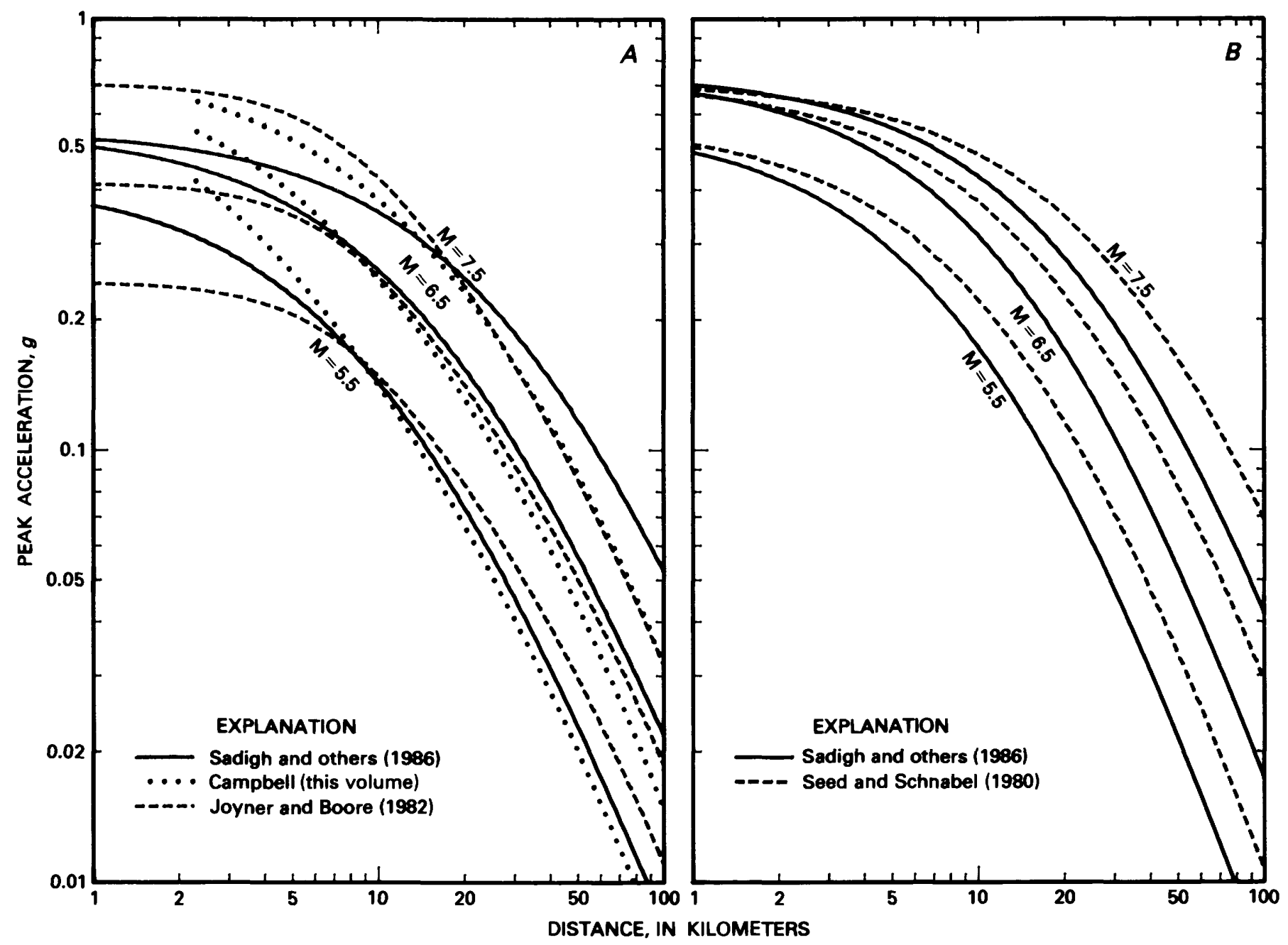

FIGURE 16.-Peak horizontal acceleration attenuation relationships used in seismic hazard analysis. $A$, Soil. $B$, Rock.

accelerations on soil and those on rock. The relationship of Campbell (this volume) uses data from soil sites only; however, Campbell (this volume) indicated that the ground-motion estimates obtained therefrom are probably also appropriate for rock, at least for source-to-site distances of about $50 \mathrm{~km}$ or less. K.W. Campbell (personal commun., 1987) indicated that predicting peak accelerations on rock and on soil may be little different at small distances but that, at large distances, predictions on rock may be substantially lower than those on soil, an indication that using his relationship for rock-site conditions may be conservative. Overall, the four rock-site relationships used in the analysis describe median peak accelerations averaging about 15 percent higher than those of the three soil-site relationships within a distance of $50 \mathrm{~km}$, decreasing to about 5 percent higher at a distance of $200 \mathrm{~km}$.
The standard deviations in the predicted accelerations recommended by the developers of each attenuation relationship are incorporated into the seismic-hazard analysis through the evaluation of the term $\mathrm{P}(Z>z \mid m, r)$ in equation 2 . The standard deviations differ significantly among the three relationships, being lowest for the relationship of Campbell (this volume) and highest for that of Joyner and Boore (1982). Seed and Schnabel (1980) did not report a standard deviation for their attenuation curves, so the standard deviations defined by Sadigh and others (1986) were used for their curves.

Separate sets of probabilistic ground-motion analyses were made by using the soil-site set and the rock-site set of attenuation relationships described above. In each set of analyses, the different attenuation relationships were given equal weight in the logic tree formulation (fig. 2). 


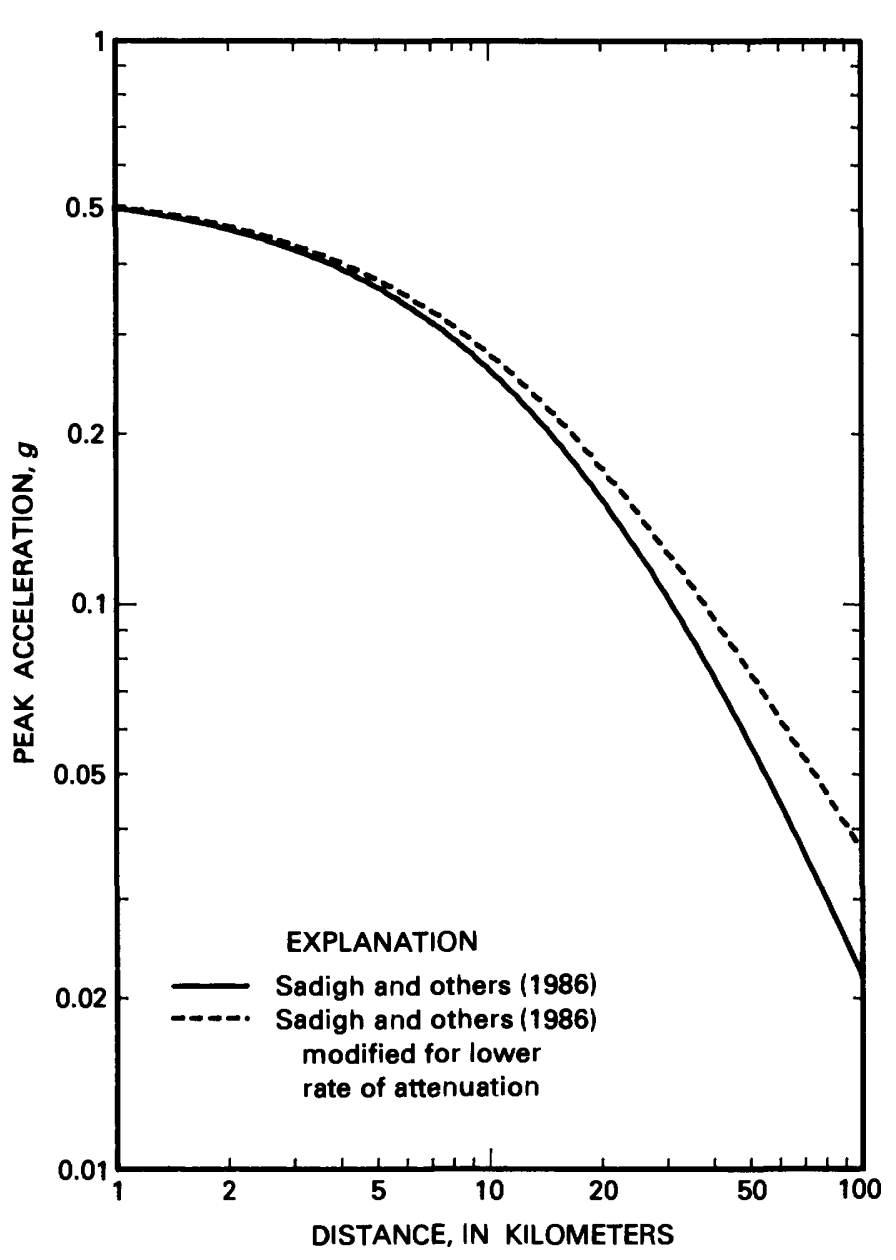

FIGURE 17.-Peak horizontal acceleration relationships for a magnitude 6.5 event modified for slower rate of attenuation.

For the sensitivity analyses conducted for a lesser rate of attenuation, the following equation was derived to modify the attenuation relationships used in the basic analyses:

$$
a_{s}=a(1+0.00675 R)
$$

where $a_{s}$ is the peak acceleration adjusted for the lesser degree of attenuation used in the sensitivity analysis, $a$ is the peak acceleration defined by each attenuation relationship used in the basic analyses, and $R$ is source-to-site distance in kilometers. The effect of this modifying relationship on attenuation is illustrated in figure 17 for an attenuation curve for magnitude 6.5 constructed from the relationship of Sadigh and others (1986).

Equation 3 was derived in the following manner. Owing to differences in anelastic attenuation between regions, the ratio of peak acceleration in a region having a slower rate of attenuation to peak acceleration in a region having a faster rate of attenuation can be expressed as

$$
a_{s} / a=\mathrm{e}^{R\left(\gamma_{f}-\gamma_{s}\right)}
$$

where $\gamma_{f}$ and $\gamma_{s}$ are the coefficients of anelastic attenuation for the regions of faster and slower attenuation, respectively. Campbell (1982) evaluated the values of the coefficient of anelastic attenuation for California and Utah on the basis of the regionalization of crustal $Q$ in the United States by Singh (1981) (see also Singh and Herrmann, 1983) and the recommendations for predominant periods of ground motion developed by Seed and others (1969). The values of $\gamma$ derived by Campbell (1982) for California are higher than those for Utah. Equation 3 is a close approximation to equation 4 if Campbell's (1982) results over the magnitude range 5.5 to 7.5 and the distance range 0 to $100 \mathrm{~km}$ are used.

Rogers and others (1986) estimated $Q$ in the southern Great Basin to be nearly frequency independent and in the range of about 700 to 900 . The corresponding value of $\gamma$ can be evaluated from the expression $\gamma=\pi f / v Q$, where $f$ is frequency and $v$ is the seismic-wave velocity. Taking $v=3.5$ $\mathrm{km} / \mathrm{s}$, as Rogers and others (1986) assumed, and $Q=800$ leads to the following approximate expression for $\gamma$ :

$$
\gamma=0.0011 f
$$

If it is assumed that Rogers and others' (1987) results are applicable to Utah, then the ratio of acceleration between Utah and California can be obtained by evaluating $\gamma$ for Utah as a function of frequency by using equation 5, taking $\gamma$ for California equal to 0.0059 (incorporated in Campbell's (1982) acceleration attenuation relationship), and applying equation 4 . The results of this analysis are that, for frequencies equal to or higher than about $5 \mathrm{~Hz}, \gamma$ $\mathrm{Utah}>\gamma$ California. For frequencies in the range of about 1 $\mathrm{Hz}$ to $5 \mathrm{~Hz}, \gamma \mathrm{Utah}<\gamma$ California, but the effect of a lower $\gamma$ for Utah would result in modifications to the basic attenuation relationships that are less than what is defined by equation 3 . Within source-to-site distances of $50 \mathrm{~km}$, it is likely that the frequencies associated with peak accelerations exceed $1 \mathrm{~Hz}$, an indication that equation 3 would provide a conservative assessment of possible modifications to the basic attenuation relationships for peak acceleration. However, for ground motions occurring at low frequencies (such as response spectral values at frequencies less than $1 \mathrm{~Hz}$ ), Rogers and others' (1987) results, if applicable to Utah, would indicate an effect on the attenuation rate greater than that defined by equation 3 .

\section{SELECTED ATTENUATION RELATIONSHIPS FOR RESPONSE SPECTRAL VALUES}

Sadigh and others (1986) and Joyner and Boore (1982) have developed attenuation relationships for response spectral values at 5-percent damping for a num- 


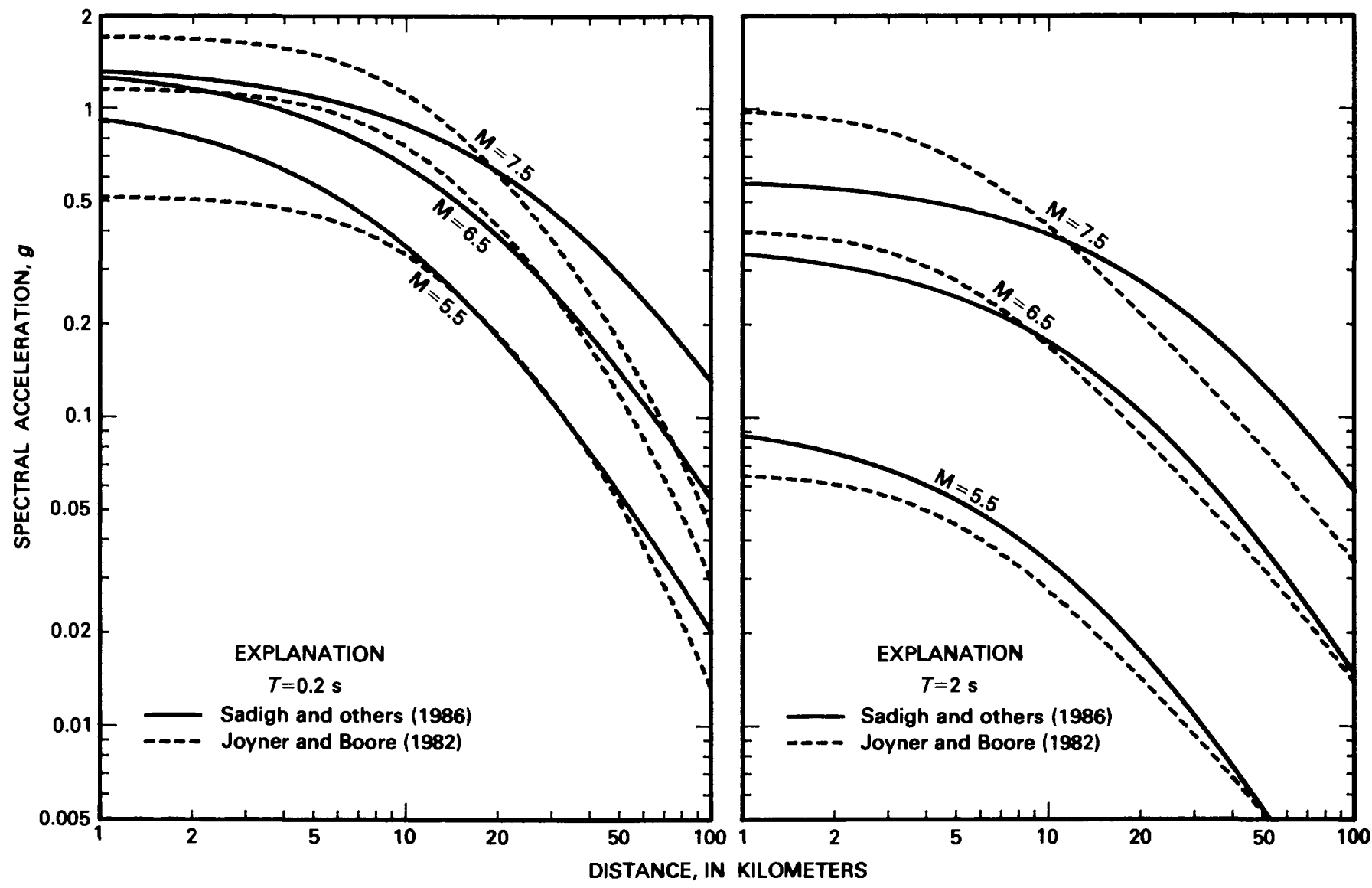

FIGURE 18.-Typical response spectral acceleration attenuation relationships (5-percent damping) for soil-site conditions used in seismic-hazard analysis. Periods of vibration $(T)$ are 0.2 and $2 \mathrm{~s}$.

ber of periods of vibration, for both soil- and rock-site conditions. Sadigh and others' (1986) relationships are summarized in table 4. Joyner and Boore's (1982) relationships have also been summarized by Joyner and Fumal (1985). The relationships of Sadigh and others (1986) and Joyner and Boore (1982), equally weighted, were used in separate sets of analyses for soil- and rock-site conditions in the study. Examples of the attenuation curves defined by both relationships for soil-site conditions are illustrated in figure 18 for periods of vibration of 0.2 and $2 \mathrm{~s}$.

\section{ANALYSIS RESULTS AND SENSITIVITY COMPUTED HAZARD}

The seismic hazard was mapped by performing hazard computations at 80 points located on an irregular grid throughout the study region defined in figure 1. For hazard computations, the individual faults were modeled as segmented planar surfaces, and the background zone was modeled as a set of closely spaced parallel fault planes occupying the background source region outlined in fig- ures 3 and 4 . The probability density function for distance to earthquake rupture for each source was computed on the assumption that earthquake ruptures were uniformly distributed horizontally along the fault and that the focal depths were distributed according to the observed depth distribution for the region independent of magnitude (see fig. 7). The distance density functions were computed consistent with the distance measure used in each of the attenuation relationships. The rupture size of an event was specified by the relationship $\ln$ (rupture area) $=2.146 \mathrm{M}-8.139$, developed from data presented by Wyss (1979). This relationship gives the mean rupture area for a specific magnitude rather than the median (mean log) rupture area. Studies by Bender (1984) have shown that using mean estimates of rupture size in the computation of hazard yields results nearly equal to those obtained when the statistical uncertainty in the size of individual ruptures is incorporated in the analysis.

The hazard was computed by considering the contributions of earthquakes of magnitude $\mathrm{M}_{\mathrm{L}} 5$ and larger. Engineering experience has shown that, even though relatively high peak accelerations have been recorded for 

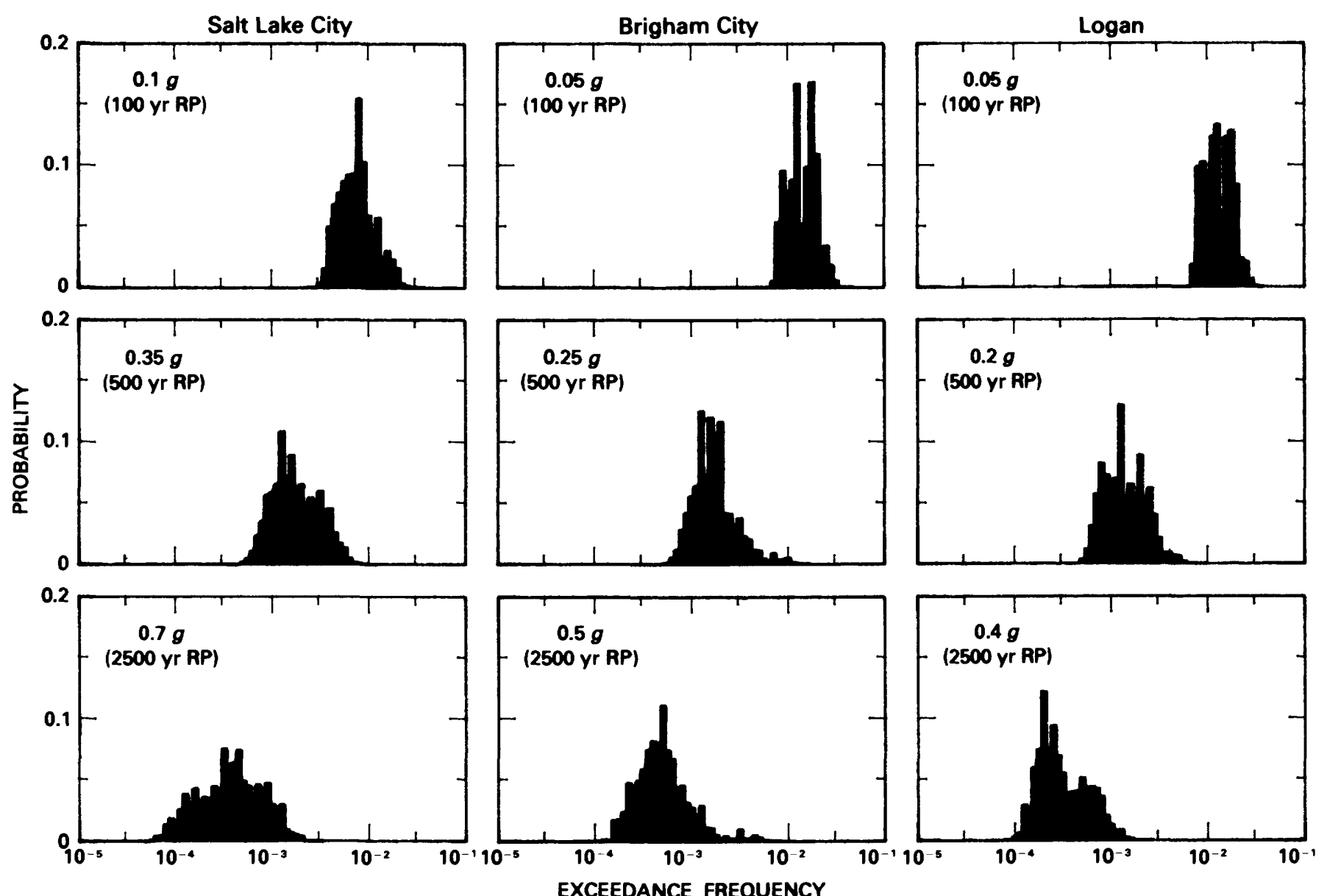

FIGURE 19.-Computed distributions for frequency of exceeding various levels of peak ground acceleration on soil at three locations. The top row of plots are for ground-motion levels having a mean frequency of exceedance corresponding to a return period (RP) of approximately 100 years, the middle row to a return period of 500 years, and the bottom row to a return period of 2,500 years.

earthquakes smaller than magnitude 5 , events of this size generally have not caused structural damage to engineered buildings. Certain facilities may be sensitive to the effects of high-frequency motions from smaller magnitude events, so sensitivity analyses were made in which the contributions to hazard from earthquakes in the magnitude 4 to 5 range were included.

At each point in the study region, distributions for the annual frequency of exceeding various levels of peak ground acceleration were developed by performing hazard computations using equation 2 , the input parameters being defined by each end branch of the logic tree shown in figure 2. At each acceleration level, the complete set of computed results forms a discrete distribution for frequency of exceedance. Figure 19 shows the computed distributions of frequency of exceedance at three locations for a range of peak accelerations on soil sites. The selected acceleration levels correspond to the hazard levels used for the regional hazard mapping discussed below, and the identified return periods represent the mean fre- quency of exceedance for the distributions shown. The results shown are representative of the range in the computed hazard obtained for the study area. At all locations, the computed distributions span approximately one order of magnitude in frequency of exceedance. The factors contributing to the uncertainty in the computed frequencies are discussed later in this section.

The computed distributions were used to obtain the mean frequency of exceeding various levels of peak ground acceleration (mean hazard curve) as well as hazard curves representing various percentiles. Figure 20 shows the resulting hazard curves for points at Salt Lake City, Brigham City, and Logan. These results are for peak horizontal acceleration on soil sites. As indicated in the figure, the distributions in frequency of exceedance are somewhat skewed about the mean value, the mean hazard curve being located at about the 60th percentile of the distributions. The 90-percent confidence interval (5th to 95th percentile levels) in peak acceleration at a given frequency of exceedance typically represent a variation of 

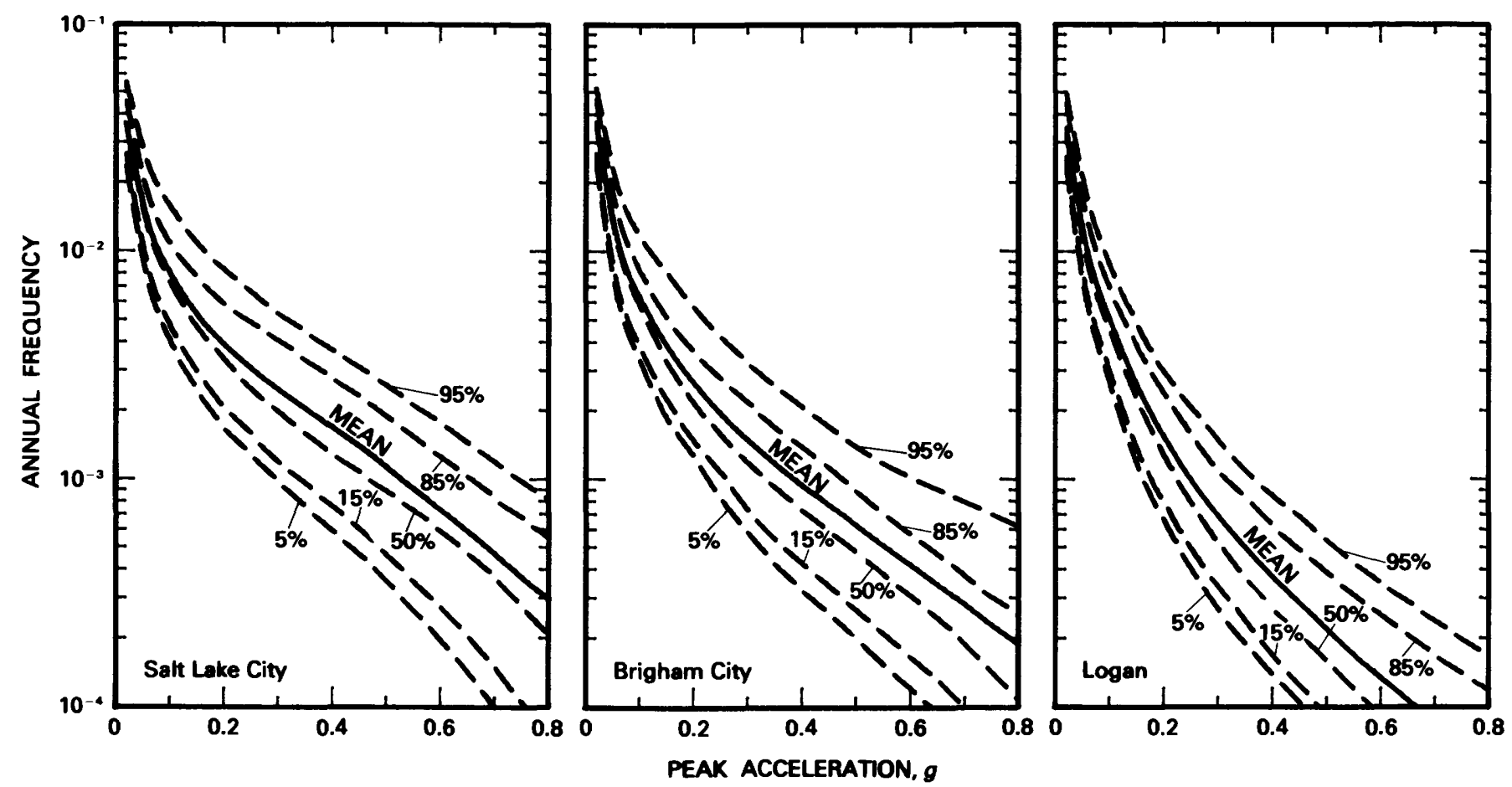

FIGURE 20.-Peak ground acceleration hazard curves on soil for three locations. Shown are the mean hazard curves and hazard curves corresponding to the 5th, 15 th, 50th, 85th, and 95th percentiles of the distributions for frequency of exceeding various levels of peak acceleration obtained at each site.

\pm 50 percent about the level given by the mean hazard curve.

The computed hazard distributions represent our best judgment as to the uncertainty in defining the input parameters and thus represent our confidence in the estimated hazard. As tables 1 through 3 indicate, extensive distributions are used to model the input parameters in the hazard model logic tree, the result being several thousand end branches. Limited sensitivity analyses conducted to investigate the effect of including more detailed modeling of the individual parameter distributions showed no significant change in the computed fractiles. However, the more extreme fractiles should be considered to be less precisely defined than the central estimates.

The results shown in figure 20 yield similar levels of peak acceleration at the three sites for return periods on the order of 100 years but substantially different peak accelerations for longer return periods. The increased variation in acceleration level at longer return periods results from changes in the relative contributions of various earthquake sources to the hazard as a function of acceleration level and return period. Figure 21 shows the contributions of various sources to the hazard at six sites. The top row of plots presents the source contributions for the three sites illustrated in figure 20. At each of these sites, the hazard at low acceleration levels is dominated by the background seismicity. Because the rate of occurrence of moderate-magnitude events is assumed to be uniform throughout the background zone of seismicity, similar hazard levels are obtained at all three sites. For longer return periods, the hazard is dominated by contributions from the identified faults, and their relative rates of seismic activity result in differences in the computed hazard, depending on proximity to the fault. This pattern was generally observed throughout the study area, as indicated by the results for additional sites shown in the bottom row of plots in figure 21 .

The differences between the computed hazard at Salt Lake City and that at Brigham City reflect the modeled variations in the rate of activity along the length of the Wasatch fault zone. Figure 22 illustrates the variation in the computed hazard along the zone from Nephi to Collinston. As indicated in the figure, nearly identical results are obtained for sites along the central, active portion of the fault (lat $40^{\circ}-41.5^{\circ} \mathrm{N}$.). The hazard decreases slightly to the south as Nephi is approached and decreases significantly to the north beyond Brigham City, where geologic evidence indicates a substantial decrease in the rate of fault movement. The spatial variation of seismic hazard throughout the study region is mapped in terms of contours of peak ground acceleration on soil sites for three 


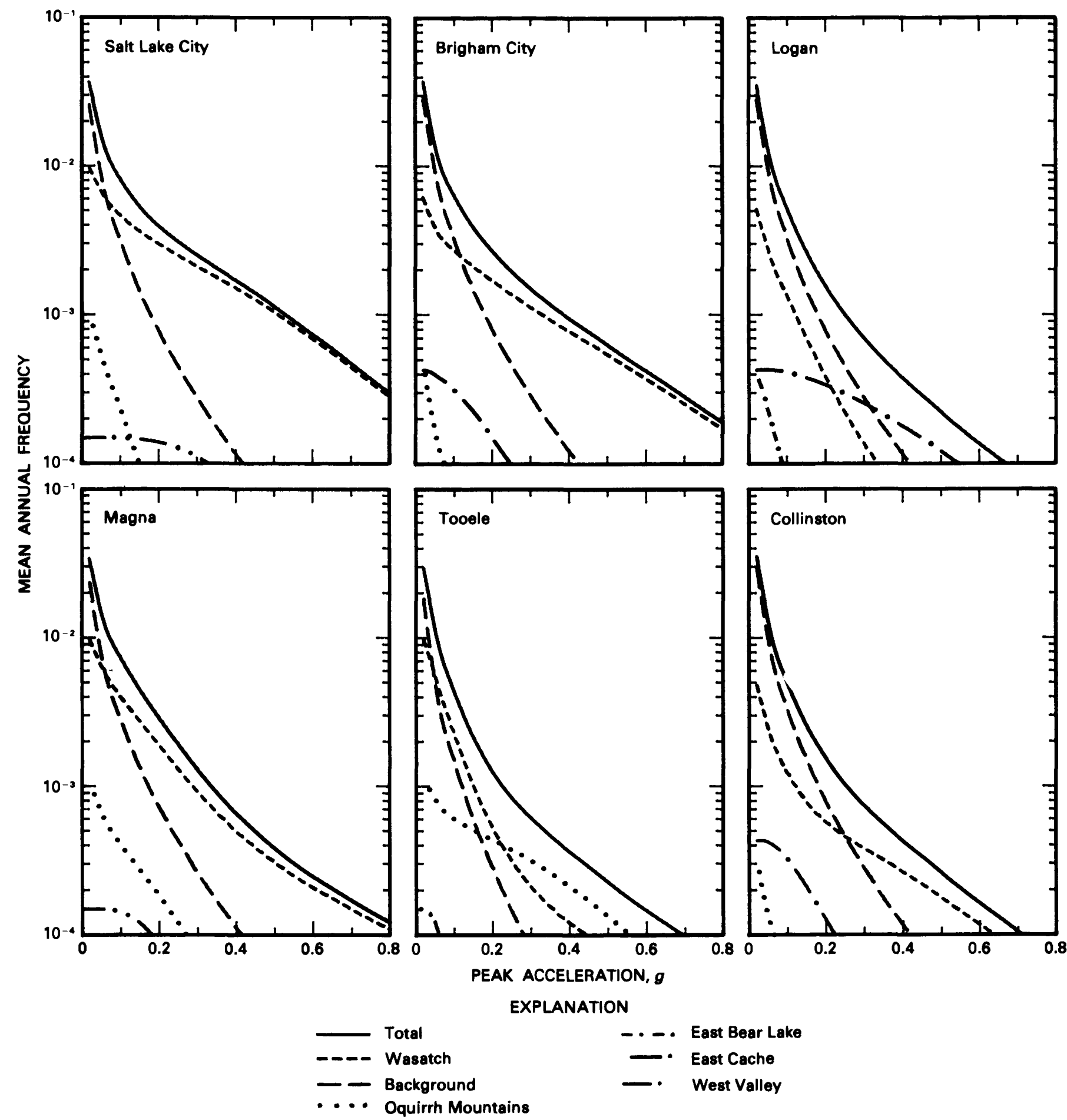

FIGURE 21.-Contributions of various sources to the computed mean hazard for six locations. Shown for each location are the mean hazard curves for various sources and the total mean hazard curve.

return periods. These hazard maps are presented later in figure 37.

Figure 23 illustrates the relative contributions of events in different magnitude and distance intervals to the computed mean hazard. Each plot in the figure presents a histogram showing the percentage of contributions of events in 0.25-magnitude-wide intervals. The histograms are in turn divided into the contributions from distance 


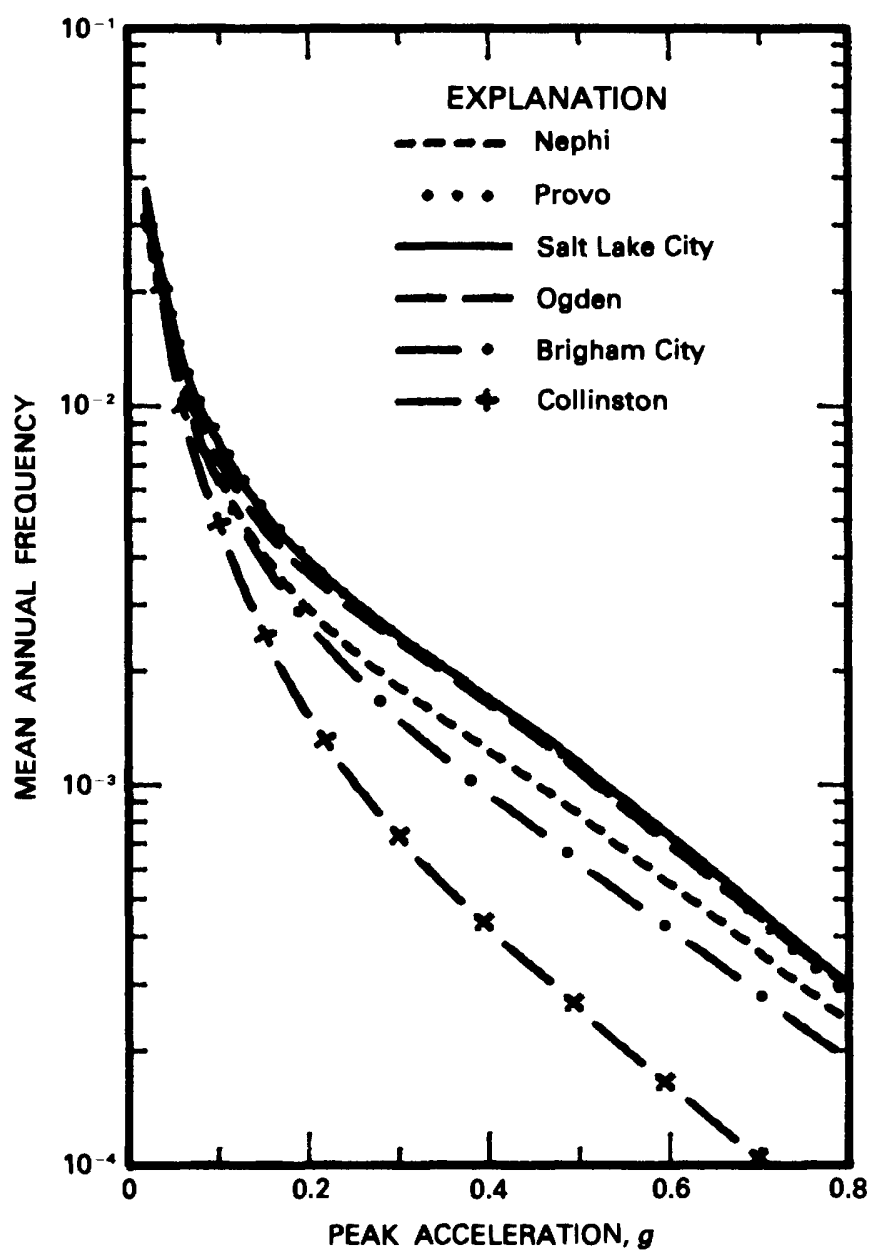

FIGURE 22.-Variation in the computed mean hazard along the length of the Wasatch fault zone from Nephi to Collinston.

ranges of 0 to $10 \mathrm{~km}, 10$ to $25 \mathrm{~km}$, and greater than $25 \mathrm{~km}$. As indicated by figure 23 , at higher probabilities of exceedance (short return periods), the contributions to hazard come from events in a wide range of magnitudes and distances. As the probability of exceedance decreases (return period increases), the hazard becomes increasingly dominated by the larger and closer events. The magnitude and distance range of contributions also narrows as the more active portion of the Wasatch fault is approached, indicative of the increasing dominance of the fault contributions to the hazard as illustrated in figure 21.

\section{CONTRIBUTIONS TO UNCERTAINTY}

The distributions in the computed hazard shown in figures 19 and 20 represent the cumulative effect of all levels of parameter uncertainty included in the hazard model (fig. 2). The relative contributions of various components of the model to the overall uncertainty can be identified readily from the logic tree formulation by computing the hazard and holding individual parameters fixed at specific values. For example, the contribution of uncertainty to the soil-site attenuation relationship can be obtained by computing the mean hazard under the assumption that each of the three attenuation relationships is, in turn, the "correct" relationship, one having a weight of 1.0 and the other two having zero weight. The resulting hazard curves are shown in figure 24 for three sites. In each plot, the solid curve corresponds to the mean hazard, and the heavy dashed curves correspond to the 5th and 95th percentiles of the distribution in exceedance frequency shown in figure 20 . The three labeled curves are the resulting mean hazard for each of the soilsite attenuation relationships, and the differences between them represent the uncertainty in the computed hazard due to uncertainty in selecting the appropriate attenuation relationship.

The results shown in figure 24 indicate that uncertainty in selecting the appropriate attenuation relationship generally has less significance at sites having higher hazard near the more active portion of the Wasatch fault than it does at sites having lower hazard away from the fault. The reason for the variability in the importance of the choice of attenuation relationship can be found by examining the contributions of events from various magnitude and distance ranges and the comparisons of the median attenuation relationships used in the analysis. At sites of lower hazard, such as Logan, there is a substantial contribution from events in the magnitude range of 5 to 6 (fig. 23). The differences in the hazard computed by using the three attenuation relationships are greatest for this range of magnitudes and result from greater variability in the predicted median accelerations (fig. 16) enhanced by differences in the standard deviation about the median. For events at distances beyond $10 \mathrm{~km}$, which have a large contribution to the hazard at Logan, Campbell's (this volume) relationship has the lowest median values and the lowest standard deviation (0.30), whereas Joyner and Boore's (1982) relationship has the highest median values and the highest standard deviation (0.62). The smallest variability between the hazard curves is obtained for a return period of 500 years at Salt Lake City (similar results were observed at other sites along the more active part of the Wasatch fault). The contributions to hazard are largely from events of magnitude 6 to 7 occurring at distances of $10 \mathrm{~km}$ or less. The best agreement between the median attenuation curves shown in figure 15 is for events of magnitude 6.5, and the differences in the median curves at distances of less than $10 \mathrm{~km}$ are partly compensated for by the differences in the standard deviation. In this magnitude and distance range, Campbell's relationship has the highest median values but the lowest standard deviation, whereas Joyner and Boore's relationship 

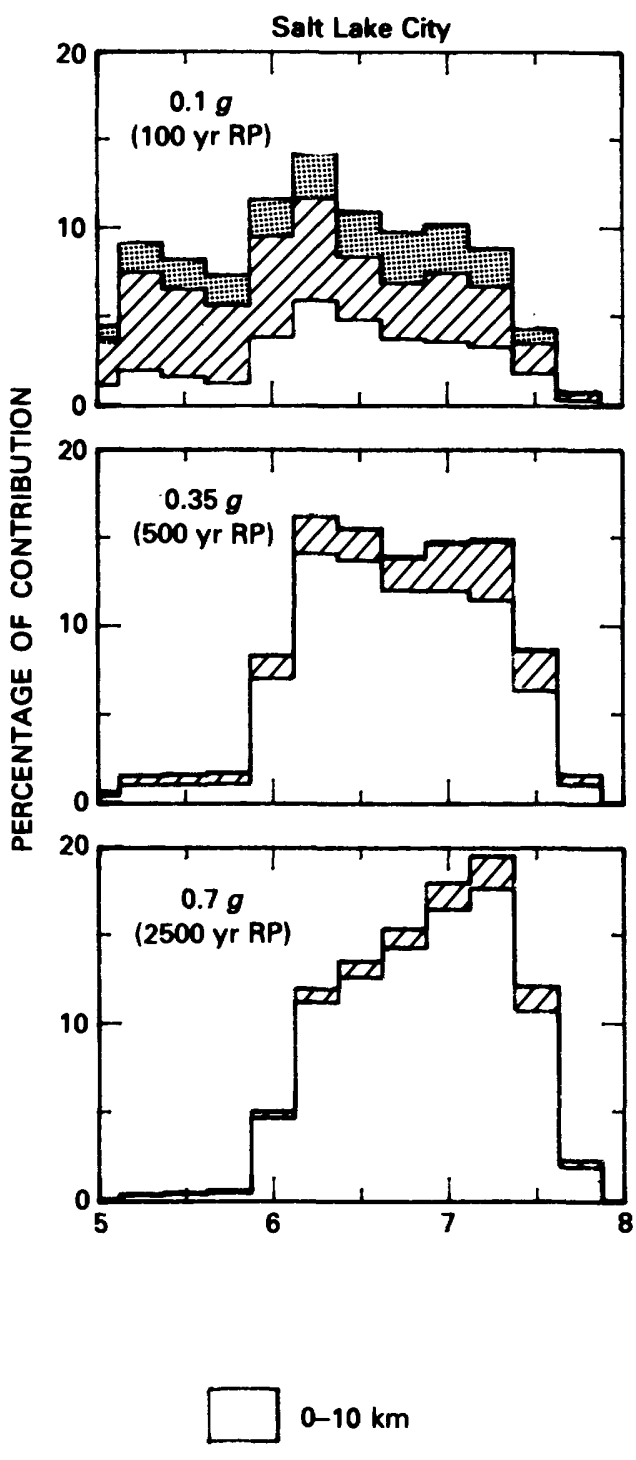
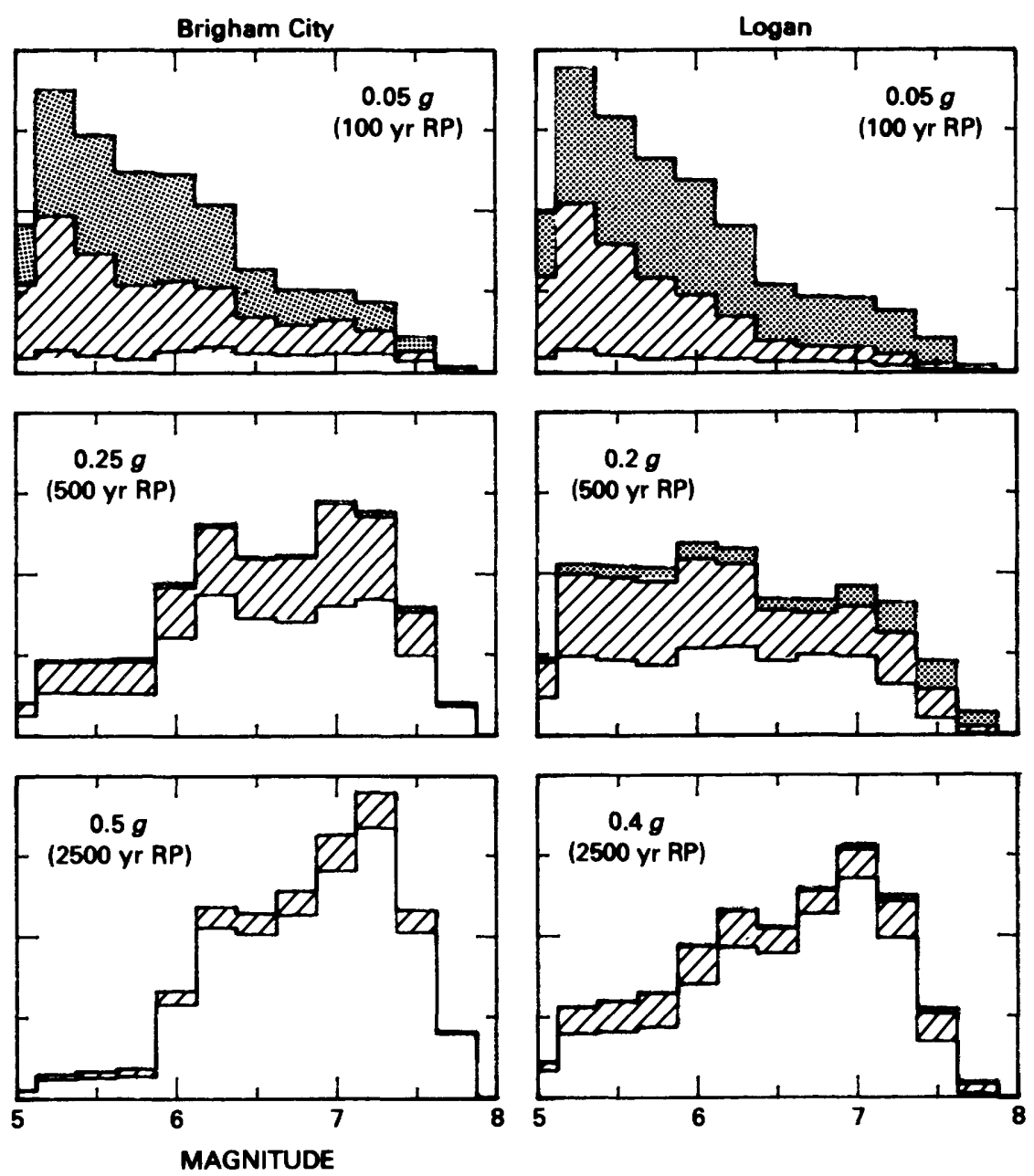

EXPLANATION

$10-25 \mathrm{~km}$
$>25 \mathrm{~km}$

FIGURE 23.-Contributions of different magnitude events to total frequency of exceeding various levels of peak ground acceleration at three locations. The top row of plots corresponds to a return period (RP) of approximately 100 years, the middle row to 500 years, and the bottom row to 2,500 years.

has the lowest median and the highest standard deviation. In general, as the range of magnitudes that contribute to the hazard increases, more variability between the median estimates of the three relationships is introduced into the analysis, and the variability in computed hazard increases.

The results shown in figure 24 also indicate that, in areas of lower hazard, such as Logan, the uncertainty in hazard due to uncertainty in selecting the appropriate attenuation relationship becomes a major part of the total uncertainty in the hazard. At such sites, the computed hazard is largely dominated by the background seismicity (fig. 21), which has been modeled with a relatively smaller amount of uncertainty in the source parameters in comparison with that used in the fault-specific sources (fig. 2). Thus, at such sites, the choice of attenuation relationship provides a relatively large proportion of the total uncertainty in the computed hazard.

The impact of uncertainty in recurrence model on the overall uncertainty in the frequency of exceedance is shown in figure 25 . Here the effect is opposite that shown in figure 24 , greater variation being obtained at locations of higher hazard. At sites where the hazard is largely due to events in the background source, such as at Logan, there is little uncertainty in the hazard because there is little uncertainty modeled for the earthquake recurrence rate in the background source. The variability increases as the dominance of the hazard by contributions from the 

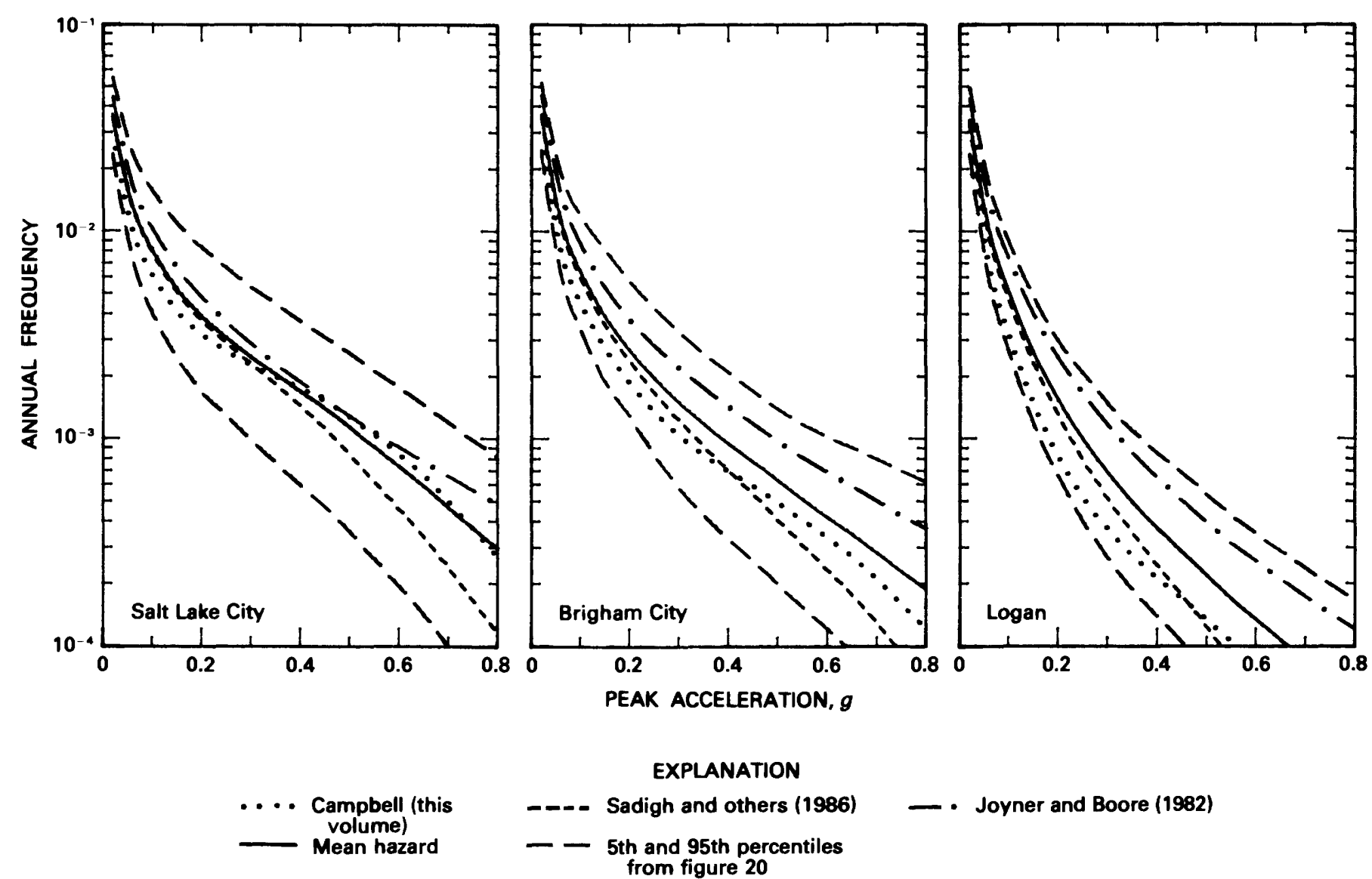

- Joyner and Boore (1982)

FIGURE 24.-Contribution to uncertainty in exceedance frequency from uncertainty in selecting the appropriate soil-site attenuation relationship. Conditional mean hazard curves obtained by using each of the three attenuation relationships used in the analysis are labeled.

faults increases (fig. 21) and reflects the large differences in the rate of magnitude 6 to 6.5 events predicted by the two recurrence models used for the faults (fig. 10). The percentage variability from the mean curve is somewhat lower at the highest acceleration levels because of the increasing contribution by the largest magnitude events, whose predicted rate is insensitive to the choice of recurrence model. The fact that the overall mean hazard is skewed toward the characteristic hazard curve reflects the greater weight assigned to this model in the hazard logic tree (fig. 2).

Figure 26 presents the influence of uncertainty in whether the faults are segmented. As indicated, the contribution to the total uncertainty is relatively small, being greatest where the contribution to hazard from the fault sources is greatest (and where the differences in recurrence estimates between the segmented and unsegmented models is the greatest). The opposite effects obtained at Salt Lake City and Brigham City reflect the difference between the recurrence estimate for individual segments and the average recurrence rate assigned to the unsegmented model. Examination of the recurrence data presented in table 1 indicates that the Wasatch fault segments near Brigham City (Ogden segment for segmentation model A, Weber segment for segmentation model B) have the highest recurrence rate relative to the average for the central active portion of the Wasatch, whereas the Salt Lake City segment has the lowest recurrence rate relative to the average.

For the Wasatch fault, two models of segmentation were considered, given that the fault is segmented. Figure 27 shows the effect of uncertainty in segmentation model at six locations along the fault. The two segmentation models produce significantly different results only in the vicinity of Brigham City. These differences arise owing to differences between the northern extent of the most active portion of the Wasatch in the two models (Brigham City in model A and approximately $15 \mathrm{~km}$ south of Brigham City in model B).

The variation in hazard due to uncertainty in fault activity is shown in figure 28 . Figure $28 \mathrm{~A}$ shows the effect of uncertainty in the existence of a tectonically active extension of the Oquirrh Mountain fault zone to the north of the Great Salt Lake. This uncertainty was modeled in 

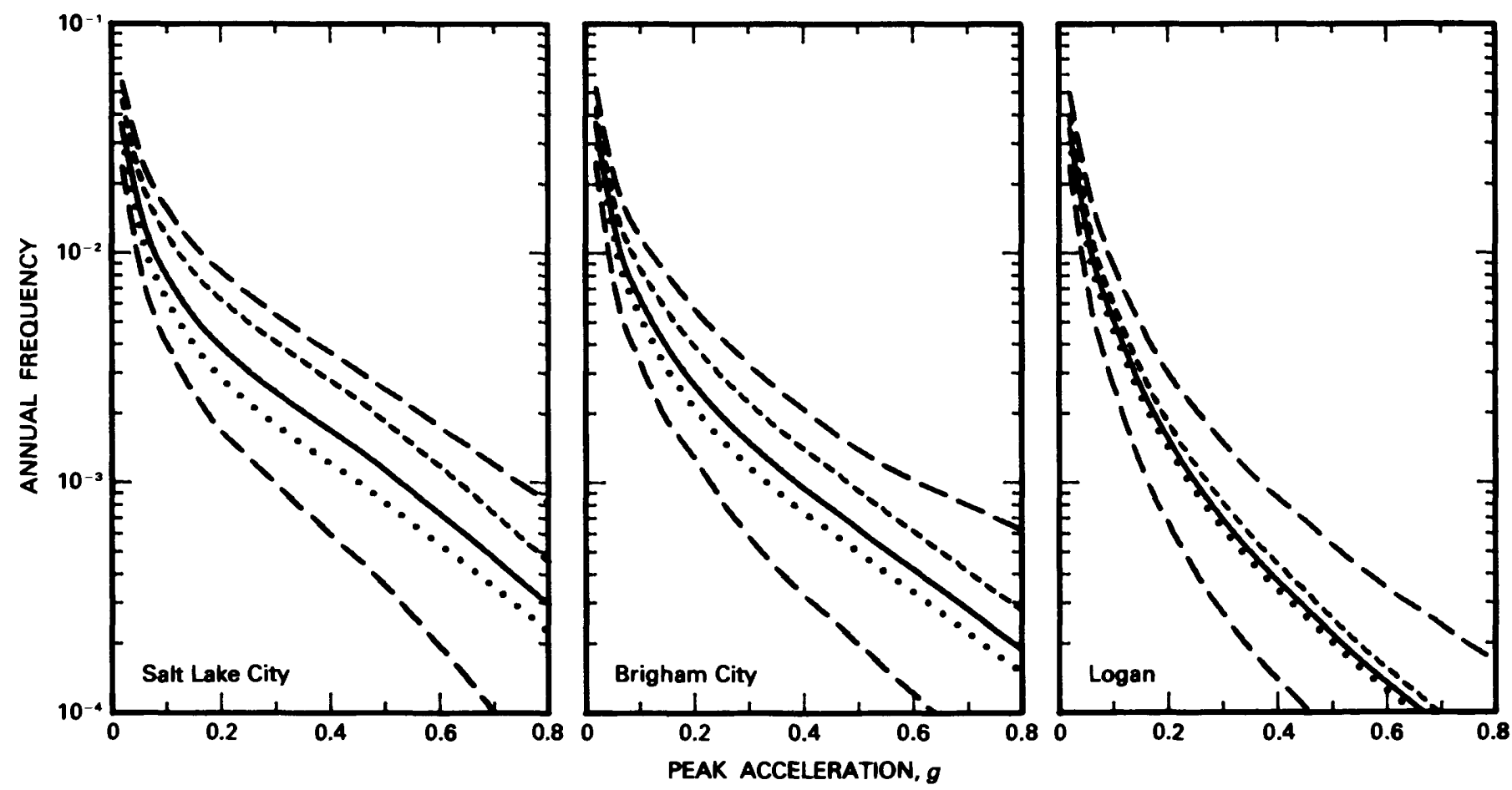

EXPLANATION
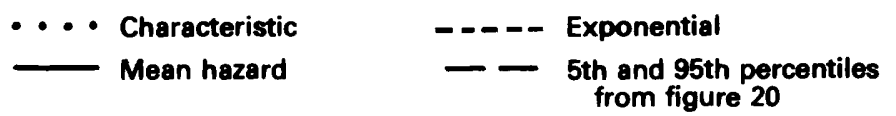

FIGURE 25.-Contribution to uncertainty in exceedance frequency from uncertainty in recurrence model. Conditional mean hazard curves obtained by using the two recurrence models are labeled.

terms of uncertainty in the total length conditional on the Oquirrh Mountain fault zone's being unsegmented or in terms of the state of activity of the northernmost segment (fig. 2, table 1). The combined effect of these two models is shown in the figure. The curve labeled "active northern extension" corresponds to an active Promontory segment for a segmented fault zone or a total length of $250 \mathrm{~km}$ for an unsegmented fault zone. The curve labeled "inactive northern extension" corresponds to an inactive Promontory segment for a segmented fault zone or a total length of $180 \mathrm{~km}$ for an unsegmented fault zone. As can be seen, only at locations near the postulated northern extension of the fault zone, such as Promontory Point, is there any noticeable effect on the hazard, and, even at this location, the effect is small owing to the dominance of the hazard by the background source and the more active Wasatch fault.

The hazard model also included uncertainty in whether the West Valley fault is an independent active source. As shown in figure $28 B$, the effect on the computed hazard in the vicinity of Salt Lake City was very small because the West Valley fault makes only a small contribution to the total hazard (see fig. 21) owing to its limited extent, both in terms of length and downdip width.

The impact of uncertainty in fault dip is illustrated in figure 29. Uncertainty in fault dip is greatest at locations, such as Magna, that lie approximately 10 to $25 \mathrm{~km}$ west of the surface trace of the Wasatch fault zone. At these locations, variations in fault dip produce the maximum relative change in the distribution for distance to earthquake rupture. However, as shown, even at these locations, the effect of uncertainty in fault dip is small.

Figure 30 shows the effect of choosing to combine data from all seginents or using only the data from an individual segment for modeling earthquake recurrence for the segments in the central portion of the Wasatch fault zone. As can be seen, the effect is variable along the fault, primarily reflecting differences between the data for an individual segment and the average behavior of the central segments of the fault zone.

For the remaining two parameters in the hazard model-maximum magnitude and recurrence rate-the contributions to total uncertainty were evaluated by computing the 5th- and 95th-percentile hazard curves, considering only the uncertainty in the individual parameter. Figures 31 and 32 show the influence of uncertainty in 

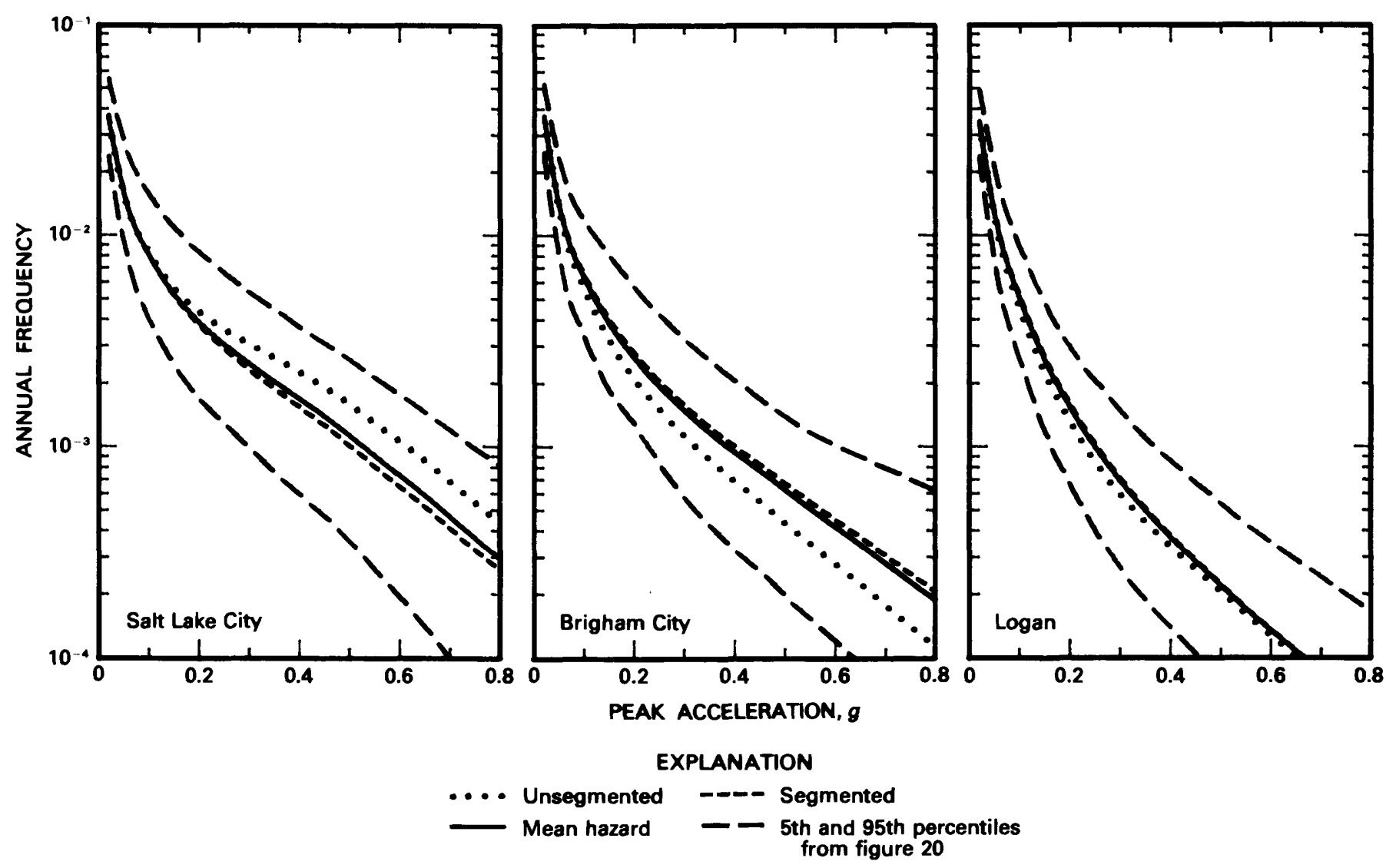

FIGURE 26.-Contribution to uncertainty in exceedance frequency from uncertainty in source segmentation. Conditional mean hazard curves obtained for unsegmented and segmented faults are labeled.

maximum magnitude and recurrence rate, respectively. The variability in the computed hazard due to uncertainty in these two parameters is generally similar throughout the study region, tending to be smaller at locations where the background source has a greater contribution to the computed hazard.

In summary, for sites near the Wasatch fault zone south of Collinston, the uncertainty in selecting the appropriate recurrence model is the largest contributor to uncertainty in the hazard, followed by uncertainty in selecting the appropriate attenuation relationship. For sites in areas of lower hazard, the uncertainty in selecting the appropriate attenuation relationship is the major contributor to uncertainty in the hazard. The uncertainties in the remaining parameters in general have relatively small contributions to the uncertainty in the hazard, although they may have more impact locally.

\section{ADDITIONAL SENSITTVITY ANALYSES}

Additional analyses were performed to evaluate the sensitivity of the results to local site conditions, possible lower rates of ground-motion attenuation, alternative lower magnitude cutoff, and use of realtime estimates of earthquake occurrence.

The hazard results presented earlier are applicable to locations underlain by firm soil deposits. As discussed previously, three published attenuation relationships were used for estimating peak ground accelerations on soil sites, and four published relationships were used for rock sites. Differences between ground motions on soil and rock sites were evaluated by repeating hazard computations for the four rock-site attenuation relationships, equally weighted. Figure 33 compares the resulting rocksite hazard curves with the soil-site hazard curves for three locations. Similar comparisons made throughout the study region indicate that peak accelerations on rock should be about 10 percent greater than those on soil for return periods of about 100 years and about 20 percent greater for return periods of 500 years or longer. These factors can be used to obtain accelerations on rock from accelerations on soil.

Sensitivity analyses were performed to evaluate the effect of a possible lower rate of ground-motion attenuation in Utah in comparison with that observed in California. The modeled lower attenuation rate is described in 

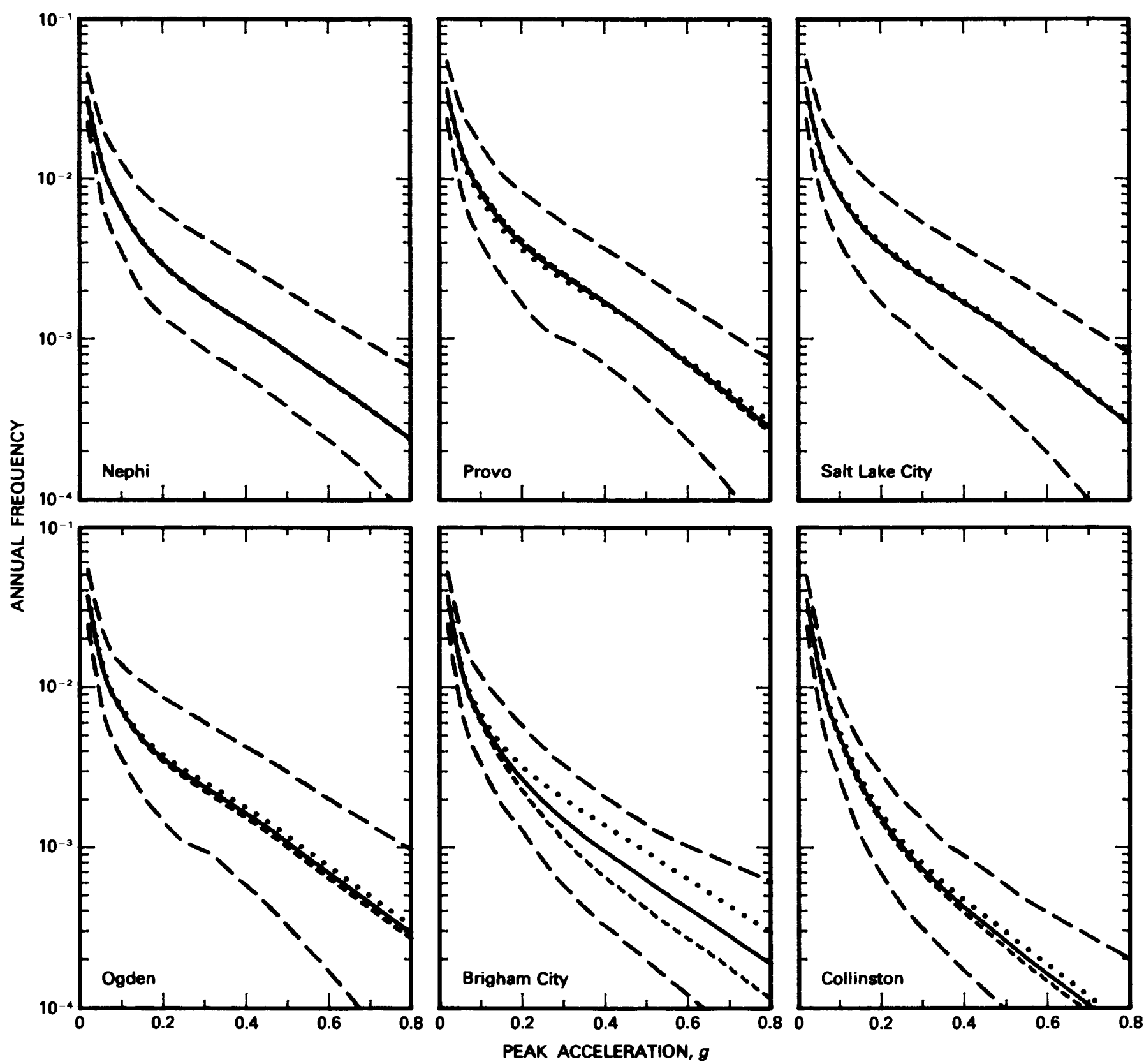

\section{EXPLANATION}

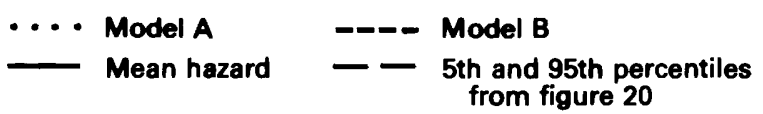

FIGURE 27.-Contribution to uncertainty in exceedance frequency from uncertainty in segmentation model at six locations along the Wasatch fault. Conditional mean hazard curves obtained by using segmentation models A and B are labeled.

the previous section and shown in figure 17. Figure 34 compares the mean hazard curves obtained by using the modified attenuation relationships with those used in the basic analysis. As can be seen, there is very little effect on the hazard, primarily because the hazard is dominated by contributions from nearby events, either occurring on adjacent faults or within the background seismicity source. The largest percentage differences occur at lower acceleration levels, where the contributions from more distant events are the greatest (see fig. 23). 


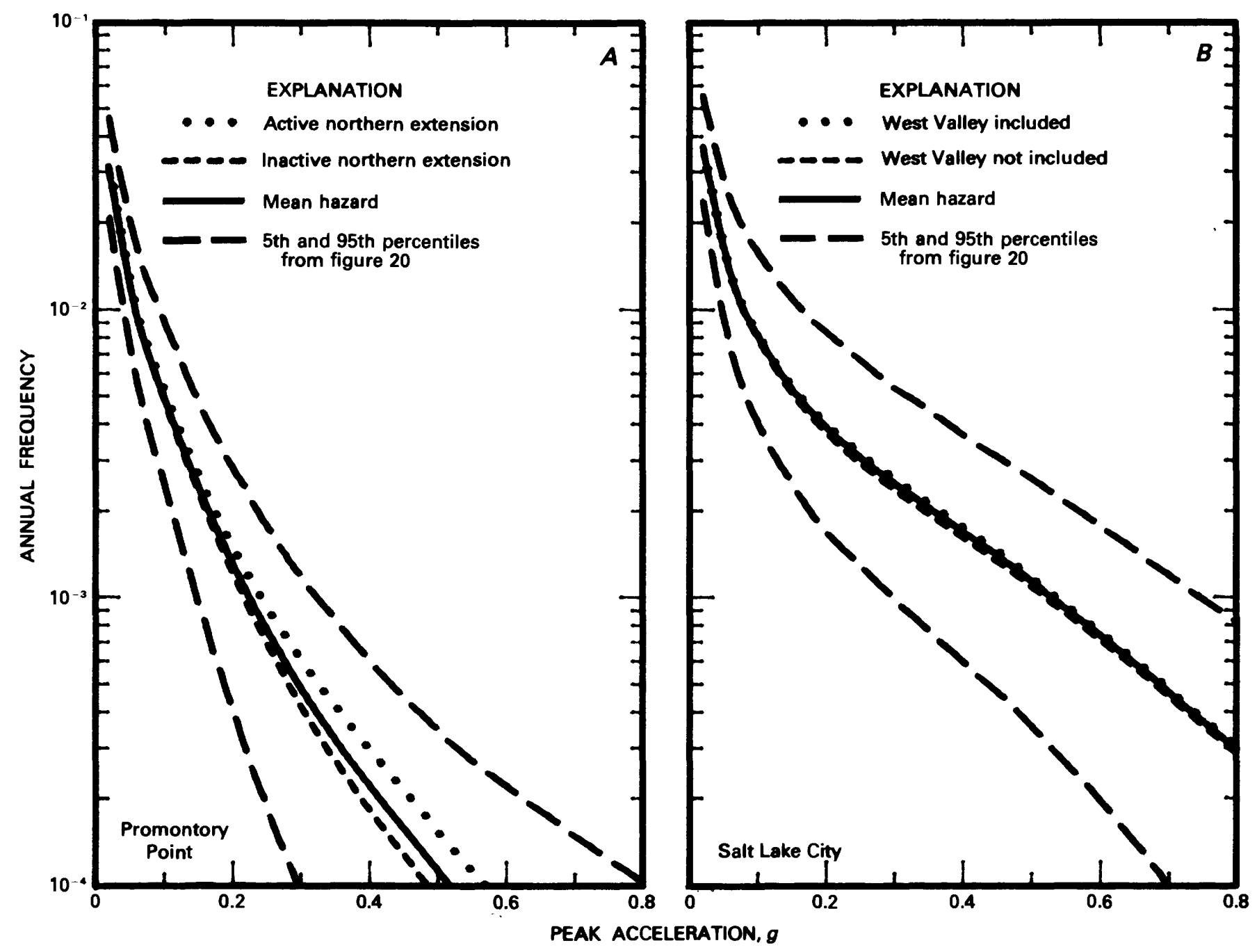

FIGURE 28-Contribution to uncertainty in exceedance frequency from uncertainty in source activity. $A$, Effect of uncertainty as to the existence of a northern extension of the Oquirrh Mountains fault zone. The curve labeled "active northern extension" corresponds to an active Promontory segment for a segmented fault zone or a total length of $250 \mathrm{~km}$ for an unsegmented

fault zone. The curve labeled "inactive northern extension" corresponds to an inactive Promontory segment for a segmented fault zone or a total length of $180 \mathrm{~km} . B$, Effect of whether the West Valley fault zone is included as an independent earthquake source.

Uncertainty in the rate of attenuation could have been directly included in the primary analysis as additional branches in the logic tree. If it had been, it would have been necessary to incorporate an alternative for both a higher and a lower rate of attenuation. The effect of a greater rate of attenuation in Utah in comparison with the rate in California is expected to be a slight reduction in the computed hazard similar in magnitude to the increase shown in figure 34 . The small effect on the results from using a lower rate of attenuation in the sensitivity study (fig. 34) indicates that the inclusion of this source of uncertainty has a negligible effect on the mean hazard. Its inclusion would slightly increase the dispersion about the mean hazard shown in figure 20.

The results in figure 34 can be viewed as showing the sensitivity to any factor that would result in an effect on the rate of attenuation of the order of magnitude given by equation 3 and shown in figure 17. Although the effect was specifically derived to model a crustal anelastic attenuation that is possibly lower in Utah than it is in California, it could also be considered to model the possible influence of soft lake deposits on attenuation. As described in the previous section, the influence of decreasing soil stiffness may be to increase peak accelerations at low amplitudes and to decrease them at high amplitudes. The tendency toward increasing accelerations at low amplitudes results in an effect on attenuation similar to that shown in figure 17 . However, the offsetting 


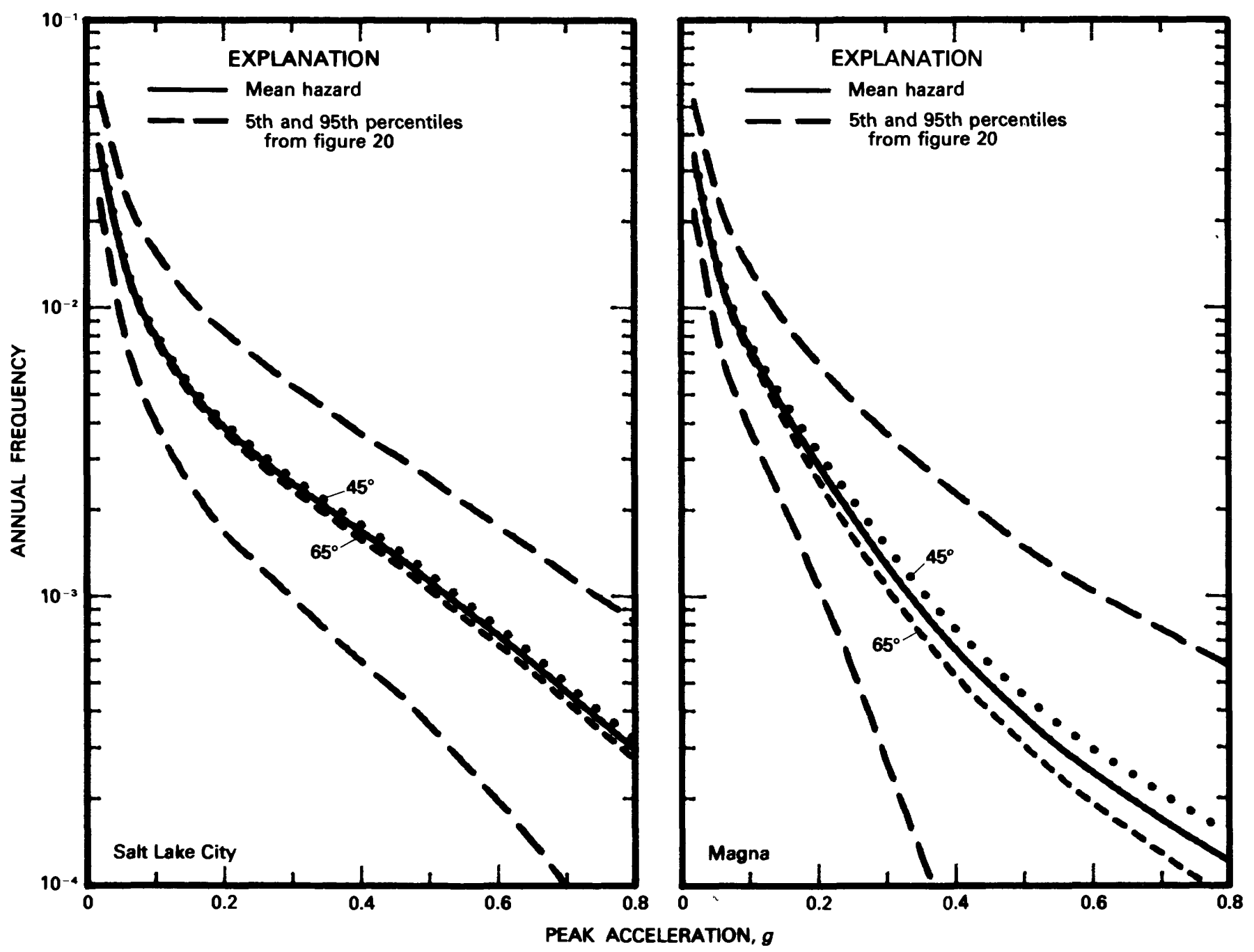

FIGURE 29.-Contribution to uncertainty in exceedance frequency from uncertainty in fault dip. Conditional mean hazard curves for each dip are labeled.

tendency toward decreasing accelerations at high amplitudes is not modeled by the relationship shown in figure 17.

The hazard curves were computed by considering the contributions to hazard from events of magnitude 5 or greater because it is judged that the ground shakmg from smaller magnitude events poses little risk to engineered structures. The effect of including the contributions from events in the magnitude range 4 to 5 on the computed hazard is shown in figure 35. As can be seen, there is a small increase in the frequency of exceedance only at low acceleration levels, for which smaller magnitude events contribute relatively more to the hazard. The increase in the computed hazard at Logan is greater than that at Salt Lake City for the same reason. When longer period ground motions are considered, the effect of including smaller magnitude events will be even less than the effect shown in figure 35.

The hazard analyses were conducted by using a memoryless, or Poisson, model for earthquake recurrence; that is, the frequency of events in the near future (for example, the expected number of events in the next 50 years) is a function of the long-term earthquake recurrence rate, no consideration being given to the time elapsed since the most recent event. Although the Poisson model is almost exclusively used in seismic-hazard analyses, it is at odds with the generally accepted physical model in which earthquake occurrence on a fault is a process of the gradual accunulation of strain, followed by sudden release. The physical model implies that, for individual faults undergoing relatively constant loading, the repeat time for those events that release the built-up 

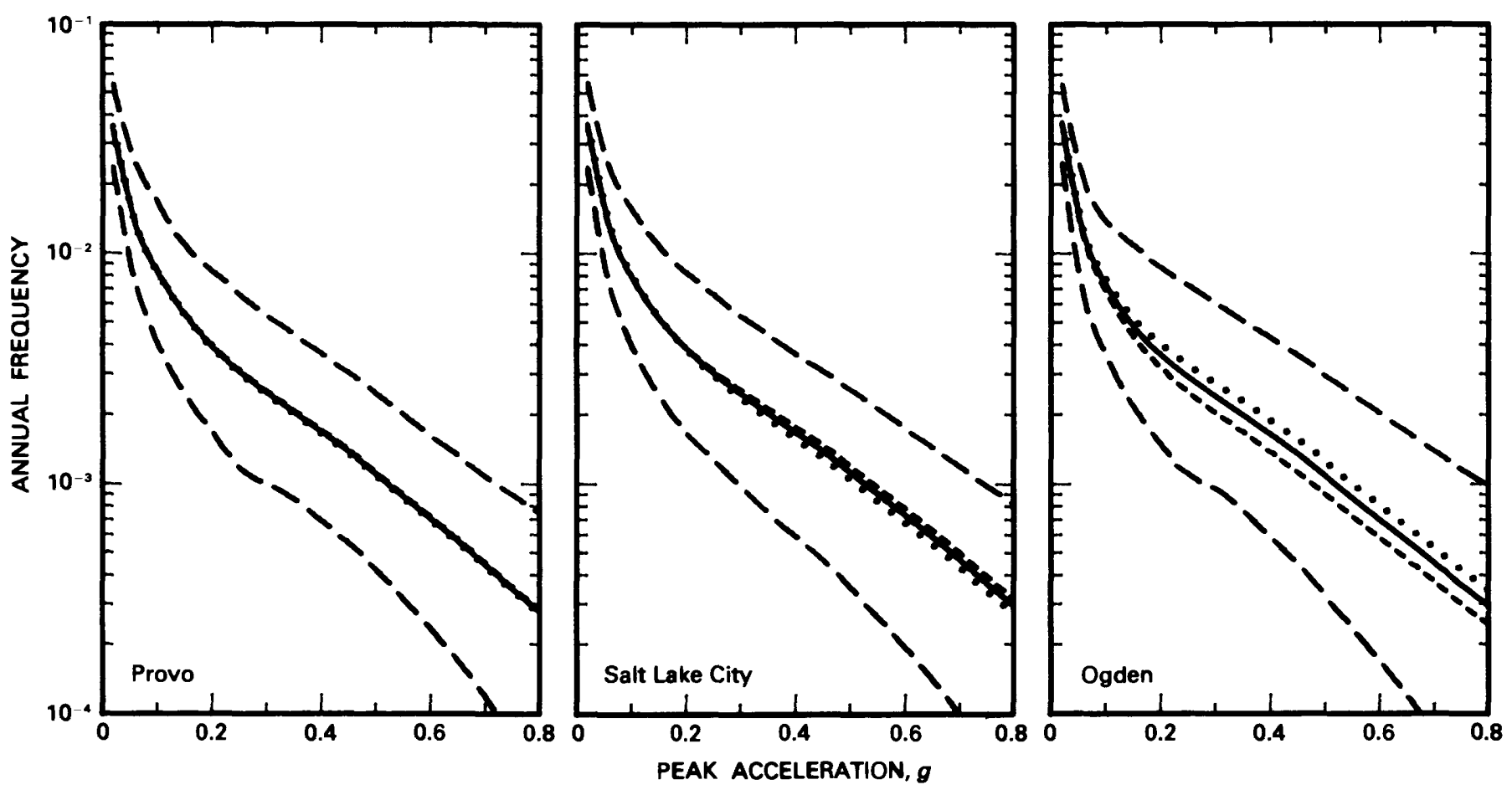

EXPLANATION

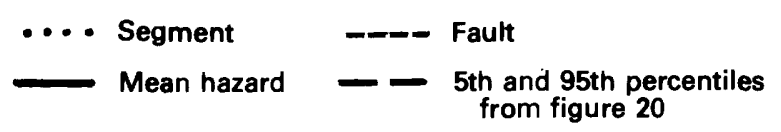

FIGURE 30.-Contribution to uncertainty in exceedance frequency along the Wasatch fault from use of either recurrence data from the segment only, denoted

"segment," or an average value for the central segments of the fault zone, denoted "fault," in modeling earthquake recurrence for the fault segments.
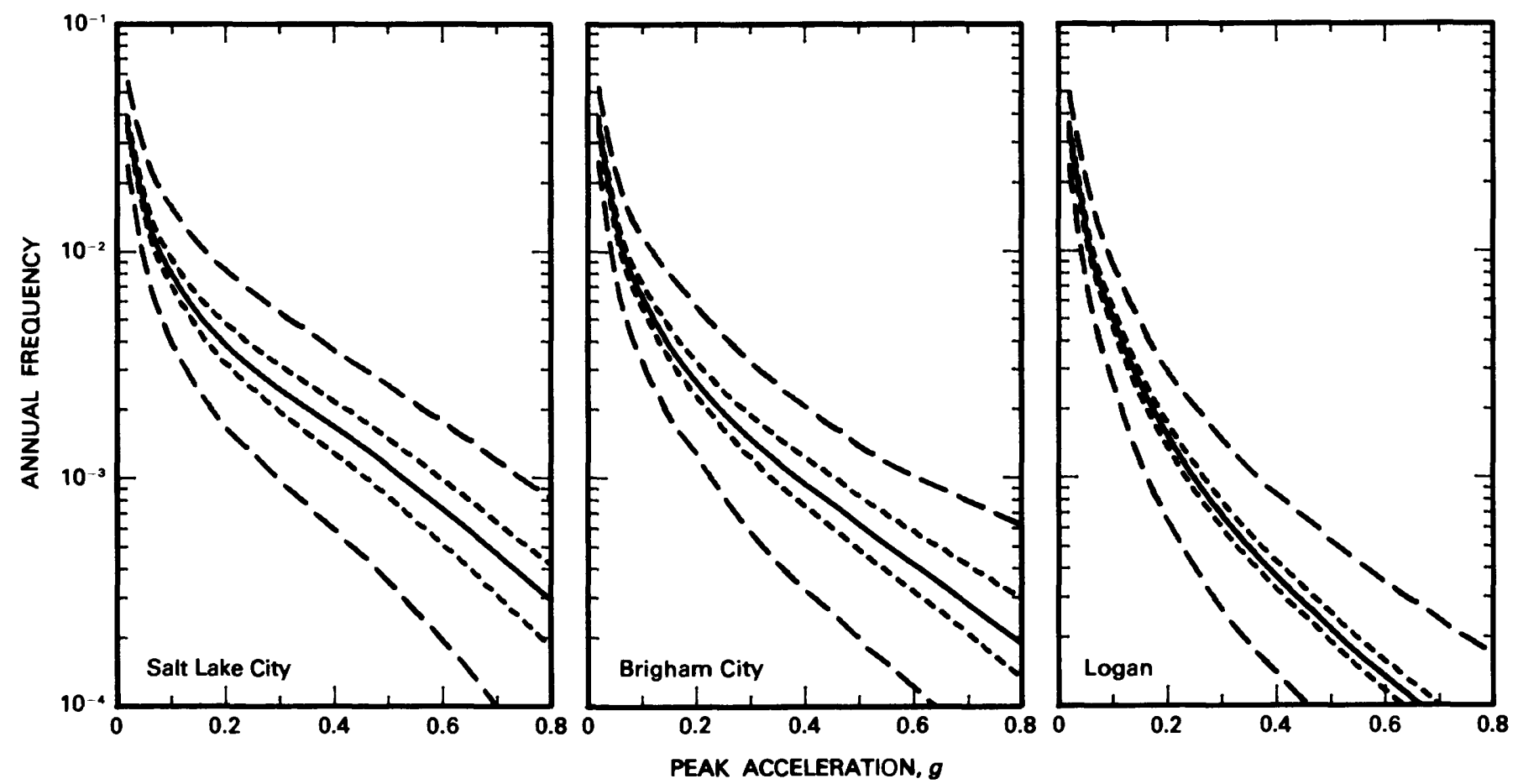

FIGURE 31.-Contribution to uncertainty in exceedance frequency from uncertainty in maximum magnitude. The long-dashed curves are the 5th and 95th percentiles for uncertainty in all parameters (see fig. 20), and the short-dashed curves are the 5th and 95th percentiles for uncertainty in maximum magnitude. 

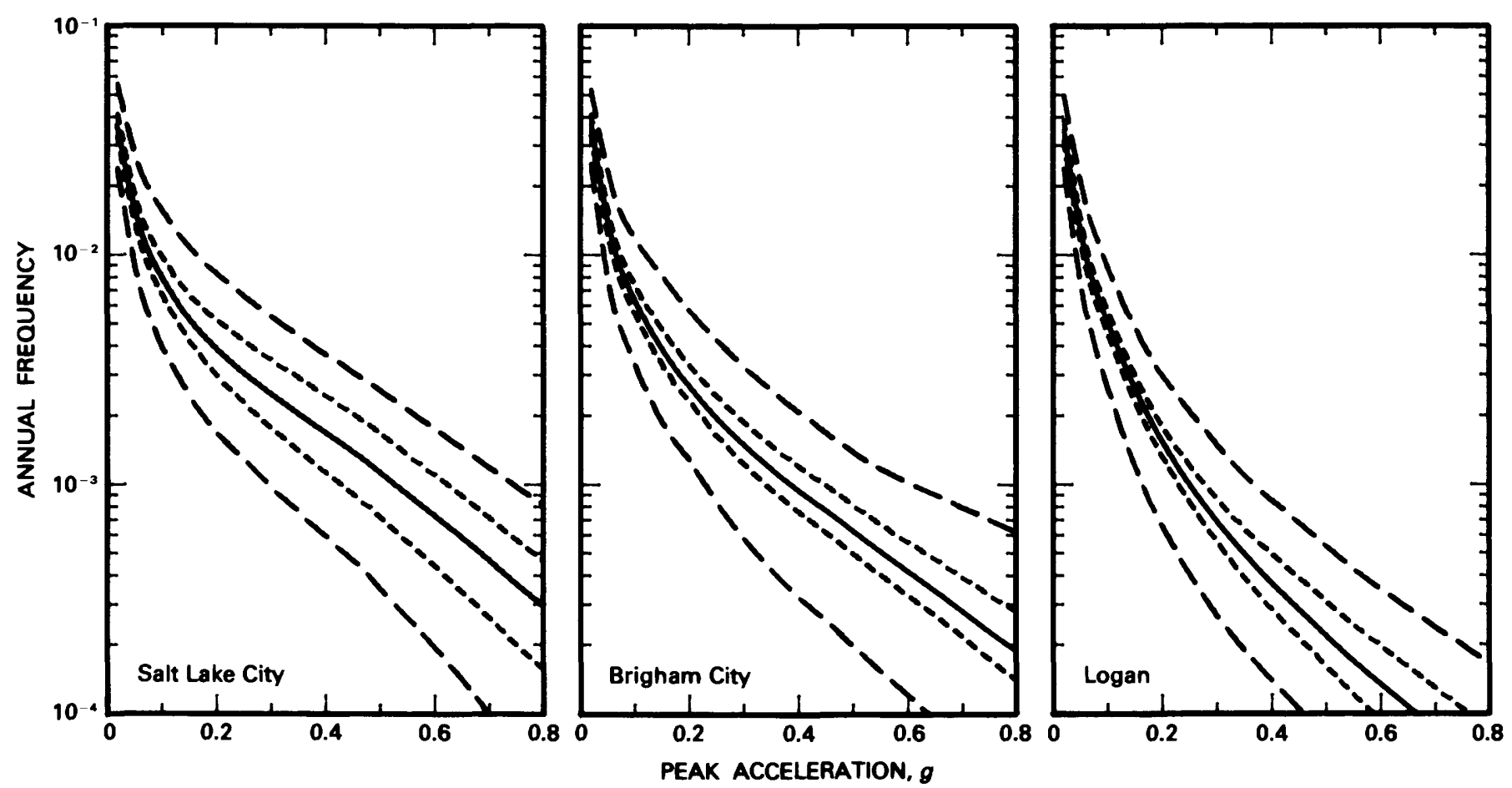

FIGURE 32.-Contribution to uncertainty in exceedance frequency from uncertainty in recurrence rate. The long-dashed curves are the 5th and 95 th percentiles for uncertainty in all parameters, and the short-dashed curves are the 5th and 95th percentiles for uncertainty in recurrence rate only.
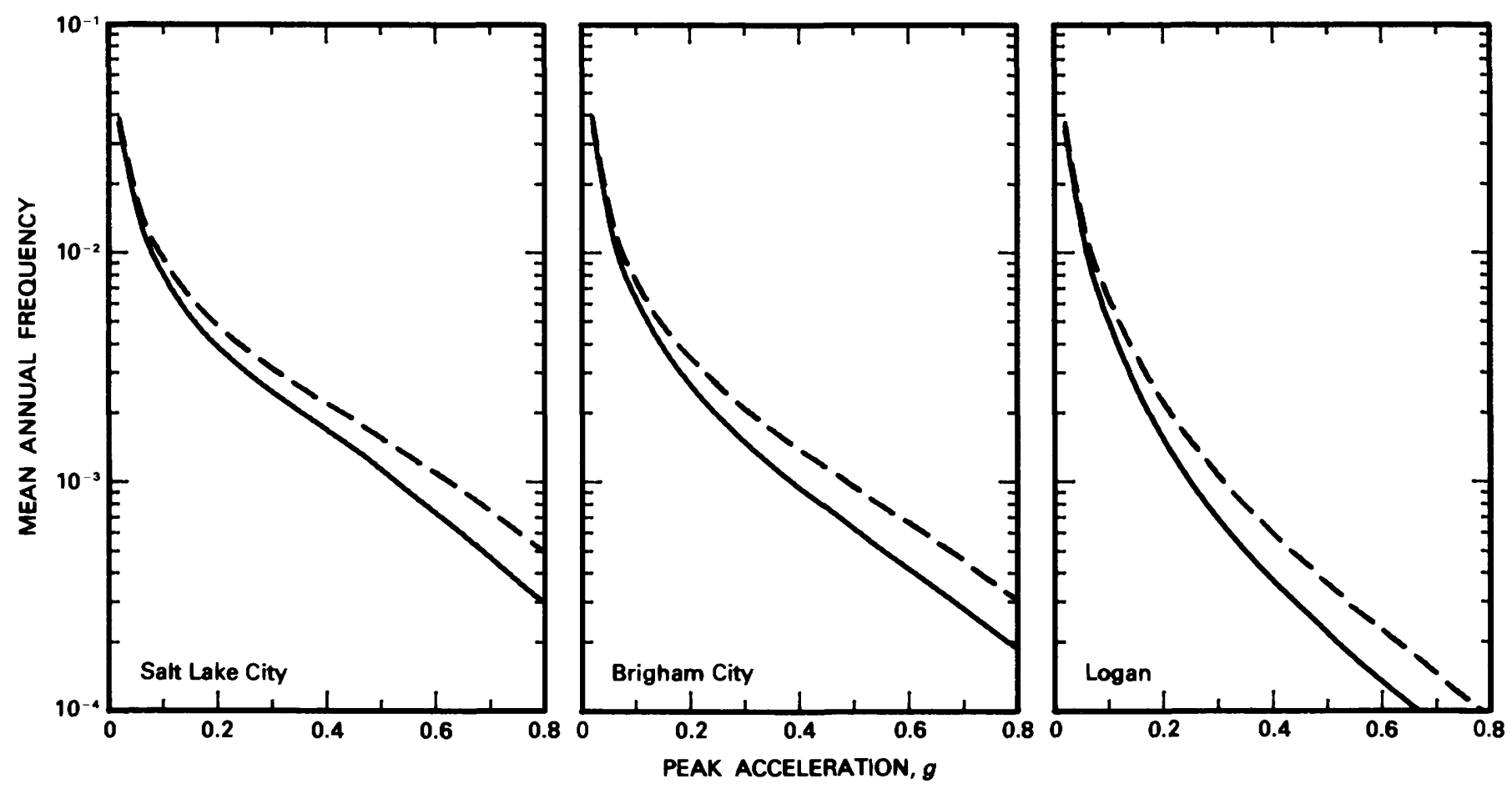

EXPLANATION

FIGURE 33--Comparison of mean hazard curves for soil and rock sites at three locations. 

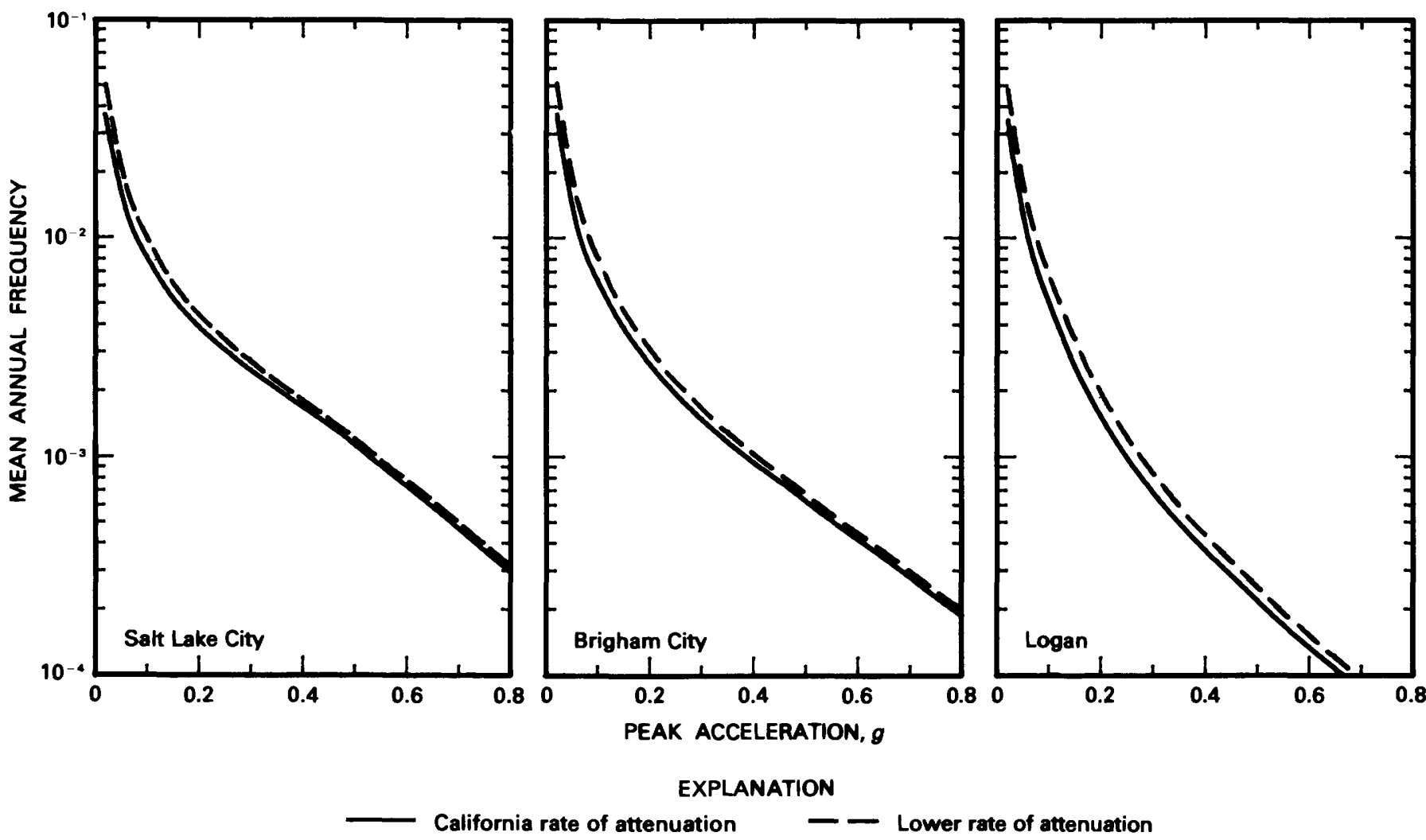

FIGURE 34.-Effect on computed hazard of postulated lower Utah attenuation rates in comparison with California rates at three locations.

stress should be more or less cyclic in nature. However, on a regional basis, the Poisson model for earthquake occurrence has been shown to be appropriate both on the basis of observation (for example, Gardner and Knopoff, 1974) and on the basis of theory as the limiting result of a number of independent or nearly independent processes of whatever type on individual features (for example, Brillinger, 1982). In addition, Cornell and Winterstein (1988) have shown that the Poisson model is conservative as long as the time elapsed since the most recent renewing event is less than the mean repeat time.

The renewal model provides the simplest approach for making realtime estimates of earthquake occurrence. The renewal model specifies that, if the occurrence of multiple events is neglected, the probability of a renewing event in the next $t$ years, given $t_{0}$ years since the last renewing event, is given by the expression

$$
\mathrm{P}\left(\text { event in } t \mid t_{0}\right)=\frac{\mathrm{F}\left(t+t_{0}\right)-\mathrm{F}\left(t_{0}\right)}{1-\mathrm{F}\left(t_{0}\right)}
$$

where $F()$ is the cumulative density function for interarrival time of events. Investigators have employed different models for the distribution of interarrival times, such as the normal, lognormal, gamma, and Weibull distributions. Cornell and Winterstein (1988) indicated that the
Weibull distribution provides the desired characteristics of a simple analytical form and a hazard function that increases monotonically with increasing $t_{0}$. (The hazard function is a measure of the likelihood of an event in the next increment of time, $\partial t$, given no events in time $t_{0}$.) They gave a simple approximation for the Weibull distribution as

$$
\mathrm{F}(t) \approx 1-\mathrm{e}^{-(\lambda t)^{1 / N[T]}}
$$

in which

$$
\lambda \approx \frac{1-0.5 \mathrm{~V}[T](1-\mathrm{V}[T])}{\mathrm{E}[T]}
$$

$\mathrm{V}[T]$ and $\mathrm{E}[T]$ being the coefficient of variation and the mean of interarrival times, respectively. Equations 7 and 8 are good approximations for $0 \leq \mathrm{V}[T] \leq 1$ and have the advantage of degenerating to the Poisson model when $V[T]=1$ (Cornell and Winterstein, 1988).

Equations 6 through 8 were used to obtain realtime estimates of the frequency of future large events at the six locations along the Wasatch fault zone for which data are available on the time since the most recent event (Schwartz and others, 1984). The coefficient of variation of interarrival time, $V[T]$, was assumed to be 0.7 , reflect- 

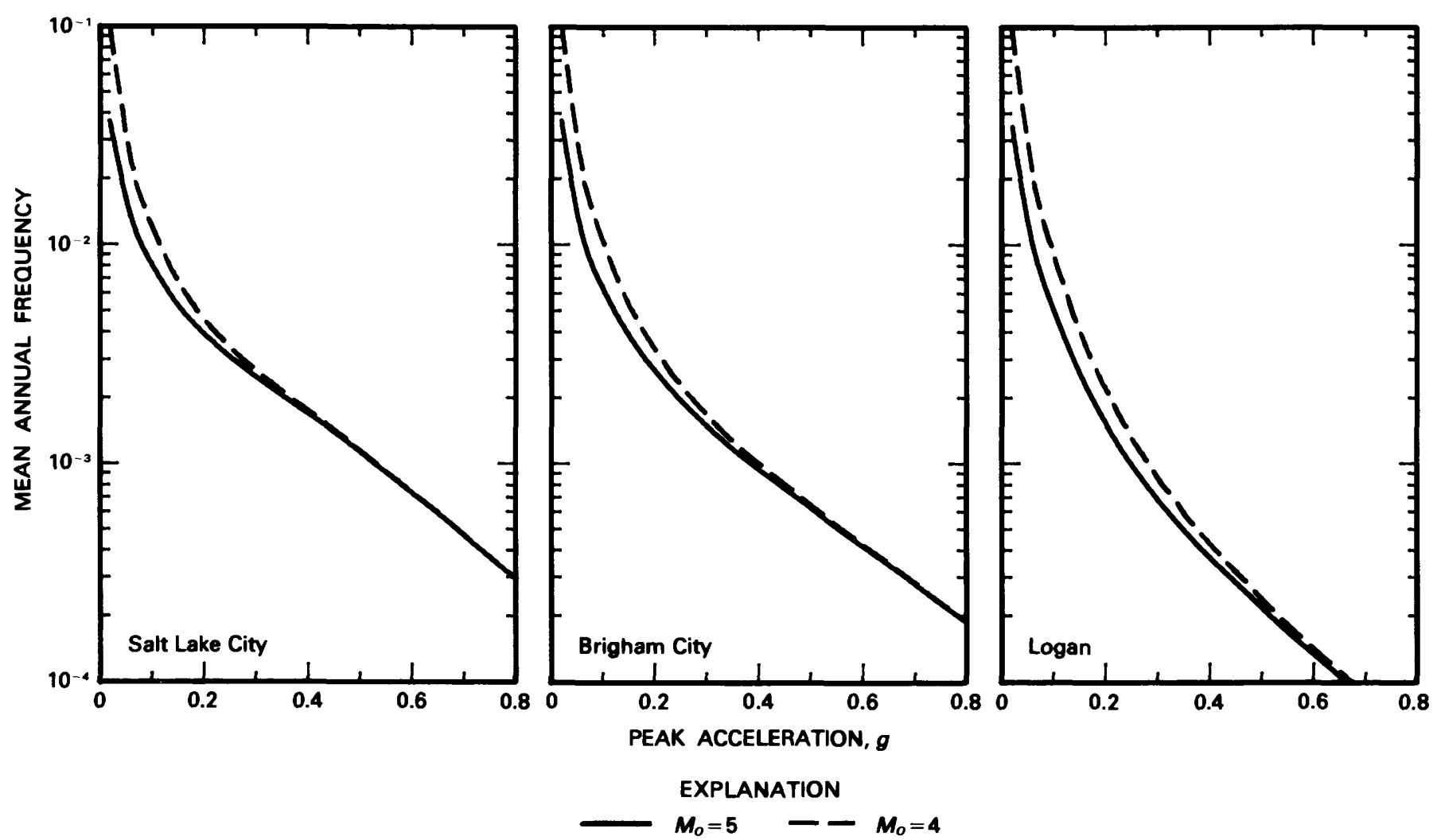

FIGURE 35.-Effect of choice of lower bound magnitude cutoff on computed hazard at three locations.

ing the large variations observed in the limited data for interarrival times for large earthquakes on the Wasatch fault zone. The ratios of the estimated number of renewing events in the next 50 years to the number given by the Poisson model at the six locations are as follows:

\begin{tabular}{|c|c|c|c|}
\hline Location & $\begin{array}{l}\text { Mèan } \\
\text { repeat } \\
\text { time } \\
\text { (years) }\end{array}$ & $\begin{array}{c}\text { Elapsed } \\
\text { time } \\
\text { since } \\
\text { most } \\
\text { recent } \\
\text { event } \\
\text { (years) }\end{array}$ & $\begin{array}{c}\text { Ratio of renewal } \\
\text { to Poisson } \\
\text { model } \\
\text { of expected } \\
\text { number } \\
\text { of events } \\
\text { in } 50 \text { years }\end{array}$ \\
\hline Kaysville & 1,300 & $\leq 500$ & $<0.83$ \\
\hline Little Cottonwood Canyon & 2,600 & ${ }^{1}>1000$ & $>.82$ \\
\hline Hobble Creek & 2,100 & $>1000$ & $>.90$ \\
\hline North Creek & 1,800 & $300-500$ & .67 \\
\hline Deep Creek & 7,000 & $<1750$ & $<.68$ \\
\hline
\end{tabular}

${ }^{1}$ Assumed to be similar to the Hobble Creek site.

The above ratios are all less than 1.0, reflecting the fact that the estimated elapsed times are less than the estimated mean repeat times at all locations. The above ratios are assumed to apply only to the largest or characteristic events on the appropriate fault segments. Smaller events are not likely to result in substantial stress release and are considered to occur randomly (Poisson) in time. The effect of the realtime estimates of the near-future rate of large events on the computed hazard along the Wasatch fault zone is shown in figure 36. The effect is a minor decrease in hazard, the largest decrease occurring at long return periods where the hazard is dominated by contributions from the largest events (fig. 23).

\section{PEAK ACCELERATION HAZARD MAPS}

The variation in seismic hazard throughout the study region is shown in figure 37 in terms of contours of peak ground-acceleration level corresponding to a 10-percent probability of exceedance in time periods of 10,50 , and 250 years. These probability levels span the range of probabilities typically considered in evaluating seismic hazard at commercial and industrial sites and also correspond to the levels used by the USGS in its national maps of seismic hazard (Algermissen and others, 1982). If it is assumed that earthquake occurrence is a Poisson process, the three probability levels can be related to the mean frequencies of exceedance (and to their inverse, return period) by applying equation 1 : 


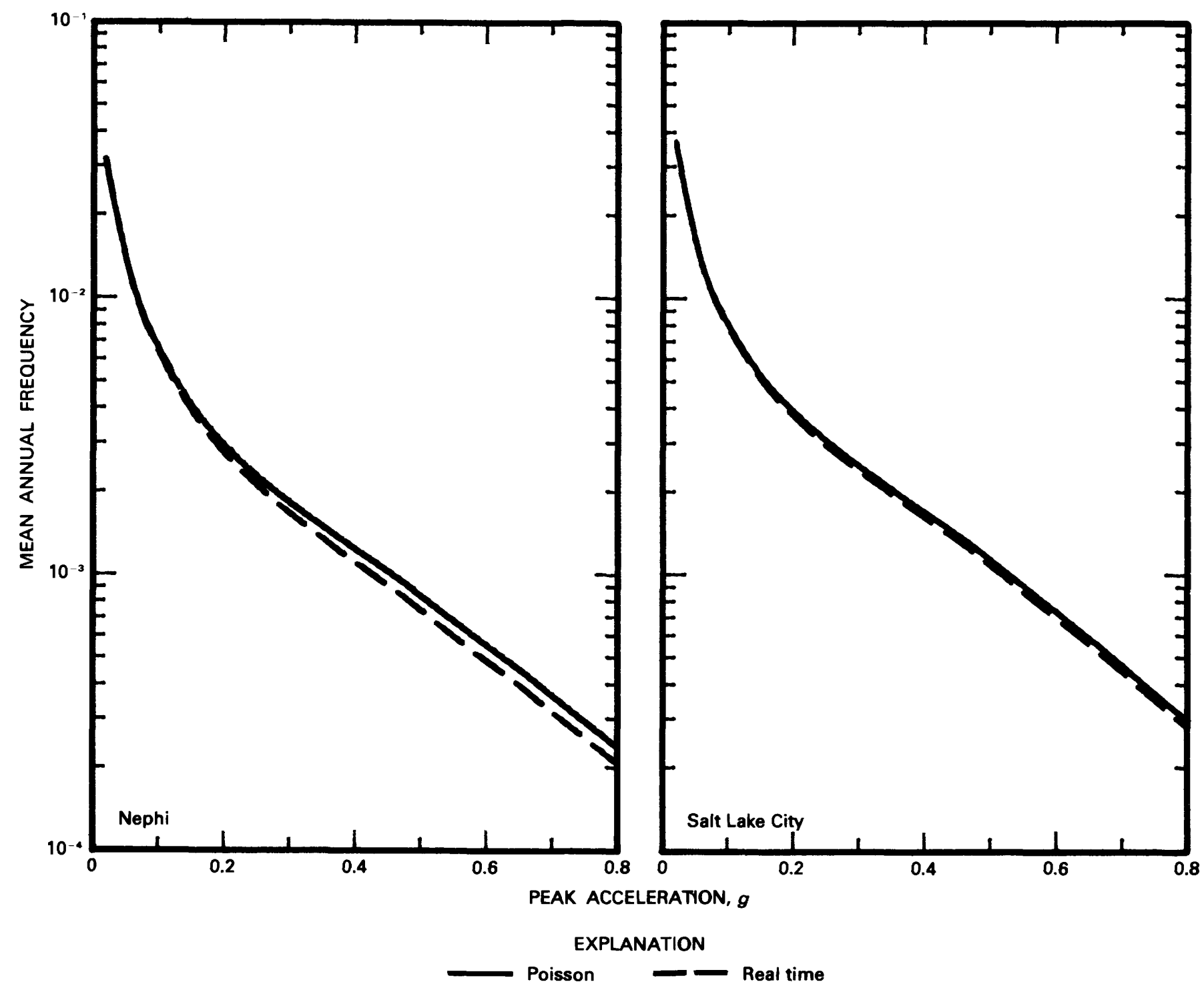

FIGURE 36.-Effect on computed hazard of using realtime estimates of earthquake occurrence probabilities at two locations along the Wasatch fault zone.

\begin{tabular}{lcc}
\hline $\begin{array}{l}\text { 10 percent probability } \\
\text { of exceedance (years) }\end{array}$ & $\begin{array}{c}\text { Equivalent exceedance } \\
\text { frequency } \\
\text { (events/year) }\end{array}$ & $\begin{array}{c}\text { Return period } \\
\text { (years) }\end{array}$ \\
\hline 10 & 0.0105 & 95 \\
50 & .0021 & 475 \\
250 & .00042 & 2,373 \\
\hline
\end{tabular}

Hazard computations were made for 80 points located on a grid in the study region. Peak accelerations corresponding to the above frequencies of exceedance were interpolated from the computed mean hazard curves, and the resulting values were contoured to produce the maps shown in figure 37 . As indicated by the exceedance frequency fractiles shown in figure 20 , the mean hazard curves are somewhat higher than the median (50th percentile) hazard curves and thus represent a more conservative estimate of the hazard. Peak accelerations obtained from the median hazard curves are about 10 percent less than those presented on the hazard maps. The computed 90-percent confidence intervals for peak ground acceleration at a given return period typically range from minus 40 percent to plus 60 percent about the values shown in figure 37 .

The hazard maps further illustrate the spatial trends shown in figure 21. The spatial variation in hazard increases with decreasing probability of exceedance (increasing return period), reflecting the increased domi- 

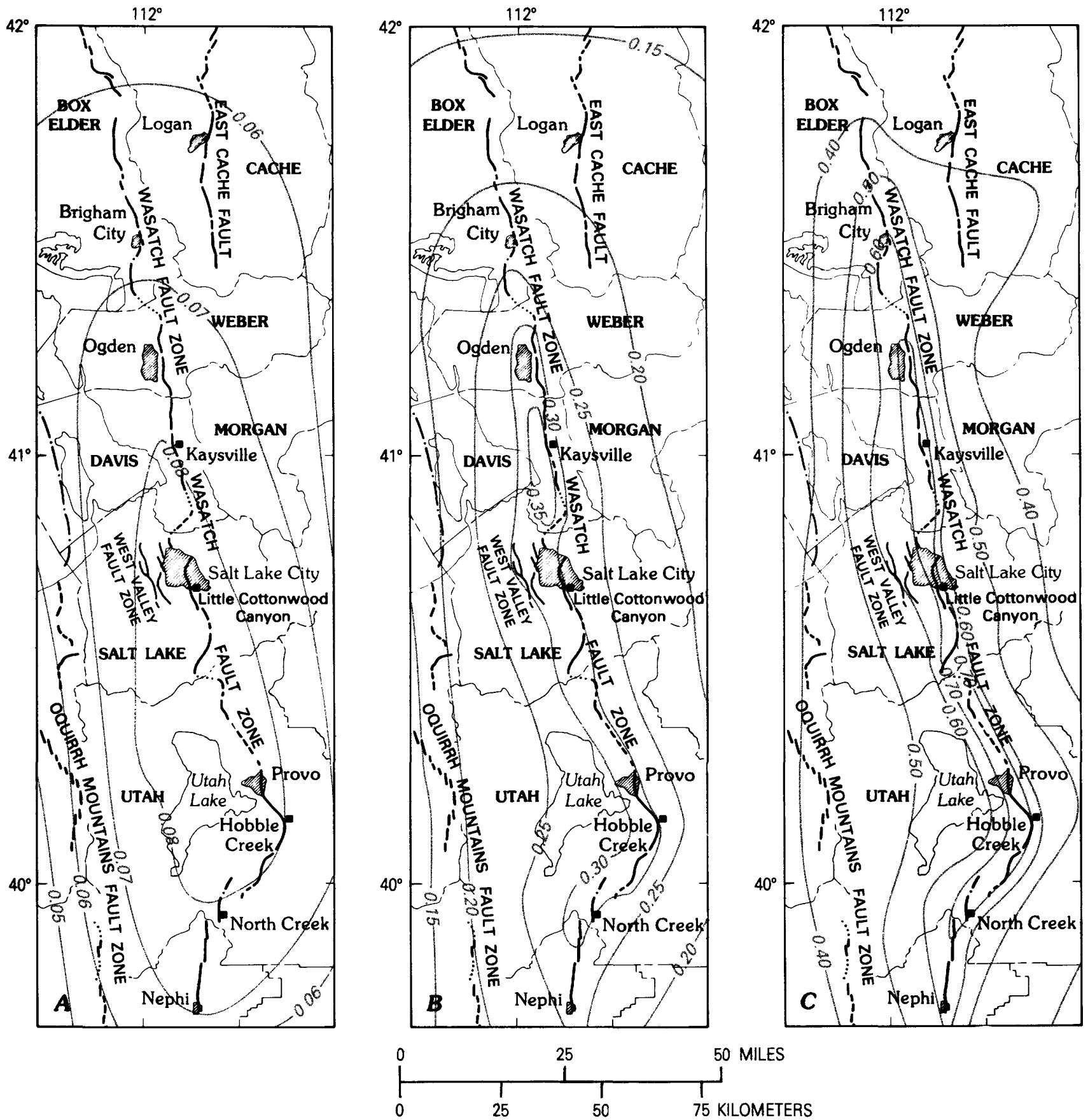

FIGURE 37.-Contours of peak ground acceleration on soil sites having 10-percent probability of being exceeded in $(A) 10$ years, $(B) 50$ years, and $(C) 250$ years. Peak accelerations on rock sites are expected to be approximately 10 percent higher than the values shown on the map for 10-percent probability of exceedance in 10 years and approximately 20 percent higher than the values shown on the maps for 50 and 250 years.

nance of the hazard by contributions from the individual faults as the probability of exceedance decreases. The increased dependence of the hazard on proximity to the mapped faults is particularly true for the central portion of the Wasatch fault zone, which has by far the highest estimated rate of activity for large events.
The hazard maps shown in figure 37 are for peak accelerations on soil-site conditions. Using rock-site attenuation relationships to repeat the analysis for all locations indicates that rock-site acceleration levels can be obtained by increasing the soil-site acceleration levels shown in figure 37 by about 10 percent for 10-percent 

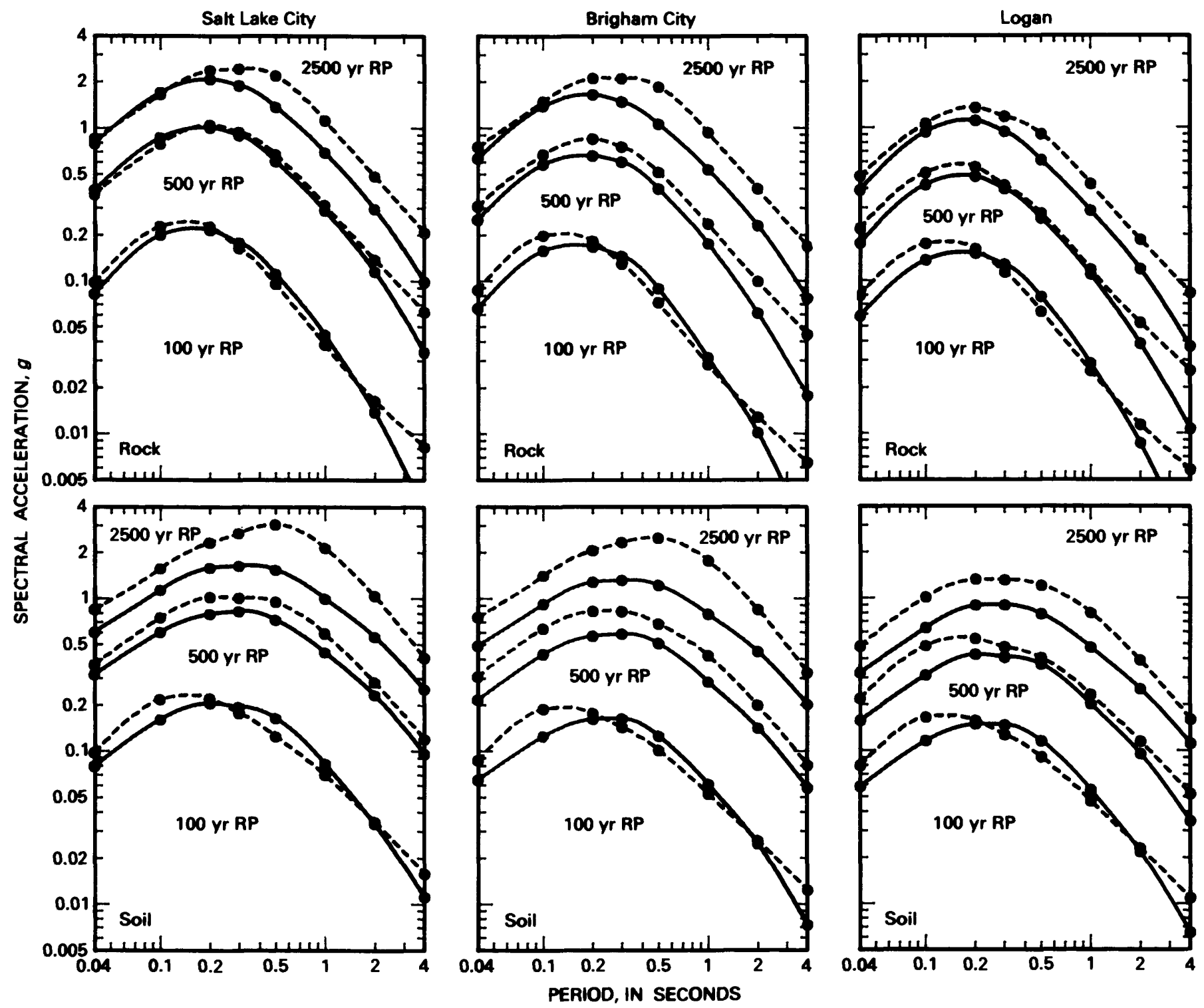

EXPLANATION

Sadigh and others (1986)

FIGURE 38.-Equal-hazard response spectra (5-percent damping) for soil and rock sites at three locations computed by using two attenuation relationships. Each plot shows the spectra for three return periods (RP).

probability of exceedance in 10 years and by about 20 percent for 10-percent probability of exceedance in 50 and 250 years.

In those areas underlain by soil, the peak accelerations in figure 37 apply directly. Soil sites are considered to be sites where the depth to bedrock is $20 \mathrm{~m}$ or greater. In areas of shallow soil or areas underlain directly by rock, it is recommended that the peak accelerations shown in figure 37 be adjusted upward, as described in the preceding paragraph.

\section{RESPONSE SPECTRA}

Response spectral accelerations appropriate for use with the mapped peak acceleration levels were evaluated by developing equal-hazard response spectra for a number of locations in the study region. The equal-hazard response spectra were developed by conducting hazard analyses using response spectral attenuation relationships described previously in this paper for periods of vibration between 0.04 and $4 \mathrm{~s}$. The levels of spectral 

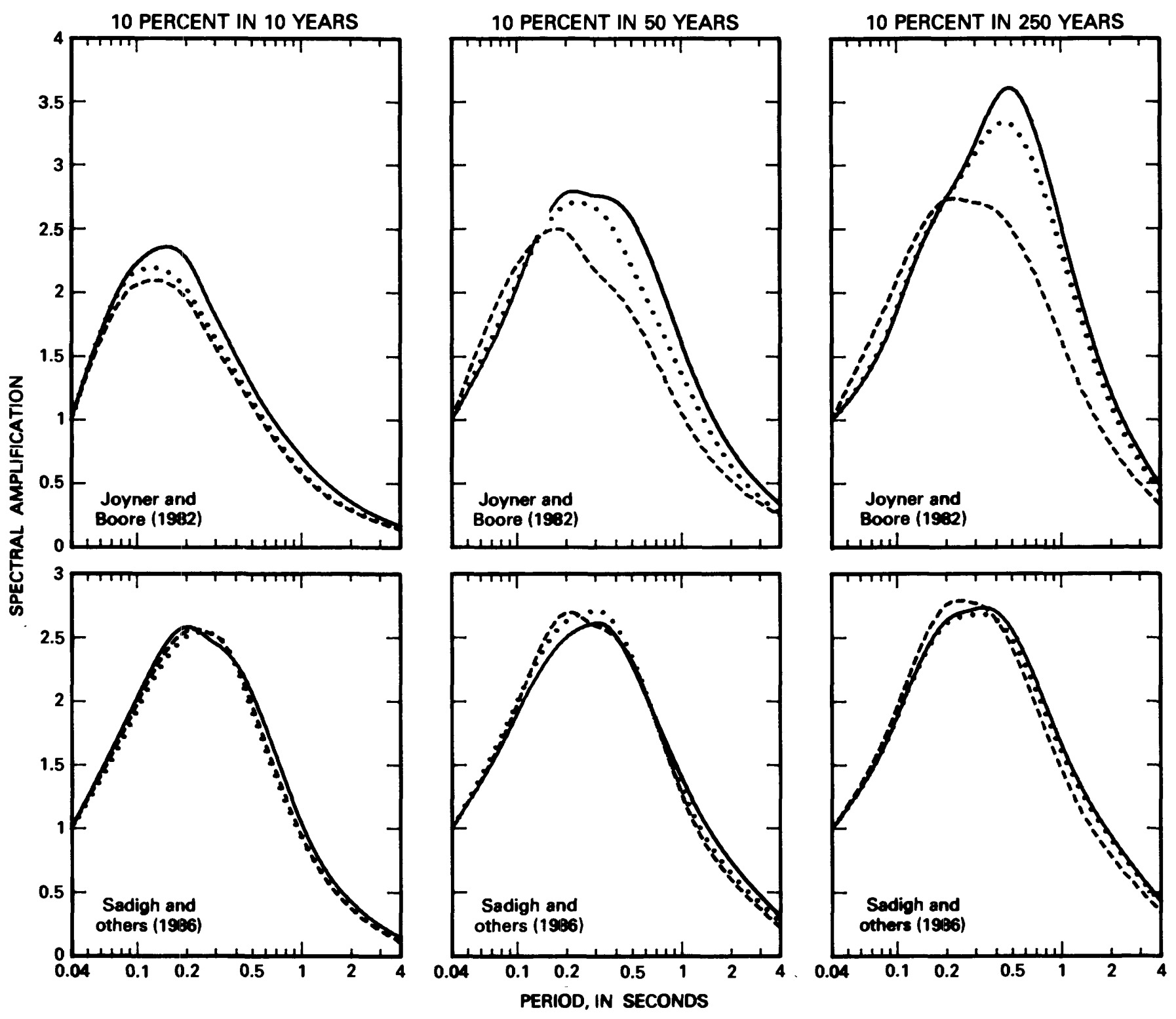

EXPLANATION

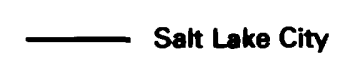

-.. Brigham City

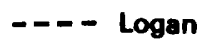

FIGURE 39.-Equal-hazard response spectra (5-percent damping) completed for soil sites at three locations. The upper row of plots shows the spectral amplifications computed by using the Joyner and Boore (1982) attenuation relationships, and the lower row of plots shows the spectral amplification computed by using the Sadigh and others (1986) attenuation relationships.

acceleration corresponding to the three probability levels used in the hazard maps were then interpolated from the hazard curves for each period of vibration, and smooth response spectra were drawn through the computed points to construct equal-hazard spectra.

Figure 38 shows the resulting soil and rock equalhazard spectra for three geographic locations. The plotted points indicate the computed spectral acceleration levels for the three probability levels. Using the Sadigh and others (1986) and Joyner and Boore (1982) response spectra attenuation relationships yields similar results except for low probability levels on soil sites, where the Joyner and Boore (1982) relationship gives spectral accelerations that are about $1 \frac{1 / 2}{2}$ to 2 times higher than those obtained by using the Sadigh and others (1986) relationships.

To directly compare the relative frequency content of the various equal-hazard spectra, the absolute spectra were normalized by their corresponding peak groundacceleration levels. The resulting spectral shapes are shown in figures 39 and 40 for soil and rock sites, respec- 

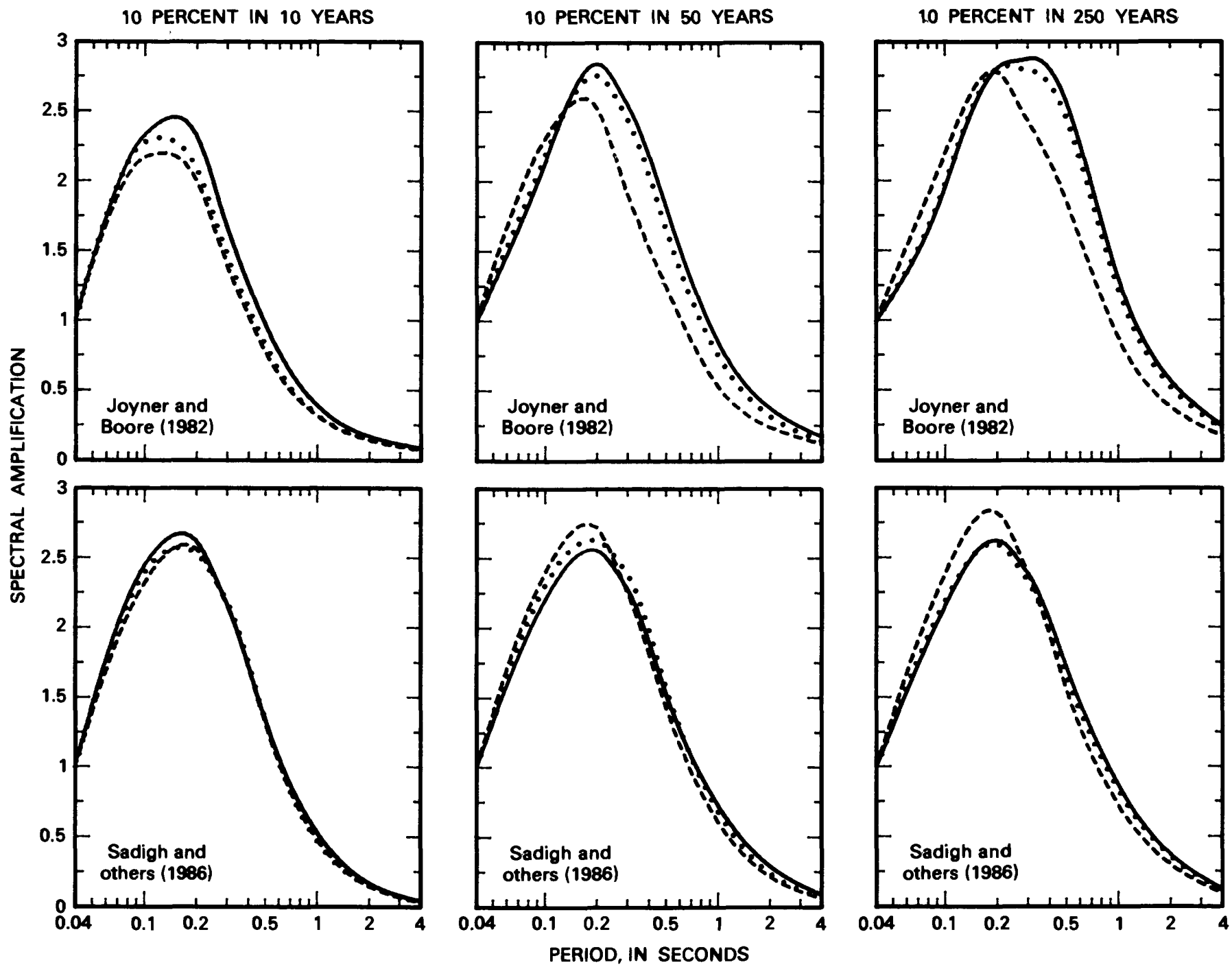

\section{EXPLANATION}

Salt Lake City

-... Brigham City

Logan

FIGURE 40.-Equal-hazard response spectral shapes (5-percent damping) computed for rock sites at three locations. The upper row of plots shows the spectral amplifications computed by using the Joyner and Boore (1982) attenuation relationships, and the lower row of plots shows the spectral amplifications computed by using the Sadigh and others (1986) attenuation relationships.

tively. In general, the computed spectral shape for a particular site classification, probability level, and attenuation relationship is similar at all three geographic locations. Average spectral shapes for each probability level and site classification were obtained by averaging the six shapes computed from the Sadigh and others (1986) and Joyner and Boore (1982) relationships at the three locations. These spectral shapes are shown in figure 41 . The average spectral shapes differ by a maximum of 20 percent from the spectral shapes obtained at any given location. Consequently, we propose that the spectral shapes shown in figure 41 be used for the respective probability level and site classifications, regardless of location within the study area.

It can be seen in figures 39 through 41 that the response spectral shapes broaden significantly with decreasing probability level. This broadening reflects the increasing contribution of large-magnitude events as the probability level decreases. It is therefore not appropriate to use a single spectral shape for all probability levels.

Absolute acceleration equal-hazard spectra for soil sites can be obtained by multiplying the soil spectral shapes shown in figure 41 by the appropriate peak ground acceleration obtained from the hazard maps for the sam- 
10 PERCENT IN 10 YEARS

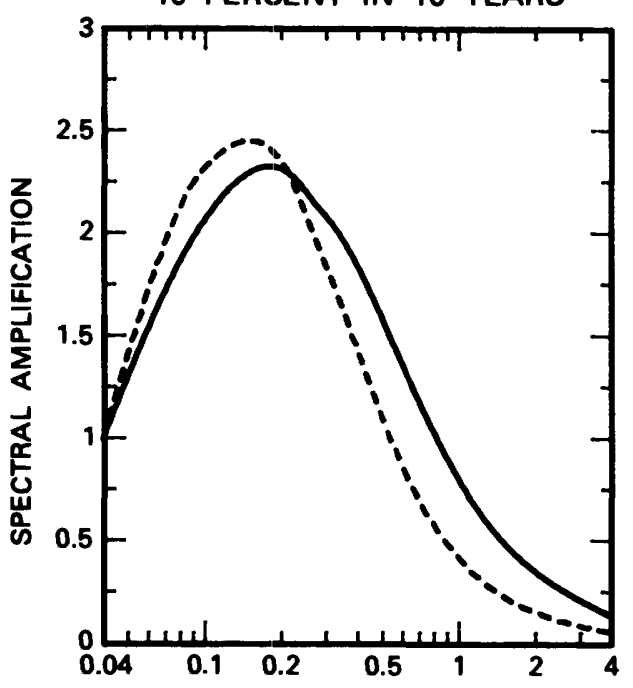

10 PERCENT IN 50 YEARS

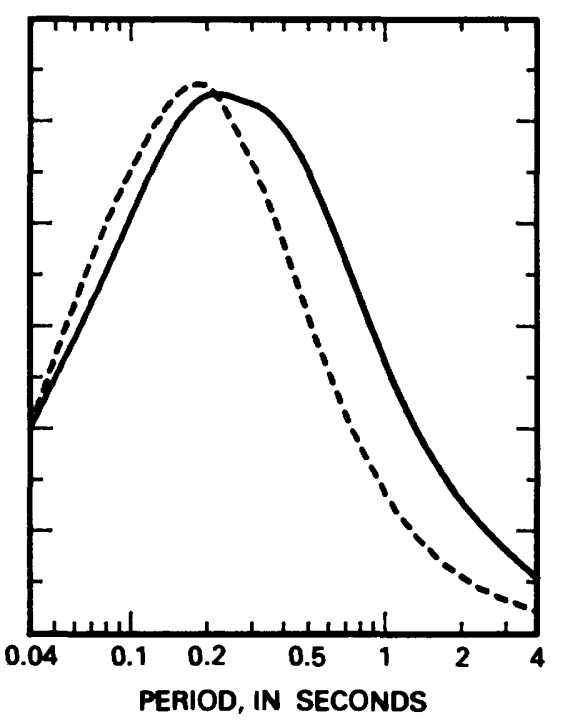

10 PERCENT IN 250 YEARS

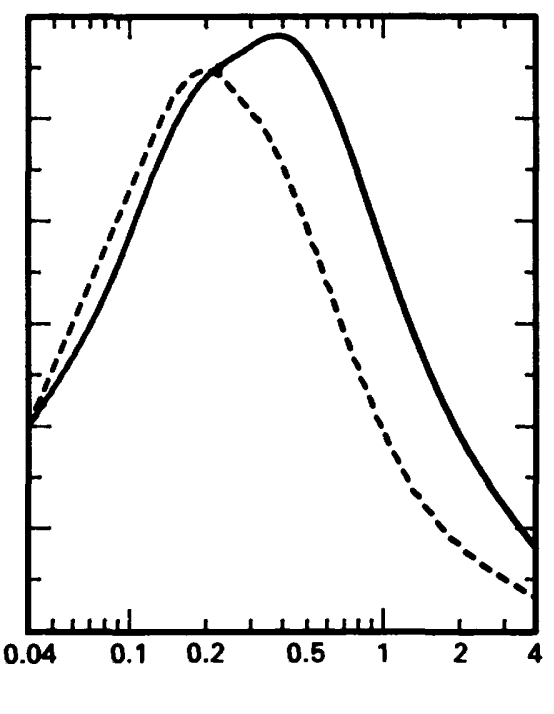

EXPLANATION

Soil _. - - Rock

FIGURE 41.-Proposed spectral shapes (5-percent damping) for developing equal-hazard response spectra. For soil sites, equal-hazard spectra are developed by multiplying the soil spectral amplifications shown in the figure by the appropriate peak ground accelerations obtained from the soil-hazard maps shown in figure 37 . For rock sites, the appropriate peak acceleration to use with the rock spectral amplifications shown in the figure is obtained by multiplying the peak ground accelerations shown on the soil-hazard maps shown in figure 37 by a factor of 1.1 for a 10-percent probability of exceedance in 10 years and by a factor of 1.2 for 10 -percent probability of exceedance in 50 and 250 years. ple probability level (fig. 37). Absolute acceleration equalhazard spectra for rock sites can be obtained by first estimating the peak acceleration on rock by multiplying the soil acceleration levels by a factor of 1.1 for 10 -percent probability of exceedance in 10 years or a factor of 1.2 for lower probability levels and then multiplying by the appropriate rock spectral shapes shown in figure 41 .

As an example application, figure 42 presents the equal-hazard response spectra that would be developed for rock and soil sites in the vicinity of Magna corresponding to a 10-percent probability of exceedance in 50 years. The hazard map shown in figure 37 indicates that the appropriate peak ground acceleration on soil sites is 0.25 $g$. If a factor of 1.2 is used, the corresponding peak acceleration on rock would be $0.30 \mathrm{~g}$. The absolute acceleration spectra shown in figure 42 were obtained by multiplying the appropriate spectral shapes in figure 41 by these two acceleration levels.

The soil-site spectra shown in figure 41 are considered appropriate for firm soil conditions. Firm soils are considered to consist of medium-dense to dense sands and gravels and stiff silts and clays. As discussed in the section of the paper describing attenuation relationships, there is uncertainty as to the relative amplitudes of ground motions on softer lake deposits (soft clays and silts). A preliminary indication of the possible additional spectral amplification in areas of soft lake deposits can be obtained from the response spectral shapes developed by Seed and others (1976b) for different generalized categories of subsurface conditions. Seed and others (1976b) found that response spectral amplifications for "soft to medium clay and sand" exceeded the amplifications for "deep cohesionless" and "stiff" soils for periods greater than about $0.4 \mathrm{~s}$ and were less than the amplifications for "deep cohesionless" and "stiff" soils at shorter periods. The average increase in amplification in the period range of about 0.75 to $1.5 \mathrm{~s}$ corresponded to a factor of about 1.6. Using this factor with the response spectral curve for soil shown in figure 41 and neglecting any possible decrease in amplification at periods less than $0.4 \mathrm{~s}$, we obtained the ranges in response spectral shapes shown in figure 43. The lower curves correspond to the shapes for soil shown in figure 41 and are for firm soil conditions. The upper curves are preliminary estimates of response spectral shapes applicable to soft lake deposits. These curves can be multiplied by the appropriate peak acceleration values in figure 37 to obtain preliminary estimates of absolute response spectra on soft lake deposits. 


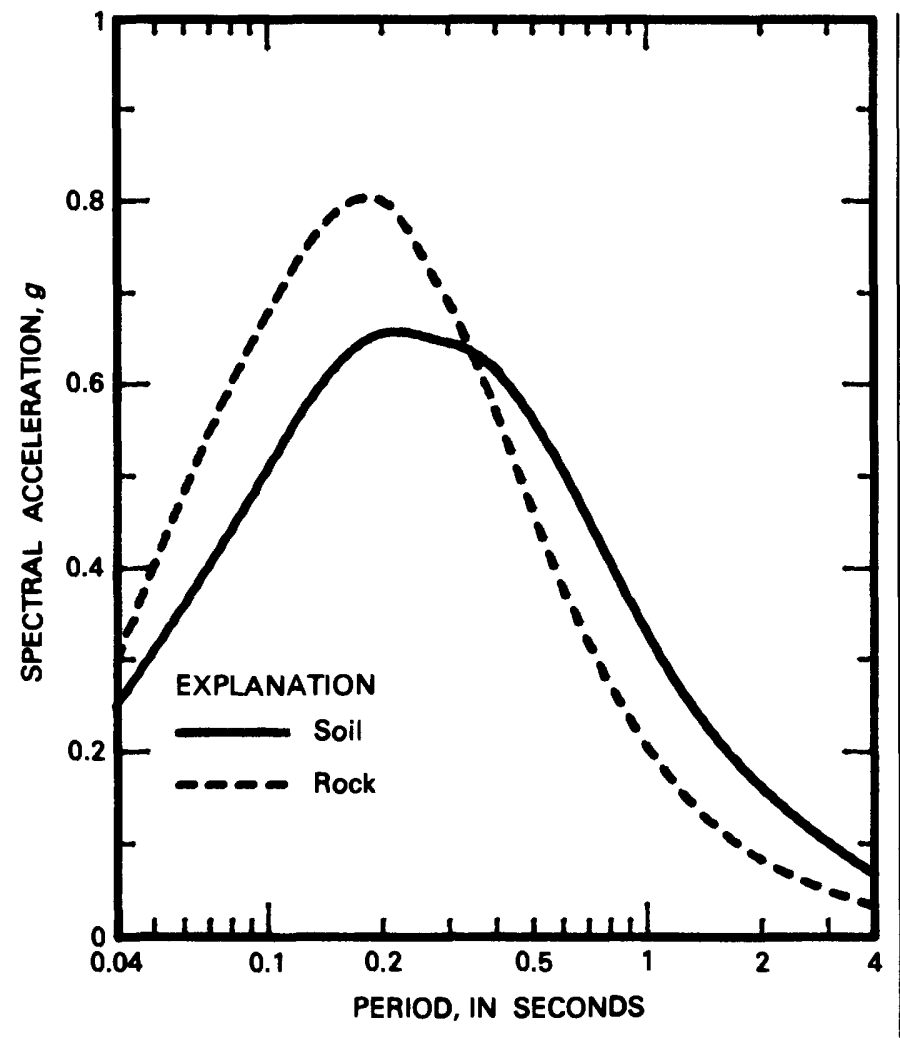

FIGURE 42.-Example of the development of equal-hazard response spectra (5percent damping) for a 10-percent probability of exceedance in 50 years for soil and rock sites near Magna, Utah.

\section{SUMMARY}

A quantitative assessment has been made of the ground-shaking hazard along the Wasatch Front urban corridor by utilizing the extensive geological and seismological data base that has been developed for the region. A probabilistic approach was used to express levels of ground motion as a function of their probability of exceedance. Using a logic tree methodology, the approach formally incorporates variations in values for earthquake source geometry and fault segmentation, maximum earthquake magnitude, earthquake recurrence rate, ground-motion attenuation, and other parameters and model components that are not known with certainty (table 1).

On the basis of probabilistic analyses conducted at 80 points located on a grid in the study area, maps were prepared showing contours of peak ground acceleration for probabilities of exceedance of 10 percent in 10 years, 10 percent in 50 years, and 10 percent in 250 years (fig. 37). These maps are for peak acceleration on soil-site conditions, considered to be sites where depth to bedrock was $20 \mathrm{~m}$ or more. By repeating the analyses using rocksite attenuation relationships, we concluded that rocksite peak accelerations can be obtained by multiplying the soil-site accelerations by a factor of 1.1 for a probability of exceedance of 10 percent in 10 years and by a factor of 1.2 for probabilities of exceedance of 10 percent in 50 years and 10 percent in 250 years.

Response spectra were also developed from the probabilistic analyses. Response spectral shapes (for a damping ratio of 0.05 ) for firm soil conditions and for rock-site conditions were developed for the same probability of exceedance levels used in mapping peak ground acceleration (fig. 41). Absolute response spectra can be obtained by multiplying these spectral shapes by the corresponding values of peak ground acceleration. In areas underlain by soft lake silts and clays, considerable uncertainty exists regarding the spectral shapes. A preliminary estimate is presented for the additional spectral amplification that might occur in areas of soft lake deposits (fig. 43).

Extensive analyses were conducted to examine the sensitivity and uncertainty of the results of this study with respect to variations in the various input parameters and models. The computed 90-percent confidence intervals for peak ground acceleration represent a range of minus 40 percent to plus 60 percent about the values shown on the hazard maps (fig. 37). The two biggest contributors to uncertainty in the results were uncertainties in selecting the appropriate models for earthquake recurrence on the faults and ground-motion attenuation.

\section{POSTSCRIPT}

The state of knowledge about earthquake hazards along the Wasatch Front has continued to evolve since the completion of this study (1986). Continued paleoseismic studies have led to a consensus model for the segmentation of the Wasatch fault zone and improved data on the timing of late Holocene surface rupturing events (Machette and others, 1991). Geophysical data obtained from the Great Salt Lake has confirmed the existence of a Great Salt Lake fault and indicated a somewhat greater slip rate than that used for the Oquirrh Mountains fault zone in this study (Pechmann and others, 1987). Continued examination of the relationship between local magnitude $\left(\mathrm{M}_{\mathrm{L}}\right)$ and seismic moment $\left(M_{o}\right)$ has led to the conclusion that the moment magnitude relationship developed for California earthquakes is appropriate for the Utah region (Shemeta and Pechmann, 1989). Studies of strong-motion data have suggested values for the standard error in peak ground acceleration (Youngs and others, 1990; Campbell, 1991) that are somewhat higher than those used in this study. In addition, Brockman and Bollinger (1992) have reported results of analyses that fur- 

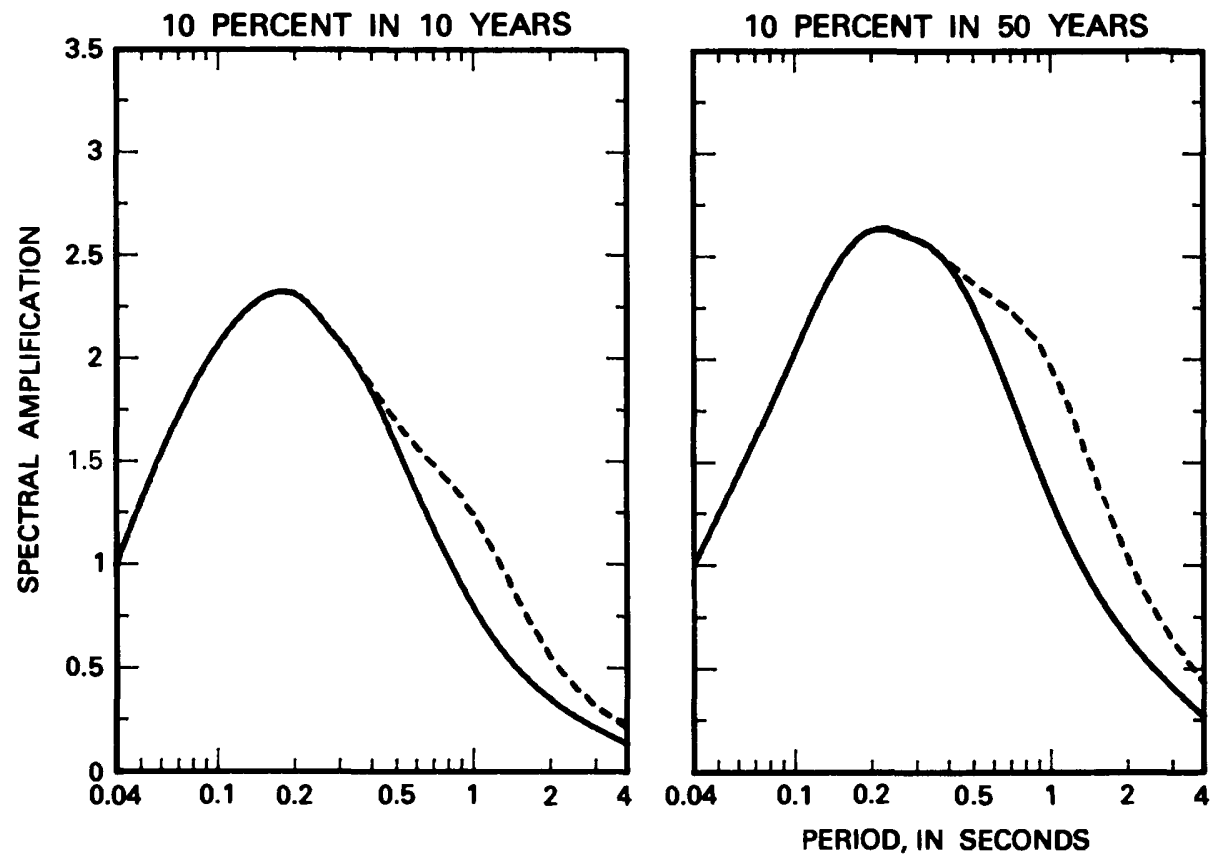

10 PERCENT IN 250 YEARS

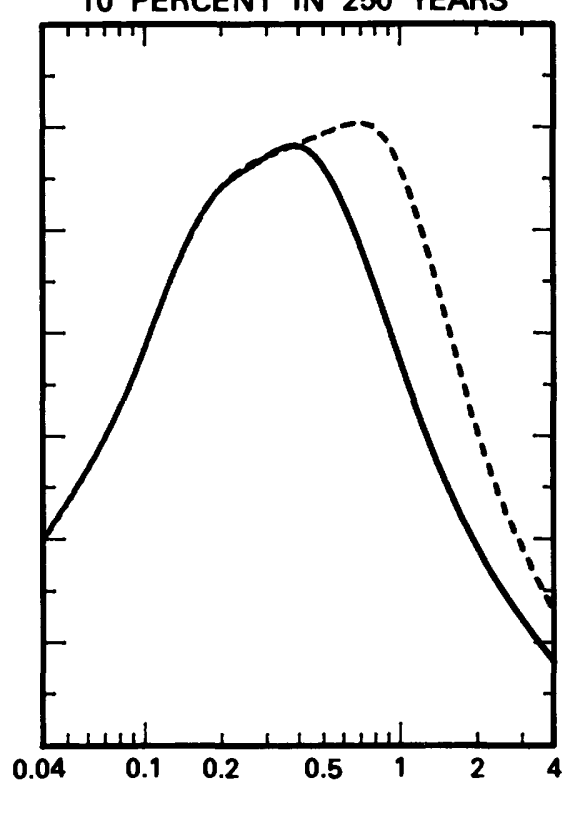

EXPLANATION

Firm soil

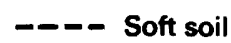

FIGURE 43.-Preliminary estimates of ranges in response spectral shapes (5-percent damping) for lake deposits. Lower curves are soil curves shown in figure 41 and are intended for firm soil conditions. Upper curves in the ranges are preliminary estimates for soft lake silts and clays.

ther confirm the assumption used in this study that the rate of attenuation of seismic waves in Utah is similar to that in California.

Many of these results would suggest modifications of the inputs to the seismic-hazard analysis. We have performed a limited number of calculations to evaluate the impact of updated input parameters on the results presented in the regional hazard maps (fig. 37). The impact varies with location and sometimes results in higher hazard and sometimes in lower hazard. Generally, the updated input parameters result in differences of 15 percent or less in peak ground acceleration for the three selected probability levels. These differences are well within the uncertainty bounds presented in our study. Therefore, we believe that figure 37 still presents a valid representation of the seismic hazard along the Wasatch Front.

\section{REFERENCES CITED}

Aki, K., 1979, Characterization of barriers on an earthquake fault: Journal of Geophysical Research, v. 84, no. B11, p. $6140-5148$.

-1984, Asperities, barriers, and characteristic earthquakes: Journal of Geophysical Research, v. 89, no. B7, p. 58675872.
Algermissen, S.T., Perkins, D.M., Thenhaus, P.C., Hanson, S.L., and Bender, B.L., 1982, Probabilistic estimates of maximum acceleration and velocity in rock in the contiguous United States: U.S. Geological Survey Open-File Report 82-1033, $99 \mathrm{p}$.

Anderson, J.G., 1979, Estimating the seismicity from geological structure for seismic risk studies: Bulletin of the Seismological Society of America, v. 69, no. 1, p. 135-158.

Anderson, L.W., and Miller, D.G., 1979, Quaternary fault map of Utah: Long Beach, Calif., FUGRO, Inc., 35 p.

Arabasz, W.J., 1979, Historical review of earthquake-related studies and seismographic recording in Utah, in Arabasz,W.J.,-Smith, R.B., and Richins W.D., eds., Earthquake studies in Utah 1850 to 1978: Salt Lake City, University of Utah Seismograph Stations Special Publication, p. 33-56.

1984, Earthquake behavior in the Wasatch front area: Association with geologic structure, space-time occurrence, and stress state, in Hays, W.W., and Gori, P.L., eds., Proceedings of Conference XXVI-A workshop on evaluation of regional and urban earthquake hazards and risk in Utah: U.S. Geological Survey Open-File Report 84-763, p. 310-339.

Arabasz, W.J., and McKee, M.E., 1979, Utah earthquake catalog 1850-June 1962, in Arabasz,W.J., Smith, R.B., and Richins W.D., eds., Earthquake studies in Utah 1850 to 1978: Salt Lake City, University of Utah Seismograph Stations Special Publication, p. 119-121. 
Arabasz, W.J., and Robinson, R., 1976, Microseismicity and geologic structure in the northern South Island, New Zealand: New Zealand Journal of Geology and Geophysics, v. 19, no. 2 , p. $561-601$.

Arabasz,W.J., Smith, R.B., and Richins, W.D., 1980, Earthquake studies along the Wasatch Front, Utah-Network monitoring, seismicity, and seismic hazards: Bulletin of the Seismological Society of America, v. 70, no. 5, p. 1479-1499.

Bender, B., 1983, Maximum likelihood estimation of $b$ values for magnitude grouped data: Bulletin of the Seismological Society of America, v. 73, no. 3, p. 831-851.

-1984, Seismic hazard estimation using a finite fault rupture model: Bulletin of the Seismological Society of America, v. 74, no. 5, p. 1899-1923.

Benz, H.M., and Smith, R.B., 1988, Elastic-wave propagation and site amplification in the Salt Lake Valley, Utah, from simulated normal faulting earthquakes: Bulletin of the Seismological Society of America, v. 78, no. 6, p. 1851-1874.

Bonilla, M.G., Mark, R.K., and Lienkaemper, J.J., 1984, Statistical relations among earthquake magnitude, surface rupture length, and surface fault displacement: Bulletin of the Seismological Society of America, v. 74, no. 6, p. 2379-2411.

Boore, D.M., 1983, Stochastic simulations of high-frequency ground motions based on seismological models of the radiated spectra: Bulletin of the Seismological Society of America, v. 73 , no. 5 , p. 1865-1894.

Brazee, R.J., 1980, An analysis of earthquake intensities with respect to attenuation, magnitude, and rate of recurrence (revised ed.): Washington, D.C., U.S. Nuclear Regulatory Commission Report NUREG/CR-1805, 35 p.

Brillinger, D.R., 1982, Some bounds for seismic risk: Bulletin of the Seismological Society of America, v. 72, no. 4, p. 14031410.

Brockman S.R, and Bollinger, G.A., 1992, $Q$ estimates along the Wasatch front in Utah derived from $S_{g}$ and $L_{g}$ wave amplitudes: Bulletin of the Seismological Society of America, v. 82 , no. 1, p 135-147.

Campbell, K.W., 1982, A preliminary methodology for the regional zonation of peak ground acceleration: International Earthquake Microzonation Conference, 3d, Seattle, Wash., 1982, Proceedings, v. I, p. 365-374.

-1987, A random-effects analysis of near-source ground motion for the Diablo Canyon Power Plant site, San Luis Obispo County, California: Bethesda, Md., report prepared for Lawrence Livermore National Laboratory, Dames and Moore.

Chandra, U., 1979, Attenuation of intensities in the United States: Bulletin of the Seismological Society of America, v. 69 , no. 6, p. 2003-2024.

Chavez, D.E., and Priestly, K.F., 1985, $\mathrm{M}_{\mathrm{L}}$ observations in the Great Basin and $M_{o}$ versus $\mathrm{M}_{\mathrm{L}}$ relationships for the 1980 Mammoth Lakes, California earthquake sequence: Bulletin of the Seismological Society of America, v. 75, no. 6, p. 1583-1598.

Cluff, L.S., Glass, C.E., and Brogan, G.E., 1974, Investigation and evaluation of the Wasatch fault north of Brigham City and Cache Valley faults, Utah and Idaho-A guide to land-use planning with recommendations for safety: Oakland, Calif., report prepared for Utah Geological and Mineralogical Survey, Woodward-Lundgren and Associates, $146 \mathrm{p}$.

Coppersmith, K.C., and Youngs, R.R., 1986, Capturing uncertainty in probabilistic seismic hazard assessments within intraplate environments: National Conference on Earthquake Engineering, 3d, Charleston, S.C., 1986, Proceedings, v. I, p. 301-312.

Cornell, C.A., 1968, Engineering seismic risk analysis: Bulletin of the Seismological Society of America, v. 58, no. 5, p. 15831606.

Cornell, C.A., and Van Marke, E.H., 1969, The major influences on seismic risk: World Conference on Earthquake Engineering, 3d, Santiago, Chile, Proceedings, v. A-1, p. 69-93.

Cornell, C.A. and S.R. Winterstein, 1988, Temporal and magnitude dependence in earthquake recurrence models: Bulletin of the Seismological Society of America, v. 78, no. 4, p. 1522-1537.

Crone, A.J., and Machette, M.N., 1984, Surface faulting accompanying the Borah Peak earthquake, central Idaho: Geology, v. 12 , p. 664-667.

Deschamps, A., Guademer, Y., and Cisternas, A., 1982, The El Asnam, Algeria earthquake of 10 October 1980-Multiplesource mechanism determined from long-period records: Bulletin of the Seismological Society of America, v. 72, no. 4, p. 1111-1128.

Doser, D.I., 1984, The 1983 Borah Peak, Idaho and 1959 Hebgen Lake, Montana earthquakes; models for normal fault earthquakes in the Intermountain Seismic Belt, in Stein, R.S., and Bucknam, R.C., convenors, Proceedings of Workshop XXVIII on the Borah Peak, Idaho, earthquake: U.S. Geological Survey Open-File Report 85-290-A, p. 368-384.

Doser, D.I. and Smith, R.B., 1982, Seismic moment rates in the Utah region: Bulletin of the Seismological Society of America, v. 72 , no. 2 , p. $525-551$.

Electric Power Research Institute, 1987, Seismic hazard methodology for the central and eastern United States, v. 1, Methodology (revised ed.): EPRI Report NP-4726, prepared for Seismicity Owners Group and Electric Power Research Institute under research projects P101-38, -45, -46, 225614.

Everitt, B.L., and Kaliser, B.N., 1980, Geology for assessment of seismic risk in the Tooele and Rush valleys, Tooele County, Utah: Salt Lake City, Utah Geological and Mineral Survey Special Studies 51, $33 \mathrm{p}$.

Evernden, J.F., 1975, Seismic intensities, "size" of earthquakes, and related parameters: Bulletin of the Seismological Society of America, v. 65, no. 5, p. 1287-1313.

compiler, 1980, Proceedings of Conference X: Earthquake hazards along the Wasatch and Sierra-Nevada frontal fault zones: U.S.Geological Survey Open-File Report 80-801, $688 \mathrm{p}$.

Gardner, J.K., and Knopoff, L., 1974, Is the sequence of earthquakes in Southern California, with aftershocks removed, Poissonian?: Bulletin of the Seismological Society of America, v. 64 , no. 5 , p. $1363-1367$.

Gilbert, G.K., 1890, Lake Bonneville: U.S. Geological Survey Monographs 1, 438 p.

Griscom, M., 1980, Space-time seismicity patterns in the Utah region and an evaluation of local magnitude as the basis of a 
uniform earthquake catalog: Salt Lake City, University of Utah, unpublished M.Sci. thesis, $95 \mathrm{p}$.

Griscom, M., and Arabasz, W.J., 1979, Local magnitude $\left(\mathrm{M}_{\mathrm{L}}\right)$ in the Wasatch front and Utah region: Wood-Anderson calibration, coda-duration estimates of $\mathrm{M}_{\mathrm{L}}$, and $\mathrm{M}_{\mathrm{L}}$ versus $\mathrm{m}_{\mathrm{B}}$, in Arabasz,W.J., Smith, R.B., and Richins W.D., eds., Earthquake studies in Utah 1850 to 1978: Salt Lake City, University of Utah Seismograph Stations Special Publication, p. 433-443.

Gutenberg, B. and Richter, C.F., 1954, Seismicity of the Earth and associated phenomena, (2d ed.): Princeton, N.J., Princeton University Press, $310 \mathrm{p}$.

-1956, Earthquake magnitude, intensity, energy, and acceleration: Bulletin of the Seismological Society of America, v. 46 , no. 3 , p. $105-145$.

Hanks, T.C., and Kanamori, H., 1979, A moment magnitude scale: Journal of Geophysical Research, v. 84, no. B5, p. 23482350.

Hanks, T.C., and McGuire, R.K., 1981, The character of high frequency ground motion: Bulletin of the Seismological Society of America, v. 71, no. 6, p. 2071-2095.

Hanson, K.L. and Schwartz, D.P., 1982, Guidebook to late Pleistocene and Holocene faulting and the vicinity-Little Cottonwood Canyon to Scipio, Utah: American Geophysical Union Chapman Conference on Fault Behavior and the Earthquake Process, Snowbird, Utah, 1982, 40 p.

Hanson, K.L., Swan, F.H., and Schwartz, D.P., 1981a, Study of earthquake recurrence intervals on the Wasatch fault, Utah (North Creek site): Sixth semiannual technical report prepared for the U.S. Geological Survey (Menlo Park, Calif.) under contract no. 14-07-0001-19842, 22 p.

1981b, Study of earthquake recurrence intervals on the Wasatch fault, Utah: Fifth semiannual technical report prepared for the U.S. Geological Survey (Menlo Park, Calif.) under contract no. 14-08-0001-19115, $15 \mathrm{p}$.

Hays, W.W., and Gori, P.L., eds., 1984, Proceedings of Conference XXVI; a workshop on evaluation of regional and urban earthquake hazards and risk in Utah: U.S. Geological Survey Open-File Report 84-763, 692 p.

Hays, W.W., and King, K.W., 1982, Zoning of the earthquake ground-shaking hazard along the Wasatch fault zone, Utah: International Earthquake Microzonation Conference, 3d, Seattle, 1982, Proceedings, v. III, p. 1307-1318.

1984a, The ground-shaking hazard along the Wasatch fault zone, Utah: World Conference on Earthquake Engineering, 8th, San Francisco, 1984, Proceedings, v. 1, p. 7-14.

$1984 \mathrm{~b}$, The ground-shaking hazard along the Wasatch fault zone, Utah, in Hays, W.W., and Gori, P.L., eds., Proceedings of Conference XXVI; a workshop on evaluation of regional and urban earthquake hazards and risk in Utah: U.S. Geological Survey Open-File Report 84-763, p. 143147.

Howell, B.F., Jr., and Schultz, T.R., 1975, Attenuation of modified Mercalli intensity with distance from the epicenter: Bulletin of the Seismological Society of America, v. 65, no. 1, p. 641665.

Idriss, I.M., 1990, Response of soft soil sites during earthquakes, in Duncan, J.M., ed., H. Bolton Seed Memorial Symposium, Berkeley, Calif., 1990: Proceedings, v. 2, p. 273-289.
Jackson, S.M., and J. Boatwright, 1987, Strong ground motion in the Borah Peak earthquake and its aftershocks: Bulletin of the Seismological Society of America, v. 77, no. 3, p. 724738.

Joyner, W.B., and Boore, D.M., 1982, Prediction of earthquake response spectra: U.S. Geological Survey Open-File Report 82-977, $17 \mathrm{p}$.

Keaton, J., Curry, D.R., and Olig, S.J., 1986, Paleoseismicity and earthquake hazards evaluation of the West Valley fault zone, Salt Lake City urban area: Report prepared for U.S. Geological Survey (Menlo Park, Calif.) under contract no. 14-080001-22048, $18 \mathrm{p}$.

King, K.W., and Hays, W.W., 1977, Comparison of seismic attenuation in Northern Utah with attenuation in four other regions of the western United States: Bulletin of the Seismological Society of America, v. 67, no. 3, p. 781-792.

King, K.W., Hays, W.W., and McDermott, P.J., 1983, Wasatch front urban area seismic response data report: U.S. Geological Survey Open-File Report 83-452, 68 p.

King, G., and Yielding, G., 1984, The evolution of a thrust fault system-Process of rupture initiation, propagation and termination in the El Asnam (Algeria) earthquake: Geophysical Journal of the Royal Astronomical Society, v. 77, p. 913933.

Kulkarni, R.B., Youngs, R.R., and Coppersmith, K.J., 1984, Assessment of confidence intervals for results of seismic hazard analysis, in World Conference on Earthquake Engineering, 8th, San Francisco, 1984, Proceedings, v. 1, p. 263270.

Lund, W.R., and Schwartz, D.P., 1986, Fault behavior and earthquake recurrence at the Dry Creek site, Salt Lake segment, Wasatch Fault Zone, Utah: Eos, Transactions of the American Geophysical Union, v. 67, no. 44, p. 1107.

Machette, M.N., Personius, S.F., Scott, W.E., and Nelson, A.R., 1986, Quaternary geology for ten fault segments and largescale changes in slip rate along the Wasatch fault zone: Paper presented at workshop on earthquake hazards along the Wasatch Front, Utah, Salt Lake City, Utah, 1986.

Machette, M.N., Personius, S.F., Nelson, A.R., Schwartz, D.P, and Lund, W.R., 1991, The Wasatch fault zone, Utah-Segmentation and history of Holocene earthquakes: Journal of Structural Geology, v. 13, no. 2, p. 137-149.

Mayer, L., and MacLean, A., 1986, Tectonic geomorphology of the Wasatch Front, Utah, using morphologic discriminant analysis-Preliminary implications for Quaternary segmentation of the Wasatch fault zone [abs.]: Geological Society of America Abstracts with Programs, v. 18, no. 2, p. 155.

McCalpin, J., 1985, Quaternary fault history and earthquake potential of the Hansel Valley area, north central Utah, in National Earthquake Hazards Reduction Program; summaries of technical reports, v. XX: U.S. Geological Survey Open-File Report 85-464, p. 105-108.

1987, Quaternary deformation along the East Cache fault, north-central Utah [abs.]: Geological Society of America Abstracts with Programs, v. 19, no. 5, p. 320.

McGarr, A., 1982, Upper bounds on near-source peak ground motion based on a model of inhomogeneous faulting: Bulletin of the Seismological Society of America, v. 72, no. 6, p. $1825-1841$. 
1984, Scaling of ground motion parameters, state of stress, and focal depth: Journal of Geophysical Research, v. 89, no. B8, p. 6969-6979.

McGuire, R.K., 1983, Estimation of seismic ground motion in northern Utah: Report submitted to U.S. Geological Survey (Menlo Park, Calif.) by Dames and Moore under contract 14-08-0001-19825, 63 p.

Mertz, H.A., and Cornell, C.A., 1973, Aftershocks in engineering seismic risk analysis: Cambridge, Mass., Research Report R73-25, Massachusetts Institute of Technology, Department of Civil Engineering, $23 \mathrm{p}$.

Nelson, A.R., and Van Arsdale, R.B., 1986, Recurrent late Quaternary movement on the Strawberry normal fault, Basin and Range-Colorado Plateau transition zone, Utah: Neotectonics, v. 1, p. 7-37.

Pechmann, J.C., Nash, W.P., Viveiros, J.J., and Smith, R.B., 1987, Slip rate and earthquake potential of the East Great Salt Lake fault, Utah [abs.]: Eos, Transactions of the American Geophysical Union, v. 68, p. 1369.

Personius, S.F., 1986, The Brigham City segment-A new segment of the Wasatch fault zone, northern Utah [abs.]: Geological Society of America Abstracts with Programs, v. 18, no. 5 , p. 402.

Power, M.S., Coppersmith, K.J., Youngs, R.R., Schwartz, D.P., and Swan, F.H., III, 1981, Seismic exposure analysis for the WNP-2 and WNP-1/4 site: Appendix 2.5K to Amendment no. 18: Richland Wash., Final Safety Analysis Report WNP-2 for Washington Public Power Supply System, 58 p.

Richins, W.J., 1979, Earthquake data for the Utah region, in Arabasz,W.J., Smith, R.B., and Richins W.D., eds., Earthquake studies in Utah 1850 to 1978: Salt Lake City, University of Utah Seismograph Stations Special Publication, p. 57-251.

Rogers, A.M., Carver, D.L., Hays, W.W., King, K.W., and Miller, R.D., 1984, Preliminary estimates of geographic variation in relative ground shaking in the Wasatch front urban corridor, in Hays, W.W., and Gori, P.L., eds., Proceedings of Conference XXVI; a workshop on evaluation of regional and urban earthquake hazards and risk in Utah: U.S. Geological Survey Open-File Report 84-763, p. 547-556.

Rogers, A. M., Harmsen, S.C., Herrmann, R.B., and Meremonte, M.E., 1986, A study of ground motion attenuation in the southern Great Basin, Nevada-California, using several techniques for estimates of $Q_{s}, \log A_{0}$, and coda $Q_{1}$ : Journal of Geophysical Research, v. 92, no.B5, p. 3527-3540.

Rogers, A.M., J.C. Tinsley, and R.D. Borcherdt, 1985, Predicting relative ground response, in Ziony, J.I., ed., Evaluating earthquake hazards in the Los Angeles region-An earthscience perspective: U.S. Geological Survey Professional Paper 1360, p. 221-247.

Sadigh, K., Egan, J.A., and Youngs, R.R., 1986, Specification of ground motion for seismic design of long period structures: Earthquake Notes, v. 57, no. 1, p. 13.

Schwartz, D.P., and Coppersmith, K.J., 1984, Fault behavior and characteristic earthquakes from the Wasatch and San Andreas faults: Journal of Geophysical Research, v. 89, no. B7, p. 5681-5698.

-1986,Seismic hazards: New trends in analysis using geologic data, in Wallace, R.E., chairperson, Active tectonics: Washington D.C., National Academy Press, p. 215-230.
Schwartz, D.P., Hanson, K.L., and Swan, F.H., 1983, Paleoseismic investigations along the Wasatch fault zone: An update, in Crone, A.J. (ed.), Paleoseismicity along the Wasatch Front and adjacent areas, central Utah: Geological Society of America Rocky Mountain and Cordilleran Sections Meeting, Guidebook pt. 2: Utah Geological and Mineral Survey Special Studies 62, p. 45-40.

Schwartz, D.P., Swan, F.H., and Cluff, L.S., 1984, Fault behavior and earthquake recurrence along the Wasatch fault zone, in Hays, W.W., and Gori, P.L., eds., Proceedings of Conference XXVI; a workshop on evaluation of regional and urban earthquake hazards and risk in Utah: U.S. Geological Survey Open-File Report 84-763, p. 113-125.

Scott, W.E., 1980, Quaternary stratigraphy of the Wasatch Front, in Evernden, J.F., compiler, Summaries of technical reports, v. IX, National Earthquake Hazards Reduction Program: U.S. Geological Survey Open-File Report 80-6, p. 62-64.

Seed, H.B., and Idriss, I.M., 1982, Ground motions and soil liquefaction during earthquakes, in Engineering monographs on earthquake criteria, structural design, and strong motion records: Berkeley, Calif., Earthquake Engineering Research Institute, v. 5, p. 134.

Seed, H.B., Idriss, I.M., and Keifer, F. W, 1969, Characteristics of rock motions during earthquakes: Proceedings of the American Society of Civil Engineers, Journal of the Soil Mechanics and Foundation Division, v. 95, no. SM5, p. 1199-1218.

Seed, H.B., Murarka, R., Lysmer, J., and Idriss, I.M., 1976a, Relationships of maximum accelerations, maximum velocity, distance a from source and local site conditions for moderately strong earthquakes: Bulletin of the Seismological Society of America, v. 66, no. 4, p. 1323-1342.

Seed, H.B., C. Ugas, and J. Lysmer, 1976b, Site-dependent spectra for earthquake-resistant design: Bulletin of the Seismological Society of America, v. 66, n. 1, p. 221-244.

Shemeta, J.E., and Pechmann, J.C., 1989, Source parameters of aftershocks of the 1983 Borah Peak, Idaho, earthquake [abs.]: Eos, Transactions of the American Geophysical Union, v. 70, p. 1188.

Singh, S., 1981, Regionalization of crustal $Q$ in the continental United States: St. Louis, Mo., St. Louis University, unpublished Ph.D dissertation, $103 \mathrm{p}$.

Singh, S., and Herrmann, R.B., 1983, Regionalization of crustal coda $Q$ in the continental United States: Journal of Geophysical Research, v. 88, no. B1, p. 527-538.

Slemmons, D.B., 1977, State-of-the-art for assessing earthquake hazards in the United States, Report 6, Faults and earthquake magnitude: U.S. Army Corps of Engineers, Waterways Experiment Station Miscellaneous Paper S-73, 129 p.

-1982, Determination of design earthquake magnitudes for microzonation, in International Earthquake Microzonation Conference, 3d, Seattle, Wash., 1982, Proceedings v. 1., p. 119-130.

Slemmons, D.B., and Depolo, G.M., 1986, Evaluation of active faulting and associated hazards, in Studies in geophysicsActive tectonics: Washington, D.C., National Academy Press, p. 45-62.

Smith, R.B., Richins, W.D., and Doser, D.I., 1985, The 1983 Borah Peak, Idaho earthquake-Regional seismicity, kinematics of faulting, and tectonic mechanism, in Stein, R.C., and Buck- 
nam, R.C., convenors and eds., Proceedings of Workshop XXVIII on the Borah Peak, Idaho, earthquake: U.S. Geological Survey Open-File Report 85-290-A, p. 236-263.

Stepp, J.C., 1972, Analysis of completeness of the earthquake sample in the Puget Sound area and its effect on statistical estimates of earthquake hazard, in International Conference on Microzonation, Seattle, Wash., 1972, Proceedings v. 2, p. 897-909.

Swan, F.H., III, Schwartz, D.P., and Cluff, L.S., 1980, Recurrence of moderate to large magnitude earthquakes produced by surface faulting on the Wasatch fault, Utah: Bulletin of the Seismological Society of America, v. 70, no. 5, p. 1431-1462.

Swan, F.H., III, Schwartz, D.P., Hanson, K.L., Knuepfer, P.L., and Cluff, L.S., 1981a, Study of earthquake recurrence intervals on the Wasatch fault at the Kaysville site, Utah: U.S. Geological Survey Open-File Report 81-0228, 52 p.

Swan, F.H., III, Hanson, K.L., Schwartz, D.P., and Knuepfer, P.L., $1981 \mathrm{~b}$, Study of earthquake recurrence intervals on the Wasatch fault at the Little Cottonwood Canyon site, Utah: U.S. Geological Survey Open-File Report 81-450, 30 p.

Swan, F.H., III, Schwartz, D.P., Cluff, L.S., Hanson, K.L., and Knuepfer, P.L., 1981c, Study of earthquake recurrence intervals on the Wasatch fault at the Hobble Creek site, Utah: U.S. Geological Survey Open-File Report 81-229, 58 p.

Swan, F.H., III, Hanson, K.L., and Schwartz, D.P., 1983, Study of earthquake recurrence intervals on the Wasatch fault, Utah: Eighth semiannual technical report prepared for the U.S. Geological Survey (Menlo Park, Calif.) under contract 1407-0001-19842, 40 p.

Tinsley, J.C., King., K.W., Trumm, D.A., Carver, D.L., and Williams, R., 1991, Geological aspects of shear-wave velocity and relative ground response in Salt Lake Valley, Utah, in McCalpin, J.P., ed., Proceedings of the Symposium on Engineering Geology and Geotechnical Engineering, 27th, Logan Utah, 1991, p. 25-1-25-9.

Townley, S.D. and Allen, M.W., 1939, Descriptive catalog of earthquakes of the Pacific coast of the United States-1769 to 1928: Bulletin of the Seismological Society of America, $v$. 29 , no. 1, p. 1-297.

Uhrhammer, R.A., 1986, Characteristics of northern and central California seismicity [abs.]: Earthquake Notes, v. 57, no. 1, p. 21.

Utah Geological Association, 1972, Environmental geology of the Wasatch Front, 1971: Utah Geological Association Publication $1,336 \mathrm{p}$.
Veneziano, D., and Van Dyck, J., 1985, Analysis of earthquake catalogs for incompleteness and recurrence rates, in Seismic hazard methodology for nuclear facilities in the Eastern United States [Electric Power Research Institute Research Project P101-29]: Palo Alto, Calif., EPRI/SOG Draft 85-1, v. 2, app. A-6.

Weichert, D.H., 1980, Estimation of the earthquake recurrence parameters for unequal observation periods for different magnitudes: Bulletin of the Seismological Society of America, v. 70 , no. 4 , p. $1337-1346$.

Westaway, R., and Smith, R.B., 1989, Strong ground motion in normal-faulting earthquakes: Geophysical Journal, v. 96, p. 529-559.

Wheeler, R., 1984, A plan for evaluating hypothesized segmentation of the Wasatch fault: in Hays, W.W., and Gori, P.L., eds., Proceedings of Conference XXVI; a workshop on evaluation of regional and urban earthquake hazards and risk in Utah: U.S. Geological Survey Open-File Report 84-763, p. 576605.

Woodward-Clyde Consultants (San Francisco), 1982, Preliminary assessment of the seismic potential of the Oquirrh fault zone, Utah: Report prepared by Woodward-Clyde for Davy McKee Corporation (San Mateo, Calif.), 16 p.

Wyss, M., 1979, Estimating maximum expectable magnitude of earthquakes from fault dimensions: Geology, v. 7, no. 7, p. 336-340.

Youngs, R.R. and Coppersmith, K.J., 1985a, Development of a fault-specific recurrence model: Earthquake Notes [abs.], v. 56, no. 1, p. 16.

-1985b, Implications of fault slip rates and earthquake recurrence models to probabilistic seismic hazard estimates: Bulletin of the Seismological Society of America, v. 75 , no. 4, p. 939-964.

Youngs, R.R., Coppersmith, K.J., Power, M.S., and Swan, F.H., III, 1985, Seismic hazard assessment of the Hanford region, eastern Washington State, in Department of Energy Natural Phenomena Hazards Mitigation Conference, Las Vegas, 1985, Proceedings, p. 169-176.

Youngs, R.R., Makdisi, F., Sadigh, K., and Abrahamson, N.A., 1990, The case for magnitude dependent dispersion in peak ground acceleration [abs.]: Seismological Research Letters, v. 61 , no. 1, p. 30 . 



\section{APPENDIX}




\section{APPENDIX: COMPARISON OF STRONG- MOTION DATA FROM THE STUDY REGION WITH SELECTED ATTENUATION RELATIONSHIPS}

This appendix compares strong-ground-motion data from recordings of earthquakes in the study region with recently developed attenuation relationships based primarily on data from California. The regional data include one recording in Logan, Utah, at a distance of about $30 \mathrm{~km}$ from the $1962 \mathrm{M}_{\mathrm{L}} 5.7$ Cache Valley earthquake; several recordings at distances of about 90 to $100 \mathrm{~km}$ from the $1983 \mathrm{M}_{\mathrm{S}}$ 7.3 Borah Peak, Idaho, earthquake; and many recordings in the distance range of about 2 to $50 \mathrm{~km}$ during aftershocks of the 1983 Borah Peak earthquake. For Borah Peak earthquake aftershocks, only data for earthquakes of $M_{L}>4$ are included. The ground-motion data from the study region are compared with the relationships of Joyner and Boore (1982), Sadigh and others (1986), and Campbell (this volume).

Figure Al compares the peak ground accelerations of the only strong-motion recording to date in Utah (the Logan recording obtained on a soil site during the $1962 \mathrm{M}_{\mathrm{L}}$ 5.7 Cache Valley earthquake) with the median attenuation curves from the three attenuation relationships. The data are higher than the curves. However, they are within the range of variation about the median curves typically found in strong-motion data, the average of the two data points being approximately $0.8,1.3$, and 2.6 standard deviations above the median relationships of Joyner and Boore (1982), Sadigh and others (1986), and Campbell (this volume), respectively (using the standard deviations presented by the authors for their respective relationships).

Figure A2 compares response spectra of the Logan recording with median and 84th-percentile spectra predicted by the relationships of Sadigh and others (1986) and Joyner and Boore (1982). The spectra of the recorded motions range from the median to well above the 84th percentile (median plus one standard deviation) of the two relationships.

Peak acceleration data recorded during the $M_{S} 7.3$ Borah Peak earthquake are compared with the respective attenuation relationships in figure A3. Because most of the data are from soil sites, Sadigh and others' (1986) relationship for soil sites rather than that for rock sites was used. The recorded data, particularly those recorded in the free field rather than in basements, as indicated in the figure, tend to be somewhat higher overall than two of the attenuation curves and about equal to or lower than the third curve. A moment magnitude of 7.1 was calculated for this earthquake by using the moment versus magnitude relationship adopted for this study (as described in the main text of this paper) and the seismic moment

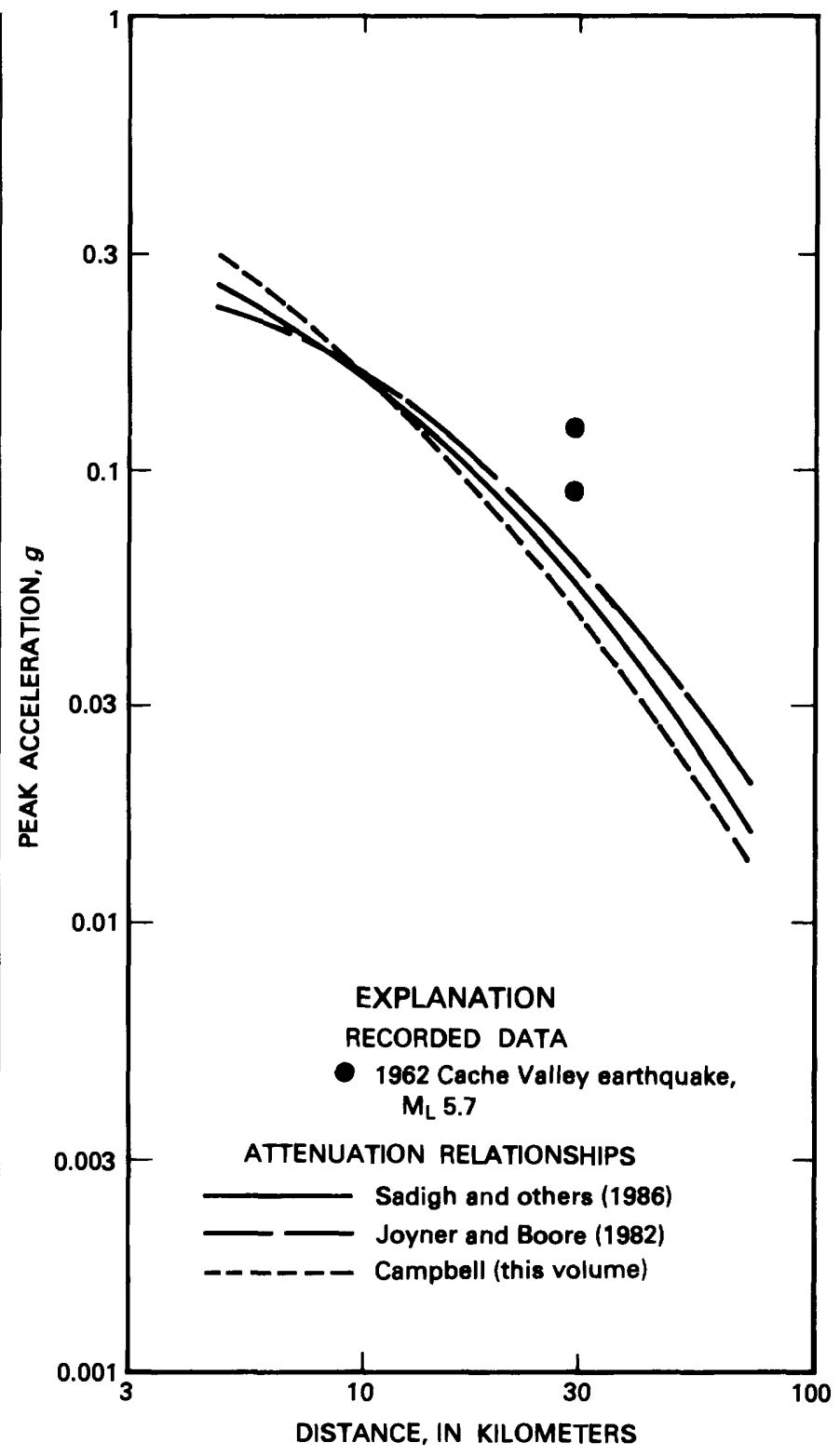

Figure A-1.-Comparison of peak ground accelerations recorded at Logan during the 1962 Cache Valley, Utah, earthquake and median attenuation relationships. 


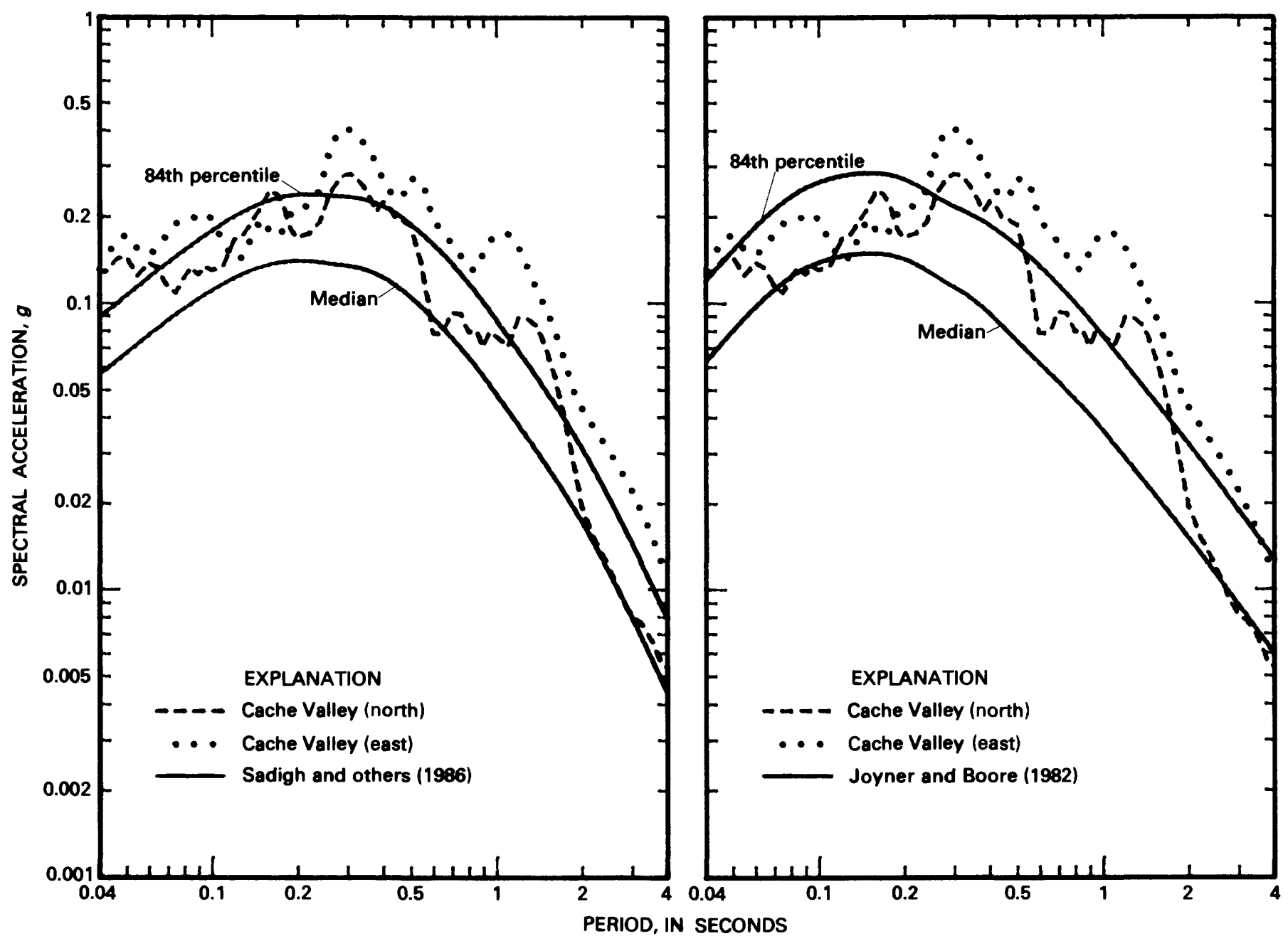

FIGURE A-2.-Comparison of response spectra (5-percent damping) of ground motions recorded during the 1962 Cache Valley, Utah, earthquake and median and 84th-percentile spectra from attenuation relationships.

reported by Jackson and Boatwright (1985). The attenuation curves for magnitude 7.1 would be slightly lower that those for $\mathrm{M}_{\mathrm{S}} 7.3$ shown in figure $\mathrm{A} 3$, which would emphasize the overall trend for the recorded data for this earthquake to be slightly above the California attenuation curves.

Figure A4 compares peak accelerations from the 1983 Borah Peak earthquake aftershocks (magnitudes greater then 4) with the respective attenuation curves. As is the case for the main shock, most of the aftershock data were recorded on soil sites, so Sadigh and others' (1986) soil-site relationship was used for the comparisons. The data are compared with the Joyner and Boore (1982) attenuation curves separate from the Sadigh and others (1986) and the Campbell (this volume) curves because of significant differences in hypocentral and epicentral distances for some of the records. Hypocentral distance is most consistent with the distance definitions used by Sadigh and others and by Campbell, and epicentral distance is most consistent with the distance definition used by Joyner and Boore (see main text for these distance definitions). However, for magnitudes less than 5 , only comparisons with the Sadigh and others and the Campbell curves are presented, because Joyner and Boore's relationships are restricted to magnitudes equal to or greater than 5. (In fact, Campbell's relationships were also developed for magnitudes equal to or greater than 5 but can be reasonably be used for magnitudes in the range of 4 to 5 (K.W. Campbell, personal commun., 1986).) For some of the aftershocks, significant differ- 


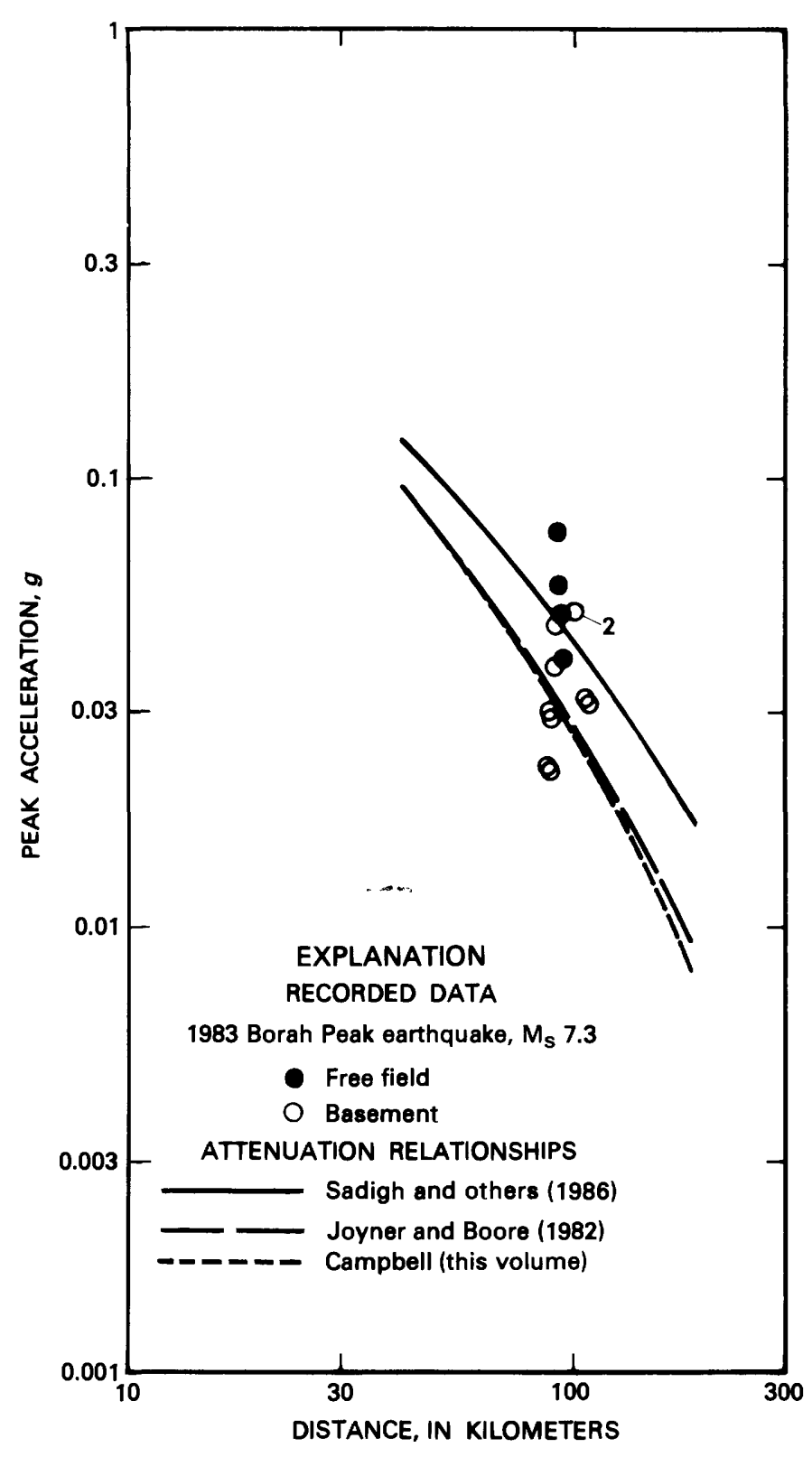

$\leftarrow$ FIGURE A-3.-Comparison of peak ground accelerations recorded during the 1983 Borah Peak, Idaho, earthquake and median attenuation relationships. ences exist between the $M_{L}$ magnitudes reported by the University of Utah Seismograph Stations and the moment magnitudes obtained by Jackson and Boatwright (1987). Therefore, the data are compared with the curves for both sets of magnitudes. Regardless of whether the data are compared with the curves for $\mathrm{M}_{\mathrm{L}}$ or for moment magnitude, it can be concluded from figure $\mathrm{A} 4$ that the data tend to lie below the attenuation curves, substantially so for some of the aftershocks.
For the Borah Peak main shock and aftershock ground-motion data, observations similar to those stated above have been made by Jackson and Boatwright (1985).

Our overall conclusion from these comparisons is that the data are too few to either strongly support or refute the applicability of California attenuation relationships to Utah. The data show no consistent trend to lie above or below the values predicted by the attenuation relationships. 

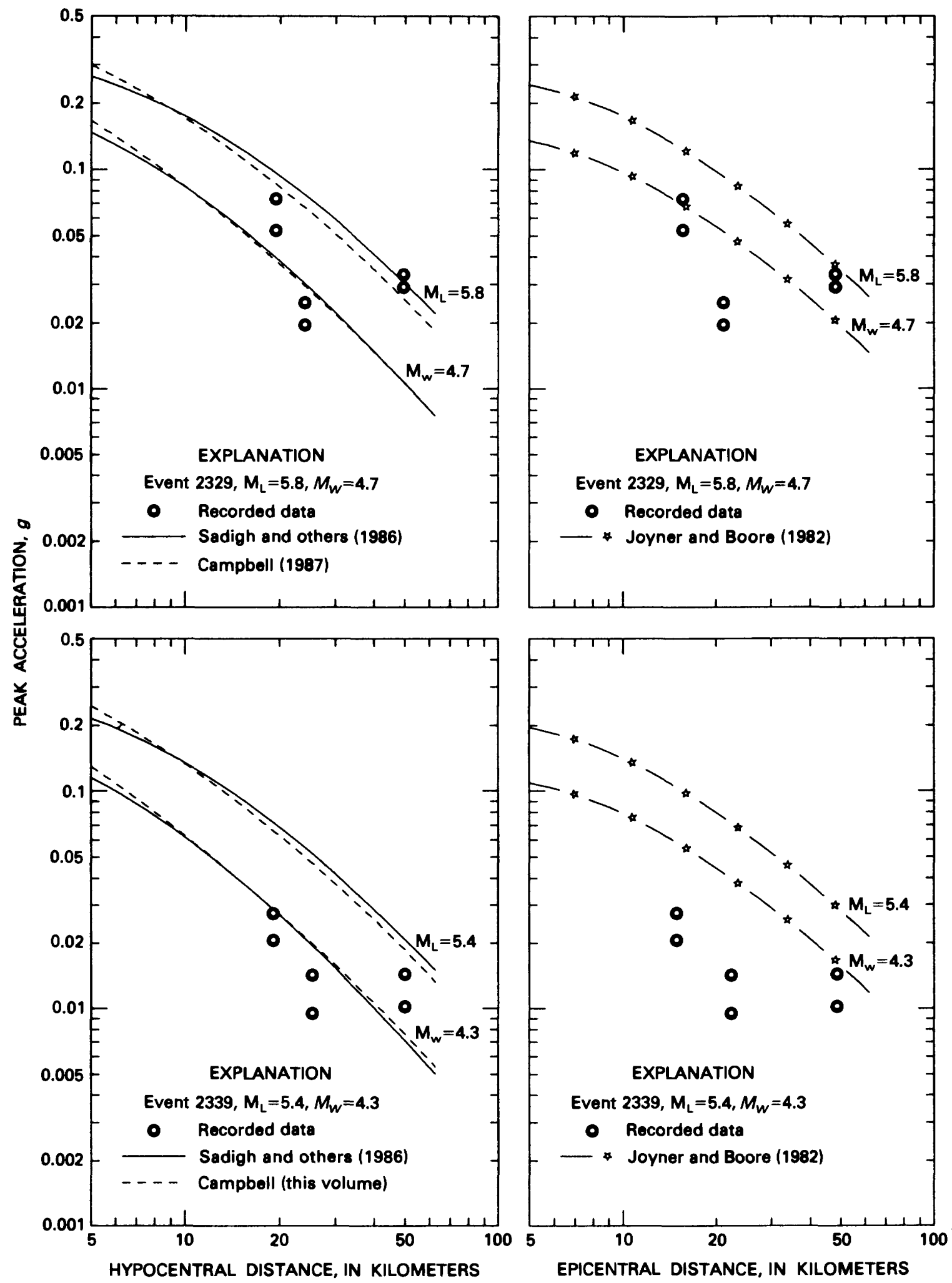

FIGURE A-4. Comparison of peak ground accelerations recorded during 1983 Borah Peak, Idaho, aftershocks and median attenuation relationships. 


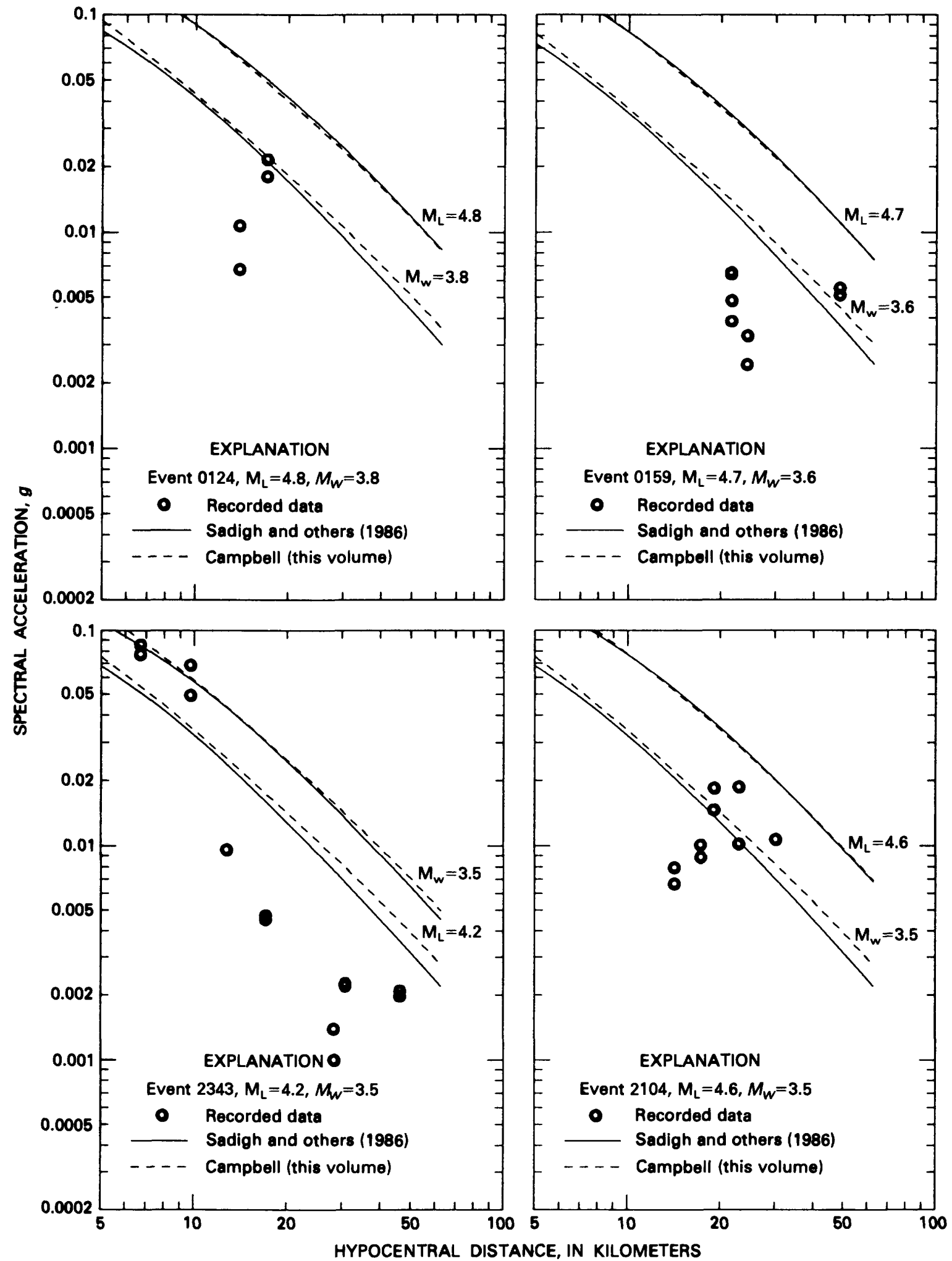

FIGURE A-4. Comparison of peak ground accelerations recorded during 1983 Borah Peak, Idaho, aftershocks and median attenuation relationships-Continued. 


\title{
Relative Ground Response in Salt Lake City and Areas of Springville-Spanish Fork, Utah
}

\author{
By KENNETH W. KING, ROBERT A. WILLIAMS, and DAVID L. CARVER
}

ASSESSMET OF REGIONAL EARTHQUAKE HAZARDS AND RISK ALONG THE WASATCH FRONT, UTAH

U.S. GEOLOGICAL SURVEY PROFESSIONAL PAPER 1500-N

A study of ground response in the Salt Lake City and

Springville, Utah, areas and correlations of response data with

reflection data 



\section{CONTENTS}

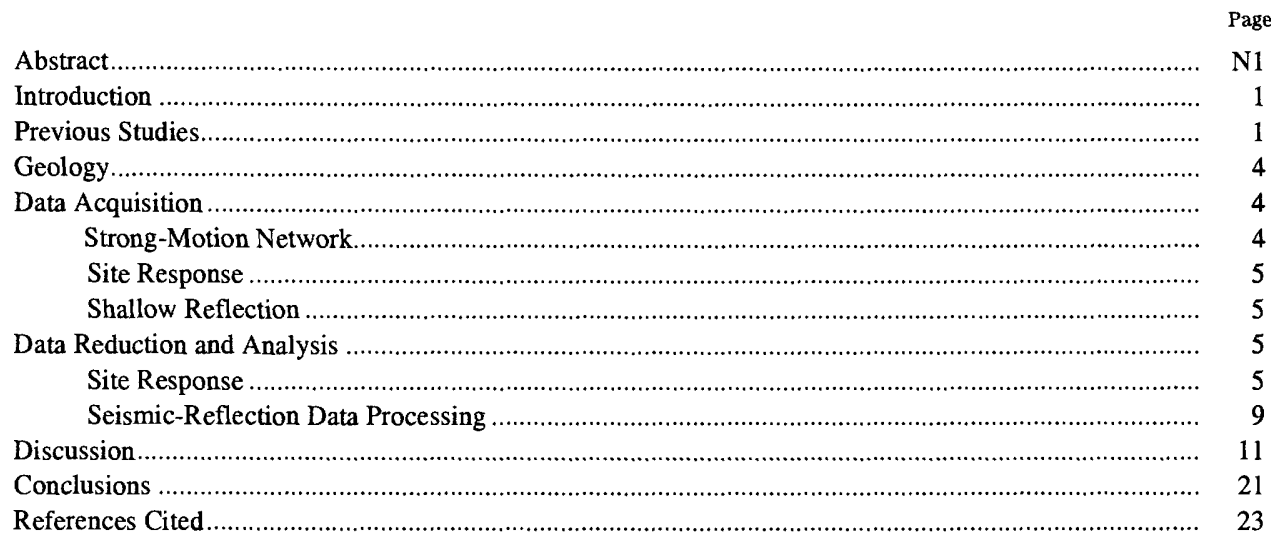

\section{ILLUSTRATIONS}

FIGURES 1, 2. Maps showing:

1. Locations of sites in Salt Lake City at which ground-motion recordings of nuclear explosions and shallow seismicreflection profiles were acquired

2. Location of sites in the Springville-Spanish Fork area at which ground-motion recordings of nuclear explosions and shallow seismic-reflection profiles were acquired.

3. Source input shooting pattern, station interval spacing, and source-to-geophone distances used on each reflection profile.

4, 5. Time histories showing vertical, horizontal north-south, and horizontal east-west components of ground motion from-

4. Nuclear explosion event B recorded simultaneously at nine sites in Salt Lake City.

5. Nuclear explosion event A recorded simultaneously at five sites in the Springville-Spanish Fork area.

6-11. Graphs showing:

6. Amplitude spectral comparison for three sites computed from recordings of vertical and horizontal ground motion generated by nuclear explosion event $B$.

7. Amplitude spectral comparison for three sites computed from recordings of vertical and horizontal ground motion generated by nuclear explosion event $\mathrm{A}$.

8. Comparison of signal and noise amplitude spectra for three sites in Salt Lake City computed from ground motion generated by nuclear explosion event $\mathrm{B}$.

9. Comparison of signal and noise amplitude spectra for three sites in the Springville-Spanish Fork area computed from ground motion generated by nuclear explosion event $\mathrm{A}$.....

10. Spectral ratios of vertical and horizontal components of ground motion recorded on sites having geologic conditions different from those at the crystalline rock site in Salt Lake City

11. Spectral ratios of vertical and horizontal components of ground motion recorded on sites having geologic conditions different from those at the crystalline rock site in the Springville-Spanish Fork area

12, 13. Maps comparing horizontal component average spectral ratios from Hays and King (1982) and from this study for-

12. Salt Lake City area

13. Springville-Spanish Fork area

14-18. Seismic reflection profiles from-

14. SLC site 5 (Bonneville Golf Course).

15. SLC site 12 (Liberty Park).

16. SLC site 8 (Forest Dale Golf Course)

17. SSF site 3 (Hobble Creek)

18. SSF site 5 (Spanish Fork Airport) 
TABLE

$T_{A B L E}$ 1. Seismic-reflection and ground-response data 


\title{
RELATIVE GROUND RESPONSE IN SALT LAKE CITY AND AREAS OF SPRINGVILLE-SPANISH FORK, UTAH
}

\author{
By Kenneth W. King, Robert A. Williams, and David L. Carver
}

\begin{abstract}
Earthquake site-response estimates were computed for 14 sites in Salt Lake City and the Springville-Spanish Fork areas of Utah. Lowstrain ground motions, generated by nuclear tests located in Nevada, were recorded on a wide range of surficial geologic materials by threecomponent digital seismographs. Site response is determined by the spectral-ratio method in which the Fourier spectrum of a site under investigation is divided by the spectrum of a reference site located on crystalline bedrock. We assume that the relative response of higher strain ground motions produced during a local earthquake at the sites in question can be estimated by low-strain ground-motion response. We do not consider local nonlinear soil response or directivity effects that could occur during a large local earthquake. High-resolution seismicreflection profiles were also acquired at some of the sites to examine the feasibility of correlating site response with the impedance structure inferred from the seismic-reflection data.

The spectral ratio values are described in terms of amplification factors relative to the crystalline bedrock site. Results indicate that an increase in ground motion can be expected westward from the Wasatch Front toward the center of the valley. In the period band 0.2 to $3.33 \mathrm{~s}$, amplification factors of 1.5 to 4.5 are common near the mountain front, whereas factors of 7 to 12 characterize sites closer to the center of the Salt Lake valley. At similar distances from the Wasatch Front in the Springville-Spanish Fork area, the amplification factors of 5 to 15 are higher than those in the Salt Lake valley. Correlations between seismic reflections and site response suggest that part of the cause for higher amplification factors is due to near-surface high-impedance contrast amplification of seismic waves.
\end{abstract}

\section{INTRODUCTION}

The principal population centers and urban areas of Utah are located near the Wasatch fault zone. Although the Wasatch fault and associated faults have not produced an earthquake larger than magnitude 6 since 1850 (Arabasz and others, 1979), the potential for a damaging and (or) life-threatening earthquake to occur within the next 100 years is very high (Swan and others, 1980). Structural damage and life risks from ground motions induced by earthquakes could be lessened if the potential groundshaking intensity for urban areas could be accurately predicted. This study is part of a U.S. Geological Survey-Utah Geological and Mineral Survey program to assess earthquake ground-shaking hazards in Utah's Wasatch Front urban areas.

The general objective of this study is to improve the understanding of how shallow underlying geology affects ground shaking. The study (1) compares site-response amplification factors derived from Fourier amplitudes with those derived from pseudo-relative velocity algorithms (Hays and King, 1982); (2) develops a detailed ground-response map of the Salt Lake City urban area in the low- to medium-response areas of Hays and King (1982); and (3) examines the feasibility of correlating site response with geologic data that have been derived from high-resolution shallow seismic-reflection profiles.

The study included analysis of ground-shaking data induced by distant nuclear explosions at the Nevada Test Site recorded at 14 sites in the Salt Lake City and Springville-Spanish Fork areas (figs. 1, 2). The methodology was similar to that used by Borcherdt (1975), Rogers and Hays (1978), Hays and King (1982), and Rogers and others (1985). High-resolution shallow-reflection profiles were acquired at five of the sites. In addition, a semipermanent network of strong-motion seismic instruments was deployed in the Salt Lake City-Ogden urban areas to record higher intensity ground shaking if local earthquakes should occur during these urban hazards studies.

\section{PREVIOUS STUDIES}

The variability of damage to structures caused by induced vibrations has been documented since the early 20th century. Milne (1908) and Reid (1910) observed that 


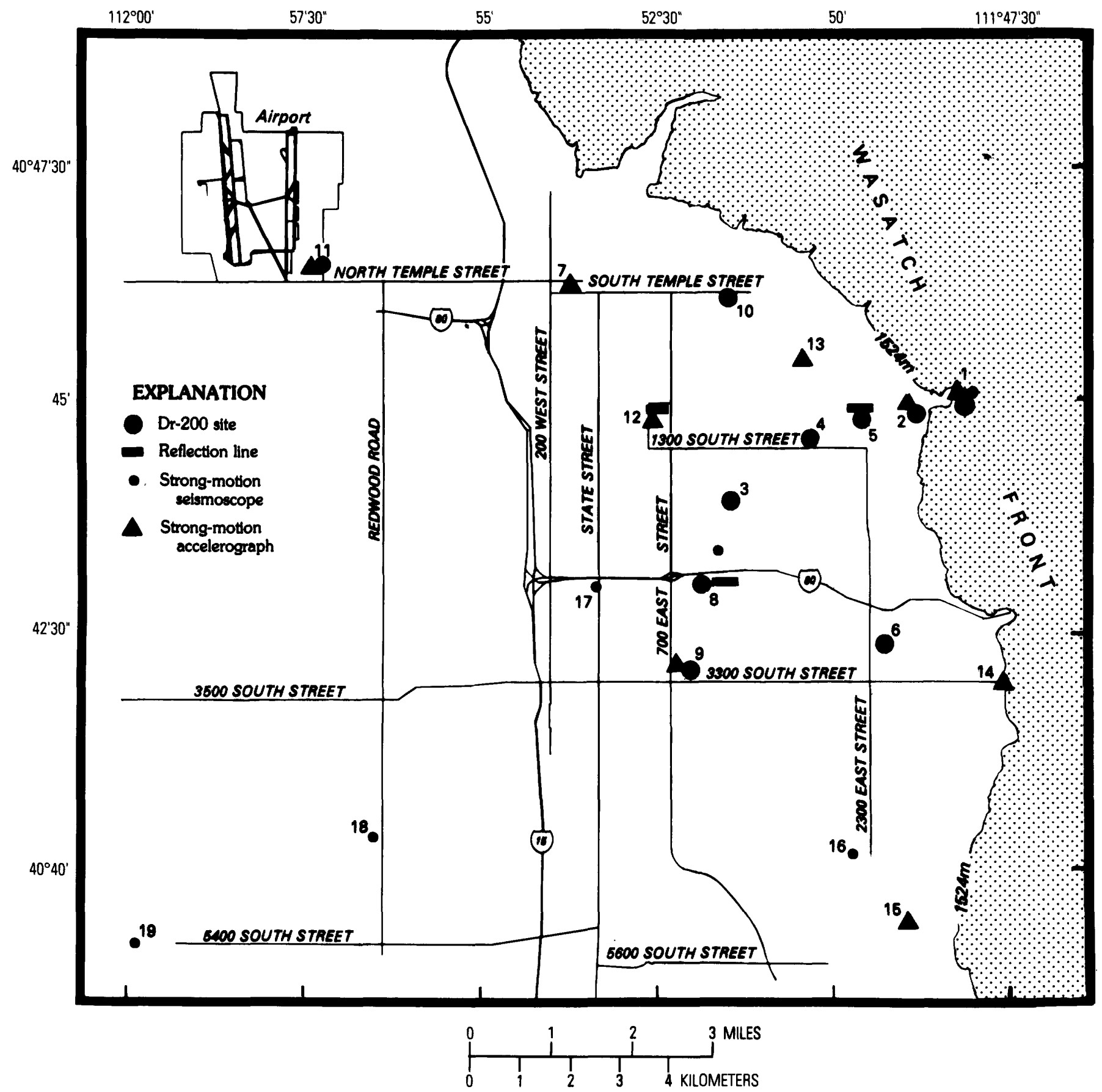

FIGURE 1.-Locations of sites in Salt Lake City at which ground-motion recordings of nuclear explosions and shallow seismic-reflection profiles were acquired. The estimated depths to basement for the Salt Lake City (SLC) sites shown on figure 4 are, from top to bottom, 0, 30, 80, 140, 140, 180, 190, 270, and $440 \mathrm{~m}$ (R. Van Horn, unpublished data, 1986).

structures underlain by loose soil, marshy deposits or filled land incurred more damage during ground shaking induced by earthquakes than similar structures underlain by bedrock. Advances in seismic instrument technology permitted Kanai (1952) and Gutenberg (1957) to make quantitative studies of ground shaking induced by earthquakes at sites underlain by different materials. Their studies indicated that sites underlain by alluvium or filled land may experience up to 10 times more earthquake ground shaking than sites underlain by bedrock. 


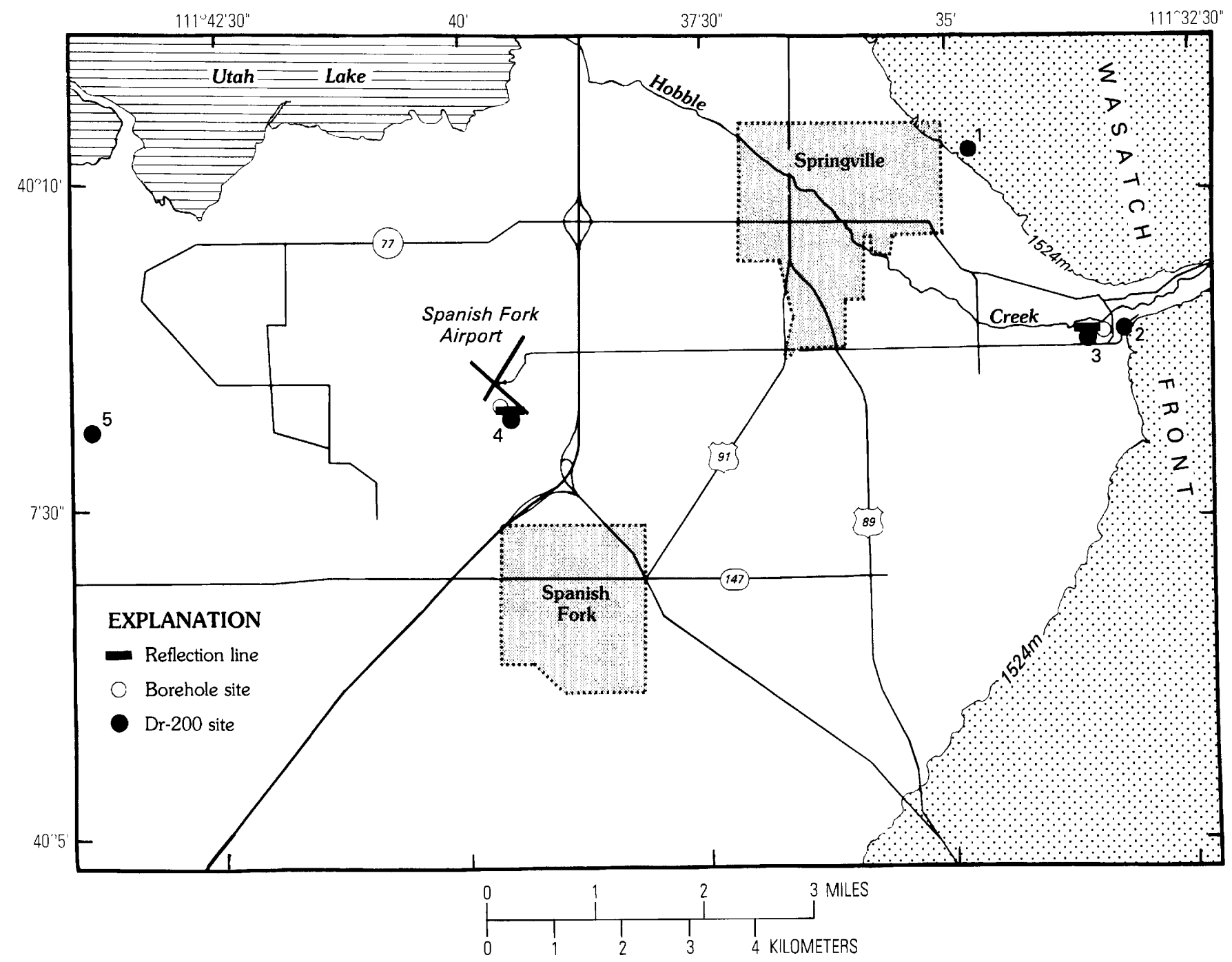

FIGURE 2.-Location of sites in the Springville-Spanish Fork area at which ground-motion recordings of nuclear explosions and shallow $\mathrm{s}$ eismic reflection profiles were acquired.

The testing of nuclear devices at the Nevada Test Site and the advancement of computer analysis have increased the sophistication of quantitative, detailed, and controlled empirical investigations into the variability of the frequency and amplitude of ground shaking at selected sites. Studies by Borcherdt (1970), Murphy and others (1971), Rogers and Hays (1978), and Hays and others (1978) have shown that realistic ground-shaking estimates for moderate-sized earthquakes can be made by using ground-motion scaling laws derived from the analysis of low-strain nuclear-explosion-induced ground motions. Studies by Borcherdt and Gibbs (1976), Hays and King (1982), and Rogers and others (1985) have shown that local site conditions have a greater influence on ground shaking than source azimuth, wave type, or angles of incidence. A ground-shaking study of the San Francisco Bay area (Borcherdt and Gibbs, 1976) showed an average spectral amplification for horizontal ground motions on bay mud sites to range between 3.7 and 11.3, relative to sites located on bedrock. A similar study of the Wasatch Front area (Hays and King, 1982) indicated that the greatest potential hazard from earthquake ground shaking would occur at sites underlain by thick, finegrained, water-saturated, nearshore and offshore lacustrine deposits of silts and clays. A ground-response study of the Los Angeles area (Rogers and others, 1985) showed a ground-motion amplification factor of 4 to 6 (at certain frequencies) at sites underlain by Holocene and Pleistocene sediments relative to sites underlain by crystalline rock. The Los Angeles area study also indicated a correla- 
tion of ground-motion amplification with the mean void ratio of near-surface inaterials when the ground-shaking period was 0.2 to $0.5 \mathrm{~s}$.

\section{GEOLOGY}

The Salt Lake City and Springville-Spanish Fork areas investigated in this study are located in similar geologic settings. The Wasatch Front borders both study areas on the east, where Jurassic to Precambrian limestone, doloinite, shale, sandstone, and quartzite are exposed (McGregor and others, 1974). These cratonderived rocks are thought to underlie the alluvial sediments upon which most of the Wasatch Front urban areas are located. These sediments are unconsolidated fluvial and lacustrine materials deposited in and around Pleistocene lakes and alluvial fans of Pleistocene age or younger (Van Horn, 1972; Swan and others, 1980). McGregor and others (1974) categorized the alluvial sequence beneath the Salt Lake City area as Quaternary alluvium at the surface underlain by Tertiary alluvial deposits, which in turn are underlain by Jurassic to Precambrian bedrock. The cumulative thickness of the alluvial stratum (Quaternary and Tertiary) increases westward as the distance from the Wasatch Front increases. The estimated range of total alluvial thickness underlying the Salt Lake City study area is from 0 to approximately $450 \mathrm{~m}$ (McGregor and others, 1974). Tertiary alluvium, varying in thickness from 0 to $200 \mathrm{~m}$, rests on Jurassic and other bedrock in the Salt Lake City study area. The Tertiary deposits are generally semiconsolidated layers whose composition ranges from boulders to clay interbedded with some well-ceinented layers.

The unconsolidated sediment classification used in the study areas of Hays and King (1982) was adapted from Miller's (1980) study of the Salt Lake valley surficial deposits. The Miller study divided the surficial deposits of the Salt Lake valley into three categories according to the environment of deposition: onshore, nearshore, and offshore. The study indicated that the deposits become more fine grained with increasing distance from the Wasatch Front. The onshore deposits are mostly fluvial in origin and generally form a narrow band along the base of the Wasatch Front and into the Salt Lake valley as terraces along the edges of the streams draining the Wasatch Range. The onshore deposits also are found as extensive flood-plain deposits overlying thick sequences of finegrained lacustrine deposits. The onshore deposits consist mainly of sand, gravel, cobbles, and boulders and grade into the nearshore deposits, which can be coarse grained and poorly sorted. The nearshore sediments were deposited chiefly in shallow water along the lakeshores and formed beaches, longshore spits and bars, deltas, and marsh deposits. The offshore deposits represent a quiet- water depositional environment and consist mainly of interbedded very fine sand, silt, and clay.

In the Salt Lake City area, the recording sites described in this report are located on the full range of surficial geological materials as defined by Miller (1980). Site 1 is located on limestone of Jurassic age, sites 2, 3, 9, and 10 are underlain by onshore deposits, sites 4 and 6 are underlain by nearshore deposits, and sites 5 and 8 are underlain by offshore deposits (fig. 1).

The geology of the Springville-Spanish Fork area is generally similar to that of the Salt Lake City area. The thickness of alluvial deposits is less well known owing to sparse subsurface geotechnical information in the area. Site 1 in the Springville area is underlain by quartzite of Pennsylvanian-Permian age. Geologic descriptions of surficial deposits near sites 2 and 3 (fig. 2) (Swan and others, 1980) and a description of the subsurface material from a nearby borehole (J.C. Tinsley, written commun., 1986) indicate that the materials at this location are similar to the Salt Lake City onshore deposits. A description of the material from a borehole at the Spanish Fork Airport (site 4) and at the Youd farm (site 5) is similar to the descriptions of the Salt Lake City offshore deposits (J.C. Tinsley, unpublished data, 1986). The subsurface geology at these and other sites is being investigated.

\section{DATA ACQUISITION}

\section{STRONG-MOTION NETWORK}

Nine strong-motion accelerographs and seven strongmotion seisinoscopes are deployed in the Salt Lake City and Ogden areas of Utah. Three strong-motion accelerographs (SMA-1) are permanently located in the Salt Lake City area in standby operation mode. Six additional SMA1 accelerographs have been added to the three-station network for the duration of the urban hazards investigation. These instruments were installed to provide expanded recording of ground shaking in the Salt Lake City area if a inedium to large earthquake should occur in or near the study area. The sites selected for the deployment of the six additional accelerographs followed criteria similar to those used for selecting site-response station locations. One accelerograph is located on a hardrock site near Salt Lake City (site 1) to establish a base against which to compare the other seismic data. The remaining five instruments were deployed at sites underlain by a variety of depths and types of alluvium. Two are located at sites occupied by Hays and King (1982), and two are located at sites investigated in this report (fig. 1).

Induced vibrations from large buildings during an earthquake could coinpromise the ground-shaking data recorded by the strong-motion instrument if the instrument is located near or in the structure. Therefore, the strong-motion instruments are located at a distance of 
more than twice the height of the nearest large building. The strong-motion instruments begin recording when ground shaking exceeds $0.1 g$ acceleration in the 1.0 - to 40-Hz bandwidth.

Seven seismoscopes were installed in the Salt Lake City area to supplement the strong-motion network. The seismoscopes will record the amplitudes of ground shaking at the instrument's natural period ( $0.75 \mathrm{~s}$ ) (Cloud and Hudson, 1961). The sites chosen for the seismoscopes represent different thicknesses of alluvium overlying the basement bedrock of the valley. The site locations (fig. 1) were selected from the Salt Lake valley gravity map data of Adhidjaja and others (1981). No earthquake large enough to trigger or record on the accelerographs or seismoscopes has occurred since the instruments were installed.

\section{SITE RESPONSE}

The site-response ground-shaking data presented in this report were recorded by portable digital seismographs. The seismometers are three-component velocitysensing transducers that have a natural period of $0.62 \mathrm{~s}$ and are damped at 60 percent of critical. The data are digitally recorded on 1/4-inch magnetic tape at 50 samples per second per channel. Carver and others (1986) have described the seismographs and their calibrations.

The sites at which response studies were conducted (1) represent sites from the low-, medium-, and highresponse areas described by Hays and King (1982); (2) are in the Salt Lake City area; (3) are at sites where additional geotechnical experiments could be done to reveal details of the underlying geology; (4) are in areas where major differences of surficial geology occur as described by Miller (1980); and (5) are in locations where there are enough open areas to conduct high-resolution shallowreflection studies, drill a borehole, and conduct future experiments. The study did not include Salt Lake City locations in high-response areas described by Hays and King (1982), because most of those sites have been inundated by the rise of the Great Salt Lake. Site-response sites selected in the Springville-Spanish Fork area (fig. 2) included two locations in the deeper parts of the basin that are believed to be similar to the high-response sites near Salt Lake City as reported by Hays and King (1982).

An underground nuclear test at the Nevada Test Site provided the seismic energy. Previous reports by Borcherdt (1970), Hays and King (1982), and Rogers and others (1985) have demonstrated the validity of using the ground motions from a Nevada Test Site nuclear test for a site-response study. A minimum of 2 min of pre-event seismic data were recorded for the tests. The pre-event data at each site were used to establish the level of ambient seismic background noise at that station before the recording of ground shaking from the nuclear event.

\section{SHALLOW REFLECTION}

High-resolution, shallow seismic-reflection profiles were collected at five sites in the Salt Lake City and Springville-Spanish Fork areas that coincided with the locations used to study relative ground shaking and site response (figs. 1, 2). The data for the reflection profiles were collected from a linear array that ranged from approximately 40 to $160 \mathrm{~m}$ in length. Station separations of 0.5 to $1.5 \mathrm{~m}$ became the positions of the geophones and the reference locations for the input sources. The data were amplified, filtered, summed, digitally sampled at $0.5-$ ms intervals, and stored on $1 / 2$-inch magnetic tape by a high-resolution 24-channel reflection system.

Single $100-\mathrm{Hz}$ (resonant frequency) compressionalwave geophones with $15-\mathrm{cm}$ ground coupling spikes were firmly planted in the ground surface at 0.5 - to $1.5-\mathrm{m}$ intervals to detect $P$-wave reflections. The $-6 \mathrm{~dB} /$ octave rolloff of the 100-Hz geophones and $-18 \mathrm{~dB} /$ octave rolloff of the 80-Hz low-cut filter in the recording system help discriminate against the surface waves generated by the energy source. The seismic energy source was a 12-gauge shotgun that fired a 28-g lead slug vertically into the ground. The slug dissipated its energy quickly and usually penetrated less than $0.2 \mathrm{~m}$ into the ground. The data from three shots at each shotpoint are summed and recorded. Summing of data from several shots at a single shotpoint improves the signal-to-noise ratio owing to enhancement of the coherent reflective seismic signal and by canceling some of the less coherent ambient seismic noise.

The shotpoints were located in the middle of the geophone array (split-spread). The minimum and maximum source-receiver remained constant (constant offsets) as the source locations were moved along the array in increments equal to the station (geophone) spacing distance. Figure 3 shows the source input shooting pattern, the station interval spacing, and the source-to-geophone distances used on each profile. The half-integer source input configuration was used to achieve $-3 \mathrm{~dB}$ ambient seismic noise attenuation during the data processing (Knapp, 1985). The array also allows common-depth-point (CDP) processing of the data (Mayne, 1962). The array pattern and CDP processing achieve a summing of 12 different source-to-geophone raypath combinations for each subsurface point along the length of the profile (twelvefold coverage).

\section{DATA REDUCTION AND ANALYSIS}

\section{SITE RESPONSE}

Ground motion due to a nuclear test in Nevada was digitally recorded at nine sites in the Salt Lake City area and at five sites in the Springville-Spanish Fork area by wideband digital-recording seismograph systems using 


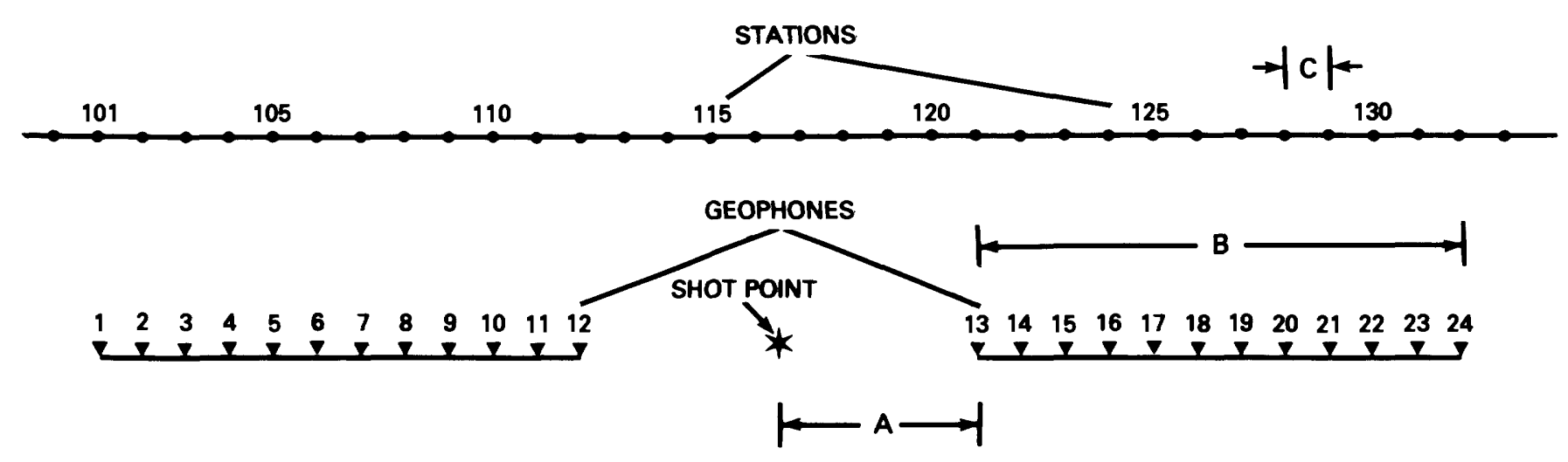

\section{EXPLANATION}

SLC site 5 (Bonneville Golf Course): A, $9.1 \mathrm{~m} ; \mathrm{B}, 33.5 \mathrm{~m} ; \mathrm{C}, 3.0 \mathrm{~m}$

SLC site 8 (Forest Dale Golf Course): A, $5.5 \mathrm{~m} ; \mathrm{B}, 13.4 \mathrm{~m} ; \mathrm{C}, 1.2 \mathrm{~m}$

SLC site 12 (Liberty Park): A, $5.5 \mathrm{~m} ; \mathrm{B}, 13.4 \mathrm{~m} ; \mathrm{C}, 1.2 \mathrm{~m}$

SSF site 3 (Hobble Creek (Orchard)): A, $5.5 \mathrm{~m} ; \mathrm{B}, 13.4 \mathrm{~m} ; \mathrm{C}, 1.2 \mathrm{~m}$

SSF site 5 (Spanish Fork Airport): A, $9.0 \mathrm{~m} ; \mathrm{B}, 33.0 \mathrm{~m} ; \mathrm{C}, 3.0 \mathrm{~m}$

FIGURE 3.-Source input shooting pattern, station interval spacing, and source-to-geophone distances used on each reflection profile. S hotpoint locations are halfway between stations. Station designations used in the reflection profiling are not related to site response $s$ tation numbers.

three-component velocity-sensing seismometers (Carver and others, 1986). Approximately 2 min of pre-event and 6 min of postevent seismic data from each site were preserved as time histories in digital form on VAX 11/750 files. These data were reduced to amplitude-normalized time histories (figs. 4,5), spectra (figs. 6, 7), spectral signal to spectral noise comparisons (figs. 8, 9), and spectral ratios (figs. 10, 11). The data-reduction methods were similar to those used by Hays and King (1982) and Rogers and others (1985). Spectral ratios (site-transfer functions of sites on rock to sites underlain by alluvium) derived from nuclear-test ground motions show reasonable agreement with site-transfer functions similarly derived from earthquake-induced ground motions (Rogers and Hays, 1978). The results presented here are a reasonable estimate of the site effects of a damaging earthquake.

The time-history data were low pass filtered $(10-\mathrm{Hz}$ corner, $-18 \mathrm{~dB}$ /octave) to help eliminate local ambient seismic noise. Rogers and others (1985) found that most of the seismic energy from nuclear tests above $5 \mathrm{~Hz}$ is attenuated before reaching recording sites that are more than approximately $400 \mathrm{~km}$ from the source. Therefore, the filtering was acceptable for this study because all the recording stations are more than $500 \mathrm{~km}$ from the source.

Approximately $200 \mathrm{~s}$ of seismic signal were selected (windowed) to the nearest power of 2 of the number of samples and tapered with a whole-cosine-bell (Hanning window) before being Fourier transformed by a Fast Fourier Transform (FFT) algorithm (A.C. Tarr and E.
Cranswick, unpublished data, 1986). A similar procedure was used on the pre-event time-history data to derive the spectra for ambient seismic noise at each site. None of the spectral amplitudes have been normalized by the window length because the spectra used for site-to-site comparisons are derived from time series of identical duration. The methods used by Rogers and others (1980) to estimate the reliability of the spectral estimates are not directly applicable to this study owing to the absence of multiple observations (recordings) from each site. The horizontal spectra were used to derive site-transfer functions from the sites located on rock relative to the sites underlain by unconsolidated sediments. The site-transfer function was calculated by the general formula $\mathrm{STF}=S_{a} / S_{r}$ where STF is the site-transfer function, $S_{a}$ is the derived spectrum of a site underlain by alluvium, $S_{r}$ is the derived spectrum of a site underlain by rock, and all spectra are in the frequency band between 0.3 and $5.0 \mathrm{~Hz}$.

Rogers and others (1979) discussed the method of deriving the site-transfer function in terms of spectral ratios. The site-transfer functions of this study were calculated directly from the unsmoothed, independent spectral amplitudes. Similarly, the frequency band of the spectral ratios in this report represents the averages of the unsmoothed spectral ratios between the defined frequency limits (A.C. Tarr and E. Cranswick, unpublished data, 1986). Only spectra with a signal-to-noise separation greater than $6 \mathrm{~dB}$ were used for deriving the spectral ratios (figs. 8,9 ). The absence of data or "holes" in some 

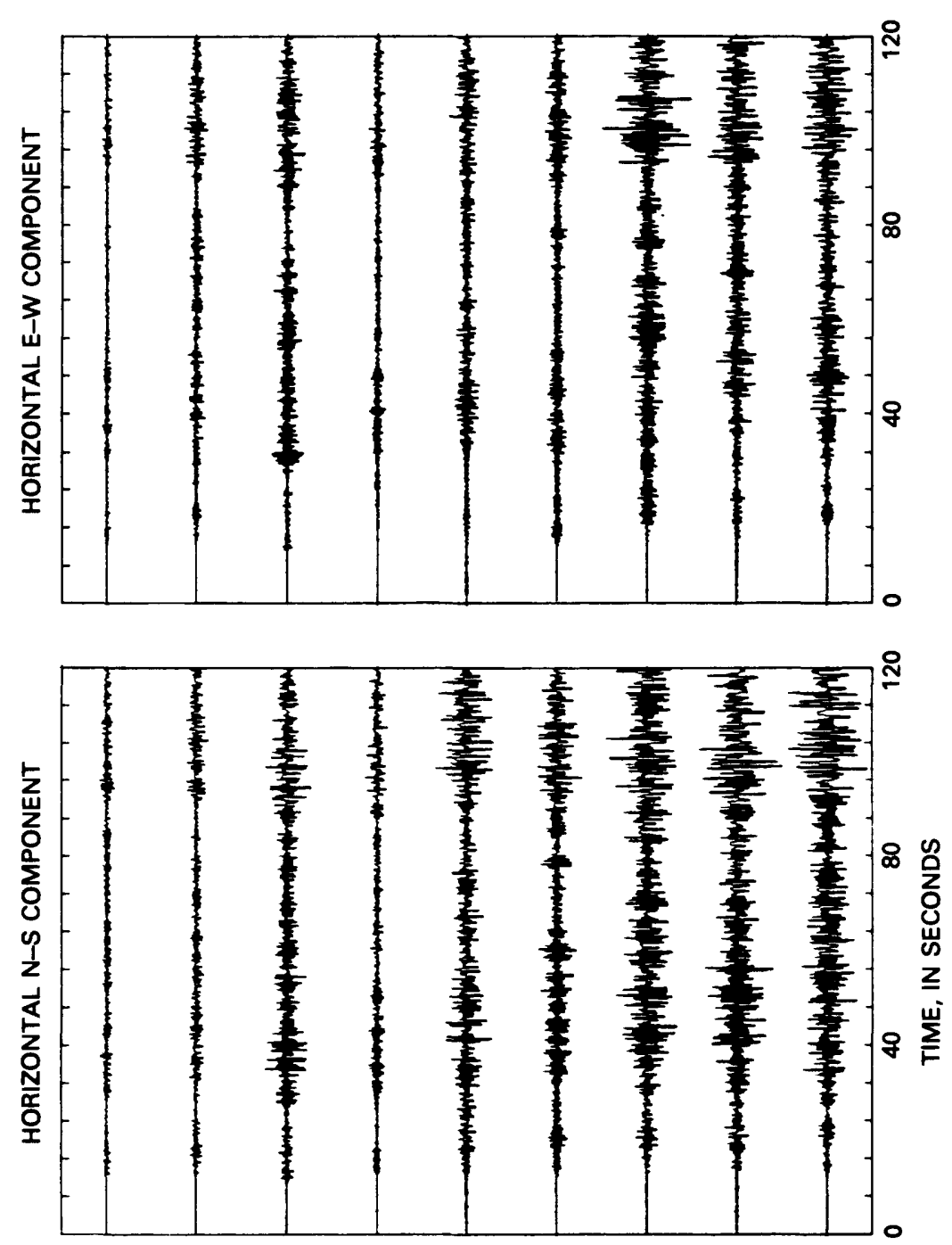

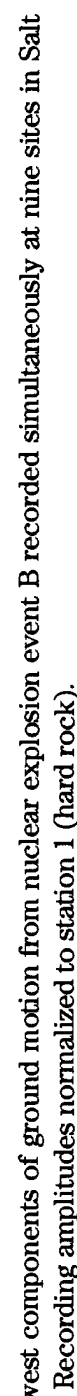

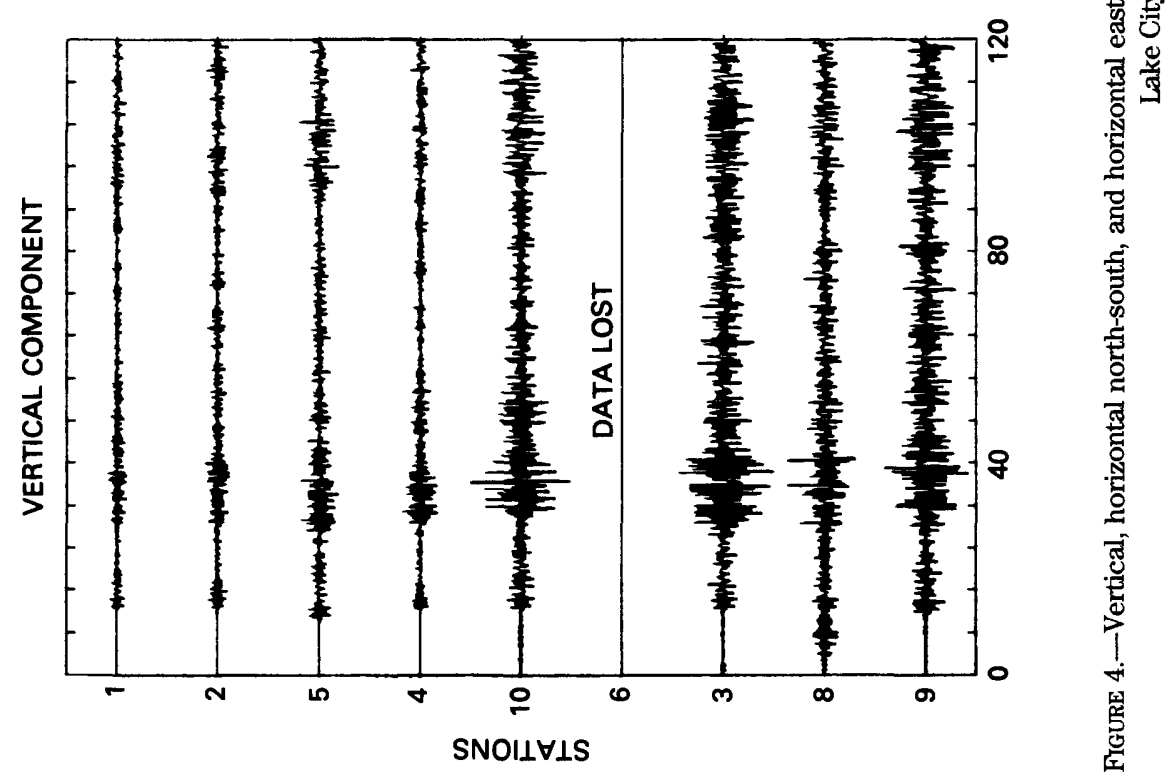



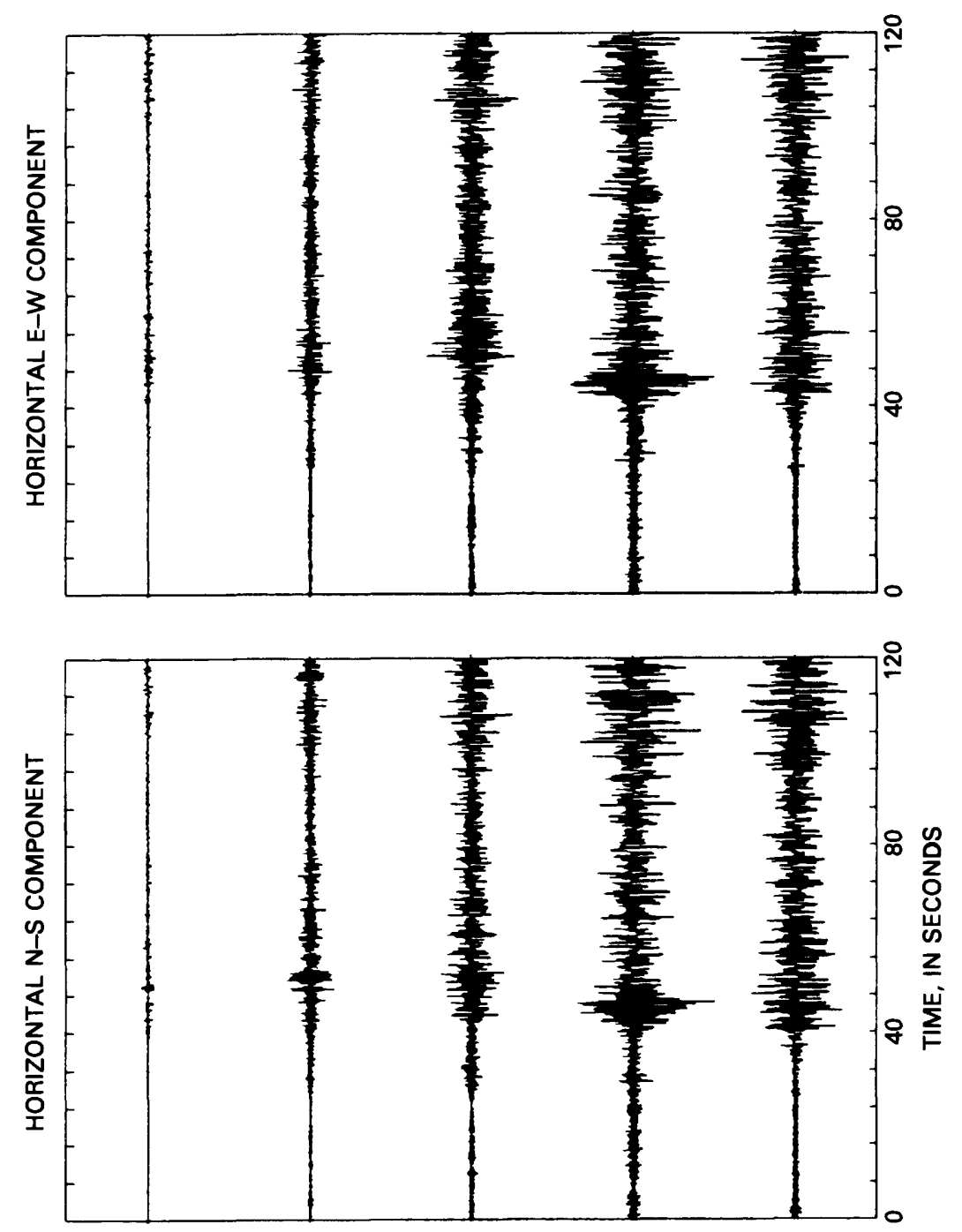

踪

-

宽.

蛋

$\stackrel{8}{3}$

要

हี้

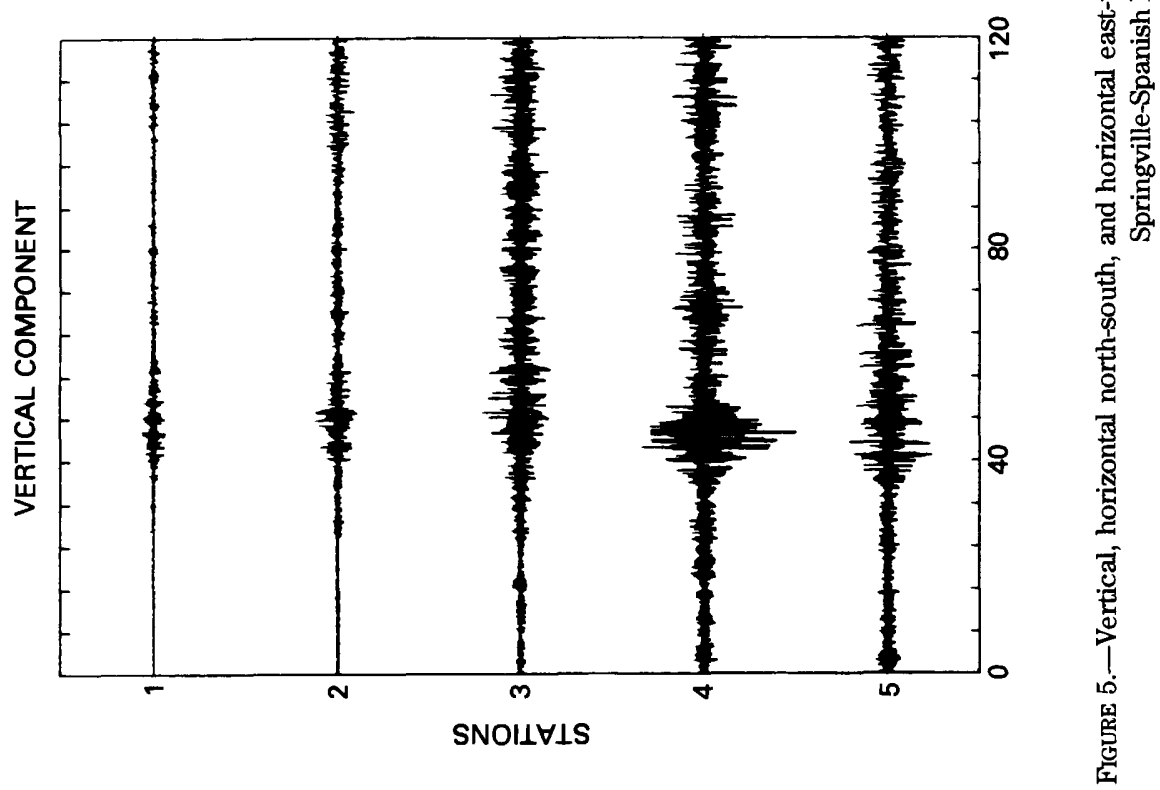




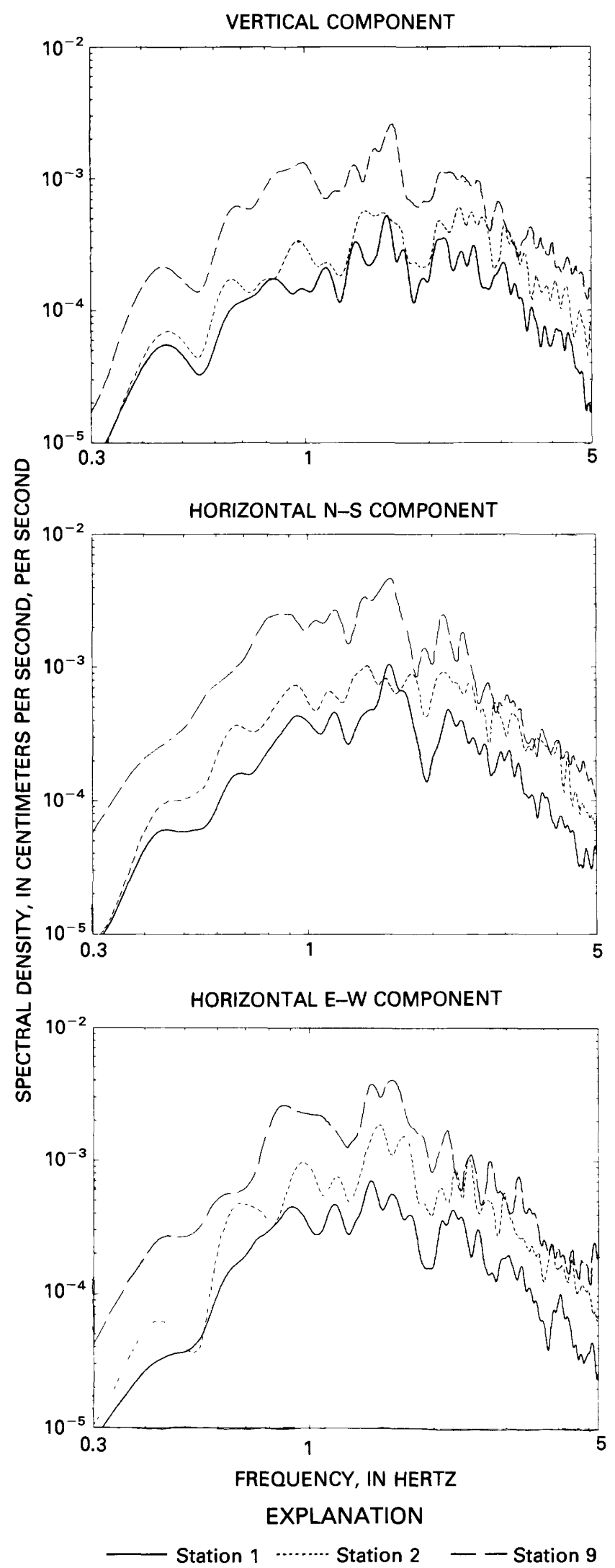

$\leftarrow$ Figure 6.-Amplitude spectral comparison for three sites computed from recordings of vertical and horizontal (north-south and eastwest) ground motion generated by nuclear explosion event $B$. The spectra are identified by station number location (see figs. 1, 2), arranged by decreasing alluvial thickness (top to bottom), and plotted at frequencies for which the signal-to-noise ratio is greater than 2.

of the spectral ratios shown on figures 10 and 11 are due to the elimination of low signal-to-noise data. The frequency bands used to derive the average ratios in this report are the same as those used in the Hays and King (1982) report to enable a direct comparison of the spectral ratio numbers. The spectra and spectal ratios shown on the figures presented in this report are smoothed by convolving the derived spectra with a whole-cosine-bell 16 samples wide. The graphic smoothing is intended to emphasize what are judged to be the significant trends in the data; the reliability of these trends can be estimated by inspecting the composite signal and noise plots shown in figures 8 and 9.

\section{SEISMIC-REFLECTION DATA PROCESSING}

Five high-resolution shallow seismic-reflection profiles were completed for this report. The sites were chosen to coincide with site-response locations, for variety of subsurface geology, and for the availability of a sufficient area in which an unobstructed reflection line could be obtained. Level sites were selected to eliminate the static corrections needed in the data processing. Correction for topography variations was needed, however, for Salt Lake City site 8 . The field data were digitally recorded on magnetic tape and processed by software on a VAX 11/780 computer. The data were first edited, sorted into CDP gathers, and then plotted in preliminary form. The CDP gathers supplied the two-way traveltime data to be used for further analysis. All seismic data for which two-way traveltime was greater than $100 \mathrm{~ms}$ were eliminated. The data truncation (or data elimination) was necessary because the arrival of surface-wave seismic signals interfered with reflection data after $100 \mathrm{~ms}$. The stacking velocities of the truncated CDP data were determined by using a constant-velocity panel search. The correct stacking velocity adjusts traveltime differences in the CDP data that were due to different source-to-receiver distances.

The velocity analysis procedure needed the input of a series of best-estimate traveltime velocities ( $V$ ) likely to be encountered in the area. The following equation: 


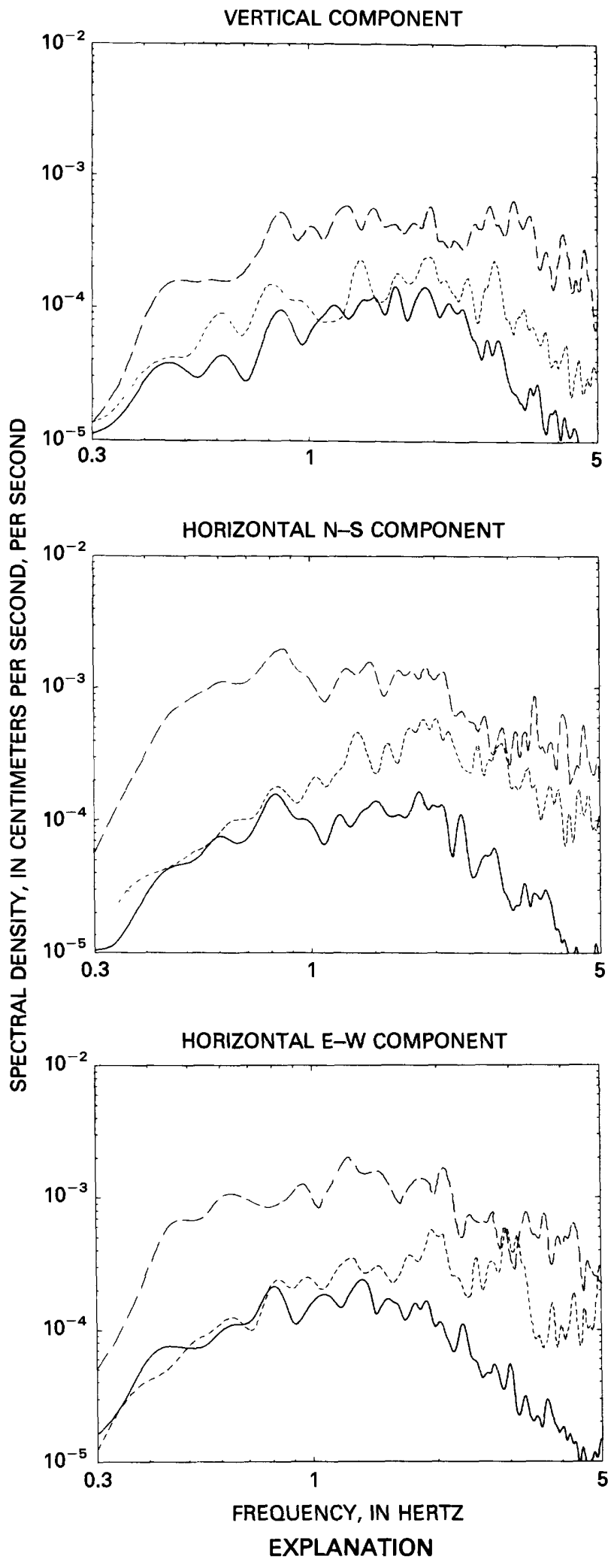

- Station 1 ....... Station $2 \quad$ - Station 5 $\leftarrow$ FigURE 7.-Amplitude spectral comparison for Springville-Spanish Fork stations 1,2 , and 5 computed from recordings of vertical and horizontal (north-south and east-west) ground motion generated by nuclear explosion event $A$. The spectra are identified by station number location (see fig. 3), arranged in order of decreasing alluvial thickness (top to bottom), and plotted at frequencies for which the signal-to-noise ratio is greater than 2 .

$$
T_{0}=\left[T_{x}^{2}-X^{2} / N^{2}\right]^{1 / 2}
$$

where $T_{x}$ is the actual two-way traveltime, $X$ is the offset distance from the analyzed trace to the source position, and $T_{0}$ is the zero-offset two-way traveltime for the given velocity, was used by the software program to automatically calculate $T_{0}$ on a sample-by-sample basis on each CDP trace for each velocity. A sequence of traveltime velocities was selected that would give CDP traces having the least amount of normal-moveout curvature.

These selected traveltime velocities also produced the maximum trace amplitude at the two-way traveltime of the reflection pulse when the CDP's were summed. The time-corrected data were again edited to remove any interfering electrical noise, spikes, or pre-first reflective pulse seismic signals that may have been moved into the desired data from the velocity-time corrections. The data were then filtered to help attenuate the seismic energy below $100 \mathrm{~Hz}$. The final data were displayed in stacked CDP sections that showed seismic-reflection amplitudes in a two-way traveltime versus horizontal distance format. The processing parameters are listed below:

1. Reformatting of field data

2. Editing of dead or bad traces

3. Definition of reflection line geometry

4. CDP sorting of common-shot gathers

5. Band-pass filter analysis of CDP gathers

6. Seismic velocity analysis of CDP gathers

7. Muting analysis of normal move-out corrected CDP gathers

8. Preliminary stack

9. Reexamination of chosen velocities, filters, and mutes

10. Amplitude scaling of final stack before plotting

11. Final stack

The average vertical resolution for the $100-$ to $150-\mathrm{Hz}$ stacked seismic data was about 1 to $2 \mathrm{~m}$, which was calculated by using the $1 / 4$-wavelength criteria on velocities derived from the reflection data (Widess, 1973). All processed data were truncated to give a minimum of 800 percent (eightfold) coverage or better on the resultant profiles. 


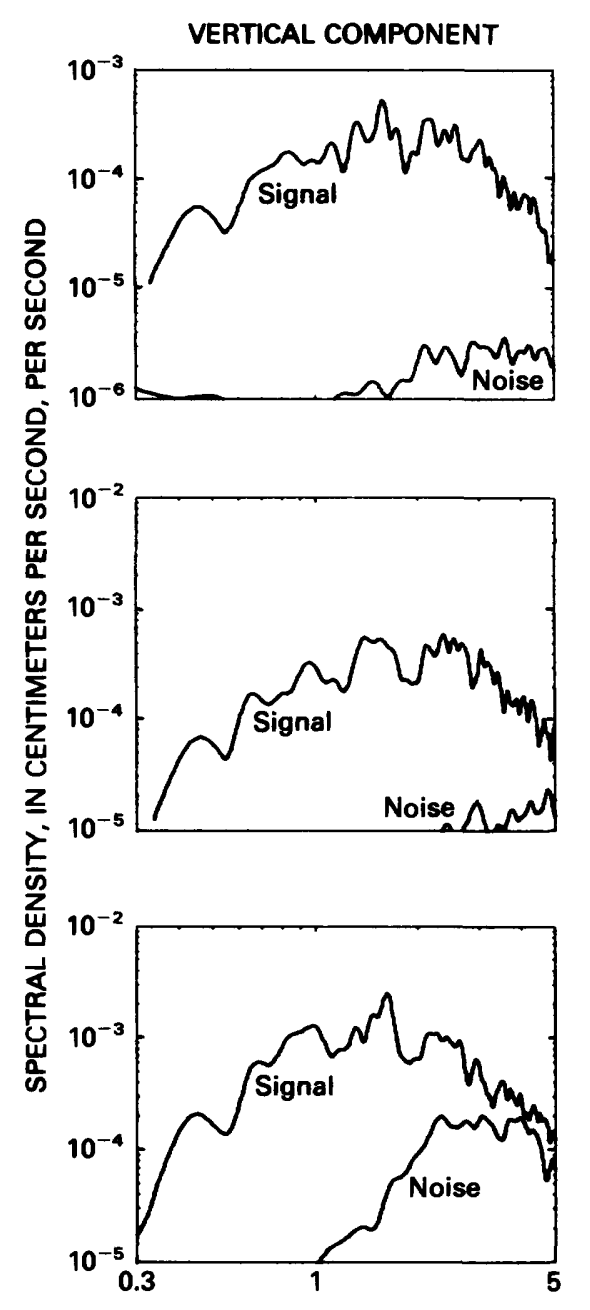

STATION 1

HORIZONTAL N-S COMPONENT

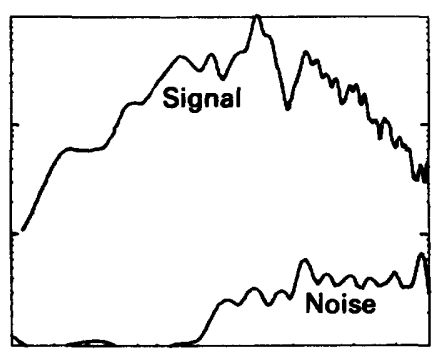

STATION 2

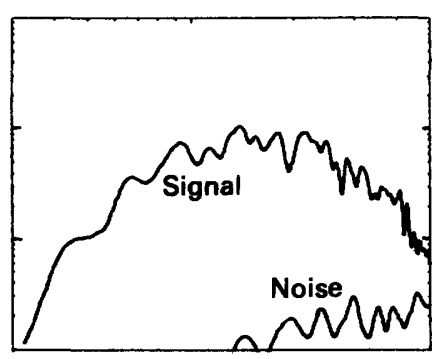

STATION 9

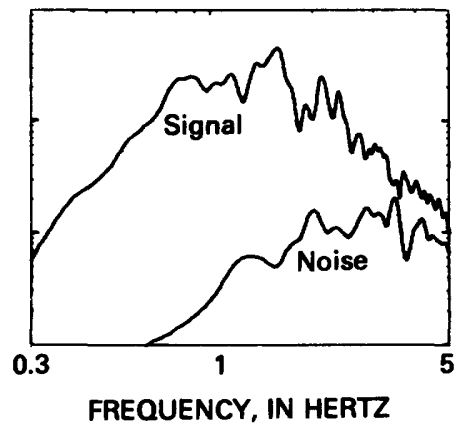

HORIZONTAL E-W COMPONENT
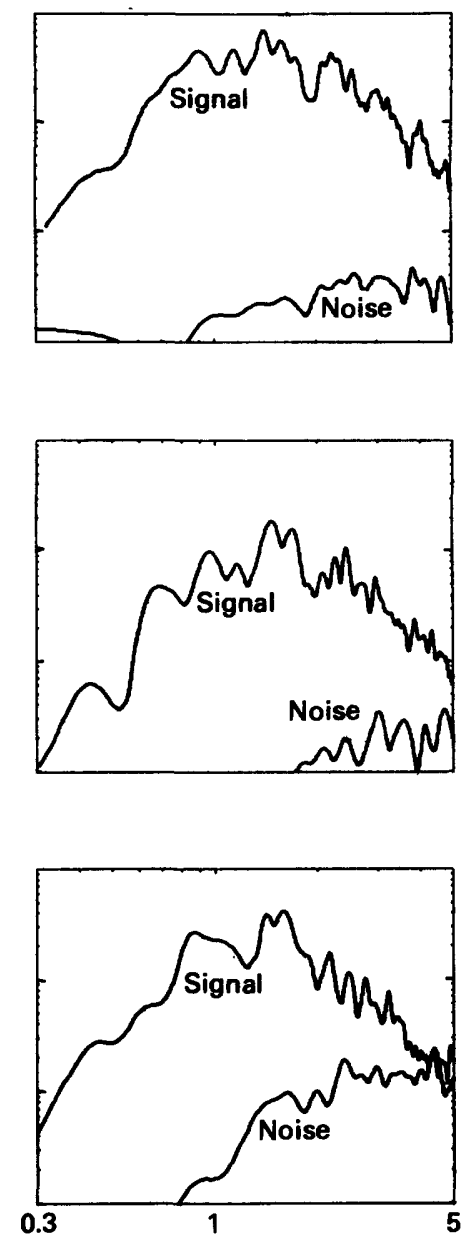

FIGURE 8.-Comparison of signal and noise amplitude spectra for three sites in Salt Lake City computed from ground motion generated by nuclear explosion event B. Noise spectra calculated from analysis of a 50 -s segment before the arrival of event $B$.

\section{DISCUSSION}

The time histories of the site-response data for the Salt Lake City and Springville-Spanish Fork areas are shown in figures 4 and 5 . The data have been amplitude normalized to the sites underlain by rock and arranged from top to bottom on the illustration, according to a general increase in the thickness of underlying alluvium and an increased distance west from the Wasatch Front toward the center of the valley. The sites in figures 4 and 5 are ordered according to thickness of underlying alluvium, this order owing to the limited amount of geologic information available at this time. The estimated depths to basement for the Salt Lake City (SLC) sites shown on figure 4 are, from top to bottom: $0,30,80,140,140,180$, 190, 270, and $440 \mathrm{~m}$ (R. Van Horn, unpublished data, 1986). The depths of alluvium at the Springville-Spanish Fork (SSF) sites are less well known. The projection of the dip of an exposed outcropping of bedrock, approximately $50 \mathrm{~m}$ from SSF site 2 , to a point at depth beneath SSF site 2 indicates that the underlying thickness of alluvium at that station probably does not exceed $30 \mathrm{~m}$. Borehole tests near SSF site 3 and SSF site 4 did not penetrate bedrock at a total depth of $150 \mathrm{~m}$, and borehole tests near SSF site 5 did not penetrate bedrock at a total depth of 300 m (R. Van Horn, unpublished data, 1986). Figures 4 


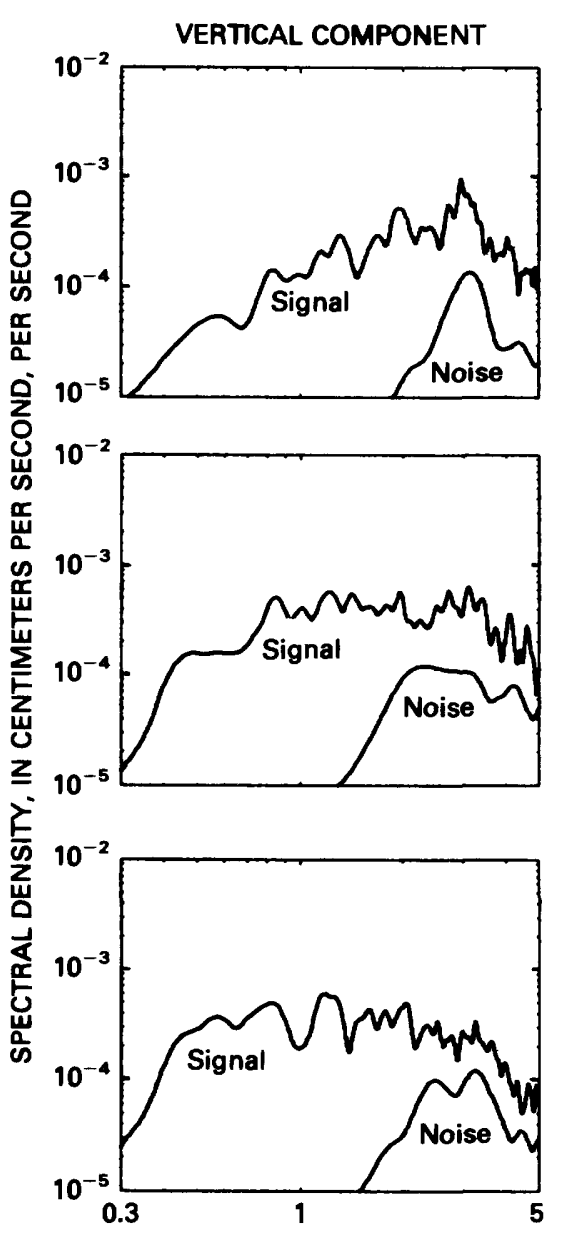

STATION 3
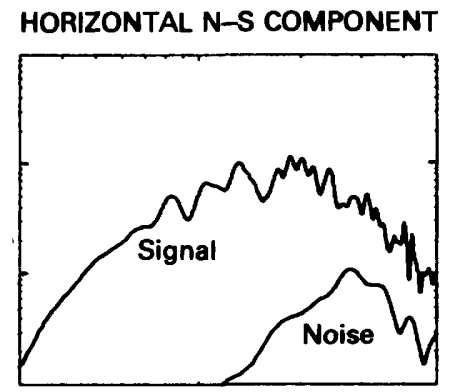

STATION 4

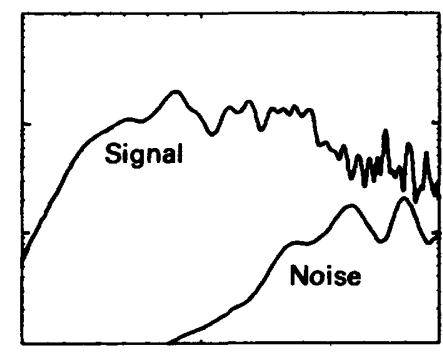

STATION 5

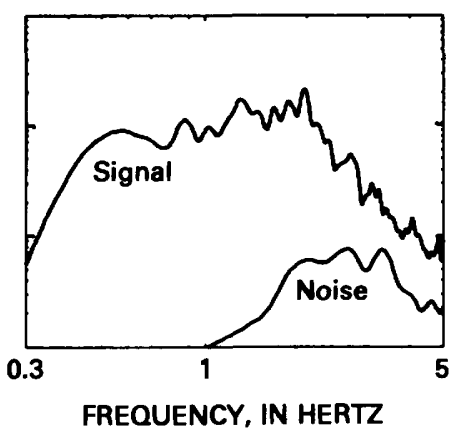

HORIZONTAL E-W COMPONENT
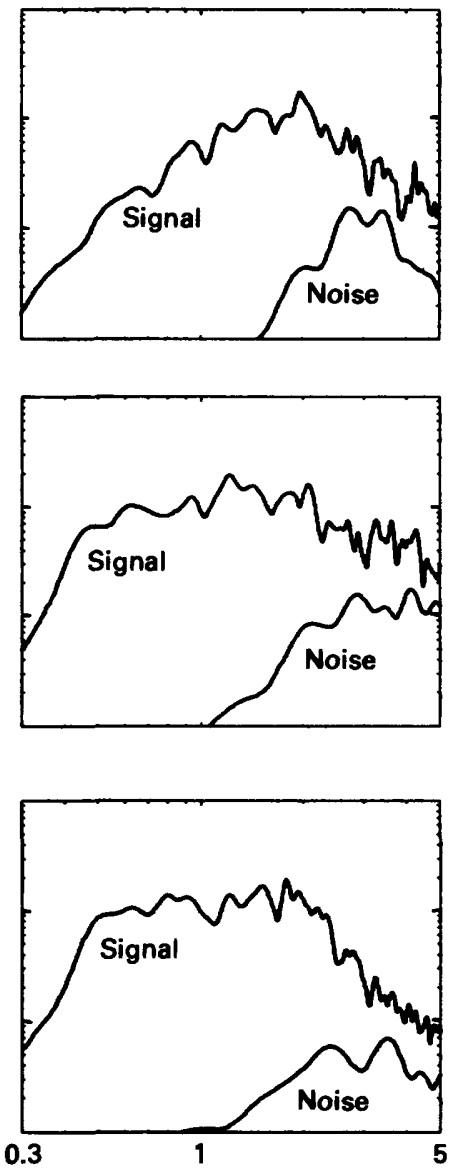

FigURE 9.-Comparison of signal and noise amplitude spectra for three sites in the Springville-Spanish Fork area computed from ground $m$ otion generated by nuclear explosion event $\mathrm{A}$. Noise spectra calculated from analysis of a 50 -s time segment before the arrival of even $\mathrm{t}$.

and 5 show an increase in signal amplitude in both $\mathrm{P}$-wave and surface-wave portions of the seismograms and an increase in the wavetrain duration with increasing alluvium depth and distance from the Wasatch Front (toward the center of the valley). Figure 6 shows the derived spectra from the data recorded at SLC site 1 (rock), SLC site 2 ( $30 \mathrm{~m}$ of alluvium), and SLC site 9 (440 $\mathrm{m}$ of alluvium). Figure 7 shows the derived spectra from the data recorded at SSF site 1 (rock), SSF site 2 (approximately $30 \mathrm{~m}$ of alluvium), and SSF site 5 (approximately $300 \mathrm{~m}$ of alluvium). The spectra show that an increased spectral amplification and a slight spectral peak shift toward the lower frequencies may correlate with increased thickness of alluvial deposits.
Transfer functions, or averaged spectral ratios, were derived from unsmoothed spectra for bandwidths similar to those used in the Hays and King (1982) report. Spectra from the stations underlain by alluvium were divided by the spectra of the stations underlain by rock. The spectral ratios show that amplification occurs over most of the frequency band for which a good signal-to-noise ratio exists (figs. 10, 11). The average spectral amplification over four period bands -0.2 to $0.7,0.7$ to $1.0,1.0$ to 2.0 , and 2.0 to $3.33 \mathrm{~s}$-are shown for Salt Lake City in figure 12 and for Springville-Spanish Fork in figure 13. The amplification factors range from approximately 1.5 to 4.5 for sites near the Wasatch Front, underlain by thinner sections of alluvium, to factors of 7 to 12 for sites in the Springville-Spanish Fork area that are located near the center of the valley 
and are underlain by more than $300 \mathrm{~m}$ of alluvium. Sites near the middle of Salt Lake valley, where Hays and King (1982) had obtained relatively high values of spectral ratio response numbers, could not be reoccupied for direct comparison owing to flooding caused by the rise of the Great Salt Lake. However, data from sites in midvalley locations in the general Springville-Spanish Fork area, similar to the midvalley Salt Lake City locations, show site response in the 0.2 - to 0.7 -s period bandwidth to be higher than that for the rock site by a factor of 7 to 12 , which compares well with Salt Lake City data given by Hays and King (1982).

Figures 4 through 13 show a general trend in increased response as the depth of alluvium or distance from the Wasatch Front increases, but anomalies in this trend are observed. For example, SLC site 5 clearly shows more time-history amplitude spectral energy and higher average spectral ratio factors in the 0.2 - to 0.7 - and the 0.7 to 1.0 -s period bandwidths than SLC site 4 . Yet SLC site 5 is located closer to the Wasatch Front and is underlain by a thinner alluvial sequence than SLC site 4. Hays and King (1982) postulated the existence of areas that would show high ground-shaking amplification in close proximity to sites displaying average ground response. An explanation for the anomalously high amplification observed at SLC site 5 can be found in the high-resolution shallowreflection profile made at that site (fig. 14). The analysis of the data shown on the reflection profile yielded seismic $P$-wave velocities of the near-surface layers that are much slower $(550-600 \mathrm{~m} / \mathrm{s})$ than those of the deeper alluvium and underlying bedrock $(4.5 \mathrm{~km} / \mathrm{s}$ ) (Arnow and Mattick, 1968). Because the difference in impedance of vertically adjacent layered media amplifies seismic waves in proportion to the contrast in impedances of these layers (Medvedev, 1962), the slow near-surface velocities calculated for this site, in contrast to the deeper rocks having higher velocities, may be producing the impedance difference needed to generate the higher ground response. An aquifer at a 50-m depth is encountered in a well located $270 \mathrm{~m}$ northeast of the recording site, but the aquifer was not detected on the reflection profile. Either the aquifer reflector is very weak, or, more reasonably, the water table is deeper than the reflection methods used can resolve (deeper than $75 \mathrm{~m}$ ). Therefore, a shallow water table, which Evernden and Thomson (1985) suggested to explain the increased ground motion, apparently does not exist at this site.

High-resolution shallow-reflection profiles were also run in Salt Lake City at SLC sites 8 and 12. The near-surface P-wave velocities measured at SLC site 12 (915-1650 $\mathrm{m} / \mathrm{s}$ ) were the highest observed among the three sites. The P-wave velocities at SLC site 12 were calculated from the reflection two-way traveltimes of the three two-cycle reflections ( $F, G$, and $H$, fig. 15) shown in the stacked record section. A shallow depth to the water table (1-3 m) (Mower and Van Horn, 1973) indicates that the sediments are saturated, a condition that probably contributed to the increased seismic velocities calculated for this site. Additionally, impedance contrast amplification across the horizons indicated by the strong reflections at SLC site 12 may also be a significant factor here in amplifying the upward-propagating waves from the nuclear test.

The P-wave velocities measured at SLC site 8 (approximately $1,000 \mathrm{~m} / \mathrm{s}$ ) were intermediate to velocities at SLC sites 5 and 12 . The high-resolution reflection profile at this site crosses the East Bench fault (A, fig. 16) and shows a reflection at 20 to $40 \mathrm{~ms}(10-20 \mathrm{~m}$ depth) downdropped to the west approximately $5 \mathrm{~ms}(2.5 \mathrm{~m})$ at position A. West of position A, other reflection discontinuities that suggest faulting are indicated at positions $B, C, D$, and E. Except for position E, the reflection offsets are down to the west. There is a slight indication that beds between positions $\mathrm{B}$ and $\mathrm{C}$ may be back rotated toward the fault. The fault probably penetrates deeper into the section than figure 16 shows; however, the surface wave and the shallower reflectors obscure later reflective arrivals from deeper structures. Ground response was also intermediate, average spectral ratio factors (ASRF) being 4.2 to 6.6 at this site, in comparison with SLC site 5 (2-4.5) or SSF site 5 (7.7-10.1).

The seismic-reflection profile from SSF site 3 is underlain by approximately $100 \mathrm{~m}$ of alluvium and shows shallow reflections in the 20 - to 50-ms two-way traveltime range (6-14 $\mathrm{m}$ depth range) $(\mathrm{J}, \mathrm{K}$, and $\mathrm{L}$, fig. 17). The origin of these undulating structures is unknown, but a possibility is that they are due to the fluvial processes of nearby Hobble Creek. The seismic P-wave velocities computed for the labeled reflections in figure 17 are relatively slow- $550 \mathrm{~m} / \mathrm{s}$. Again, the slow seismic-reflection velocities, calculated at this site for near-surface deposits, may be an indicator of an acoustic impedance contrast that would amplify upward-traveling seismic waves into the intermediate ground-response range (ASRF between 4.0 and 8.0).

The reflection profile from SSF site 4, a high-groundresponse site (ASRF between 8 and 12), shows a moderately deep (approximately $55 \mathrm{~m}$ ), flat-lying two-cycle reflection at about 80 -ms two-way traveltime (M, fig. 18). A shallow water-table depth $(1.5 \mathrm{~m})$, measured in the borehole at this site, probably improved the source coupling to the ground and therefore allowed deeper penetration of the seismic signal. Resolution of any horizons above this event was unsuccessful because ground roll and air blast dominate this part of the record. Also, the absence of acoustic contrasts large enough to generate an observable reflection earlier in the record may have contributed to the lack of reflections. Still, the reflection recorded in this profile is the latest event (in two-way 
A
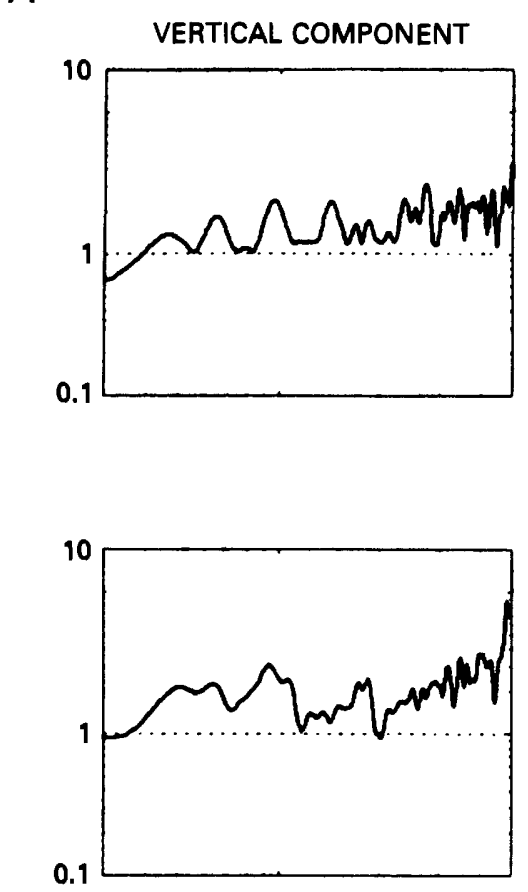

은

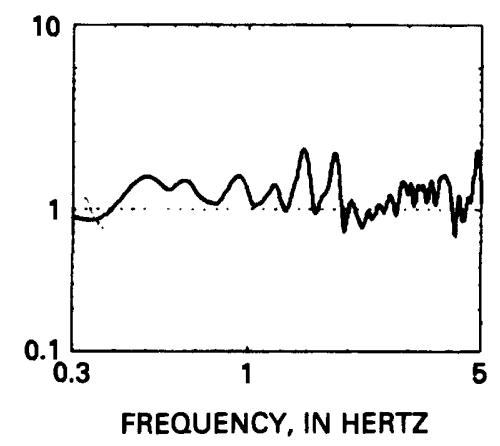

VERTICAL DATA LOST
STATION 2/STATION 1
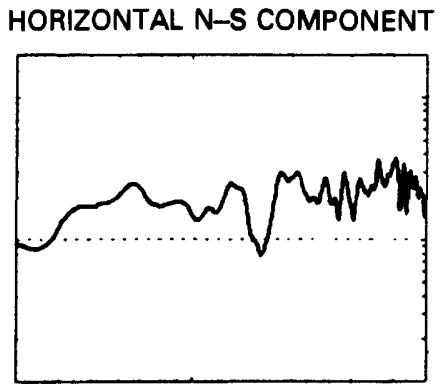

STATION 5/STATION 1

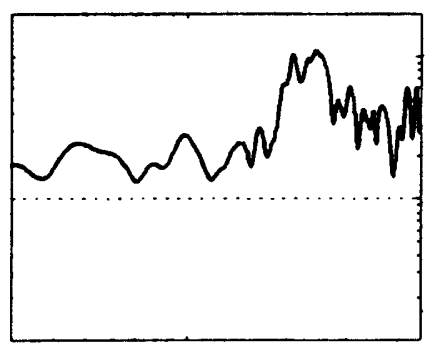

STATION 4/STATION 1

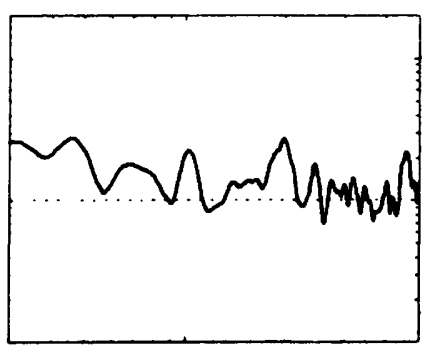

STATION 6/STATION 1

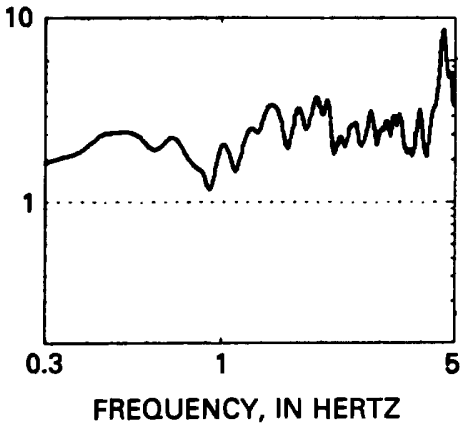

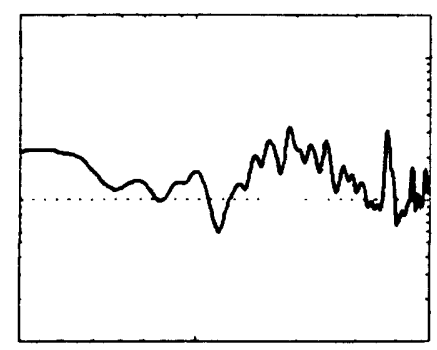

HORIZONTAL E-W COMPONENT
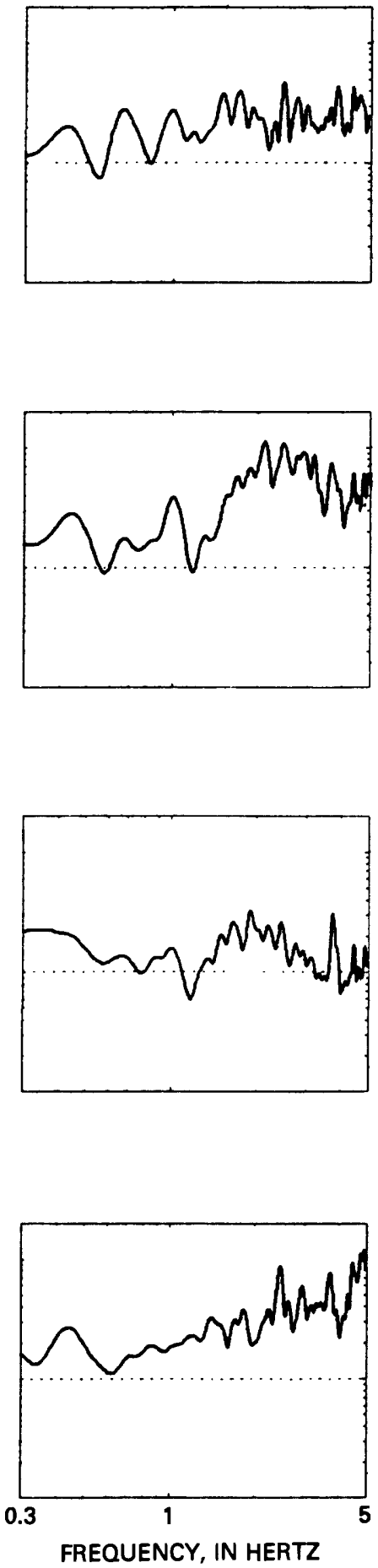

FIGURE 10.-Spectral ratios of vertical and horizontal (north-south and east-west) components of ground motion recorded on sites having geologic conditions different from those at the crystalline rock site (station 1) in Salt Lake City. Spectral ratios are not plotted where the signal-to-noise ratio is less than 2 . 
$\boldsymbol{B}$
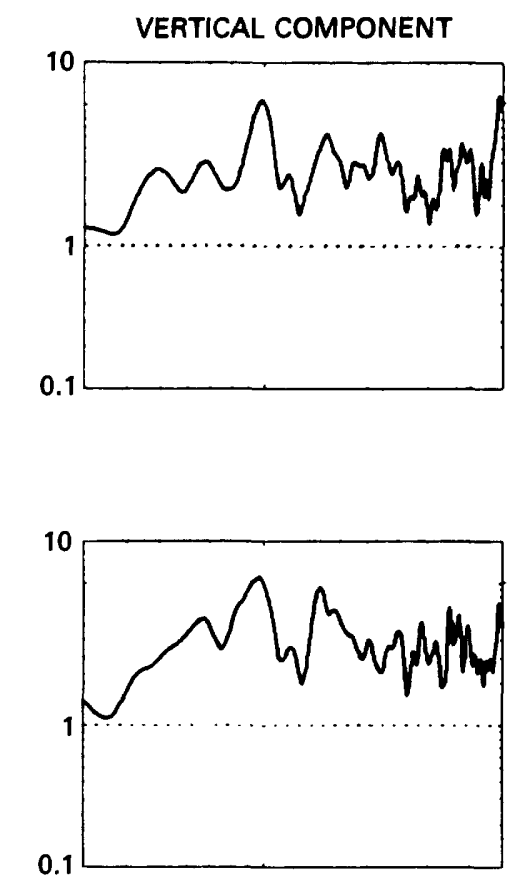

$\frac{}{5}$
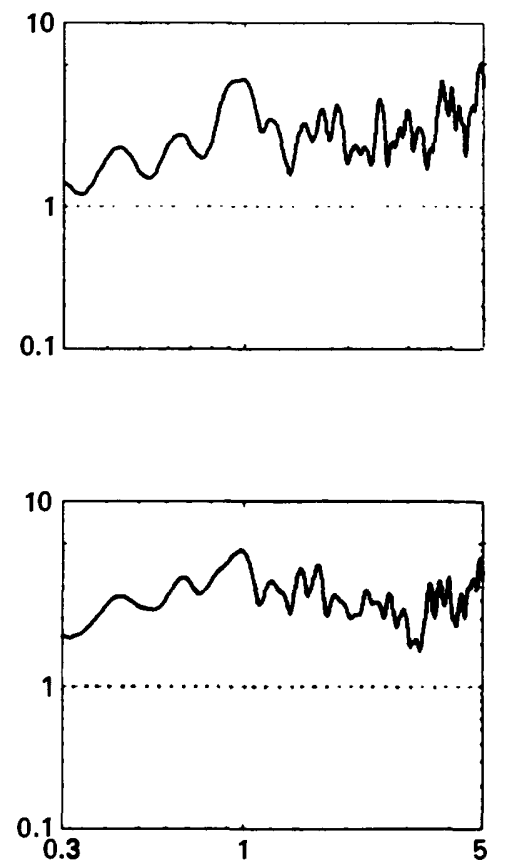

STATION 10/STATION 1

HORIZONTAL N-S COMPONENT

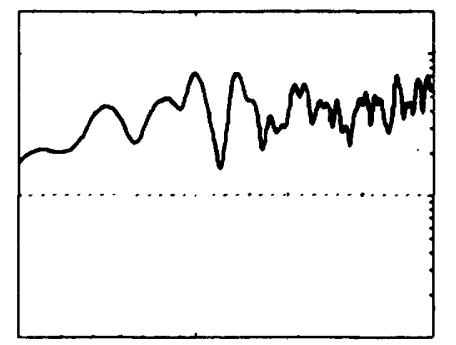

HORIZONTAL E-W COMPONENT

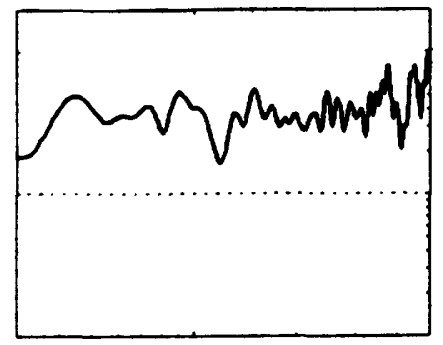

STATION 3/STATION 1
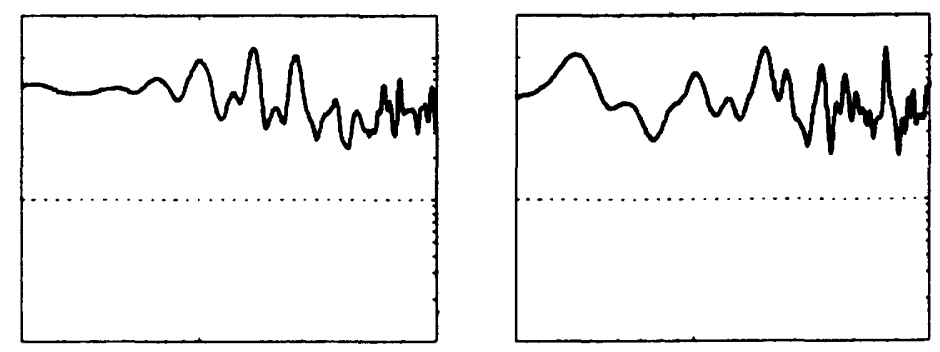

STATION 8/STATION 1
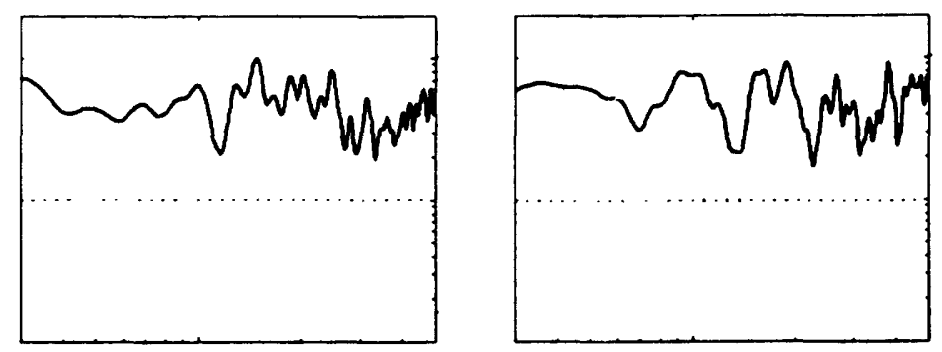

STATION 9/STATION 1
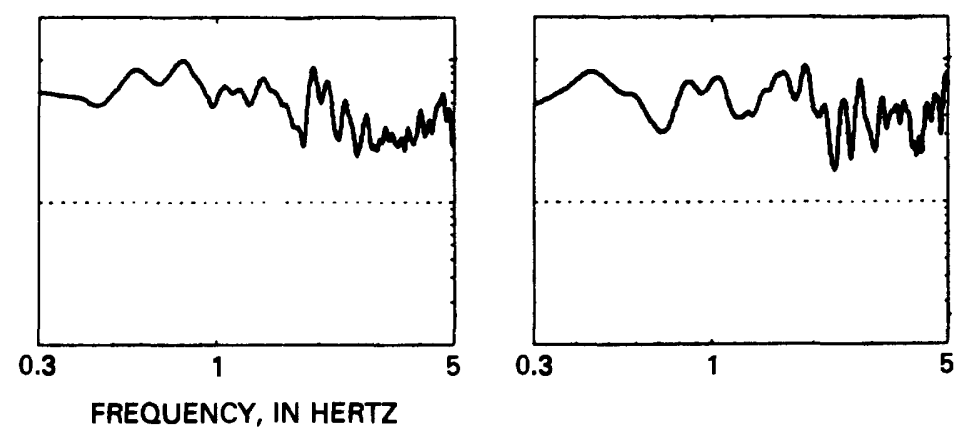

FIgURE 10.-Continued. 
STATION 10/STATION 1
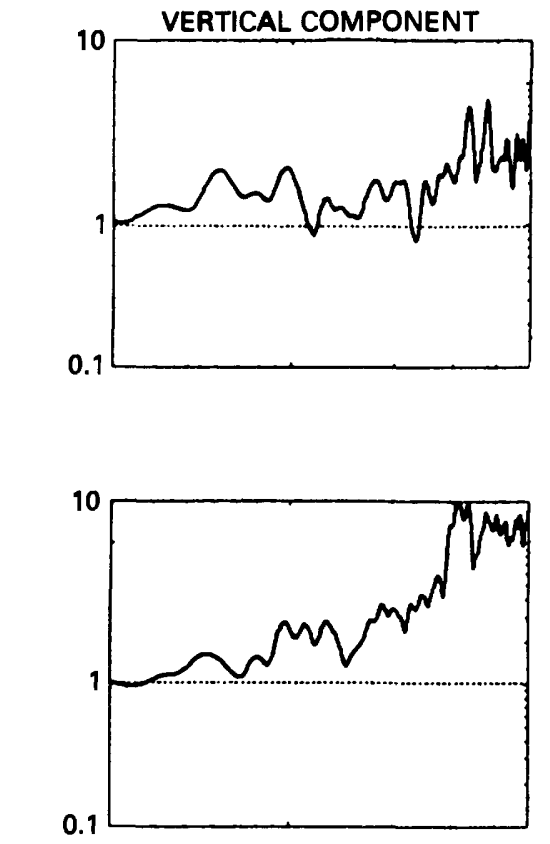

을
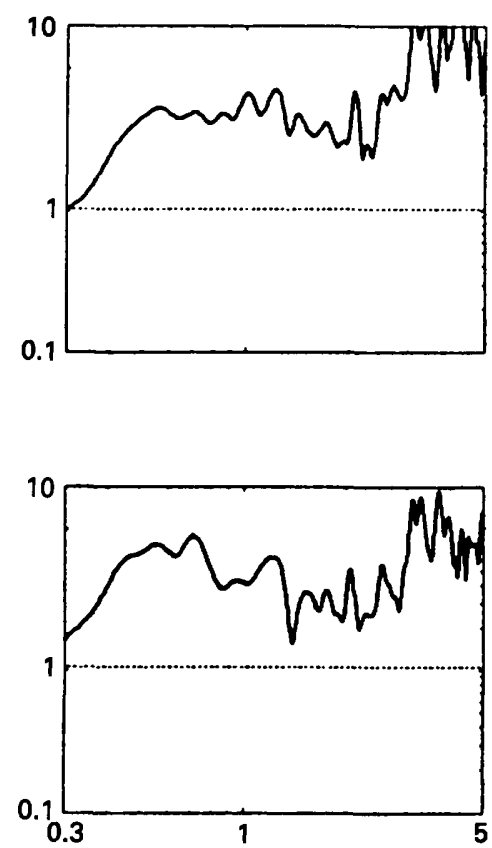

HORIZONTAL N-S COMPONENT

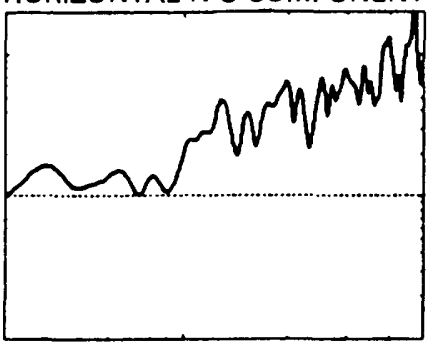

STATION 3/STATION 1

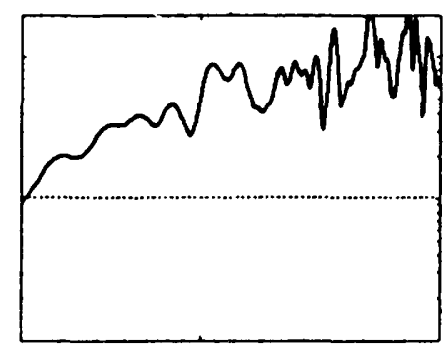

STATION 4/STATION 1

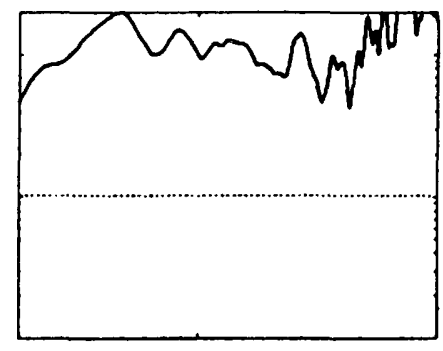

STATION 5/STATION 1

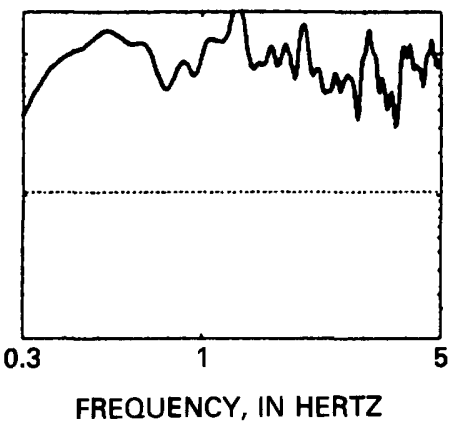

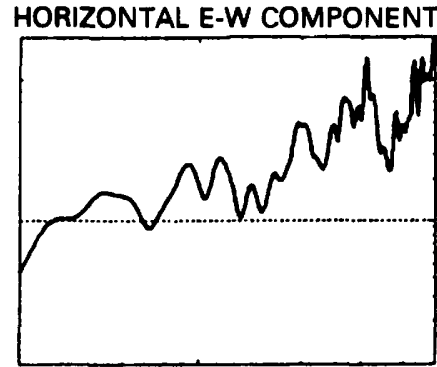
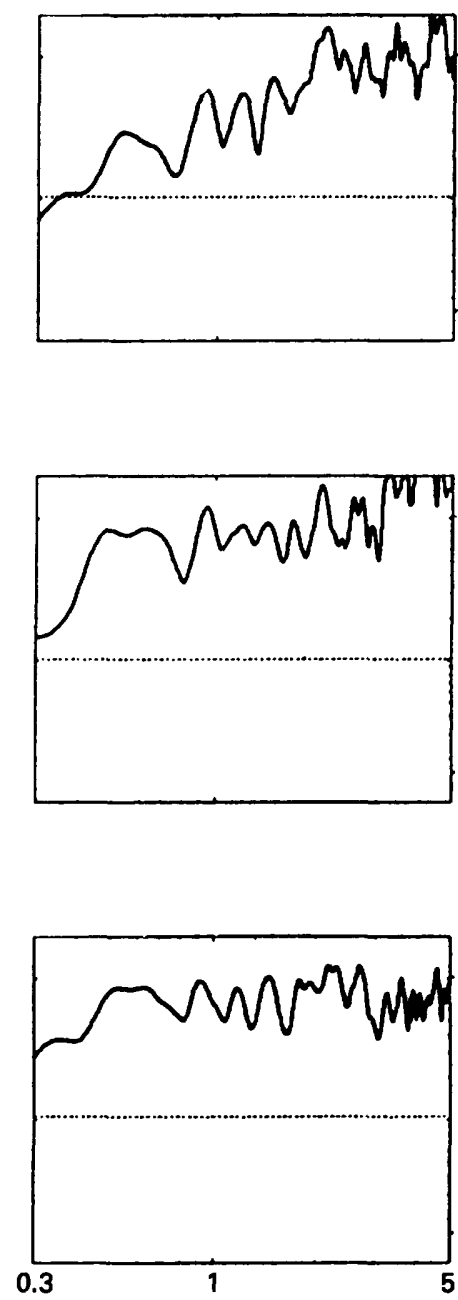

FIGURE 11.--Spectral ratios of vertical and horizontal (north-south and east-west) components of ground motion recorded on sites having geologic conditions different from those at the crystalline rock site in the Springville-Spanish Fork area. Spectral ratios not plotted where the signal-to-noise ratio is less than 2. 
$\boldsymbol{A}$
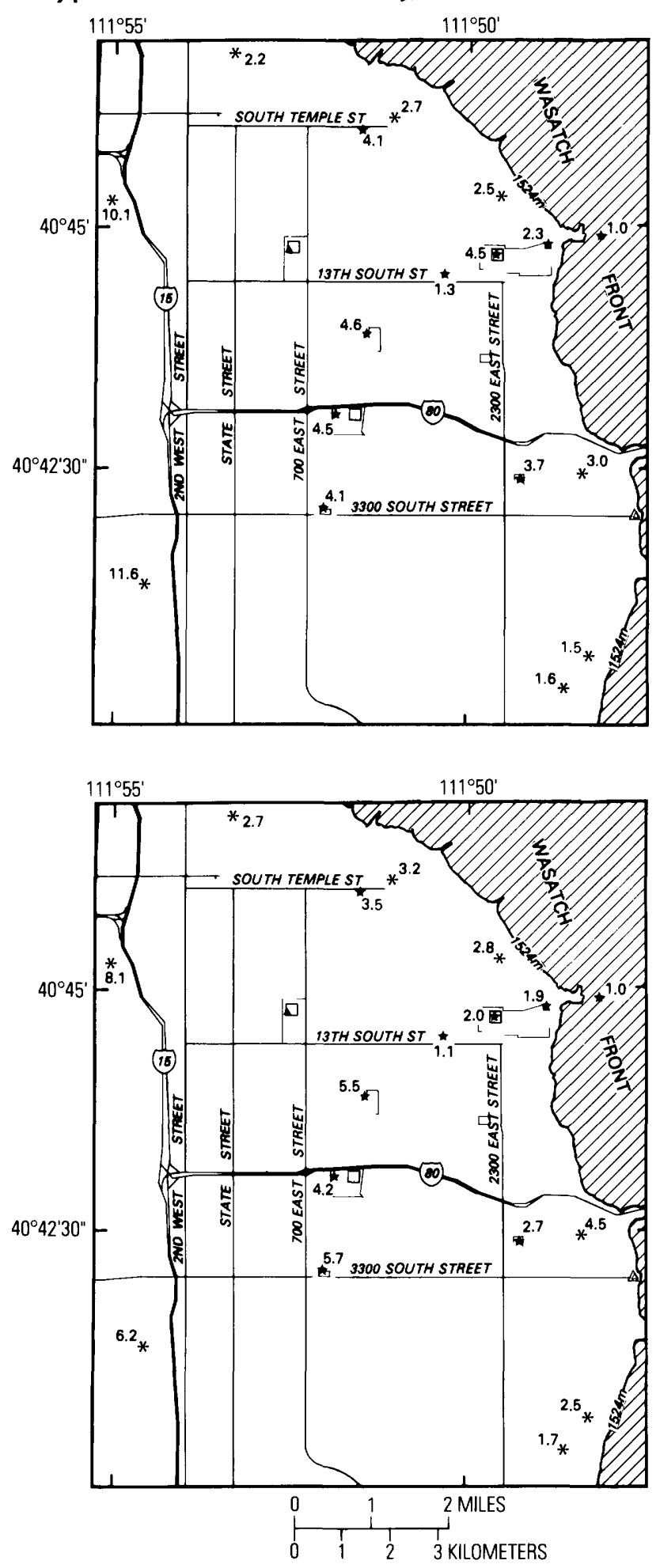

EXPLANATION

- Dr-200 site

* Pseudo-relative velocity response

$\square$ Shallow reflection site (Hays and King, 1982)
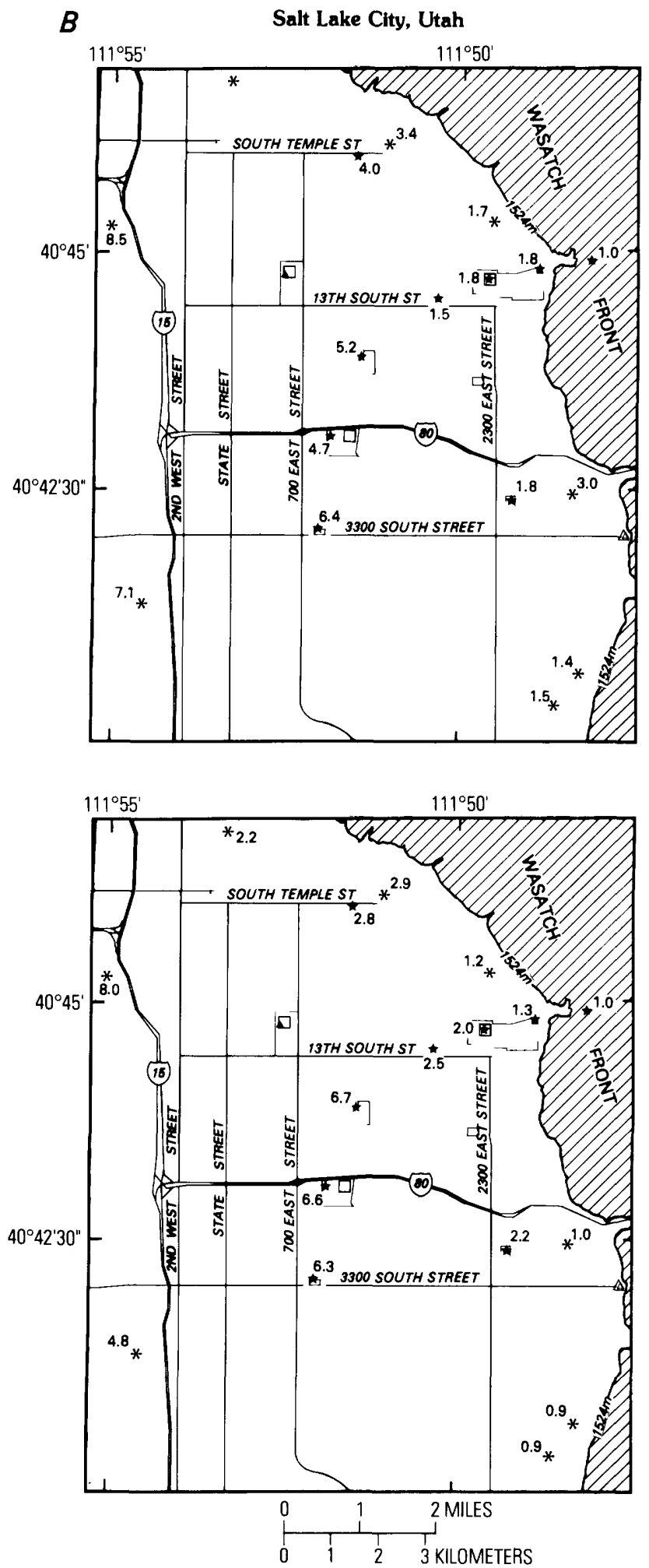

EXPLANATION

- Dr-200 site

* Pseudo-relative velocity response

$\square$ Shallow reflection site (Hays and King, 1982)

FIGURE 12.-Horizontal component average spectral ratios from Hays and King (1982) and from this study for the Salt Lake City area. A, Top shows ratios for the period band 0.2 to $0.7 \mathrm{~s}$; bottom shows ratios for the period band 0.7 to $1.0 \mathrm{~s}$. $B$, Top shows ratios for the period band 1.0 to $2.0 \mathrm{~s}$; bottom shows ratios for the period band 2.0 to $3.33 \mathrm{~s}$. 
A
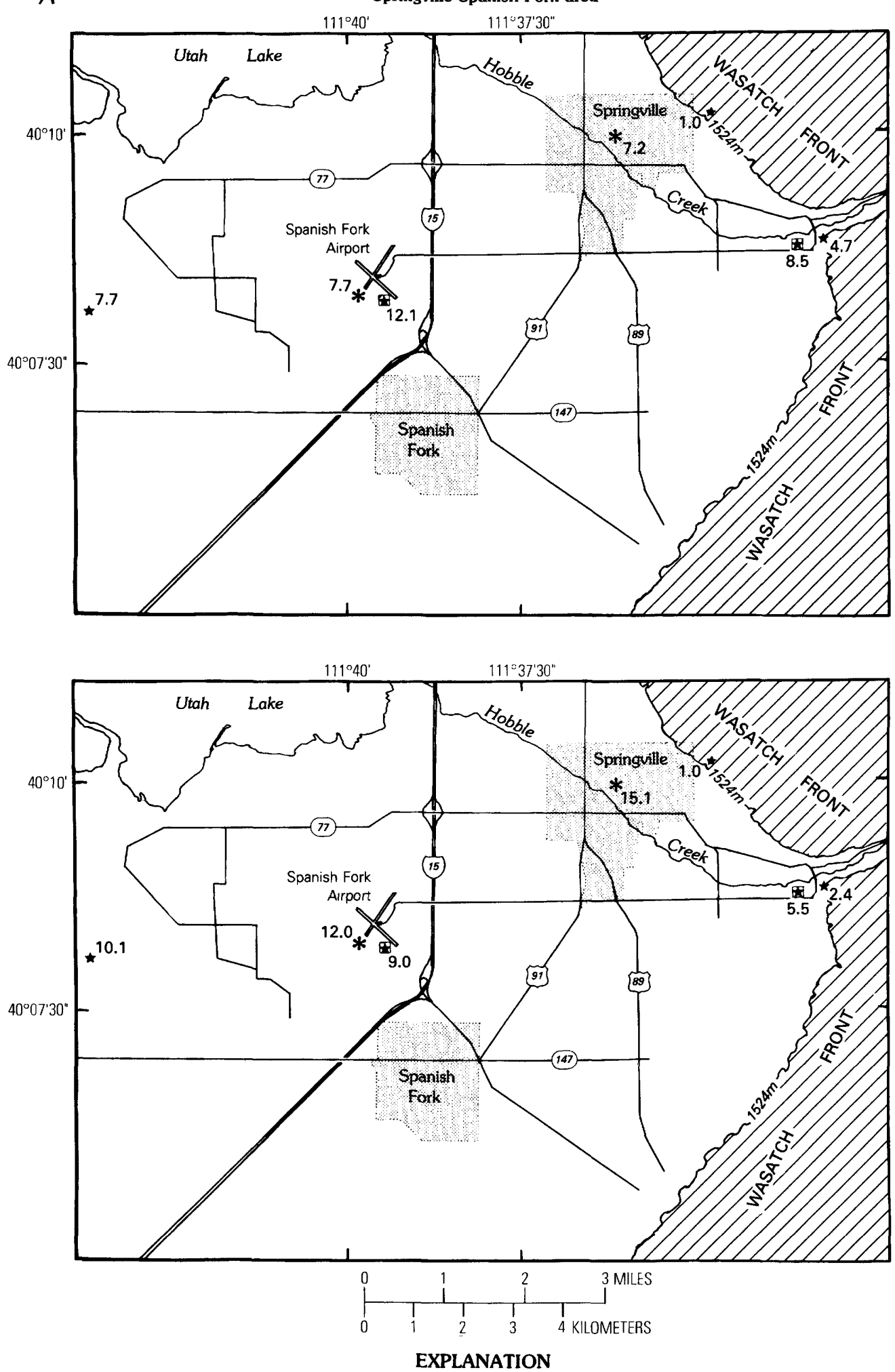

- Dr-200 site

* Shallow reflection site $\square$ Pseudo-relative velocity response (Hays and King, 1982) $\leftarrow$ FIGURE 13.-Horizontal component average spectral ratios from Hays and King (1982) and from this study for the Springville-Spanish Fork area. $A$, Top shows ratios for the period band 0.2 to $0.7 \mathrm{~s}$; bottom shows ratios for the period band 0.7 to $1.0 \mathrm{~s}$. $B$, Top shows ratios for the period band 1.0 to $2.0 \mathrm{~s}$; bottom shows ratios for the period band 2.0 to $3.33 \mathrm{~s}$. 
B

Springville-Spanish Fork area

$\leftarrow$ FIgURE 13.-Continued.
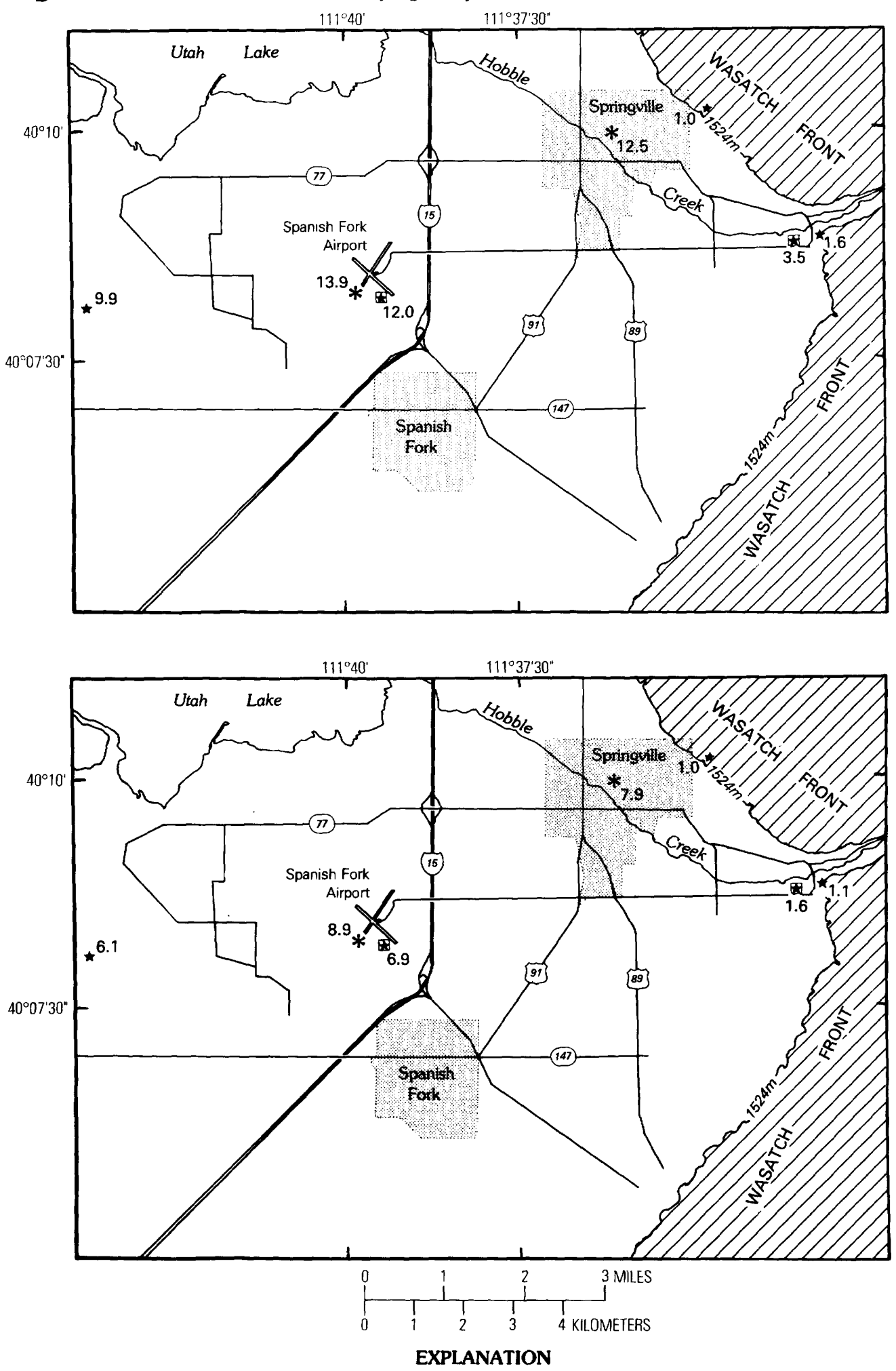

$\star$ Dr-200 site

$\square$ Pseudo-relative velocity response

* Shallow reflection site

(Hays and King, 1982) 


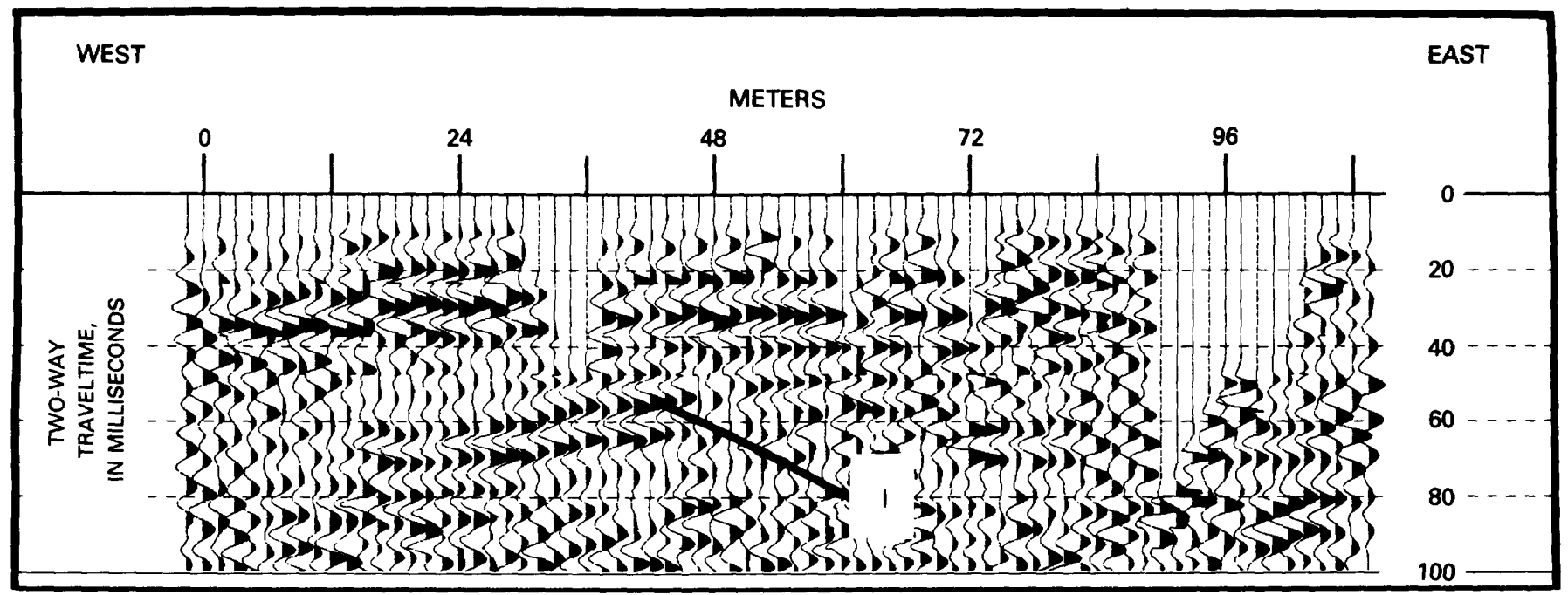

FIGURE 14.-Seismic reflection profile from SLC site 5 (Bonneville Golf Course) showing reflection labeled I.

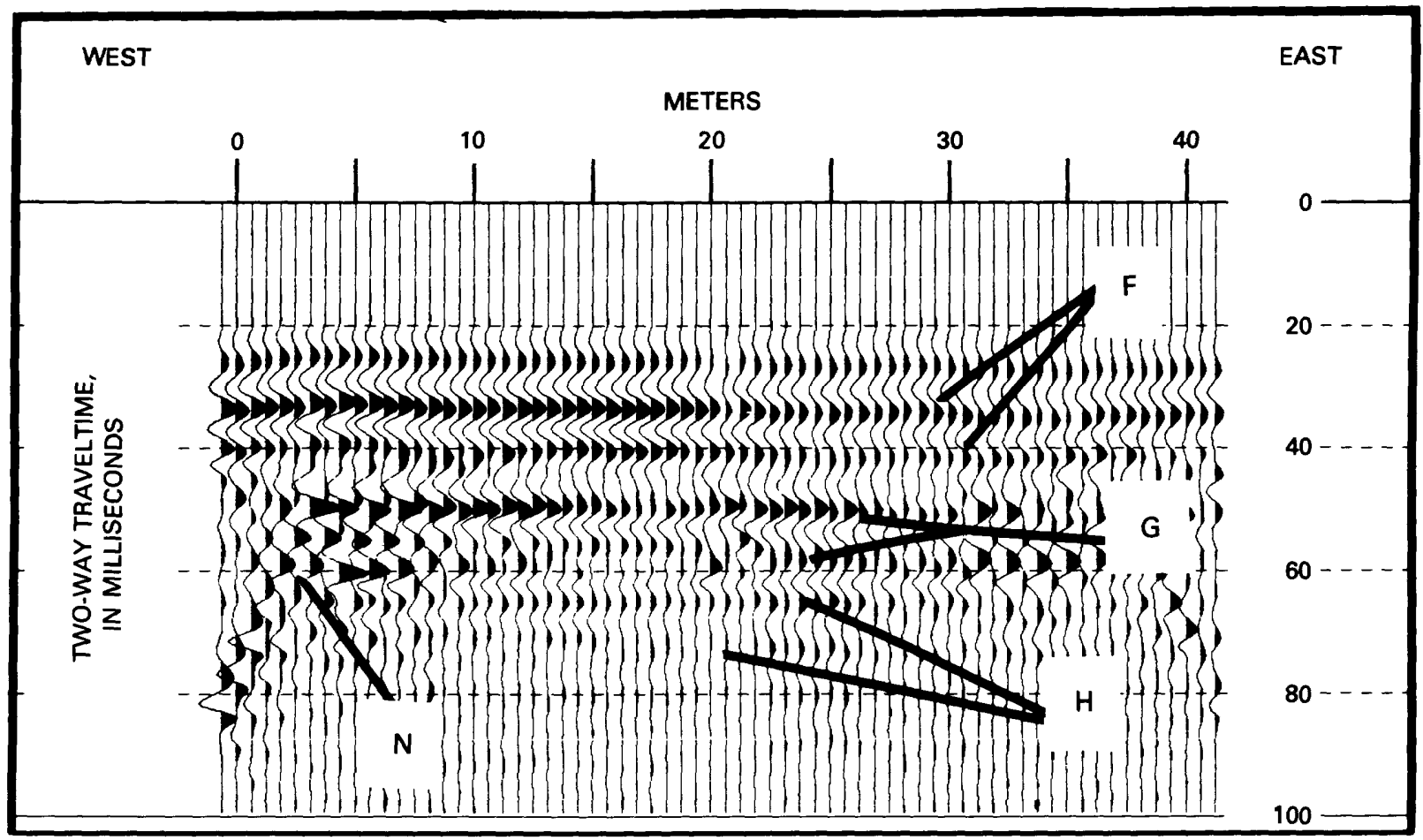

FIGURE 15.-Seismic reflection profile from SLC site 12 (Liberty Park) showing reflections labeled F, G, and H. Ground roll dominates in the zone labeled $\mathrm{N}$. 


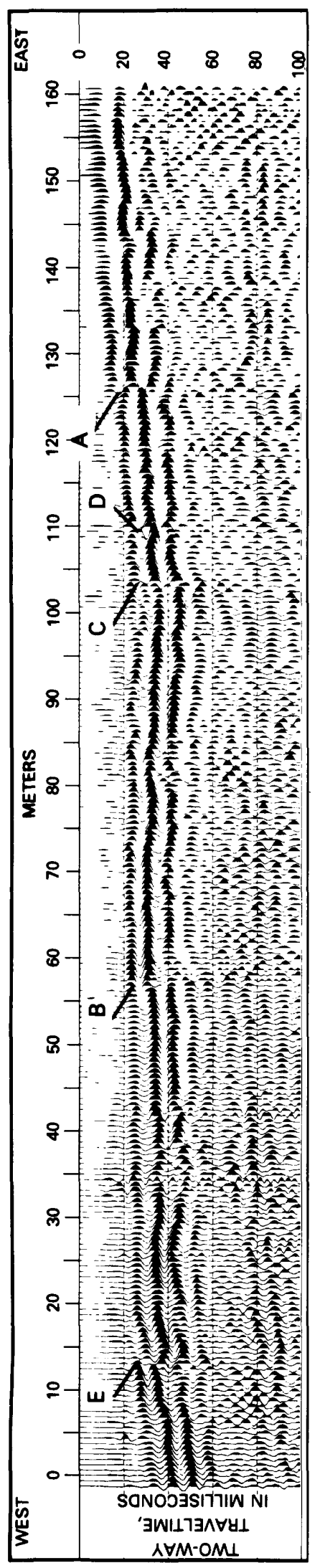

traveltime) seen on any of the profiles. The seismic Pwave velocity determined for the reflection labeled $M$ (fig. 18) is $1,370 \mathrm{~m} / \mathrm{s}$, which is significantly higher than the velocity determined for the reflections at SSF site 3.

The data in table 1 suggest a weak correlation between ground response and the results of the seismicreflection work. Two sites, SLC 12 and SSF 4, have high ground response (ASRF 8-12.1) - the only two sites where seismic-reflection data were collected in which a reflector was detected in the 70- to 80-ms time range (55to $60-\mathrm{m}$ depth range). Two other sites, SLC 8 and SSF 3, have intermediate ground response (ASRF 4.5-8.5) and a reflection arrival in the 30 - to 45 -ms range. The remaining reflection profile, SLC 5 , does not fit into this pattern of ground response versus depth and arrival time of reflections; it has low response (ASRF 1.8-4.5) and a moderately deep reflection $(60 \mathrm{~ms})$. It is possible that the calculated velocities for SLC 5 are in error or that different field methods would resolve more reflections that might fit the above pattern. However, the reflection depth versus ground response database is too small to be considered statistically significant at this time. Additional reflection profiles have been acquired and are being added to the data set.

\section{CONCLUSIONS}

The results obtained by Hays and King (1982), who developed a contoured site-response map of the Salt Lake City area based on transfer functions derived from pseudo-velocity spectra ratios, and those in this report, which used transfer functions derived from Fourier transformed spectra ratios, show good agreement (figs. 12, 13). Both data sets show an increase in response westward from the Wasatch Front toward the center of the valley. Also, both data sets show that the average spectral ratio factors for Salt Lake City, at similar distances from the Wasatch Front, differ from those for Springville-Spanish Fork; for sites near the Wasatch Front in Salt Lake City, the ASRF vary from 1.5 to 4 , whereas, for sites at similar distances from the Wasatch Front in the Springville-Spanish Fork area, the factors are 5 to 15 . The good agreement between the results of this study and those of Hays and King (1982) demonstrates the repeatability of generating site-response values and gives a sense of reliability to the overall procedure used by Borcherdt and Gibbs (1976), Hays and King (1982), and Rogers and others (1985) for mapping ground response and developing groundresponse predictions. The site-response estimates in this study are made without consideration of directivity effects, source characteristics, or high-strain effects of nearby earthquakes.

The analysis of the high-resolution shallow-reflection profiles shows that the technique is a viable means of 


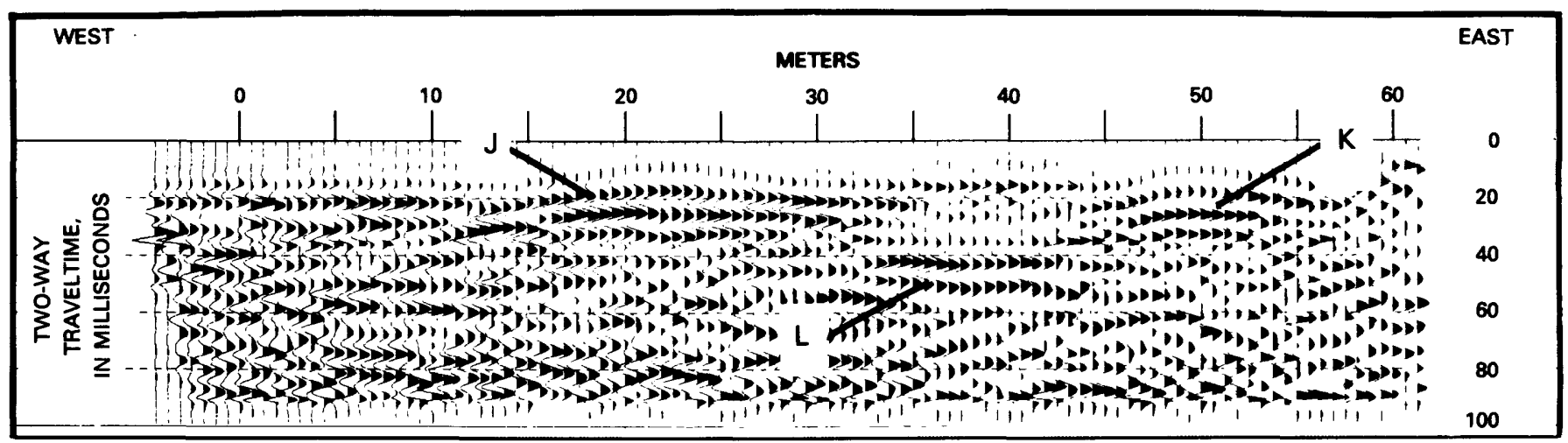

FIGURE 17.-Seismic reflection profile from SSF site 3 (Hobble Creek) showing reflections labeled J, K, and L.

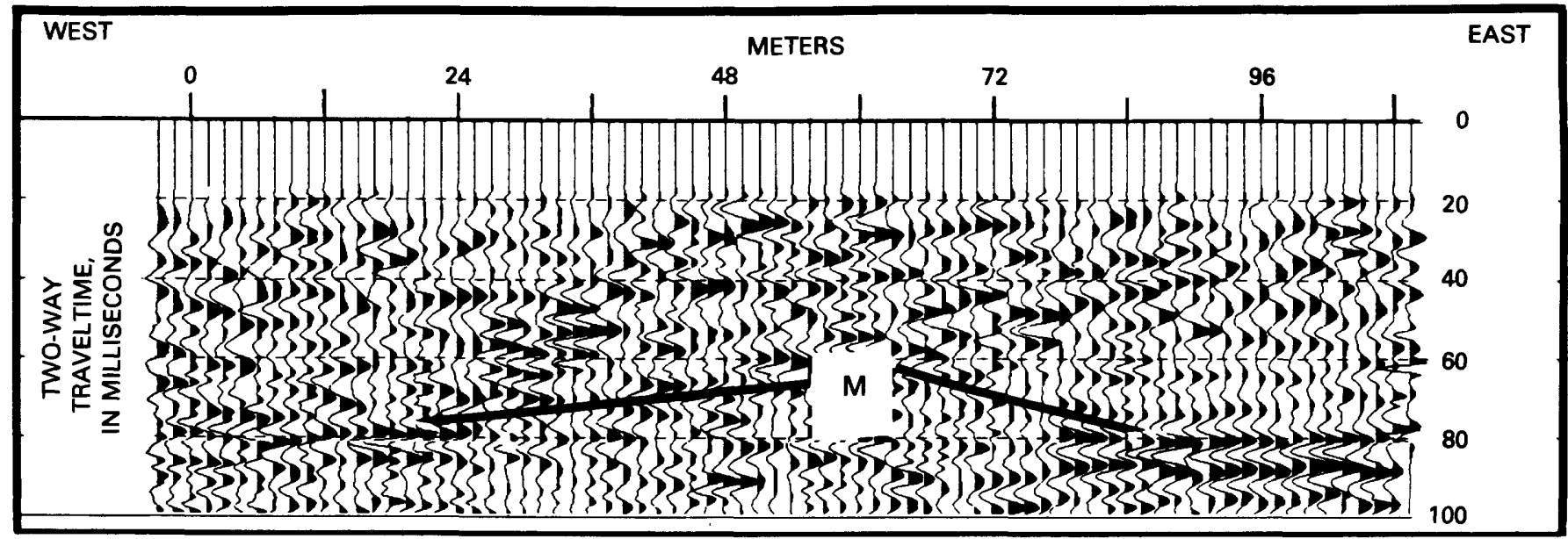

FIGURE 18.-Seismic reflection profile from SSF site 5 (Spanish Fork Airport) showing reflection labeled M.

mapping shallow structures in urban areas underlain by unconsolidated sedimentary sections. The profiles suggest promising correlations between the later arriving reflections (70-80 $\mathrm{ms}$ ) and higher ground response and between intermediate site response and earlier arriving reflections ( $30-45 \mathrm{~ms})$. However, the high-resolution shallow-reflection method will need a larger database to show if a statistically significant correlation exists. Additional site-specific geologic studies and high-resolution shallowreflection studies are being conducted at the groundresponse sites used in this study and in the Hays and King (1982) report. The resultant geotechnical analysis and correlations among geologic factors and the site-response factors are in progress. 
TABLE 1.-Seismic-reflection and ground-response data

$[-$, not observed at this site $]$

\begin{tabular}{|c|c|c|c|c|c|}
\hline & $\begin{array}{c}\text { Bonneville } \\
\text { Golf Course } \\
\text { (SLC 5) }\end{array}$ & $\begin{array}{c}\text { Forest Dale } \\
\text { Golf Course } \\
\text { (SLC 8) }\end{array}$ & $\begin{array}{l}\text { Liberty Park } \\
\text { (SLC 12) }\end{array}$ & $\begin{array}{l}\text { Hobble Creek } \\
\text { (SSF 3) }\end{array}$ & $\begin{array}{l}\text { Spanish Fork } \\
\text { Airport } \\
\text { (SSF 4) }\end{array}$ \\
\hline \multicolumn{6}{|l|}{ Average spectral ratio factor: } \\
\hline $0.2-0.7 \mathrm{~s}$ & 4.5 & 4.5 & 8.0 & 8.5 & 12.1 \\
\hline $0.7-1.0 \mathrm{~s}$ & 2.0 & 4.2 & 9.0 & 5.5 & 9.0 \\
\hline $1.0-2.0 \mathrm{~s}$ & 1.8 & 4.7 & 8.5 & 3.5 & 12.0 \\
\hline $2.0-3.3 \mathrm{~s}$ & 2.0 & 6.6 & 6.0 & 1.6 & 6.9 \\
\hline No. of reflections on the profile & 1 & 1 & 3 & 2 & 1 \\
\hline \multirow[t]{3}{*}{ Reflection continuity (percentage of total profile) ................... } & 39 & 100 & 100 & 66 & 51 \\
\hline & - & - & 40 & 25 & - \\
\hline & - & - & 40 & - & - \\
\hline \multirow[t]{3}{*}{ 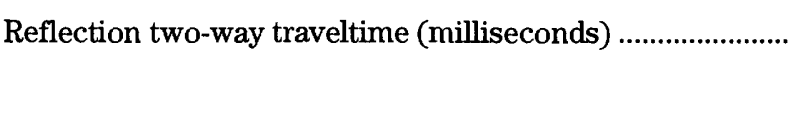 } & 60 & 30 & 30 & 20 & 80 \\
\hline & - & - & 50 & 45 & - \\
\hline & - & - & 70 & - & - \\
\hline \multirow[t]{3}{*}{ 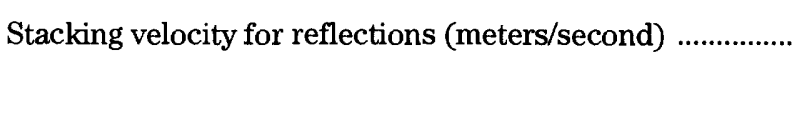 } & 600 & 1,000 & 915 & 550 & 1,370 \\
\hline & - & - & 1,475 & 600 & - \\
\hline & - & - & 1,660 & - & - \\
\hline \multirow[t]{3}{*}{ Depth to reflection (meters) } & 18 & 15 & 14 & 8 & 55 \\
\hline & - & - & 37 & 14 & - \\
\hline & - & - & 58 & - & - \\
\hline
\end{tabular}

\section{REFERENCES CITED}

Adhidjaja, J.I., Cook, K.L., and Serpa, L.F., 1981, Salt Lake Valley gravity map and data: Utah Geological and Mineral Survey, Open-File Report 39.

Arabasz, W.J., Smith, R.B., and Richins, W.D., eds., 1979, Earthquake studies in Utah, 1850 to 1978: Salt Lake City, University of Utah Special Publication, $552 \mathrm{p}$.

Arnow, T., and Mattick, R.E., 1968, Thickness of valley fill in the Jordan Valley east of the Great Salt Lake, Utah, in Geological Survey research 1968: U.S. Geological Survey Professional Paper 600-B, p. B79-B82.

Borcherdt, R.D., 1970, Effects of local geology on ground motion near San Francisco Bay: Bulletin of the Seismological Society of America, v. 60, p. 29-61.

-ed., 1975, Studies for seismic zonation of the San Francisco Bay region: U.S. Geological Survey Professional Paper 941-A, 102 p.

Borchèrdt, R.D., and Gibbs, J.F., 1976, Effects of local geological conditions in the San Francisco Bay region on ground motions and the intensities of the 1906 earthquake: Bulletin of the Seismological Society of America, v. 66, p. 467-500.

Carver, D.L., Cunningham, D.R., and King, K.W., 1986, Calibration and acceptance testing of the DR-200 digital seismograph with $\mathrm{S}-6000$ and the $\mathrm{L}-4 \mathrm{C}$ seismometers: U.S. Geological Survey Open-File Report 86-340, 28 p.
Cloud, W.K., and Hudson, D.E., 1961, A simplified instrument for recording strong motion earthquakes: Bulletin of the Seismological Society of America, v. 51, p. 159-274.

Evernden, J.F., and Thomson, J.M., 1985, Predicting seismic intensities, in Ziony, J.I., ed., Evaluating earthquake hazards in the Los Angeles region-An earth-science perspective: U.S. Geological Survey Professional Paper 1360, p. 151-202.

Gutenberg, B., 1957, Effects of ground on earthquake motion: Bulletin of the Seismological Society of America, v. 47, p. 221-250.

Hays, W.W., and King, K.W., 1982, Zoning of the earthquake ground-shaking hazard along the Wasatch fault zone, Utah: International Earthquake Microzonation Conference, 3d, Seattle, 1982, Proceedings, p. 1307-1318.

Hays, W.W., Algermissen, S.T., Miller, R.D., and King, K.W., 1978, Preliminary ground response maps for the Salt Lake City area: International Conference on Microzonation, 2d, San Francisco, 1978, Proceedings, v. 2, p. 497-508.

Kanai, K., 1952, Relation between the nature of the surface layer and the amplitude of earthquake motion: Tokyo University Earthquake Research Institute Bulletin, v. 30, p. 31-37.

Knapp, R.W., 1985, Using half-integer source offset with split spread CDP seismic data: Geophysics: The Leading Edge of Exploration, v. 4, no. 1, p. 66-69, 108.

Mayne, W.H., 1962, Common reflection point horizontal data stacking techniques: Geophysics, v. 27, p. 952-965. 
McGregor, E.E., Van Horn, Richard, and Arnow, Ted, 1974, Map showing the thickness of loosely packed sediments and the depth to bedrock in the Sugar House quadrangle, Salt Lake County, Utah: U.S. Geological Survey Miscellaneous Investigations Map I-766-M, scale 1:24,000.

Medvedev, J.V., 1962, Engineering seismology: Moscow, Academia Nauk. [Translated into English by Israel Program for Scientific Translations, 1965, 260 p.]

Miller, R.D., 1980, Surficial geologic map along part of the Wasatch Front, Salt Lake Valley, Utah: U.S. Geological Survey Miscellaneous Field Studies Map MF-1198, scale 1:100,000, 2 sheets, pamphlet.

Milne, J., 1908, Seismology (2d ed.): London, K. Paul, Trench, Trubner, and Col, 320 p.

Mower, R.W., and Van Horn, Richard, 1973, Map showing minimum depth to water in shallow aquifers (1963-1972) in the Sugar House quadrangle, Salt Lake County, Utah: U.S. Geological Survey Miscellaneous Investigations Map I-766-I, scale 1:24,000.

Murphy, J.R., Weaver, N.L., and Davis, A.H., 1971, Amplification of seismic body waves by low-velocity surface layers: Bulletin of the Seismological Society of America, v. 61, p. 109145.

Reid, H.F., 1910, The California earthquake of April 18, 1906The mechanics of the earthquake: Carnegie Institute of Washington Publication 87, v. 2, 192 p.

Rogers, A.M., and Hays, W.W., 1978, Preliminary evaluation of site transfer functions developed from nuclear explosions and earthquakes: International Conference on Microzonation, 2d, San Francisco, 1978, Proceedings, v. 2, p. 753-764.

Rogers, A.M., Covington, P.A., Park, R.B., Borcherdt, R.D., and Perkins, D.M., 1980, Nuclear event time histories and computed site transfer functions for locations in the Los Angeles region: U.S. Geological Survey Open-File Report 80$1173,207 \mathrm{p}$.

Rogers, A.M., Tinsley, J.C., and Borcherdt, R.D., 1985, Predicting relative ground response, in Ziony, J.I., ed., Evaluating earthquake hazards in the Los Angeles region-An earthscience perspective: U.S. Geological Survey Professional Paper 1360, p. 221-247.

Rogers, A.M., Tinsley, J.C., Hays, W.W., and King, K.W., 1979, Evaluation of the relation between near-surface geological units and ground response in the vicinity of Long Beach, California: Bulletin of the Seismological Society of America, v. 61, p. $1603-1622$.

Swan, F.H., III, Schwartz, D.P., and Cluff, L.S., 1980, Recurrence of moderate to large magnitude earthquakes produced by surface faulting on the Wasatch fault zone, Utah: Bulletin of the Seismological Society of America, v. 70, p. 1431-1462.

Van Horn, Richard, 1972, Surficial geologic map of the Sugar House quadrangle, Salt Lake County, Utah: U.S. Geological Survey Miscellaneous Investigations Map I-766-A, scale $1: 24,000$.

Widess, M.B., 1973, How thin is a thin bed?: Geophysics, v. 38, p. $1176-1180$. 


\section{In Situ Poisson's Ratio Measurements Near Provo, Utah}

By RICHARD D. MILLER and DON W. STEEPLES, Kansas Geological Survey, KENNETH W. KING, U.S. Geological Survey, and RALPH W. KNAPP, Kansas Geological Survey

ASSESSMNT OF REGIONAL EARTHQUAKE HAZARDS AND RISK ALONG THE WASATCH FRONT, UTAH

U.S. GEOLOGICAL SURVEY PROFESSIONAL PAPER 1500-O 



\section{CONTENTS}

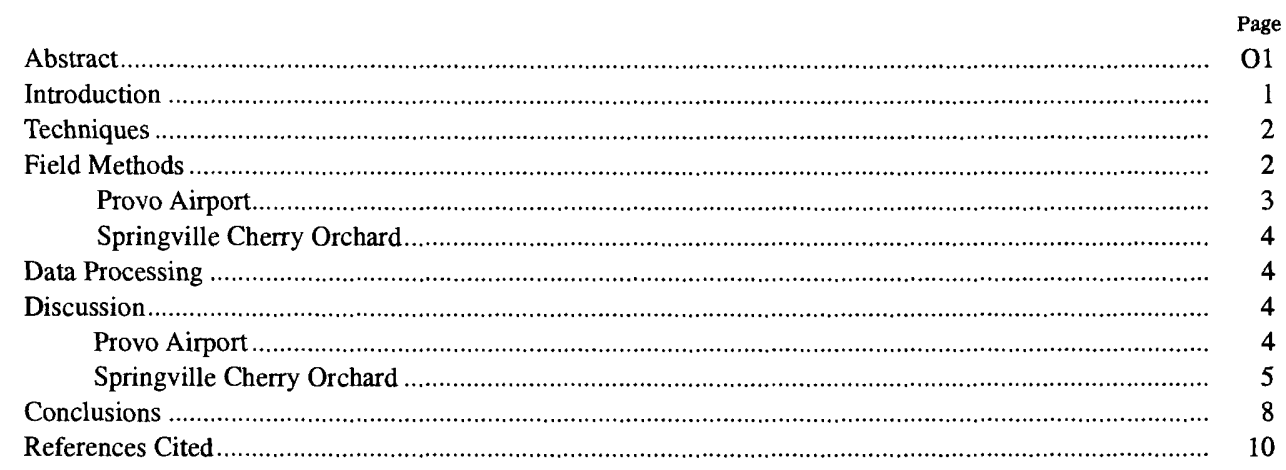

\section{ILLUSTRATIONS}

Figures 1, 2. Twelve-fold CDP stacks from the Provo Airport showing:

1. P waves acquired with the .50 -caliber rifle

2. S waves acquired with the rotational arrow

3-5. Twelve-fold CDP stacks from the cherry orchard showing:

3. P waves acquired with the $.30-06$ rifle.

7

4. $P$ waves acquired with the .50 -caliber rifle

5. $\mathrm{S}$ waves acquired with the rotational arrow 



\title{
ASSESSMENT OF REGIONAL EARTHQUAKE HAZARDS AND RISK \\ ALONG THE WASATCH FRONT, UTAH
}

\section{IN SITU POISSON'S RATIO MEASUREMENTS NEAR PROVO, UTAH}

\author{
By Richard D. Miller, Don W. Steeples, Kenneth W. King, and Ralph W. KnapP
}

\begin{abstract}
Intensity variations of several units on the Modified Mercalli scale at sites only a few kilometers apart have been well documented. Classification of sites according to response to earthquake energy would enable engineers to accurately determine minimum structural requirements for individual sites in zones of high to moderate earthquake risk. It is possible to produce shallow $\mathrm{P}$-wave and $\mathrm{S}$-wave reflection data containing the necessary information to allow direct in situ determination of Poisson's ratio (which is directly related to site response). During two separate visits to Provo, Utah, and the surrounding area, high-resolution shallow $\mathrm{P}$ - and S-wave surveys were conducted. The P- and S-wave data from Provo airport are of excellent quality and yield average velocity values accurately enough to allow determination of Poisson's ratio as a function of depth in the upper $50 \mathrm{~m}$ of the geologic section. Poisson's ratio at the Provo airport (a high-response site) is calculated to be 0.44 , whereas a low-response site near a cherry orchard has a Poisson's ratio of 0.27 .
\end{abstract}

\section{INTRODUCTION}

Intensity of ground shaking during an earthquake is determined in part by local near-surface geologic conditions. Intensity differences of three to four units on the Modified Mercalli scale at sites no more than a few kilometers apart have been well established for nearly a century (Lawson, 1908). Because of these differences, prediction of individual site response is an important part of urban earthquake-hazard mitigation. To estimate such specific site responses in the San Francisco Bay area, Borcherdt and others (1975) used intensity maps from the 1906 San Francisco earthquake and data obtained from recording far-field ground motion in the San Francisco Bay area from explosions at the Nevada Test Site (NTS).

The use of NTS explosions in other urban areas is not feasible now because of the decreasing size of NTS explosions in the past few years and the distance of many of these areas from NTS (for example, Seattle, Los Angeles, Salt Lake City, Memphis, St. Louis, Evansville, Charleston, and Boston). Although moderate to strong future earth- quakes in these areas will provide an energy source for evaluating ground motions, it is the hazards of these very earthquakes that we wish to mitigate.

Knowledge of site response would allow engineers the data necessary to better calculate minimum structural requirements for development of individual sites in zones of high to moderate earthquake risk. It also would help to determine more accurately the present risk to structures already completed and occupied.

Shallow P- and S-wave reflection data contain the necessary information for direct in situ determination of some dynamic properties of materials within the upper $100 \mathrm{~m}$ of the Earth's surface. It has long been known that the ratio of the acoustic impedances of juxtaposed layers theoretically relates to amplification. Medvedev (1965) empirically demonstrated the use of seismic shear impedance (the product of density and S-wave velocity) to predict relative ground response. The potential for amplification of shaking increases as the impedance contrast between layers increases, provided other parameters are constant.

Producing shallow P- and S-wave reflection profiles along the same surface line allows interpretation of more geological information than using $\mathrm{P}$ waves or $\mathrm{S}$ waves alone. Once interval velocities have been determined, it is possible to determine variations in Poisson's ratio with depth. Equation 1 uses average $P$ and $S$ wave velocities from the surface to a reflecting interface to determine Poisson's ratio.

$$
\sigma=\frac{1}{2}\left(\frac{\alpha^{2}-2 \beta^{2}}{\alpha^{2}-\beta^{2}}\right)
$$

where $\sigma$ is Poisson's ratio, $\alpha$ is P-wave velocity, and $\beta$ is Swave velocity.

Although it would be possible to produce similar results with an expensive drilling program that included 
cross-hole, downhole, or uphole $\mathrm{P}$ - and S-wave velocity measurements, logistical problems that accompany drilling are sometimes significant, particularly in urban areas. High-resolution seisinic surveys can be safely performed by shallow-reflection techniques in areas such as parks and school yards, essentially without causing any environmental damage. For example, we performed one such survey across the baseball fields at Sylmar High School in the San Fernando Valley of California while the students were practicing baseball and softball.

\section{TECHNIQUES}

Seisinic-reflection techniques have been used in petroleuin prospecting for about half a century. Although examples are occasionally cited in the literature, the use of shallow-reflection techniques in engineering and ground-water applications has met with only limited success because of the difficulty encountered in identifying reflections from layers at shallow depths. The shallowest reflections documented in the literature are from $10 \mathrm{~m}$ (Steeples and Knapp, 1982). The amplitudes of the reflected waves at commonly recorded frequencies, when present, are sinaller than the amplitudes of unwanted waves, particularly ground roll composed of Rayleigh waves and Love waves. Further, the generation and recording of frequencies much above $100 \mathrm{~Hz}$ have not been done routinely on land.

Typical energy sources that have been tried include a sledge haminer (Hunter and others, 1981; Meidav, 1969), weight drop (Doornenbal and Helbig, 1983), and sinall explosive charges (Pakiser and Warrick, 1956). These energy sources normally produce seisinic waves having unfiltered dominant frequencies less than $100 \mathrm{~Hz}$. In order to provide better resolution (both precision and accuracy) of shallow reflective interfaces, high frequencies are needed. Resolution of "thin beds" is theoretically limited to about $1 / 8$ wavelength ( $1 / 4$ wavelength by conventional nethods) of the recorded seisinic energy (Widess, 1973), so improvement in resolution and imaging of shallower reflectors can be obtained directly by increasing the frequency of the energy recorded.

A worthy goal of shallow-reflection surveys is to provide bed resolution in the approximate dimension of 0.5 in. Typical velocities of near-surface soil and (or) alluvial materials range from about 300 to about $1,200 \mathrm{~m} / \mathrm{s}$ for $P$ waves and from 100 to about $300 \mathrm{~m} / \mathrm{s}$ for $\mathrm{S}$ waves. Using classic 1/4-wavelength methods, the desired 0.5 -n resolution cannot be obtained without frequencies greater than $75 \mathrm{~Hz}$ for a P-wave velocity of $300 \mathrm{~m} / \mathrm{s}$ and $25 \mathrm{~Hz}$ for Swave velocity of $100 \mathrm{~m} / \mathrm{s}$. We have been able to routinely produce dominant $\mathrm{P}$-wave frequencies greater than 200 $\mathrm{Hz}$ and S-wave frequencies greater than $75 \mathrm{~Hz}$.
The source for a shallow high-resolution reflection survey must possess a high-frequency signature, and it must be field durable and time efficient enough for costeffective seismic data acquisition. Most of our P-wave reflection research has involved the use of common hunting rifles modified for safe and quiet operation when fired vertically into the ground. Our most productive source has been a steel arrow forced hydraulically into the ground, rotated by hammer impact, and then removed hydraulically. The arrow is equipped with an arm protruding laterally from its base. This arm is impacted by a sledge hammer, causing a rotational motion about the center of the arrow.

High-resolution compressional-wave surveys have generally had the best success when severe low-cut filtering and high-natural-frequency geophones were used (Hunter and others, 1984; Steeples and Knapp, 1982; Miller and Steeples, 1986). As previously inentioned, the higher the dominant frequency of the seismic data, the greater the bed resolution. Our inost cominonly used lowcut filter suppresses energy down $3 \mathrm{~dB} /$ octave at $220 \mathrm{~Hz}$ and down $24 \mathrm{~dB} /$ octave below $220 \mathrm{~Hz}$. We have had success with single $100-\mathrm{Hz}$ geophones spaced as closely as $0.25 \mathrm{~m}$. In certain environments, higher low-cut filters ( 340 or $480 \mathrm{~Hz}$ ) have proven useful in improving near-surface bed resolution (Treadway and others, 1985).

Field parameters for obtaining good shallow shearwave reflections are extremely site dependent. Usually, the low-frequency spectrum of $\mathrm{S}$ waves in comparison with that of $P$ waves from the same site dictates the use of lower natural frequency geophones sensitive to ground motion perpendicular to the direction of wave propagation. Recently, we have had the best results with $30-\mathrm{Hz}$ horizontal geophones. The most frequently used low-cut filter has a $-3-\mathrm{dB}$ point at $110 \mathrm{~Hz}$.

S-wave reflection surveys have an added potential for suppressing undesirable noise. Owing to the nature of $\mathrm{S}$ waves, the polarity of reflections recorded is dependent on the direction of initial particle displacement. Independently recording shots having initial clockwise source rotations and subsequent counterclockwise rotations and then subtracting the recorded signal from the two shots improve the signal-to-noise ratio.

Geophone spacing is dictated by the degree of lateral resolution needed and the desired accuracy of the velocity function. In most instances when the target depth range is from 5 to $50 \mathrm{~m}$, we space single geophones at $1.25-\mathrm{m}$ intervals.

\section{FIELD METHODS}

We use an Input/Output, Inc., DHR-2400 seisinic recording system to amplify, filter, and digitize the data in 
the field and to record the data on digital tape. Our amplifier gains can be adjusted from 42 to $120 \mathrm{~dB}$ for the individual channels, depending upon the distance from the shot point to the geophone. The upper limit of amplifier gains to avoid clipping of the signal is determined by digital work size rather than by the amplifier gains available. Our low-cut filters have a 24-dB/octave rolloff to decrease the amplitude of ground roll. The data sample interval on each channel can vary from 0.25 to $4 \mathrm{~ms}$, the total record length being 1,000 samples per channel. Anti-alias filters are used to attenuate energy at frequencies above the Nyquist frequency (signal down $60 \mathrm{~dB}$ at that frequency).

Relatively severe low-cut filters have the beneficial effect of eliminating substantial amounts of cultural noise. Cultural noise in urban areas is relatively severe at frequencies below $50 \mathrm{~Hz}$, but vehicular traffic and other vibratory sources do not produce much energy above 100 to $150 \mathrm{~Hz}$. The noise that is produced at these high frequencies attenuates rapidly with distance from the source because of the low-pass nature of the Earth's transfer function. Low-cut filtering also allows limited control over the dominant frequency of the recorded energy. Boosting the dominant frequency increases the possible bed resolution and, therefore, the accuracy of the survey. Care must be taken, however, when increasing the lowcut filter. Overly severe filtering of lower frequencies decreases the signal-to-noise ratio and causes a ringiness in the data, the general result being a poorer quality section and a loss of bed resolution.

\section{PROVO AIRPORT}

Compressional-wave data were recorded at the Provo airport in the spring of 1985 . The line for the Pwave data consisted of 65 shot locations occupied by two different sources. The line was set up with a 1.25-m shot interval and single $100-\mathrm{Hz}$ geophones spaced at $1.25-\mathrm{m}$ intervals. A .30-06 hunting rifle with a specially designed airblast containment device was used. Recording was done with $220-\mathrm{Hz}$ low-cut filters, and the dominant frequency of the .30-06 seismic data was about $150 \mathrm{~Hz}$. The second source was a .50-caliber single-shot sport rifle equipped with its own airblast and particle containment apparatus. Recording was done with $110-\mathrm{Hz}$ low-cut filters, and the dominant frequency of the .50-caliber data was about $100 \mathrm{~Hz}$.

The .50-caliber source was fired twice at each source location, the second projectile being fired into the hole made by the first projectile. The repetitious firing of projectiles into the same hole allows the energy from later shots to dissipate more efficiently into more competent material. The two shots were recorded on tape separately and processed through a common depth point (CDP) stack as independent data sets. Then the two stacked sections were cross-correlated and CDP stacked into a single twelve-fold CDP seismic section.

The S-wave survey conducted in the spring of 1985 at the Provo airport was the first real test of the arrow shearwave source in a twelve-fold CDP production mode of operation. The source was a quad-winged arrow pointing vertically downward, each wing being oriented either parallel or perpendicular to the survey line. After insertion into the ground, the arrow was forced (by sledge hammer) to rotate clockwise and then counterclockwise, and each impact was recorded independently. The receivers were single $40-\mathrm{Hz}$ horizontal geophones. The low-cut filter used had a $-3-\mathrm{dB}$ point at $55 \mathrm{~Hz}$. Source and receivers were laid out in a split-spread orientation, the offset from source to closest receiver being $5 \mathrm{~m}$. Owing to the lower bandpass recorded, the dominant frequency of the CDP stacked section was only about $50 \mathrm{~Hz}$. Therefore, resolution was poor, and surface waves overpowered the early portions of the seismograms.

As a result of the inappropriate choice of field recording parameters in the spring, a second shear-wave survey was conducted at the Provo airport during the summer of 1985. After analysis of the spring survey data and slight modifications to the acquisition technique, new field parameters were chosen to improve the previous data quality. The new low-cut filter had a $-3-\mathrm{dB}$ point at $110 \mathrm{~Hz}$. Because the S-wave velocity was slower than expected and the S-wave radiation pattern was complex, the end-on source/receiver chosen had an 11-m source-toclosest-receiver offset.

A new source was designed for the summer trip. Although similar to the previous quad-winged arrow, the new arrow had only two wings separated by $180^{\circ}$ and by $0.25 \mathrm{~m}$ from the base. The new arrow design exploited some basic principles in an attempt to boost the frequency spectrum as well as reduce the generation of Love waves. The surface area of the second arrow head was reduced by about 70 percent by cutting off the base half of the arrow and replacing it with a $0.15-\mathrm{m}$ long shaft $2.5 \mathrm{~cm}$ in diameter. The smaller surface area of the doublewinged arrow decreased the energy source volume and increased the dominant frequency. Also, the addition of the shaft allowed the arrow to penetrate more deeply into the soil layer, the result being a noticeable reduction in recorded Love waves.

It has been well documented that shear waves have a direction-dependent radiation pattern. Onsite studies showed that the radiation pattern of $S$ waves generated by the smaller arrow was strongly dependent on the orientation of the arrow's wings. A lobe maximum traveled in the direction of the line when the arrow's wings were oriented $45^{\circ}$ to the line, so that orientation was used for the summer survey. 


\section{SPRINGVILLE CHERRY ORCHARD}

Compressional-wave data were collected at a cherry orchard in Springville; field parameters were similar to those used at the airport in Provo. On both runs, the receiver (single $100-\mathrm{Hz}$ geophones) and shot spacing was $1 \mathrm{~m}$. The low-cut filter on the .30-06 survey attenuated the signal by $3 \mathrm{~dB}$ at $220 \mathrm{~Hz}$, the result being a dominant frequency on the twelve-fold CDP stack of about $130 \mathrm{~Hz}$. The .30-06 survey required only a single shot per shot point in a split-spread source/receiver array, the source-to-closestreceiver spacing being $1.5 \mathrm{~m}$. The .50 -caliber rifle occupied about the first 50 of the 100 shot locations recorded for the $.30-06$ rifle. The low-cut filter for the .50 -caliber survey attenuated the signal by $3 \mathrm{~dB}$ at $110 \mathrm{~Hz}$. These field and recording parameters resulted in a dominant frequency on the stacked section of about $90 \mathrm{~Hz}$. The .50caliber data set at the cherry orchard had two shots per shot point, the second projectile traveling down the hole made by the first projectile. The data were collected by using a split-spread array and a source-to-closest-receiver spacing of $4.5 \mathrm{~m}$.

The shear-wave survey at the Springville cherry orchard was conducted by using the same field parameters used in the spring S-wave survey at the Provo airport. The cherry orchard survey included the use of single 30$\mathrm{Hz}$ horizontal geophones, $55-\mathrm{Hz}$ low-cut filters, and the quad-winged arrow.

\section{DATA PROCESSING}

The processing flow of the data was similar to ordinary oil company routines. The seismic computer software that was used limits flexibility in engineering applications because it was originally intended for largescale petroleum exploration surveys. However, techniques normally used to reduce $10 \mathrm{~s}$ of data can be scaled down to work on $0.1 \mathrm{~s}$ of data by processing in units of Poisson's and tenths of seconds instead of meters and seconds.

The 24-channel compressional-wave field data were reduced to twelve-fold stacked CDP sections. If more than a single shot was fired at a location, a time shift was generally necessary to align the same CDP's from different shots. This time mismatch was the result of sourcesensor irregularities and delays in the energy transfer of a second projectile fired into the hole made by a previous projectile. Determining the value of this time shift was accomplished by cross-correlating traces from the same CDP and shot location for successive projectiles.

Shear-wave data were processed quite similarly to the compressional-wave data up to the point where the same CDP's from two different shots at the same source location were mixed to form a single CDP trace. To com- pensate for possible time inconsistencies between shot 1 (straight polarity) and shot 2 (reverse polarity), the same cross-correlation performed on compressional-wave data was used (after the signal from shot 2 was reversed in polarity). The resulting calculated time shift necessary to align reflecting events was then applied to the individual trace in the same fashion as with the two-shot compressional-wave process. When the data were time shifted, polarity matched, and stacked, a pseudo twenty-four-fold S-wave reflection section resulted.

\section{DISCUSSION}

\section{PROVO AIRPORT}

The seismic line at the Provo airport was occupied during two separate visits in 1985 . The line was located in the flat, grassy runway median, where an apparently uniform soil layer was underlain by lacustrine sediments. Geophone and source coupling with the ground on both the spring and summer trips were excellent and yielded high-quality seismic data.

The P-wave seismic section from the Provo airport, using the .50 -caliber rifle, is shown in figure 1 . Excellent reflections were detected to $450 \mathrm{~ms}$, a depth of roughly $300 \mathrm{~m}$. Depth estimates are difficult to make for these data because the maximum source-to-receiver offset was only $20 \mathrm{~m}$. The short sampling of the normal-moveout curve restricted the capability to do velocity analysis. The data seemed to process equally well at velocities as low as $450 \mathrm{~m} / \mathrm{s}$ and as high as $2,000 \mathrm{~m} / \mathrm{s}$. This example illustrates the shallow reflection seismologist's dilemma: close source-to-receiver offsets are necessary to detect shallow-reflections, but, if deep reflections are present as a bonus on the data, their depth cannot be accurately calculated because of velocity uncertainties.

Two other facets of this $\mathrm{P}$-wave section should be pointed out. First, there is a lack of reflections between 150 and $250 \mathrm{~ms}$. The choice of offsets was such that this time window was nearly saturated with surface waves, obliterating any reflections that might have been present. During the CDP stacking process, the surface waves were attenuated but not to the extent of showing any reflections. In this case, absence of evidence is not necessarily evidence of absence of reflections. Second, the top two coherent wavelets on the section above $50 \mathrm{~ms}$ may be refractions that stacked in during processing. Overall, however, the P-wave data are excellent at this locality.

The S-wave seismic section from the second survey at Provo airport is shown in figure 2. There are reasonably good reflections in the time window between 250 and 500 ms. The stacking velocity used was $170 \mathrm{~m} / \mathrm{s}$ for the S-wave data as compared with $550 \mathrm{~m} / \mathrm{s}$ for $\mathrm{P}$-wave data. This comparison suggests possible correlation of the S-wave reflec- 


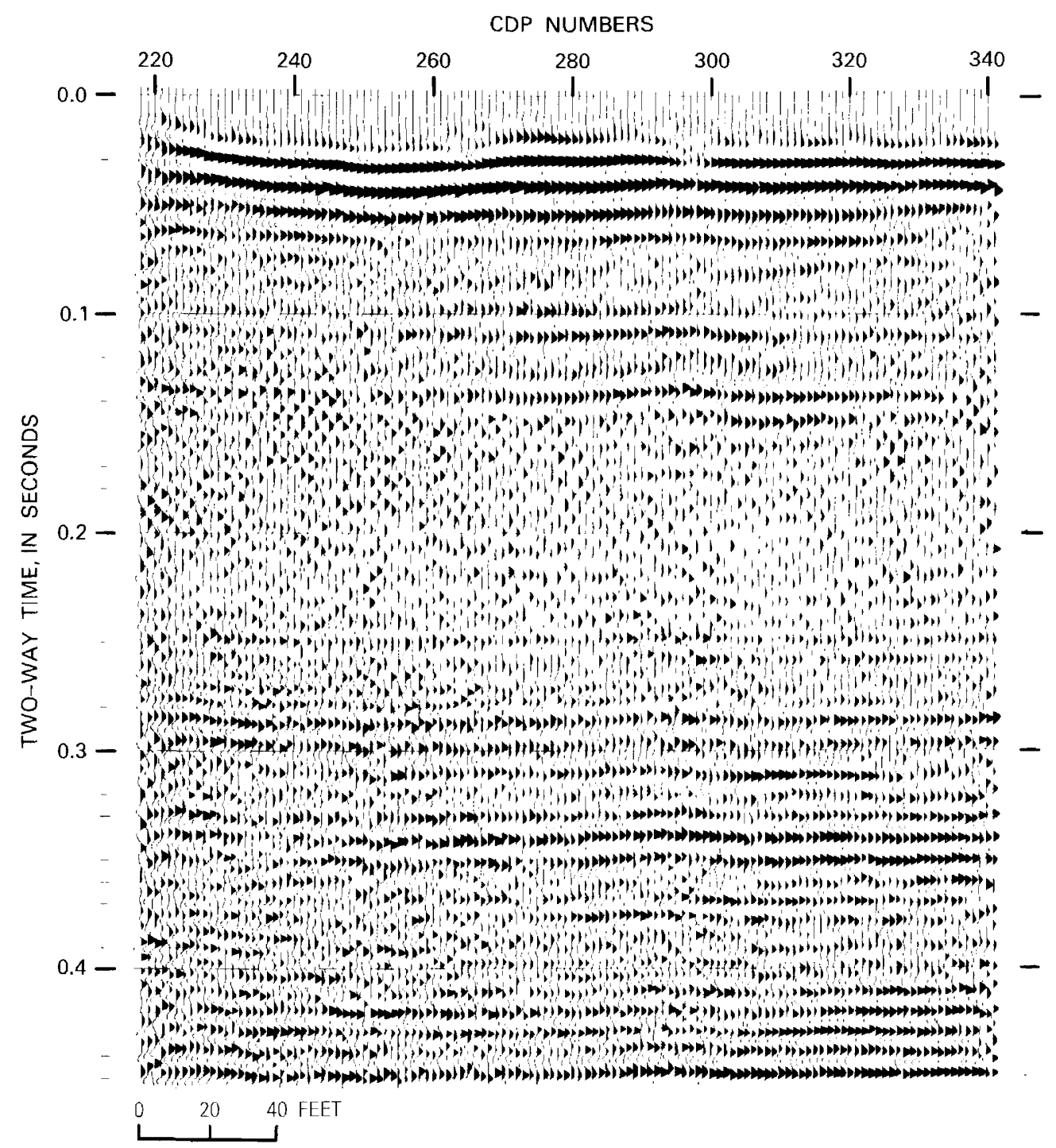

FIGURE 1.-A twelve-fold P-wave CDP stack from the Provo airport that was acquired with the 50-caliber rifle and possesses several reflection events of excellent quality.

tion at 400 to $450 \mathrm{~ms}$ with the $\mathrm{P}$-wave reflection at $140 \mathrm{~ms}$. The S-wave reflection at 340 to $350 \mathrm{~ms}$ could correlate with the P-wave reflection at $110 \mathrm{~ms}$. The S-wave reflection at 270 to $280 \mathrm{~ms}$ could correlate with the P-wave reflection at 90 to $100 \mathrm{~ms}$.

Although the above-mentioned time correlations are reasonable with a compressional-wave velocity $\left(V_{p}\right)$ to the shear-wave velocity $\left(V_{s}\right)$ ratio of 3.1 which, using equation 1, yields a Poisson's ratio of 0.44 within the upper $50 \mathrm{~m}$ of sediment, the character of the reflections is different between the $\mathrm{P}$-wave section and the S-wave section. This difference can be explained in part by noting that the frequency is almost identical between the two sections. Because the frequency is the saine and the velocity differs by a factor of 3 , the resolution is better by a factor of 3 on the S-wave sections. In other words, what one sees on the seismic sections is resolution dependent to some degree. In any event, the combined data sets from the Provo airport represent our first successful effort to record shallow (less than $50 \mathrm{~m}$ ) P- and S-wave reflections along the saine line.

\section{SPRINGVILIE CHERRY ORCHARD}

During the spring 1985 trip to Provo, high-resolution $\mathrm{P}$ - and S-wave reflection surveys were conducted at a cherry orchard in Springville, Utah. Compressional-wave surveys were done with both a .30-06 rifle and a .50caliber rifle. The shear-wave survey used as its source the quad-winged arrow discussed in the previous section. All 


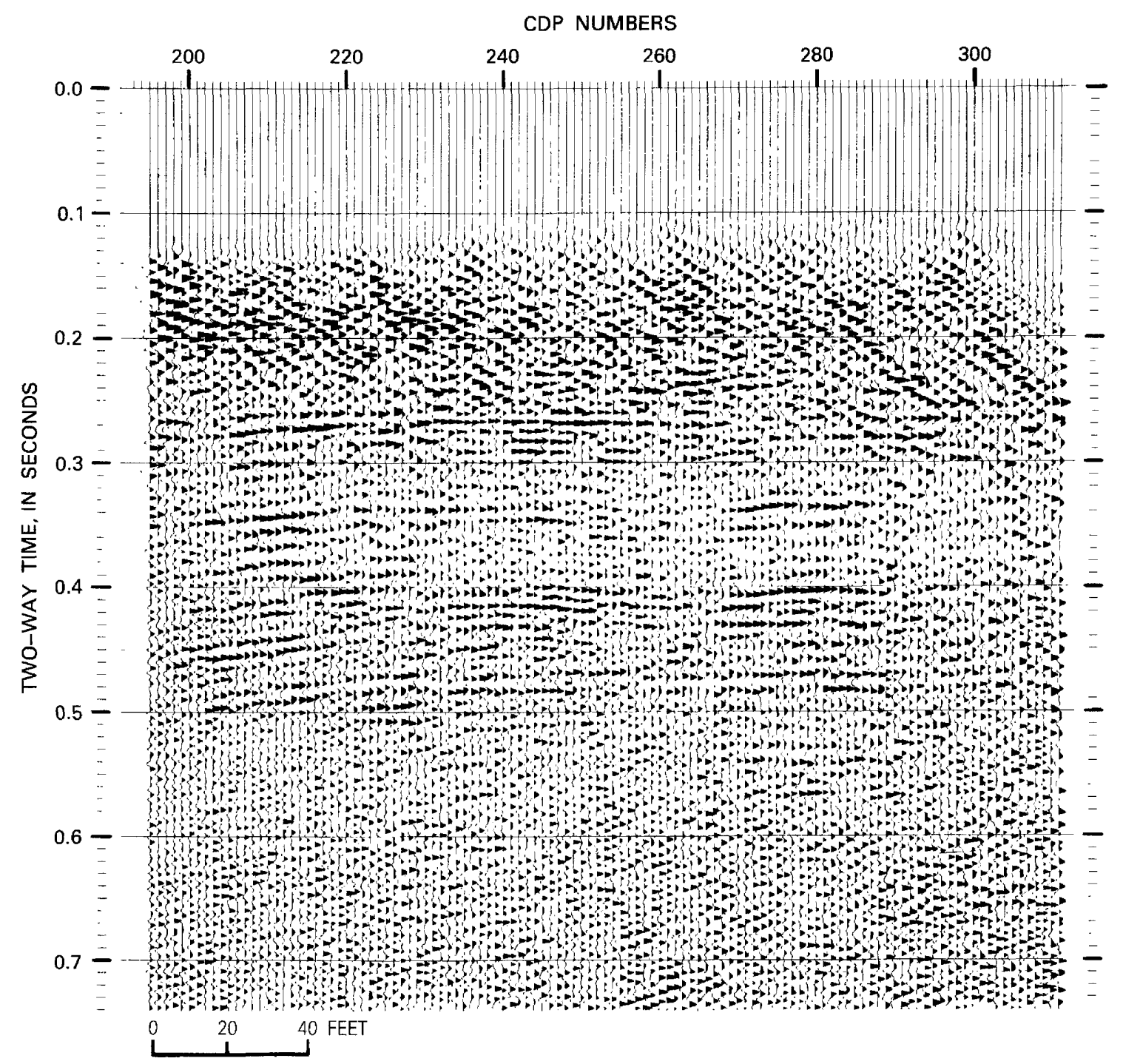

FIGURE 2.-A twelve-fold S-wave CDP stack from the Provo airport that was acquired with the rotational arrow and possesses several good-quality reflection events.

three surveys occupied the same source and receiver locations, the equipment being unique to each particular technique.

Soil conditions hampered penetration of both source and receivers. Poor coupling to the ground from these soil conditions, in part, is responsible for these data being of lower quality than the data from the Provo airport. The soil layer consisted of very poorly sorted, unconsolidated sediments having grain sizes ranging from silts to cobbles and scattered boulders.

Although the data from the cherry orchard generally are not as good as those from the Provo airport, there are several notable features. Figures 3 and 4 represent the Pwave sections from the .30-06 rifle and the .50-caliber rifle, respectively, and figure 5 is a shear-wave section.
The .50-caliber rifle shell ejector broke during fieldwork on this line, so the line in figure 3 is shorter than originally planned. The .30-06 data shown in figure 4 are of low quality because of the poor near-surface seismic recording conditions discussed earlier.

The important point about this line is the anticlinal nature of the most prominent reflector in figures 3 through 5, between CDP 210 and CDP 290. The fact that all three seismic sections show this feature suggests that it is geologically prominent in the subsurface. It is not known what causes this reflection, but it is apparently in the depth range between 35 and $60 \mathrm{~m}$. The U.S. Geological Survey (USGS) also ran an independent P-wave survey along this line, using similar recording equipment and field parameters but different personnel and seismic pro- 


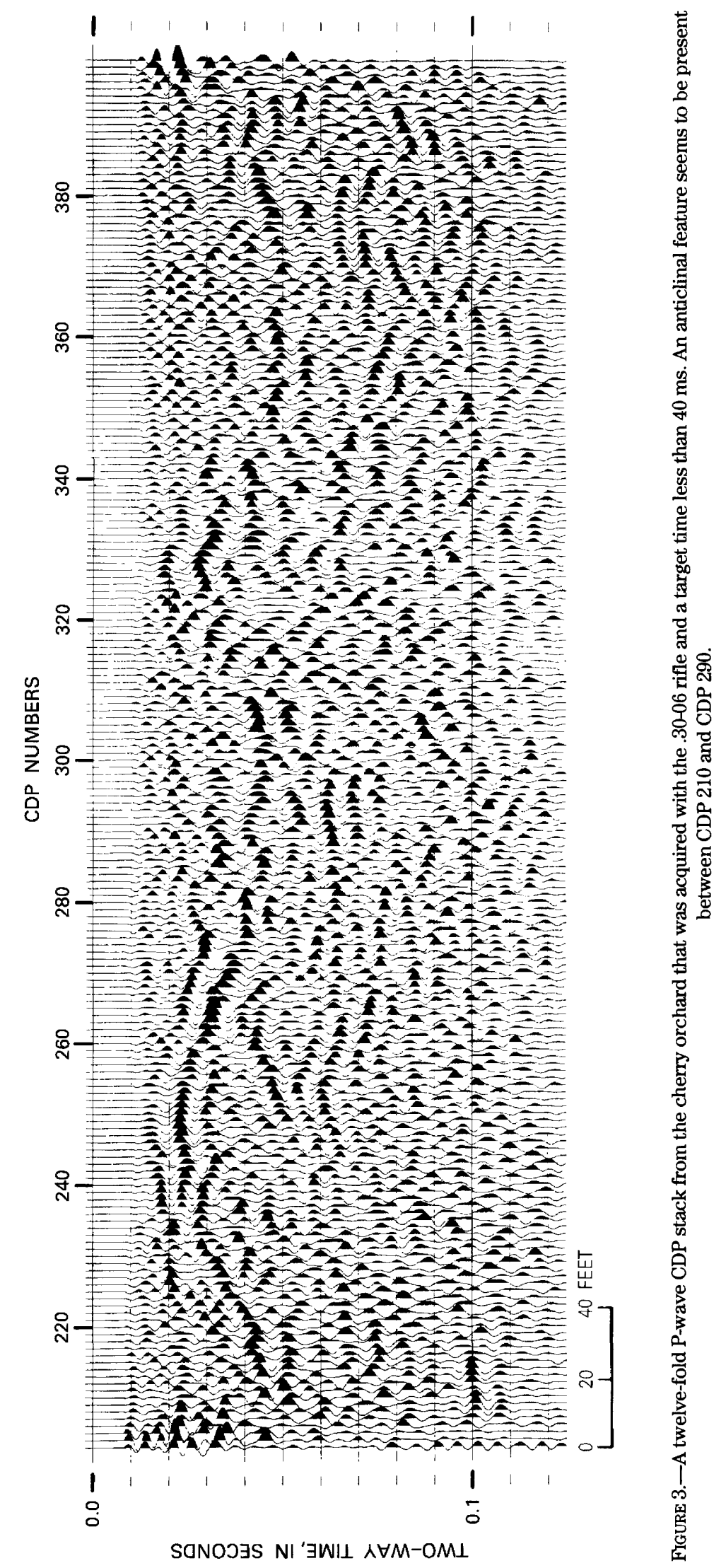




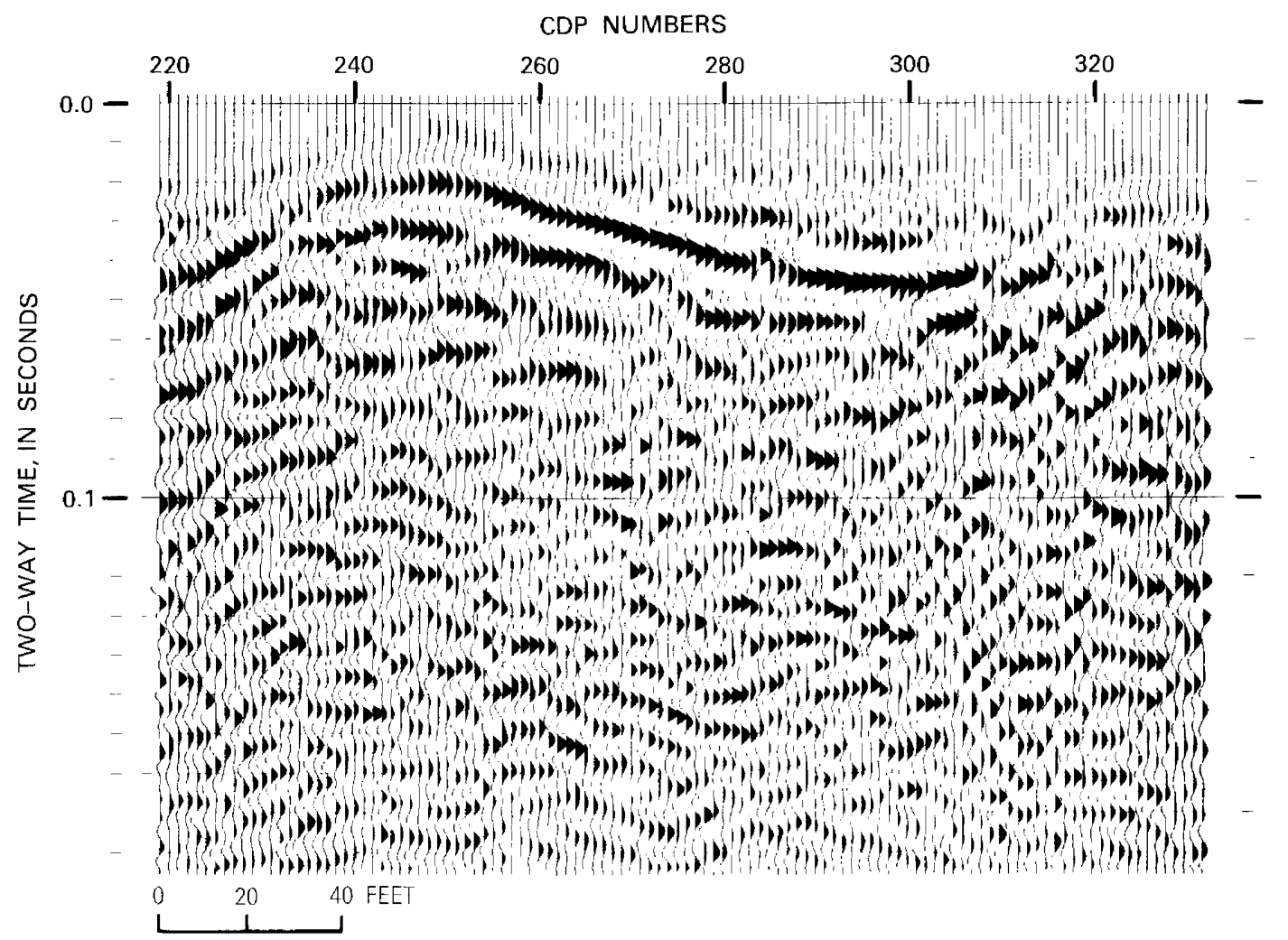

FIGURE 4.-A twelve-fold P-wave CDP stack from the cherry orchard that was acquired with the .50-caliber rifle and possesses coherent reflection to times in excess of $140 \mathrm{~ms}$. The same anticlinal feature present on figure 3 can be interpreted on the deeper reflection on this line.

cessing software. The anticlinal nature of the profile is similar in both studies.

The processing of the data from the shear-wave survey was very similar to that of the Provo airport S-wave data. Two shots of opposite polarity were recorded separately at each shot location. The individual shots were time shifted, the second shot being reversed, and then they were stacked together. The resulting section possesses dominant frequency around $40 \mathrm{~Hz}$. The processed section lacked the good-quality, continuous reflecting events observed on the summer S-wave survey at the Provo airport.

The $V_{p} / V_{s}$ ratio at this section is lower than that at the Provo airport, the ratio being about 1.8 in the near-surface sediments at the cherry orchard. Using this value in equation 1 yields a Poisson's ratio of 0.27 .

Although we do not have .50-caliber data beyond the middle of figures 4 and 5 owing to equipment malfunction, the data quality from CDP 290 to CDP 340 is poor on the S-wave section and even worse on the $30-06 \mathrm{P}$-wave section. Beyond CDP 340 , the data quality improves somewhat on both sections.
In brief, the cherry orchard data provide another example of using P- and S-wave reflection data to determine the dynamic properties of the near-surface materials to a depth of about $50 \mathrm{~m}$. The S-wave reflection technique has been improved since these data were shot, and the .50-caliber rifle would most certamly give better seismic sections for $\mathrm{P}$ waves than did the $.30-06$. These two factors lead us to conclude that, although the data from the cherry orchard discussed here are useful, considerable improvement can be expected in the future.

\section{CONCLUSIONS}

The shallow-seismic P-wave reflection method is now a well-developed technique. The seismic P-wave sections shown in this chapter are typical of the resolution that can be obtained by proper selection of recording parameters. The seismic sections at the cherry orchard demonstrate the repeatability of the technique. The results obtamed with the $.30-06$ source and the .50-caliber source were essentially the same in the upper $60 \mathrm{~ms}$. Fur- 


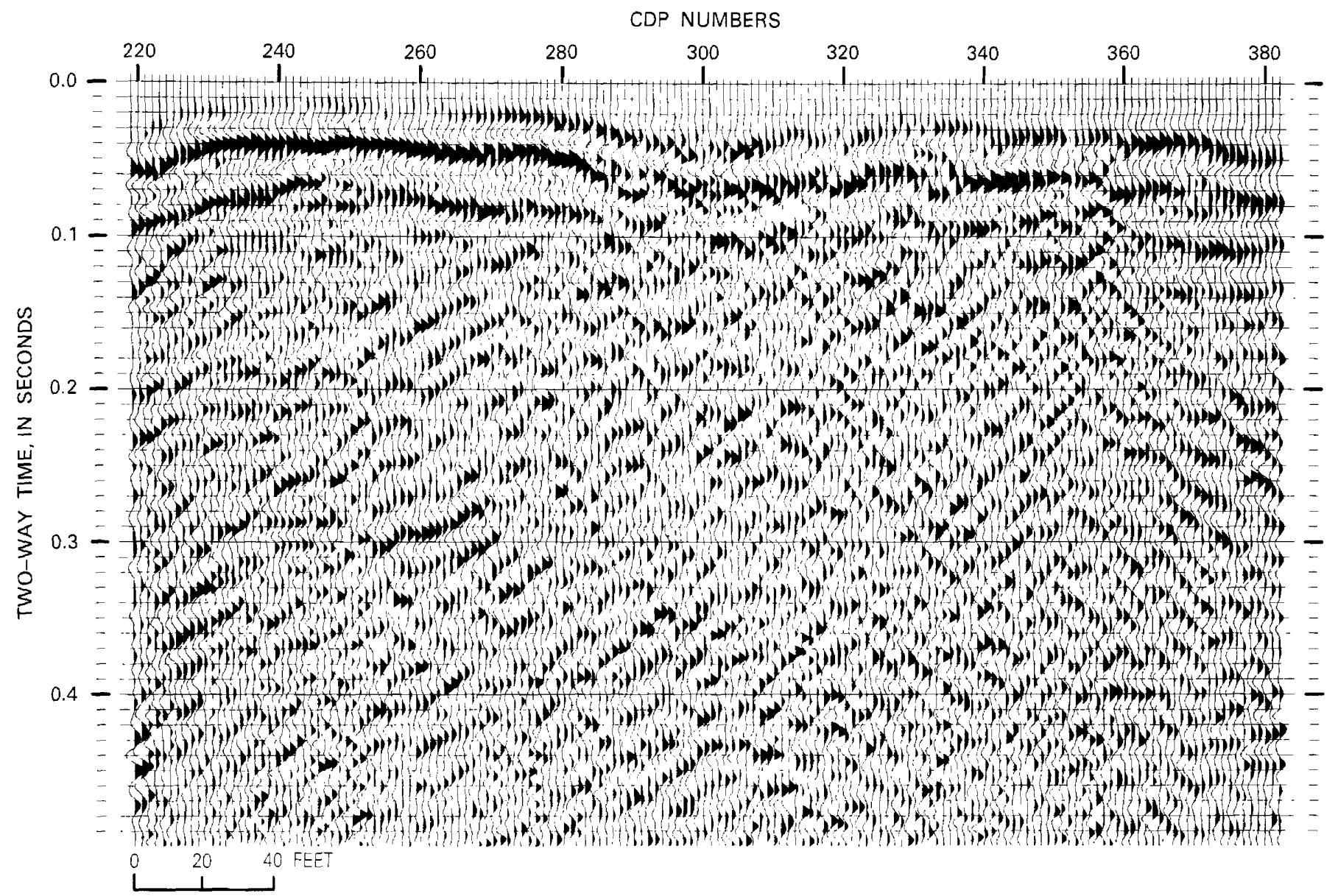

FIGURE 5.-A twelve-fold S-wave CDP stack from the cherry orchard that was acquired with the rotational arrow. An anticlinal feature is interpreted that is consistent with the $\mathrm{P}$-wave data from this site.

thermore, the USGS used its own crew and equipment to shoot the same line for comparison purposes. The prominent features of the two lines are identical, even though the data were processed by different people using different software. In particular, the anticlinal feature between CDP 210 and CDP 290 is obvious on all three Pwave sections as well as on the S-wave section.

The shallow S-wave reflection technique has room for improvement. At the Provo airport, the second survey provided excellent reflection data. The dominant frequency of the S-waves using the arrow source appears to be somewhere between $60 \mathrm{~Hz}$ and $100 \mathrm{~Hz}-\mathrm{a}$ bit higher than expected. We have not yet been able to record Swave reflections shallower in time than $100 \mathrm{~ms}$. The problem involves getting rid of substantial amounts of Lovewave energy. Because Love waves are essentially multiply reflected $S$ waves trapped in near-surface layers, they exhibit many of the same characteristics as the desired S- wave reflections. We have made progress toward solving that problem by moving the S-wave source below the surface and by increasing its frequency.

The actual calculation of Poisson's ratio is simple arithmetic once the $\mathrm{P}$ - and S-wave velocities are known. For example, at the Provo airport, P-wave velocity (determined from the normal-moveout equation) is approximately $550 \mathrm{~m} / \mathrm{s}$, and S-wave velocity approximately $170 \mathrm{~m} /$ $\mathrm{s}$ within the upper $100 \mathrm{~m}$ of lake sediments, for an average Poisson's ratio of 0.44 . At the cherry orchard, P-wave velocity is approximately $355 \mathrm{~m} / \mathrm{s}$, and S-wave velocity approximately $200 \mathrm{~m} / \mathrm{s}$ in the upper $30 \mathrm{~m}$, for an average Poisson's ratio in the upper $100 \mathrm{~m}$ of 0.27 . We are not able to correlate individual reflections between the P- and Swave seismic sections well enough to allow direct calculation of Poisson's ratio, depth interval by depth interval. Part of this difficulty stems from the fact that the resolution of the S-wave reflections was greater than that of the 
P-wave reflections at the Provo airport by a factor of 3 and greater than that at the cherry orchard by a factor of 2 .

Finally, the ultimate goal of this project is to relate the engineering properties of near-surface materials to amplification of ground shaking at specific sites.

\section{REFERENCES CITED}

Borcherdt, R.D., Joyner, W.B., Warrick, R.E., and Givvs, J.F., 1975, Response of local geologic units to ground shaking, in Borcherdt, R.D., ed., Studies for seismic zonation of the San Francisco Bay region: U.S. Geological Survey Professional Paper 941-A, p. A52-A68.

Doornenbal, J.C., and Helbig, K., 1983, High-resolution reflection seismics on a tidal flat in the Dutch Delta-Acquisition, processing, and interpretation: First Break, May, p. 9-20.

Hunter, J.A., Burns, R.A., and Good, R.L., 1981, Optimum field techniques for bedrock mapping with the multichannel engineering seismograph [abs.]: Geophysics, v. 46, p. 451.

Hunter, J.A., Pullan, S.E., Burns, R.A., Gagne, R.M., and Good, R.L., 1984, Shallow seismic reflection mapping of the overburden-bedrock interface with the engineering seismograph: Some simple techniques: Geophysics, v. 49, p. 13811385.
Lawson, A.C., 1908, The California earthquake of April 18, 1906: Report of the State Earthquake Investigation Commission, v. I: Washington, D.C., Carnegie Institute of Washington, $451 \mathrm{p}$.

Medvedev, S.V., 1965, Engineering seismology: Springfield, Va, National Technical Information Service, Report TT6550011,260 p.

Meidav, T., 1969, Hammer reflection seismics in engineering geophysics: Geophysics, v. 34, p. 383-395.

Miller, R.D., and Steeples, D.W., 1986, Shallow structure from a seismic reflection profile across the Borah Peak, Idaho, fault scarp: Geophysical Research Letters, v. 13, p. 953-956.

Pakiser, L., and Warrick, R., 1956, A preliminary evaluation of the shallow reflection seismograph: Geophysics, v. 21, p. 388-405.

Steeples, D.W., and Knapp, R.W., 1982, Reflections from 25 feet or less, [exp. abs.]: Society of Exploration Geophysicists program, p. 469-471.

Treadway, J.A., Steeples, D.W., and Miller, R.D., 1985, Seismic reflections within the upper 100 feet near Borah Peak, Idaho, earthquake scarp, in Technical Program, Abstracts, and Biographies [exp. abs.]: Society of Exploration Geophysicists annual meeting, 55th, Washington, D. C., p. 161163.

Widess, M. B., 1973, How thin is a thin bed?: Geophysics, v. 38, p. 1176. 


\section{Earthquake Losses in Central Utah}

By S.T ALGERMISSEN and E.P. ARNOLD, U.S. Geological Survey, K.V. STEINBRUGGE, Consulting Structural Engineer, El Carrito, Calif., and MARGARET G. HOPPER and P.S. POWERS, U.S. Geological Survey

ASSESSMNT OF REGIONAL EARTHQUAKE HAZARDS AND RISK ALONG THE WASATCH FRONT, UTAH

U.S. GEOLOGICAL SURVEY PROFESSIONAL PAPER 1500-P 
11-13. Summaries of estimated losses in the four-county area from a strong $\left(M_{s}=6.5\right)$ earthquake on the Wasatch fault:

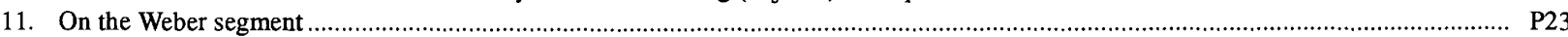

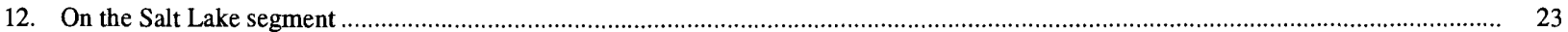

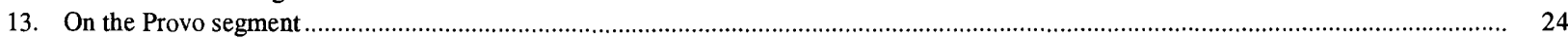

14-16. Summaries of estimated losses in the four- county area from a moderate $\left(M_{L}=5.5\right)$ earthquake on the Wasatch fault:

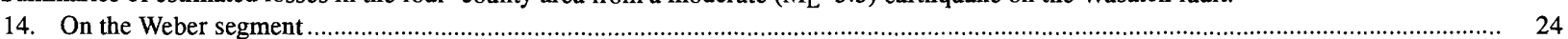

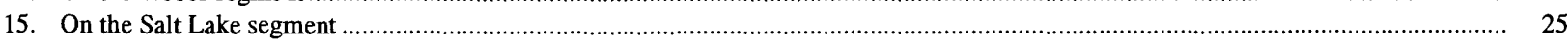

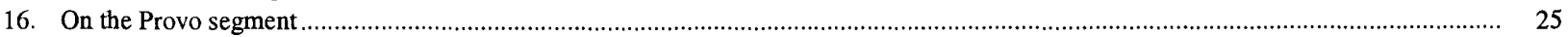

17-19. Summaries of estimated losses in Salt Lake City from a major $\left(\mathrm{M}_{\mathrm{s}}=7.5\right)$ earthquake on the Wasatch fault:

17. On the Salt Lake segment

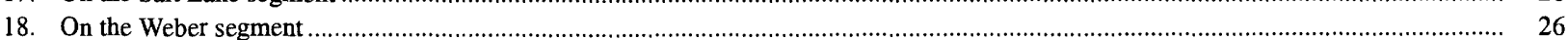

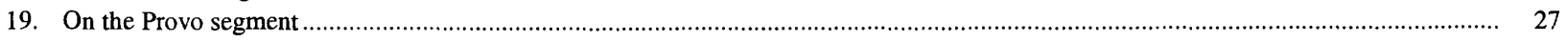

20. Summary of expected maximum losses in the four-county area over a 50-year period with a 10-percent chance of exceedance

21-23. Variations of losses with intensity on the Salt Lake segment of the Wasatch fault zone for:

21. A major $\left(M_{s}=7.5\right)$ earthquake

22. A strong $\left(\mathrm{M}_{\mathrm{S}}=6.5\right)$ earthquake ...

23. A moderate $\left(M_{L}=5.5\right)$ earthquake 


\title{
ASSESSMENT OF REGIONAL EARTHQUAKE HAZARDS AND RISK \\ ALONG THE WASATCH FRONT, UTAH
}

\section{EARTHQUAKE LOSSES IN CENTRAL UTAH}

\author{
By S.T. Algermissen, E.P. Arnold, K.V. Steinbrugge, Margaret G. Hopper, and P.S. Powers
}

\begin{abstract}
Estimates of earthquake losses in central Utah have been made for a series of simulated earthquakes modeled as both deterministic (scenario) and probabilistic events. Losses from scenario earthquakes of $\mathbf{M}_{s}=7.5$ and 6.5 and $\mathrm{M}_{L}=5.5$ on the Provo, Salt Lake, and Weber segments of the Wasatch fault were considered, as was an $M_{s}=7.5$ earthquake on a hypothetical fault about $30 \mathrm{~km}$ west of Salt Lake City. Expected maximum losses in the Salt Lake City urban corridor in 50 years with a 10percent chance of exceedance were also calculated. Inventory of building stock was obtained for all classes of construction. Expected losses range from $\$ 830$ million for a $M_{L}=5.5$ shock on the Provo segment to $\$ 5.5$ million for a $M_{s}=7.5$ quake on the Salt Lake segment. The sensitivity of these loss estimates to changes in intensity, vulnerability relationships, and surficial materials is discussed.
\end{abstract}

\section{INTRODUCTION}

Only limited attention has been given in the technical literature to the potential for earthquake losses in central Utah. The most important previous study was done by Rogers and others (1976), who dealt primarily with the severity of damage to facilities that would be critical in the aftermath of an earthquake, such as hospitals and related medical services, dams, State buildings, transportation, public utilities, food supplies, and debris removal. Casualties were also estimated. No estimates of monetary loss were given. In their study, the effects of $\mathrm{M}_{s}=7.5$ earthquakes located both on the Wasatch fault and approximately $10 \mathrm{~km}$ west of the fault in the vicinity of Salt Lake City, Ogden, and Provo were simulated.

Algermissen and Steinbrugge (1984) provided estimates of monetary losses for Salt Lake City for two probabilistic ground-motion models and one deterministic scenario-type $\left(\mathrm{M}_{s}=7.5\right)$ earthquake located on the Wasatch fault in Salt Lake City. Site response, based on the work of Hays and others (1978), was included in the deterministic models.
Improvements in our understanding of the seismotectonics of the Wasatch fault, recent studies of site response, and an improved and expanded inventory of buildings in Utah, Salt Lake, Weber, and Davis Counties (Steinbrugge, 1986) provided incentive for undertaking the present work.

\section{ACKNOWLEDGMENTS}

The authors wish to acknowledge the help of Richard M. Lockwood of the Salt Lake Board of Realtors, Linda Pollock of the Ogden Board of Realtors, and Neil Olson of the Salt Lake City Planning Commission.

\section{PURPOSE AND SCOPE OF THIS STUDY}

The purpose of this study is to estimate primary monetary losses associated with an ensemble of earthquakes to a range of buildings in Utah, Salt Lake, Davis, and Weber Counties (fig. 1). These four counties contain 77 percent of the population of Utah and over 90 percent of the buildings exceeding $\$ 1.0$ million in original cost. The five classes of buildings (referred to as classes I-V) considered in the study are described in table 1 . These classes encompass the majority of buildings in the fourcounty area, with the exception of schools, government buildings, and heavy industrial complexes. Estimated earthquake losses to the water-supply system and to certain selected types of structures are contained in other papers in this volume.

Both deterministic (scenario) and probabilistic loss studies were undertaken. Losses were estimated for scenario earthquakes on the Provo, Salt Lake City (or Salt Lake), and Weber segments of the Wasatch fault. Earthquakes of magnitude $\left(\mathrm{M}_{s}\right) 7.5,6.5$, and $\left(\mathrm{M}_{L}\right) 5.5$ were simulated on each fault segment. Additionally, an earthquake 

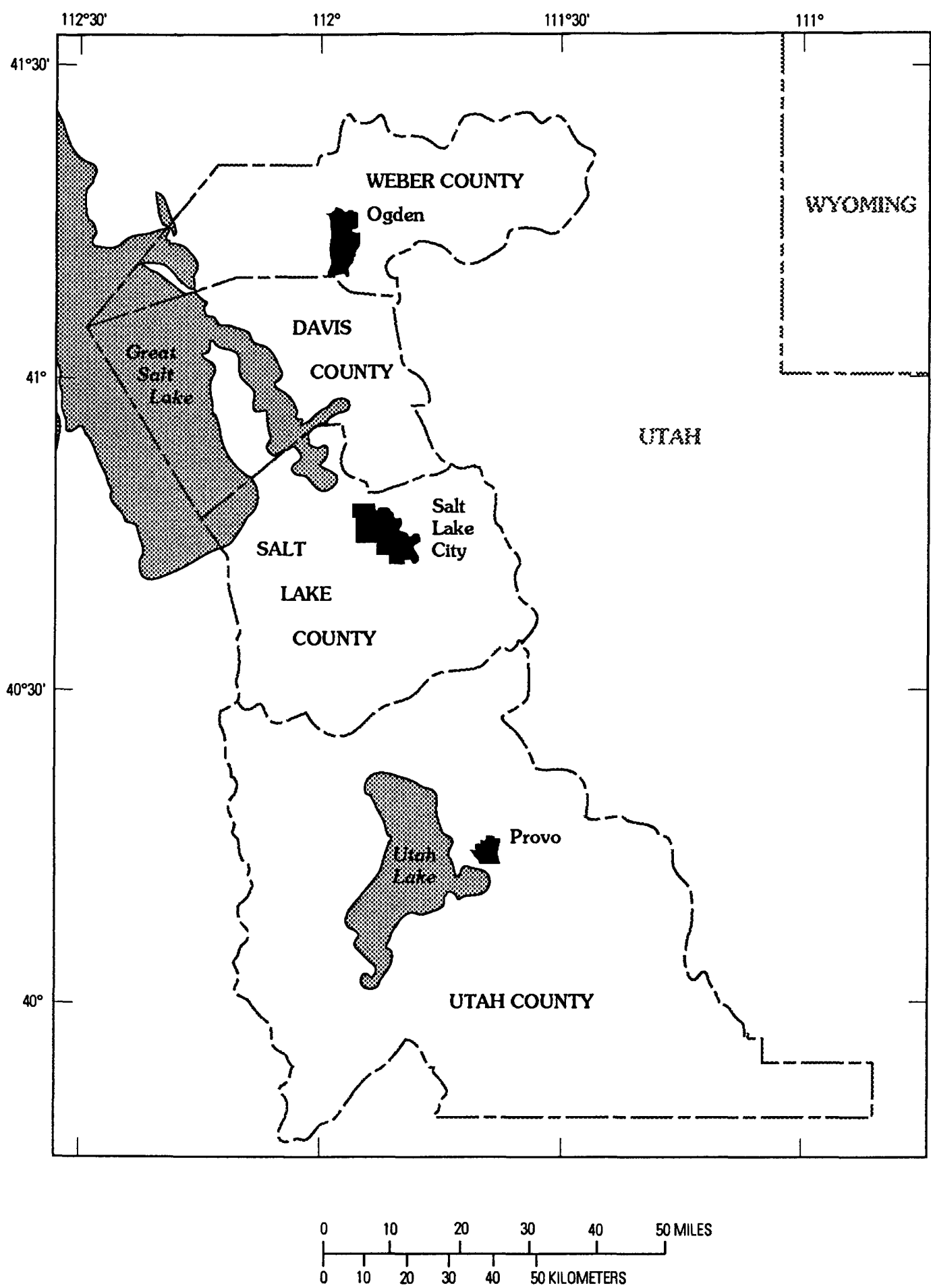

FIGURE 1.-Location of the four-county area. 
TABLE 1.-Building classifications used in this study

Class I-Wood frame

\section{Class I-A}

1. Wood-frame and frame stucco dwellings regardless of area and height.

2. Wood-frame and frame stucco buildings, other than dwellings, that do not exceed three stories in height and do not exceed $3,000 \mathrm{ft}^{2}$ in ground-floor area.

3. Wood-frame and frame stucco habitational structures that do not exceed three stories in height regardless of area.

Class I-B

Wood-frame and frame stucco buildings not qualifying under class I-A

\section{Class II-All-metal buildings}

Class II-A

One-story all-metal buildings that have a floor area not exceeding $20,000 \mathrm{ft}^{2}$

Class II-B

All-metal buildings not qualifying under class II-A

Class III-Steel-frame buildings

\section{Class III-A}

Buildings having a complete steel frame that carries all loads. Floors and roofs shall be of poured-in-place reinforced concrete or of concrete fill on metal decking welded to the steel frame (open-web steel joists excluded). Exterior walls shall be of poured-in-place reinforced concrete or of reinforced unit masonry placed within the frame. Buildings shall have at leastwidth-to-height-above-ground (or above any setback) ratio not exceeding 1:4. Not qualifying are buildings having column-free areas greater than 2,500 $\mathrm{ft}^{2}$ (such as auditoriums, theaters, public halls, and so on).

\section{Class III-B}

Buildings having a complete steel frame that carries all loads. Floors and roofs shall be of poured-in-place reinforced concrete or metal or any combination thereof, except that roofs on buildings over three stories may be of any material. Exterior and interior walls may be of nonload-carrying material.

Class III-C

Buildings having some of the favorable characteristics of class III-A but otherwise falling into class III-B.

Class III-D

Buildings having a complete steel frame, floors and roofs of any material, and walls of any nonload-bearing material.

Class IV-Reinforced concrete, combined reinforced concrete, and structural steel frame ${ }^{1}$

\section{Class IV-A}

Buildings having a structural system as defined by footnote 1 and poured-in-place reinforced concrete exterior walls or reinforced unit masonry exterior walls placed within the frame. Buildings shall have a least-width-to-height-above ground (or above any setback) ratio not exceeding 1:3. Not qualifying are buildings having column-free areas greater than $2,500 \mathrm{ft}^{2}$ (such as auditoriums, theaters, public halls, and so on).

\section{Class IV-B}

Buildings having a structural system as defined by footnote 1 and exterior and interior nonbearing walls of any material.

\section{Class V-Mixed construction}

\section{Class V-A}

1. Dwellings, not over two stories in height, constructed of poured-in-place reinforced concrete and having roofs and second floors of wood frame.

2. Dwellings, not over two stories in height, constructed of adequately reinforced brick or hollow concrete-block masonry and roofs and floors of wood.

Class V-B

One-story buildings having superior earthquake-damage-control features including exterior walls of (1) poured-in-place reinforced concrete and (or) (2) precast reinforced concrete and (or) (3) reinforced hollow concrete-block masonry. Roofs and supported floors shall be of wood or metal diaphragm assemblies. Interior bearing walls shall be of wood frame or any one of a combination of the aforementioned wall materials.

Class V-C

One-story buildings having construction materials listed for class $\mathrm{V}-\mathrm{B}$ but having ordinary earthquake-damage-control features, Class V-D

1. Buildings having reinforced concrete load-beating walls and floors and roofs of wood and not qualifying for class IV-E.

2. Buildings of any height having class $\mathrm{V}-\mathrm{B}$ materials of construction, including wall reinforcement; also included are buildings having roofs and supported floors of reinforced concrete (precast or otherwise) not qualifying for class IV.

Class V-E

Buildings having unreinforced solid-unit masonry of unreinforced brick, unreinforced concrete brick, unreinforced stone, or unreinforced concrete, where the loads are carried in whole or in part by the walls and partitions. Interior partitions may be wood frame or any of the aforementioned materials. Roofs and floors may be of any material. Not qualifying are buildings having nonreinforced load-carrying walls of hollow tile or other hollow-unit masonry, adobe, or cavity-wall construction.

Class V-F

1. Buildings having load-carrying walls of hollow tile or other hollow-unit masonry construction, adobe, or cavity-wall construction.

2. Any building not covered by any other class.

$$
\begin{aligned}
& \text { Classes VI-A, B, C, D, and E-Earthquake-resistive } \\
& \text { construction }
\end{aligned}
$$

Any building or structure having any combination of materials and earthquake-damage-control features equivalent to those found in class I through $\mathrm{V}$ buildings. Alternatively, a qualifying building or structure may be classed as any class from I through V (instead of VI-A, B, C, D, or E) if the construction resembles that described for one of these classes and if the qualifying building or structure has an equivalent damageability.

\footnotetext{
${ }^{1}$ Class IV-A, B, and C buildings shall have all vertical loads carried by a structural system consisting of one of or a combination of the following: (1) poured-inplace reinforced concrete frame, (2) poured-in-place reinforced-concrete bearing walls, (3) partial structural steel frame and 1 or 2 . Floors and roofs all be of pouredin-place reinforced concrete, except that materials other than reinforced concrete may be used for the roofs on buildings over three stories.
} 


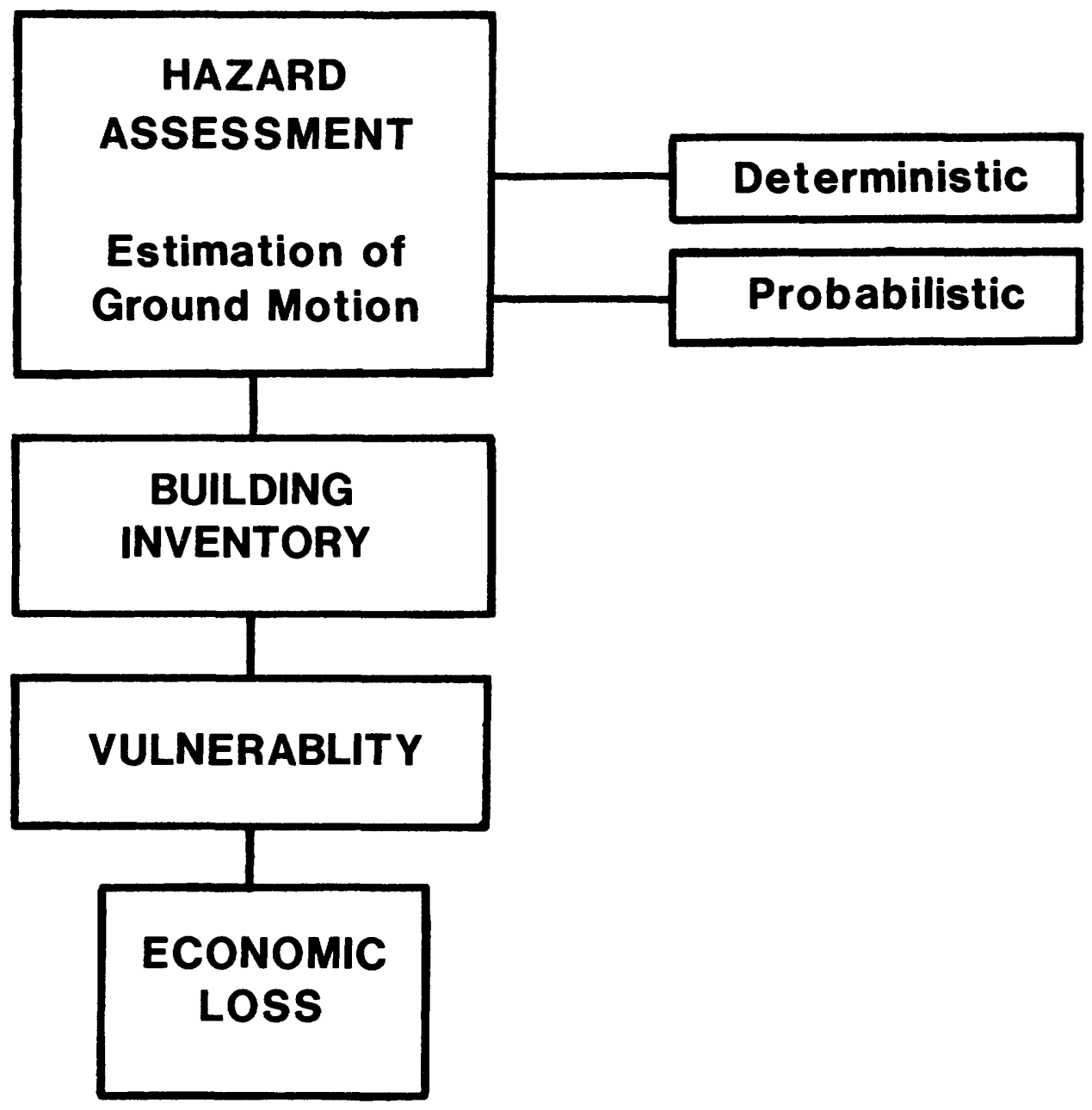

FIGURE 2.-Risk-assessment procedure and its parameters.

of magnitude $\mathrm{M}_{s}=7.5$ was simulated on a hypothetical fault on the western side of the Oquirrh Mountains, approximately $30 \mathrm{~km}$ west of Salt Lake City. The expected maximum losses in 50 years with a 10-percent chance of exceedance were also calculated by using a slightly modified version of the probabilistic model described by Algermissen and others (1982).

\section{ASSESSMENT OF LOSSES}

\section{INTRODUCTION}

A general flow diagram for earthquake ground-shaking loss (risk) studies is shown in figure 2. The following sections describe each parameter in the loss-estimation procedure shown in figure 2 (hazard assessment, building inventory, and vulnerability) as it applies to this study.

\section{GROUND-SHAKING HAZARD ASSESSMENT}

Both deterministic and probabilistic ground-motion hazard models were developed for estimating earthquake losses. Deterministic (scenario) ground-shaking models were developed for hypothesized earthquakes of magnitude $\left(\mathrm{M}_{s}\right) 7.5,6.5$, and $\left(\mathrm{M}_{L}\right) 5.5$ located on the Provo, Salt Lake, and Weber segments of the Wasatch fault (Machette and others, 1992) and a $\mathrm{M}_{s}=7.5$ shock wave west of Salt Lake City. All of the earthquakes were assumed to have surface ruptures, which begin at the center of each fault segment and rupture bilaterally over a distance log $L=1.915+0.389 \mathrm{M}$ (Mark, 1977), where $L$ is the fault rupture length (in meters) and $M$ is taken to be $M_{L}$ for magnitudes of less than 6.5 and $\mathrm{M}_{s}$ for magnitudes of 6.5 and larger. The earthquakes are not allowed to rupture out of the fault segment in which they occur. Because some of 
TABLE 2.-Scenario earthquake parameters

$\left[-\right.$, no losses calculated for earthquakes of $M_{s}=6.5$ and $M_{L}=5.5$ for this fault]

\begin{tabular}{llcccc}
\hline & \multicolumn{5}{c}{ Length of faulting $(\mathrm{km})$} \\
\cline { 2 - 6 } Magnitude & $\begin{array}{c}I_{0} \\
\text { (maximum) }^{1}\end{array}$ & $\begin{array}{c}\text { Provo } \\
\text { segment }\end{array}$ & $\begin{array}{c}\text { Salt Lake } \\
\text { segment }\end{array}$ & $\begin{array}{c}\text { Weber } \\
\text { segment }\end{array}$ & $\begin{array}{c}\text { Oquirrh } \\
\text { Mountains }\end{array}$ \\
\hline $7.5 \mathrm{M}_{s}$ & $X+(10.3)$ & 18 & 30 & 50 & 30 \\
$6.5 \mathrm{M}_{s}$ & $\mathrm{IX}(9.0)$ & 18 & 28 & 28 & - \\
$5.5 \mathrm{M}_{L}$ & VII (8.0) & 11 & 11 & 11 & - \\
\hline
\end{tabular}

${ }^{1}$ The number in parentheses is the actual maximum intensity $\left(I_{0}\right)$ used in the calculation of intensity in equation 1. $4 B)$.

${ }^{2}$ Hypothetical fault on the western side of the Oquirrh Mountains (see fig.

TABLE 3.-Site-response factors

\begin{tabular}{lccc}
\hline Material & $\begin{array}{c}\text { Mean relative } \\
\text { site response } \\
(0.2-0.7 \mathrm{~s})^{1}\end{array}$ & $\Delta I$ & $K^{2}$ \\
\hline Silt and clay & 6.2 & 2.6 & 0 \\
Sand and gravel & 3.7 & 1.9 & -.7 \\
Rubble & 2.8 & 1.4 & -1.2 \\
Rock & 1.0 & 0 & -2.6 \\
\hline
\end{tabular}

\footnotetext{
${ }^{1}$ Computed by Rogers and others (1984). The mean relative response is the log normal mean of the mean spectral ratios in the ground-motion period band 0.2 to $0.7 \mathrm{~s}$.

${ }^{2}$ Correction term for intensity attenuation in equation $1 . K$ reduces the simulated intensity at a site if that site is underlain by sand and gravel, rubble, or rock. No correction to equation 1 is needed (that is, the correction is zero) if the site is underlain by silt and clay.
}

the Wasatch fault segments are much shorter than the fault rupture lengths given by Mark's (1977) regression equation, the length of the fault rupture for the larger simulated earthquakes is generally controlled by the length of the Wasatch fault segment. The assumed magnitudes and rupture lengths are summarized in table 2.

A magnitude $\mathrm{M}_{s}=7.5$ shock was selected as the largest earthquake to be simulated on the Wasatch fault (and west of Salt Lake City) because (1) earthquakes of this magnitude have occurred historically in the Basin and Range province (in the Nevada seismic zone) and (2) paleoseismic evidence supports the idea that earthquakes of this magnitude are possible on segments of the Wasatch fault (Machette and others, 1992). The maximum Modified Mercalli (MM) intensities assigned to the earthquakes to be simulated are based on (1) consideration of maximum intensities observed in recent earthquakes characterized by surface faulting and (2) the high amplification ratios (amplitudes on alluvium to amplitudes on rock) observed in the Salt Lake urban corridor. All of the
$I_{O}$ values in table 2 represent an estimate of the most intense shaking that might occur on surficial materials for the greatest site response. For this study, this material is taken to be silt and clay (as classified by Rogers and others, 1984). An $I_{O}$ of intensity $\mathrm{X}+$ is considered appropriately conservative for the maximum shaking on silt and clay for a $\mathrm{M}_{s}=7.5$ earthquake. Maximum intensities of IX were widely observed in the $\mathrm{M}_{s}=6.2$ Managua, Nicaragua, earthquake of 1972 (Algermissen and others, 1974; Dewey and Algermissen, 1974) and the $M_{s}=6.5$ San Fernando, Calif., earthquake of 1971 (Murphy, 1973). Both of these earthquakes had surface faulting. A maximum intensity of VIII was used for the maximum shaking for the $M_{L}=5.5$ earthquake simulated. Intensity VIII was widely observed after the $1986 \mathrm{M}_{s}=5.4$ earthquake that occurred at very shallow depth beneath the city of San Salvador (Ríos and others, 1986). The above examples suggest that reasonable choices for maximum MM intensity have been made for the earthquakes simulated in the Utah urban corridor.

The ground-shaking attenuation in terms of MM intensity was calculated for the simulated earthquakes by combining an attenuation curve derived from 475 intensity observations in Utah reported by Hopper (this volume) with site-response data generalized by Rogers and others (1984). The equation used is

$$
\left(I_{0}-I\right)=10 \exp [-4.21873+0.604413 \ln (x)]+K
$$

where $I_{0}$ is the maximum MM intensity for each earthquake (see table 2) and $I$ is MM intensity at $x$, the closest distance from the surface trace of the fault to the center of housing of each census tract in the four-county area. The standard deviation of one intensity observation, $\sigma_{I}$, is 1.038. $K$ is a correction factor for site response (table 3 ).

The $K$ term in equation 1 modifies the intensity attenuation, making use of the site response data of Rogers and others (1984), who used recordings by King and others (1983) of small earthquakes and blasts at 42 locations in the Wasatch Front urban corridor to derive the log normal mean of the mean spectral ratios in two period bands for three lithologic categories (silt and clay, sand and gravel, and rubble) with respect to rock. The two period bands over which the spectral ratios were averaged are 0.2 to 0.7 and 0.7 to $1.0 \mathrm{~s}$. For two reasons, only the $\log$ normal means for the short-period band (0.2-0.7 s) are used here. First, most of the structures of interest in this loss study are best represented by short-period band amplification; that is, the fundamental periods of vibration of the majority of buildings in the four-county area are best represented by the site-response data in the $0.2-$ to 0.7 -s period band. Second, Rogers and others (1984) did not find the amplification data in the longer period band $(0.7-1.0 \mathrm{~s})$ to be statistically significant. 
It has been found (Borcherdt, 1970; Borcherdt and others, 1975) that a factor of two in mean spectral velocity response level corresponds roughly to a change of about one MM intensity unit. A similar relationship has been shown to hold for peak velocity. For values of intensity up to X, Rosenblueth (1964) found that the relationship $I=\log 14 v / \log 2$ (where $I$ is MM intensity and $v$ is the maximum ground velocity in centimeters per second) was a reasonable approximation. On the basis of the above relationships, the amplification of intensity with respect to rock was approximated for each of the three lithologic categories selected by Rogers and others (1984). The lithologic categories are listed in table 3 , together with their mean relative responses in the period band 0.2 to 0.7 $\mathbf{s}$, the incremental increase of intensity with respect to rock $(\Delta I)$, and the $K$ factor in equation 1 . Because the maximum intensity $I_{0}$ in equation 1 is assumed to occur on sand and silt, the $K$ site correction is zero for sites with this category of lithology. For sites located on the other lithologic categories (sand and gravel, rubble, and rock), the $K$ factor is a negative correction in the intensity attenuation relationship.

In summary, the distributions of intensities for the scenario earthquakes listed in table 2 were obtained by using equation 1 and the intensity correction factors listed in table 3. Typical intensity attenuation curves for silt and clay, sand and gravel, rubble, and rock are shown in figure 3. The site-response amplification factor of Rogers and others (1984) together with the associated $K$ values for equation 1 are given in table 3 . The distributions of surface materials listed in table 3 are shown in figure 4 , together with the fault seginents assumed to rupture in the earthquakes simulated on each fault. The simulated distribution of MM intensity for a portion of the area shaken by a $\mathrm{M}_{s}=7.5$ earthquake on the Salt Lake segment of the Wasatch fault is shown in figure 5. An isometric view of the same simulated ground shaking is shown in figure 6 .

The probabilistic hazards model used to estimate losses in the Wasatch Front urban corridor is essentially the model described by Algermissen and others (1982). Earthquakes are exponentially distributed with regard to magnitude and randomly distributed with regard to time in this model. The exponential magnitude distribution is an assumption based on empirical observation. The distribution of earthquakes in time is assumed to be Poissonian. The model has essentially four parts (fig. 7):

1. A seismic source model that serves to define the spatial distribution of earthquakes within the region of concern.

2. An occurrence model of earthquakes that describes the recurrence of events in time within the seismic source zones (fig, $7 B$ ). In practice, the magnitude distribution of earthquakes described by the relationship $\log _{10} \mathrm{~N} /$ unit area $=a-b m$, where $N$ is the number of earthquakes greater than magnitude $m$ and $a$ and $b$ are constants determined for each source zone.

3. A ground-motion-attenuation model that is a description of the manner in which earthquake ground motions decrease with distance from an earthquake source for various magnitude levels (fig. $7 C$ ).

4. A probability model for calculating the expected maximum amplitude of ground motion within a given period of time corresponding to a chosen probability level for a number of individual sites in the region (fig. $7 D, E$ ).

Figure $7 D$ shows an idealized cumulative distribution function for intensity at a site, and figure $7 E$ depicts the probability of occurrence (for a Poisson model) of an expected maximum intensity $I$ for various exposure times $T$.

The seismic source zones used in the model differ from those of Algermissen and others (1982) in that the eight fault segments described by Machette and others (1992) have been assigned individual rates of occurrence of large earthquakes $\left(\mathrm{M}_{s}=6.4-7.6\right)$ based on new paleoseismic data. The attenuation of MM intensity used in the probabilistic model is that given in equation 1 , the same attenuation used for the deterministic (scenario) earthquake modeling. The maximum MM intensity in a 50-year period with a 10-percent chance of exceedance is for a portion of the study area as shown in figure 8; an isometric view of the same ground shaking is shown in figure 9 .

\section{INVENTORY DEVELOPMENT}

The inventory development consists of two parts: (1) dwellings (classes I-A, I-B, V-B, V-E (table 1) and (2) all other classes of buildings.

Buildings other than dwellings.-The inventory for all buildings other than dwellings is based on a procedure developed by Steinbrugge (1986). The nondwelling inventory includes structures valued at $\$ 1,000,000$ or more at the time of construction; replacements values at $1985 \mathrm{lev}$ els are not considered.

In addition to the largest cities-namely, Salt Lake City, Ogden, and Provo and some sections of Salt Lake County-most of the outlying areas have major buildings costing in excess of $\$ 1,000,000$; generally, these are located in either shopping malls, shopping centers, or Church of Jesus Christ of the Latter Day Saints (LDS) church complexes. Malls are defined as large structures having several entries and exits and housing major department stores and many smaller stores all under one roof structure. Shopping centers are similar, consisting of some major buildings but not being part of a single covered complex.

These malls and shopping centers are generally located on or near major State roads, usually near the 


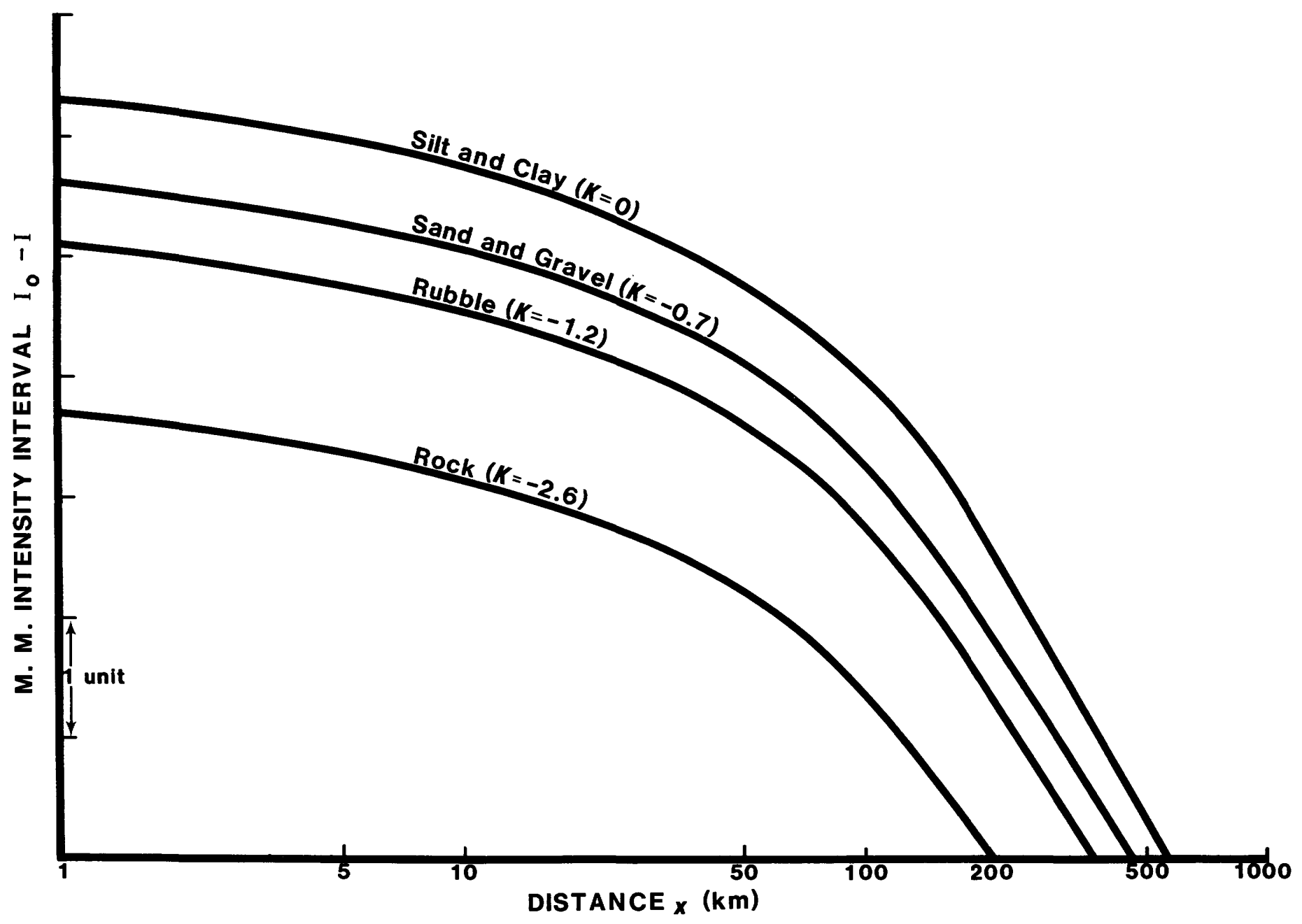

FIGURE 3.-Intensity attenuation curves, where $I_{0}$ is the maximum Modified Mercalli intensity for each earthquake (table 2), $I$ is the intensity at a distance $x$ from the surface fault rupture, and $K$ is a correction for site response (table 3 ).

intersections of major traffic routes. Although the malls are few in number, there are numerous shopping centers, only a few of which feature structures valued at more than $\$ 1,000,000$. Most of the buildings are small stores and shops, located in residential areas where few other major structures exist.

The remote sections of the study area are unique in that usually the only constructions exceeding $\$ 1,000,000$ in value are LDS church structures. These buildings are generally of high-quality mixed construction designed to resist major seismic forces. They occur in most of the small outlying communities and farming areas where no other large structures exist. Most are in residential areas. There are literally hundreds of such buildings within the study area, many costing in excess of $\$ 1,000,000$. Most of these structures are of recent construction and are included in the total square footage areas of table 4.

Schools, government buildings, and heavy industrial complexes are not included in the inventory.
A number of data sources were used to derive the nondwelling inventory. The major sources of data were (1) building permit records, (2) LDS records, (3) Sanborn maps, (4) reports to the F.W. Dodge-McGraw Hill Company, published as building statistics, (5) census tract maps, and (6) field investigations.

Possibly the most effective method of locating, listing, and describing buildings exceeding $\$ 1,000,000$ in value not listed in county or other records was extensive field investigation. Because records for much of the fourcounty area are incomplete, considerable on-site inspection was required. Many of the available records list buildings that have been demolished and consequently cannot be included in the inventory. The location of these buildings can generally be determined only by field inspection.

A summary of the building inventory for all classes of buildings other than dwellings is given in table 4. Replacement cost values for nondwelling buildings were taken from Steinbrugge (1986) and are based on a review of 
actual costs of replacement in Utah in 1985 . The replacement costs per square foot are summarized in table 5 .

Dwelling inventory.-The inventory of housing is taken as of July 1, 1985 for consistency with the nondwelling inventory. The dwelling or housing inventory was constructed from the 1980 Census of Housing as published by the Bureau of the Census (1983a, b) auginented by other information from Bureau of Census unpublished data and the various Boards of Realtors and county and city planning commissions. Details of these calculations are given below.

Tooele County, house trailers, and other nonpermanent, year-round housing units were not included in this inventory. Tooele County, although included by the Bureau of the Census in the Salt Lake Standard Metropolitan Statistical Area (SMSA), was excluded both because it is sparsely populated and because information is difficult to obtain, especially for valuations. Trailers were excluded from the counts simply because the vulnerability of house trailers is difficult to quantify. As a result, total calculated losses will be slightly less conservative than the actual ones. There were 9,229 trailers in the Salt Lake SMSA and 2,153 in the Provo SMSA in 1980 in comparison with 223, 097 and 42,104 single-family dwellings, respectively; thus, the error will be small.

A dwelling or housing unit is loosely defined as a selfcontained structure or partial structure serving as a yearround dwelling for a family. Dwellings are divided into two classes according to the number of housing units per structure-those with four units or less per structure and those with five or more. The former are mostly singlefamily detached dwellings and probably large, older houses that have been divided into apartments as well as the more modern town houses. The larger buildings are mostly apartments in the category of 10 to 49 units per building. The apportionment between these two classes was made by using the ratios given by the Bureau of the Census (1983a, b) for 1980. Because the amount of housing erected between 1980 and 1985 is small, these ratios should still be fairly accurate.

The total number of housing units in each census tract was updated to 1985 by obtaining the number of building permits issued in the years 1980 to 1984 from the Bureau of the Census and, assuming that building was uniform over each county, prorating that number over the census tracts.

Housing units are further divided into wood-frame and masonry construction and are listed as either class I or class $\mathrm{V}$ of the building classification given by Algermissen and others (1978) (table 1). Unfortunately, no good estimate of the ratio of wood-frame to masonry housing units is available from the Bureau of the Census or elsewhere. In this case, the figure of approximately 60 percent masonry for the region was used after consultation with staff members of the Salt Lake City Planning Commission.

All housing units in the masonry category were then subdivided into class V-E or V-B, depending on whether they were built before or after 1950, respectively. Again, the ratios are the ones given by the Bureau of the Census by county for 1980 . No consideration was given to brick veneer on wood-frame construction; it was assumed that all of the veneer dwellings were constructed after 1949 and had vulnerability similar to that of class V-B structures. The replacement cost of individual units was determined in the following manner. For one- to four-unit structures, the current value was obtained from the Salt Lake Board of Realtors, which has divided Salt Lake County into 12 regions. An average sale price in 1985 for each of the 12 regions was obtained. The Ogden Board of Realtors has divided Davis and Weber Counties into 18 regions, and the Provo Board of Realtors has provided similar divisions for Utah County. Seventy-five percent of the average cost of dwellings in each of the areas sampled was taken as the replacement cost, 25 percent being taken as the land value.

In the case of structures having five or more units, the area of the average unit was taken to be $950 \mathrm{ft}^{2}$, a figure considered average in the estimation of each realty board consulted. The price of wood-frame structures was taken to be $\$ 55 / \mathrm{ft}^{2}$ and that of the masonry units $\$ 63 / \mathrm{ft}^{2}$ (Steinbrugge, 1986) (table 5). Any units in class III or IV structures will be slightly underpriced by this calculation, but damage will be calculated as if they were class V-B, the higher result having a compensating effect.

In addition to obtaining a value for all housing in a tract, it is necessary to locate the housing spatially by assuming it to exist at a "center of housing." The Bureau of the Census gives a center of population for each tract, which can reasonably be taken to be the center of housing. In addition, because of the irregular boundaries of many municipalities, there are many tracts that are "split" between a number of municipalities. This split necessitated combining the partial tracts by using means weighted by numbers of housing units. The centers of housing are expressed in geographic coordinates.

FigURE 4.-Distribution of site-response amplification factors $\rightarrow$ (adopted from Rogers and others, 1984). Intensity corrections $(K)$ used in conjunction with equation 1 are shown in table 3 . The fault segments assumed to rupture in the simulated earthquakes are shown by heavy black lines. Assumed lengths of rupture for each magnitude earthquake are given in table 2. $A$, Weber segment. $B$, Salt Lake segment. The heavy dashed line represents the fault rupture length for a $\mathrm{M}_{s}=7.5$ earthquake on a hypothetical fault located approximately along the western flank of the Oquirrh Mountains. $C$, Provo segment. 


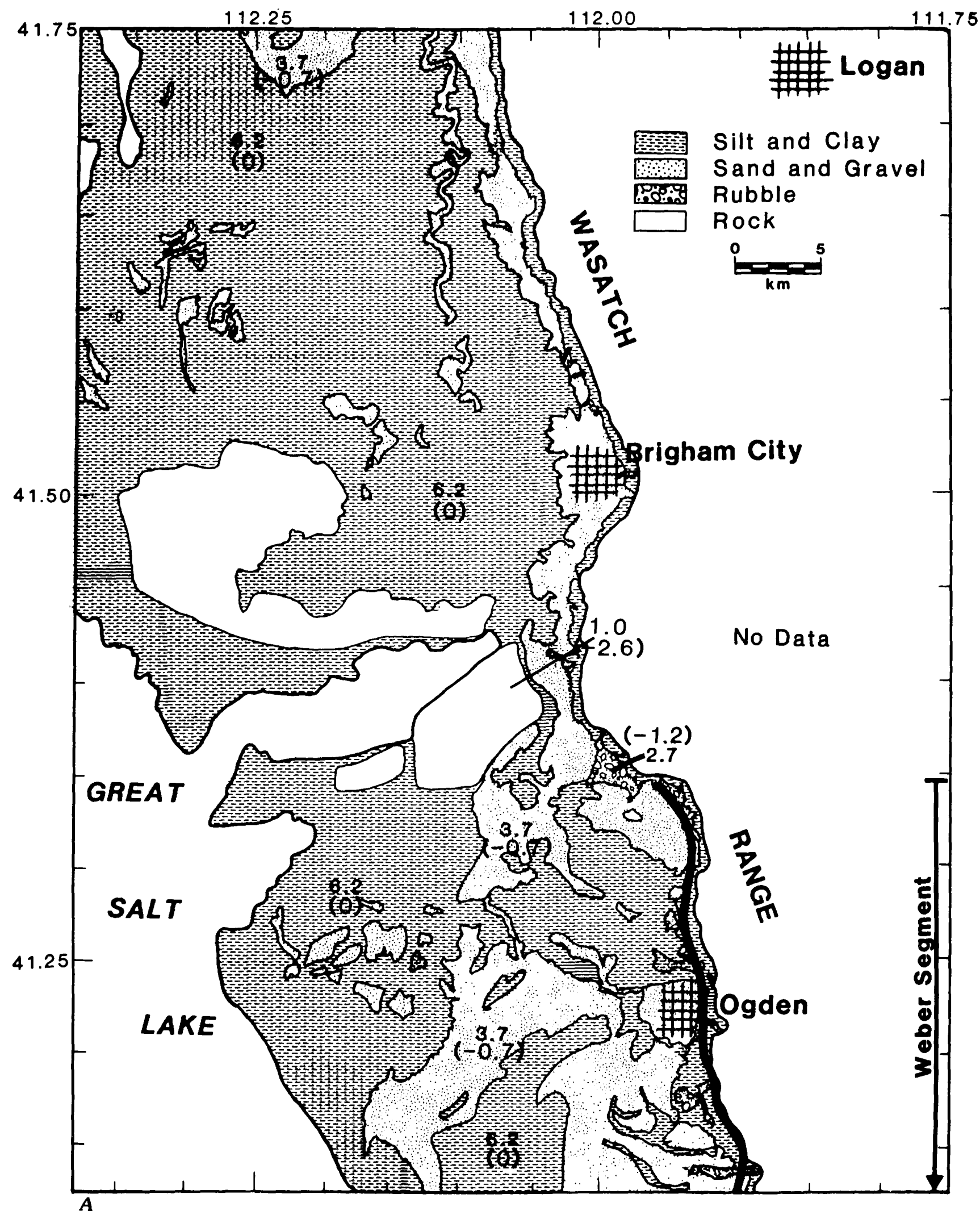




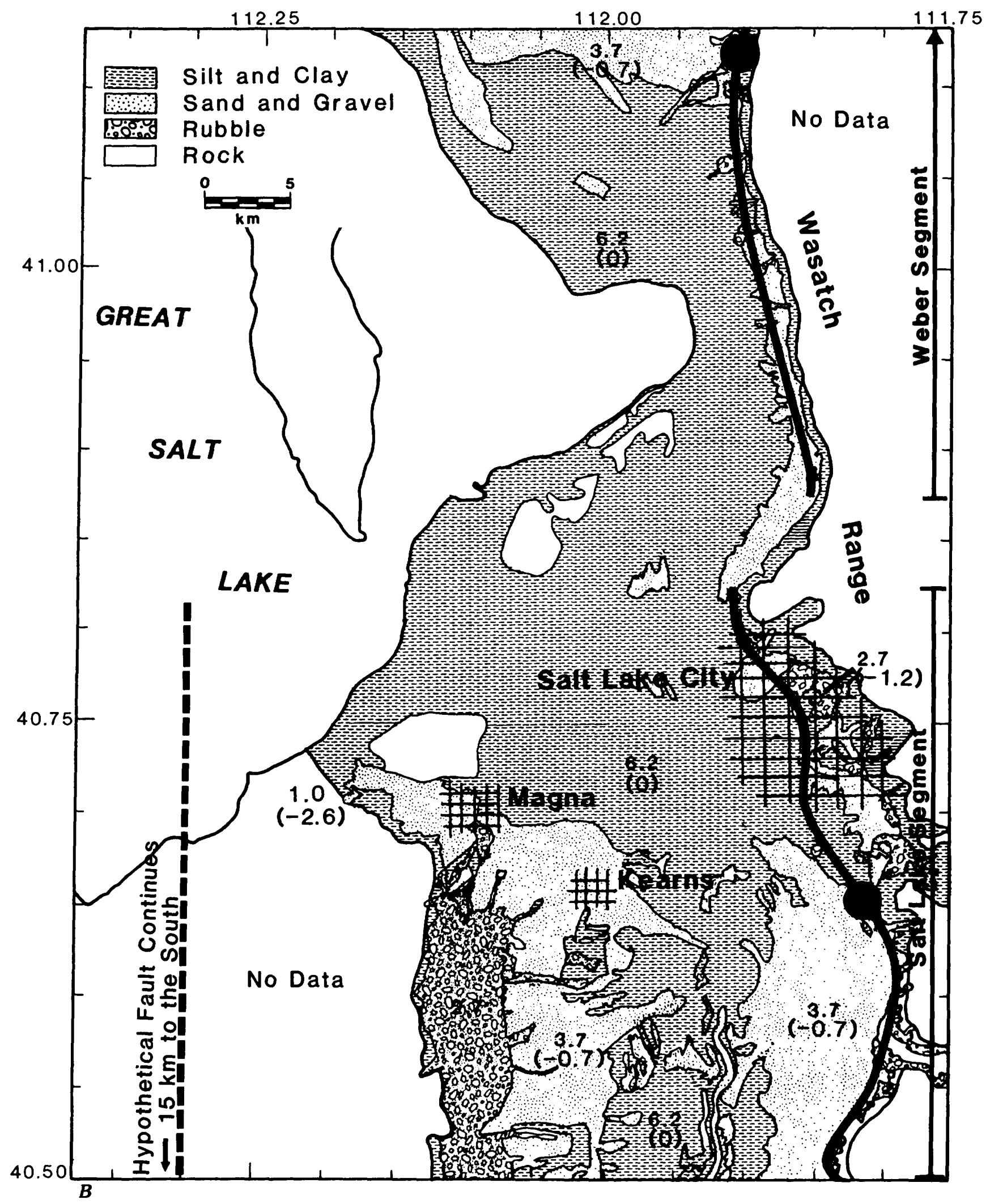

Figure 4.-Continued. 


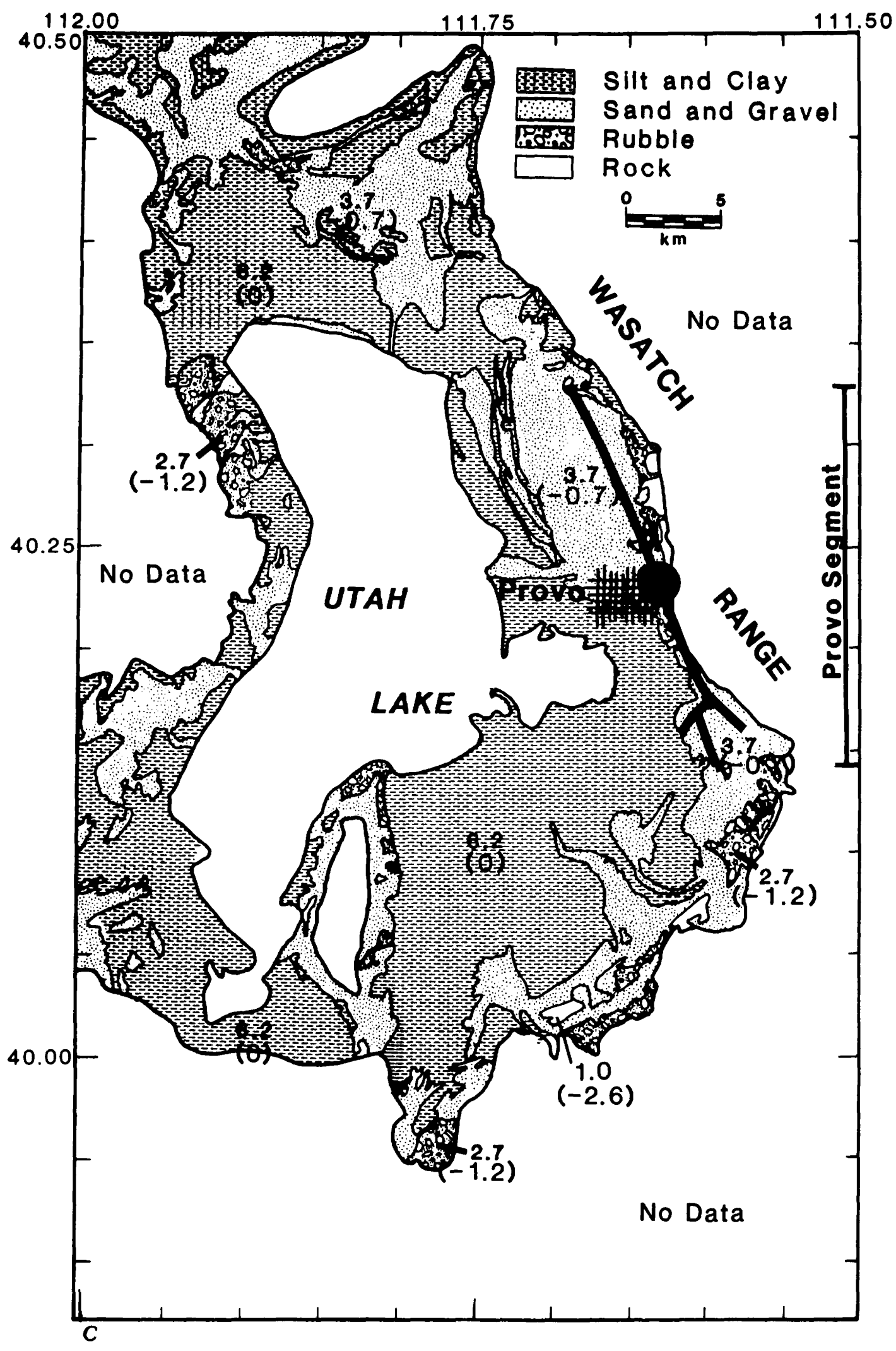

FIGURE 4.-Continued. 


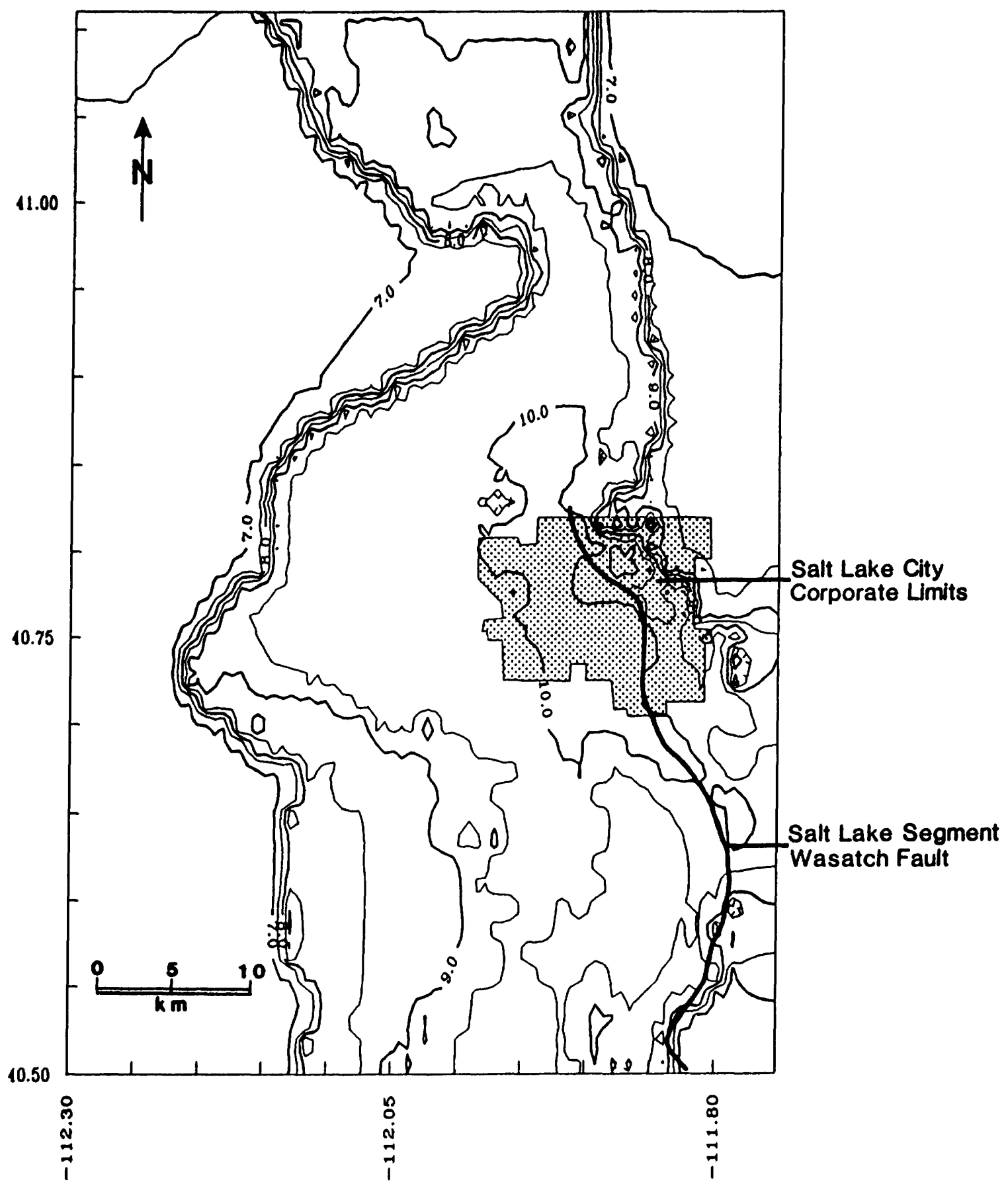

FIGURE 5.-Isoseismals for a simulated $\mathrm{M}_{s}=7.5$ earthquake on the Salt Lake segment of the Wasatch fault. The intensities have been slightly smoothed. The emphasized line segment is the Salt Lake segment of the Wasatch fault. 


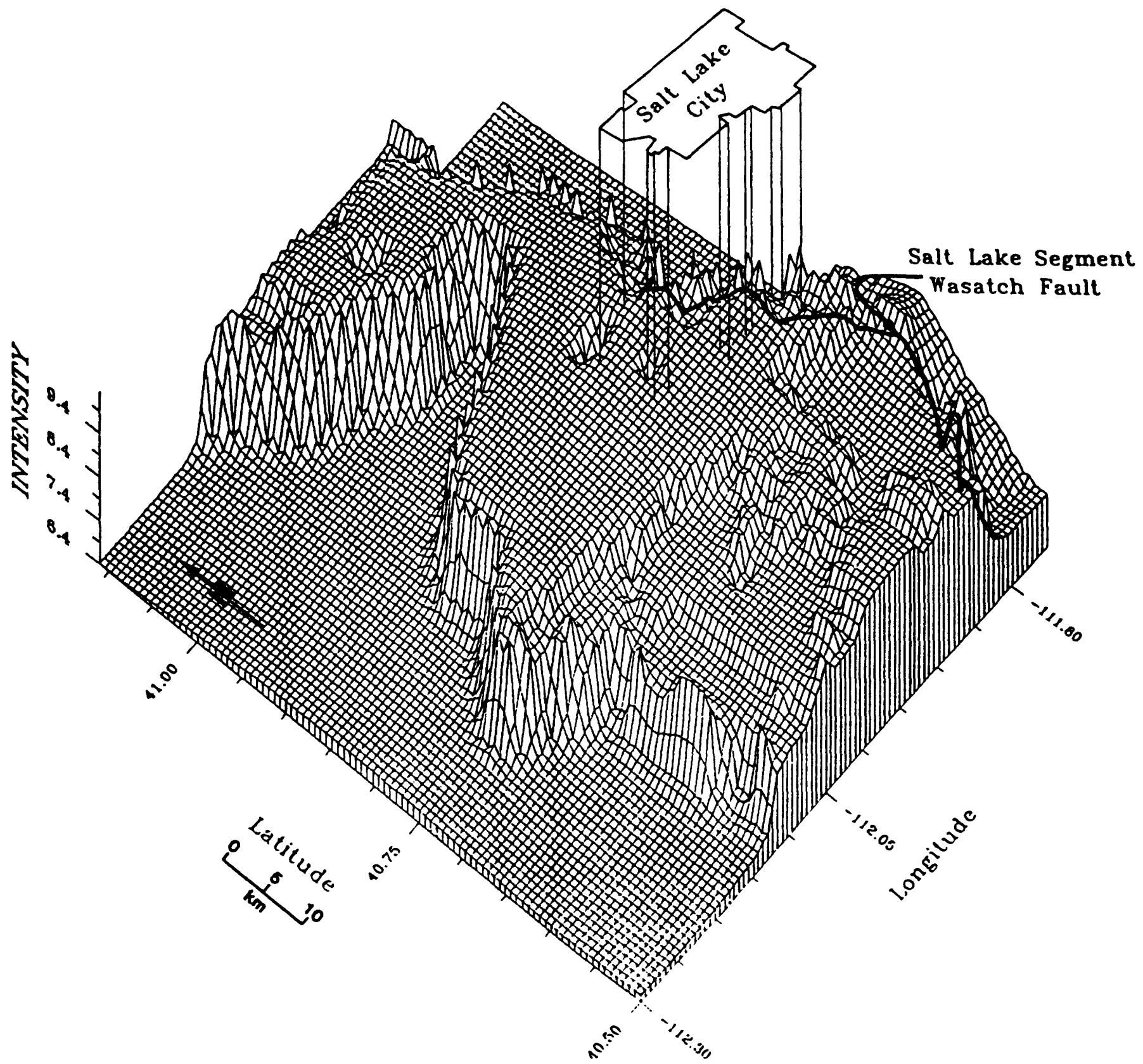

FIGURE 6.-Isometric view of the distribution of Modified Mercalli intensity for a simulated $\mathrm{M}_{s}=7.5$ earthquake on the Salt Lake segment of the Wasatch fault as seen from the northeast. The data are the same as in figure 5. 

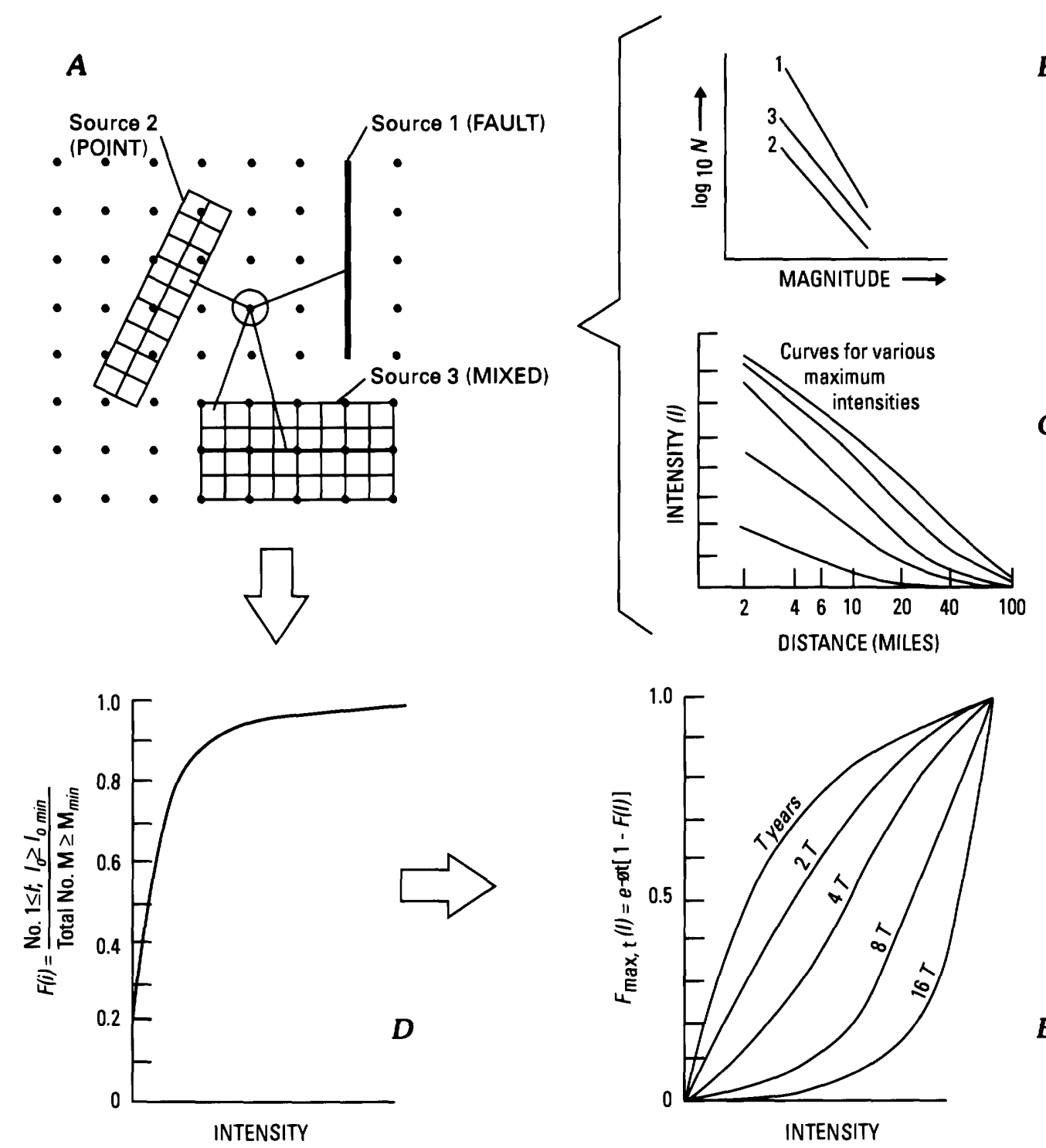

$E$

FIGURE 7.-Model for calculating probabilistic maximum Modified Mercalli intensity. $A$, Typical source areas and grid of points at which the hazard is to be computed. Circled grid point represents a typical location for intensity calculation. $B$, Statistical analysis of seismicity data and, $C$, typical attenuation curves. The straight lines labeled 1,2, and 3 represent maximum likelihood regressions applied to historical earthquakes that have occurred in typical sources shown in $A . D, F(i)$ is the cumulative conditional probability distribution of intensity for each geographic location where expected Modified Mercalli intensity is computed. $F(i)$ is the cumulative number of intensities $i \leq I$ (some $I$ ) for $I_{0} \geq I_{\min }$ (some minimum maximum Modified Mercalli intensity). $E, F_{\max , t}(I)$ is the extreme probability for various levels of intensity $(I)$ and exposure times $(T) ; \phi$ is the average rate of occurrence per unit time $(t)$ of intensity level $I \geq I_{\min }$. 


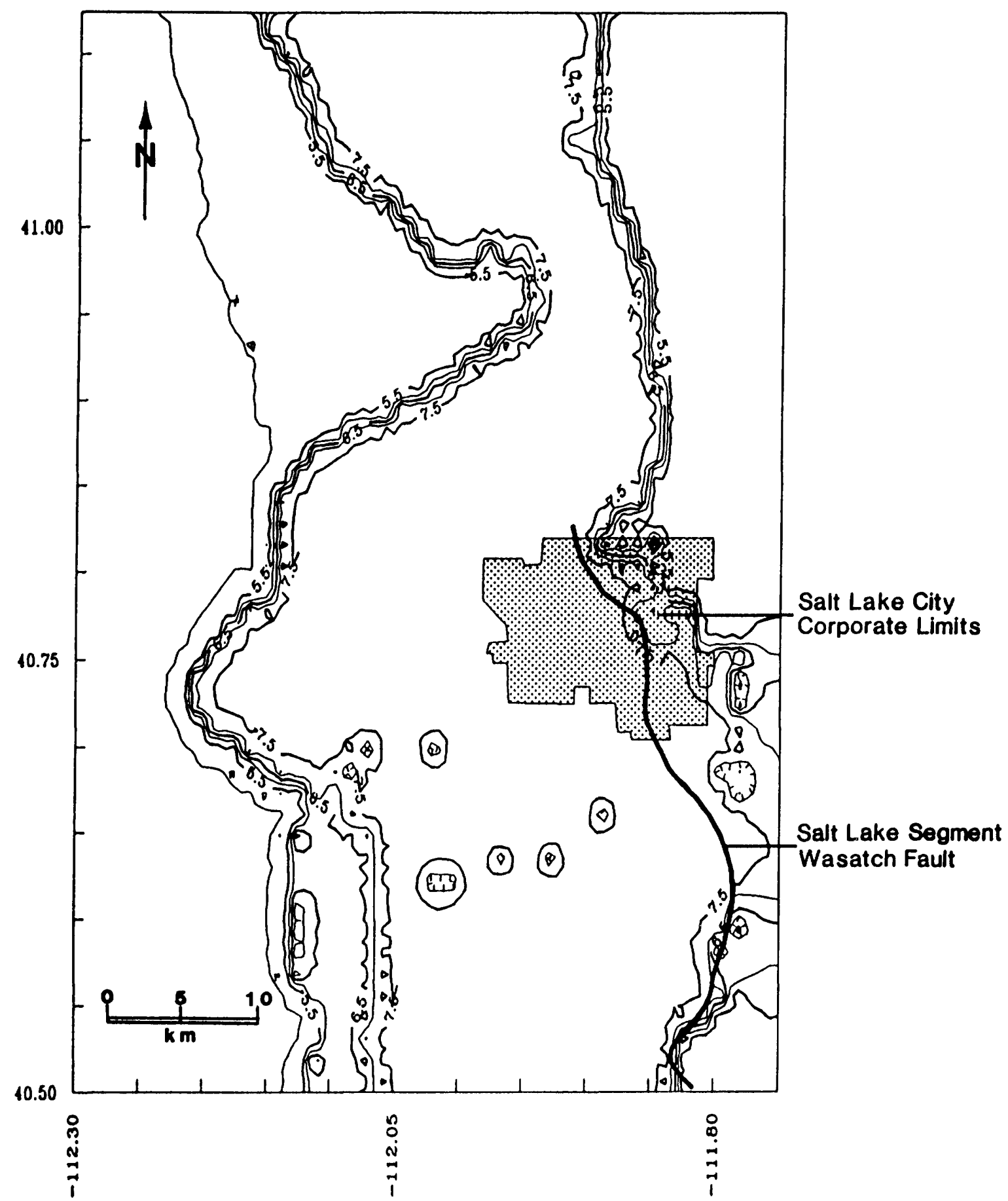

FIGURE 8.-Distribution of maximum Modified Mercalli intensity in the Salt Lake area in 50 years with a 10-percent chance of exceedance. 


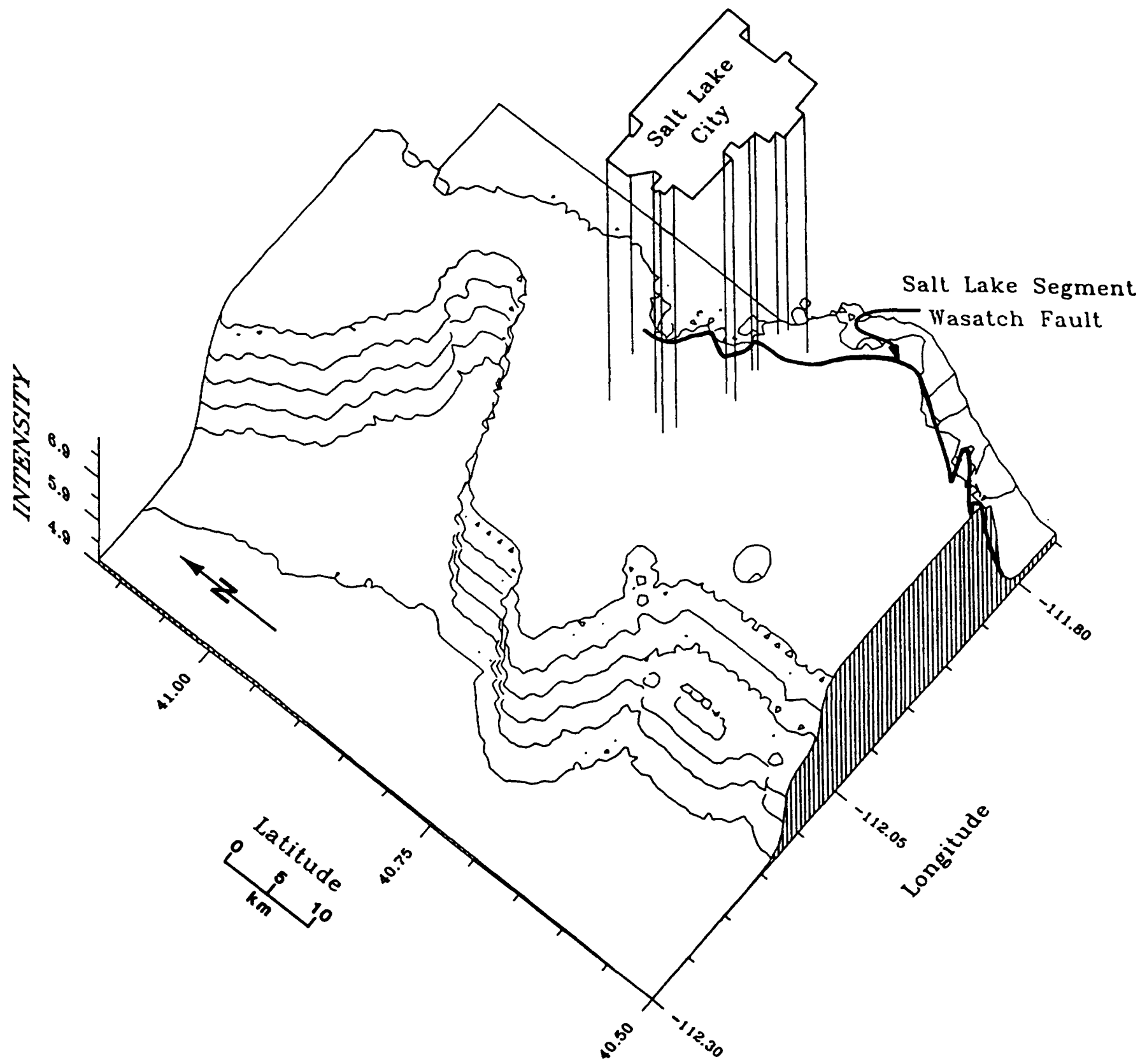

FIGURE 9.-Isometric view of the distribution of maximum Modified Mercalli intensity in the Salt Lake area in 50 years with a 10-percen $t$ chance of exceedance. The perspective is the same as in figure 6 , and the data are the same as in figure 8. 
TABLE 4.-Building classes other than dwellings in the four-county area

[-, buildings having a replacement value of less than $\$ 1,000,000$, which are not included in these classes. Building areas in square feet $\times 1,000]$

\begin{tabular}{|c|c|c|c|c|c|c|c|}
\hline \multirow{2}{*}{ County } & \multirow{2}{*}{$\frac{\text { All metal }}{\text { Class II-A, B }}$} & \multicolumn{2}{|r|}{ Steel } & \multicolumn{2}{|c|}{ Reinforced concrete } & \multicolumn{2}{|c|}{ Mixed construction } \\
\hline & & Class III-A & Class III-B, C, D & Class IV-A & Class IV-B, C, D, E & Class V-B, C & Class V-D, E, F \\
\hline Weber County & - & - & 204.0 & $1,105.0$ & $1,413.0$ & $1,636.8$ & $1,090.7$ \\
\hline Davis County & 700.0 & - & 445.0 & 739.0 & 880.0 & $2,284.4$ & - \\
\hline Salt Lake County & $1,950.2$ & $3,394.8$ & $6,252.8$ & $16,025.2$ & $8,929.1$ & $19,646.6$ & 860.0 \\
\hline
\end{tabular}

The replacement value for all classes of buildings (used to estimate losses) is taken as the total cash value required to fully repair or rebuild in kind any building of a particular class.

Vulnerability. - Vulnerability as used in this study is taken to mean the relationship between percentage of loss and MM intensity. Percentage of loss is defined as the average percentage of the total actual cash value required to fully repair or rebuild in kind any building of a particular class experiencing ground motion represented by a particular level of the MM intensity scale.

The two sets of vulnerability relationships used are (1) those developed by Steinbrugge (1979), further reviewed by Steinbrugge (1986), and (2) those developed by the Applied Technology Council (1985). The Steinbrugge vulnerability relationships are shown graphically in figures 10 and 11 and numerically in table 6. It should be clearly understood that both vulnerability relationships used are for ground-shaking damage only.

\section{LOSS CALCULATIONS}

Losses were calculated in a totally automated manner on microcomputers. The only exception to the above statement is the hand digitization of geologic features, such as areas of varying soil amplification and fault traces. These exceptions are still less time consuming than previously used methods. The flow of the calculations is outlined below.

Calculations of losses to dwellings.-Inputs are coordinates of the centers of housing for the 229 census tracts in the four-county urban area; a map of the various surficial materials underlying the urban corridor; a map of the Wasatch fault zone; numbers of housing units in the various construction classes in each tract along with estimates of value; floor areas of nondwelling structures in each tract and an estimate of values; a function giving the

\begin{tabular}{lc}
$\begin{array}{c}\text { TABLE 5.-Replacement cost (1985) per } \\
\text { unit area for building classes other } \\
\text { than dwellings (Steinbrugge, 1986) }\end{array}$ \\
\hline Class & $\begin{array}{c}\text { Price per square foot } \\
\text { (1985 dollars) }\end{array}$ \\
\hline I & 55 \\
II & 41 \\
III & 71 \\
IV & 72 \\
V & 63 \\
\hline
\end{tabular}

attenuation of intensity with respect to distance from a fault rupture; and a set of vulnerability curves giving losses as a function of intensity.

The two maps are first digitized and the points converted to the State plane (north) projection-in this case, a Lambert conformal conic projection having standard parallels at $40^{\circ} 43^{\prime} \mathrm{N}$. and $41^{\circ} 47^{\prime} \mathrm{N}$. and a central meridian at $111^{\circ} 30^{\prime} \mathrm{W}$. The centers of housing are transformed into the same projection.

The distances from the active fault segment to each center of housing are then computed. The distance is measured along the normal from the housing centers to the fault or, for housing centers beyond the ends of the active fault segment, the distance from the housing center to the closest end of the fault segment. The centers of housing and the soil amplification map are also plotted. A utility program is then used to produce a list of tract identification numbers together with the soil types underlying each center.

As previously explained, each soil type and earthquake magnitude correspond to a specific maximum intensity, $I_{0}$, in equation 1 , repeated here for convenience:

$$
\left(I_{0}-I\right)=10 \exp [-4.21873+0.604413 \ln (x)]+K
$$




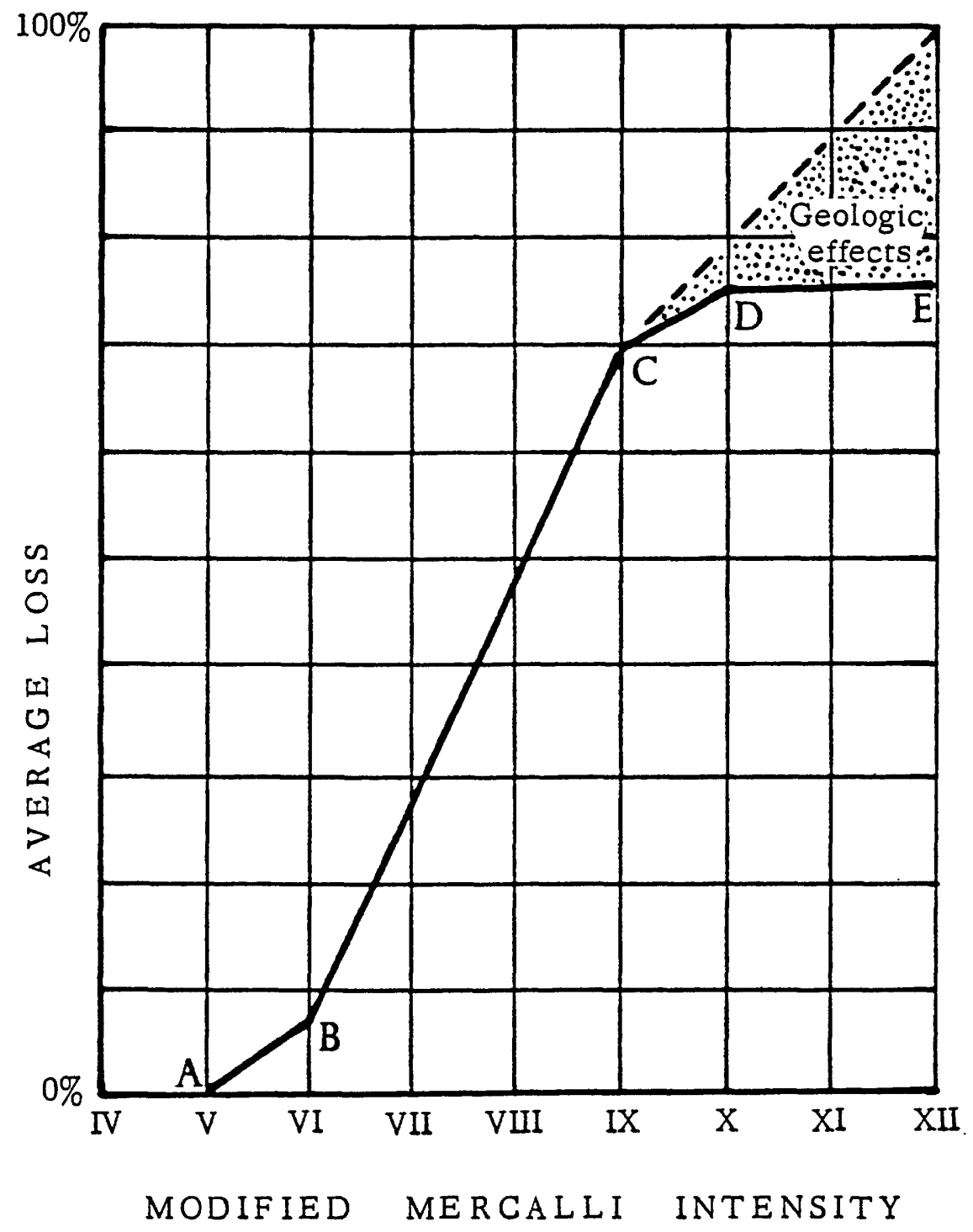

FIGURE 10.-Characteristic intensity loss curve showing inflection points tabulated in table 6.

where $x$ is the distance from the fault to the housing center (in kilometers). Once a list of tracts, distances, and $I_{0}$ 's has been compiled by using equation 1 , the intensity $I$ at each housing center is calculated and rounded to the nearest 0.1 intensity unit.

The only step not yet completely automated in the calculation of losses is finding whether the fault trace intersects the tract. The present calculation makes this determination by overlying a tract map giving actual boundaries on the fault map and flagging the intersected tracts by hand, thus creating a list to augment the one giving tract identification and intensity.
The number of units in each tract that belong to each of the four dwelling construction classes are then calculated. Total numbers of housing units are obtained from the Bureau of the Census (1983c) on magnetic tape. The ratios of one to four dwelling units per structure to one of five or more dwelling units per structure were obtained from the Bureau of the Census (1983a, b), as were the ratios of pre-1950 housing units to post-1950 units. The total number of units added from 1980 to 1985 was obtained from the Bureau of the Census' unpublished records of building permits. The total units were adjusted to reflect 1985 numbers and then divided into wood frame 

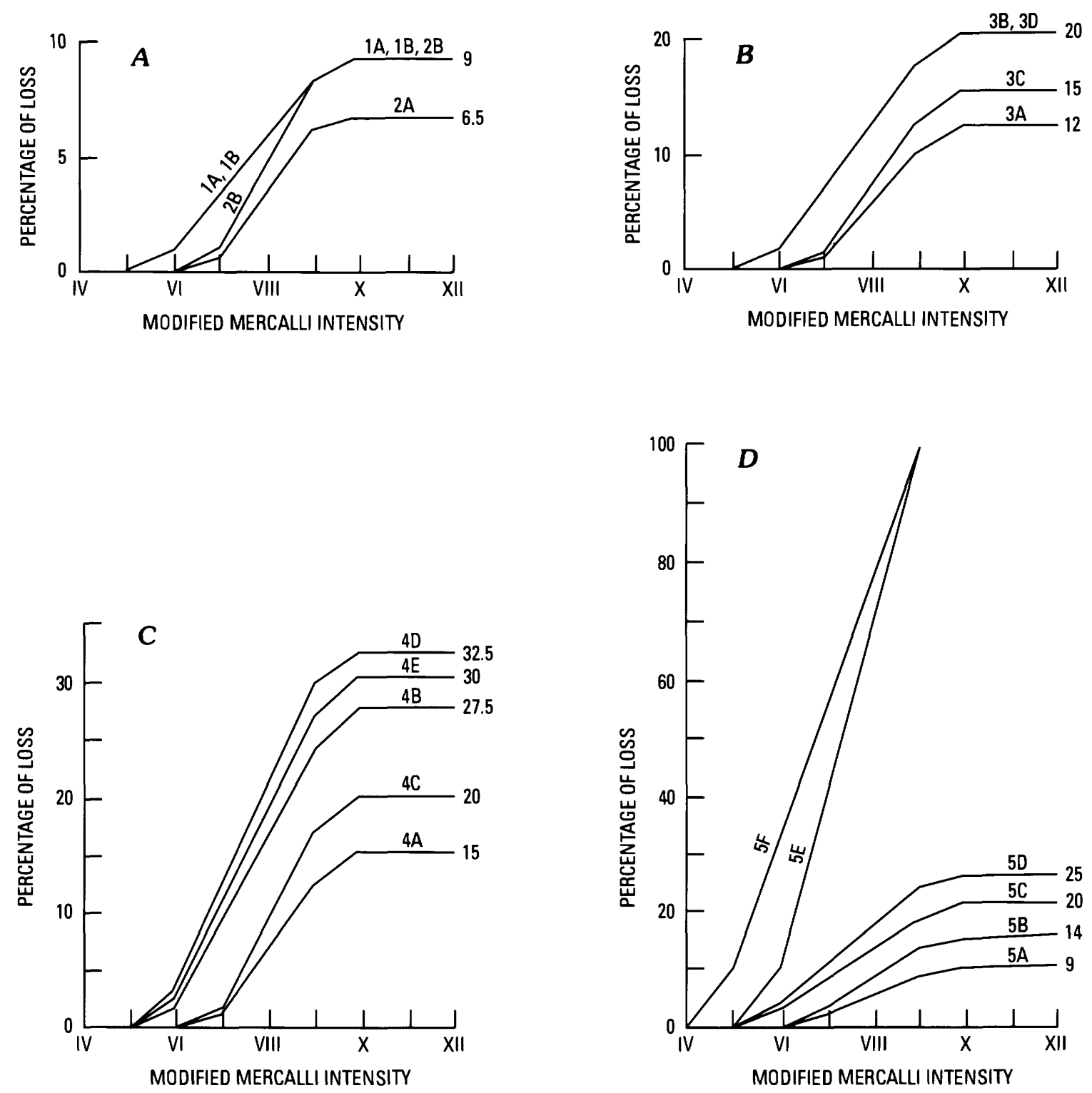

FIGURE 11.-Vulnerability relationships used in this study (Steinbrugge, 1986). The inflection points of the curves are shown in figure 10 and tabulated in table 6 . $A$, Classes 1 and 2 (I and II); $B$, class 3 (III); $C$, class 4 (IV); $D$, class 5 (V).

and masonry (assuming 60 percent masonry) and further apportioned into large and small structures. The masonry structures were further divided into classes V-E and V-B, depending on whether the unit was built before or after 1950.

Dwelling values for 1985 were then calculated. For all structures having one to four units, the value of each dwelling unit is the one given by the board of realtors in its area. That is to say, the census tracts were allotted to each realtor's areas, the latter always being larger than the former; no distinction was made between wood frame and masonry.
For all housing in structures having four units or fewer, an arbitrary 25 percent of the value was subtracted to account for the value of the land, which, of course, is not generally damaged.

The loss calculations for housing units were computed by using the vulnerability curves of Steinbrugge (1986) and those developed by the Applied Technology Council (1985). This comparison provides some degree of sensitivity analysis with regard to vulnerability. As a special case, for those tracts through which a fault trace passes, total destruction due to ground disruption was assumed to occur in a path $50 \mathrm{~m}$ wide along the fault. On a 
TABLE 6.-Coordinates of loss-intensity curves for figure 11 (Steinbrugge, 1986)

[N/A, not applicable]

\begin{tabular}{|c|c|c|c|c|c|c|c|c|}
\hline \multirow{2}{*}{$\begin{array}{l}\text { Building } \\
\text { class }\end{array}$} & \multicolumn{2}{|c|}{ Point A } & \multicolumn{2}{|c|}{ Point B } & \multicolumn{2}{|c|}{ Point C } & \multicolumn{2}{|c|}{ Points $D$ and $E$} \\
\hline & $\begin{array}{c}\text { Loss } \\
\text { (percent) }\end{array}$ & $\begin{array}{l}\text { Modified } \\
\text { Mercalli }\end{array}$ & $\begin{array}{c}\text { Loss } \\
\text { (percent) }\end{array}$ & $\begin{array}{l}\text { Modified } \\
\text { Mercalli }\end{array}$ & $\begin{array}{c}\text { Loss } \\
\text { (percent) }\end{array}$ & $\begin{array}{l}\text { Modified } \\
\text { Mercalli }\end{array}$ & $\begin{array}{c}\text { Loss } \\
\text { (percent) }\end{array}$ & $\begin{array}{l}\text { Modified } \\
\text { Mercalli }\end{array}$ \\
\hline I-A & 0 & V & 0.80 & VI & 8.00 & IX & 9.00 & X/XII \\
\hline I-B & 0 & $\mathrm{~V}$ & .80 & VI & 8.00 & IX & 9.00 & X/XII \\
\hline II-A & 0 & VI & .60 & VII & 6.00 & IX & 6.50 & $\mathrm{X} / \mathrm{XII}$ \\
\hline II-B & 0 & VI & .80 & VII & 8.00 & IX & 9.00 & X/XII \\
\hline Inl-A & 0 & VI & 1.00 & VII & 10.00 & IX & 12.00 & X/XII \\
\hline IIl-B & 0 & $\mathrm{~V}$ & 1.75 & VI & 17.50 & IX & 20.00 & X/XII \\
\hline III-C & 0 & VI & 1.25 & VII & 12.50 & IX & 15.00 & X/XII \\
\hline IIl-D & 0 & $\mathrm{~V}$ & 1.75 & VI & 17.50 & IX & 20.00 & X/XII \\
\hline IV-A & 0 & VI & 1.25 & VII & 12.50 & IX & 15.00 & X/XII \\
\hline IV-B & 0 & $\mathrm{~V}$ & 2.50 & VI & 25.00 & IX & 27.50 & X/XII \\
\hline IV-C & 0 & VI & 1.75 & VII & 17.50 & IX & 20.00 & X/XII \\
\hline IV-D & 0 & $\mathrm{~V}$ & 3.00 & VI & 30.00 & IX & 32.50 & X/XII \\
\hline IV-E & 0 & V & 2.75 & VI & 27.50 & IX & 30.00 & X/XII \\
\hline $\mathrm{V}-\mathrm{A}$ & 0 & VI & .75 & VII & 7.50 & IX & 9.00 & X/XII \\
\hline V-B & 0 & VI & 1.25 & VII & 12.50 & IX & 14.00 & X/XII \\
\hline $\mathrm{V}-\mathrm{C}$ & 0 & $\mathrm{~V}$ & 1.75 & VI & 17.50 & IX & 20.00 & X/XII \\
\hline V-D & 0 & V & 2.25 & VI & 22.50 & IX & 25.00 & X/XII \\
\hline$V-E$ & 0 & V & 10.00 & VI & 100.00 & XII & N/A & N/A \\
\hline V-F & 0 & IV & 10.00 & $\mathrm{~V}$ & 100.00 & XII & N/A & N/A \\
\hline
\end{tabular}

typical tract, which has a length and width of about $1 \mathrm{~km}$, about 5 percent of the tract, on average, experiences 100 percent loss. This part of the loss was computed on the total valuation including land. Values for nondwelling structures were computed by multiplying the area of structures in each construction class by the 1985 value per unit given by Steinbrugge (1986). These replacement costs are given in table 5 .

Calculation of losses to nondwellings.-Losses for nondwelling structures were computed by using only the Steinbrugge (1986) vulnerability relationships because there were no comparable Applied Technology Council (1985) ones for the Wasatch urban region.

Summary of loss estimations.-The earthquake loss estimates for all the scenario earthquakes and the expected maximum losses in a 50-year period with a 10 percent chance of exceedance are listed in tables 7 through 20 . The loss estimates are organized in the following manner. Tables 7 through 16 give losses in the four-county area for $\mathrm{M}_{s}=7.5$ and 6.5 and $\mathrm{M}_{L}=5.5$ scenario earthquakes on the Weber, Salt Lake, and Provo segments of the Wasatch fault and for a $M_{s}=7.5$ earthquake striking north-south $30 \mathrm{~km}$ west of Salt Lake City and located approximately on the western flank of the Oquirrh Mountains. Tables 17 through 19 list losses only in Salt Lake City for $\mathrm{M}_{s}=7.5$ scenario earthquakes on the Weber, Salt Lake, and Provo segments of the Wasatch fault. These losses were computed to provide additional data for earthquakes that might occur at some distance from a particular urban area and also to facilitate comparison 
TABLE 7.-Summary of estimated losses in the four-county area from a major $\left(M_{S}=7.5\right)$ earthquake on the Weber segment of the Wasatch fault

\begin{tabular}{|c|c|c|c|c|}
\hline & Number & $\begin{array}{c}\text { Value } \\
\left(\$ \times 10^{6}\right)\end{array}$ & $\begin{array}{l}\text { Losses } \\
\left(\$ \times 10^{6}\right)^{1}\end{array}$ & $\begin{array}{c}\text { Losses } \\
\left(\$ \times 10^{6}\right)^{2}\end{array}$ \\
\hline \multicolumn{5}{|c|}{ Dwellings } \\
\hline \multicolumn{5}{|l|}{ Wood frame: } \\
\hline 1-4 units (class I-A) & 122,695 & $6,308.6$ & 689.6 & 489.7 \\
\hline$\geq 5$ units (class I-B) & 21,824 & $1,140.3$ & 131.9 & 89.2 \\
\hline \multicolumn{5}{|l|}{$\begin{array}{l}\text { Masonry (classes V-B } \\
\text { and V-E): }\end{array}$} \\
\hline $1-4$ units & 184,042 & $9,462.9$ & $1,848.7$ & $2,960.9$ \\
\hline$\geq 5$ units & 32,736 & $1,959.2$ & 441.7 & 764.9 \\
\hline Total & 361,297 & $18,871.0$ & $3,111.9$ & $4,304.7$ \\
\hline
\end{tabular}

\begin{tabular}{|c|c|c|}
\hline \multicolumn{3}{|c|}{ Nondwellings } \\
\hline Wood frame (class I-B) & 40.1 & 3.5 \\
\hline All metal (class II) & 108.5 & 8.6 \\
\hline Steel frame (class III) & 761.3 & 111.5 \\
\hline Concrete frame (class IV) & $2,175.7$ & 403.8 \\
\hline \multicolumn{3}{|l|}{ Mixed construction } \\
\hline$($ class V) & $1,782.3$ & 347.4 \\
\hline Total & $4,867.9$ & 874.8 \\
\hline \multicolumn{3}{|c|}{ Dwellings and nondwellings } \\
\hline Total & $23,738.9$ & $5,179.5$ \\
\hline $\begin{array}{l}{ }^{1} \text { Losses computed from vu } \\
\text { Technology Council (1985). } \\
{ }^{2} \text { Losses computed from v }\end{array}$ & $\begin{array}{l}\text { lationships } \\
\text { elationship }\end{array}$ & $\begin{array}{l}\text { the Applie } \\
\text { gure } 11 \text { an }\end{array}$ \\
\hline
\end{tabular}

with earlier work (Algermissen and Steinbrugge, 1984). Table 20 gives expected maximum losses in the fourcounty area in 50 years with a 10-percent chance of exceedance.

\section{DISCUSSION}

Estimates of primary losses for 10 simulated earthquakes on four different faults together with a probabilistic estimate of maximum losses in 50 years have been presented for the Utah, Salt Lake, Davis, and Weber County urban area. The total replacement cost or value of the buildings surveyed in the four-county area (1985 values) is $\$ 23.7$ billion. Losses for all earthquakes considered
TABLE 8.-Summary of estimated losses in the four-county area from a major $\left(M_{S}=7.5\right)$ earthquake on the Salt Lake segment of the Wasatch fault

\begin{tabular}{|c|c|c|c|c|}
\hline & Number & $\begin{array}{l}\text { Value } \\
\left(\$ \times 10^{6}\right)\end{array}$ & $\begin{array}{c}\text { Losses } \\
\left(\$ \times 10^{6}\right)^{1}\end{array}$ & $\begin{array}{c}\text { Losses } \\
\left(\$ \times 10^{6}\right)^{2}\end{array}$ \\
\hline \multicolumn{5}{|c|}{ Dwellings } \\
\hline \multicolumn{5}{|l|}{ Wood frame: } \\
\hline 1-4 units (class I-A) & 122,695 & $6,308.6$ & 850.3 & 550.4 \\
\hline$\geq 5$ units (class I-B) & 21,824 & $1,140.3$ & 172.5 & 103.3 \\
\hline \multicolumn{5}{|l|}{$\begin{array}{l}\text { Masonry (classes V-B } \\
\text { and V-E): }\end{array}$} \\
\hline $1-4$ units & 184,042 & $9,462.9$ & $2,143.8$ & $3,094.6$ \\
\hline$\geq 5$ units & 32,736 & $1,959.2$ & 537.4 & 802.7 \\
\hline Total & 361,297 & $18,871.0$ & $3,704.0$ & $4,551.0$ \\
\hline \multicolumn{5}{|c|}{ Nondwellings } \\
\hline Wood frame (class I-B) & & 40.1 & & 3.6 \\
\hline All metal (class II) & & 108.5 & & 8.5 \\
\hline Steel frame (class III) & & 761.3 & & 119.7 \\
\hline Concrete frame (class IV) & & $2,175.7$ & & 417.1 \\
\hline \multicolumn{5}{|l|}{$\begin{array}{l}\text { Mixed construction } \\
(\text { class } V)\end{array}$} \\
\hline$($ class V) & & $1,782.3$ & & 362.9 \\
\hline Total & & $4,867.9$ & & 911.8 \\
\hline \multicolumn{5}{|c|}{ Dwellings and nondwellings } \\
\hline Total & & $23,739.9$ & & $5,462.8$ \\
\hline
\end{tabular}

${ }^{1}$ Losses computed from vulnerability relationships developed by the Applied Technology Council (1985).

${ }^{2}$ Losses computed from vulnerability relationships shown in figure 11 and table 6.

ranged from $\$ 830$ million $\left(\mathrm{M}_{L}=5.5\right.$ on the Provo seginent) to $\$ 5.5$ billion ( $\mathrm{M}_{s}=7.5$ on the Salt Lake seginent), a range of from 3 to 22 percent of the total value at risk. The expected maximum loss in a 50-year period with a 10percent chance of exceedance is $\$ 3.2$ billion. Dwellings constituted between 82 and 88 percent of the total losses for all of the earthquakes considered, including the probabilistic model.

The relatively high loss estimates for the area are a result of two important factors: (1) the relatively high proportion of brick dwellings in the four-county area and (2) the high site response associated with the surface and near-surface materials underlying the area.

Extensive damage to unreinforced brick buildings is a well-documented result of severe earthquakes. Recent 
TABLE 9.-Summary of estimated losses in the four-county area from a major $\left(M_{s}=7.5\right)$ earthquake on a hypothetical fault segment $30 \mathrm{~km}$ west of Salt Lake City

\begin{tabular}{|c|c|c|c|c|}
\hline & Number & $\begin{array}{c}\text { Value } \\
\left(\$ \times 10^{6}\right)\end{array}$ & $\begin{array}{l}\text { Losses } \\
\left(\$ \times 10^{6}\right)^{1}\end{array}$ & $\begin{array}{c}\text { Losses } \\
\left(\$ \times 10^{6}\right)^{2}\end{array}$ \\
\hline \multicolumn{5}{|c|}{ Dwellings } \\
\hline \multicolumn{5}{|l|}{ Wood frame: } \\
\hline 1-4 units (class l-A) & 122,695 & $6,308.6$ & 490.5 & 454.4 \\
\hline$\geq 5$ units (class I-B) & 21,824 & $1,140.3$ & 97.0 & 84.0 \\
\hline \multicolumn{5}{|l|}{$\begin{array}{l}\text { Masonry (classes V-B } \\
\text { and V-E): }\end{array}$} \\
\hline $1-4$ units & 184,042 & $9,462.9$ & $1,477.8$ & $2,792.3$ \\
\hline$\geq 5$ units & 32,736 & $1,959.2$ & 363.5 & 737.1 \\
\hline Total & 361,297 & $18,871.0$ & $2,428.8$ & $4,067.8$ \\
\hline
\end{tabular}

\begin{tabular}{lrr}
\hline \multicolumn{2}{c}{ Nondwellings } \\
\hline Wood frame (class I-B) & 40.1 & 3.3 \\
All metal (class II) & 108.5 & 8.2 \\
Steel frame (class III) & 761.3 & 107.2 \\
Concrete frame (class IV) & $2,175.7$ & 375.2 \\
Mixed construction & & \\
$\quad$ class V) & $1,782.3$ & 330.2 \\
$\quad$ Total & $4,867.9$ & 824.1 \\
\hline
\end{tabular}

Dwellings and nondwellings

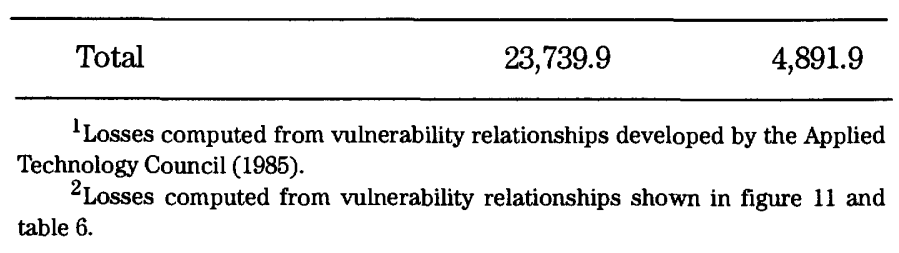

large, damaging earthquakes have established the importance of site response in earthquake damage and have also shown that site response can, at least in a general way, be estimated from analysis of small earthquakes and blasts. Examples are the large site-response factors that radically affected the patterns of ground shakimg in the large 1985 earthquakes in Chile (Algermissen, 1985) and Mexico (Stone and others, 1987; Cassaro and Romero, 1986) and the small but damaging 1986 shock in El Salvador (Ríos and others, 1986).

A source of possible uncertainty in the estimation of losses to brick buildings in the four-county area is the
TABLE 10.-Summary of estimated losses in the four-county area from a major $\left(M_{s}=7.5\right)$ earthquake on the Provo segment of the Wasatch fault

\begin{tabular}{|c|c|c|c|c|}
\hline & Number & $\begin{array}{l}\text { Value } \\
\left(\$ \times 10^{6}\right)\end{array}$ & $\begin{array}{l}\text { Losses } \\
\left(\$ \times 10^{6}\right)^{1}\end{array}$ & $\begin{array}{c}\text { Losses } \\
\left(\$ \times 10^{6}\right)^{2}\end{array}$ \\
\hline \multicolumn{5}{|c|}{ Dwellings } \\
\hline \multicolumn{5}{|l|}{ Wood frame: } \\
\hline $1-4$ units (class I-A) & 122,695 & $6,308.6$ & 413.8 & 426.8 \\
\hline$\geq 5$ units (class I-B) & 21,824 & $1,140.3$ & 84.8 & 81.3 \\
\hline \multicolumn{5}{|l|}{$\begin{array}{l}\text { Masonry (classes V-B } \\
\text { and V-E): }\end{array}$} \\
\hline $1-4$ units & 184,042 & $9,462.9$ & $1,279.7$ & $2,563.1$ \\
\hline$\geq 5$ units & 32,736 & $1,959.2$ & 326.0 & 699.2 \\
\hline Total & 361,297 & $18,871.0$ & $2,104.3$ & $3,770.4$ \\
\hline \multicolumn{5}{|c|}{ Nondwellings } \\
\hline Wood frame (class I-B) & & 40.1 & & 3.0 \\
\hline All metal (class II) & & 108.5 & & 6.4 \\
\hline Steel frame (class III) & & 761.3 & & 97.0 \\
\hline Concrete frame (class IV) & & $2,175.7$ & & 321.6 \\
\hline \multicolumn{5}{|l|}{ Mixed construction } \\
\hline (class V) & & $1,782.3$ & & 298.9 \\
\hline Total & & $4,867.9$ & & 726.9 \\
\hline \multicolumn{5}{|c|}{ Dwellings and nondwellings } \\
\hline Total & & $23,739.9$ & & $4,497.3$ \\
\hline
\end{tabular}

\footnotetext{
${ }^{1}$ Losses computed from vulnerability relationships developed by the Applied Technology Council (1985).

${ }^{2}$ Losses computed from vulnerability relationships shown in figure 11 and
} table 6 .

ratio of brick to wood-frame dwellings. The ratio used in this study (60 percent brick) was based on limited sampling in the study area and expert opinion from staff of the Salt Lake City Planning Commission. We believe that additional sampling may be warranted in future studies, particularly because of the large site-response factors that exist throughout the area.

Sensitivity studies of the effect of variability im MM intensity on the loss estimations are included in tables 21 through 23 for all of the scenario earthquakes on the Salt Lake segment of the Wasatch fault. The losses for each of these scenario earthquakes have been recomputed by 
TABLE 11.-Summary of estimated losses in the four-county area from a strong $\left(M_{S}=6.5\right)$ earthquake on the Weber segment of the Wasatch fault

\begin{tabular}{|c|c|c|c|c|}
\hline & Number & $\begin{array}{l}\text { Value } \\
\left(\$ \times 10^{6}\right)\end{array}$ & $\begin{array}{l}\text { Losses } \\
\left(\$ \times 10^{6}\right)^{1}\end{array}$ & $\begin{array}{c}\text { Losses } \\
\left(\$ \times 10^{6}\right)^{2}\end{array}$ \\
\hline \multicolumn{5}{|c|}{ Dwellings } \\
\hline \multicolumn{5}{|l|}{ Wood frame: } \\
\hline 1-4 units (class I-A) & 122,695 & $6,308.6$ & 218.0 & 301.2 \\
\hline$\geq 5$ units (class I-B) & 21,824 & $1,140.3$ & 40.7 & 55.1 \\
\hline \multicolumn{5}{|l|}{$\begin{array}{l}\text { Masonry (classes V-B } \\
\text { and V-E): }\end{array}$} \\
\hline 1-4 units & 184,042 & $9,462.9$ & 699.4 & $1,713.3$ \\
\hline$\geq 5$ units & 32,736 & $1,959.2$ & 168.9 & 472.6 \\
\hline Total & 361,297 & $18,871.0$ & $1,127.0$ & $2,560.2$ \\
\hline
\end{tabular}

\begin{tabular}{lrr}
\hline \multicolumn{2}{c}{ Nondwellings } \\
\hline Wood frame (class I-B) & 40.1 & 2.3 \\
All metal (class II) & 108.5 & 5.2 \\
Steel frame (class III) & 761.3 & 64.2 \\
Concrete frame (class IV) & $2,175.7$ & 236.6 \\
Mixed construction & & \\
$\quad$ (class V) & $1,782.3$ & 198.1 \\
$\quad$ Total & $4,867.9$ & 506.4 \\
\hline
\end{tabular}

\begin{tabular}{ccc}
\hline \multicolumn{3}{c}{ Dwellings and nondwellings } \\
\hline Total & $23,739.9$ & $3,066.6$ \\
\hline
\end{tabular}

\footnotetext{
${ }^{1}$ Losses computed from vulnerability relationships developed by the Applied Technology Council (1985).

${ }^{2}$ Losses computed from vulnerability relationships shown in figure 11 and table 6 .
}

assuming a one-unit increase and decrease in the MM intensity throughout the four-county area. The changes in loss levels are striking and are a representative measure of the change in loss estimates when the MM intensity is varied over a realistic range. These sensitivity studies reveal some interesting characteristics of the loss estimates. For example, for a $\mathrm{M}_{s}=7.5$ earthquake on the Salt Lake segment (table 21), a decrease of one intensity unit decreases losses by 20 percent ( $\$ 1.03$ billion), whereas an increase of one intensity unit reverses the losses by only 6 percent ( $\$ 353$ million). This variation in rate of change is associated with saturation of the vulnerability curves at
TABLE 12.-Summary of estimated losses in the four-county area from a strong $\left(M_{s}=6.5\right)$ earthquake on the Salt Lake segment of the Wasatch fault

\begin{tabular}{|c|c|c|c|c|}
\hline & Number & $\begin{array}{l}\text { Value } \\
\left(\$ \times 10^{6}\right)\end{array}$ & $\begin{array}{l}\text { Losses } \\
\left(\$ \times 10^{6}\right)^{1}\end{array}$ & $\begin{array}{c}\text { Losses } \\
\left(\$ \times 10^{6}\right)^{2}\end{array}$ \\
\hline \multicolumn{5}{|c|}{ Dwellings } \\
\hline \multicolumn{5}{|l|}{ Wood frame: } \\
\hline 1-4 units (class I-A) & 122,695 & $6,308.6$ & 330.0 & 396.4 \\
\hline$\geq 5$ units (class I-B) & 21,824 & $1,140.3$ & 68.7 & 77.8 \\
\hline \multicolumn{5}{|l|}{$\begin{array}{l}\text { Masonry (classes V-B } \\
\text { and V-E): }\end{array}$} \\
\hline $1-4$ units & 184,042 & $9,462.9$ & $1,025.6$ & $2,214.3$ \\
\hline$\geq 5$ units & 32,736 & $1,959.2$ & 273.1 & 629.2 \\
\hline Total & 361,297 & $18,871.0$ & $1,697.4$ & $3,317.7$ \\
\hline \multicolumn{5}{|c|}{ Nondwellings } \\
\hline Wood frame (class I-B) & & 40.1 & & 3.0 \\
\hline All metal (class II) & & 108.5 & & 5.9 \\
\hline Steel frame (class III) & & 761.3 & & 89.6 \\
\hline Concrete frame (class IV) & & $2,175.7$ & & 301.1 \\
\hline \multicolumn{4}{|l|}{ Mixed construction } & 236.3 \\
\hline Total & & $4,867.9$ & & 635.9 \\
\hline \multicolumn{5}{|c|}{ Dwellings and nondwellings } \\
\hline Total & & $23,739.9$ & & $3,953.6$ \\
\hline
\end{tabular}

\footnotetext{
${ }^{1}$ Losses computed from vulnerability relationships developed by the Applied Technology Council (1985).

${ }^{2}$ Losses computed from vulnerability relationships shown in figure 11 and
} table 6 .

high intensities. The variation in rate of change is still evident, but to a lesser extent, for the $M_{s}=6.5$ earthquake on the Salt Lake segment (table 22). For the $\mathrm{M}_{L}=5.5$ earthquake, the vulnerability curves are in a more linear range, and the change in losses from $\Delta I=-1$ to $\Delta I=+1$ is much more linear $(-61.9$ percent) for $\Delta I=-1$ and +89.4 percent for $\Delta I=+1)$ than it is for the larger shocks.

We also provide some information in this study on variation in loss estimates with changes in vulnerability. A measure of the sensitivity of loss estimations to changes in vulnerability assumptions is provided by comparing the losses calculated for dwellings by using the vulnerability 
TABLE 13.-Summary of estimated losses in the four-county area from a strong $\left(M_{s}=6.5\right)$ earthquake on the Provo segment of the Wasatch fault

\begin{tabular}{llrrr}
\hline & Number & $\begin{array}{c}\text { Value } \\
\left(\$ \times 10^{6}\right)\end{array}$ & $\begin{array}{c}\text { Losses } \\
\left(\$ \times 10^{6}\right)^{1}\end{array}$ & $\begin{array}{c}\text { Losses } \\
\left(\$ \times 10^{6}\right)^{2}\end{array}$ \\
\hline \multicolumn{4}{c}{ Dwellings } \\
& & & \\
\hline Wood frame: & & & \\
$\quad 1-4$ units (class I-A) & 122,695 & $6,308.6$ & 157.9 & 242.9 \\
$\geq 5$ units (class I-B) & 21,824 & $1,140.3$ & 34.7 & 50.1 \\
Masonry (classes V-B & & & & \\
$\begin{array}{l}\text { and V-E): } \\
1-4 \text { units }\end{array}$ & 184,042 & $9,462.9$ & 489.5 & $1,307.7$ \\
$\geq 5$ units & 32,736 & $1,959.2$ & 135.4 & 392.4 \\
$\quad$ Total & 361,297 & $18,871.0$ & 817.5 & $1,993.1$ \\
\hline
\end{tabular}

\begin{tabular}{|c|c|c|}
\hline \multicolumn{3}{|c|}{ Nondwellings } \\
\hline Wood frame (class I-B) & 40.1 & 1.8 \\
\hline All metal (class II) & 108.5 & 2.0 \\
\hline Steel frame (class III) & 761.3 & 49.2 \\
\hline Concrete frame (class IV) & $2,175.7$ & 148.5 \\
\hline \multicolumn{3}{|l|}{ Mixed construction } \\
\hline (class V) & $1,782.3$ & 136.3 \\
\hline Total & $4,867.9$ & 337.8 \\
\hline \multicolumn{3}{|c|}{ Dwellings and nondwellings } \\
\hline Total & $23,739.9$ & $2,330.9$ \\
\hline $\begin{array}{l}{ }^{1} \text { Losses computed from vul } \\
\text { Technology Council (1985). } \\
{ }^{2} \text { Losses computed from vul } \\
\text { table } 6 .\end{array}$ & $\begin{array}{l}\text { lationships d } \\
\text { elationships }\end{array}$ & the Applied \\
\hline
\end{tabular}

relationship developed by the Applied Technology Council (1985) with those calculated by using Steinbrugge's (1986) relationship. These results are shown in tables 7 through 20 . The differences in losses computed by using the two different vulnerability curves are not very significant for wood-frame dwellings; however, they are quite significant for inasonry dwellings. This difference suggests that further review and research on the vulnerability of brick dwellings are important. Loss comparisons for structures other than dwellings made by using the Applied Technology Council (1985) and the Steinbrugge (1986) vulnerability relationships were not possible
TABLE 14.-Summary of estimated losses in the four-county area from a moderate $\left(M_{L}=5.5\right)$ earthquake on the Weber segment of the Wasatch fault

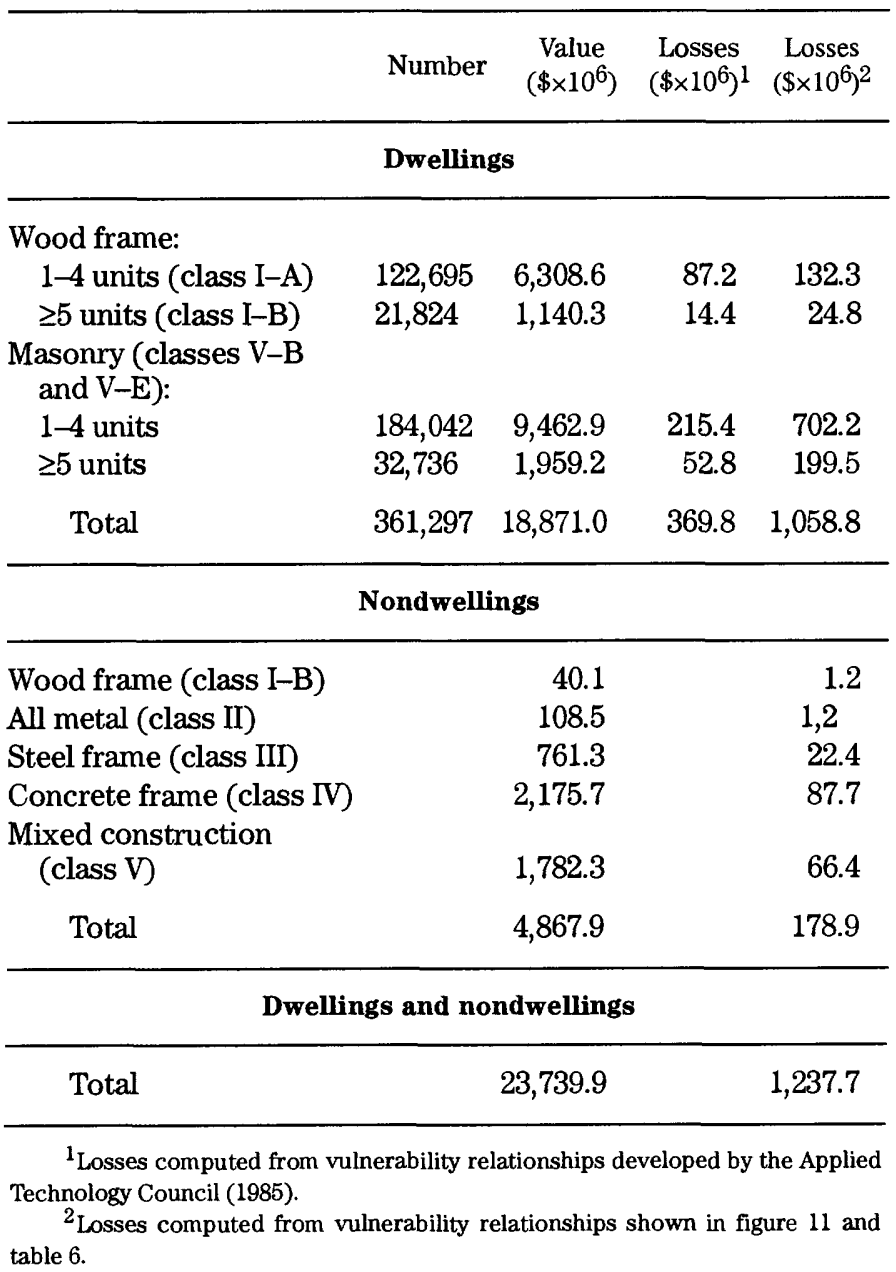

because of differences in the way nondwellings are classified in the two vulnerability studies.

Most of the areas covered by this study is underlain by silt and clay having a very high site-response factor (that is, 2.6 intensity units greater than rock) (compare with table 3 ), so losses nay appear very large. The effects of site response can be deduced from the data in tables 21 through 23. Decreasing the intensities by one unit is the equivalent of decreasing the soil amplification to slightly more than that associated with rubble in table 3; this decrease, in turn, reduces the losses very significantly, especially at low intensities. In the case of the $\mathrm{M}_{L}=5.5$ 
TABLE 15.-Summary of estimated losses in the four-county area from a moderate $\left(M_{L}=5.5\right)$ earthquake on the Salt Lake segment of the Wasatch fault

\begin{tabular}{|c|c|c|c|c|}
\hline & Number & $\begin{array}{c}\text { Value } \\
\left(\$ \times 10^{6}\right)\end{array}$ & $\begin{array}{l}\text { Losses } \\
\left(\$ \times 10^{6}\right)^{1}\end{array}$ & $\begin{array}{l}\text { Losses } \\
\left(\$ \times 10^{6}\right)^{2}\end{array}$ \\
\hline \multicolumn{5}{|c|}{ Dwellings } \\
\hline \multicolumn{5}{|l|}{ Wood frame: } \\
\hline 1-4 units (class I-A) & 122,695 & $6,308.6$ & 139.3 & 210.0 \\
\hline$\geq 5$ units (class I-B) & 21,824 & $1,140.3$ & 27.4 & 40.1 \\
\hline \multicolumn{5}{|l|}{$\begin{array}{l}\text { Masonry (classes V-B } \\
\text { and V-E): }\end{array}$} \\
\hline $1-4$ units & 184,042 & $9,462.9$ & 395.3 & $1,081.1$ \\
\hline$\geq 5$ units & 32,736 & $1,959.2$ & 105.7 & 329.1 \\
\hline Total & 361,297 & $18,871.0$ & 667.7 & $1,660.3$ \\
\hline
\end{tabular}

\begin{tabular}{lrr}
\hline \multicolumn{2}{c}{ Nondwellings } \\
\hline Wood frame (class I-B) & 40.1 & 1.8 \\
All metal (class II) & 108.5 & 2.0 \\
Steel frame (class III) & 761.3 & 44.2 \\
Concrete frame (class IV) & $2,175.7$ & 137.8 \\
Mixed construction & & \\
$\quad$ (class V) & $1,782.3$ & 91.8 \\
$\quad$ Total & $4,867.9$ & 277.6
\end{tabular}

\begin{tabular}{lcc}
\hline \multicolumn{3}{c}{ Dwellings and nondwellings } \\
\hline Total & $23,739.9$ & $1,937.9$
\end{tabular}

\footnotetext{
${ }^{1}$ Losses computed from vulnerability relationships developed by the Applied Technology Council (1985).

${ }^{2}$ Losses computed from vulnerability relationships shown in figure 11 and table 6.
}

earthquake on the Salt Lake segment, the losses are reduced from $\$ 1,937.9$ million to $\$ 735.7$ million. This latter estimate is still larger than the $\$ 385$ million loss sustained in the intensity VIII Whittier Narrows, Calif., earthquake of October 1, 1987 (Hauksson and others, 1988), but this difference may be attributed to the comparatively high proportion of very vulnerable masonry buildings in the Salt Lake area.

Thus, these analyses provide considerable additional information about the structure of the losses and how they change.
TABLE 16.-Summary of estimated losses in the four-county area from a moderate $\left(M_{L}=5.5\right)$ earthquake on the Provo segment of the Wasatch fault

\begin{tabular}{|c|c|c|c|c|}
\hline & Number & $\begin{array}{c}\text { Value } \\
\left(\$ \times 10^{6}\right)\end{array}$ & $\begin{array}{l}\text { Losses } \\
\left(\$ \times 10^{6}\right)^{1}\end{array}$ & $\begin{array}{l}\text { Losses } \\
\left(\$ \times 10^{6}\right)^{2}\end{array}$ \\
\hline \multicolumn{5}{|c|}{ Dwellings } \\
\hline \multicolumn{5}{|l|}{ Wood frame: } \\
\hline 1-4 units (class I-A) & 122,695 & $6,308.6$ & 66.3 & 91.0 \\
\hline$\geq 5$ units (class I-B) & 21,824 & $1,140.3$ & 15.6 & 22.9 \\
\hline \multicolumn{5}{|l|}{$\begin{array}{l}\text { Masonry (classes V-B } \\
\text { and V-E): }\end{array}$} \\
\hline $1-4$ units & 184,042 & $9,462.9$ & 129.7 & 446.5 \\
\hline$\geq 5$ units & 32,736 & $1,959.2$ & 45.3 & 154.4 \\
\hline Total & 361,297 & $18,871.0$ & 256.9 & 714.8 \\
\hline \multicolumn{5}{|c|}{ Nondwellings } \\
\hline Wood frame (class 1-B) & & 40.1 & & 0.7 \\
\hline All metal (class II) & & 108.5 & & .3 \\
\hline Steel frame (class III) & & 761.3 & & 17.2 \\
\hline Concrete frame (class IV) & & $2,175.7$ & & 46.5 \\
\hline \multicolumn{5}{|l|}{ Mixed construction } \\
\hline (class V) & & $1,782.3$ & & 45.3 \\
\hline Total & & $4,867.9$ & & 110.0 \\
\hline \multicolumn{5}{|c|}{ Dwellings and nondwellings } \\
\hline Total & & $23,739.9$ & & 824.8 \\
\hline
\end{tabular}

${ }^{1}$ Losses computed from vulnerability relationships developed by the Applied Technology Council (1985).

${ }^{2}$ Losses computed from vulnerability relationships shown in figure 11 and table 6.

Losses associated with liquefaction and landsliding have not been considered in this report because of uncertainty in the areal relationships for these types of geologic hazards. Rojahn and others (1977) have recently provided information on areas of possible liquefaction damage in Salt Lake County and discussed a general methodology for incorporating estimates of damage caused by liquefaction and landsliding into damage estimates based on shaking and fault rupture. The losses associated with geological hazards are, however, not simply additive, the total damage to a structure being some complex combination of damage from shaking, landsliding, and liquefaction. 
TABLE 17.-Summary of estimated losses in Salt Lake City from a major $\left(M_{s}=7.5\right)$ earthquake on the Salt Lake segment of the Wasatch fault

\begin{tabular}{|c|c|c|c|c|}
\hline & Number & $\begin{array}{c}\text { Value } \\
\left(\$ \times 10^{6}\right)\end{array}$ & $\begin{array}{l}\text { Losses } \\
\left(\$ \times 10^{6}\right)^{1}\end{array}$ & $\begin{array}{c}\text { Losses } \\
\left(\$ \times 10^{6}\right)^{2}\end{array}$ \\
\hline \multicolumn{5}{|c|}{ Dwellings } \\
\hline \multicolumn{5}{|l|}{ Wood frame: } \\
\hline 1-4 units (class I-A) & 21,506 & $1,115.7$ & 223.7 & 112.9 \\
\hline$\geq 5$ units (class I-B) & 8,409 & 439.4 & 88.4 & 46.2 \\
\hline \multicolumn{5}{|l|}{$\begin{array}{l}\text { Masonry (classes V-B } \\
\text { and V-E): }\end{array}$} \\
\hline $1-4$ units & 32,260 & $1,673.5$ & 684.5 & $1,047.0$ \\
\hline$\geq 5$ units & 12,614 & 754.9 & 309.5 & 473.4 \\
\hline Total & 74,789 & $3,983.5$ & $1,306.1$ & $1,679.5$ \\
\hline \multicolumn{5}{|c|}{ Nondwellings } \\
\hline Wood frame (class I-B) & & 40.1 & & 3.6 \\
\hline All metal (class II) & & 79.8 & & 6.4 \\
\hline Steel frame (class III) & & 551.6 & & 84.9 \\
\hline Concrete frame (class IV) & & $1,692.4$ & & 327.3 \\
\hline \multicolumn{5}{|l|}{ Mixed construction } \\
\hline$($ class V) & & $1,013.7$ & & 178.1 \\
\hline Total & & $3,377.6$ & & 600.3 \\
\hline \multicolumn{5}{|c|}{ Dwellings and nondwellings } \\
\hline Total & & $7,361.1$ & & $2,279.8$ \\
\hline
\end{tabular}

${ }^{1}$ Losses computed from vulnerability relationships developed by the Applied Technology Council (1985).

${ }^{2}$ Losses computed from vulnerability relationships shown in figure 11 and table 6.
TABLE 18.-Summary of estimated losses in Salt Lake City from a major $\left(M_{s}=7.5\right)$ earthquake on the Weber segment of the Wasatch fault

\begin{tabular}{|c|c|c|c|c|}
\hline & Number & $\begin{array}{c}\text { Value } \\
\left(\$ \times 10^{6}\right)\end{array}$ & $\begin{array}{l}\text { Losses } \\
\left(\$ \times 10^{6}\right)^{1}\end{array}$ & $\begin{array}{c}\text { Losses } \\
\left(\$ \times 10^{6}\right)^{2}\end{array}$ \\
\hline \multicolumn{5}{|c|}{ Dwellings } \\
\hline \multicolumn{5}{|l|}{ Wood frame: } \\
\hline $1-4$ units (class I-A) & 21,506 & $1,115.7$ & 153.9 & 94.0 \\
\hline$\geq 5$ units (class I-B) & 8,409 & 439.4 & 61.2 & 36.9 \\
\hline \multicolumn{5}{|l|}{$\begin{array}{l}\text { Masonry (classes V-B } \\
\text { and V-E): }\end{array}$} \\
\hline $1-4$ units & 32,260 & $1,673.5$ & 535.4 & $1,026.0$ \\
\hline$\geq 5$ units & 12,614 & 754.9 & 241.9 & 460.4 \\
\hline Total & 74,789 & $3,983.5$ & 992.4 & $1,617.3$ \\
\hline \multicolumn{5}{|c|}{ Nondwellings } \\
\hline Wood frame (class I-B) & & 40.1 & & 3.5 \\
\hline All metal (class II) & & 79.8 & & 6.3 \\
\hline Steel frame (class III) & & 551.6 & & 80.1 \\
\hline Concrete frame (class IV) & & $1,692.4$ & & 311.8 \\
\hline \multicolumn{5}{|l|}{ Mixed construction } \\
\hline (- & & 22776 & & 5726 \\
\hline Iotal & & $0,0 / 1.0$ & & 010.0 \\
\hline \multicolumn{5}{|c|}{ Dwellings and nondwellings } \\
\hline Total & & $7,361.1$ & & $2,190.9$ \\
\hline
\end{tabular}

${ }^{1}$ Losses computed from vulnerability relationships developed by the Applied Technology Council (1985).

${ }^{2}$ Losses computed from vulnerability relationships shown in figure 11 and able 6 . 
TABLE 19.-Summary of estimated losses in Salt Lake City from a major $\left(M_{s}=7.5\right)$ earthquake on the Provo segment of the Wasatch fault

\begin{tabular}{lrrrr}
\hline & Number & $\begin{array}{c}\text { Value } \\
\left(\$ \times 10^{6}\right)\end{array}$ & $\begin{array}{c}\text { Losses } \\
\left(\$ \times 10^{6}\right)^{1}\end{array}$ & $\begin{array}{c}\text { Losses } \\
\left(\$ \times 10^{6}\right)^{2}\end{array}$ \\
\hline \multicolumn{5}{c}{ Dwellings } \\
& & & \\
\hline Wood frame: & & & \\
$\begin{array}{l}1-4 \text { units (class I-A) } \\
\geq 5 \text { units (class I-B) }\end{array}$ & 21,506 & $1,115.7$ & 73.5 & 79.7 \\
$\begin{array}{l}\text { Masonry (classes V-B } \\
\text { and V-E): }\end{array}$ & 8,409 & 439.4 & 28.4 & 31.0 \\
$\begin{array}{l}1-4 \text { units } \\
\geq 5 \text { units }\end{array}$ & 32,260 & $1,673.5$ & 343.1 & 914.1 \\
$\quad 12,614$ & 754.9 & 151.8 & 407.0 \\
Total & 74,789 & $3,983.5$ & 596.8 & $1,431.8$ \\
\hline
\end{tabular}

Nondwellings

\begin{tabular}{lrr}
\hline Wood frame (class I-B) & 40.1 & 3.0 \\
All metal (class II) & 79.8 & 5.2 \\
Steel frame (class III) & 551.6 & 66.2 \\
Concrete frame (class IV) & $1,692.4$ & 249.6 \\
Mixed construction & $1,013.7$ & 143.2 \\
$\quad$ (class V) & $3,377.6$ & 467.2 \\
$\quad$ Total & \\
\hline \multicolumn{2}{c}{ Dwellings and nondwellings } \\
\hline \multicolumn{2}{c}{ Total }
\end{tabular}

\footnotetext{
${ }^{1}$ Losses computed from vulnerability relationships developed by the Applied Technology Council (1985).

${ }^{2}$ Losses computed from vulnerability relationships shown in figure 11 and table 6.
}

TABLE 20.-Summary of expected maximum losses in the fourcounty area over a 50-year period with a 10-percent chance of exceedance

\begin{tabular}{|c|c|c|c|c|}
\hline & Number & $\begin{array}{c}\text { Value } \\
\left(\$ \times 10^{6}\right)\end{array}$ & $\begin{array}{l}\text { Losses } \\
\left(\$ \times 10^{6}\right)^{1}\end{array}$ & $\begin{array}{c}\text { Losses } \\
\left(\$ \times 10^{6}\right)^{2}\end{array}$ \\
\hline \multicolumn{5}{|c|}{ Dwellings } \\
\hline \multicolumn{5}{|l|}{ Wood frame: } \\
\hline 1-4 units (class I-A) & 122,695 & $6,308.6$ & 128.0 & 221.4 \\
\hline$\geq 5$ units (class I-B) & 21,824 & $1,140.3$ & 25.7 & 43.0 \\
\hline \multicolumn{5}{|l|}{$\begin{array}{l}\text { Masonry (classes V-B } \\
\text { and V-E): }\end{array}$} \\
\hline $1-4$ units & 184,042 & $9,462.9$ & 416.0 & $1,214.5$ \\
\hline$\geq 5$ units & 32,736 & $1,959.2$ & 109.0 & 352.6 \\
\hline Total & 361,296 & $18,871.0$ & 678.7 & $1,831.4$ \\
\hline \multicolumn{5}{|c|}{ Nondwellings } \\
\hline Wood frame (class I-B) & & 40.1 & & 1.7 \\
\hline All metal (class II) & & 108.5 & & 2.6 \\
\hline Steel frame (class III) & & 761.3 & & 44.8 \\
\hline Concrete frame (class IV) & & $2,175.7$ & & 150.1 \\
\hline \multicolumn{5}{|l|}{ Mixed construction } \\
\hline (class V) & & $1,782.3$ & & 125.7 \\
\hline Total & & $4,867.3$ & & 324.9 \\
\hline \multicolumn{5}{|c|}{ Dwellings and nondwellings } \\
\hline Total & & $23,738.9$ & & $2,156.3$ \\
\hline
\end{tabular}

${ }^{1}$ Losses computed from vulnerability relationships developed by the Applied Technology Council (1985).

${ }^{2}$ Losses computed from vulnerability relationships shown in figure 11 and table 6 . 
TABLE 21.-Variation of losses with intensity for a major $\left(M_{s}=7.5\right)$ earthquake on the Salt Lake segment of the Wasatch fault [N/A, not applicable]]

\begin{tabular}{lrrrrrrc}
\hline Class & $\begin{array}{c}\text { Value } \\
\left(\$ \times 10^{6}\right)\end{array}$ & $\begin{array}{c}\text { Loss }^{-1} \\
\left(\$ \times 10^{6}\right)^{1}\end{array}$ & $\begin{array}{c}\text { Loss }^{0} \\
\left(\$ \times 10^{6}\right)^{2}\end{array}$ & $\begin{array}{c}\text { Loss }^{+1} \\
\left(\$ \times 10^{6}\right)^{3}\end{array}$ & $\begin{array}{c}\text { Loss }^{-1} \\
(\text { percent })^{1}\end{array}$ & $\begin{array}{c}\text { Loss }^{0} \\
(\text { percent })^{2}\end{array}$ & $\begin{array}{c}\text { Loss }^{+1} \\
(\text { percent })^{3}\end{array}$ \\
\hline I & $7,489.0$ & 530.8 & 657.3 & 712.2 & -19.2 & 0 & 8.4 \\
II & 108.5 & 6.8 & 8.5 & 8.8 & -20.0 & 0 & 3.5 \\
III & 761.3 & 100.9 & 119.7 & 122.7 & -15.7 & 0 & 2.5 \\
IV & $2,175.7$ & 336.7 & 417.1 & 438.0 & -19.3 & 0 & 5.0 \\
V & $13,204.4$ & $3,443.7$ & $4,260.2$ & $4,546.2$ & -19.2 & 0 & 6.7 \\
\multicolumn{1}{c}{ Total } & $23,739.9$ & $4,418.9$ & $5,462.8$ & $5,827.9$ & N/A & N/A & N/A \\
& & & & &
\end{tabular}

${ }^{1}$ Loss $^{-1}\left(\$ \times 10^{-6}\right)$ and loss $^{-1}$ (percent) are the losses and change in losses, respectively, when all intensities have been reduced by one intensity unit.

${ }^{2}$ Loss $^{0}\left(\$ \times 10^{-6}\right)$ and loss ${ }^{0}$ (percent) are the same losses given in table 8 .

${ }^{3}$ Loss $^{+1}\left(\$ \times 10^{-6}\right)$ and loss ${ }^{+1}$ (percent) are the losses and change in losses, respectively, when all intensities have been increased by one intensity unit.

TABLE 22.-Variation of losses with intensity for a strong $\left(M_{s}=6.5\right)$ earthquake on the Salt Lake segment of the Wasatch fault [N/A, not applicable]]

\begin{tabular}{|c|c|c|c|c|c|c|c|}
\hline Class & $\begin{array}{c}\text { Value } \\
\left(\$ \times 10^{6}\right)\end{array}$ & $\begin{array}{c}\text { Loss }^{-1} \\
\left(\$ \times 10^{6}\right)^{1}\end{array}$ & $\begin{array}{c}\operatorname{Loss}^{0} \\
\left(\$ \times 10^{6}\right)^{2}\end{array}$ & $\begin{array}{c}\operatorname{Loss}^{+1} \\
\left(\$ \times 10^{6}\right)^{3}\end{array}$ & $\begin{array}{c}\operatorname{Loss}^{-1} \\
\text { (percent) }\end{array}$ & $\begin{array}{c}\operatorname{Loss}^{0} \\
\text { (percent) }\end{array}$ & $\begin{array}{c}\text { Loss }^{+1} \\
\text { (percent) }\end{array}$ \\
\hline I & $7,489.0$ & 301.6 & 477.2 & 620.4 & -19.2 & 0 & 8.4 \\
\hline II & 108.5 & 2.4 & 5.9 & 8.2 & & -59.3 & 0 \\
\hline III & 761.3 & 51.7 & 89.6 & 114.5 & & -42.3 & 0 \\
\hline IV & $2,175.7$ & 163.3 & 301.1 & 399.4 & & -45.8 & 0 \\
\hline V & $13,204.4$ & $1,711.8$ & $3,079.8$ & $4,052.0$ & & -44.4 & 0 \\
\hline Total & $23,739.9$ & $2,230.8$ & $3,953.6$ & $5,194.5$ & N/A & N/A & N/A \\
\hline
\end{tabular}

${ }^{1}$ Loss $^{-1}\left(\$ \times 10^{-6}\right)$ and loss ${ }^{-1}$ (percent) are the losses and change in losses, respectively, when all intensities have been reduced by one intensity unit.

${ }^{2} \operatorname{Loss}^{0}\left(\$ \times 10^{-6}\right)$ and loss ${ }^{0}$ (percent) are the same losses given in table 8 .

${ }^{3}$ Loss $^{+1}\left(\$ \times 10^{-6}\right)$ and loss ${ }^{+1}$ (percent) are the losses and change in losses, respectively, when all intensities have been increased by one intensity unit.

TABLE 23.-Variation of losses with intensity for a moderate $\left(M_{L}=5.5\right)$ earthquake on the Salt Lake segment of the Wasatch fault

[N/A, not applicable]

\begin{tabular}{lrrrrrrr}
\hline Class & $\begin{array}{c}\text { Value } \\
\left(\$ \times 10^{6}\right)\end{array}$ & $\begin{array}{c}\text { Loss }^{-1} \\
\left(\$ \times 10^{6}\right)^{1}\end{array}$ & $\begin{array}{c}\text { Loss }^{0} \\
\left(\$ \times 10^{6}\right)^{2}\end{array}$ & $\begin{array}{c}\text { Loss }^{+1} \\
\left(\$ \times 10^{6}\right)^{3}\end{array}$ & $\begin{array}{c}\text { Loss }^{-1} \\
(\text { percent })^{1}\end{array}$ & $\begin{array}{c}\text { Loss }^{0} \\
(\text { percent })^{2}\end{array}$ & $\begin{array}{c}\text { Loss }^{+1} \\
(\text { percent })^{3}\end{array}$ \\
\hline I & $7,489.0$ & 105.7 & 251.9 & 426.0 & -58.0 & 0 & 69.1 \\
II & 108.5 & .3 & 2.0 & 5.4 & -85.0 & 0 & 170.0 \\
III & 761.3 & 15.1 & 44.2 & 81.4 & -65.8 & 0 & 84.2 \\
IV & $2,175.7$ & 43.8 & 137.8 & 274.6 & -68.2 & 0 & 99.3 \\
V & $13,204.4$ & 570.8 & $1,502.0$ & $2,844.8$ & -61.9 & 0 & 89.4 \\
\multicolumn{1}{c}{ Total } & $23,739.9$ & $4,418.9$ & $5,462.8$ & $5,827.9$ & N/A & N/A & N/A \\
\hline
\end{tabular}

${ }^{1} \operatorname{Loss}^{-1}\left(\$ \times 10^{-6}\right)$ and loss ${ }^{-1}$ (percent) are the losses and change in losses, respectively, when all intensities have been reduced by one intensity unit.

${ }^{2}$ Loss $^{0}\left(\$ \times 10^{-6}\right)$ and loss $^{0}$ (percent) are the same losses given in table 8 .

${ }^{3}$ Loss $^{+1}\left(\$ \times 10^{-6}\right)$ and loss ${ }^{+1}$ (percent) are the losses and change in losses, respectively, when all intensities have been increased by one intensity unit. 


\section{REFERENCES CITED}

Algermissen, S.T., ed., 1985, Preliminary report of investigations of the central Chile earthquake of March 3, 1985: U.S. Geological Survey Open-File Report 85-542, 180 p.

Algermissen, S.T., and Steinbrugge, K.V., 1984, Seismic hazard and risk assessment: Some case studies, in The Geneva papers on risk and insurance: Association International pour l'Etude de l'Economie de l'Assurance, v. 9, no. 30, p. 826.

Algermissen, S.T., Dewey, J.W., Langer, C.J., and Dillinger, W.H., 1974, The Managua, Nicaragua, earthquake of December 23, 1972: Location, focal mechanism, and intensity distribution: Bulletin of the Seismological Society of America, v. 64, p. 993-1004.

Algermissen, S.T., Perkins, D.M., Thenhaus, P.C., Hanson, S.L., and Bender, B.L., 1982, Probabilistic estimates of maximum acceleration and velocity in rock in the contiguous United States: U.S. Geological Survey Open-File Report 82-1033, 99 p., 6 pls.

Algermissen, S.T., Steinbrugge, K.V., and Lagorio, H.L., 1978, Estimation of earthquake losses to buildings (except single family dwellings): U.S. Geological Survey Open-File Report 78-441, 174 p., 38 figs.

Applied Technology Council, 1985, Earthquake damage evaluation data for California: Redwood City, Calif., Report ACT$13,492 \mathrm{p}$.

Borcherdt, R.D., 1970, Effects of local geology on ground motion near San Francisco Bay: Bulletin of the Seismological Society of America, v. 60, p. 29-61.

Borcherdt, R.D., Joyner, W.B., Warrick, R.E., and Gibbs, J.F., 1975, Response of local geologic units to ground shaking, in Borcherdt, R.D., ed., Studies for seismic zonation of the San Francisco Bay region: U.S. Geological Survey Professional Paper 941-A, p. A52-A67.

Cassaro, M.A., and Romero, E.M., eds., 1986, The Mexico earthquakes-1985: New York, American Society of Civil Engineers, $473 \mathrm{p}$.

Dewey, J.W., and Algermissen, S.T., 1974, Seismicity of the Middle American arc-trench system near Managua, Nicaragua: Bulletin of the Seismological Society of America, v. 64, p. 1033-1048.

Hauksson, E., Jones, L.M., Davis, T.L., and others, 1988, The 1987 Whittier Narrows earthquake in the Los Angeles metropoli$\tan$ area, California: Science, v. 239, p. 1409-1412.

Hays, W.W., Algermissen, S.T., Miller, R.D., and King, K.W., 1978, Preliminary ground response maps for the Salt Lake City, Utah, area: International Conference on Microzonation, 2d, San Francisco, 1978, Proceedings, $12 \mathrm{p}$.

King, K.W., Hays, W.W., and McDermott, P.J., 1983, Wasatch Front urban area seismic response data report: U.S. Geological Survey Open-File Report 83-452, 68 p.

Machette, M.N., Personius, S.F., and Nelson, A.R., 1992, Paleoseismology of the Wasatch fault zone: A summary of recent investigations, interpretations, and conclusions, in Gori, P.L., and Hays, W.W., eds., Assessment of regional earthquake hazards and risks along the Wasatch Front, Utah: U.S. Geological Survey Professional Paper 1500-A, p. A1-A71.

Mark, R.K., 1977, Application of linear statistical models of earthquake magnitude versus fault length in estimating maximum expectable earthquakes: Geology, v. 5, p. 464466.

Murphy, L., 1973, San Fernando, California earthquake of February 9, 1971: Washington, D.C., U.S. Department of Commerce, v. III, $432 \mathrm{p}$.

Ríos, R., Grases, J., Ponce, L., Weidmann, N., and Zegarra, L., 1986, El terremoto de San Salvador 10 de Octubre 1986: Lima, CERESIS/UNESCO, 56 p., 3 apps.

Rogers, A.M., Algermissen, S.T., Hays, W.W., Perkins, D.M., Van Strein, D.O., Hughes, H.C., Hughes, R.C., Lagorio, H.J., and Steinbrugge, K.V., 1976, A study of earthquake losses in the Salt Lake City, Utah, area: U.S. Geological Survey Open-File Report 76-89, 375 p.

Rogers, A.M., Carver, D.L., Hays, W.W., King, K.W., and Miller, R.D., 1984, Preliminary estimates of geographic variation in relative ground shaking in the Wasatch Front urban corridor: U.S. Geological Survey Open-File Report 84-763, p. 547-556.

Rojahn, C., King, S.A., Scholl, R.E., Kiremidjian, A.S., Reaveley, L.D., and Wilson, R.R., 1997, Earthquake damage and loss estimation methodology and data for Salt Lake County, Utah (ATC-36): Earthquake Spectra, v. 13, p. 623-642.

Rosenblueth, E., 1964, Probabilistic design to resist structures: Proceedings of the American Society of Civil Engineers, Journal of the Engineering Mechanics Division, v. EM-90, p. 182-219.

Steinbrugge, K.V., 1979, Estimation of loss estimation techniques to metropolitan Salt Lake City, Utah: Report to the U.S. Geological Survey under contract 14-08-0001-17423, $55 \mathrm{p}$.

1986, Building inventory data and loss estimation methods for Salt Lake City-Ogden-Provo, Utah: Report to the U.S. Geological Survey under contract 14-08-0001-22408, 48 p., 2 apps.

Stone, W.C., Yokel, F.Y., Celebi, M., Hanks, T., and Leyendecker, E.V., 1987, Engineering aspects of the September 19, 1985 Mexico earthquake: Washington, D.C., National Bureau of Standards, $215 \mathrm{p}$.

Bureau of the Census, 1983a, Census tracts, Provo-Orem, Utah Standard Metropolitan Statistical Area: Washington, D.C., Report PHC80-2-294.

1983b, Census tracts, Salt Lake City-Ogden, Utah Standard Metropolitan Statistical Area: Washington, D.C., Report PHC80-2-317.

$1983 c$, Census of population and housing: Washington, D.C., Master Area Reference File (MARF) 2 (magnetic tape). 

Isoseismals of Some Historical Earthquakes Affecting the Wasatch Front Area, Utah

By MARGARET G. HOPPER

ASSESSMENT OF REGIONAL EARTHQUAKE HAZARDS AND RISK ALONG THE WASATCH FRONT, UTAH

U.S. GEOLOGICAL SURVEY PROFESSIONAL PAPER 1500-Q 



\section{CONTENTS}

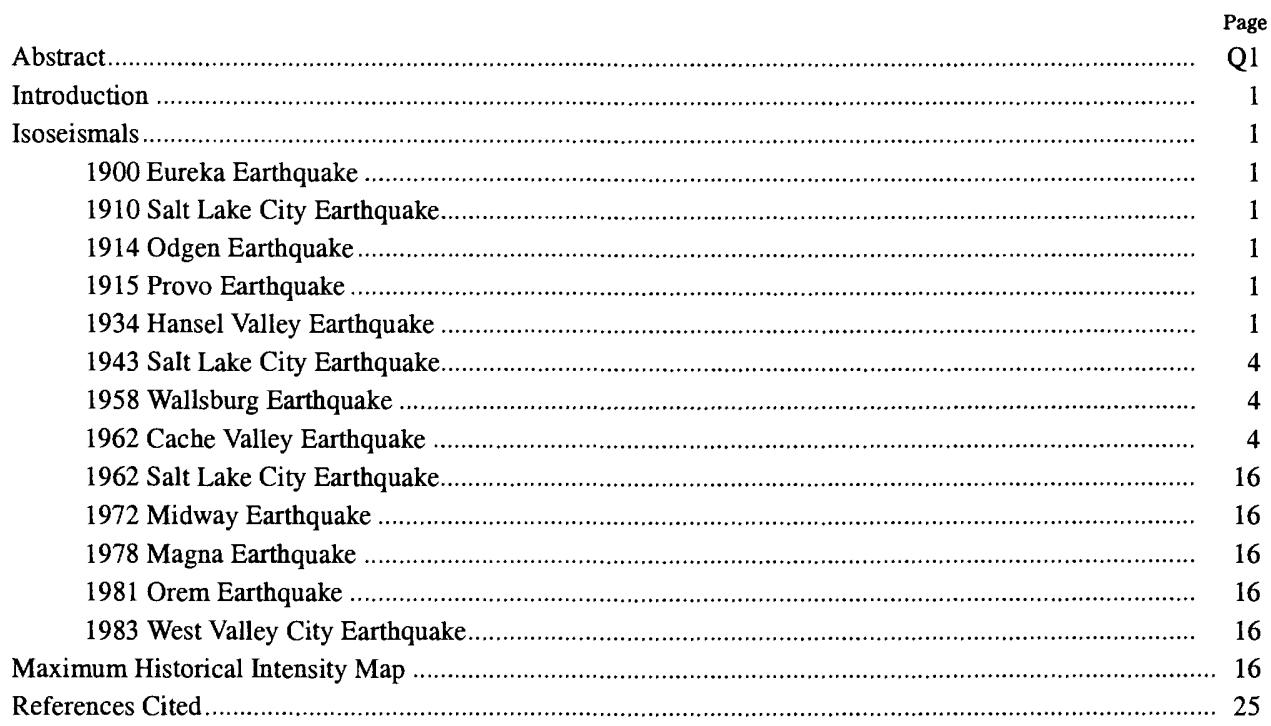

\section{ILLUSTRATIONS}

FIgures 1,2. Maps showing epicenters of historical Utah earthquakes:

1. Having maximum Modified Mercalli intensities of VI or greater.......

2. Used in this study

3-15. Isoseismal maps showing:

3. August 1, 1900, Eureka earthquake

4. May 22, 1910, Salt Lake City earthquake

5. May 13, 1914, Ogden earthquake

6. July 15,1915 , Provo earthquake

7. March 12, 1934, Hansel Valley earthquake

8. February 22,1943 , Salt Lake City earthquake

9. February 13, 1958, Wallsburg earthquake.

10. August 30, 1962, Cache Valley earthquake...

11. September 5,1962 , Salt Lake City earthquake

12. October 1, 1972, Midway earthquake .

13. March 9, 1978, Magna earthquake

14. February 20, 1981, Orem earthquake...

15. October 8, 1983, West Valley City earthquake

17, 18. Isoseismal maps showing:

17. March 28, 1975, Malad City and Pocatello Valley, Idaho, earthquakes.

18. Sevier County, Utah, earthquakes of November 14, 1901, September 29, 1921, September 30,1921, and October 1, 1921 
TABLES

$T_{A B L E}$ 1. Earthquakes shown in figure 1

Page

2. Earthquakes used in this study 


\title{
ISOSEISMALS OF SOME HISTORICAL EARTHQUAKES AFFECTING THE WASATCH FRONT AREA, UTAH
}

\author{
By MARgARET G. Hopper
}

\begin{abstract}
Isoseismals were drawn for 13 historical earthquakes that caused damage-level Modified Mercalli intensities (MMI greater than or equal to VI) in the four Wasatch Front counties of Weber, Davis, Salt Lake, and Utah. The highest historical intensity within any of the four counties was found to be MMI VII. Davis, Salt Lake, and most of Weber Counties were found to be in an area commonly reporting intensity VI. However, historical intensities in Utah County have been below damage level, with the exception of those in the Provo area to the northeast of Utah Lake and in the Eureka mining district in the southwestern corner of Utah County and adjoining Juab County. High historical intensities in the northern part of the four-county study area are the result of the 1934 Hansel Valley earthquakes and large earthquakes in southern Idaho.
\end{abstract}

\section{INTRODUCTION}

Simulations of earthquake shaking in the Wasatch Front area require a knowledge of intensities generated by historical earthquakes affecting the area. Epicenters for all historical shocks in or near Utah having maximum Modified Mercalli intensities $\left(M M I_{0}\right)$ of at least VI (Wood and Neumann, 1931) are shown in figure 1 and listed in table 1. For this study, isoseismal maps were made showing a four-county study area (Weber, Davis, Salt Lake, and Utah Counties). The set of 13 earthquakes mapped in this study (table 2, fig. 2) all caused damage ( $M M I \geq \mathrm{VI})$ within this four-county area. Most were small local shocks $\left(M M I_{0}=\mathrm{VI}\right)$, but a few were larger, more distant shocks that produced $M M I \geq V I$ within the study area. There was available for each earthquake at least enough intensity information at locatable points for rough isoseismals to be contoured.

\section{ISOSEISMALS} 1900 EUREKA EARTHQUAKE

The Eureka earthquake of August 1, 1900 (fig. 3), twisted the deep shaft of the Mammoth Mine so that the cage could not be lowered. At Santaquin, an adobe house was split in two (Townley and Allen, 1939).

\section{SALT LAKE CITY EARTHQUAKE}

The Salt Lake City earthquake of May 22, 1910 (fig. 4), on the Wasatch fault damaged several buildings in Salt Lake City, shaking plaster from ceilings and toppling chimneys on poorly constructed buildings but leaving well-constructed buildings unharmed. The earthquake did minor damage at Bingham and Garfield but was not felt more than $50 \mathrm{mi}$ from Salt Lake City. It was followed by two lighter shocks (Williams and Tapper, 1953).

\section{OGDEN EARTHQUAKE}

The Ogden earthquake of May 13, 1914 (fig. 5), on the Wasatch fault cracked walls, toppled a few chimneys, and broke plate glass windows in Ogden. In Salt Lake City, dishes were broken. The shock was followed by a second, lighter shock (Williams and Tapper, 1953).

\section{PROVO EARTHQUAKE}

The Provo earthquake of July 15, 1915 (fig. 6), on the Wasatch fault cracked ceilings at Provo (Williams and Tapper, 1953).

\section{HANSEL VALLEY EARTHQUAKE}

The Hansel Valley earthquake of March 12, 1934 (fig. $7 A, B)$, occurred in a sparsely populated area and did very little damage except for fissures, ground cracks, and liquefaction. At Kosmo, a poorly constructed brick building was severely cracked; at Monument, all the chimneys were thrown down. Beyond the immediate meizoseismal area, chimneys fell at Bacchus, Blue Creek, Hooper, 


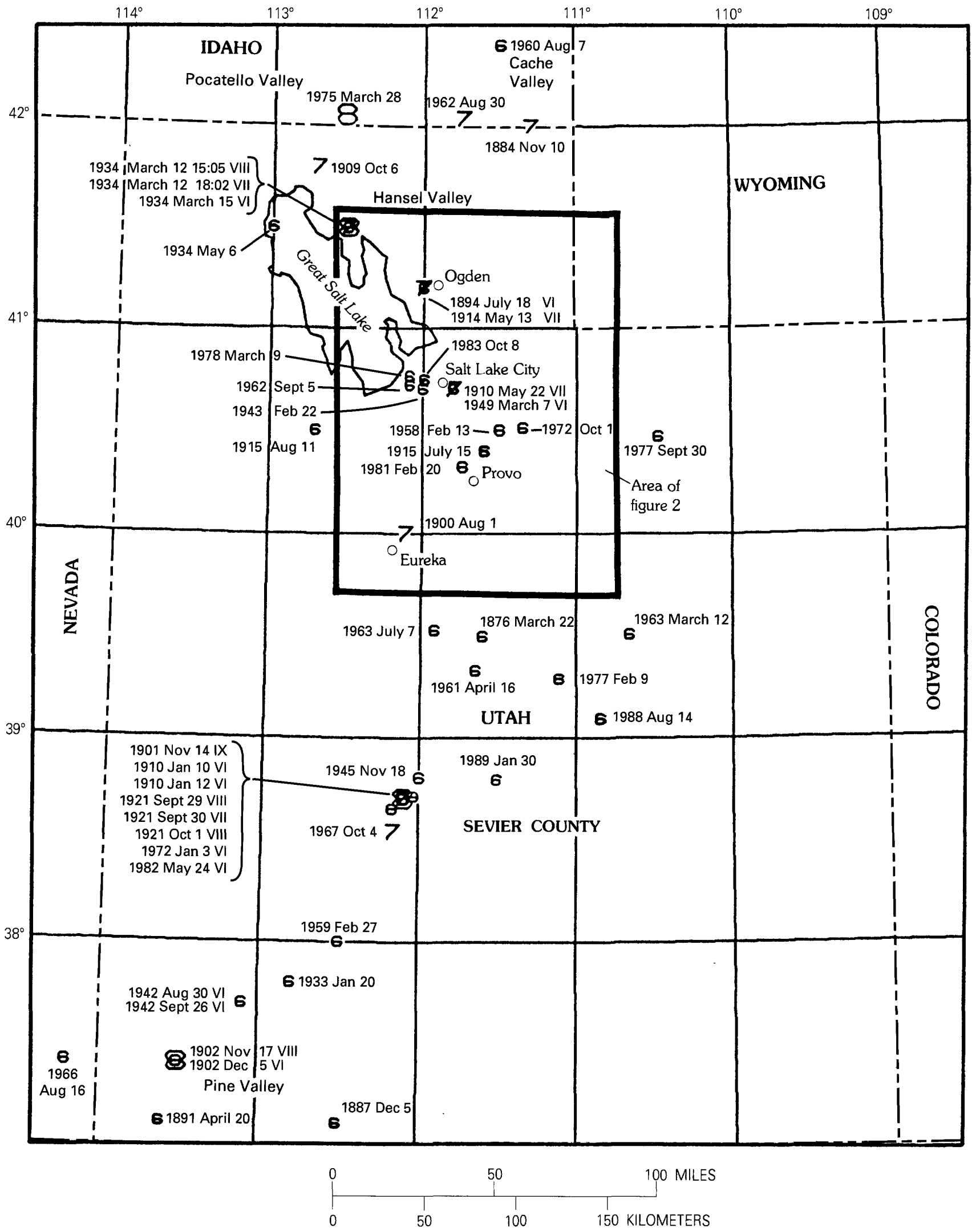

FIGURE 1.-Epicenters of historical earthquakes having maximum Modified Mercalli intensities $\left(M M I_{0}\right)$ of VI or greater. Numbers are plotted at epicenters and indicate the $M M I_{O}$ 's. The earthquakes shown are listed in table 1. 
TABLE 1.-Earthquakes shown in figure 1

[All information in this table is from Stover and others (1986a, b), except as noted. This list includes all earthquakes with $M M I_{0} \geq \mathrm{VI}$ located between $37.0^{\circ}$ and $42.5^{\circ} \mathrm{N}$. and between $108.5^{\circ}$ and $114.5^{\circ} \mathrm{W}$ - - data not available. All locations in Utah unless otherwise indicated]

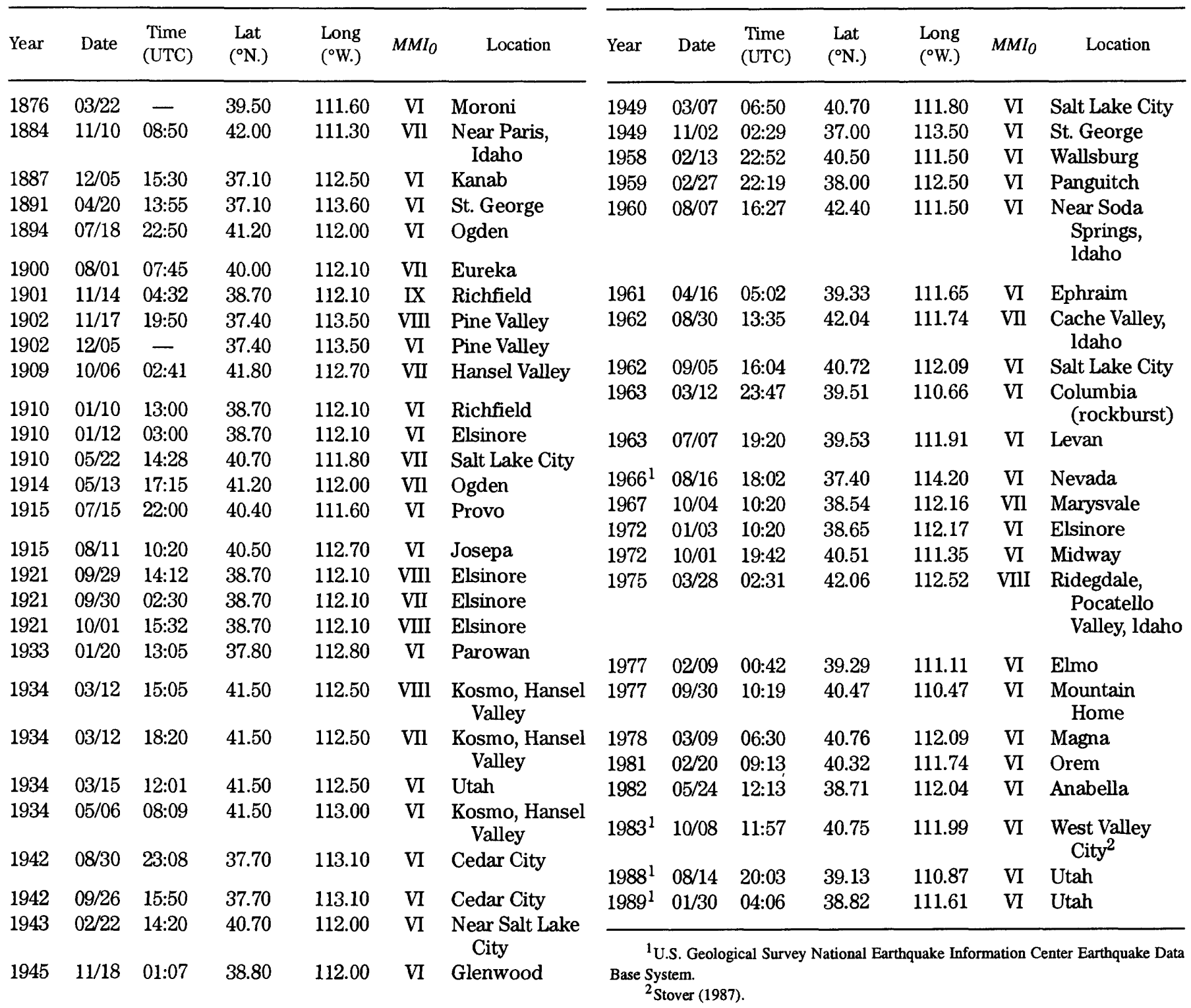


TABLE 2.-Earthquakes used in this study

[All information in this table is from Stover and others (1986a), except as noted. All locations in Utah except as noted.-, data not available]

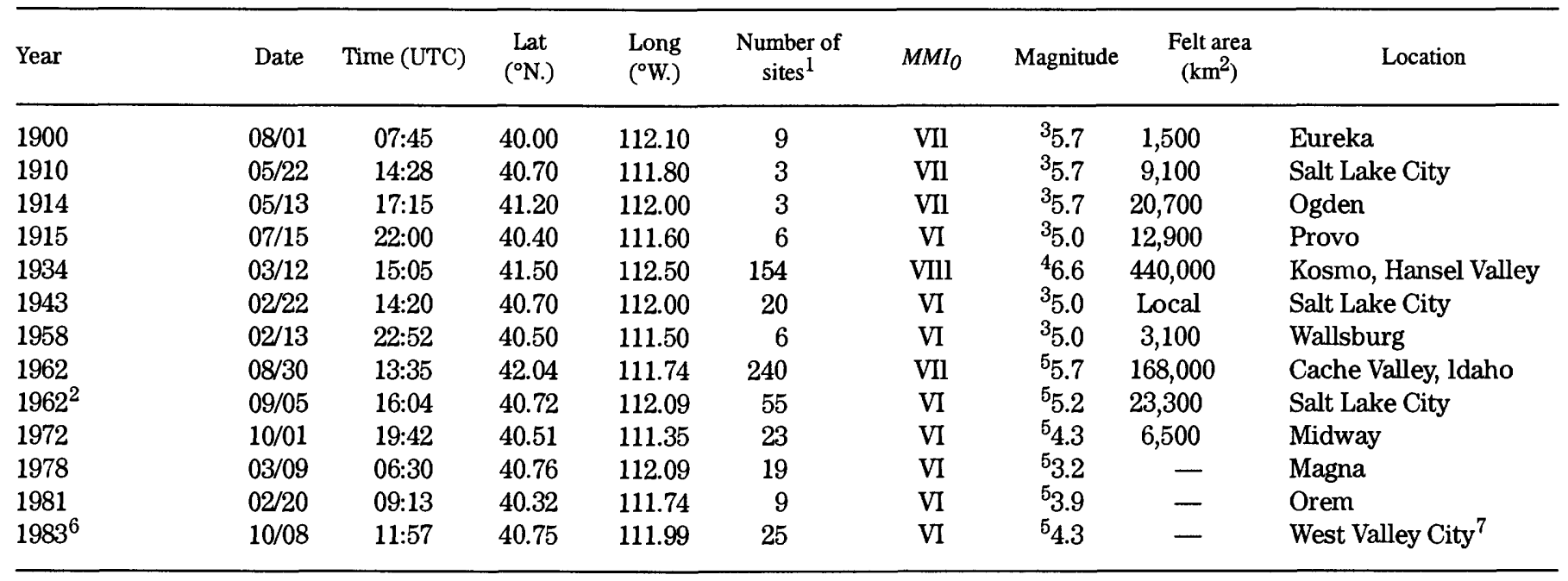

\footnotetext{
${ }^{1}$ Number of located sites having assigned Modified Mercalli intensities.

${ }^{2}$ Coffman and others (1982).

${ }^{3}$ Magnitude estimated from $M M I_{O}$ (Arabasz and McKee, 1979).

${ }^{4}$ Gutenberg-Richter magnitude.

${ }^{5}$ University of Utah magnitude.

${ }^{6}$ U.S. Geological Survey National Earthquake Information Center Earthquake Data Base System.

${ }^{7}$ Stover (1987).
}

Kelton, Locomotive Springs, Promontory, and Snowville (Neumann, 1936).

\section{SALT LAKE CITY EARTHQUAKE}

The Salt Lake City earthquake of February 22, 1943 (fig. 8), was felt most strongly in the Salt Lake Valley west of Salt Lake City. It shook down much plaster from the new brick Bingham High School; cracked plaster, windows, and chimneys at Magna; and cracked plaster and windows in Salt Lake City (Bodle, 1945). The shock is presumed to have been located at depth on a branch of the Wasatch fault (Williams and Tapper, 1953).

\section{WALLSBURG EARTHQUAKE}

The Wallsburg earthquake of February 13, 1958 (fig. 9), caused minor damage at Wallsburg and Provo. At Provo, a wall was cracked and plaster fell (Brazee and Cloud, 1960).

\section{CACHE VALLEY EARTHQUAKE}

The Cache Valley earthquake of August 30, 1962 (fig. $10 A, B)$, on the East Cache Valley fault caused the most severe damage at Richmond, where numerous houses lost walls, a large church was damaged beyond repair, and 75 percent of the older chimneys fell. Buildings in downtown Logan suffered severe damage from cracked and distorted walls, and parapets fell at the junior high school. At Lewiston, there was much chimney damage, and a large parapet and the second-story part of a brick wall fell. At Hyde Park, there was considerable chimney damage but no damage to newer brick structures. At Smithfield, plaster, walls, and chimneys cracked, and bricks fell from most old chimneys. At Franklin, Idaho, plaster, walls, and chimneys cracked, chimneys twisted and fell, and some foundations cracked. At Preston, Idaho, a few chimneys fell, and a few homes had cracked walls and fireplaces (Lander and Cloud, 1964).

FIGURE 2.-Epicenters of historical earthquakes used in this study. $\rightarrow$ Solid circles show the locations of the epicenters; the roman numerals indicate their maximum Modified Mercalli intensities $\left(M M I_{O}\right)$. Each of these earthquakes caused damaging intensities $(M M I \geq \mathrm{VI})$ within the four-county study area. In addition, the Cache Valley earthquake (August 30, 1962), north of this map, caused damage within the study area. All earthquakes used in this study are listed in table 2. Where there are multiple shocks at a single location, only the largest shock was used in this study. Thus, the smaller shocks at the sites of multiple shocks appear in table 1 and figure 1 but not in table 2 or figure 2 . 


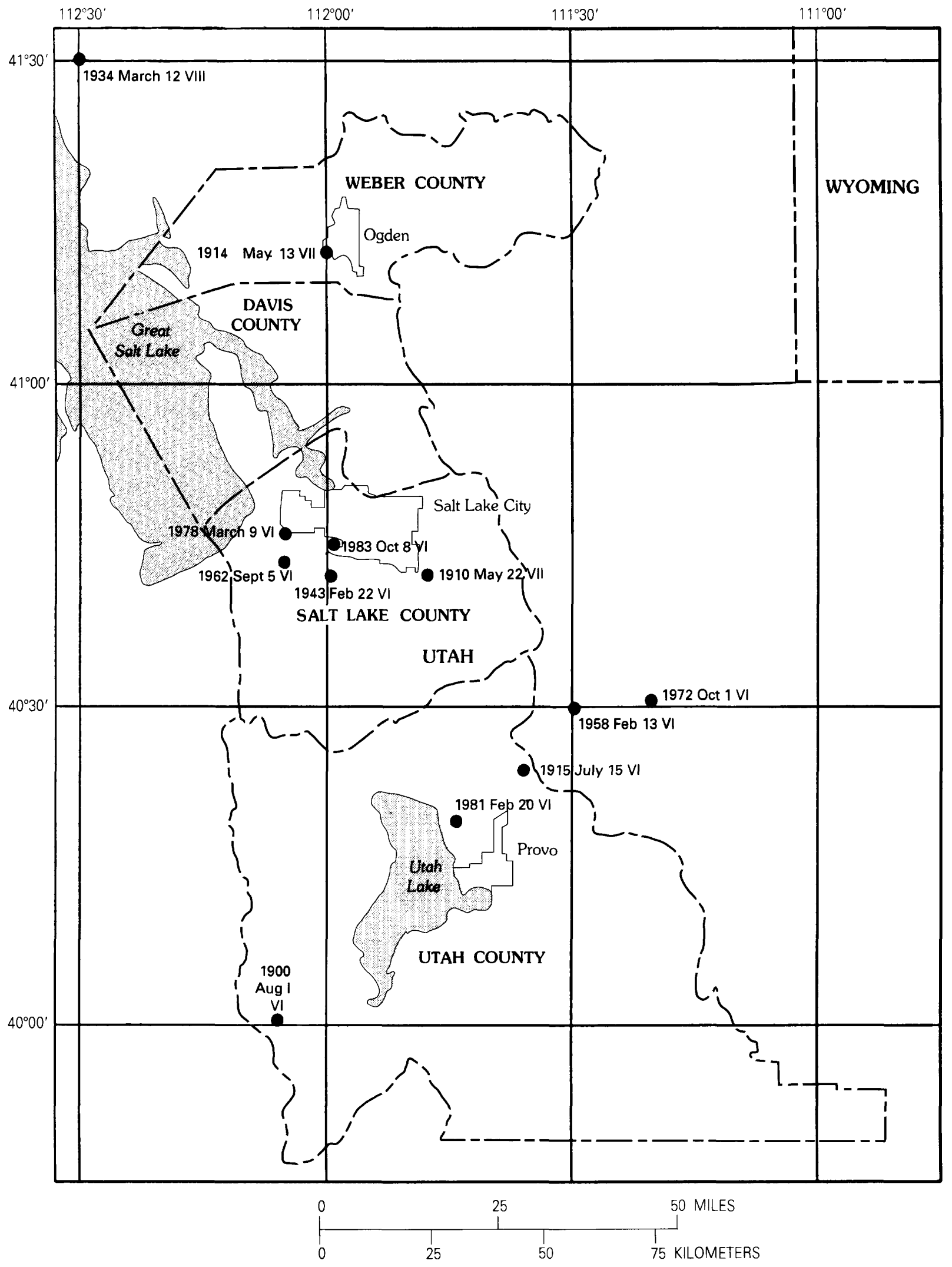




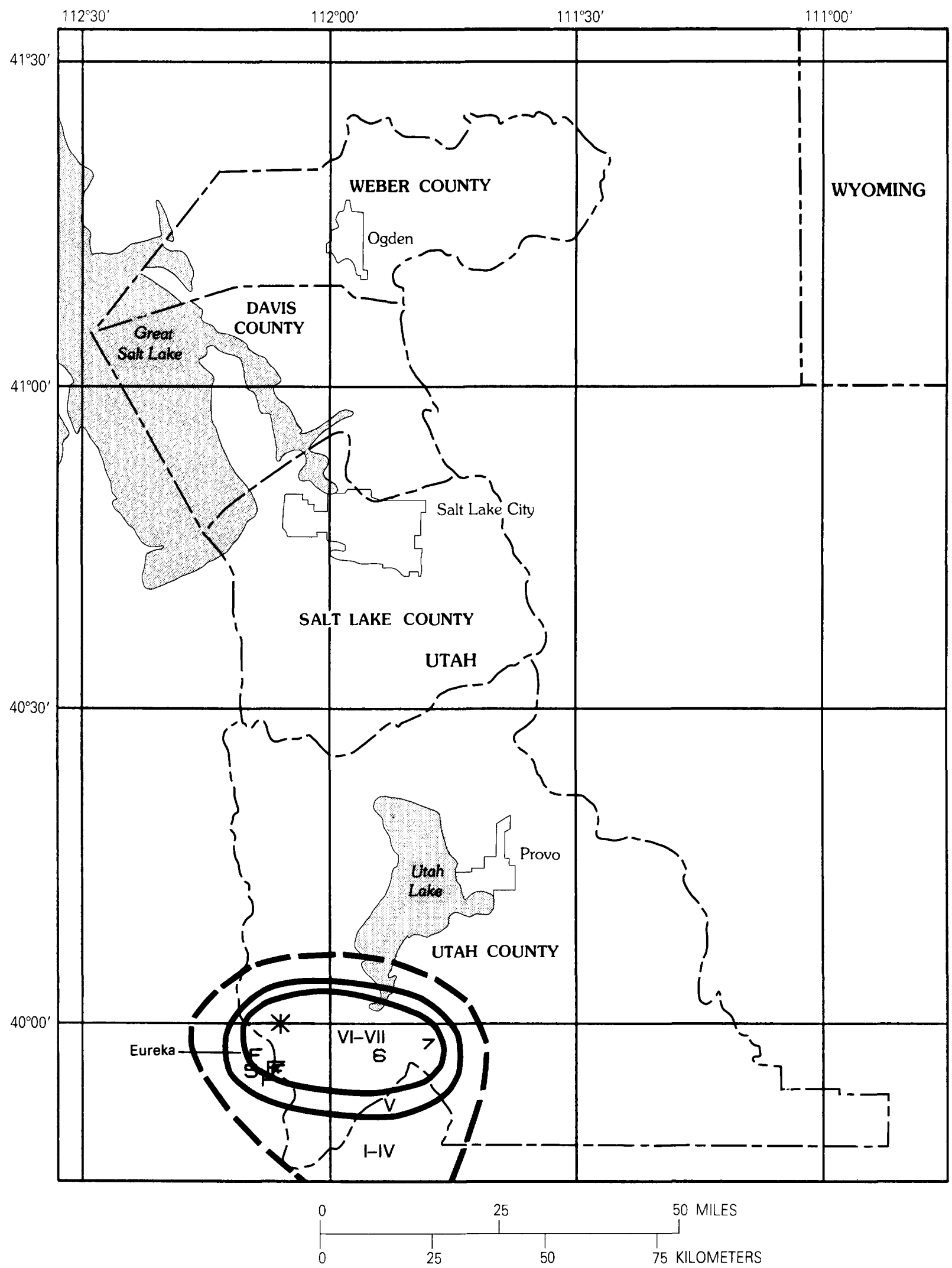

Figure 3.-Isoseismal map for the earthquake of August 1, 1900, Eureka, Utah. The maximum Modified Mercalli intensity ( $M M I_{O}$ ) is VII. The star indicates the epicenter. Arabic numbers indicate site intensities $(M M I)$, and roman numerals indicate isoseismal intensities. F indicates report of "felt" that was not assigned a $M M I$. Isoseismals are dashed where uncertain. 


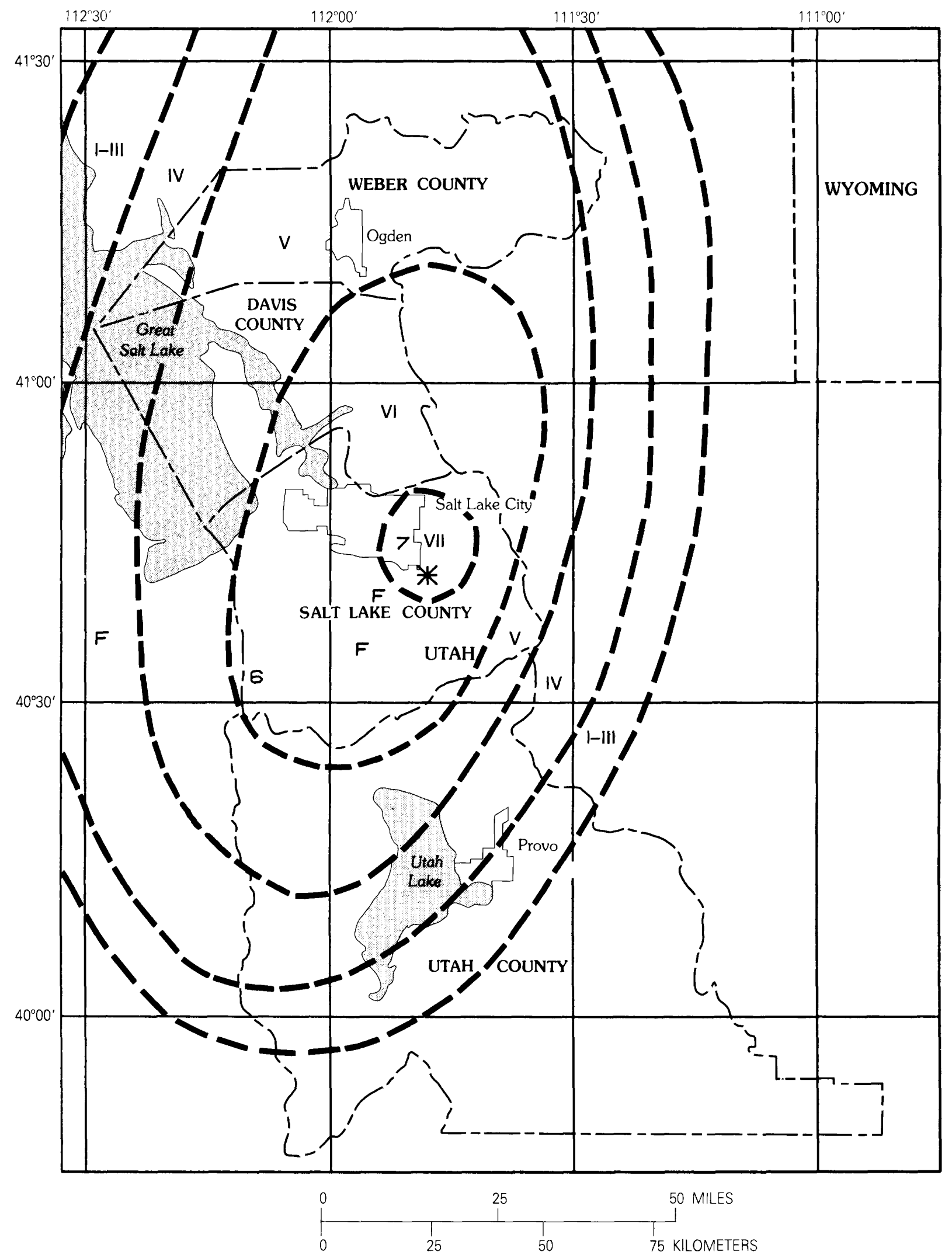

FIGURE 4.-Isoseismal map for the earthquake of May 22, 1910, Salt Lake City, Utah. The maximum Modified Mercalli intensity $\left(M M I_{0}\right)$ is VII. The star indicates the epicenter. Arabic numbers indicate site intensities ( $\left.M M I\right)$, and roman numerals indicate isoseismal intensities. F indicates a report of "felt" that was not assigned a MMI. Isoseismals are dashed where uncertain. 


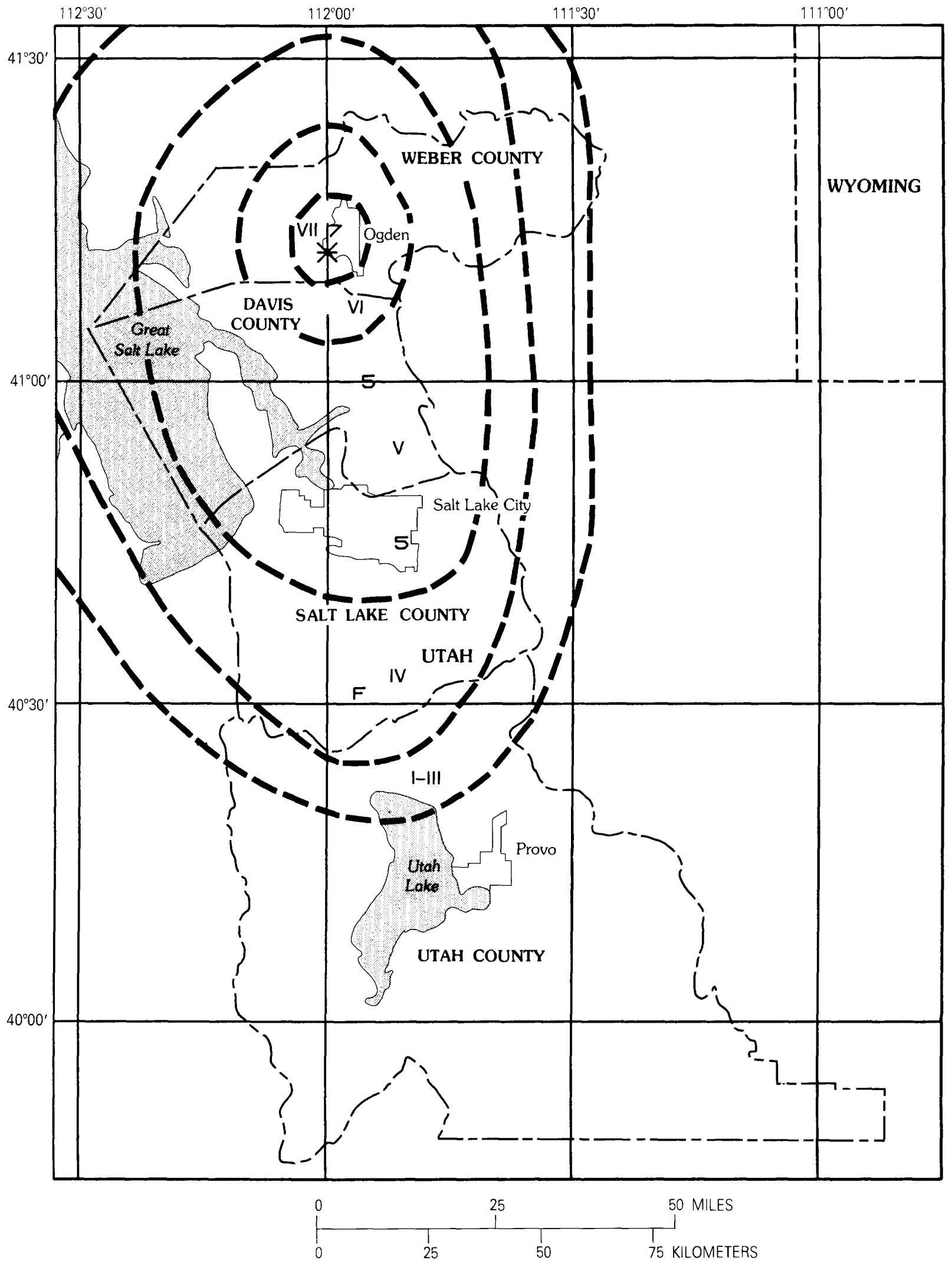

FIGURE 5.-Isoseismal map for the earthquake of May 13, 1914, Ogden, Utah. The maximum Modified Mercalli intensity ( $M M I_{0}$ ) is VII.

The star indicates the epicenter. Arabic numbers indicate site intensities ( $M M I$ ), and roman numerals indicate isoseismal intensities. F indicates a report of "felt" that was not assigned a $M M I$. Isoseismals are dashed where uncertain. 


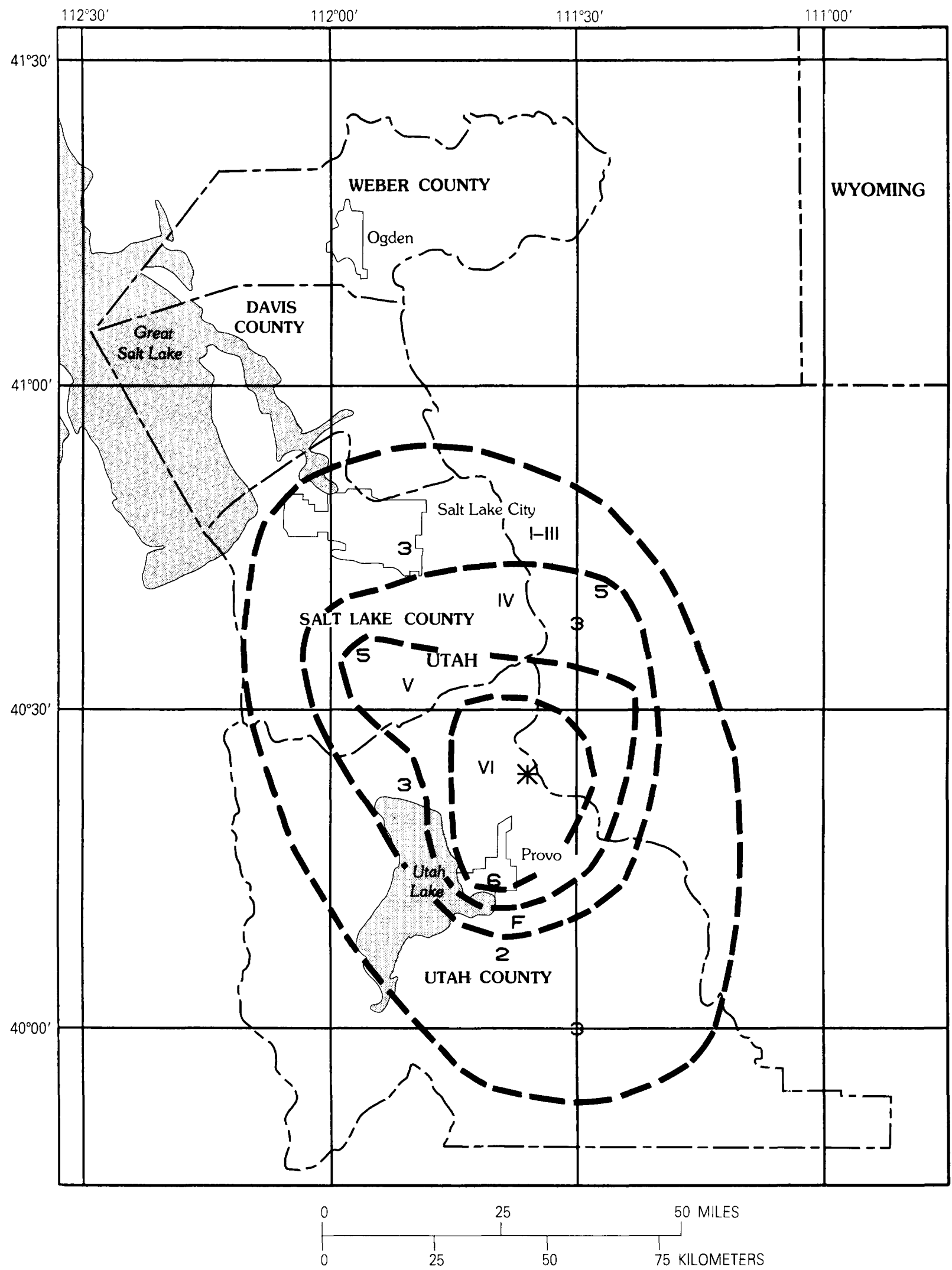

FIGURE 6.-Isoseismal map for the earthquake of July 15, 1915, Provo, Utah. The maximum Modified Mercalli intensity ( $\left.M M I_{0}\right)$ is VI. The star indicates the epicenter. Arabic numbers indicate site intensities ( $M M I$ ), and roman numerals indicate isoseismal intensities. F indicates a report of "felt" that was not assigned a $M M I$. Isoseismals are dashed where uncertain. 


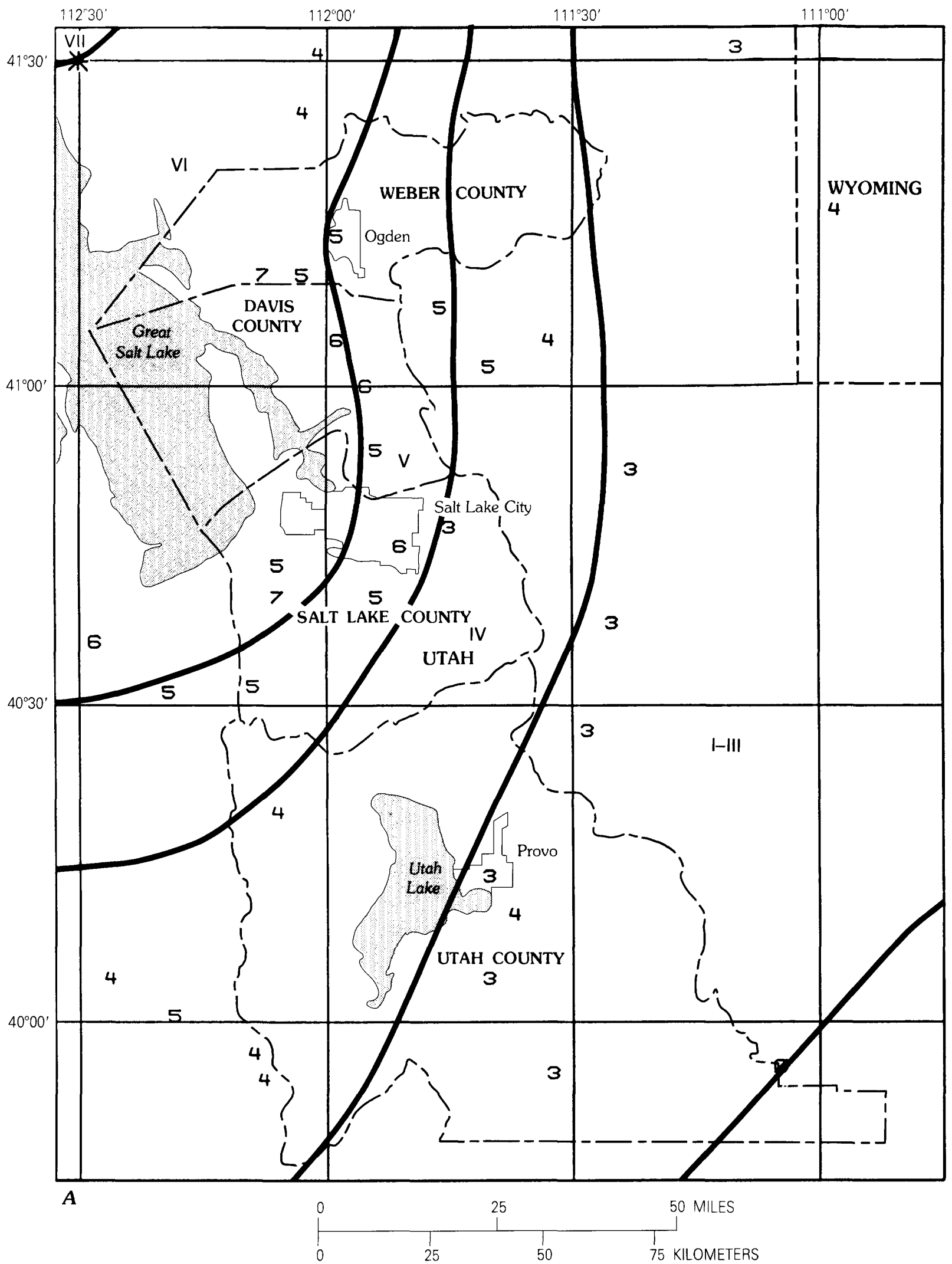

FIGURE 7.-Isoseismal map for the earthquake of March 12, 1934, Hansel Valley, Utah (near Kosmo, Utah). The maximum Modified Mercalli intensity $\left(M M I_{O}\right)$ is VIII; $M_{L}$ is 6.6. Arabic numbers indicate site intensities $(M M D$ ), and roman numerals indicate isoseismal intensities. Isoseismals are from Neumann (1936). $A$, Within the four-county study area. The star indicates the epicenter. $B$, Entire isoseismal map. Area of $A$ is indicated. 

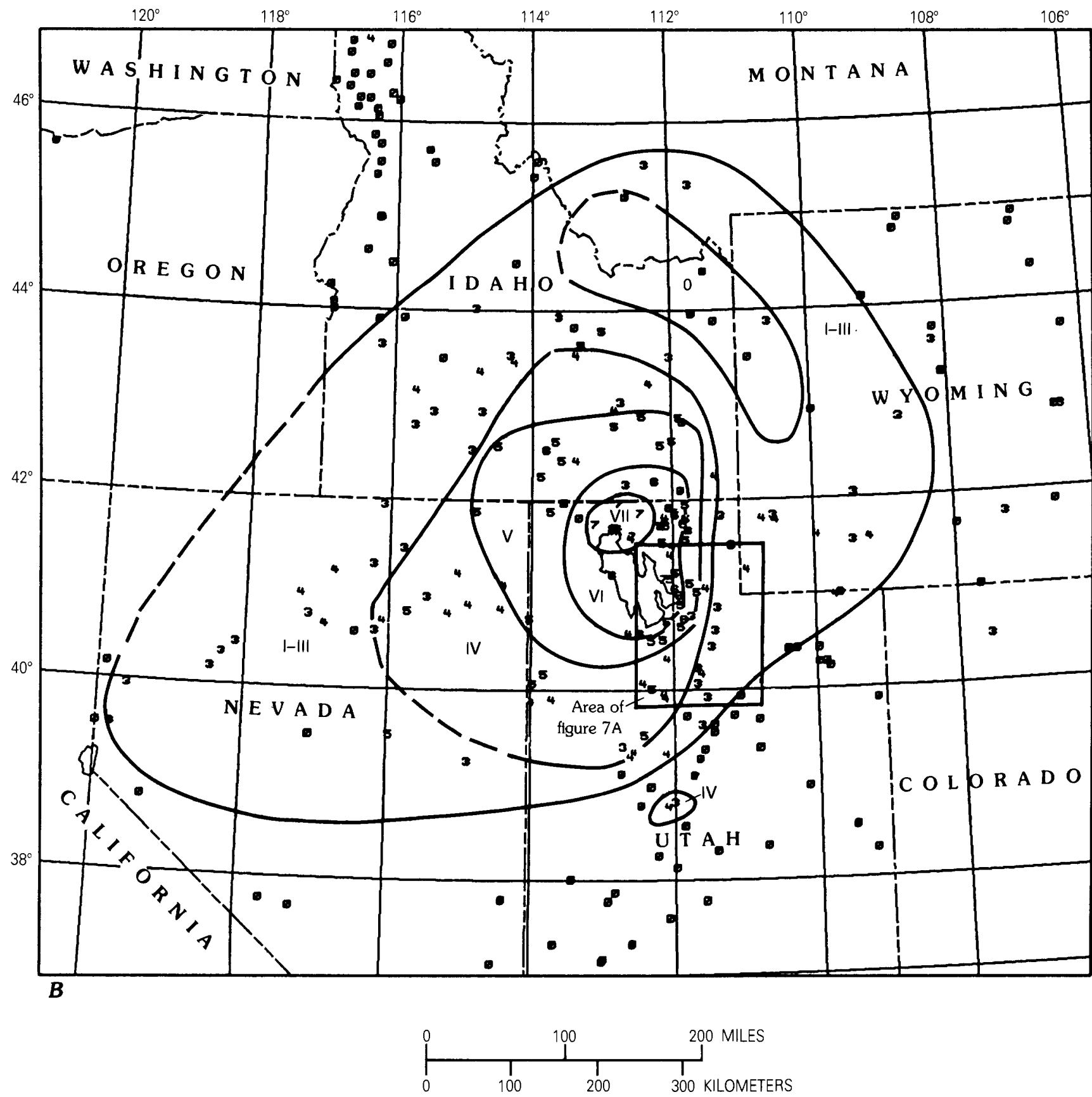

FIgURE 7.-Continued. 


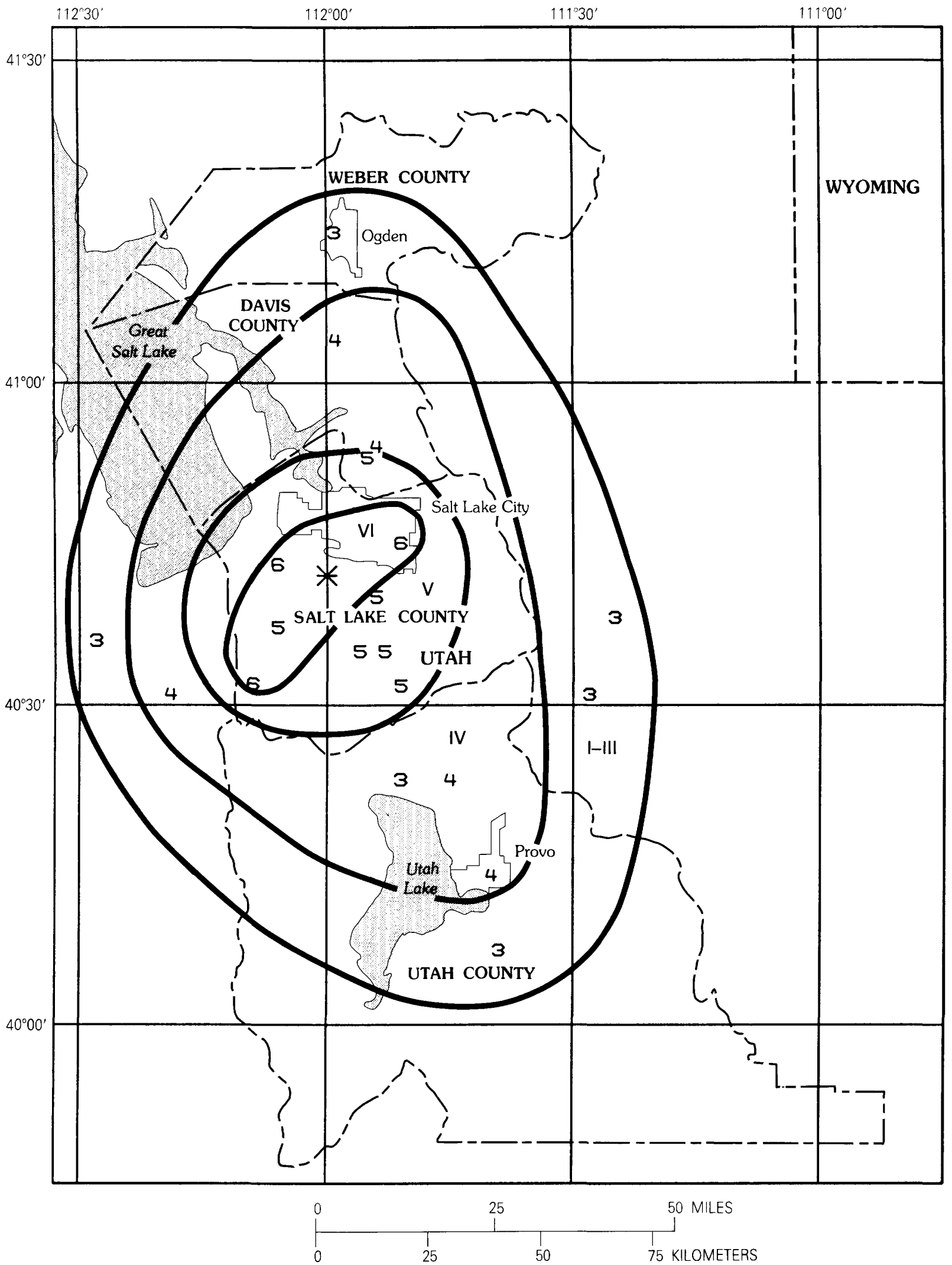

FigURE 8.-Isoseismal map for the earthquake of February 22, 1943, Salt Lake City, Utah. The maximum Modified Mercalli intensity $\left(M M I_{O}\right)$ is VI. The star indicates the epicenter. Arabic numbers indicate site intensities $(M M I)$, and roman numerals indicate isoseismal intensities. 


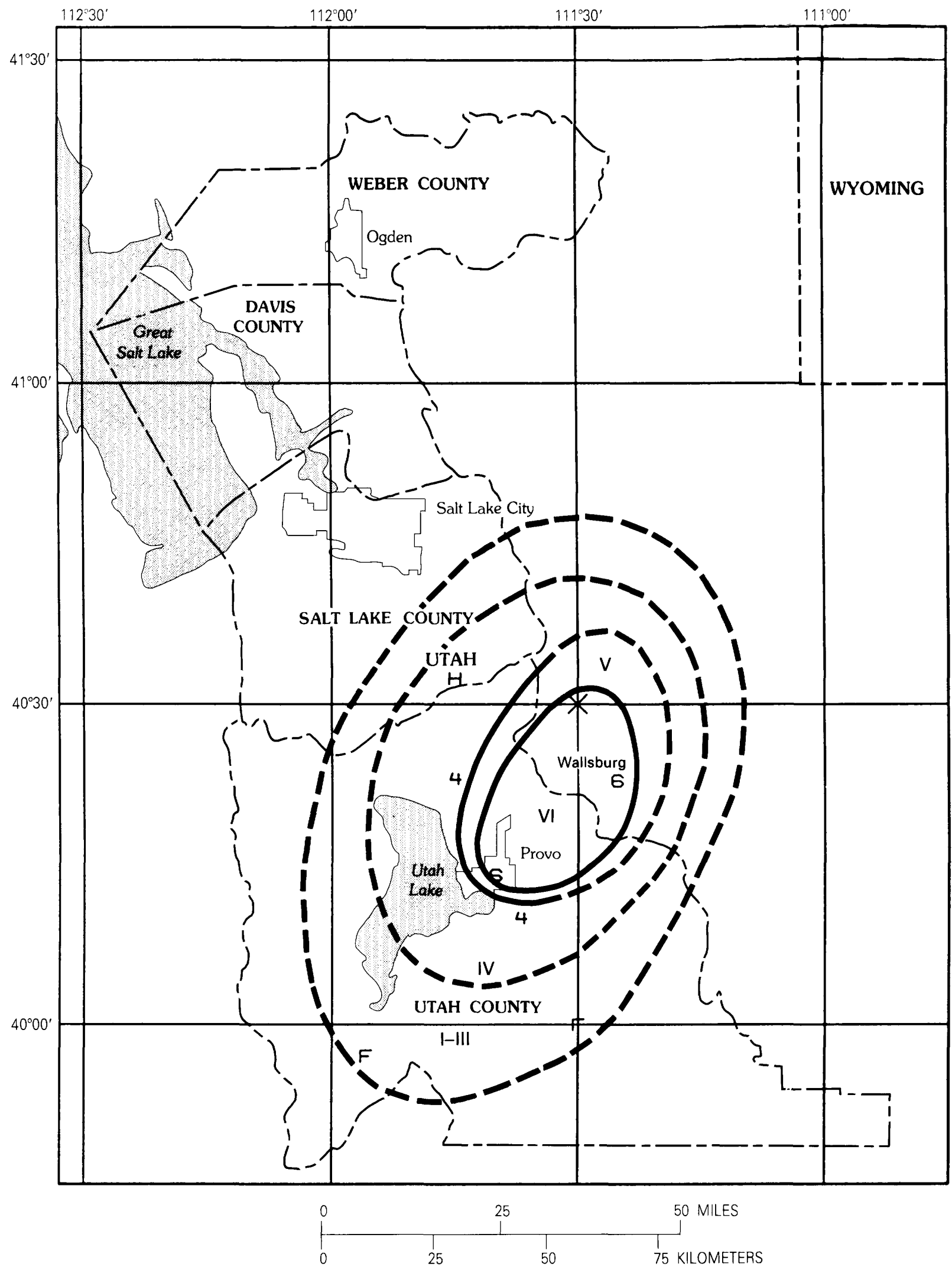

FIGURE 9.-Isoseismal map for the earthquake of February 13, 1958, Wallsburg, Utah. The maximum Modified Mercalli intensity $\left(M M I_{0}\right)$ is VI. The star indicates the epicenter. Arabic numbers indicate site intensities ( $M M I$ ), and roman numerals indicate

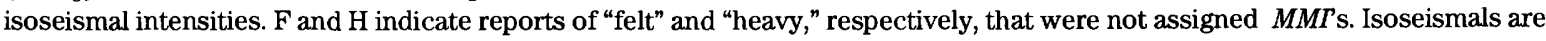
dashed where uncertain. Berg and Resler (1958) developed a similar isoseismal map. 


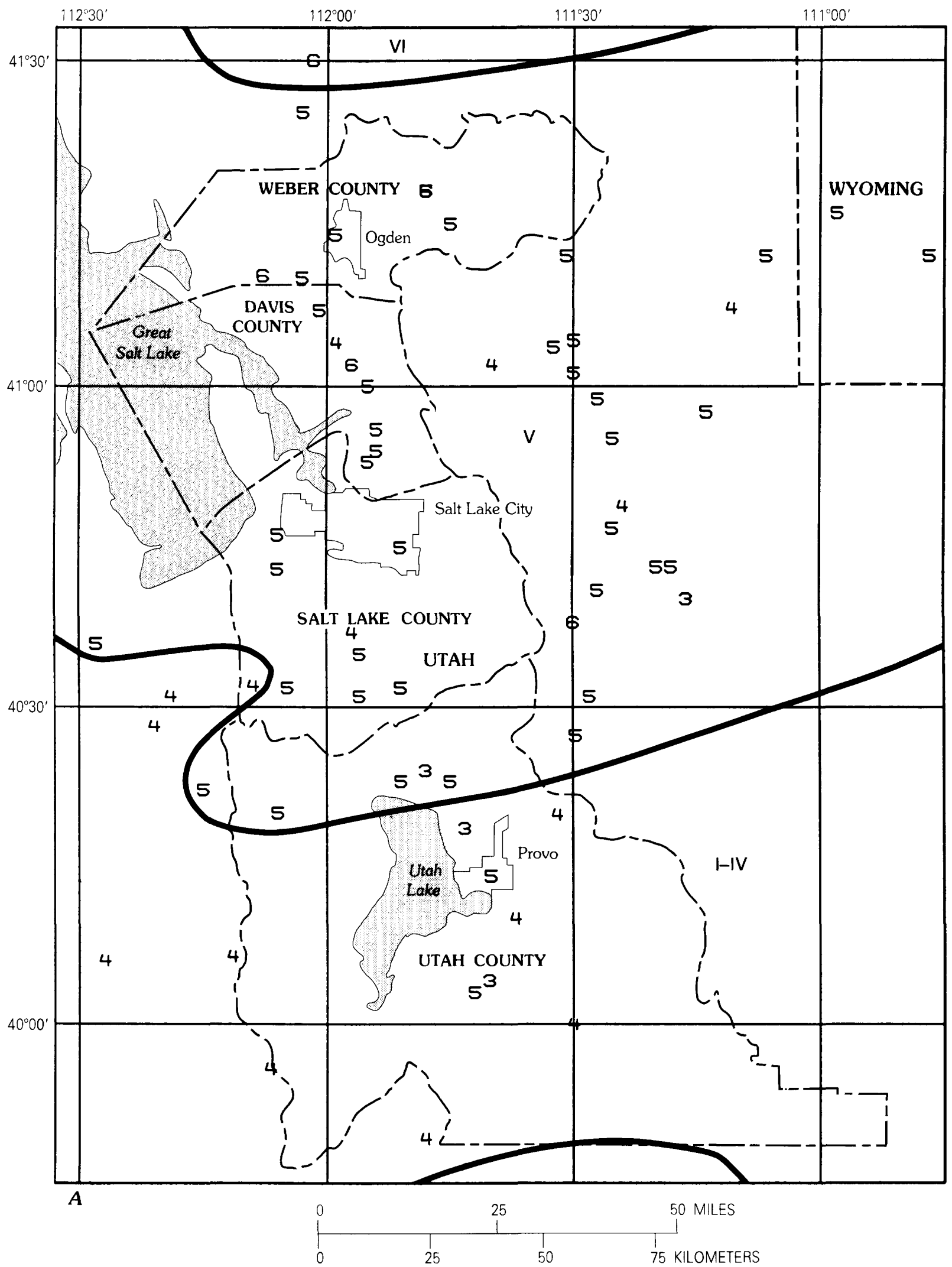

FiguRE 10.-Isoseismal map for the earthquake of August 30, 1962, Cache Valley, Utah. The maximum Modified Mercalli intensity $\left(M M I_{0}\right)$ is VII; $M_{L}$ is 5.7. Arabic numbers indicate site intensities (MMI), and roman numerals indicate isoseismal intensities. Isoseismals are from Lander and Cloud (1964). $A$, Within the four-county study area. Epicenter is off the map to the north. $B$, Entire isoseismal map. Star indicates the epicenter. Area of $A$ is indicated. 

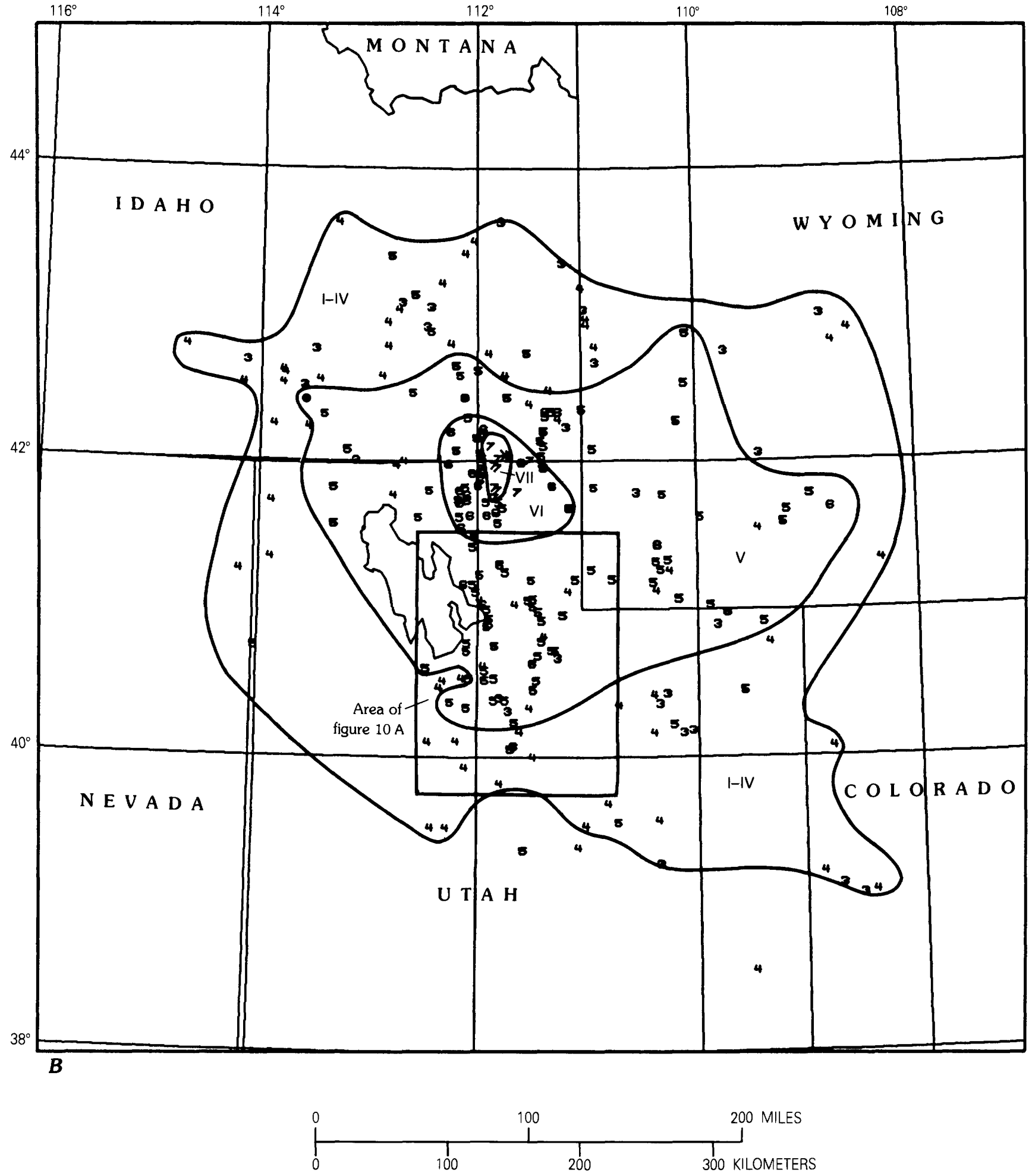

FIGURE 10.-Continued. 


\section{SALT LAKE CITY EARTHQUAKE}

The Salt Lake City earthquake of September 5, 1962 (fig. 11), damaged three older houses in Salt Lake City. In one, the outside front wall cracked and fell through the ceiling; portions of inside walls and ceiling plaster fell in the other two. There were slight interior cracks in some large buildings in Salt Lake City and cracks and loosened acoustical tile in some of the schools. An old parapet facade pulled $2 \mathrm{in}$. away from one school building, and the parapet had to be removed. At the newspaper office, 16 windows were cracked, a light fixture fell, and there were many small cracks in walls and ceilings.

In North Salt Lake, plaster, windows, walls, and chimneys were cracked. At the Bingham Canyon Mine, there were slight cracks in freshly painted concrete-block walls. At Draper, plaster, walls, and cement were cracked. At Lark, walls cracked. At Magna, plaster, windows, walls, and chimneys cracked. At Midvale, plaster cracked. At Morgan, there were slight wall and foundation cracks. At Murray, plaster cracked. At Provo, bricks fell from chimneys (Lander and Cloud, 1964).

\section{MIDWAY EARTHQUAKE}

The Midway earthquake of October 1, 1972 (fig. 12), shook down some bricks from chimneys and cracked plaster at two schools and other places in Midway (Coffman and von Hake, 1974).

\section{MAGNA EARTHQUAKE}

The Magna earthquake of March 9, 1978 (fig. 13), caused damage only at Magna, where there were broken windows in several houses, cracked plaster, and cracks in the exterior walls of a fire station (Cook, 1979; Stover and von Hake, 1980).

\section{OREM EARTHQUAKE}

The Orem earthquake of February 20, 1981 (fig. 14), cracked a foundation and caused hairline cracks in plaster and drywall in Orem (Stover, 1984).

\section{WEST VALLEY CITY EARTHQUAKE}

The West Valley City earthquake of October 8, 1983 (fig. 15), caused damage only in West Valley City and Granger, which are western suburbs of Salt Lake City. In West Valley City, chimneys were cracked, and one chimney fell. In Granger, bricks fell from a chimney (Stover, 1987).

\section{MAXIMUM HISTORICAL INTENSITY MAP}

A map was made of the highest intensities experienced within the four-county study area (fig. 16). This map, which was derived from the isoseismals and site intensities of the 13 earthquakes listed in table 2, shows the maximum intensity experienced at any point due to any one of the 13 shocks.

Intensities from two of the earthquakes (1934 Hansel Valley, 1962 Cache Valley) override most of the map. These two large shocks determine the maximum historical intensities for wide areas. Small areas of higher intensities within these wide areas are caused by local shocks.

Three other sets of earthquakes deserve mention in connection with the maximum intensity map:

1. The 1975 Pocatello Valley, Idaho, earthquake (fig. 17) caused high intensities across the northern part of Utah (Stover and others, 1986b; Coffman and Stover, 1977). However, nowhere within the study area did its isoseismals exceed those of the 1962 Cache Valley earthquake, and nowhere did its damage-level isoseismals ( $M M I \geq \mathrm{VI}$ ) intrude upon the four-county study area. Therefore, the 1975 shock was not used in the development of the maximum intensity map.

2. The group of shocks in Sevier County, Utah (fig. 18), includes shocks having maximum intensities estimated by various authors to range from $M M I_{0}=$ VII to IX (one in 1901 and three in 1921) (Townley and Allen, 1939; Williams and Tapper, 1953; Coffman and others, 1982; Stover and others, 1986a; Hopper, 1988). All these shocks had very rapid intensity attenuation and frequently were not felt much beyond the county borders; they were probably extremely shallow events. The 1901 event, which was reported felt in Salt Lake City, could have produced isolated damaging intensities within the southern part of the study area, but there is not enough information about the 1901 earthquake's effects to know for certain.

3. Several small local earthquakes were not included in the maximum historical intensity map because little is known about their intensity distributions and because their epicentral intensities are no higher than other, better reported shocks at nearby epicenters. For example, shocks in 1894 and 1949 produced MMI VI at their epicenters at Ogden and Salt Lake City, respectively, but the effects of the shocks beyond those cities are unknown. Neither earthquake affects the maximum intensity map (fig. 16) because both locations already show MMI VII from earthquakes in 1914 (fig. 5, VII at Ogden) and 1910 (fig. 4, VII at Salt Lake City). 


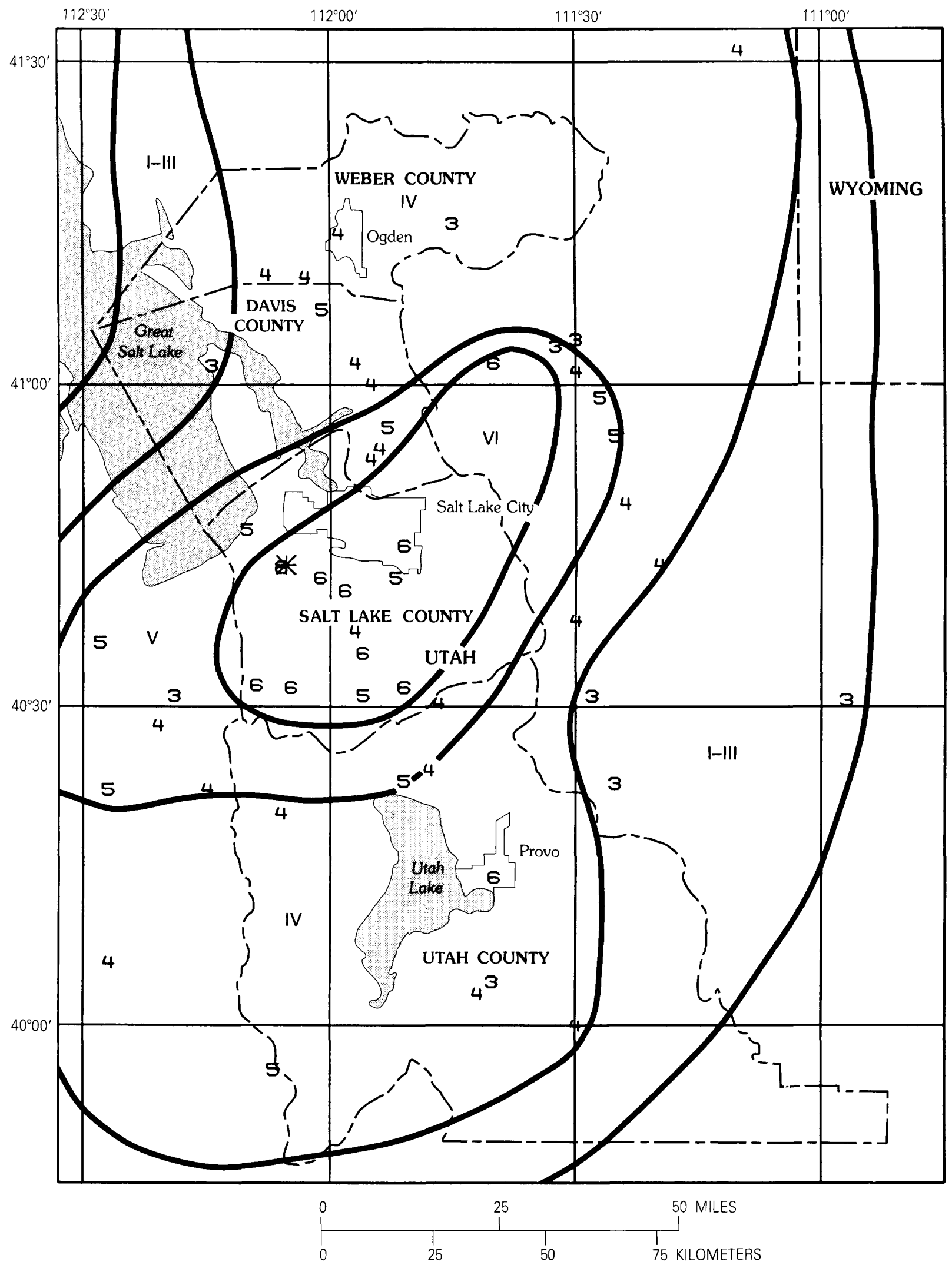

FIGURE 11.--Isoseismal map for the earthquake of September 5, 1962, Salt Lake City, Utah. The maximum Modified Mercalli intensity $\left(M M I_{0}\right)$ is $\mathrm{VI} ; M_{L}$ is 5.2. The star indicates the epicenter. Arabic numbers indicate site intensities ( $M M I$ ), and roman numerals indicate isoseismal intensities. 


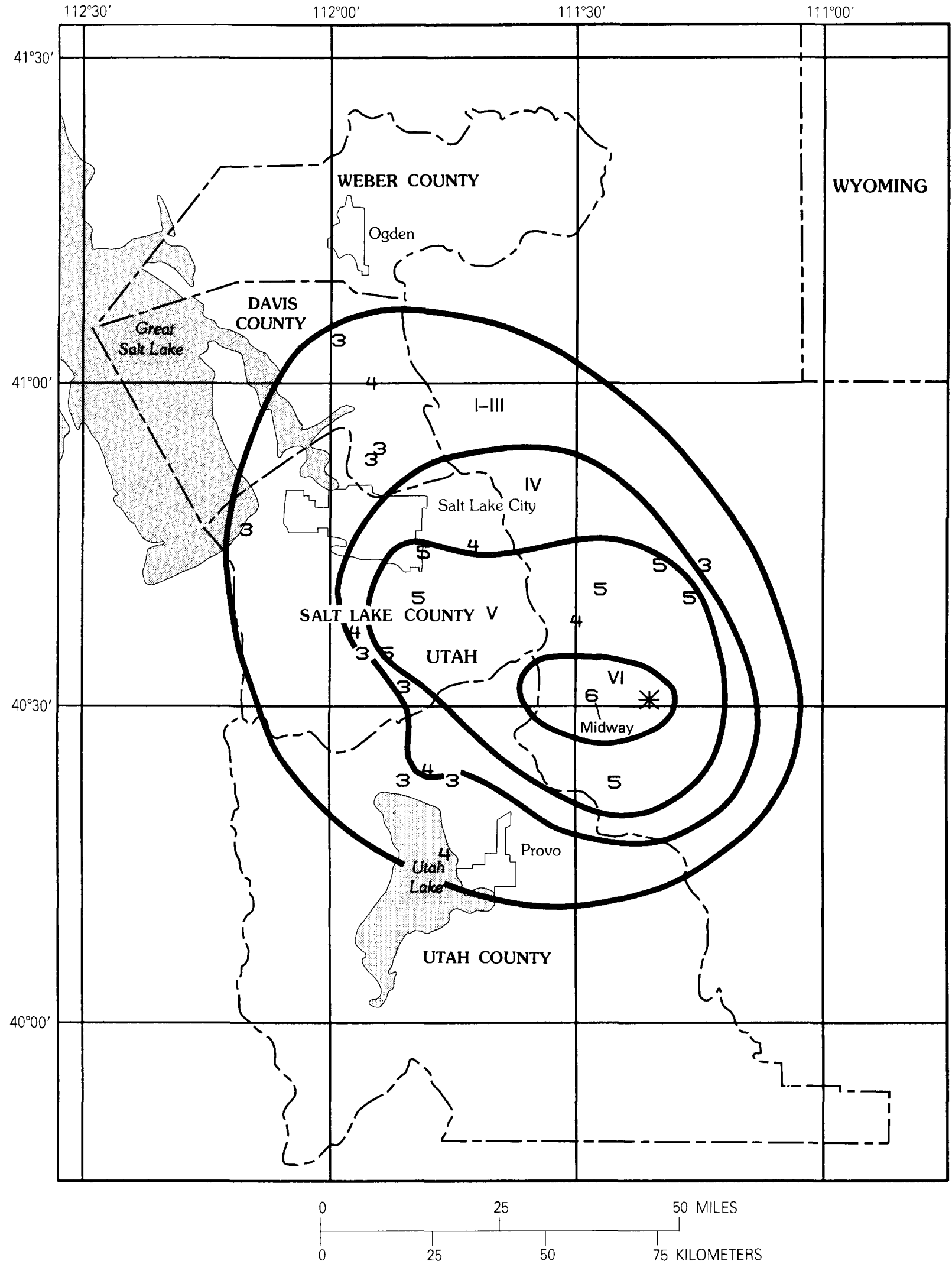

FIGURE 12.-Isoseismal map for the earthquake of October 1, 1972, Midway, Utah. The maximum Modified Mercalli intensity ( $M M I_{O}$ ) is VI; $M_{L}$ is 4.3. The star indicates the epicenter. Arabic numbers indicate site intensities ( $M M I$ ), and roman numerals indicate isoseismal intensities. 


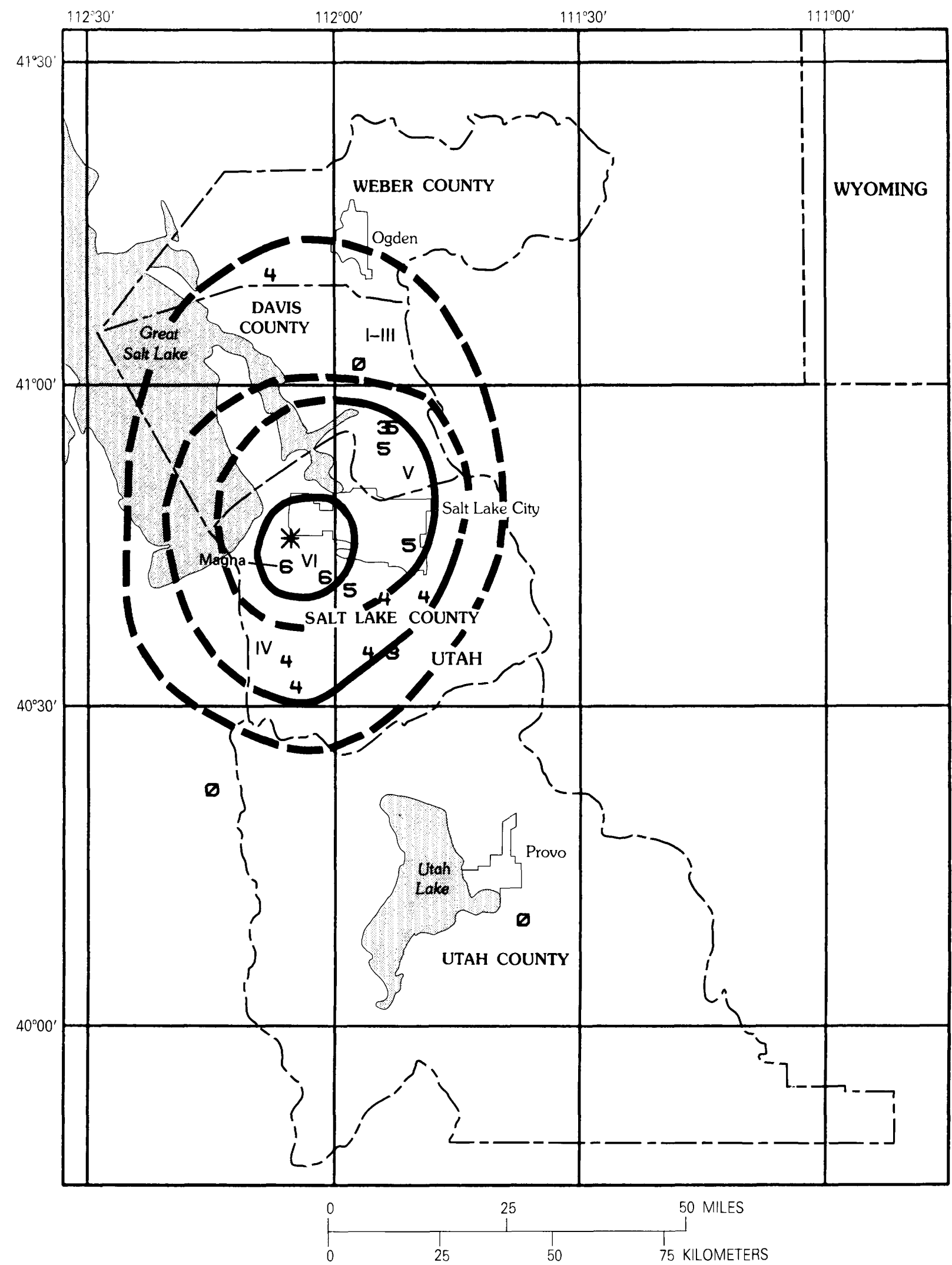

FigURE 13.--Isoseismal map for the earthquake of March 9, 1978, Magna, Utah. The maximum Modified Mercalli intensity ( $M M I_{O}$ ) is VI; $M_{L}$ is 3.2. The star indicates the epicenter. Arabic numbers indicate site intensities ( $M M I$ ), and roman numerals indicate isoseismal intensities. Isoseismals are dashed where uncertain. 


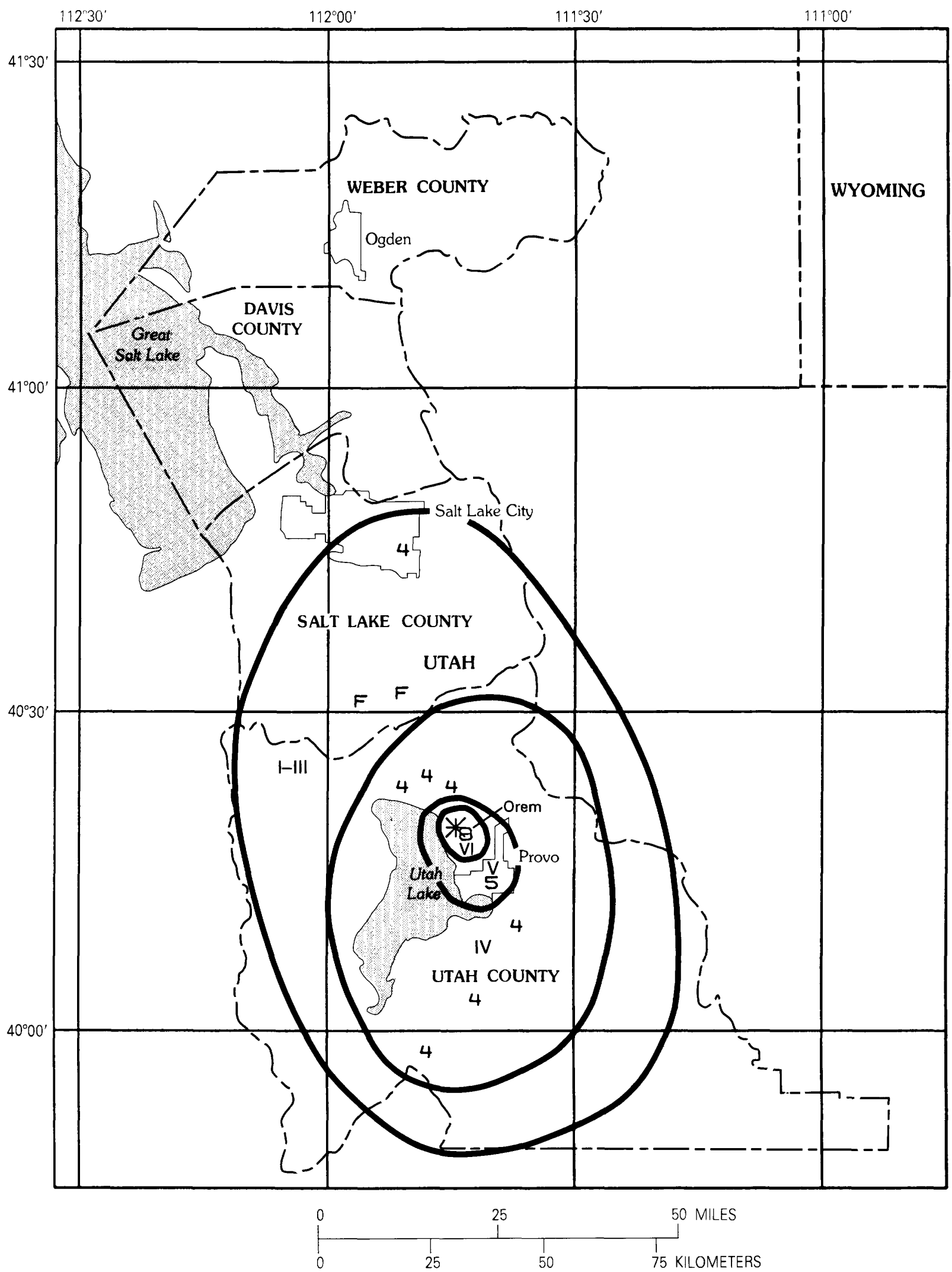

FIGURE 14.-Isoseismal map for the earthquake of February 20, 1981, Orem, Utah. The maximum Modified Mercalli intensity ( $M M I_{0}$ ) is VI; $M_{L}$ is 3.9 . The star indicates the epicenter. Arabic numbers indicate site intensities $(M M I)$, and the roman numerals indicate isoseismal intensities. F indicates a report of "felt" that was not assigned a $M M I$. 


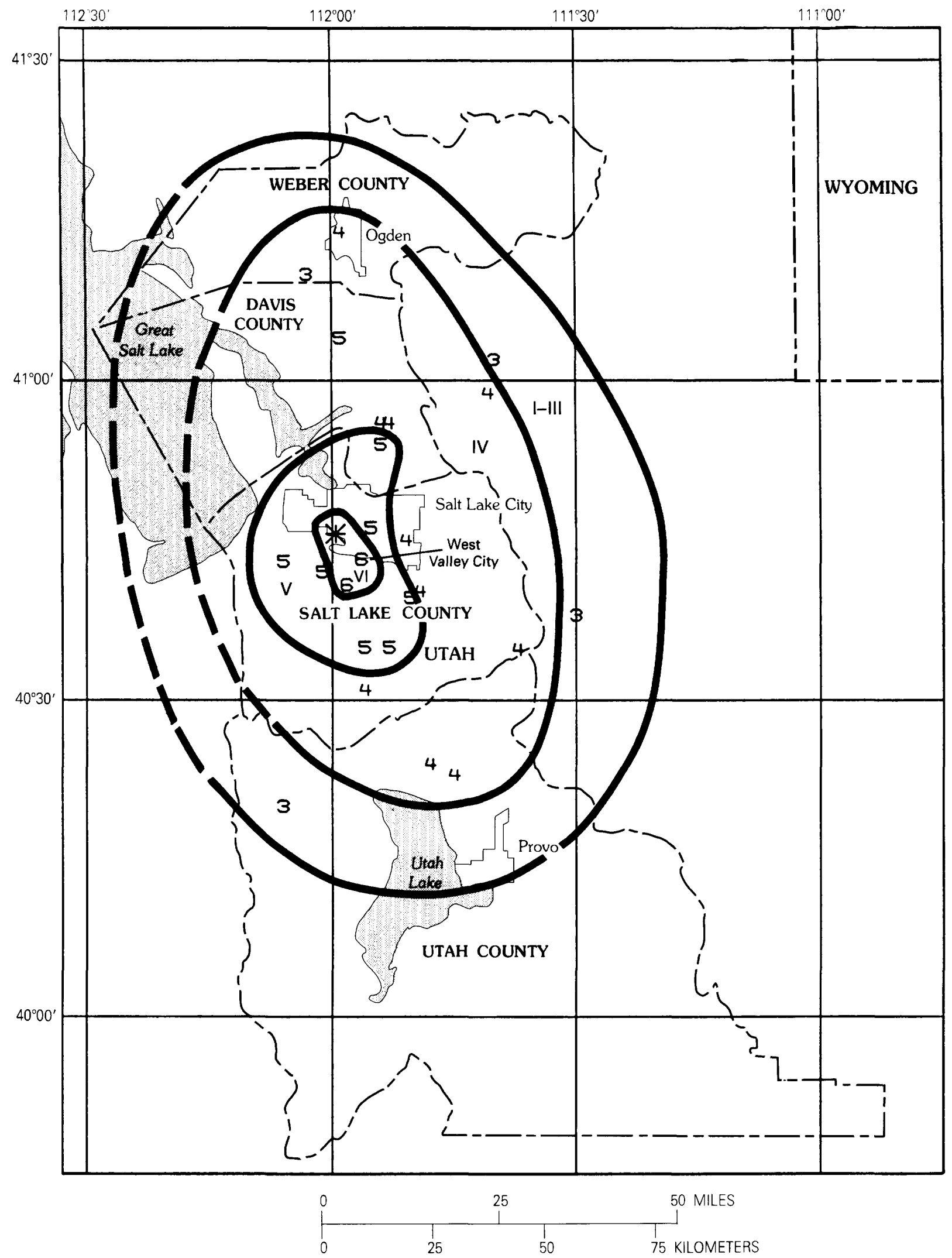

FiguRE 15.-Isoseismal map for the earthquake of October 8, 1983, West Valley City, Utah. The maximum Modified Mercalli intensity $\left(M M I_{0}\right)$ is VI; $M_{L}$ is 4.3 . The star indicates the epicenter. Arabic numbers indicate site intensities ( $M M I$ ), and roman numerals indicate isoseismal intensities. 


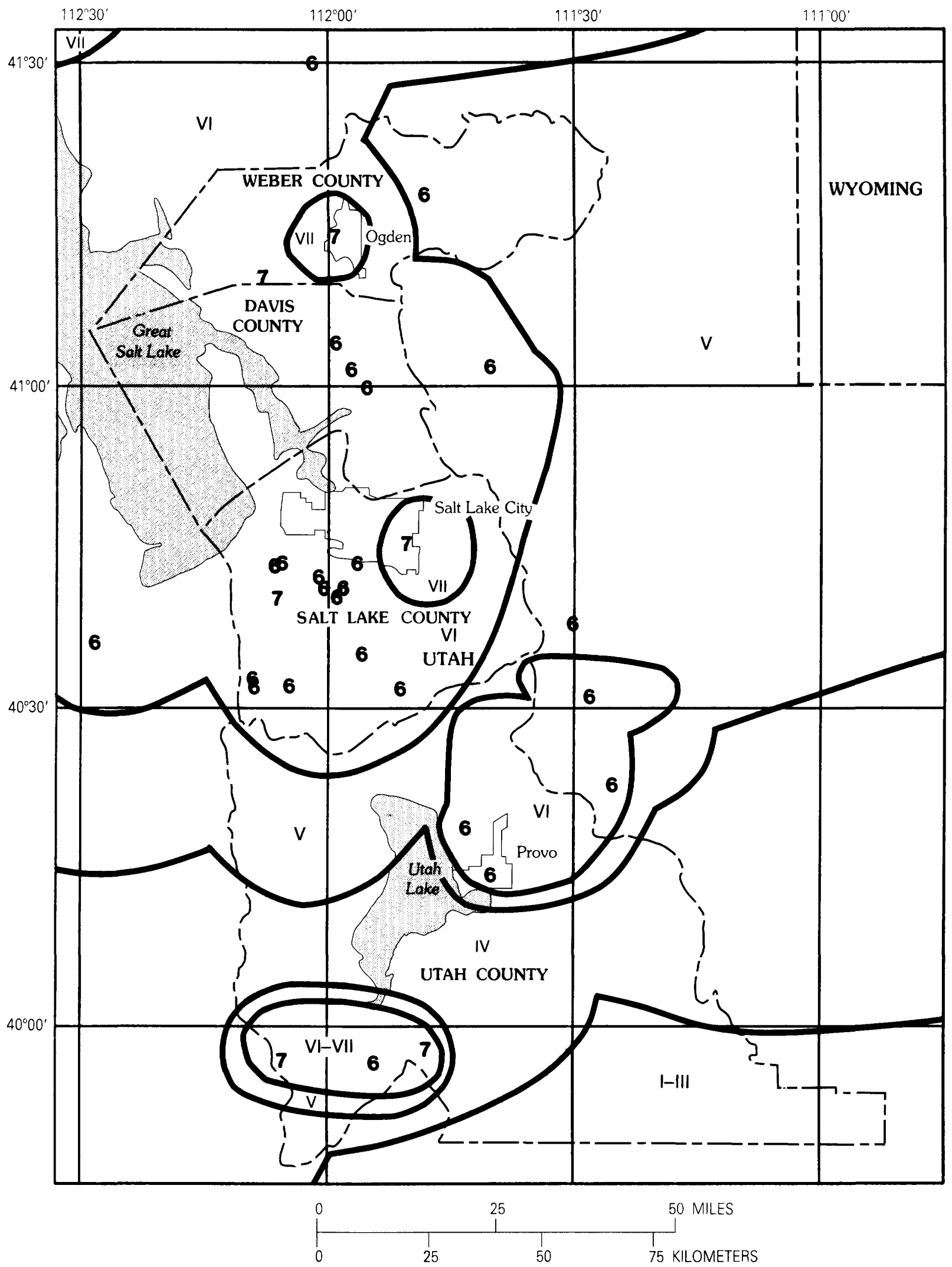


$\leftarrow$ FIGURE 16.-Maximum historical intensity map for the Utah counties of Weber Davis, Salt Lake, and Utah. Contours and roman numerals indicate areas of highest historical isoseismals ( $M M I)$ based on the maps in figures 3 through 15. Arabic numbers indicate historical site intensities strong enough to cause damage ( $M M I \geq \mathrm{VI}$ ). Outlying high intensities (for example, 7's in the VI area) are all due to the larger distant earthquakes (Hansel Valley and Cache Valley).

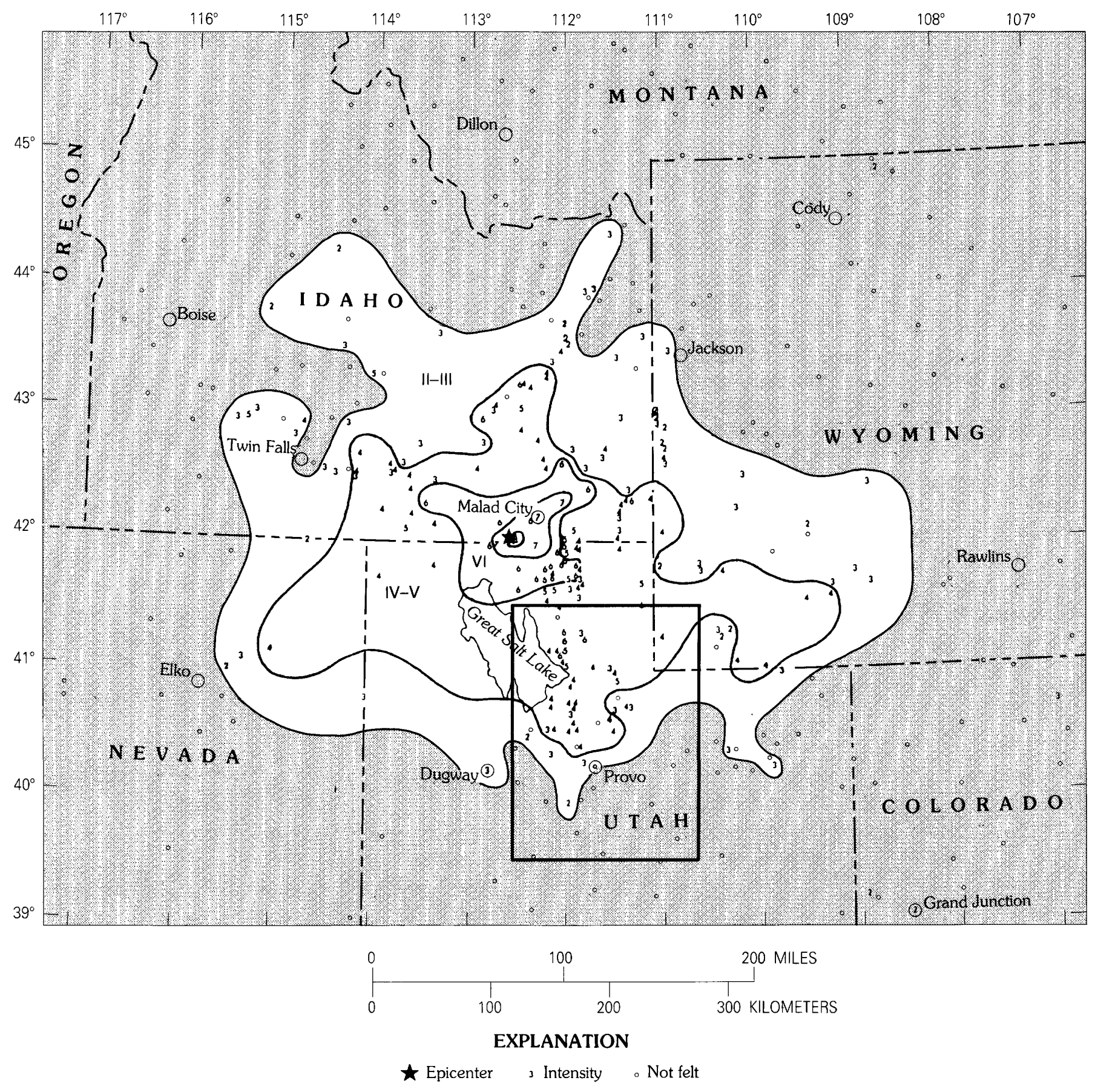

FiguRE 17.-Isoseismal map for the earthquake of March 28, 1975, Pocatello Valley, Idaho. The maximum Modified Mercalli intensity ( $M M I_{0}$ ) is VIII; $M_{L}$ is 6.0. The star indicates the epicenter. Arabic numbers indicate site intensities ( $\left.M M I\right)$, and roman numerals indicate isoseismal intensities. The map is from Coffman and Stover (1977). The area of this study is indicated by the rectangle. 

Seismic-Risk Methods and Estimates for Utility Systems and State-Owned Buildings Along the Wasatch Front

By CRAIG E. TAYLOR, Dames and Moore, Inc., and DELBERT B. WARD, Structural Facilities, Inc.

ASSESSMENT OF REGIONAL EARTHQUAKE HAZARDS AND RISK ALONG THE WASATCH FRONT, UTAH

U.S. GEOLOGICAL SURVEY PROFESSIONAL PAPER 1500-R 



\section{CONTENTS}

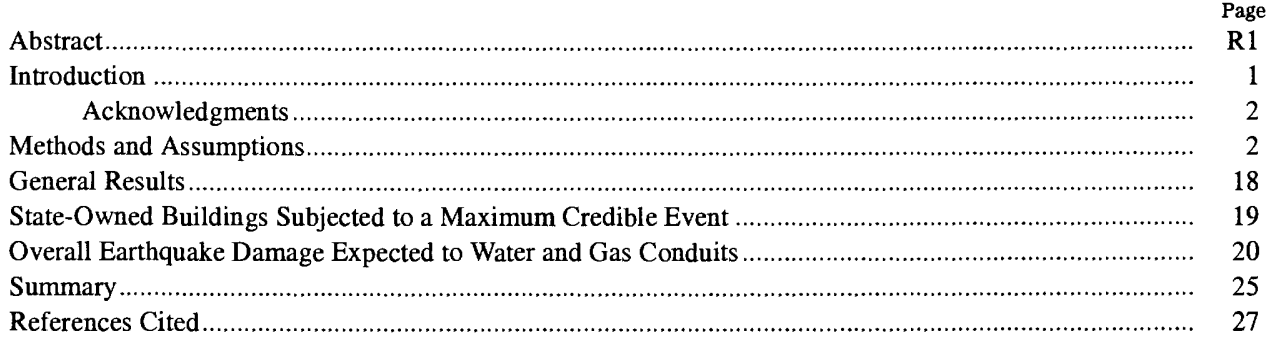

\section{ILLUSTRATIONS}

FIGURE 1. Map of study areas showing exposures in Weber, Davis, Salt Lake, and Utah Counties

2. Flow chart showing hazard assessment procedures

3. Plan view of the Wasatch fault system underlying facilities in Salt Lake County ...................................................................................

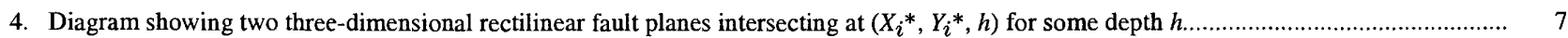

5-8. Maps showing:

5. Isocontours indicating estimated distances from sites to the Salt Lake segment of the Wasatch fault zone ............................................. 8

6. Expected relative ground-shaking response in the central part of the Wasatch Front urban area ..................................................... 10

7. Thickness of low-density sedimentary rocks in Wasatch Front valleys and Cache Valley inferred from gravity data............................ 12

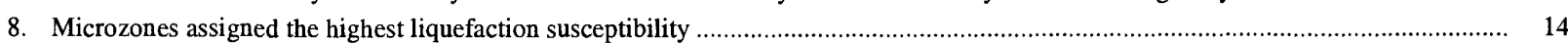

9. Flow chart showing procedures for estimating earthquake loss for insurance purposes .................................................................... 16

10. Map of Salt Lake City showing number of State-owned buildings having assumed (above-threshold) occupancies by microzone

11. Flow chart showing damage estimation procedures used for natural gas and culinary water systems

12, 13. Graphs showing:

12. Percentage of pipeline surveyed estimated to be subjected to permanent ground displacement in worst-case earthquake events .............. 22

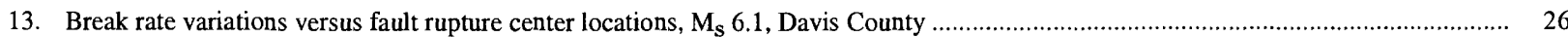

\section{TABLES}

TABLE 1. Assumed geometric characteristics of the Salt Lake segment of the Wasatch fault

2. Alternative magnitude scaling factors derived from equations by Youd and Perkins (1987), Joyner and Fumal (1985), and Campbell (1987)...

3. Property values for State-owned buildings by microzone and and seismic building quality

4. Mean building loss, contents loss, and downtime estimates to State-owned buildings in a hypothetical $\mathrm{M}_{\mathrm{S}} 7.3$ earthquake on the Salt Lake segment of the Wasatch fault zone

5. Average break rates estimated for utility systems surveyed for maximum credible and worst-case $M_{S} 6.7$ events simulated ...

6. Percent of estimated repairs attributed to different hazard modes in worst-case events

7. Ratio comparisons of pipe repair rates based on diverse assumptions for maximum credible earthquakes affecting water and gas systems in Utah and Weber Counties.....

8. Sensitivity of worst-case repair rates at lower magnitude levels to assumptions on magnitude scaling factors..... 



\title{
SEISMIC-RISK METHODS AND ESTIMATES FOR UTILITY SYSTEMS AND STATE-OWNED BUILDINGS ALONG THE WASATCH FRONT
}

\author{
By Craig E. Taylor and Delbert B. Ward
}

\begin{abstract}
This paper summarizes the methodology and results of two seismic-risk projects on Utah facilities. The topics selected in these projects are explained in relation to past seismic-risk projects on Utah facilities and in relation to potential uses of seismic-risk estimates. Results are highlighted with reference to project goals. A longer discussion of methods used and technical obstacles addressed indicates the iterative nature of seismic-risk projects. Finally, a more detailed presentation of results is made. Detailed results in the form of computer printouts of expected earthquake damage have been presented to specific usersnamely, local culinary water and natural gas utility officials and to the State of Utah Risk Administrator.
\end{abstract}

\section{INTRODUCTION}

In early 1985, we began a 1-year U.S. Geological Survey (USGS)-sponsored project to examine (1) expected losses and casualties in State-owned buildings as a result of a maximum credible earthquake and (2) expected damage to culinary water and natural gas facilities in Salt Lake and Davis Counties as a result of a broad range of possible earthquakes affecting them. In early 1987, we began a second 1-year USGS-sponsored project to examine expected damage to water and gas facilities in Weber and Utah Counties as a result of a broad range of possible earthquakes affecting them.

Project topics were selected so that (1) they did not duplicate previous work or work in progress (including studies by the J.H. Wiggins Company, 1979; Algermissen and others, 1976; Liu, 1977; Bresko and others, 1981; Taylor and Ward, 1979, 1981; Highland, 1987; Algermissen and Steinbrugge, 1984); (2) project results could illuminate some of the more recent methodological and data developments in the geosciences and engineering as they pertained to the region of study; and (3) project results might assist in advancing earthquake hazard reduction pro- grams. As a result of this third consideration, for instance, we decided not to reexamine average annual loss estimates for various classes of buildings. Although new findings would likely change and improve those estimates (as Taylor and Ward (1979) found, for instance), we did not believe that significant policy conclusions would deviate from those developed by the Utah Seismic Safety Advisory Council (1981) and the Utah Geological and Mineral Survey (1983). Furthermore, this third consideration implied that the primary objective outputs-detailed computer printouts of damage and casualty estimatesshould be designed for those who might use them (that is, the State of Utah Risk Administrator and utility officials whose systems were analyzed).

Results of the first project reaffirm that shaking losses and potential casualties would be severe for Stateowned buildings affected by a maximum credible earthquake (whether from the Salt Lake or the Ogden segment of the Wasatch fault). Principal factors affecting results are the magnitude of these maximum credible earthquakes $\left(\mathrm{M}_{s} .7 .0-7.5\right)$, the close proximity of exposures to the Wasatch fault at depth, and the seismic vulnerability of many State-owned buildings. Further study of the seismic vulnerability of State-owned structures-especially with regard to life-safety factors-could greatly assist in identifying those structures most vulnerable and hence in need of long-term removal, replacement, or occupancy reduction. Whether the current State of Utah practice of self-insurance is adequate to respond to expected damage to State-owned buildings deserves careful review based on the results of this study.

Although building damage from these maximum credible events is expected to be severe, so is damage to and disruption of culinary water and natural gas systems. With the possible exception of portions of the natural gas 
systems, local gas or water systems can be expected to have little or no immediate reliability once they have been affected by a maximum credible Wasatch fault event in their county. Mountain Fuel Supply representatives have used detailed computer printouts of damage estimates made in this study to confirm this expectation for their systems. The damage estimates for culinary water systems, which contain much more seismically vulnerable facilities, were many times more severe than those for the natural gas systems.

In addition to the comparative vulnerabilities of facilities, primary factors affecting these results include the magnitudes of these maximum credible events, the close proximity of the Wasatch fault at depth to exposures, high, soft soil site amplification factors for many exposures, and severe potential liquefaction problems, especially near the Jordan River and the Great Salt Lake. Although fault-zone crossings are significant, detailed results indicate that damage from fault displacement is generally only a small proportion of the overall expected damage to water and gas facilities.

An important characteristic of these projects is that we have emphasized smaller magnitude events (from 5.57.0 ) as much as maximum credible ones for two major reasons. First, owing to high liquefaction susceptibilities in the four counties, local water utility catastrophes can occur from low-magnitude earthquakes (possibly as low as 5.5 in some instances). Second, utility damage estimates from maximum credible earthquakes tend to be so high that no obvious limited measures can be used to improve immediate system reliability. In contrast, smaller magnitude earthquake scenarios can help utility officials to define those portions of the system that can be seismically enhanced to provide increased system reliability. Measures designed to increase system reliability in these smaller magnitude events also tend to (1) improve expected system performance (long-term reliability) through reduced expected damage in larger magnitude earthquakes as well and (2) concentrate efforts on the more seismically vulnerable portions of systems-those portions expected to be damaged by a wide variety of potential earthquakes.

Some of the more important methodological problems encountered in these projects are highlighted below. Methodological revisions from the first project to the second have included incorporations of changes made by K.W. Campbell in defining attenuation functions for the Wasatch Front region, simplification of the fault models used as a consequence of findings in the first project, and adjustment of damage algorithms for pipelines subjected to severe ground shaking. To estimate probabilities of liquefaction-induced ground failure, makeshift methods had to be devised for both projects. Our study findings strongly suggest the need to develop a research program to assess probabilities. The program should include an empirical and (or) experimental reassessment of multipliers used to adjust critical accelerations to account for the effects of different numbers of cycles of shaking. Although seismic-risk methods used often require working assumptions or imperfect data, these limitations are best approached by (1) sensitivity and other statistical analyses that determine the impact of alternative assumptions and (2) continued investigations in science and engineering to improve pertinent information and algoritlıms used.

\section{ACKNOWLEDGMENTS}

We thank J. Keaton (Dames and Moore), L. Reaveley (Reaveley \& Reaveley Engineers), D. Ford (Ductile Iron Pipe Research Association), and S.T. Algermissen, L. Highland, and D. Perkins (U.S. Geological Survey) for their careful reviews. We also thank the American Society of Civil Engineers for permission to reproduce figures 2, $6,8,11$, and 12 in this paper from an earlier publication. These projects were supported by U.S. Geological Survey contracts 14-08-001-22013 and 14-08-0001-G1394. This support is gratefully acknowledged.

\section{METHODS AND ASSUMPTIONS}

A significant consideration in structuring a database for these projects is the selection of a basic geographic reference system. The township system was selected for the primary study areas. (fig. 1). In the course of these projects, many advantages and disadvantages of this system became apparent. A very compelling advantage for these risk projects has been the widespread and customary used of the township system by those who select pertinent data and by potential users of data and results. Two examples are the culinary water systems of GrangerHunter (in Salt Lake County) and Orem (in Utah County), which are laid out on the township system. Disadvantages arise because the ideal microzone size varies with particular purposes, Thus, township sections $(1 \times 1 \mathrm{mi})$ used as microzones are, at times, too large or too small. This study areas was 2,504 microzones. In some cases, especially in Weber and Utah Counties, liquefaction susceptibility data developed by Utah State University and Dames \& Moore are too sparse to make meaningful estimates for each microzone. In other cases, these data are diverse enough to suggest that smaller microzones might be desirable. On the whole, however, given the large number of microzones used, the township system was adequate for study purposes.

Figure 2 outlines the primary hazard steps in these projects. Unique to this approach in Utah seismic-risk studies is the choice of many earthquake scenarios repre- 


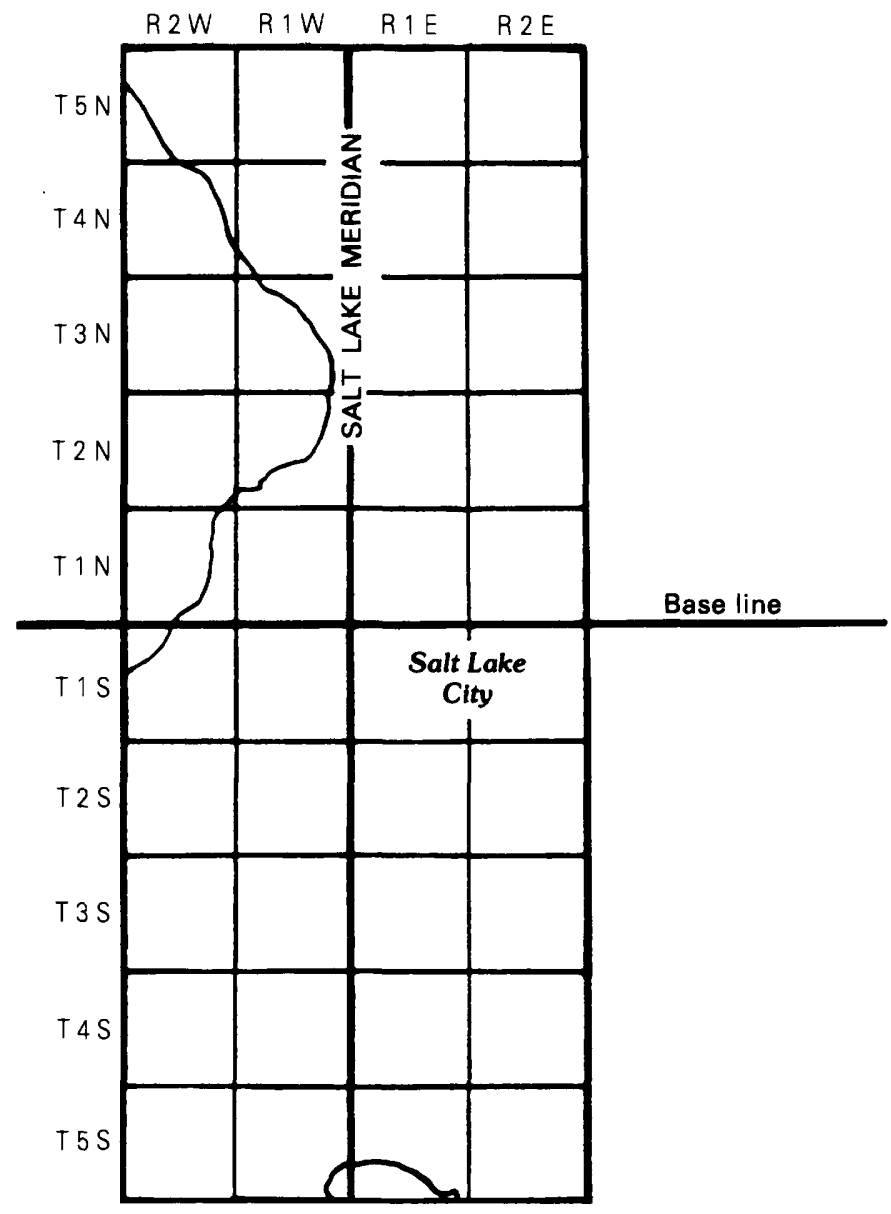

FIGURE 1.-Study areas showing exposures in Weber, Davis, Salt Lake, and Utah Counties.

senting the gamut of possible magnitudes and the range of rupture locations that may damage exposures in the study area. The annual probabilities of magnitude and rupturelocation occurrences can be assessed to place risk results within a probabilistic framework. First, we explain why we selected multiple scenarios rather than either selecting maximum ones only or selecting methods to develop probabilistic estimates of hazards affecting individual sites. We then describe how these earthquake scenarios were selected to accommodate a probabilistic framework.

A severe limitation of using only maximum credible earthquakes has been that, because this method greatly underestimates long-term primary losses expected from earthquakes, it consequently underestimates the benefits of seismic-risk reduction measures as well. To draw an example from California, exclusive concern with potential losses from major San Andreas faulting scenarios (affecting either San Francisco and Los Angeles) would ignore losses from the Whittier, Coalinga, Imperial Valley, San Fernando Valley, Long Beach, and Hayward events, to name but a few. Total estimated benefits from earthquake hazard reduction measures comprehend the entire range of potential earthquakes.

One traditional weakness of procedures designed to estimate total primary losses from all earthquakes potentially damaging to facilities has been that these procedures ignore or provide a poor account of secondary losses, including systematic consequences of individual earthquakes. These consequences include business interruption losses, governmental discontinuities, fires, losses of heating and lighting, water and gasoline shortages, and problems in caring for those left homeless. These sorts of losses are clearly illustrated with respect to lifeline networks, for which direct dollar loss is not linearly related to system performance. In a highly redundant portion of a system, service may continue at pre-disaster levels even though direct dollar loss is large. In a portion of a system that has no alternative service paths or supply sources, damage to a single facility may cause extensive service outages over a long period of time. Traditional probabilistic approaches also have difficulties treating resources that are limited, such as inventories of piping, local medical personnel, local capital for reconstruction, and insurance reserves available for paying the insured. Using individual scenarios, to evaluate earthquake risks has the advantage of indicating not only whether specific critical levels of resources will be surpassed for given events but also how soon critical infrastructure services will be available for use in response, recovery, and reconstruction.

Accordingly, these projects have used a large number of individual scenarios within a probabilistic framework. This approach overcomes the limitations of using traditional probabilistic methods and of emphasizing only a small set of mainly maximum credible earthquake scenarios.

To accommodate this probabilistic framework, we first treated major fault traces as sequences of straight lines. The faults used include the Granger, the Hansel Valley, the Cache Valley, and the Taylorsville faults and various segments of the Wasatch fault (Keaton and others, 1987; Robinson, 1986). For the sake of simplicity, we have followed Wheeler and Krystinik (1987) in modeling the Wasatch fault as consisting of four persistent segment boundaries and five main segments: a northernmost, the Weber, the Salt Lake, the Provo, and a southernmost. Relative to exposures examined in this project, the chief controversial aspect of this treatment is that it allows the possibility of larger magnitude events on the Provo segment than the smaller American Fork $(22.5 \mathrm{~km})$ and Provo $(18.5 \mathrm{~km})$ segments would allow if they were used 


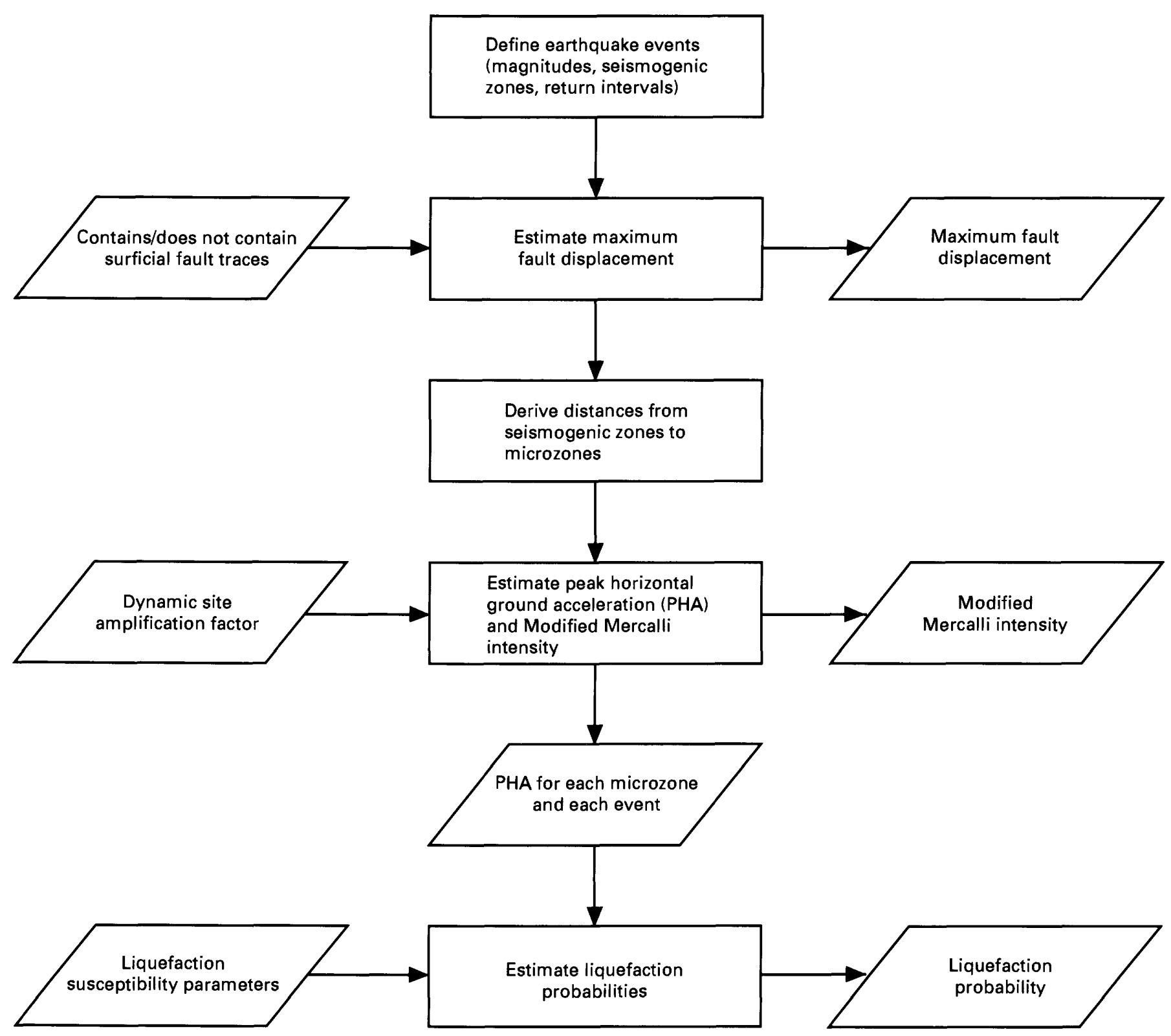

FIGURE 2.-Hazard assessment procedures used. (Reproduced with permission of the American Society of Civil Engineers.)

to define maximum earthquakes in this region (Machette and others, 1987).

As the 1987 Whittier Narrows and 1983 Coalinga, Calif., earthquakes have shown, not all earthquakes occur on fault zones known to be active, and few normal or thrust zones have been mapped at depth (Hutton, 1987; Alfors, 1983). Accordingly, our treatment of possible earthquakes permits the development of a random source zone and the designation of a dip angle for whatever fault system is used. Some random source zones for the 
TABLE 1.-Assumed geometric characteristics of the Salt Lake segment of the Wasatch fault

[Origin is defined as the intersection of the base line and the Salt Lake meridian]

\begin{tabular}{|c|c|c|c|c|c|c|c|c|c|c|}
\hline \multirow{2}{*}{ Section } & \multirow{2}{*}{$\begin{array}{l}\text { End } \\
\text { point } \\
\text { index }\end{array}$} & \multicolumn{3}{|c|}{ Coordinates (mi) } & \multirow{2}{*}{$\begin{array}{l}\text { Strike angle } \\
\phi_{i}(\mathrm{deg})\end{array}$} & \multirow{2}{*}{$\begin{array}{l}\text { Dip angle } \\
\beta_{i}(\text { deg })\end{array}$} & \multicolumn{2}{|c|}{$\begin{array}{l}\text { Intersection points } \\
\text { at } 7.46 \text { mi deep (mi) }\end{array}$} & \multirow{2}{*}{$\begin{array}{c}\begin{array}{c}\text { Calculated } \\
\text { trend (deg) }\end{array} \\
\phi_{i}^{*}\end{array}$} & \multirow{2}{*}{$\begin{array}{c}\begin{array}{c}\text { Calculated } \\
\text { plunge (deg) }\end{array} \\
B_{i}^{*}\end{array}$} \\
\hline & & $x_{i}$ & $y_{i}$ & $z_{i}$ & & & $x_{i}^{*}$ & $y_{i}^{*}$ & & \\
\hline Draper & 1 & 3.36 & -16.82 & 4.35 & 035 & 65 & 3.72 & -20.88 & 232 & 31 \\
\hline Cottonwood & 2 & 5.86 & -13.26 & 4.35 & 005 & 40 & -3.38 & -16.96 & 232 & 31 \\
\hline Olympus & 3 & 6.24 & -8.93 & 7.46 & 328 & 31 & -7.26 & -10.76 & 230 & 31 \\
\hline Foothill & 4 & 2.29 & -2.61 & 3.11 & 360 & 38 & -7.26 & -7.43 & 230 & 31 \\
\hline University & 5 & 2.29 & .50 & 1.86 & 030 & 60 & -6.40 & -5.94 & 230 & 31 \\
\hline City Creek & 6 & 3.22 & 2.11 & 6.22 & 005 & 40 & -5.88 & -.03 & 230 & 31 \\
\hline
\end{tabular}

Wasatch fault region have included very narrow zonesbetween 10 and $20 \mathrm{~km}$ on each side of the Wasatch fault (Taylor and Ward, 1979; Algermissen and others, 1982). Other accounts of background seismicity (earthquakes having magnitudes below 6.5) have employed a very wide random source zone (Arabasz and others, 1987). Our method is to develop earthquakes along lines parallel to and at any specified distance from either a known fault trace (such as the Wasatch) or a north-south line. To account for rupture lengths relative to specified magnitudes, we have used empirical work (Bonilla and others, 1984) relating magnitude and rupture length for all fault systems. Given these rupture lengths, a number of earthquakes can be specified from north to south along the designated sequence of lines (representing fault traces, lines parallel to fault traces, or lines parallel to northsouth lines). Our method is therefore compatible with either very narrow or very wide source zones and with the view that either an entire Wasatch fault segment must rupture in a Wasatch fault event or that only a portion of a given Wasatch fault segment may rupture.

Designation of a dip angle enables us to provide a crude account of distances for exposures to the Wasatch fault at depth. Currently, models of the Wasatch normal fault are either listric or planar (Smith and Richins, 1984). In our first project, we explored the use of a complex planar model hypothesized by Ronald Bruhn (written commun., 1985) and others but modified by Bruhn and others (1987). That model suggests that the Salt Lake segment of the Wasatch fault can be modeled as a series of rectilinear planes whose surface projections are shown in figure 3.

Table 1 indicates the assumed geometric characteristics of this segment, and figure 4 clarifies the variables used in table 1. This model comes from an attempt to derive a fairly constant slip vector for the planes composing the Salt Lake segment, so that a single slip can be modeled along all such planes.

This model suggests that sites in Salt Lake County are much closer to the dipping planes of the Salt Lake segment of the Wasatch fault than an estimate based on the distances to the surface expression of this zone would indicate. Figure 5 shows the estimated shortest distances to these Wasatch fault planes as modeled in figure 3 . This figure suggests that, for exposures to the west of the Wasatch fault trace (Salt Lake segment), distances to the surface trace are approximately twice the distances to the fault at depth.

These findings, along with the presence of alternative Wasatch fault models (including listric ones) confirming the above result, have persuaded us that a designated dip angle is currently adequate for seismic risk purposes to model each Wasatch fault segment at depth. (In our current program, this dip angle applies uniformly to each straight-line section of the segment; variations in dip angles for each section, as table 1 implies, might be slightly preferable.) Modeling distances to the surface expression of the fault has the disadvantage of ignoring the Wasatch fault dipping planes underlying most 


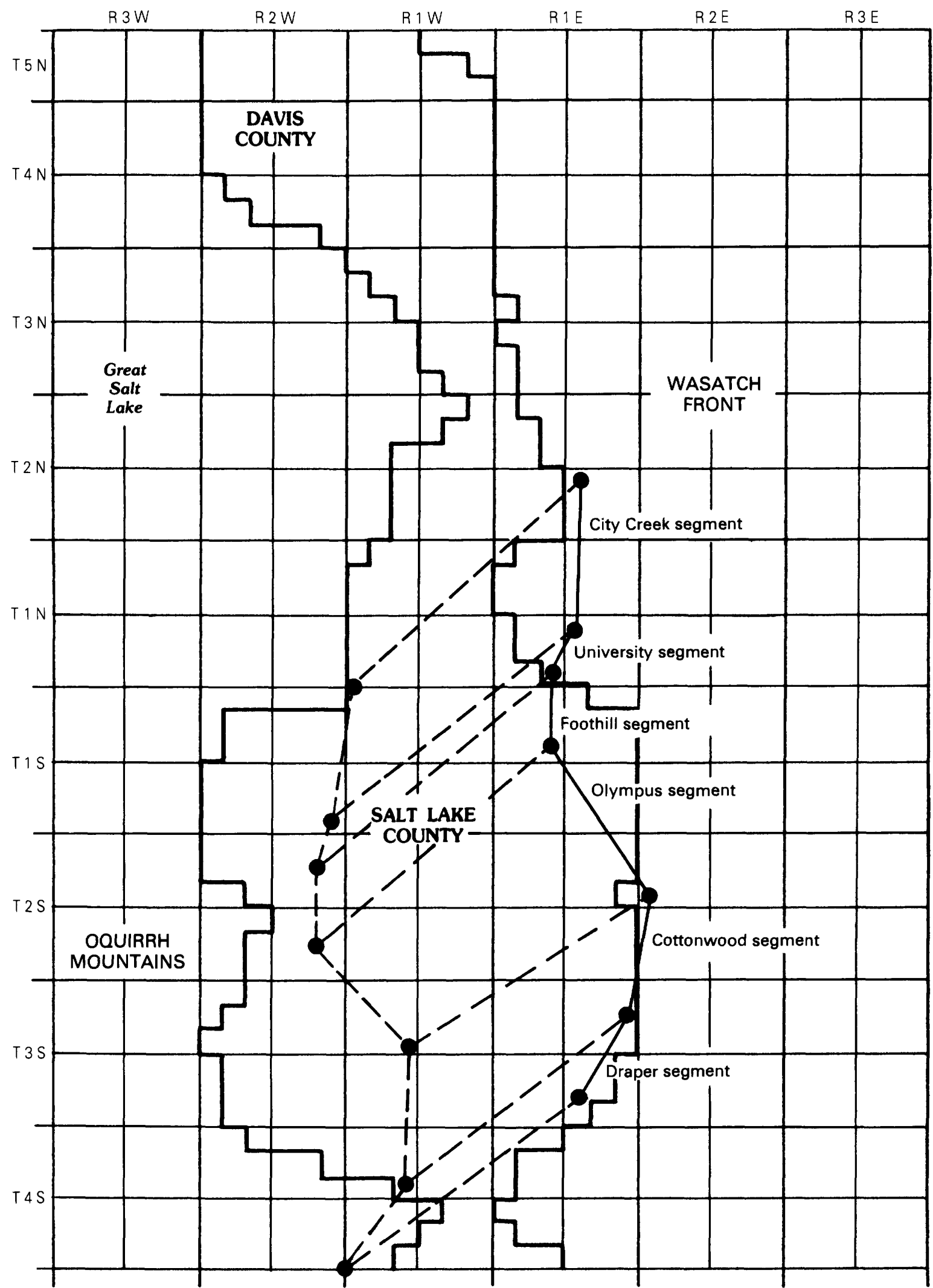

FiguRE 3.-Plan view of Wasatch fault system (Salt Lake segment, $12 \mathrm{~km}$ deep) underlying facilities in Salt Lake County. Dashed lines indicate projection of fault planes to depth below the ground surface. 


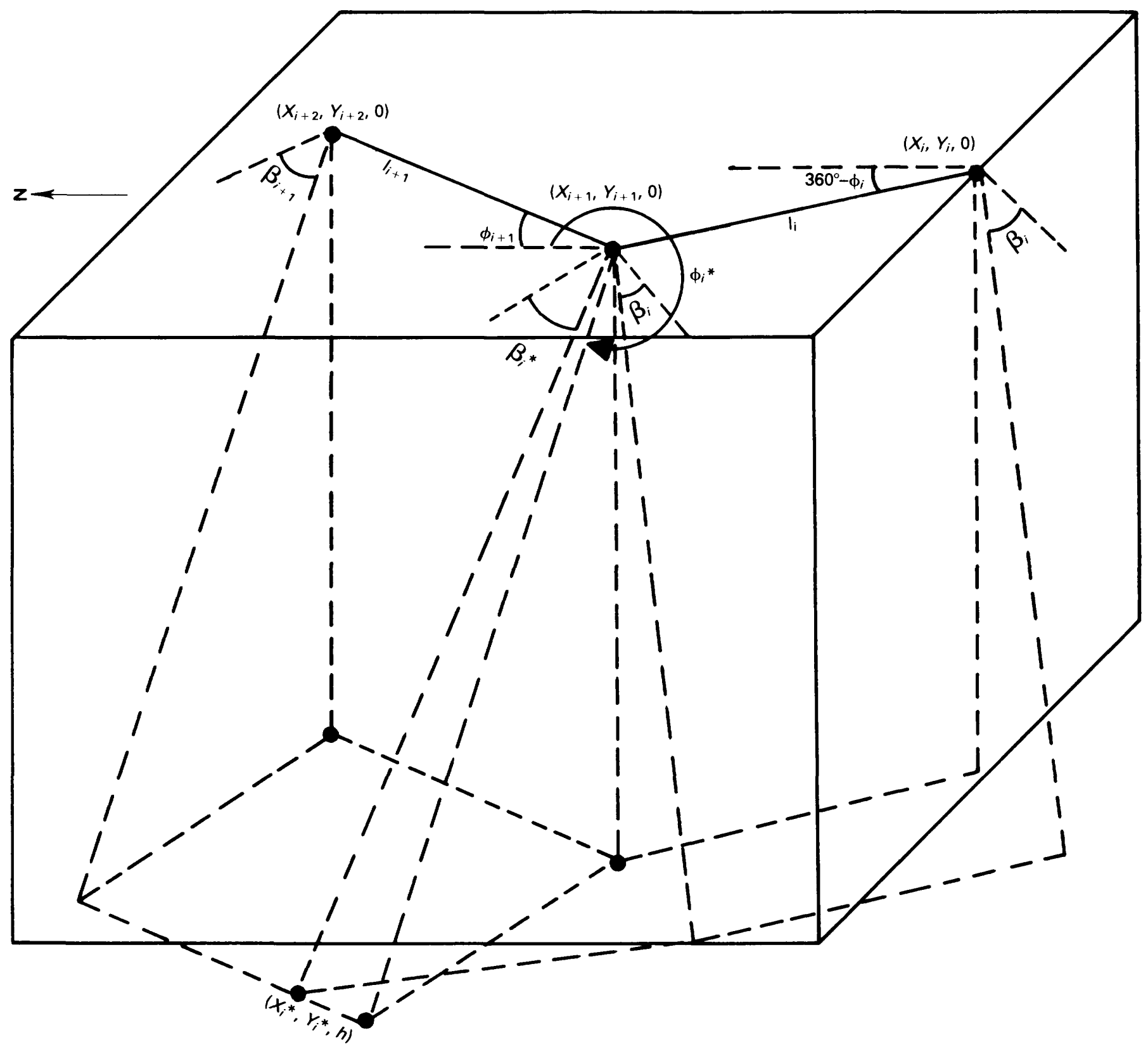

EXPLANATION

$\phi \quad$ Strike angle

$\beta$ Dip angle-Defined normal to each surface segment

$\phi^{*}$ Trend angle

$\beta^{*}$ Plunge angle-Calculated with respect to the line normal to $\phi^{*}$

1 Length of surface trace

FIGURE 4.- -Two three-dimensional rectilinear fault planes intersecting at the $\left(X_{i}^{*}, Y_{i}^{*}, h\right)$ for some depth $h$ (no elevations are assumed on the Earth's surface). $\phi$, strike angle; $ß$, dip angle (defined normal to each surface segment); $\phi^{*}$, trend angle; $\beta^{*}$, plunge angle (calculated with respect to the line normal to $\left.\phi^{*}\right) ; l$, length of surface trace. 


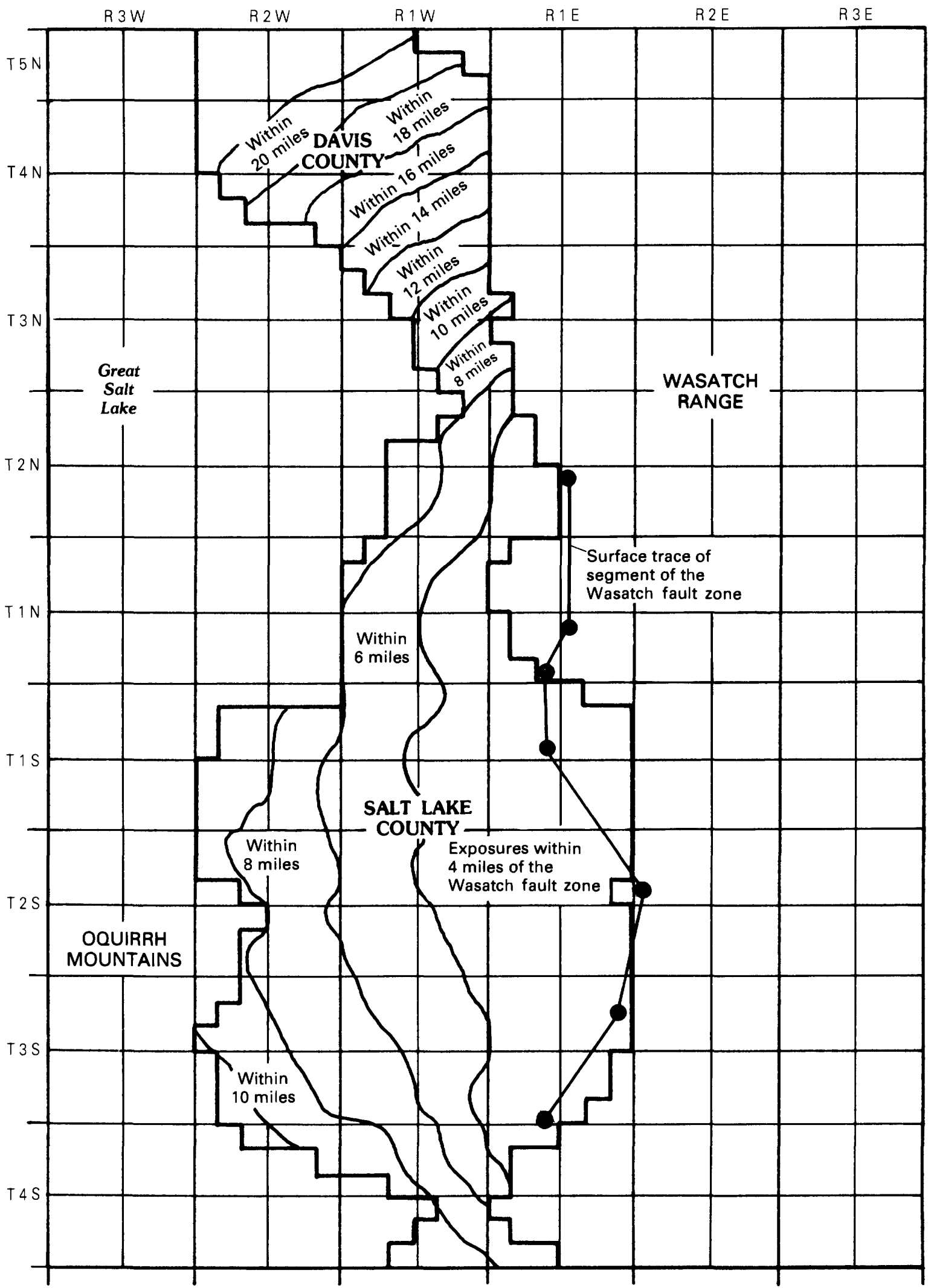

FIGURE 5.-Isocontours indicating estimated distances (in miles) from sites to the Salt Lake segment of the Wasatch fault zone (modeled in three dimensions). 
exposures; more refined fault models-worth exploring for their implications-nonetheless have the disadvantage of not being fully corroborated.

Figure 5 illustrates how larger magnitude (6.5 and above) earthquakes from the Wasatch fault (especially the Salt Lake, Ogden, and Provo segments) are expected to affect many exposures in the near field. Because the problem of defining attenuation patterns in the Wasatch region includes this near-field aspect and because large error terms hence arise from using attenuation functions based on hypocentral distance, Campbell's (1984, 1987) work has been used as a basis for developing both peak horizontal accelerations and Modified Mercalli intensities. For assessing peak horizontal acceleration (PHA) in the first project, the following equation from Campbell (1984) was used:

$\mathrm{PHA}=\exp \{-2.817+0.702 \mathrm{M}-1.02 \ln [R+0.0921 \exp (0.584 \mathrm{M})]\}$

where $M$ is earthquake magnitude $\left(M_{s}\right.$ when $M>6$ and $M$ otherwise), $R$ is the shortest distance to the seismogenic surface (in kilometers), and PHA is the mean of the two horizontal components of peak accelerations (in units of $g$ ).

For the second project, following Campbell (1987), we used the equation

$$
\begin{aligned}
\mathrm{PHA}= & \exp \{-3.303+0.850 \mathrm{M}-1.25 \ln [R+0.0872 \exp \\
& \left.(0.678 \mathrm{M})]-0.0059 R+\left(0.34 K_{1}+0.53 K_{\mathcal{Z}}+0.41 K_{3}\right)\right\}
\end{aligned}
$$

where $K_{1}$ is 0 for strike-slip faults and 1 for reverse and thrust faults, $K_{2}$ is 0 if the rupture is not directed toward the site (or directivity is unknown) and 1 if the rupture is directed toward the site, and $K_{3}$ is 0 if soils are over $10 \mathrm{~m}$ deep and 1 otherwise.

In programming these additional variables, we have permitted options to analyze the sensitivity of results to various selections of values for $K_{1}, K_{2}$, and $K_{3}$. For somewhat conservative results for the natural gas system, we have used $K_{1}=1, K_{2}=0$, and $K_{3}=1$ (rupture directivity is largely unknown). For less conservative results, we have used $K_{1}=0, K_{2}=0$, and $K_{3}=1$. For sensitivity analyses, we have $K_{1}=0, K_{2}=0$, and $K_{3}=0$.

To derive estimates of Modified Mercalli shaking intensities, we first developed estimates of peak horizontal velocities and derived estimated intensities from both relative response data for the region and an equation relating shaking intensities to peak horizontal velocity.

In the first project and following Campbell (1984), we used the following equation to derive estimates of peak horizontal velocity (PHV):

$\mathrm{PHV}_{\text {rock }}=\exp \{0.798+1.02 \mathrm{M}-1.26 \ln [R+0.015 \exp (0.812 \mathrm{M})]\}$ where PHV is the median value of the mean of two horizontal components of peak velocity (in centimeters per second) ("rock" refers to basement rock).

To derive surficial estimates of peak horizontal velocity, the following relationship was used:

$$
\mathrm{PHV}_{\text {surface }}=\left(\mathrm{DAF}_{\text {site }}\right) \mathrm{PHV}_{\text {rock }}
$$

where $\mathrm{DAF}_{\text {site }}$ indicates the soft surficial soil dynamic amplification factors.

Spectral values used in equation 4 were derived for the short-period band ( $0.2-0.7 \mathrm{~s})$ results of Rogers and others (1984) and are as shown for Salt Lake, Davis, and Weber Counties in figure 6. Spectral values tend to be slightly higher for the long-period band ( $0.7-1.0 \mathrm{~s})$. Nonetheless, as figure 6 shows, extensive portions of the study area were assigned spectral dynamic amplification factors of 6.2. The chief rationale for this procedure was that it yielded intensity increases of slightly over 2 relative to basement rock estimates.

In the second project, following Campbell (1987), we used the following equations to derive estimates of PHV:

$$
\begin{aligned}
\mathrm{PHC}_{c}= & \exp \{-1.584+1.18 \mathrm{M}-1.24 \ln [R+0.00907 \exp \\
& (0.951 \mathrm{M})]-0.0059 R+0.49 K_{1}+0.99 K_{2}+0.53 K_{3} \\
& \tanh (0.41 D)+0.60\left(1-K_{3^{\prime}}\right) \tanh (0.88 D\}
\end{aligned}
$$

where $\mathrm{PHV}_{c}$ is peak horizontal velocity normalized primarily to California earthquake data, $D$ is the depth (in kilometers) of sediments beneath the site (that is, the depth to basement rock), and $K_{3^{\prime}}$ is 0 for buildings over four stories and 1 otherwise.

For estimates of depth to basement rock, we used maps developed by Mabey (1987) and shown in figure 7 . Following Campbell (1987), we have used $K_{3^{\prime}}=1$ to establish upper bound median estimates of PHV; for establish-

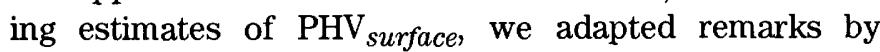
Campbell in the following equation:

$$
\mathrm{PHV}_{\text {surface }}=\left[\left(\mathrm{PHV}_{c}\right)\left(\mathrm{DAF}_{\text {site }}\right)\right] / 4.0
$$

This equation assists in adjusting for the high relative site response factors found along the Wasatch fault. We again used $K_{1}=1$ for somewhat conservative results (for the natural gas system). The value of 4.0 in the denominator of equation 6 is used because $K_{3^{\prime}}=1$ already includes site amplification factors typical of California soft soils, relative site response factors being generally between 3.6 and 4.5 (see Campbell, 1987).

To derive estimates of shaking intensities $(I)$, we used the following equation from Wiggins and others (1981):

$$
I=\left(\log \mathrm{PHV}_{\text {surface }}+1.484\right) / 0.366
$$




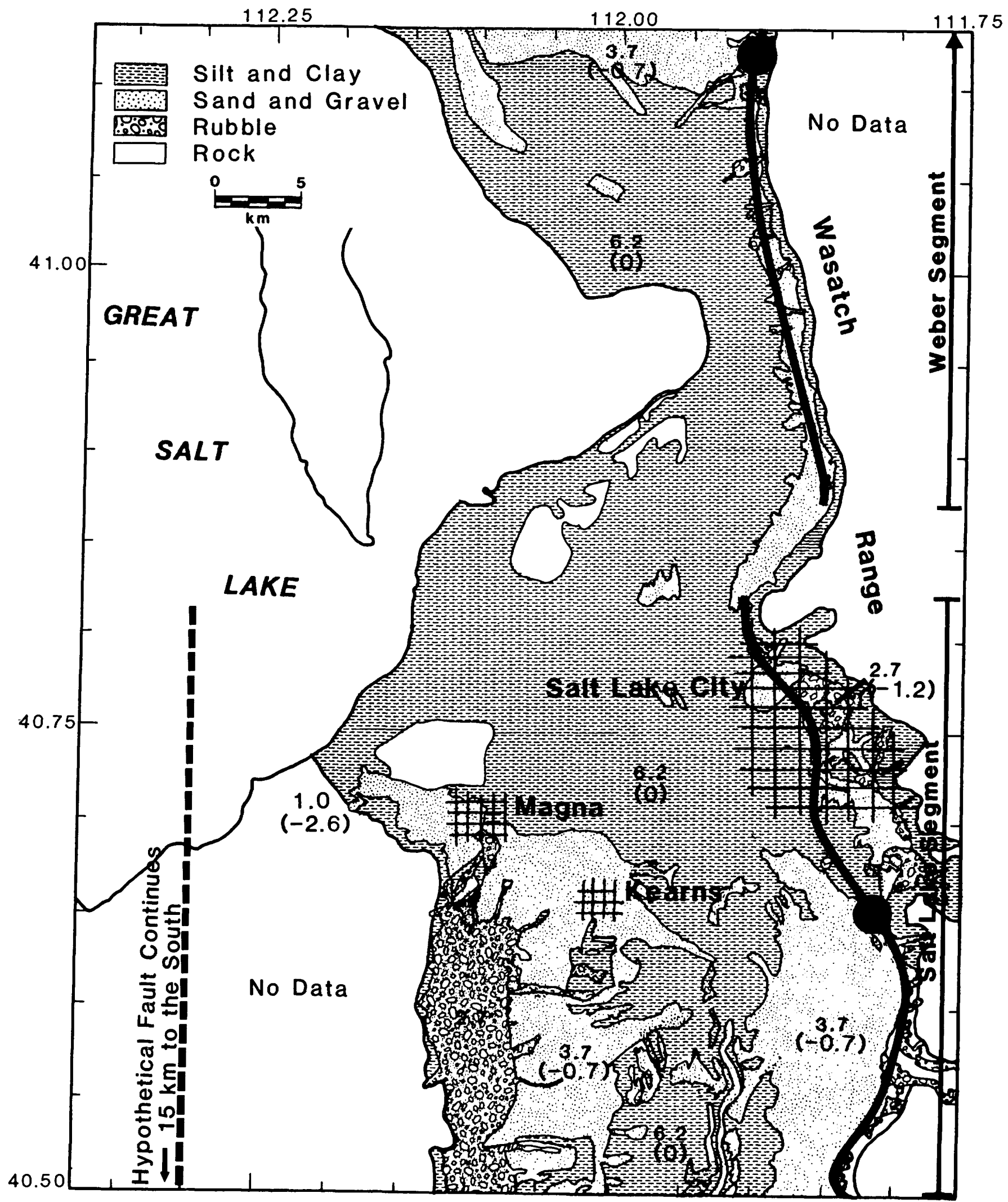

FTGURE 6.-Expected relative ground-shaking response in the central part of the Wasatch Front urban area. Numbers indicate mean ground response relative to bedrock locations. (Reproduced with permission of the American Society of Civil Engineers.) 
The notion of intensity used here is that of shaking intensity only. Ground-failure effects such as liquefaction are accounted for with reference to input strong-motion values, such as PHA, and hence are excluded from the shaking-intensity scale implied here. Given equations 4 and 7 , sites having soft surficial soil amplification values of 6.2 are assumed to have intensities exceeding basement rock values by over 2 intensity increments. Given equations 6 and 7 , sites having amplification values of 6.2 exceed normal soft soil sites (chiefly from California earthquake data) by 0.5 intensity increment. These simplifying relationships should be used for general planning purposes only, inasmuch as effects of high strain, surface faulting, and seismic radiations are not accounted for.

Obviously, values derived by using these equations depend significantly on how distances from sites to the seismogenic source are estimated. In comparison with results using a three-dimensional model, illustrated in figure 1, one may as a rule of thumb state that distances in the near field of an earthquake from the Salt Lake segment of the Wasatch fault are overestimated by a factor of roughly 2 if they are calculated from the surface trace of this fault. More generally, if the dip angle is $B$, the distance is overestimated by a factor of $1 / \cos ß$. On the basis of equation 2 , the relative decrease in PHA to near-field sites (resulting from estimating distances to the surficial trace of the fault zone can be expressed as

$$
\operatorname{ratio}_{P H A}=\exp (A+B-C-D)
$$

where $A=-1.25 \ln [(R / \cos ß)+0.0872 \exp (0.678 \mathrm{M})], B=-$ $0.0059 R / \cos B, C=-1.25 \ln [R+0.0872 \exp (0.678 \mathrm{M}]$, and $D=-0.0059 R$. For instance, given magnitude 7.3 and a site $6 \mathrm{~km}$ west of the fault assumed to have a dip angle $\beta$ of $60^{\circ}$, this ratio is 0.68 .

To express the underestimate in intensities derived from using distances to the surface trace, the difference in intensity estimates is a convenient mode of expression. On the basis of equations 5,6 , and 7 , this difference can be expressed as

$$
\operatorname{diff}_{I}=\left(F+G-F^{\prime}-G^{\prime}\right) / 0.366 \ln 10
$$

where $F=-1.24 \ln [R+0.00907 \exp (0.951 M)], G=-0.0059 R$, and $F^{n}=-1.24 \ln [(R / \cos B)+0.00907 \exp (0.951 M)]$, and $G^{\prime}=-0.0059 R / \cos B$. When the same example presented for PHA (60 dip angle, magnitude 7.3, and 6-km distance to the dipping plane) is used, there is an underestimate of 0.53 intensity increment if distance to the surficial fault trace is used. These findings, along with the definition of distance required to use Campbell's equations, confirm that significant errors may arise if one estimates distances relative to the surface fault trace only. In spite of the deficiencies inherent in ignoring dip angles, our studies also indicate that Salt Lake County results are most affected by use of more complex fault models. In Weber, Davis, and Utah Counties, less space is available between the Wasatch Range and the Great Salt Lake or Utah Lake for suitable development of exposures. As a consequence, in these counties, most exposures are extremely close to the surface trace of the Wasatch fault.

The general approach of simulating many earthquake scenarios within a probabilistic framework also has advantages in estimating liquefaction probabilities. To estimate these probabilities, we first used raw data provided by Utah State University and Dames and Moore. These data include critical blow counts, water table depths, and critical accelerations for various sites examined (see Anderson and others, 1982). Critical accelerations are those peak horizontal accelerations that may lead to liquefaction relative to a magnitude 7.5 earthquake. This definition does not suggest that liquefaction will occur if the critical acceleration is equaled or exceeded in a magnitude 7.5 event. To adjust critical accelerations for earthquakes of other magnitudes, the following magnitude scaling factors have been proposed to account for cyclic effects (Seed and Idriss, 1983):

\begin{tabular}{cc}
\hline Magnitude & $\begin{array}{c}\text { Magnitude scaling } \\
\text { factor (MSF) }\end{array}$ \\
\hline 7.5 & 1.0 \\
6.75 & 1.13 \\
6.0 & 1.32 \\
5.25 & 1.5 \\
\hline
\end{tabular}

Hence, if the critical acceleration for magnitude 7.5 event is $0.10 \mathrm{~g}$ for a given site, then the above magnitude scaling factors suggest that 0.113-, 0.132-, and 0.15- $g$ PHA's must occur in earthquakes having magnitudes of $6.75,6.0$, and 5.25 , respectively, for liquefaction possibly to occur. Our general approach assists in incorporating such multipliers for earthquakes having magnitudes other than 7.5. Moreover, if these magnitude scaling factors and equation 2 are used and if it is assumed that $K_{1}=0, K_{2}=0$, and $K_{3}=0$, then a site having a critical acceleration of $0.10 \mathrm{~g}$ for a magnitude 7.5 earthquake (an adjusted critical acceleration of $0.15 \mathrm{~g}$ for a magnitude 5.25 earthquake) can have this acceleration exceeded as far as $8 \mathrm{~km}$ from a magnitude 5.25 event. Although these magnitude scaling factors may be too low, this finding partially confirms our later conclusions that liquefaction-induced ground failure may be a major problem even in smaller magnitude earthquakes.

It has been suggested that these standard magnitude scaling factors are too low. As a consequence, we examined the sensitivity of our pipe break estimates to alternative magnitude scaling factors. To develop these alternative factors, we used the following equation from 


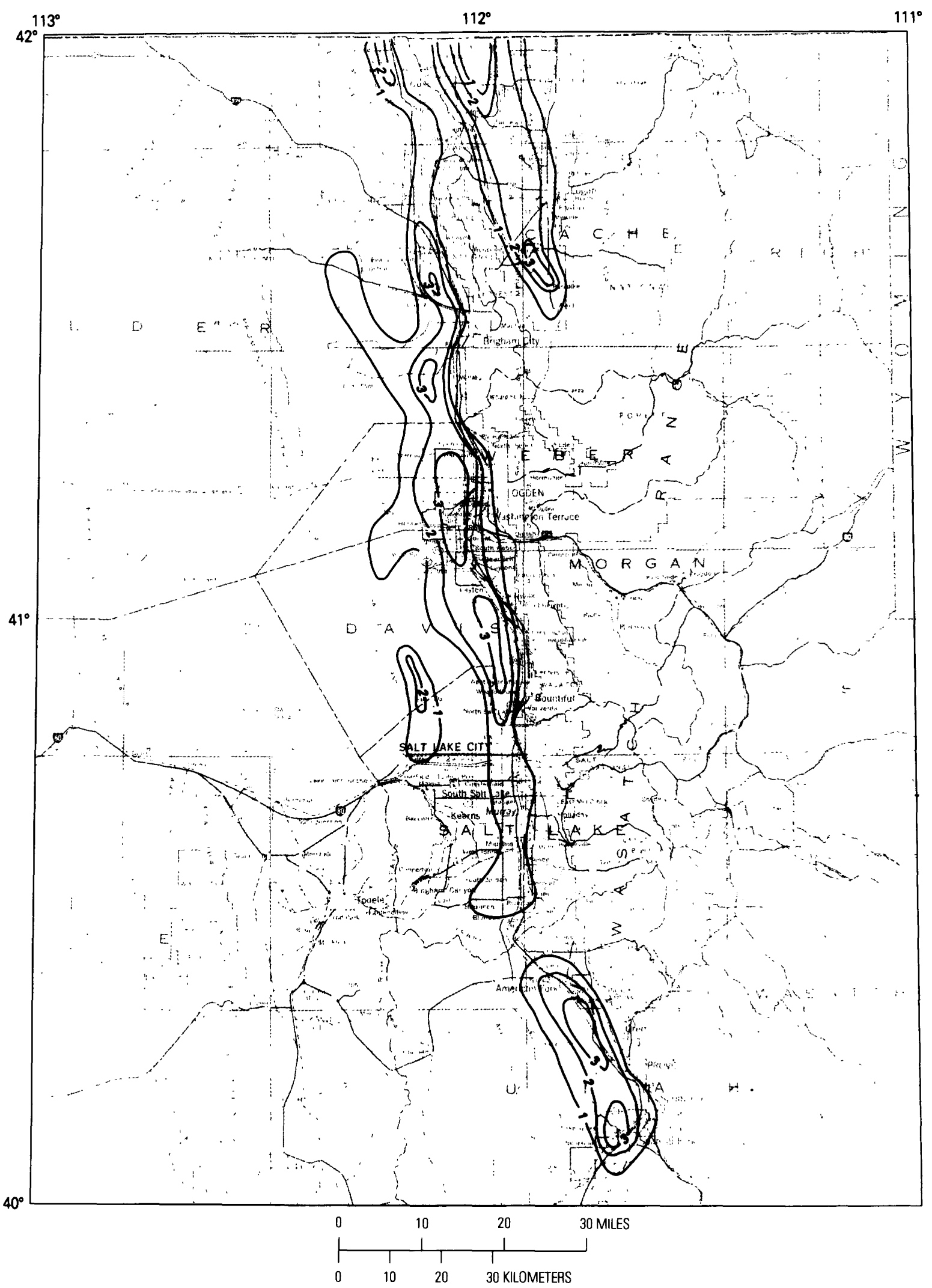


TABLE 2.-Alternative magnitude scaling factors derived from equations by Youd and Perkins (1987), Joyner and Fumal (1985), and Campbell (1987)

[LSI, severity of liquefaction (in inches)]

\begin{tabular}{|c|c|c|c|c|c|c|c|c|}
\hline \multirow[b]{2}{*}{ Magnitude $\left(\mathbf{M}_{w}\right)$} & \multicolumn{4}{|c|}{$\begin{array}{l}\text { Calculated critical acceleration } \\
\text { at specified magnitude (percent } g \text { ) }\end{array}$} & \multicolumn{4}{|c|}{$\begin{array}{l}\text { Derived magnitude scaling factors } \\
\text { relative to } M 7.5 \text { event }\end{array}$} \\
\hline & 7.5 & 6.75 & 6.0 & 5.25 & 7.5 & 6.75 & 6.0 & 5.25 \\
\hline \multicolumn{9}{|l|}{ Equations 11 and 12} \\
\hline $\begin{array}{l}\mathrm{LSI}=1 \\
\mathrm{LSI}=4\end{array}$ & $\begin{array}{l}0.027 \\
0.084\end{array}$ & $\begin{array}{l}0.07 \\
.164\end{array}$ & $\begin{array}{l}0.13 \\
.236^{1}\end{array}$ & $\begin{array}{l}0.174 \\
.210^{1}\end{array}$ & $\begin{array}{l}1.0 \\
1.0\end{array}$ & $\begin{array}{l}2.6 \\
2.0\end{array}$ & $\begin{array}{l}4.8 \\
2.8^{1}\end{array}$ & $\begin{array}{l}6.4 \\
2.5^{1}\end{array}$ \\
\hline \multicolumn{9}{|l|}{ Equation 2} \\
\hline $\begin{array}{l}\mathrm{LSI}=1 \\
\mathrm{LSI}=4\end{array}$ & $\begin{array}{c}0.0237 \\
.075\end{array}$ & $\begin{array}{r}0.056 \\
.135\end{array}$ & $\begin{array}{c}0.099 \\
.21\end{array}$ & $\begin{array}{r}0.16 \\
.29\end{array}$ & $\begin{array}{l}1.0 \\
1.0\end{array}$ & $\begin{array}{l}2.4 \\
1.8\end{array}$ & $\begin{array}{l}4.2 \\
2.7\end{array}$ & $\begin{array}{l}6.5 \\
3.8\end{array}$ \\
\hline
\end{tabular}

${ }^{1}$ Value demonstrates that combining equations 11 and 12 yields paradoxes (recognized by T.L. Youd in his review of study findings).

Youd and Perkims (1987) relating severity of liquefaction to magnitude for Western U.S. earthquakes:

$$
\log \text { LSI }=-3.49-1.86 \log R^{\prime}+0.98 \mathrm{M}_{w}
$$

where LSI is the severity of liquefaction (in inches), $R^{\prime}$ is the distance to the energy source (in kilometers), and $\mathrm{M}_{w}$ is moment magnitude.

For estimating the onset of liquefaction, we used two alternative assumptions: $\mathrm{LSI}=1$ in and $\mathrm{LSI}=4$ in. To develop magnitude scaling factors, it is necessary to use only a suitable attenuation relation relating PHA to magnitude and distance. Equation 2 is only partially suitable. If $\mathrm{M} \cong \mathrm{M}_{w}$ and $R \cong \mathrm{R}^{\prime}$, equation 2 can be used. (The values ascribed to $K_{i}$ make no difference to the magnitude scaling factors derived.) However, more directly suitable equations from Joyner and Fumal (1985) are

$$
\begin{gathered}
\log \mathrm{PHA}=0.49+0.23\left(\mathrm{M}_{w^{-}}-6\right)-\log D^{\prime}-0.0027 D^{\prime} \\
D^{\prime}=\left[\left(R^{\prime}\right)^{2}+64\right]^{1 / 2}
\end{gathered}
$$

From these alternative equations for PHA and alternative assumptions for LSI at the boundary threshold, we developed four sets of magnitude scaling factors in table 2 . Values derived are much higher than those normally used. We examined, for instance, consequences of using the

$\leftarrow$ FIGURE 7.-Thickness of low-density sedimentary rocks in Wasatch Front valleys and Cache Valley inferred from gravity data (Mabey, 1987). Contour interval is $1 \mathrm{~km}$. multipliers 1.3 for magnitude 6.75 events, 2.55 for magnitude 6.0 events, and 4.1 for magnitude 5.25 events (half the values derived from using LSI= 1 in and equations 11 and 12. These results greatly reduced the expected liquefaction-induced ground failures and consequently reduced the expected pipe breaks associated with these failures for smaller magnitude $(<6.4)$ scenarios. Accordingly, further research is required to determine the merits of the objection that standard magnitude scaling factors (Seed and Idriss, 1983) are too low.

Because the exceedance of adjusted critical accelerations by calculated PHA's only implies that liquefaction may occur, actual estimates of liquefaction probabilities also remain a problematic area. In the first project, we distinguished among microzones having high, medium, and low susceptibilities:

\begin{tabular}{lc}
$\begin{array}{c}\text { Liquefaction susceptibility } \\
\text { of microzone }\end{array}$ & Characterization of average site \\
\hline High & $\begin{array}{c}\text { Critical blow counts below } 12 \text { and } \\
\text { water table depths below } 3 \mathrm{~m} . \\
\text { Critical blow counts below } 25 \text { and } \\
\text { water table depths below } 6 \mathrm{~m} .\end{array}$ \\
Ledium & All other average sites.
\end{tabular}

Figure 8 indicates the highly susceptible zones (generally near the Great Salt Lake or Jordan River) in Salt Lake and Davis Counties.

In the first project, we assumed that no liquefactioninduced ground failure occurs in microzones having high liquefaction susceptibilities or in microzones where calculated PHA's were below adjusted critical accelerations. 


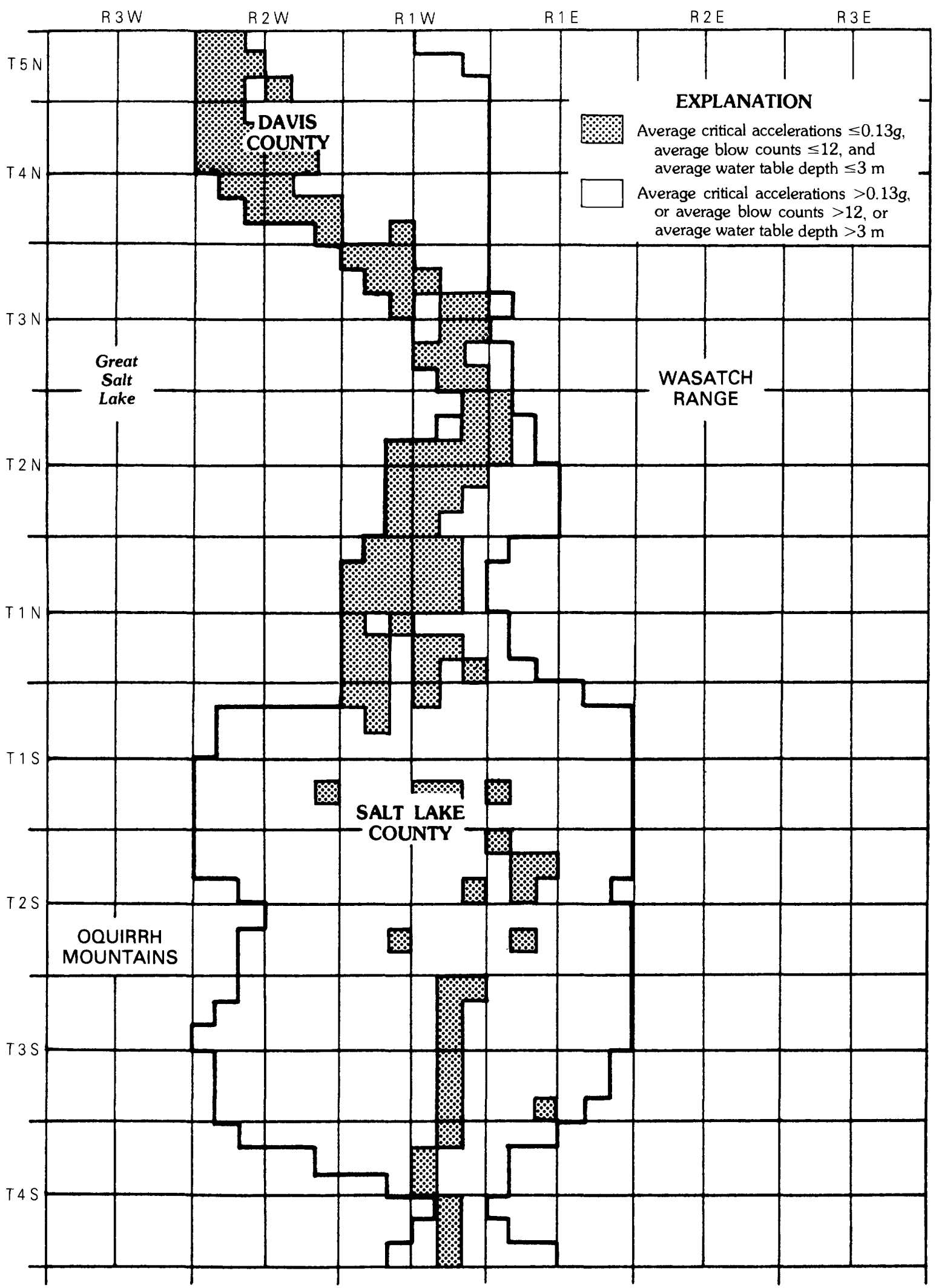


Otherwise, we assumed that highly susceptible microzones had probabilities of liquefaction-induced ground failure of 50 percent; for medium susceptible zones, this value dropped to 10 percent.

These makeshift procedures were replaced with others in the second project, in which we used the following general function for estimating the probability of liquefaction:

liquefaction probability $=f\left(\mathrm{CSR}_{e s t}, 0.011 N_{1}, \mathrm{MSF}, \Delta\right)(13)$

where $\mathrm{CSR}_{\text {est }}$ is the calculated cyclic shear ratio for a given microzone, $N_{1}$ is the critical blow count (average for sites in the microzone), MSF is the magnitude scaling factor (based on earthquake magnitude), and $\Delta$ is a function dependent on the amount by which CSR $_{e s t}$ exceeds $N_{1}$.

In the standard magnitude 7.5 earthquake, we assumed that no liquefaction occurs if $N_{1} \geq 25$ or $\mathrm{PHA}<a_{c}{ }^{*} \mathrm{MSF}$ or if $\mathrm{CSR}_{e s t}<0.011 N_{1}$, where $a_{c}$ is the critical acceleration and MSF is the adjustment for earthquake magnitude. Otherwise, we assumed that the probability of liquefaction is a function of $\Delta$, the amount

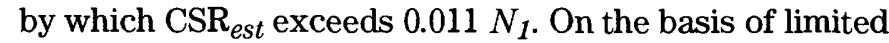
data from Youd and Perkins (1987), we drew a working analogy between the degree of liquefaction severity that may occur and the probability of liquefaction-induced ground failure. We assumed that the probability is 15 percent if $\Delta=0.03,60$ percent if $\Delta=0.09$, and 99 percent if $\Delta=0.22$. For other magnitude-level earthquakes simulated, we used the same procedure, except that $\mathrm{CSR}_{\text {est }} / \mathrm{MSF}$ is used in place of $\mathrm{CSR}_{e s t}$. (Similar methods have been reported by Liao (1986), except that magnitude scaling factor problems are ignored.)

Previous National Science Foundation (NSF) studies and earthquake insurance studies were adapted to develop procedures for making loss estimates for Stateowned buildings. Summaries of data and methods have been given by Wiggins and Taylor (1986) and Taylor and others (1986a); Steinbrugge (1982) has also provided useful data summaries. No published comprehensive raw loss data are available for U.S. structures (see National

FIGURE 8.-Microzones assigned the highest liquefaction susceptibility (based on data furnished by Utah State University and Dames and Moore). Shaded boxes indicate an average critical acceleration of $0.13 \mathrm{~g}$ or less, an average blow count of 12 or less, and a water table depth of $3 \mathrm{~m}$ or less. Open boxes indicate an average critical acceleration greater than $0.13 \mathrm{~g}$, an average blow count greater than 12 , and a water table depth greater than $3 \mathrm{~m}$. (Reproduced with permission of the American Society of Civil Engineers.)
Research Council, 1989), in contrast to the routine practice of collecting systematic loss data in the Balkan region as reported by Wiggins and Taylor (1985). The loss estimation tools used employ probabilistic methods (for example, Monte Carlo simulations, beta distributions to estimate probability of degree of damage relative to a sample mean) as opposed to deterministic ones. They were adapted from methods approved by the State of California in fulfillment of the annual requirement that earthquake insurance carriers report expected maximum credible losses and other insurance estimates for their California portfolio. Principally developed and refined for proprietary insurance studies (and from proprietary computer codes), the probabilistic methods were derived from the deterministic ones by probabilistic modeling of the sources of uncertainty (for example, distance to the fault plane, intensity, site dynamic amplification, seismic building quality, exposed population) in loss estimation. Properly speaking, the methods employed are probabilistic, not deterministic. Even though one fixed rupture zone and magnitude are assumed, the method used implies that many loss outputs are conceivable from these assumptions. These loss outputs were calculated through Monte Carlo simulations to yield statistics such as means and variances.

The general procedures for earthquake loss estimation are outlined in figure 9 . Inventory data were provided by the Utah State Risk Administrator and the Utah State Division of Facilities Construction and Management. These data include facility name, address, building frame system, number of stories, construction date(s), total square footage, and replacement value of buildings and contents. To these data, we added occupancy usage, township section, and building and contents vulnerability categories. Four major building vulnerability categories were used, defined at the minimum level with reference to the Uniform Building Code (International Conference of Buildings Officials, 1988) earthquake zone for which a structure is designed. Contents vulnerability categories are similar to those given by Steinbrugge (1982). Procedures to estimate deaths and injuries are based on severity of expected building damage, where this severity is treated probabilistically in terms of the aforementioned beta distributions applied to deterministic loss estimates. The chief bases for estimating casualties relative to severity of building damage are derived from methods explicated by Whitman and others (1975) and critiqued by Wiggins and Taylor (1985).

Given what at first appears to be the limited seismic resistance of many State-owned buildings (as indicated by the seismic codes governing them), the concentration of these buildings in Salt Lake County (see fig. 10), and the high shaking intensities expected in a $\mathrm{M}_{s} 7.0$ to 7.5 earthquake on the Salt Lake segment of the Wasatch fault, we 


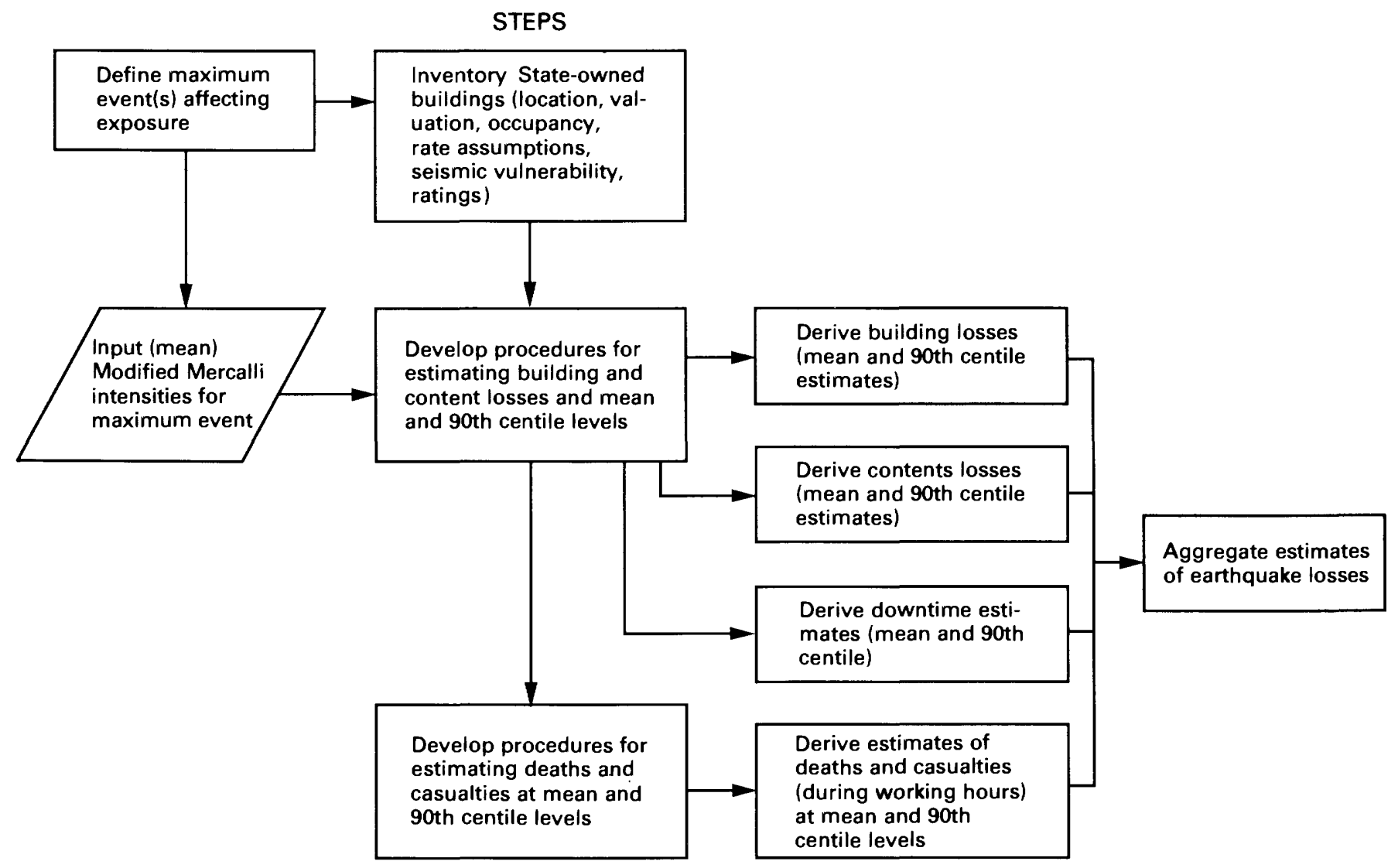

FIGURE 9.-Procedures for estimating earthquake loss for insurance purposes.

originally expected property and casualty losses to be significant-likely larger than those losses estimated from previous studies.

Our only surprise in this regard arose during the first project, when we decided to distinguish between economic building vulnerability ratings and ratings for lifesafety estimates. We discovered that many State-owned buildings contain features such as numerous interior partitions and are in good physical condition, so that they are more seismically safe than economic damageability factors such as age (indicative of building code used) and frame system alone would indicate. As a result, we recommend further study to formalize life-safety factors for Utah buildings so that future casualty estimates can be based on explicit procedures like those developed for California structures (see Wiggins and Taylor, 1985). Those life-safety visual inspection and rating procedures originally were developed to estimate potential casualties in assessing risks and retrofit needs in Long Beach, Calif.

We adapted previous NSF lifeline research (Eguchi and others, 1983; Taylor and others, 1986b) to define procedures for making earthquake risk estimates to culinary water and natural gas systems. These procedures are outlined in figure 11. These projects inventoried the natural gas system for each of the four main counties and the following culinary water systems: Clinton (Davis County), Granger-Hunter Improvement District (Salt Lake County), Weber Basin Conservancy District (Weber and Davis Counties), Salt Lake County Conservancy District, South Ogden City (Weber County), Ogden City, Provo City (Utah County), and Orem City (Utah County). The Salt Lake Department of Public Utilities was not inventoried because it has been the subject of several past seismic risk studies (Algermissen and others, 1976; Bresko and others, 1981; Taylor and Ward, 1981; Taylor and Bigler, 1982; Highland, 1987). These inventories included types of component, locations distributed by township sections, pipe material, pipe joint, pipe length and diameter, and percentage of pipe in the Wasatch fault zone of deformation. To characterize this last input, we used the broad conservative definition of the fault zone of deformation given by Algermissen and others (1976): $457 \mathrm{~m}$ on the downthrown side and $61 \mathrm{~m}$ on the upthrown side of the fault trace. Further details of the inventory process for 


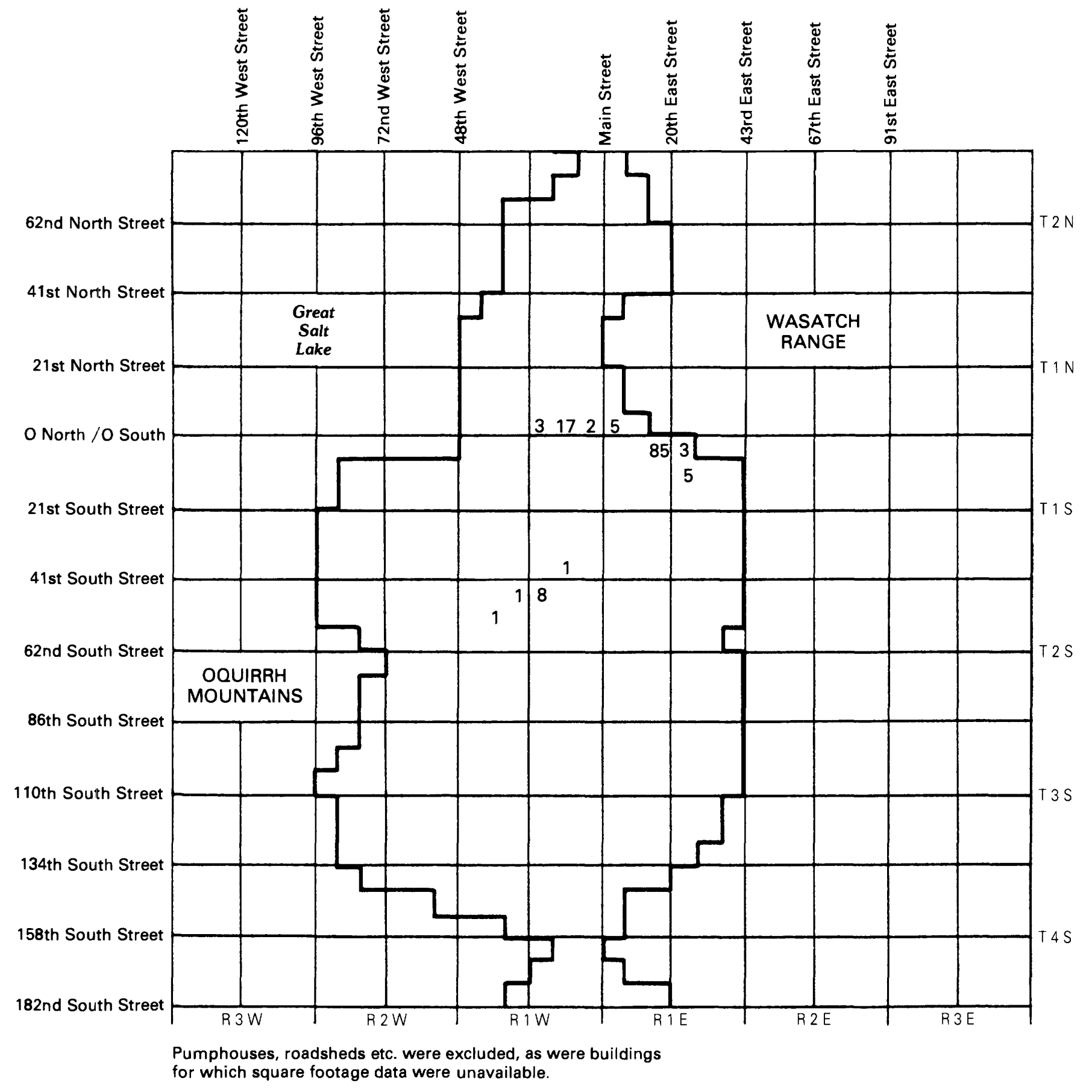

FIGURE 10.--Number of State-owned buildings having assumed (above-threshold) occupancies by microzone. Pumphouses, roadsheds, and so on were excluded, as were buildings for which square footage data were unavailable.

the natural gas system were developed by McDonough and Taylor (1986). In the second project, R. Campbell and M. Salmon of EQE made engineering site inspections of various wells, booster stations, and filtration plants in the four counties to develop earthquake fragility models (fail- ure probabilities as a function of $\mathrm{PHA}$ ) and seismic-risk reduction recommendations.

Figure 11 distinguishes among three hazard modes: vibrations, liquefaction, and fault displacement. In the first project, we found that pipeline vulnerability models 

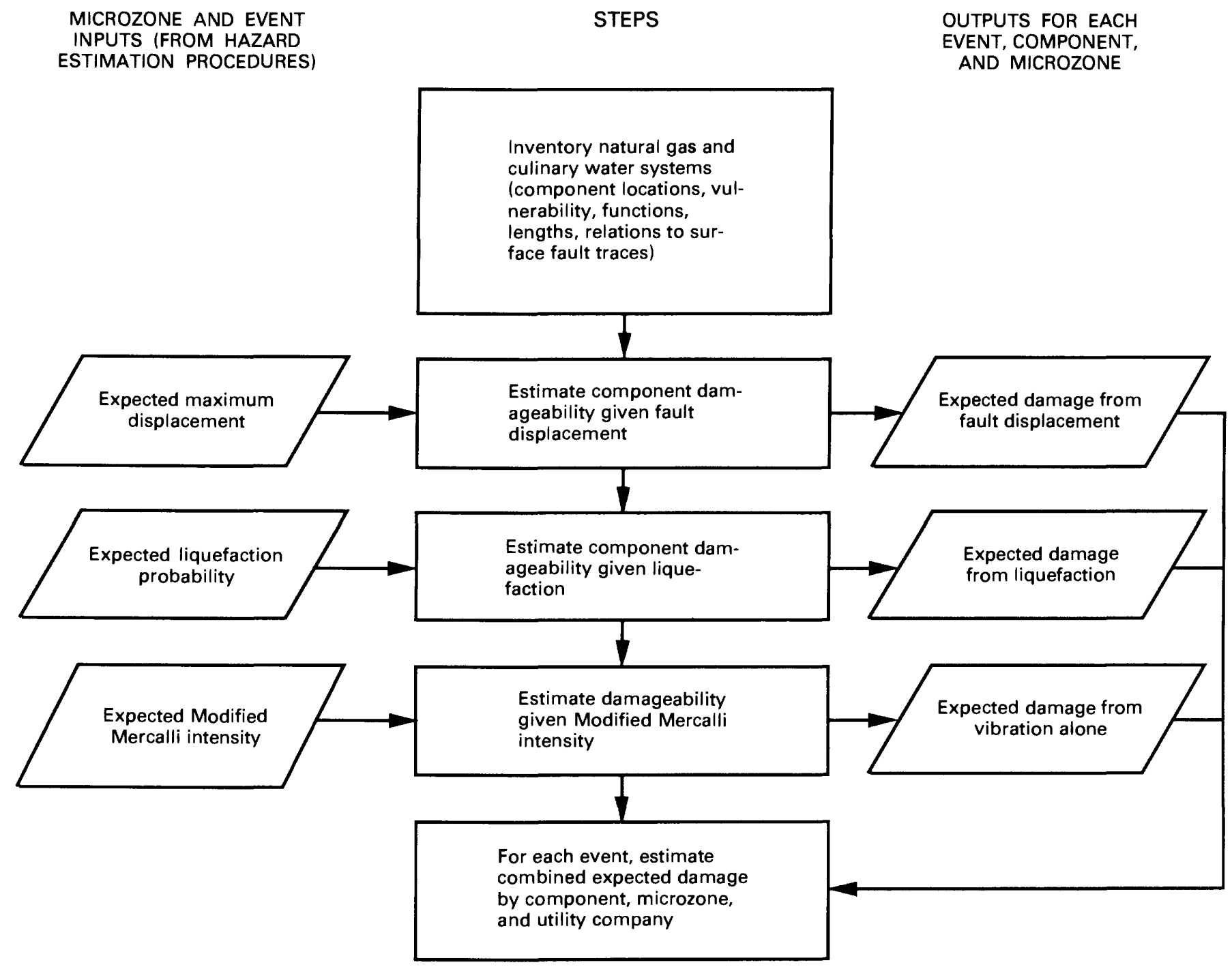

FIGURE 11.-Damage estimation procedures used for natural gas and culinary water systems. (Reproduced with permission of the American Society of Civil Engineers.)

developed by Eguchi and others (1983) yielded estimates of breakage that were excessive at higher shaking intensities (Modified Mercalli intensities of IX and above). As a consequence, with the assistance of the project consultant, $R$. Eguchi of EQE, we revised those pipeline vulnerability models to reflect first project findings. Revised models are shown in the final report for the second project. (Taylor and others, 1988). Empirical data on which pipeline vulnerability models are based lead us to believe that results developed at lesser intensities and for the hazard failure modes examined are meaningful. Data summaries forming the basis for pipeline vulnerability models-especially for the 1971 San Fernando Valley, 1983 Coalinga, and 1987 Whittier earthquakes-have been given by Eguchi and others (1983), Isenberg and Taylor (1984), Taylor and others (1986), Trautmann and others (1986), and Schiff (1988).

\section{GENERAL RESULTS}

The probabilistic approach used in this study has provided new unaterials to address unresolved issues on the validity of Wasatch fault loss estimates. In general, results are as expected-hazard estimates are higher than previous estimates, and worst-case earthquakes yield very high damage estimates. Some specific results, however, were surprising. 
Risk estimates are improved by employing a nearsource approach-one that uses at least dip angles for the Wasatch fault and attenuation functions especially designed to account for near-field effects-principally because the Wasatch fault is held to be the major source of larger $\left(M_{s}>6.4\right)$ earthquakes and because so many Wasatch fault exposures are close to the fault itself, especially when defined in two or more dimensions (see fig. 5 and its discussion for technical confirmation). Liquefaction susceptibility and dynamic amplification studies, combined with this fault modeling, show that risks are significantly greater than estimates obtained from simpler models, especially for Salt Lake County exposures.

Indeed, vibrational hazards are severe enough in the largest earthquakes postulated $\left(\mathrm{M}_{s}>6.4\right)$ that modeling ground-failure hazards initially made little difference to damage estimates in the near field-except with respect to the most seismically resistant facilities exposed to ground-failure hazards. As a result of high pipe-breakage rates developed in the first project for these larger magnitude events, we were forced to revise (downwards) breakage estimates for piping subjected to strong ground motion so that these estimates did not exceed those for piping subjected to ground failures. Extrapolation from lower intensity data has long been a problem in pipe breakage algorithms, and ground-failure estimates serve as a useful upper boundary on those pipe breaks expected from strong ground motion.

At the high levels of ground motion expected in these larger earthquake scenarios, a high degree of uncertainty also applies to building loss and casualty estimates derived for the least seismically resistant classes of building (see Wiggins and Taylor (1986) for a discussion of different estimates among investigators for the worst classes of buildings and for preliminary loss estimates and loss distributions for unreinforced masonry construction the 1983 Coalinga, Calif., earthquakes). In other words, such high levels of strong motion test the vulnerability and damageability models principally developed from Modified Mercalli intensity VIII data.

Liquefaction hazards, moreover, appear to be significant enough to yield potential ground-failure hazards and consequent pipeline breaks even in some near-field events of $\mathrm{M}_{L}$ 5.5. For instance, modeling earthquake events of comparatively low magnitudes (5.5-6.4) beneath selected portions of Salt Lake County or Davis County initially suggests that these localized hypothetical earthquakes could yield significant ground-failure problems and resulting pipeline breaks in local systems such as the GrangerHunter Improvement District or the Clinton Water Department. However, these results raise questions about research tools used. Our analysis of the sensitivity of pipe repair rates to magnitude scaling factors (MSF's) shows that nonstandard multipliers (derived from table 2) reduce expected repair estimates considerably. Even if research is appropriately directed to this topic, another topic remains - the development of liquefaction probabilities for those sites and (or) microzones affected by earthquakes so that adjusted critical accelerations are exceeded by PHA's. Assignment of probabilities in these cases also greatly affects study results in both large- and small-magnitude earthquakes simulated.

The risk estimates produced in this study have been presented to potential users-the State of Utah Risk Administrator and representatives of local utilities inventoried and analyzed. Currently, the most significant use has been to assist in the natural gas system seismic mitigation program. Key elements in this use involve participation by gas utility representatives in providing facility data, checking vulnerability models and other kinds of models, and using detailed damage estimates from several postulated earthquakes to make system flow analyses and hence to identify weak system links. Thus, full-scale seismic risk analyses have been developed to estimate consequences for various categories of customers (industrial, commercial, and residential) and of reduced losses through alternative mitigations. These risk analyses, moreover, have been the basis for mitigation planning and actions.

\section{STATE-OWNED BULDINGS SUBJECTED TO A MAXIMUM CREDIBLE EVENT}

The high intensities estimated in maximum credible events $\left(M_{s} \cong 7.3\right)$ generated from the Salt Lake segment of the Wasatch fault zone indicate that State-owned buildings in Salt Lake County are expected to suffer very high property (building and content) losses; additional losses are expected to result from potentially long downtimes. Table 3 summarizes replacement values at risk by microzone (township sections) and seismic building qualities. Table 4 summarizes mean estimates of building losses, contents losses, and downtime by microzone. For all buildings surveyed, mean loss estimates are 39 percent of the replacement value ( $\$ 480$ million) of buildings surveyed; downtime estimates are two-thirds of a year for many buildings.

Population exposure estimates in State-owned buildings vary considerably, depending primarily on university and governmental schedules. Nonetheless, the severe building damage estimated resulted in high estimates of death ( 3 percent), severe injuries ( 4 percent), and moderate injuries (10 percent) (expressed as ratios of the population exposed). For the least seismically resistant class of buildings surveyed, these property and casualty loss estimates were much higher. The upper limit of mean deaths estimated was 20 percent of occupants. (See the project report by Taylor and others (1986a) for details.) 
TABLE 3.-Property values (in thousands of 1984 dollars) for State-owned buildings by microzone and seismic building quality

[Seismic building quality $(Q)$ is the minimum level, without inspection and rating; $Q=1$ refers to buildings designed to Uniform Building Code (UBC) seismic zone $O-1$ standards; $Q=2$ refers to UBC seismic zone $2 ; Q=3$ refers to UBC seismic zone 3]

\begin{tabular}{|c|c|c|c|c|c|c|c|c|}
\hline \multicolumn{5}{|c|}{ Building replacement values } & \multicolumn{4}{|c|}{ Contents values } \\
\hline Microzone & $Q=1$ & $Q=2$ & $Q=3$ & Total & $Q=1$ & $Q=2$ & $Q=3$ & Tota \\
\hline T1NR1WS34 & 0 & 5,338 & 5,022 & 10,360 & 0 & 481 & 443 & 924 \\
\hline T1NR1WS35 & 4,573 & 140 & 0 & 4,713 & 48 & 0 & 0 & 48 \\
\hline T1NR1WS36 & 2,636 & 274 & 0 & 2,910 & 1,884 & 0 & 0 & 1,884 \\
\hline T1NR1ES31 & 53,056 & 9,947 & 0 & 63,003 & 5,378 & 1,146 & 0 & 6,524 \\
\hline T1SR1ES6 & 3,276 & 3,120 & 19,283 & 25,679 & 432 & 432 & 5,091 & 5,955 \\
\hline T1SR1ES4 & 46,380 & 108,494 & 158,854 & 313,728 & 9,205 & 55,016 & 89,991 & 154,212 \\
\hline T1SR1ES3 & 196 & 3,179 & 5,235 & 8,610 & 12 & 20 & 7 & 39 \\
\hline T1SR1WS12 & 467 & 0 & 0 & 467 & 0 & 0 & 0 & 0 \\
\hline T1SR1ES8 & 5 & 0 & 0 & 5 & 0 & 0 & 0 & 0 \\
\hline T1SR1ES9 & 2,906 & 3,386 & 7,237 & 13,529 & 18 & 312 & 900 & 1,230 \\
\hline T1SR1WS14 & 0 & 0 & 2,557 & 2,557 & 0 & 0 & 6,246 & 6,246 \\
\hline T1SR1WS35 & 843 & 843 & 0 & 1,686 & 93 & 93 & 0 & 186 \\
\hline T2SR1WS4 & 192 & 192 & 0 & 384 & 22 & 22 & 0 & 44 \\
\hline T2SR1WS3 & 0 & 2,577 & 29,526 & 32,103 & 0 & 236 & 6,611 & 6,846 \\
\hline T2SR1WS8 & 0 & 99 & 99 & 198 & 0 & 19 & 19 & 38 \\
\hline T2SR1WS13 & 157 & 157 & 0 & 314 & 5 & 5 & 0 & 10 \\
\hline T2SR1WS30 & 0 & 153 & 0 & 153 & 0 & 8 & 0 & 8 \\
\hline $\begin{array}{l}\text { Total } \\
\text { (Percentage of total) }\end{array}$ & $\begin{array}{l}114,687 \\
(23.9)\end{array}$ & $\begin{array}{l}137,899 \\
(28.7)\end{array}$ & $\begin{array}{l}227,813 \\
\quad(47.4)\end{array}$ & $\begin{array}{c}480,399 \\
(100)\end{array}$ & $\begin{array}{r}17,097 \\
(9.3)\end{array}$ & $\begin{array}{l}57,790 \\
\quad(31.4)\end{array}$ & $\begin{array}{l}109,308 \\
(59.3)\end{array}$ & $\begin{array}{l}184,195 \\
(100)\end{array}$ \\
\hline
\end{tabular}

As high as these estimates are, they reflect a refinement in characterization of the hazards posed by these buildings. Our initial estimates, based on standard seismic categorization loss procedures that focus on construction features known to be seismically vulnerable, were still higher. Vulnerability categories were carefully reassessed through the adaptation of visual inspection and rating methods discussed by Wiggins and Taylor (1986), which emphasize both economic and life-safety building hazards. Two sets of seismic ratings were subsequently developed, one for property loss estimates and the other for casualty estimates. As a result of this reassessment, aggregate property and casualty loss estimates were reduced considerably. For instance, estimated deaths dropped by a factor of 3.7 once university and teclinical school buildings were reassessed more carefully. Loss results for this maximum credible event are clearly very sensitive to how buildings are evaluated for seismic property and safety issues. This sensitivity suggests that continued refinement of seismic inspection and rating procedures-especially with respect to crucial safety issues - should be encouraged for and applied to Wasatch Front buildings.

To our surprise, the dynamic amplification estimates used made less of a difference in property and casualty estimates than we had expected. When dynamic amplification factors were ignored and only basement rock intensities were used, mean building loss estimates were reduced from 39 to 28 percent, and contents loss estimates were reduced from 39 to 20 percent. Estimated deaths were reduced from 3 to 2 percent, severe injuries from 4 to 3 percent, and moderate injuries from 10 to 8 percent of the population exposed. The magnitude $\left(\mathrm{M}_{s}\right.$ 7.3) of the earthquake postulated and the very short distances of buildings from the Salt Lake segment of the Wasatch normal fault zone (generally within $5 \mathrm{mi}$ ) imply very high shaking intensities even if dynamic amplification factors are ignored. We expect these factors to have more of an influence on risk estimates for earthquakes of lesser magnitudes.

\section{OVERALL EARTHQUAKE DAMAGE EXPECTED TO WATER AND GAS CONDUITS}

On the basis of vulnerability models developed by Eguchi and others (1983), we had originally anticipated that earthquake damage to buried conduits would be dominated by liquefaction-induced ground failure; lesser contributions could be expected from fault rupture and 
TABLE 4.-Mean building loss, contents loss, and downtime estimates to State-owned buildings in a hypothetical Ms 7.3 earthquake on the Salt Lake segment of the Wasatch fault zone

[Seismic building quality $(Q)$ is the minimum level, without inspection and rating; $Q=1$ refers to buildings designed to Uniform Building Code (UBC) seismic zone $0-1$ standards; $Q=2$ refers to $\mathrm{UBC}$ seismic zone $2 ; Q=3$ refers to UBC seismic zone 3 ]

\begin{tabular}{|c|c|c|c|c|c|c|c|c|c|}
\hline \multicolumn{4}{|c|}{$\begin{array}{l}\text { Buildings loss } \\
\text { (thousands of } 1984 \text { dollars) }\end{array}$} & \multicolumn{3}{|c|}{$\begin{array}{c}\text { Contents loss } \\
\text { (thousands of } 1984 \text { dollars) }\end{array}$} & \multicolumn{3}{|c|}{$\begin{array}{l}\text { Downtime } \\
\text { (years) }\end{array}$} \\
\hline Microzone & $Q=1$ & $Q=2$ & $Q=3$ & $Q=1$ & $Q=2$ & $Q=3$ & $Q=1$ & $Q=2$ & $Q=3$ \\
\hline T1NR1WS34 & 0 & 2,595 & 1,008 & 0 & 468 & 178 & 0 & 0.41 & 0.09 \\
\hline T1NR1WS35 & 4,573 & 140 & 0 & 48 & 0 & 0 & .66 & .66 & 0 \\
\hline T1NR1WS36 & 2,636 & 88 & 0 & 1,884 & 0 & 0 & .66 & .30 & 0 \\
\hline T1NR1WS31 & 53,056 & 3,188 & 0 & 5,378 & 735 & 0 & .66 & .32 & 0 \\
\hline T1SR1ES6 & 3,276 & 3,120 & 4,329 & 432 & 432 & 2,286 & .66 & .66 & .11 \\
\hline T1SR1ES4 & 46,380 & 24,899 & 16,779 & 9,205 & 25,252 & 19,010 & .66 & .29 & .05 \\
\hline T1SR1ES3 & 196 & 3,179 & 1,175 & 12 & 20 & 3 & .66 & .66 & .09 \\
\hline T1SR1WS12 & 467 & 0 & 0 & 0 & 0 & 0 & .66 & 0 & 0 \\
\hline T1SR1ES8 & 5 & 0 & 0 & 0 & 0 & 0 & .66 & 0 & 0 \\
\hline T1SR1ES9 & 2,906 & 1,085 & 1,017 & 18 & 200 & 253 & .66 & .31 & .06 \\
\hline T1SR1ES14 & 0 & 0 & 575 & 0 & 0 & 2,805 & 0 & 0 & .33 \\
\hline T1SR1WS35 & 843 & 346 & 0 & 93 & 76 & 0 & .66 & .37 & 0 \\
\hline T2SR1WS4 & 192 & 57 & 0 & 22 & 13 & 0 & .66 & .30 & 0 \\
\hline T2SR1WS3 & 0 & 2,577 & 6,571 & 0 & 236 & 2,942 & 0 & .66 & .11 \\
\hline T2SR1WS8 & 0 & 25 & 11 & 0 & 10 & 4 & 0 & .12 & .04 \\
\hline T2SR1WS13 & 157 & 157 & 0 & 5 & 5 & 0 & .66 & .66 & 0 \\
\hline T2SR1WS30 & 0 & 56 & 0 & 0 & 6 & 0 & 0 & .33 & 0 \\
\hline Total & 114,687 & 41,512 & 31,465 & 17,097 & 27,453 & 27,481 & & & \\
\hline Grand total & & 187,66 & & & 72,031 & & & & \\
\hline
\end{tabular}

intensity shaking. The chief reason for this hypothesis was the greater extent of buried conduits exposed to potential liquefaction than to fault-related hazards. Figure 12 indicates provisionary estimates of the percentage of piping exposed to fault rupture and liquefactioninduced ground failure in worst-case events for various utilities surveyed. These estimates are provisionary principally because they are based on the liquefaction probabilities used for the first project (50 percent for highly susceptible microzones and 10 percent for the medium susceptible microzones) and on the broad fault zone definition used earlier and applied to maps by Cluff and others (1974) and Scott and Shroba (1985). Figure 12 nonetheless illustrates how, in Salt Lake and Davis Counties, potential liquefaction-induced ground failure covers a much greater exposure than fault rupture and appears to be a more significant hazard on an aggregate level even for worst-case earthquakes. Moreover, fault rupture is not modeled for smaller magnitude $\left(\mathrm{M}_{s}<6.5\right)$ events, whereas liquefaction-induced ground failure can be extensive in smaller magnitude events. At the same time, our inven- tory has indicated critical facilities that traverse the Wasatch fault zone of deformation.

These origmal hypotheses were by and large confirmed with respect to natural gas system piping. The most serious damage to this piping, especially for the highly resistant piping surveyed, naturally takes place when permanent displacement occurs. (Details of the seismic vulnerability characteristics of natural gas piping have been discussed by McDonough and Taylor (1986) and Taylor and McDonough (1986); shaking vulnerabilities for both butt-welded polyethylene piping and weldedsteel piping have been treated as X-grade welded steel piping by Eguchi and others (1983).) Furthermore, our inventory showed that over one-fourth of the Weber and Davis aqueducts in the Weber Basin Conservancy District were contained in the Ogden segment of the Wasatch fault zone. Rupture of key sites in this segment would therefore likely stop ample Weber Basin Conservancy District water supplies from being conveyed to local utilities until repairs could be made. Several water-distribution storage facilities and at least one Davis County filtration plant 


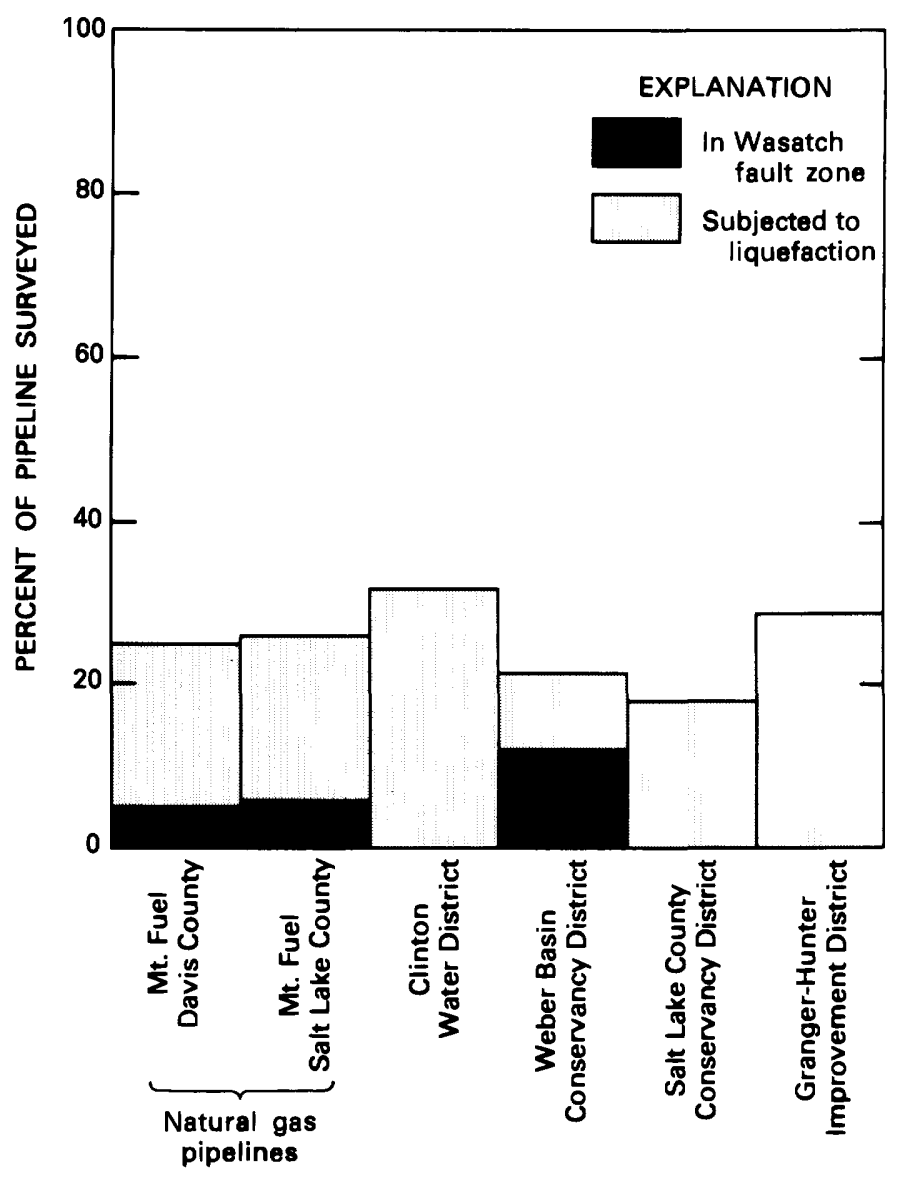

FIGURE 12.-Percentage of pipeline surveyed estimated to be subjected to permanent ground displacement (fault rupture or liquefaction) in worst-case $\left(\mathrm{M}_{s}\right)$ earthquake events. (Reproduced with permission of the American Society of Civil Engineers.)

also appear to be located in the Wasatch fault zone of deformation. (Earlier evidence of water tanks in this zone were reported by B. Kaliser and found by Taylor and Ward (1981).)

We modified our original hypothesis with respect to aggregate culinary water piping in larger $\left(M_{s}>6.4\right)$ magnitude events. High shaking levels in these events contributed significantly to expected culinary water damage. At first, we speculated that significant dainage could occur to seismically vulnerable pipelines even at Modified Mercalli intensities as low as VIII and when no permanent ground displacement occurred (see Isenberg and Taylor (1986) on the Coalinga earthquake; later estimates by Thiel and Zsutty (1987) suggest that intensity IX or X may have occurred in the city of Coalinga). Eventually, we determined that pipe vulnerability models need to be modified (downward) at these higher intensities. In the first project, it was only through an exaunination of an entire suite of earthquakes-of varying magnitude and with both distant and near-field rupture centers-that a geographical distribution of damage dependent in liquefaction susceptibility as well as exposure became evident.

Table 5 provides a summary of piping damage expected in larger magnitude events postulated. For each utility and for each event evaluated, we aggregated estimated piping breaks. For a given utility, these total breaks were divided by total pipeline lengths to calculate piping break rates. We then selected the worst rates for any $\mathbf{M}_{\boldsymbol{s}}$ 6.7 event simulated to construct table 5. To put these rates into perspective, approximately 2,800 miles (14.78 million lineal feet) of natural gas piping exists in Salt Lake and Davis Counties. Hence, a break rate of 10 breaks per million lineal feet would indicate approximately 148 expected breaks to natural gas piping in those two counties.

Table 5 thus shows the widespread piping damage expected from events in which rupture occurs on either the Ogden or Salt Lake segment of the Wasatch fault zone. As a result of the comparative invulnerability of natural gas piping (either butt-welded polyethylene plastic or welded steel with arc-welded joints) to shaking damage, its pipe-break rates are much lower than those of culinary water piping. Much of the Provo and Orem city piping systems surveyed, moreover, consisted of flexible-jointed ductile piping. But even the natural gas system surveyed and evaluated would have limited immediate reliability in these larger magnitude near-field events-except for the Utah County system, which is exposed to few potential ground-failure hazards.

As contrasts between Mt. Fuel supply break rates and culinary water system break rates partially indicate, breaks from strong ground motion are expected to be numerous. However, since the revision (downward) of pipe-break estimates ar higher shaking intensities, overall pipe-break estimates are currently especially sensitive to estimates of liquefaction probability. In the $\mathbf{M}_{s} 7.45$ earthquake from the Weber segment that affected Ogden city water, for exaunple, only 18 percent of all breaks estimated were from strong ground motion; 23 percent were estimated to be from surficial fault displacement, and the remaining 59 percent were from liquefaction-induced ground failures. Still, the high levels of ground shaking also suggest significant potential damage to less resistant above-ground utility structures such as unanchored water-distribution storage tanks. Table 6 provides repair results in the second project broken down by the hazard that affected these results in worst-case events for each system surveyed. Standard assumptions are those hazard assumptions already explored, including standard magnitude scaling factors. The relative contribution of groundshaking to estimated breaks is higher for lower magnitude events and is higher in Utah County than it is in Weber County. 
TABLE 5.--Average break rates (per million lineal feet of pipe) estimated for utility systems surveyed for maximum credible and worst-case $M_{s} 6.7$ events simulated

[NC, not calculated]

\begin{tabular}{|c|c|c|c|c|c|c|}
\hline \multirow{2}{*}{ Utility system } & \multicolumn{2}{|c|}{ Weber segment } & \multicolumn{2}{|c|}{ Salt Lake segment } & \multicolumn{2}{|c|}{ Provo segment ${ }^{2}$} \\
\hline & $\mathrm{M}_{s} 7.45$ & $\begin{array}{l}\text { Worst case } \\
\mathrm{M}_{s} 6.7\end{array}$ & $\mathrm{M}_{s} 7.3$ & $\begin{array}{l}\text { Worst case } \\
\mathrm{M}_{s} 6.7\end{array}$ & $\mathrm{M}_{s} 7.4$ & $\begin{array}{c}\text { Worst case } \\
\mathrm{M}_{s} 6.7\end{array}$ \\
\hline Salt Lake County Conservancy District & 190 & 100 & 240 & 200 & $\mathrm{NC}$ & NC \\
\hline Granger-Hunter Improvement District & 350 & 210 & 390 & 330 & $\mathrm{NC}$ & NC \\
\hline Weber Basin Conservancy District & 260 & 150 & 100 & 50 & $\mathrm{NC}$ & $\mathrm{NC}$ \\
\hline Clinton Water (Davis County) & 280 & 160 & 110 & 50 & $\mathrm{NC}$ & $\mathrm{NC}$ \\
\hline Ogden City Water & $577^{1}$ & $512^{1}$ & $\mathrm{NC}$ & $\mathrm{NC}$ & $\mathrm{NC}$ & NC \\
\hline South Ogden Water & $522^{1}$ & $494^{1}$ & NC & $\mathrm{NC}$ & $\mathrm{NC}$ & $\mathrm{NC}$ \\
\hline \multicolumn{7}{|l|}{ Mt. Fuel Supply: } \\
\hline Weber County & $40^{1}$ & $37^{1}$ & $\mathrm{NC}$ & $\mathrm{NC}$ & $\mathrm{NC}$ & $\mathrm{NC}$ \\
\hline Davis County & 70 & 50 & 40 & 35 & $\mathrm{NC}$ & $\mathrm{NC}$ \\
\hline Salt Lake County & 25 & 20 & 50 & 40 & $\mathrm{NC}$ & NC \\
\hline Utah County & $\mathrm{NC}$ & $\mathrm{NC}$ & NC & $\mathrm{NC}$ & $14^{1}$ & $11^{1}$ \\
\hline Provo City Water & $\mathrm{NC}$ & $\mathrm{NC}$ & $\mathrm{NC}$ & $\mathrm{NC}$ & $84^{1}$ & $76^{1}$ \\
\hline Orem City Water & $\mathrm{NC}$ & NC & NC & $\mathrm{NC}$ & $71^{1}$ & $57^{1}$ \\
\hline
\end{tabular}

${ }^{1}$ Preliminary results from second project.

Both projects so far suggest that liquefaction-induced ground failure is the most significant hazard mode for earthquakes possibly damaging water and gas systems in the four-county area. Concentration on pipes traversing fault systems may in general ignore that breaks from fault displacements, when they occur, will be concurrent with many breaks from other hazard modes (liquefactioninduced ground failure, strong ground motion, and other hazard modes not studied explicitly here such as landsliding).

Table 7 examines the sensitivity of pipe repair rate estimates in maximum credible earthquakes to the various geoseismic hazard assumptions used. These assumptions consist of two alternative shaking hazard assumptions (the extreme assumption of basement rock estimates and the assumption that the rupture propagates toward all sites in the system) and one alternative assumption concerning liquefaction probability (10 percent as a maximum). Results for all systems are clearly sensitive to the maximum liquefaction probability assignment. Utah County water systems are especially sensitive to alternative assumptions concerning shaking hazards.

The results of this research indicate that earthquakes in Salt Lake, Davis, or Weber Counties having magnitudes perhaps as small as M 5.5 can also yield numerous breaks to local culinary water piping, especially for those systems having much nonductile piping. Preliminary results also suggest that smaller magnitude events $\left(\mathbf{M}_{s}<6.5\right)$ are expected to produce over half of all expected earthquakerelated breaks to culinary water piping in systems evaluated, largely because of high liquefaction potential for many sites even in smaller magnitude events. Table 8 explores the sensitivity of repair rate results in smaller magnitude earthquakes to the selection of magnitude scaling factors. For systems having much nonductile piping, even strong motions from near-field smaller magnitude events can yield considerable breaks. Clearly, though, the magnitude scaling factors used make dramatic differences in pipe repair estimates ar lower magnitude levels.

Break estimates naturally vary considerably with the various earthquakes postulated in this study. Figure 13 shows how break-rate estimates vary for a hypothetical Davis County system composed of welded-steel pipelines (not $\mathrm{X}$ grade, as in the more resistant natural gas piping). Aggregate system damage decreases with distance of the rupture center from the system. Moreover, on the basis of mathematical reasoning by Taylor and others (1985), a region of rupture centers, identified by the intersection of intervals $R_{x}$ and $R_{y}$ (fig. 13), contains rupture centers for which utility system reliability is minimum relative to the earthquake magnitude level examined.

For the natural gas system, which was sectionalized by county, rupture centers were determined for the magnitude levels $5.5,6.1,6.7$, and 7.0 to 7.5 , depending on the fault segment length and equations from Arabasz and 
TABLE 6.-Percent of estimated repairs attributed to different hazard modes in worst-case events [Standard assumptions include $60^{\circ}$ dip angle; $K_{1}=0$ for water systems, $K_{1}=1$ for gas systems; $K_{2}=0 ; K_{3}=1 ; K_{3}^{\prime}=1$ ]

\begin{tabular}{|c|c|c|c|c|c|}
\hline \multirow[b]{2}{*}{ System } & \multirow[b]{2}{*}{ Magnitude } & \multicolumn{4}{|c|}{ Hazards } \\
\hline & & $\begin{array}{c}\text { Faulting } \\
\text { (conservative } \\
\text { definition) } \\
\text { (percent) }\end{array}$ & $\begin{array}{l}\text { Liquefaction } \\
\text { (percent) }\end{array}$ & $\begin{array}{c}\text { Shaking } \\
\text { (percent) }\end{array}$ & $\begin{array}{c}\text { Total } \\
\text { (percent) }\end{array}$ \\
\hline \multirow[t]{4}{*}{ Odgen City Water } & 7.45 & 23.4 & 58.6 & 18.0 & 100 \\
\hline & 6.7 & 16.8 & 65.4 & 17.8 & 100 \\
\hline & 6.1 & 0 & 82.3 & 17.8 & 100 \\
\hline & 5.5 & 0 & 71.6 & 28.4 & 100 \\
\hline \multirow[t]{4}{*}{ South Odgen Water } & 7.45 & 8.0 & 75.4 & 16.6 & 100 \\
\hline & 6.7 & 5.4 & 79.3 & 15.3 & 100 \\
\hline & 6.1 & 0 & 86.2 & 13.8 & 100 \\
\hline & 5.5 & 0 & 81.1 & 18.9 & 100 \\
\hline \multirow[t]{4}{*}{ Mt. Fuel Supply (Weber County) } & 7.45 & 21.7 & 68.8 & 9.4 & 100 \\
\hline & 6.7 & 15.3 & 75.2 & 9.6 & 100 \\
\hline & 6.1 & 0 & 89.4 & 10.6 & 100 \\
\hline & 5.5 & 0 & 91.1 & 8.9 & 100 \\
\hline \multirow[t]{4}{*}{ Provo City Water } & 7.39 & 28.7 & 38.1 & 33.2 & 100 \\
\hline & 6.7 & 21.6 & 42.4 & 36.0 & 100 \\
\hline & 6.1 & 0 & 46.0 & 54.0 & 100 \\
\hline & 5.5 & 0 & 50.8 & 49.2 & 100 \\
\hline \multirow[t]{4}{*}{ Orem City Water } & 7.39 & 18.7 & 25.9 & 55.4 & 100 \\
\hline & 6.7 & 15.0 & 29.5 & 55.5 & 100 \\
\hline & 6.1 & 0 & 30.9 & 69.1 & 100 \\
\hline & 5.5 & 0 & 8.7 & 91.3 & 100 \\
\hline \multirow[t]{4}{*}{ Mt. Fuel Supply (Utah County) } & 7.39 & 43.7 & 48.6 & 7.8 & 100 \\
\hline & 6.7 & 34.2 & 60.7 & 5.1 & 100 \\
\hline & 6.1 & 0 & 91.8 & 8.2 & 100 \\
\hline & 5.5 & 0 & 93.3 & 6.7 & 100 \\
\hline
\end{tabular}

TABLE 7.-Ratio comparisons of pipe repair rates based on diverse assumptions for maximum credible earthquakes affecting water and gas systems in Utah and Weber Counties

\begin{tabular}{|c|c|c|c|c|c|c|}
\hline & \multicolumn{3}{|c|}{ Weber County systems } & \multicolumn{3}{|c|}{ Utah County systems } \\
\hline & $\begin{array}{l}\text { Ogden City } \\
\text { Water }\end{array}$ & $\begin{array}{l}\text { South Ogden } \\
\text { Water }\end{array}$ & $\begin{array}{l}\text { Mt. Fuel } \\
\text { Supply }\end{array}$ & $\begin{array}{l}\text { Provo City } \\
\text { Water }\end{array}$ & $\begin{array}{l}\text { Orem City } \\
\text { Water }\end{array}$ & $\begin{array}{l}\text { Mt. Fuel } \\
\text { Supply }\end{array}$ \\
\hline Standard assumptions $\mathbf{s}^{1}$ & 1.0 & 1.0 & 1.0 & 1.0 & 1.0 & 1.0 \\
\hline Standard but basement rock PHA and PHV estimates & 94 & 94 & 95 & 91 & 80 & 92 \\
\hline $\begin{array}{l}\text { Standard but maximum liquefaction probability } \\
\text { of } 10 \text { percent }\end{array}$ & .61 & .52 & .50 & .79 & .86 & .63 \\
\hline
\end{tabular}

\footnotetext{
${ }^{1}$ Dip angle $60^{\circ} ; K_{1}=0$ for water systems, $K_{1}=1$ for gas systems; $K_{2}=0 ; K_{3}=1 ; K_{3}^{\prime}=1$.
} 
TABLE 8.-Sensitivity of worst-case repair rates at lower magnitude levels to assumptions on magnitude scaling factors

Expected repairs per million lineal feet of piping

\begin{tabular}{|c|c|c|c|}
\hline System & $\begin{array}{c}\text { Magnitude } \\
\text { level }\end{array}$ & $\begin{array}{l}\text { Standard } \\
\text { multipliers }\end{array}$ & $\begin{array}{l}\text { One-half } \\
\text { highest } \\
\text { multipliers } \\
\text { in table } 2\end{array}$ \\
\hline
\end{tabular}

Mt. Fuel Supply (Weber County)

South Ogden Water

Ogden City Water

Mt. Fuel Supply (Utah

County)

Provo City Water

Orem City Water

$\begin{array}{rcr}5.5 & 26.3 & 4.4 \\ 6.1 & 30.0 & 6.6 \\ 5.5 & 200 & 50.1 \\ 6.1 & 393 & 94.1 \\ 5.5 & 158 & 60.6 \\ 6.1 & 424 & 129.5 \\ & & \\ 5.5 & 2.1 & .3 \\ 6.1 & 5.4 & 1.0 \\ 5.5 & 30.3 & 16.4 \\ 6.1 & 48.1 & 30.0 \\ 5.5 & 13.8 & 12.7 \\ 6.1 & 34.3 & 24.4\end{array}$

others (1987), so that minimum system reliability could be assessed at each such magnitude level. The selection of rupture centers for magnitude 7.0 to 7.5 earthquakes was dependent only on the segment modeled-a degenerate case of techniques used. System flow analyses were performed by the natural gas utility on the basis of detailed damage estimates for each scenario so selected. These analyses in turn were used to identify system weak links and to prioritize component retrofit and system enhancement alternatives.

Using smaller magnitude earthquakes proved to have several important practical advantages in this report. First, as is the case for the building industry (except for sites where seismicity is dominated by a single very active fault system or for structures designed to special standards), earthquake scenarios typically used for design or redesign are smaller in magnitude than maximum credible events. The maximum credible events are less probable and can be expected to cause only a small portion of overall long-term expected earthquake losses. Second, using smaller magnitude earthquake scenarios can provide greater assistance in identifying weak system links (for example, those elements that, if strengthened, could improve system reliability). Even many seismically resistant facilities (not necessarily weak links and not typically priorities in a seismic risk reduction program) tend to be damaged in maximum credible earthquakes. This tendency held in all systems surveyed except for the natural gas system in Utah County, which contains highly resis- tant piping and which is exposed to comparatively few permanent ground-failure hazards.

\section{SUMMARY}

The combined probabilistic and near-source approach to Wasatch Front risk estimation yields new insights and raises difficulties concerning the extent of losses and risks expected. Using many scenarios within a probabilistic framework assists in incorporating elements such as magnitude scaling factors and in developing damage statistics that can be used as a basis for examining systemic and secondary losses. Using many scenarios of varying magnitudes also assists in defining the types of earthquakes that are potentially dangerous and the parameters that could be studied further to improve risk estimates in these various earthquakes.

In maximum credible and other high-magnitude $\left(\mathrm{M}_{s}\right.$ 6.7) localized events studied, high levels of ground shaking estimated indicated that previous pipe vulnerability models needed to be revised at intensities IX and above. Partly as a result of findings on soil effects, these high levels still suggest that significant culinary water piping damage and damage to above-ground utility structures (many of which have limited seismic resistance or have equipment having limited lateral resistance) are expected from strong ground motion, even in somewhat smaller magnitude earthquakes.

But, for natural gas and culinary water piping, estimates of expected damage are especially sensitive to liquefaction probabilities (estimated for diverse sites and (or) microzones as affected by a variety of simulated earthquakes). Methods have been improvised in these projects to estimate these probabilities, but improved methods would greatly assist in refining damage estimates to buried piping. Of special interest would be a review of this project's findings that even selected (nearfield) earthquakes having magnitudes perhaps as low as 5.5 could cause extensive localized liquefaction-induced ground failures and consequent high levels of pipe breakage. This result has been demonstrated to be extremely dependent on the magnitude scaling factors used.

Results of liquefaction susceptibility studies are useful in delineating regions where overall earthquake damage to buried conduits is expected to be greater, particularly so with respect to smaller magnitude $\left(\mathrm{M}_{s}<6.5\right)$, more distant earthquake scenarios or more seismically resistant buried conduits. More detailed analysis of microzones having large exposures and high liquefaction susceptibilities would provide information valuable to Wasatch Front earthquake risk reduction problems. This analysis may involve gathering additional data on sites within these microzones, developing improved 


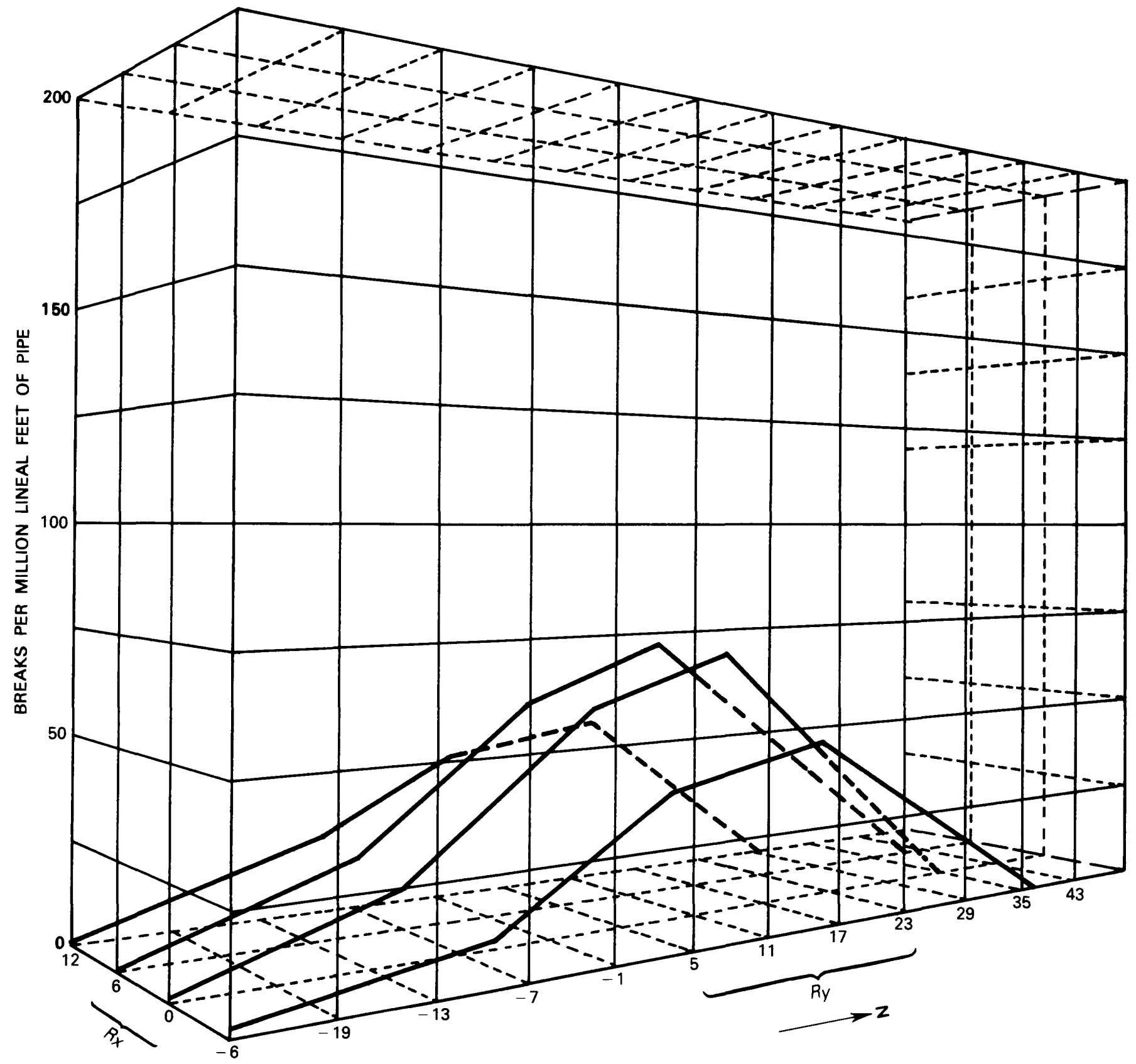

$R$ represents location of rupture centers causing highest damage to the systems (for $x$ - and $y$ - axes respectively)

FIGURE 13.-Break rate variations versus fault rupture center locations, $\mathrm{M}_{s} 6.1$ (Davis County) (origin is intersection of base line and Salt Lake meridian). $R$ represents the location of rupture centers causing the most damage to the system (for $x$ and $y$ axes).

procedures for defining liquefaction potentials for areas rather than sites, associating liquefaction susceptibility data with specific facilities, or using smaller cell grids.

Losses to less seismically resistant State-owned building are estimated to be extremely high-even higher than the 39 percent estimated for all State-owned build- ings-in worst-case events. These losses include probable long-term downtime and consequent disruption of governmental and university operations. Because life-safety hazards may also be significant, we recommend a more detailed visual inspection and rating of the most seismically vulnerable and densely occupied facilities. 
The approach used here has also proved to be practical. Its use by the natural gas utility in defining seismic risk reduction plans indicates that a probabilistic approach can be successfully applied to network problems as well as to building problems. Participation by utility representatives in study phases lends both credibility and meaning to results for those who can employ them in strengthening systems.

\section{REFERENCES CITED}

Alfors, J.T., 1983, Regional geology of the Coalinga, California area, in The 1983 Coalinga, California earthquakes, Sacramento, CA: California Department of Conservation, Division of Mines and Geology, Special Publication 66, p. 105112.

Algermissen, S.T., and Steinbrugge, K.V., 1984, Seismic hazard and risk assessment: Some case studies: Geneva Papers on Risk and Insurance, v. 9, no. 30, p. 8-26.

Algermissen, S.T., Perkins, D.M., Thenhaus, P.C., Hanson, S.L., and Bender, B.L., 1982, Probabilistic estimates of maximum acceleration and velocity in rock in the contiguous United States: U.S. Geological Survey Open-File Report 82-1033, $107 \mathrm{p}$.

Algermissen, S.T., Rogers, A.M., Hays, W.W., Perkins, D.M., Van Strien, D.O., Hughes, H.C., Hughes, R.C., Lagorio, H.J., and Steinbrugge, K.V., 1976, A study of earthquake losses in the Salt Lake City, Utah area: U.S. Geological Survey Open-File Report 76-89, 357 p.

Anderson, L.R., Keaton, J.R., Audrey, K., and Ellis, S.J., 1982, Liquefaction potential map for Davis County, Utah: Logan and Salt Lake City, Utah State University Department of Environmental Engineering and Dames and Moore, under USGS contract 14-08-0001-19127, 49 p.

Arabasz, W.J., Pechmann, J.C., and Brown, E.D., 1987, Observational seismology and the evaluation of earthquake hazards and risk in the Wasatch Front area, Utah, in Gori, P.L., and Hays, W.W., eds., A'ssessment of regional earthquake hazards and risk along the Wasatch Front, Utah: U.S. Geological Survey Open-File Report 87-585, p. D1-D58.

Bonilla, M.G., Mark, R.K., and Lienkaemper, J.J., 1984, Statistical relations among earthquake magnitude, surface rupture length, and surface fault displacement: Bulletin of the Seismological Society of America, v. 74, no. 6, p. 2379-2411.

Bresko, D., Hendrickson, D., and Oppenheim, I., 1981, Seismic risk analysis of an urban water system, in Lifeline earthquake engineering, Proceedings of the Second Specialty Conference: New York, American Society of Civil Engineers, $138 \mathrm{p}$.

Bruhn, R.L., Gibler, P.R., Houghton, W., and Parry, W.T., 1987, Structure of the Salt Lake segment, Wasatch normal fault zone: Implications for rupture propagation during large earthquakes, in Gori, P.L., and Hays, W.W., Assessment of regional earthquake hazards and risk along the Wasatch Front, Utah: U.S. Geological Survey Open-File Report 87585, p. H1-H57.

Campbell, K.W., 1984, Near-source attenuation of strong ground motion for moderate to large earthquake; an updated and suggested application to the Wasatch fault zone of northcentral Utah: U.S. Geological Survey Open-File Report 84763, p. 483-499.

1987, Predicting strong ground motion in Utah, in Gori, P.L., and Hays, W.W., eds., Assessment of regional earthquake hazards and risk along the Wasatch Front, Utah: U.S. Geological Survey Open-File Report 87-585, p. L1-L90.

Cluff, L.S., Glass, C., and Brogan, G., 1974, Wasatch fault investigation maps: Salt Lake City, Utah Geological and Mineral Survey, scale 1:2000.

Eguchi, R.T., Legg, M.R., Taylor, E.C., Philipson, L.L., and Wiggins, J.H., 1983, Earthquake performance of water and gas supply systems: Redondo Beach, Calif., J.H. Wiggins Company Report 83-1396-5 to the National Science Foundation, $206 \mathrm{p}$.

Highland, L.M., 1987, Earthquake hazards to domestic water distribution systems in Salt Lake County, Utah, in Gori, P.L., and Hays, W.W., eds., Assessment of regional earthquake hazards and risk along the Wasatch Front, Utah: U.S. Geological Survey Open-File Report 87-585, p. Q1-Q76.

Hutton, L.K., 1987, 1987 Whittier Narrows earthquake: Prior seismicity and comparison with the 1919 Whittier sequence: California Institute of Technology Seismological Laboratory Report $252.21,8 \mathrm{p}$.

International Conference of Building Officials, 1988, Uniform building code: Whittier, Calif.

Isenberg, J., and Taylor, C.E., 1984, Performance of water and sewer lifelines in the May 2, 1983 Coalinga, California earthquake, in Lifeline earthquake engineering: New York, American Society of Civil Engineers, p. 190-211.

Joyner, W.B., and Fumal, T.E., 1985, Predictive mapping of earthquake ground motion, in Ziony, J.I., ed., Earthquake hazards in the Los Angeles region-An earth-science perspective: U.S. Geological Survey Professional Paper 1360, p. 203-220.

Keaton, J.R., Currey, D.R., and Olig, S.J., 1987, Paleoseismicity and earthquake hazards evaluation of the West Valley fault zone, Salt Lake City urban area, Utah: Salt Lake City, Dames and Moore and University of Utah Department of Geography report under U.S. Geological Survey contract 14-080001-22048, 54 p.

Liao, S.S.C., 1986, Statistical modeling of earthquake induced liquefaction: Cambridge, Massachusetts Institute of Technology Department of Civil Engineering, unpublished Ph.D. dissertation, $470 \mathrm{p}$.

Liu, S.C., 1977, Earthquake protection of communications facilities, in World Conference on Earthquake Engineering, 6th, New Delhi, 1977, Proceedings, p. 3304-3309.

Mabey, D.R., 1987, Subsurface geology along the Wasatch Front, in Gori, P.L., and Hays, W.W., eds., Assessment of regional earthquake hazards and risk along the Wasatch Front, Utah: U.S. Geological Survey Open-File Report 87-585, p. C1-C39.

Machette, M.N., Personius, S.F., and Nelson, A.R., 1987, Quaternary geology along the Wasatch fault zone: Segmentation, recent investigations, and preliminary conclusions, in Gori, P.L., and Hays, W.W., eds., Assessment of regional earthquake hazards and risk along the Wasatch Front, Utah: U.S. Geological Survey Open-File Report 87-585, p. A1-A72. 
McDonough, P.W., and Taylor, C.E., 1986, Assessing seismic response of Utah gas systems: Earthquake Spectra, v. 2, no. 4, p. 747-766.

National Research Council Panel on Earthquake Loss Estimation Methodology, 1989, Estimating losses from future earthquakes: Washington, D.C., National Academy Press, $231 \mathrm{p}$.

Robison, R.M., 1986, The surficial geology and neotectonics of Hansel Valley, Box Elder County, Utah: Logan, Utah State University, unpublished M.Sci. thesis.

Rogers, A.M., Carver, D.L., Hays, W.W., King, K.W., and Miller, R.D., 1984, Preliminary estimates of geographic variations in relative ground shaking in the Wasatch Front urban corridor, in Hays, W.W., and Gori, P.L., eds., Proceedings of Conference XXVI; a workshop on evaluation of regional and urban earthquake hazards and risk in Utah: U.S. Geological Survey Open-File Report 84-763, p. 547-556.

Schiff, A.J., 1988, Response of lifelines to the Whittier Narrows earthquake of 1987 and their effect on the emergency response: Earthquake Spectra, v. 4, no. 2, p. 367-376.

Scott, W.E., and Shroba, R.R., 1985, Surficial geologic map of an area along the Wasatch fault zone in the Salt Lake Valley, Utah: U.S. Geological Survey Open-File Report 85-448, 18 p.

Seed, H., and ldriss, I.M., 1983, Ground motions and soil liquefaction during earthquakes: Berkeley, Calif., Earthquake Engineering Research Institute, $134 \mathrm{p}$.

Smith, Robert, and Richins, William, 1984, Seismicity and earthquake hazards of Utah and the Wasatch Front: Paradigm and paradox, in Hays, W.W., and Gori, P.L., eds., Proceedings of Conference XXVI; a workshop on evaluation of regional and urban earthquake hazards and risk in Utah: U.S. Geological Survey Open-File Report 84-763, p. 73-112.

Steinbrugge, K.V., 1982, Earthquakes, volcanos, and tsunamis: An anatomy of hazards: New York, Skandia American Group, 392 p.

Taylor, C.E., and Bigler, E., 1982, A preliminary study of possible earthquake problems to Salt Lake County water supply system: Report to the Governor of Utah.

Taylor, C.E., and McDonough, P.W., 1986, Earthquake risks to Utah water and gas systems, in Lifeline seismic risk analysis-Case studies: New York, American Society of Civil Engineers, p. 70-87.

Taylor, C.E., and Ward, D.B., 1979, Seismic risk assessment of Utah primary and secondary schools and recommendations for risk reduction: Salt Lake City, Utah Seismic Safety Advisory Council, $91 \mathrm{p}$.

__ 1981, Seismic risk assessment of Utah culinary water supply systems and recommendations for risk reduction: Salt Lake City, Utah Seismic Safety Advisory Council, 94 p.

Taylor, C.E., Legg, M.R., Haber, J.M., and Wiggins, J.H., 1985, New lifeline multi-scenario seismic risk techniques with a model application: Civil Engineering Systems, v. 2, p. 77-83.

Taylor, C.E., Wiggins, J.H., Haber, J.M., and Ward, D.B., 1986a, A systems approach to Wasatch Front seismic risk problems: Long Beach, Calif., NTS Engineering Technical Report to
U.S. Geological Survey under contract 14-08-001-22013, $169 \mathrm{p}$.

Taylor, C.E., Haber, J.M., Legg, M.R., Heubach, W.F., and Wiggins, J.H., 1986b, Earthquake vulnerability of water and natural gas supply systems: Long Beach, Calif., NTS Engineering Technical Report 86-1466 to the National Science Foundation.

Taylor, C.E., Salmon, M., Eguchi, R., Campbell, R., and Tillman, C., 1988, Continuing investigations of earthquake risks to Utah water and gas systems: Long Beach, Calif., NTS Engineering Technical Report to U.S. Geological Survey under contract 14-08-001-22013, $192 \mathrm{p}$.

Thiel, C.C., and Zsuttys, T.C., 1987, Earthquake parameters and damage statistics: San Francisco, Forell/Elsesser Engineers, report under U.S. Geological Survey contract 14-080001-G1181, $264 \mathrm{p}$.

Trautmann, C.H., O'Rourke, T.D., Grigoriu, M.D., and Khayer, M.J., 1986, Systems model for water supply following earthquakes, in Lifeline seismic risk analysis-Case studies: New York, American Society of Civil Engineers, p. 3050.

Utah Geological and Mineral Survey, 1983, Governor's Conference on Geologic Hazards, Salt Lake City, Utah: Utah Geological and Mineral Survey Circular 74, $98 \mathrm{p}$.

Utah Seismic Safety Advisory Council, 1981, Earthquake safety in Utah and abbreviated recommendations for risk reduction: Utah Seismic Safety Advisory Council Report, 38 p.

Wheeler, R.L., and Krystinik, K.B., 1987, Persistent and nonpersistent segmentation of the Wasatch fault zone, Utah: Statistical analysis for evaluation of seismic hazard, in Gori, P.L., and Hays, W.W., eds., Assessment of regional earthquake hazards and risk along the Wasatch Front, Utah: U.S. Geological Survey Open-File Report 87-585, p. B1-B124.

Whitman, R.V., Biggs, J.M., Brennan, J.E., III, Cornell, C.A., de Neufville, R.L., and Varmarcke, E.H., 1975, Seismic design decision analysis: Journal of the Structural Division, May 1975, ST5, p. 1067-1084.

J.H. Wiggins Company, 1979, Considerations and alternatives for abatement of seismically hazardous existing buildings in Utah: Redondo Beach, Calif., report prepared for the Utah Seismic Safety Advisory Council.

Wiggins, J.H., and Taylor, C.E., eds., 1985, Earthquake rehabilitation manual for buildings, in Building construction under seismic conditions: Vienna, United Nations Industrial Development Programme, v. 4, $246 \mathrm{p}$.

1986, Earthquake performance of low-rise construction: Long Beach, Calif., NTS Engineering Technical Report 861442, prepared for the National Science Foundation, v. 2, $189 \mathrm{p}$.

Wiggins, J.H., Taylor, C.E., Eguchi, R.T., and Slosson, J.E., 1981, Earthquake hazards and risk mitigations: ldentification and evaluation methods: Redondo Beach Calif., J.H. Wiggins Company Technical Report 1373-1, prepared for the Federal Emergency Management Agency, 438 p.

Youd, T.L., and Perkins, D.M., 1987, Mapping of liquefaction severity index: Journal of Geotechnical Engineering, v. 113, no. 11 , p. 433-445. 